Jochen Plikat

\title{
FREMDSPRACHLICHE \\ DISKURSBEWUSSTHEIT ALS \\ ZIELKONSTRUKT DES
}

FREMDSPRACHENUNTERRICHTS

Eine kritische Auseinandersetzung mit der Interkulturellen Kompetenz 


\section{Mehrsprachigkeit in $S$ chule und $U_{\text {nterricht }}$}

Interkulturelle Kompetenz spielt für das Lernen fremder Sprachen aktuell eine Schlüsselrolle. Der Autor untersucht die Leitfragen, wofür eine solche Kompetenz steht und welches Verständnis von Kultur ihr zu Grunde liegt. Er arbeitet die Problemlage auf, in welchem Maße das Gebot, alle Kulturen zu tolerieren, wünschenswert und umsetzbar ist, und diskutiert zentrale Beiträge zum Thema kritisch. Der Autor schlägt vor, den Fremdsprachenunterricht in Zukunft auf das neue Zielkonstrukt Fremdsprachliche Diskursbewusstheit auszurichten. Für den Umgang mit Konflikten lehnt er relativistische Beliebigkeit ab. Vielmehr empfiehlt er eine konsequente Rückbesinnung auf jene Werte, welche die Grundlage des friedlichen Zusammenlebens in pluralen Gesellschaften bilden: Menschenrechte, Demokratie und Rechtsstaatlichkeit.

Jochen Plikat studierte Französisch, Spanisch und Geschichte an der Universität Freiburg im Breisgau. Er ist Lehrkraft für besondere Aufgaben im Arbeitsbereich Didaktik der romanischen Sprachen am Institut für Romanistik der Humboldt-Universität zu Berlin.

www.peterlang.com 
Fremdsprachliche Diskursbewusstheit als Zielkonstrukt des Fremdsprachenunterrichts 


\section{MEHRSPRACHIGKEIT IN SCHULE UND UNTERRICHT}

Herausgegeben von Stephan Breidbach, Gerhard Bach, Dieter Wolff

BAND 16

Zu Qualitätssicherung und Peer Review der vorliegenden Publikation

Die Qualität der in dieser Reihe erscheinenden Arbeiten wird vor der Publikation durch die Herausgeber der Reihe geprüft.
Notes on the quality assurance and peer review of this publication

Prior to publication, the quality of the work published in this series is reviewed by the editors of the series. 


\author{
Jochen Plikat
}

\title{
Fremdsprachliche \\ Diskursbewusstheit als \\ Zielkonstrukt des \\ Fremdsprachenunterrichts
}

Eine kritische Auseinandersetzung mit der

Interkulturellen Kompetenz

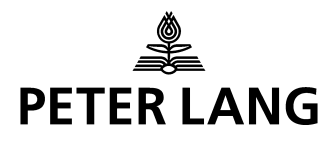




\section{Bibliografische Information der Deutschen Nationalbibliothek \\ Die Deutsche Nationalbibliothek verzeichnet diese Publikation in der Deutschen Nationalbibliografie; detaillierte bibliografische Daten sind im Internet über http://dnb.d-nb.de abrufbar.}

Zugl.: Berlin, Humboldt-Univ., Diss., 2016

Umschlaggestaltung: Joachim Knappe

11

ISSN 1615-925X

ISBN 978-3-631-70362-5 (Print)

E-ISBN 978-3-631-70363-2 (E-PDF)

E-ISBN 978-3-631-70364-9 (EPUB)

E-ISBN 978-3-631-70365-6 (MOBI)

DOI 10.3726/b10728

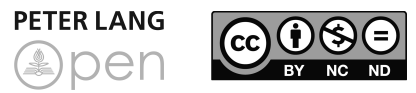

Open Access: Dieses Werk ist lizensiert unter der Creative Commons Lizenz Namensnennung - Nicht kommerziell - Keine Bearbeitungen 4.0 International (CC BY-NC-ND 4.0). Den vollständigen Lizenztext finden Sie unter: https://creativecommons.org/licenses/by-nc-nd/4.0/deed.de

(C) Jochen Plikat, 2017

Peter Lang GmbH

Internationaler Verlag der Wissenschaften

Berlin

Peter Lang - Berlin · Bern · Bruxelles · New York ·

Oxford $\cdot$ Warszawa $\cdot$ Wien

Diese Publikation wurde begutachtet.

www.peterlang.com 
Für meine Eltern, Elisabeth \& Wolfgang

Jochen Plikat - 978-3-631-70364-9

Downloaded from PubFactory at 01/11/2019 10:12:35AM

via free access 
Jochen Plikat - 978-3-631-70364-9

Downloaded from PubFactory at 01/11/2019 10:12:35AM

via free access 


\section{Danksagung}

Die vorliegende Arbeit wurde Anfang 2016 an der Philosophischen Fakultät II der Humboldt-Universität zu Berlin als Promotionsschrift angenommen. In der Zeit ihrer Entstehung wurde ich von verschiedenen Seiten unterstützt, wofür ich mich an dieser Stelle ganz herzlich bedanken möchte.

Prof. Dr. Lutz Küster hat seine Aufgabe als Betreuer sehr kompetent, engagiert und geduldig wahrgenommen. Von seinen zeitnahen und detaillierten Rückmeldungen zu den sukzessive eingereichten Teilkapiteln hat die Arbeit in hohem Maße profitiert. Prof. Dr. Stephan Breidbach hat den Werdegang der Arbeit ebenfalls treu und kritisch begleitet, nicht nur in dem von ihm moderierten Forschungskolloquium, sondern auch in vielen informellen Gesprächen beim gemeinsamen Mittagessen. Den Teilnehmerinnen und Teilnehmern seines Kolloquiums bin ich ebenfalls zu Dank verpflichtet.

Ebenfalls möchte ich mich herzlich bei Prof. Dr. Andrea Rössler und Prof. Dr. Gabriele Blell für die regelmäßigen Einladungen in ihr Forschungskolloquium an der Leibniz-Universität Hannover bedanken. Ich habe sehr davon profitiert, dass ich ab und an mein gewohntes universitäres Umfeld verließ, um meine Ideen einem auswärtigen Publikum zu präsentieren.

Im Rückblick auf die Entstehung der Arbeit erinnere ich mich an Impulse, die sich im Laufe der Zeit als wichtige Weichenstellungen herausstellten. Einer dieser Impulse kam von Prof. Dr. Andreas Grünewald. Er ermunterte mich 2010 im Rahmen der DGFF-Sommerschule dazu, dem starken empirischen Trend in der Fremdsprachendidaktik zu widerstehen und eine theoretische Grundlagenarbeit zu schreiben. Ein weiterer wichtiger Impuls ging von Prof. Dr. Claus Gnutzmann aus: Als ich 2013 im Rahmen eines Langscape-Treffens in Istanbul mein Forschungsprojekt vorstellte, empfahl er mir, doch einmal einen tiefen Blick in die Theorie der language awareness zu werfen - ein Hinweis, der sich in vollem Umfang gelohnt hat. Beiden sei an dieser Stelle ebenfalls herzlich gedankt.

Mein herzlicher Dank gilt auch Christian Lüpke, der mich nicht nur als studentische Hilfskraft durch zahlreiche Gänge in diverse Berliner Bibliotheken unterstützt hat, sondern mir auch immer ein interessierter, kluger und kritischer Gesprächspartner war. 
Für viele anregende Diskussionen und Hinweise geht mein Dank darüber hinaus an meine langjährigen Freunde Dr. Christian Buder, Dr. Christoph Gumb und Hannes Langendörfer.

Schließlich geht mein besonderer Dank an meine Frau Marta, die mich bei allen meinen beruflichen und privaten Vorhaben mit viel Geduld, Ermunterung und Liebe begleitet. 


\section{Inhalt}

\section{Vorbemerkungen und Einleitung}

\section{Kapitel 1: Problemstellung}

1.1 Rückblick: Landeskunde als Wissensvermittlung über Nationalkulturen

1.2 Aufstieg des Kulturbegriffs zur Leitkategorie der Humanwissenschaften

1.3 Pluralisierung von Gesellschaften als Folge der Globalisierung 25

1.4 Interkulturelle Fremdsprachendidaktik als Reaktion auf den ,Cultural turn' und die Globalisierung .26

1.5 Terminologischer Exkurs: Interkulturelle Bildung, interkulturelles Lernen oder interkulturelle Kompetenz? .28

1.6 Unbehagen angesichts des Interkulturalitätsbegriffs in der Fremdsprachendidaktik

1.7 Unbehagen angesichts kulturrelativistischer Tendenzen in der Fremdsprachendidaktik

1.8 Arbeitshypothese und Forschungsfragen .......................................................37

1.9 Methodisches Vorgehen ...................................................................................38

Kapitel 2: Kulturwissenschaftliche Grundlagen .................................45

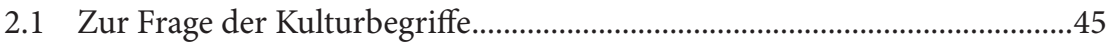

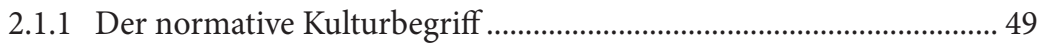

2.1.2 Der totalitätsorientierte Kulturbegriff...................................................... 51

2.1.3 Der differenzierungstheoretische Kulturbegriff ..................................... 55

2.1.4 Der bedeutungs- und wissensorientierte Kulturbegriff......................... 60

2.1.5 Exkurs: Das Konzept der, Transkulturalität'......................................... 61

2.1.6 Kulturbegriffe: Zusammenfassung ....................................................... 71 
2.2 Zum Dilemma von Universalismus und Kulturrelativismus .73

2.2.1 Kulturrelativismus als Reaktion auf Rassismus

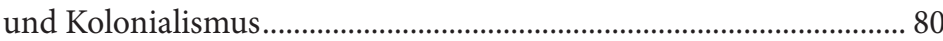

2.2.2 Selbstwidersprüche und Fehlschlüsse des Kulturrelativismus............ 87

2.2.3 Historisch-philosophische Einwände gegen

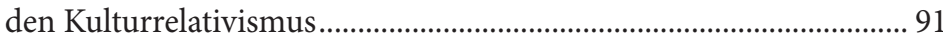

2.2.4 Rechtlich-politische Einwände gegen den Kulturrelativismus .......... 97

2.2.5 Bildungs- und demokratietheoretische Einwände gegen den Kulturrelativismus.

2.2.6 Aufgeklärter Eurozentrismus‘ als Versuch der Versöhnung von Universalismus und Kulturrelativismus.

\section{Kapitel 3: Ansätze interkultureller Fremdsprachendidaktik} in der Diskussion

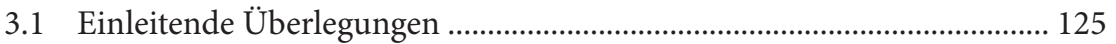

3.2 Vom Verstehen zur Verständigung: Der hermeneutische

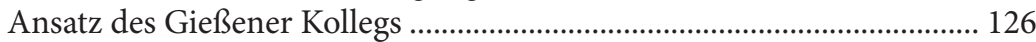

3.2.1 Problemstellung der Didaktik des Fremdverstehens ........................ 126

3.2.2 Von Lothar Bredella diskutierte Ansätze zur Dichotomie des Eigenen und Fremden ................................................................. 128

3.2.3 Exkurs: Diskussion der von Bredella referierten Ansätze................... 133

3.2.4 Grundzüge der Didaktik des Fremdverstehens ................................... 137

3.2.5 Die Didaktik des Fremdverstehens im Licht der Forschungsfragen .......................................................................... 141

3.3 Interkulturalität als ,Dritter Ort': Claire Kramschs

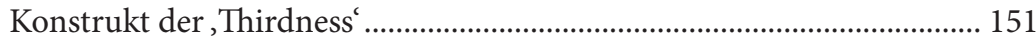

3.3.1 Problemstellung der, Thirdness '............................................................. 151

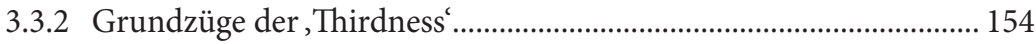

3.3.3 ,Thirdness' im Licht der Forschungsfragen ...................................... 158

3.4 Umgang mit Komplexität und Mehrdeutigkeit: Claire Kramschs ,symbolic competence '.................................................................................. 165

3.4.1 Problemstellung der symbolic competence '........................................ 165 


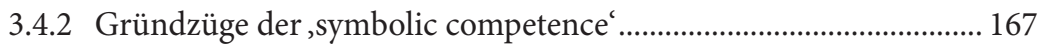

3.4.3 Symbolic competence im Licht der Forschungsfragen .................... 170

3.5 Schwerpunkte interkultureller Kompetenz:

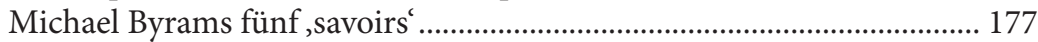

3.5.1 Problemstellung der, Intercultural communicative competence ‘... 177

3.5.2 Grundzüge der, Intercultural communicative competence ‘............ 179

3.5.3 ,Intercultural communicative competence im Licht der Forschungsfragen......................................................................... 182

3.6 Fazit: Problemfelder der interkulturellen Fremdsprachendidaktik......... 191

\section{Kapitel 4: Theoriebildung: Umrisse des Konstruktes} ,Fremdsprachliche Diskursbewusstheit '.............................................. 193

4.1 Einleitende Überlegungen ............................................................................. 193

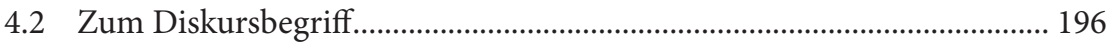

4.2.1 Vorüberlegungen zum Diskursbegriff ................................................. 196

4.2.2 Klärung des Diskursbegriffs ................................................................... 199

4.2.3 Zur Verwendung des Diskursbegriffs in fremdsprachendidaktischen Beiträgen ................................................ 211

4.2.4 Zur Bedeutung des Diskursbegriffs für die Fremdsprachliche

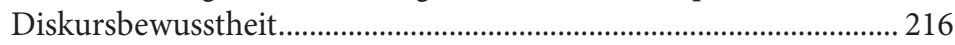

4.3 Zum Konzept der ,language awareness'/Sprachbewusstheit...................... 230

4.3.1 Bewusstsein als philosophisches Rätsel ................................................ 230

4.3.2 Grundzüge des Konstruktes, language awareness'/ Sprachbewusstheit ............................................................................. 235

4.3.3 Zur Bedeutung der Sprachbewusstheit für die Fremdsprachliche Diskursbewusstheit ................................................. 248

4.4 Zur Theorie transformatorischer Bildungsprozesse ................................... 263

4.4.1 Problemstellung der Theorie transformatorischer

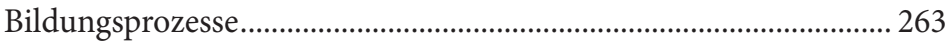

4.4.2 Grundzüge der Theorie transformatorischer Bildungsprozesse...... 267

4.4.3 Zur Bedeutung der Theorie transformatorischer Bildungsprozesse für die Fremdsprachliche Diskursbewusstheit .......278 
4.5 Didaktische Prinzipien zur Anbahnung Fremdsprachlicher Diskursbewusstheit.

Fazit und Ausblick 295

Abbildungsverzeichnis 303

Tabellenverzeichnis 303

Literatur 305 


\section{Vorbemerkungen und Einleitung}

Man muß sich das vorstellen: Ein Gläubiger kniet nieder und beginnt ein Gebet. Ein Intellektueller stellt sich neben ihn und sagt: „Wie interessant! Weißt du, daß andere Völker an ganz andere Götter glauben?" Wie kann der Gläubige, der an seinen Gott glaubt, darauf reagieren? Natürlich lehnt er die Zumutung des Vergleichs ab, hält den Intellektuellen für einen Neunmalklugen und die anderen Völker für ungläubig. Aber in Wahrheit ist er bereits erschüttert. In Wahrheit hat ihn bereits eine Unruhe erfaßt. Wie kann er glauben, wenn andere anders glauben? Was kann er wissen, wenn andere anderes wissen? Wer ist sein Gott, wenn andere ihn nicht kennen? Wie weit reicht die Macht seines Gottes, wenn andere ungestraft ihren Götzen huldigen dürfen? (Baecker 2001: 48)

Interkulturelle Kompetenz, interkulturelles Lernen, interkulturelle fremdsprachige Handlungsfähigkeit - ohne Zweifel nimmt der Interkulturalitätsgedanke in der aktuellen Fremdsprachendidaktik einen zentralen Platz ein. Seit das Prinzip der Interkulturalität in den 1990er-Jahren zu seiner aktuellen Bedeutung aufgestiegen ist, geht es nach anfänglich noch grundlegenden Diskussionen (vgl. Hu 1999) inzwischen weniger um die Frage, $o b$ interkulturelle Kompetenz ein Ziel fremdsprachlichen Lernens sein sollte, sondern vielmehr darum, wie sie angebahnt und möglicherweise auch gestuft und evaluiert werden kann. Innerhalb weniger Jahre wurde es zu einer Selbstverständlichkeit, dass Lehrkräfte fremder Sprachen in Deutschland neben sprachlichen Kompetenzen auch interkulturelle Kompetenzen in den Fokus ihrer unterrichtlichen Arbeit stellen sollen. Sie haben seither gewissermaßen den Auftrag, ihren Lernenden im Umgang mit, fremden Kulturen' eine Haltung zu vermitteln, die der Soziologe Dirk Baecker im Eingangszitat mit den Worten „Wie interessant!“ zuspitzt. Dieses „Wie interessant!“ hat jedoch auf fast unvermeidliche Weise zur Folge, dass auch der Blick auf die ,eigene Kultur' sich verändert, und auch dies ist ein Anliegen interkultureller Didaktik.

Als ich ab 2003 im Rahmen meines Referendariats in den Fächern Französisch und Spanisch damit begann, mich mit fremdsprachendidaktischen Problemstellungen zu beschäftigen, leuchtete es auch mir zunächst ein, sprachliches und ,interkulturelles' Lernen zu verbinden. Das klang nach Völkerverständigung, Toleranz, Offenheit und Empathie - wer hätte also etwas dagegen einwenden können, dass ein Begriff' ${ }^{1}$, mit dem man so hehre Ziele verbindet, im Mittelpunkt

1 Wenn ich in dieser Arbeit von ,Begriff' spreche, dann ist der jeweilige Terminus gemeint; ,Verständnis' bezieht sich dagegen auf die jeweilige Bedeutung. Dies geschieht 
des Lehrens und Lernens fremder Sprachen stehen sollte? Und schien nicht der Fremdsprachenunterricht mehr als alle anderen schulischen Fächer geeignet, ja geradezu prädestiniert, den Interkulturalitätsgedanken tief in den Köpfen der Lernenden zu verankern?

Zwei Fragen ließen mich jedoch nicht los. Die eine wurde zumindest im wissenschaftlichen Kontext bisweilen gestellt. Sie lautet: Was genau ist eigentlich ,Kultur'? ${ }^{2}$ Vordergründig eine banale Frage - durch die feste Verankerung des Begriffs in der Alltagssprache hatte ich zunächst das sichere Gefühl zu wissen, was darunter zu verstehen sei. Diese Sicherheit wurde jedoch allmählich brüchig. Mir fiel auf, dass wir meist ohne zu zögern von der lateinamerikanischen Kultur, der spanischen Kultur, der russischen Kultur und der italienischen Kultur sprechen, dass mir (und vielen anderen) die Rede von der, deutschen Kultur dagegen weniger leicht oder gar nicht über die Lippen gehen wollte. Hierzu dürfte auch die damals öffentlich geführte Debatte um die, deutsche Leitkultur beigetragen haben. Wann immer jemand versuchte, den Kern, die Essenz der ,deutschen Kultur' zu beschreiben, beschlich mich der teils amüsante, teils irritierende Eindruck, dass er oder sie mit einem aussichtslosen Vorhaben beschäftigt war - nämlich, man gestatte mir die saloppe Formulierung, einen Pudding an eine Wand zu nageln. 2008 wurde sogar ein Test eingeführt, den Kandidat_ innen für Einbürgerungen seither ablegen müssen und der im Grunde nichts anderes als ein Sprach- und ,Kulturtest' ist. Kritiker wiesen damals darauf hin, dass auch viele gebürtige Deutsche bei diesen Tests Schwierigkeiten hätten (vgl. Haimerl 2010).

Zeitgleich mit meiner Sensibilisierung durch eine gesellschaftliche Debatte nahm auch meine Empfindlichkeit zu, wenn ich mit Stereotypen über, die Deutschen' oder, die deutsche Kultur' konfrontiert wurde, unabhängig davon, ob diese positiv oder negativ waren, ob sie in den Medien oder in persönlichen Begegnungen wiederholt wurden, ob ich in die jeweilige Schublade passte oder eher als Ausnahme galt, welche die Regel angeblich bestätigte. Was bedeutete all dies für die Rede von interkulturellem Lernen und interkultureller Kompetenz, die

in Analogie zu Ferdinand de Saussures Unterscheidung zwischen signifiant und signifié. Wenn es in dieser Arbeit um einen bestimmten Terminus in einem bestimmten Verständnis geht, dann wird mit dem Ziel besserer Lesbarkeit häufig von einem ,Begriff gesprochen, während sich das jeweilige Verständnis in einem Adjektivattribut findet, z.B. der „normative Kulturbegriff“ oder der „linguistische Diskursbegriff“ (vgl. v.a. Kap. 2.1. und 4.2.).

2 Auch in der deutschen Medienöffentlichkeit wurde in den Nullerjahren leidenschaftlich über die Begriffe, deutsche Leitkultur' bzw. ,europäische Leitkultur' diskutiert. 
meinem Eindruck nach zumindest in Lehrwerken und didaktischen Publikationen für Lehrkräfte ziemlich sorglos geführt wurde? Welches Kulturverständnis dominierte die fremdsprachendidaktische Diskussion?

Eine Durchsicht verschiedener unterrichtspraktischer Publikationen unter diesem Aspekt bestätigte erste Befürchtungen. Dort wurde häufig mit Kulturverständnissen operiert, die sich näher an homogenisierenden und simplifizierenden Alltagstheorien als an der differenzierten Begriffsbildung der Kulturwissenschaften bewegten. Insbesondere war in didaktischen Materialien immer wieder ein Kulturverständnis zu erkennen, welches auf der Vorstellung von mehr oder weniger klar voneinander abgegrenzten Nationalkulturen basierte. Zwar wurde in fremdsprachendidaktischen Diskussionsbeiträgen mit einer gewissen Regelmäßigkeit angemahnt, den Kulturbegriff zu reflektieren und diese problematischen Kulturverständnisse zu vermeiden. Jedoch schienen weder diese Mahnungen noch die deutlichen Worte, die auch aus benachbarten Disziplinen zu hören waren - etwa von dem Philosophen Wolfgang Welsch (1994, 1999, 2010) - auf allen Ebenen der Fremdsprachendidaktik ernst genommen zu werden. Dass es sich dabei, zumindest was didaktische Materialien angeht, nicht nur um meine für dieses Problem inzwischen vielleicht besonders geschärfte Wahrnehmung handelte, belegt eine zur Zeit in Dresden entstehende Dissertation. ${ }^{3}$

Da didaktische Materialien für die Qualität des tatsächlich stattfindenden interkulturellen Lernens eine wichtige Rolle spielen dürften, halte ich deren kritische Analyse für einen wichtigen Beitrag zur fachdidaktischen Forschung. Nur so lässt sich überprüfen, inwieweit und in welcher Form Beiträge der Theorieebene in Unterrichtsmaterialien tatsächlich aufgegriffen werden und inwieweit sich damit die Wahrscheinlichkeit erhöht, dass diese theoretischen Überlegungen auch in der Schule rezipiert werden. Mich interessiert dagegen die Frage Was ist Kultur? auf der Ebene der fremdsprachendidaktischen Theoriebildung selbst. Welche Kulturvorstellungen sind in breit rezipierten Grundlagenkonzepten zu Interkulturalität zu finden, auf welche sich alle nachgeordneten Ebenen zumindest mutmaßlich beziehen? Dies zu klären ist eines der Anliegen dieser Arbeit.

Die zweite Frage, die ich mir immer häufiger privat, verstärkt aber auch bei der Beschäftigung mit fremdsprachendidaktischen Themen stellte, ist pädagogisch und politisch mindestens ebenso brisant wie das Denken in den Kategorien homogener Gruppen, denen bestimmte gemeinsame, ,kulturelle

3 Vgl. Klöppner (in Vorbereitung). Bei den untersuchten Lehrwerken handelt es sich nach Auskunft der Autorin um Línea verde, Encuentros Edición 3000, RUTAS Uno und $A \_$tope.com. 
Charaktereigenschaften zugeschrieben werden. Diese Frage wurde und wird in öffentlichen Debatten teils leidenschaftlich diskutiert, ist jedoch, so scheint mir, in fremdsprachendidaktischen Kontexten kaum präsent. Sie ergibt sich aus der These, dass alle Kulturen, alle Lebensweisen und Vorstellungen in gleichem Maße zu tolerieren und zu schützen seien. Diese These, so mein Eindruck, bildete und bildet die unausgesprochene Prämisse zahlreicher Beiträge zur interkulturellen Fremdsprachendidaktik. Gleichzeitig herrschen jedoch ein großer gesellschaftlicher Konsens und, zumindest auf den Gebieten der sogenannten westlichen Industrienationen, auch rechtliche Verbindlichkeit über die genau entgegengesetzte Haltung, die darin besteht, dass eben nicht jede Art zu sprechen oder zu Handeln akzeptabel ist, auch wenn dies Individuen oder Gruppen möglicherweise als Teil ihrer jeweiligen kulturellen Identität verstehen mögen.

Die zweite Frage lautet somit, wie die interkulturelle Fremdsprachendidaktik $\mathrm{zu}$ Weltansichten und Lebensweisen steht, die mit jenen Prinzipien kollidieren, welche aktuell als unverzichtbare Grundlage des friedlichen Zusammenlebens in einer pluralen Gesellschaft angenommen werden. Der Europarat etwa sieht diese Grundlage in den Prinzipien Menschenrechte, Demokratie und Rechtsstaatlichkeit und empfiehlt sie allen Bildungseinrichtungen der Europäischen Union als normativen Rahmen ihrer Arbeit (vgl. Council of Europe 2010).

An Konflikten, die sich aus den partikularen Vorstellungen gesellschaftlicher Gruppen und den genannten Prinzipien ergeben, herrscht bekanntlich kein Mangel. Wie ist etwa die Entscheidung von Eltern zu sehen, ihrem Kind auf Grundlage religiöser Überzeugungen die Verabreichung einer Bluttransfusion zu verweigern, auch wenn es dann stirbt? Greift in diesem Fall das Gebot, eine abweichende Weltansicht zu tolerieren (vgl. Dettmeyer 2006: 217-223)? Wie steht es dagegen mit der Zwangsverheiratung von Mädchen - ebenfalls eine kulturelle Praxis, die es als solche zu schützen gilt (vgl. Mirbach et al. 2011)? Und wenn Eltern ihre Kinder ausschließlich streng religiös und fern staatlicher Schulen unterrichten möchten und dabei den Brauch pflegen, ihnen bei Bedarf mit Hilfe einer $30 \mathrm{~cm}$ langen Rute Gehorsam zu vermitteln (vgl. Mayr 2013) handelt es sich dann ebenfalls um eine Gelegenheit für Lernende, „[...] kulturelle Besonderheiten als Bereicherung zu empfinden und sich daran zu erfreuen“" (Senatsverwaltung für Bildung, Jugend und Sport Berlin 2006: 11), wie es im Berliner Rahmenlehrplan Spanisch für die Sekundarstufe I heißt?

Auch wenn ich zu Illustrationszwecken plakative Beispiele wähle - wenn die Antwort auf diese Fragen jeweils lautet, dass das mit interkultureller Toleranz natürlich nicht gemeint ist, liegt die Vermutung nahe, dass sich interkulturelles 
Lernen eben doch nur auf den Umgang mit harmloser Folklore bezieht, dass man sich ansonsten aus ethisch und politisch relevanten und damit komplizierten Diskussionen aber lieber heraushalten möchte. ${ }^{4}$

Wohlgemerkt vertrete ich hier keineswegs die Position, dass gesellschaftliche, ,kulturelle' Minderheiten sich eben an die Regeln der dominierenden Mehrheit anpassen müssen. Vielmehr halte ich auch bei den Angehörigen gesellschaftlicher Mehrheiten die Anbahnung der Fähigkeit und der Bereitschaft, das ,Eigene' zu hinterfragen und zu kritisieren, für eine zentrale Aufgabe schulischer Bildung, und diese Aufgabe findet sich auch in fast allen Ansätzen interkulturellen Lernens und Modellen interkultureller Kompetenz (vgl. Byram 1997: 45). Es ist jedoch fraglich, wie genau das ,Eigene` und ,Fremde` in der Arbeit mit einer heterogenen Schülerschaft überhaupt bestimmt werden kann. Ebenso fraglich ist, ob eine ,interkulturelle' Kritikfähigkeit ethisch-politisch neutral sein kann, oder ob sie nicht vielmehr einen normativen, gleichzeitig aber reflexiv erschließbaren Rahmen benötigt. Aktuell verfügt die Fremdsprachendidaktik jedoch - so zumindest mein Eindruck - weder über die für nicht-triviale ethisch-politische Fragen unabdingbaren normativen Setzungen noch reflektiert sie diesen $\mathrm{Zu}$ stand in angemessener Weise. Der Umgang mit sogenannten ,kulturellen' Konflikten bleibt somit in letzter Konsequenz sowohl für Lehrkräfte als auch für Lernende eine individuelle Entscheidung (vgl. Europarat 20015: 107).

Die vorliegende Arbeit beginnt in den Kapiteln 1.1.-1.7. mit einer ausführlichen Problemstellung in Bezug auf das oben umrissene Kernkonzept fremdsprachendidaktischer Theorie, die Interkulturalität. Diese Problemstellung mündet in die Formulierung von Arbeitshypothesen und Forschungsfragen (Kap. 1.8.). Anschließend folgen methodologische Überlegungen zum Aufbau der Arbeit (Kap. 1.9.). Im daran anschließenden Kapitel 2 werden die kulturwissenschaftlichen Grundlagen gelegt, die zur Bearbeitung der Forschungsfragen benötigt werden. Dabei werden zum einen verschiedene Kulturverständnisse dargestellt (Kap. 2.1.), zum anderen wird das Dilemma von Universalismus und Kulturrelativismus ausführlich erörtert (Kap. 2.2.). Auf dieser Grundlage werden in Kapitel

4 Der Philosoph Slavoj Žižek sieht den Toleranzbegriff gar als Teil einer neoliberalen kapitalistischen Ideologie. Ich teile seine Einschätzung nicht, sehe aber wie er die Gefahr, dass der Kulturbegriff zur Entpolitisierung von Konflikten eingesetzt werden kann: „Political differences, differences conditioned by political inequality, economic exploitation, etc., are naturalized/neutralized into ,cultural' differences, different, ways of life, which are something given, something that cannot be overcome, but merely ,tolerated. ““ (Žižek 2009: 119)

5 Gemeinsamer europäischer Referenzrahmen, im Folgenden abgekürzt mit GeR. 
3 ausgewählte theoretische Ansätze zum interkulturellen Fremdsprachenunterricht untersucht. Hierdurch wird der Bedarf an einem Zielkonstrukt festgestellt, das zu einer Lösung der zuvor festgestellten zentralen Probleme interkultureller Fremdsprachendidaktik beitragen könnte. Im daran anschließenden theoriebildenden Kapitel 4 werden die Umrisse eines solchen neuen Konstruktes erarbeitet, das als Fremdsprachliche Diskursbewusstheit bezeichnet wird. Der unterrichtspraktische Bezug wird in Form von didaktischen Prinzipien hergestellt, deren Berücksichtigung im Fremdsprachenunterricht zur Anbahnung Fremdsprachlicher Diskursbewusstheit beitragen kann (Kap. 4.5.). Die Arbeit schließt mit einem Fazit und einem Ausblick auf Forschungsdesiderata. 


\section{Kapitel 1: Problemstellung}

\subsection{Rückblick: Landeskunde als Wissensvermittlung über Nationalkulturen}

In der zweiten Hälfte des 20. Jahrhunderts spielte in der Fremdsprachendidaktik der Begriff der Landeskunde eine wichtige Rolle (vgl. Schumann 2010). Das Konzept der Landeskunde beruhte auf der Grundidee, dass Lernende neben den sprachlichen Fertigkeiten (Hörverstehen, Leseverstehen, Sprechen, Schreiben, sowie Wortschatz und Grammatik) auch ein Grundwissen über das Land, dessen (National-)Sprache sie lernten, und über die „Kultur, Geschichte, Geographie, Politik, dann das Wissen um Alltagssituationen“" (Bischof et al. 1999: 7) vermittelt werden sollte. Im Unterricht für Deutsch als Fremdsprache ging es daher vorwiegend um (West-)Deutschland (manchmal auch um die Schweiz, Österreich oder die DDR), im Englischunterricht um Großbritannien und die USA (Nebenschauplätze stellten Irland, Kanada, Australien und Neuseeland dar), im Französischunterricht ging es um Frankreich (und ein wenig um Québec und den Maghreb), und im Spanischunterricht um Spanien und ausgewählte Länder Lateinamerikas. Dabei wurde durchaus berücksichtigt, dass im Unterricht nicht nur „Faktisches der Zielkultur“ (ebd.) behandelt werden sollte, sondern es sollte auch Wissen über „Wertvorstellungen, Glauben, Konzepte von Raum und Zeit“ (ebd.) vermittelt werden. Trotz dieser Erweiterung der Perspektive wurde die Ausrichtung auf Nationalkulturen im Laufe der 1990er-Jahre immer stärker in Frage gestellt, setzte sie doch einerseits voraus, dass es in sich homogene Zielkulturen gebe, die man durch das Erlernen einer bestimmten Sprache erschließen und verstehen könne, und andererseits, dass die Beschäftigung mit einer bestimmten Sprache zu einem Wissenserwerb über bestimmte Staaten und über die in ihnen als dominant angenommenen Lebensentwürfe verpflichte. Im Fremdsprachenunterricht überwog dabei die Bedeutung der EU-Partner England, Frankreich und Spanien. Dies ließ sich zwar einerseits durch die geographische und politische Nähe zu Deutschland rechtfertigen. Andererseits wurde es immer mehr als problematisch empfunden, das Übergewicht der alten Kolonialmächte unhinterfragt fortzuschreiben.

Die Trias von Nation, Sprache und Kultur als einander weitgehend entsprechende Größen des landeskundlichen Fremdsprachenunterrichts geriet jedoch nicht nur wegen der mutmaßlichen Übernahme kolonialer Dominanzverhältnisse unter Legitimationsdruck. Immer stärker wurde dabei auch das Kulturverständnis 
selbst hinterfragt, welches dem landeskundlichen Ansatz zugrunde lag. Dieses lässt sich zurückführen auf Johann Gottfried Herder (vgl. Kap. 2.1.2.). Für ihn stellten Kulturen Kugeln dar, die man sich als nach innen geschlossene und nach außen abgegrenzte Gebilde vorstellen sollte. ${ }^{6}$

Das Herder'sche Kugelmodell wurde u. a. in der Anthropologie ${ }^{7}$ stark rezipiert, denn die Beschreibung und Interpretation einer fremden Kultur wird wesentlich vereinfacht, wenn man sie sich als nach innen tendenziell homogenes und daher nach außen abgrenzbares Gebilde vorstellt. Ähnlich wie Individuen haben in dieser Vorstellung auch Gruppen und Völker eine mehr oder weniger stimmige und stabile Identität:

A culture, like an individual, is a more or less consistent pattern of thought and action. Within each culture there come into being characteristic purposes not necessarily shared by other types of society. In obedience to these purposes, each people further and further consolidates its experience, and in proportion to the urgency of these drives the heterogeneous items of behavior take more and more congruous shape. Taken up by a well-integrated culture, the most ill-assorted acts become characteristic of its peculiar goals, often by the most unlikely metamorphoses. (Benedict 1989 [1934]: 46) ${ }^{8}$

Kulturen sind somit nach Ruth Benedict in der Lage, in ihrer historischen Entwicklung Differenzen und Widersprüche zu überwinden und diese allmählich $\mathrm{zu}$ einem stimmigen Gesamtbild zu integrieren, ganz ähnlich wie Individuen dies im Zuge der Reifung ihrer Persönlichkeit tun können.

Die Landeskunde arbeitete mit diesem Kulturverständnis der Anthropologie. Während diese ihren Fokus jedoch längst von der ,hohen' Kultur auf die Alltagskultur ausgeweitet hatte, erfolgte im nach wie vor philologisch geprägten Fremdsprachenunterricht der Nachkriegszeit der Zugriff auf die Kultur des betreffenden Landes aber noch häufig über dessen als besonders wertvoll angesehene literarische Werke. Von diesem Vorgehen versprach man sich je nach politischer Lage entweder den Zugang zu universalem Wissen oder aber zu nationalen Besonderheiten (vgl. Kramsch 1995: 56).

6 Herders Kulturkonzept wurde vielfach kritisiert, Wolfgang Welsch (vgl. Kap. 2.1.5.) stellte es gar als Wegbereiter des Nationalismus und Rassismus dar.

7 Anthropologie und Ethnologie sind nicht immer leicht voneinander abzugrenzen. Ich verwende hier durchgehend die allgemeinere Bezeichnung Anthropologie. Zur Einführung in die Anthropologie vgl. Wulf (2009). Boas und seine Schüler_innen gelten heute als Begründer und Entwickler der Teildisziplin der Kulturanthropologie (cultural anthroplogy), auch wenn Boas sich selbst vorwiegend als Ethnologe verstand.

8 Zur Kritik am Kulturbegriff der amerikanischen Anthropologie vgl. Kap. 2.1.2. und 2.2.1. 
Im Zuge der kommunikativen Wende nahm die Fremdsprachendidaktik dann auch verstärkt die Ebene der Alltagskultur in den Blick. Ein beliebtes didaktisches Vorgehen bestand hierbei in Vergleichen zwischen Ausgangs- und Zielkultur. Dass dies erstens möglich und zweitens sinnvoll sei, wurde meist stillschweigend vorausgesetzt (vgl. Meißner 2003: 63; Grünewald et al. 2011: 50f.).

Die Ziele landeskundlichen Unterrichts waren in Abhängigkeit von den herrschenden politischen Verhältnissen starken Veränderungen unterworfen. Während in der nationalsozialistischen Zeit die Aufwertung des Eigenen in einem völkisch-nationalen Sinn bei gleichzeitiger scharfer Abgrenzung vom Ausland betrieben wurde, drehte sich die Intention nach Ende des 2. Weltkriegs um. Nun ging es um eine positive Öffnung, in den beiden deutschen Staaten insbesondere im Hinblick auf die jeweiligen Siegermächte (vgl. Decke-Cornill/Küster 2015: 219). Als sich der Fremdsprachenunterricht in den 1970er- und 1980er-Jahren dann zunehmend auf das Leitziel kommunikative Kompetenz ausrichtete, setzte sich immer stärker auch die Auffassung durch, dass landeskundliche Inhalte nicht vom sprachlichen Lernen getrennt, sondern als dessen notwendiger Bestandteil integriert vermittelt werden sollten (vgl. ebd.).

Unabhängig von Fragen nach der politischen Zielsetzung, nach den Inhalten und nach der Integration landeskundlichen Lernens blieb die Ausrichtung auf Nationalkulturen im landeskundlichen Paradigma als Grundproblem aber bestehen. Durch die schnell voranschreitende Globalisierung und die mit ihr einhergehende zunehmende weltweite Verflechtung und Überlappung von Denk- und Lebensweisen lösten sich nationale Grenzen aber immer stärker auf. Bereits 1992 weist Meinert A. Meyer auf den Umstand hin, dass der Begriff, Zielkultur problematisch geworden sein könnte. In seiner Äußerung schwingt dabei geradezu eine Sehnsucht nach den (vermutlich guten) alten Zeiten mit, als es noch klare nationale Grenzen gab, an denen sich der Fremdsprachenunterricht orientieren konnte:

Wenn die ganze Welt,Zielkultur' des Englischunterrichts für deutsche Schüler wird, verschwimmt das, was man landeskundlich-interkulturell machen kann, in diffusem allerlei. (Meyer 1992: 16)

Das Problem stellt sich selbstredend damals wie heute in gleichem Maße auch für die romanischen Schulfremdsprachen Französisch und Spanisch.

Neben der Schwierigkeit, eine Weltsprache nationalen ,Kulturen' einzelner Staaten zuzuordnen, wurde zudem immer häufiger auch auf die Schwächen einer Didaktik hingewiesen, in welcher über eine bestimmte Zielkultur Wissen vermittelt werden sollte, das eben diese Kultur verständlich machen sollte. In diesem Bemühen um Verstehen blieben jedoch, wie man erkannte, wichtige Aspekte 
unberücksichtigt. Zum einen fehlte meist eine systematische reflexive Brechung des ,Eigenen', das ja einem ,Fremden' gegenübergestellt wurde. Der vorwiegend kognitiv-analytische Zugriff auf landeskundliche Inhalte führte zudem dazu, dass diese Reflexion besonders im Hinblick auf deren affektive und attitudinale Dimensionen in der Regel nicht erfolgte (vgl. Meißner 2003: 63; Decke-Cornill/ Küster 2015: 220; Küster 2010: 40).

Die Ausrichtung auf den Erwerb von Wissen über eine ,Zielkultur' und die Vernachlässigung der affektiven und persönlichkeitsbildenden Aspekte bei der Beschäftigung mit diesen Inhalten führten dazu, dass landeskundliches Lernen sich als wenig geeignet zeigte, die Identitätskonstruktionen von Lernenden in Frage zu stellen. Im Gegenteil, die Beschäftigung mit dem ,Fremden' war teilweise explizit darauf angelegt, die Besonderheit des,Eigenen' hervorzuheben, es nach innen zu stabilisieren und nach außen schärfer abzugrenzen. Auch als die Ablösung des Landeskundebegriffs durch den Begriff der interkulturellen Kompetenz bereits eingesetzt hatte, fand sich weiterhin die Ansicht, es solle zwar um eine möglichst differenzierte und empathische Auseinandersetzung mit dem Fremden gehen, aber doch mit dem Ziel, das Eigene zu affirmieren. So schreibt Meyer (1992: 16, Hervorhebung J. P.):

Ich definiere: Interkulturelle Kompetenz ist die Fähigkeit, sich adäquat und flexibel gegenüber den Erwartungen der Kommunikationspartner aus anderen Kulturen zu verhalten, sich der kulturellen Differenzen und Interferenzen zwischen eigener und fremder Kultur und Lebensform bewußt zu werden und in der Vermittlung zwischen den Kulturen mit sich und seiner kulturellen Herkunft identisch zu bleiben.

Von einem solchen Standpunkt aus übersieht man jedoch leicht, dass kulturelle Verortungen nicht nur auf kollektiver, sondern auch auf individueller Ebene erfolgen und damit oft erheblich voneinander abweichen (vgl. Hu 1996; Decke-Cornill/ Küster 2015: 220; Bach 2010: 27). Darüber hinaus bleibt dabei die Vorläufigkeit, Hybridität und Narrativität von Identitätskonstruktionen unberücksichtigt, Themen, mit denen sich die neuere Identitätsforschung ausführlich beschäftigt und die auch für Bildungsprozesse hoch relevant sind (vgl. Koller 2012: 34-44). Eine Didaktik, welche sich die Stabilisierung des, Eigenen' zum Ziel setzt, steht zudem unter dem Verdacht, einseitig konservative Ziele zu verfolgen: Auf der Ebene der Individuen verschenkt sie möglicherweise Gelegenheiten, Fremdheitserfahrungen als Bereicherung zu erleben, als Chance, die eigenen „Welt- und Selbstverhältnisse" (ebd.: 19) selbst zu hinterfragen und gegebenenfalls zu aktualisieren. Im Hinblick auf die gesellschaftlichen Auswirkungen muss sie sich den Vorwurf gefallen lassen, nicht die Modernisierung, sondern die Bewahrung der dominierenden gesellschaftlichen Strukturen zu betreiben. 
In Bezug auf den Kulturbegriff stellte sich die Problemlage in der Fremdsprachendidaktik in den 1980er und 1990er-Jahren dergestalt dar, dass aus mehreren Bezugswissenschaften längst Einwände vorlagen gegen die Auffassung, das ,Fremde könne überhaupt als tendenziell homogene und statische Größe und in Abgrenzung von einem, Eigenen ' beschriebenen werden, das dabei ja zwangsläufig mitgedacht werden muss (vgl. aus soziologischer Sicht z.B. Simmel 1908: 509-512 und Hahn 1994; aus psychoanalytischer Sicht z.B. Kristeva 1988; aus anthropologischer Sicht z.B. Geertz 1973). Die genannten Autor_innen sind sich einig in dem Anliegen, die Beziehung zwischen dem ,Eigenen' und dem ,Fremden' als komplexes Wechselspiel herauszuarbeiten (vgl. Kap. 2.1.4.), dessen Ausgangspunkte und Ergebnisse vorläufige, fließende, hybride Identitäten und Gemeinschaften sind. Der Ansatz, das ,Fremde‘ in Gestalt einer Nationalkultur zum Gegenstand des Fremdsprachenunterrichts zu machen, war in diesem Licht kaum mehr zu halten. Genau darin bestand aber häufig der Kern des am Konzept der Landeskunde ausgerichteten Fremdsprachenunterrichts.

\subsection{Aufstieg des Kulturbegriffs zur Leitkategorie der Humanwissenschaften}

Die Dichotomie des ,Eigenen' und ,Fremden' stand aufgrund der Entwicklungen in verschiedenen Nachbardisziplinen bereits unter Druck, und mit ihr die Landeskunde, die ohne diese Dichotomie nicht auskam. Zusätzlich wurde die Landeskunde aber durch zwei weitere Tendenzen immer stärker in Frage gestellt.

Zum einen erlebten die Humanwissenschaften insgesamt ab den 1960erJahren eine verstärkte Hinwendung zum Kulturbegriff, ein Paradigmenwechsel, der heute üblicherweise mit ,Cultural turn' bezeichnet wird (vgl. Geertz 1973, Reckwitz 2000: 22-38, Bachmann-Medick 2006). Die Impulse für diese Entwicklung gingen vorwiegend von der Soziologie, der Anthropologie, der Literatur- und der Geschichtswissenschaft aus. Wie sehr Kultur zum Leitkonzept wurde, zeigen einerseits die entsprechenden Tendenzen innerhalb der etablierten akademischen Fächer. Am deutlichsten lässt sich der Aufschwung des Kulturbegriffs zum zentralen Begriff der Humanwissenschaften aber an der Entstehung der Kulturwissenschaften als neuer Disziplin festmachen. Entscheidend ist, dass diese sich nicht einfach als ein weiteres Fach im Kanon der Humanwissenschaften verstehen. Vielmehr sehen sie sich als Metawissenschaft, als Forschungsprogramm, welches alle etablierten humanwissenschaftlichen Disziplinen überspannt (vgl. Reckwitz 2004: 1-3; Böhme 1996). 
Mit dem Aufstieg der Kulturwissenschaften erfolgte auch eine intensivere Auseinandersetzung mit deren zentralem Bezugskonzept - ,Kultur' (vgl. Kap. 2.1.). Zwar monierte Claire Kramsch (1995: 60) noch Mitte der 1990er Jahre, es gebe „[...] leider auch gar keine gegenseitige Befruchtung zwischen Sprachunterricht und dem Bereich, der sich ,cultural studies' nennt.“ Zumindest allmählich zeigten sich jedoch bereits damals Ansätze, kulturwissenschaftliche Kulturverständnisse für den Fremdsprachenunterricht zu erschließen (vgl. Hu 1996). Auf welche Konzepte von Kultur konnte die Fremdsprachendidaktik dabei zurückgreifen?

Kulturwissenschaftliche Konzepte von Kultur versuchen, die Vorstellung von homogenen Kulturräumen zu überwinden, indem sie an semiotische Theorien anknüpfen und Kultur als Gewebe von Bedeutungen modellieren. In diese Gewebe, so eine verbreitete Auffassung, ist jeder Mensch durch seine Sozialisation einerseits verflochten. Andererseits spinnt er aber durch sein Handeln und durch sein Sprechen auch selbst ständig neue Fäden. So heißt es bei Clifford Geertz (1973: 5) in einer häufig zitierten Passage:

Believing, with Max Weber, that man is an animal suspended in webs of significance he himself has spun, I take culture to be those webs, and the analysis of it to be therefore not an experimental science in search of law but an interpretive one in search of meaning.

Ein anderes, an Clifford Geertz' Ansatz jedoch anschlussfähiges Konzept wurde maßgeblich von dem deutschen Kulturwissenschaftler Andreas Reckwitz (vgl. Kap. 2.1.4.) geprägt. Er stellt den Kontingenzgedanken in den Mittelpunkt seiner Überlegungen $\mathrm{zu}$ einem bedeutungs- und wissensorientierten, ,kulturwissenschaftlichen' Kulturverständnis.

Auf den indischstämmigen Kulturtheoretiker Homi Bhabha gehen ebenfalls wichtige Impulse für die kulturwissenschaftliche Theoriebildung zurück, insbesondere das Konzept des, dritten Ortes. Claire Kramsch kommt das Verdienst $\mathrm{zu}$, es für die fremdsprachendidaktische Diskussion erschlossen und weiterentwickelt zu haben (vgl. Bhabha 1994; Kramsch 1995, 1999; vgl. Kap. 3.3.).

Diese kulturtheoretischen Ansätze sind in mehrerlei Hinsicht kompatibel, unter anderem in der Absage, welche sie Kulturvorstellungen erteilen, die von nach innen homogenen und nach außen abgrenzbaren (national-)kulturellen Räumen ausgehen. Eben diese Vorstellungen sind aber die Grundlage einer Fremdsprachendidaktik, die sich am Begriff der Landeskunde orientiert. 


\subsection{Pluralisierung von Gesellschaften als Folge der Globalisierung}

Die Landeskunde stand somit spätestens seit Beginn der 1990er-Jahre insofern auf dem Prüfstand, als ihre Grundannahmen - allen voran die Existenz tendenziell homogener und statischer Nationalkulturen und die darauf aufbauende Dichotomie des Eigenen und Fremden - nur noch zu halten waren, solange man die Erkenntnisse wichtiger Bezugsdisziplinen wie der Soziologie, der Psychologie, der Literatur- und Kulturwissenschaft ignorierte.

Während nun der cultural turn in den Humanwissenschaften als zwar einschneidende, aber doch theoretische und daher in ihrer Wirkmacht vorwiegend den akademischen Bereich betreffende Entwicklung gesehen werden kann, hatte und hat ein weiterer Faktor Auswirkungen auf alle Lebensbereiche. Für diesen Faktor hat sich der mittlerweile zum Klischee gewordene Begriff der Globalisierung etabliert. Er stellt einen Versuch dar, die in ihren Ursachen und Auswirkungen außerordentlich komplexen epochalen Veränderungen zu bündeln, die sich ab etwa 1990 beobachten lassen. Schlagwortartig können in diesem Zusammenhang mehrere Aspekte genannt werden, die untereinander in dynamischen, sich teilweise gegenseitig verstärkenden Wechselwirkungen stehen: der Fall des eisernen Vorhangs; die Auflösung nationaler zugunsten transnationaler Strukturen; das starke Anwachsen des Welthandels; die Entwicklung und weltweite Verfügbarkeit digitaler Kommunikationsmedien; die Zunahme an Migrationsbewegungen (vgl. Beck 2002).

Das Konzept der Landeskunde befand sich also gleich in doppelter Hinsicht unter Druck: zum einen durch die spätestens seit den 1970er-Jahren nicht mehr zu übersehende Überarbeitung des Kulturbegriffs, zum anderen durch das Phänomen der Globalisierung, welche die Durchmischung und Hybridisierung von Gesellschaften befeuerte und dies bis heute tut. In diesem Zusammenhang ist zu betonen, dass kulturelle Heterogenität keine historische Neuheit darstellt. Die Großreiche der Antike (Persien, Griechenland, Rom) waren ebenso multikulturell wie das Heilige Römische Reich Deutscher Nationen es war und die Nationalstaaten der Neuzeit es sind. Für letztere gilt jedoch, dass sie diese Unordnung nicht mehr als gottgegeben akzeptierten, sondern gestaltend unter Kontrolle bringen wollten. Der Historiker Jörg Baberowski (2006: 37) erinnert in diesem Zusammenhang daran, dass die Bestrebungen der Neuzeit, Bevölkerungen zu homogenisieren, immer zu ihrem exakten Gegenteil geführt haben: „Es ist das Dilemma des modernen Strebens nach Ordnung, dass es die Unordnung, die es beseitigen will, stets neu hervorruft. " Die zeitgenössische Forderung nach gesellschaftlicher Akzeptanz von Pluralität wird zu Recht auch mit Verweis auf diesen 
historischen Zusammenhang gestellt. Das politische Projekt der Überwindung nationalstaatlicher Grenzen und die damit verbundene Zunahme von Migration, Warenaustausch und Kommunikation setzen jedoch die Notwendigkeit, mit Pluralität umzugehen, insbesondere für die demokratischen Gesellschaften der Gegenwart mit neuer Dringlichkeit auf die Tagesordnung.

\subsection{Interkulturelle Fremdsprachendidaktik als Reaktion auf den ,Cultural turn' und die Globalisierung}

Die Überarbeitung und Ausdifferenzierung des Kulturbegriffs, seine wachsende Bedeutung in wichtigen Bezugswissenschaften der Fremdsprachendidaktik sowie die Auswirkungen der Globalisierung stellten die Landeskunde als didaktisches Konzept grundlegend in Frage. Die von Herder sowie von der Anthropologie des 19. und der ersten Hälfte des 20. Jahrhunderts übernommene Vorstellung, man habe es beim Lernen fremder Sprache mit homogenen Gruppen zu tun, welche sich in abgrenzbaren geographischen Räumen aufhielten und dort ihr Leben nach festen Codices gestalteten, war spätestens durch die genannten Entwicklungen obsolet geworden. Die deutschsprachige Fremdsprachendidaktik reagierte, indem sie Impulse sowohl aus den genannten Bezugsdisziplinen als auch aus der englisch-amerikanischen Fachdiskussion aufnahm (vgl. z.B. Byram 1997; Kramsch 1999) und den Begriff der Interkulturalität zu einem Forschungsschwerpunkt erhob. Exemplarisch sei hierfür das Gießener Graduiertenkolleg Didaktik des Fremdverstehens genannt, das von 1991-2003 bestand und aus dem zahlreiche Forschungsarbeiten hervorgingen (vgl. Bredella et al. 2000 sowie Kap. 3.2.). Auch außerhalb des Gießener Kollegs widmen sich seither zahlreiche Einzelbeiträge und Sammelpublikationen dem Thema (u.a. Hu/Byram 2009; Caspari/Küster 2010).

In der seit den 1990er Jahren entwickelten, auf die Interkulturalität fremdsprachlichen Lernens ausgerichteten Didaktik bleiben Elemente der Landeskunde jedoch durchaus erhalten, oft in Gestalt des sogenannten soziokulturellen Orientierungswissens. In den Bildungsstandards für den mittleren Schulabschluss von 2003 etwa wird es als einer der drei Hauptbestandteile von „Interkulturellen Kompetenzen" aufgeführt (KMK 2003: 8). ${ }^{9}$

9 Die beiden anderen sind „verständnisvoller Umgang mit kultureller Differenz“ und „praktische Bewältigung interkultureller Begegnungssituationen“ (KMK 2003: 8). 
Auch Michael Byrams stark rezipierte Monographie Teaching and assessing intercultural communicative competence führt landeskundliches Wissen als eines der fünf savoirs an. ${ }^{10}$ Byram (1997: 35) definiert dort savoir/knowledge wie folgt:

The knowledge individuals bring to an interaction with someone from another country can be described in two broad categories: knowledge about social groups and their cultures in one's own country, and similar knowledge of the interlocutor's country on the one hand; knowledge of the processes of interaction at individual and societal levels, on the other hand.

An den genannten Beispielen ist zu sehen, dass es sich beim Übergang zum Interkulturalitätsbegriff nicht um eine vollständige Ablösung der Landeskunde handelte, sondern eher um deren Weiterentwicklung. An folgender von FranzJoseph Meißner (2003: 60-63) zusammengestellten Übersicht lassen sich die wesentlichen Aspekte ablesen, die man durch den Übergang von der Landeskunde zur Interkulturalität zu verwirklichen hoffte:

- von einem statischen zu einem dynamischen Kulturbegriff

- von der Repräsentativität zur Exemplarizität des Lernens

- von einem kognitiv-analytischen zu einem affektiv-empathischen Zugang

- von der Wissens- und Verstehensorientierung zur Handlungsorientierung

- von der Stabilisierung von Selbstkonzepten zu deren Infragestellung

Auch wenn Meißner hier das innovative Potential der Interkulturalität betont: Diese Entwicklungen erfolgten im besten Fall allmählich und ließen Raum für eine Fortdauer der landeskundlichen Didaktik im neuen Paradigma.

Die in der zweiten Hälfte der 1990er-Jahre mit Nachdruck einsetzende Theoriebildung zu einer Didaktik der Interkulturalität, die Meißner im genannten Beitrag in einer Art Zwischenbilanz mit dem landeskundlichen Ansatz kontrastiert, wurde von der Aufnahme des Begriffs in administrative Vorgaben sogar überholt. Zu einer Zeit, als konzeptionelle Fragen noch zum Teil äußerst kontrovers diskutiert wurden (zusammenfassende Darstellungen finden sich z.B. bei Hu 1999 und Rathje 2006, neuere Beiträge zur anhaltenden Debatte sind z.B. Bonnet/Breidbach 2007 und Bredella 2010b), hatte sich interkulturelle Kompetenz als tragende Säule des Fremdsprachenunterrichts in administrativen Leitdokumenten auf europäischer (vgl. Europarat 2001), nationaler (vgl. KMK 2003) und länderspezifischer Ebene (vgl. z.B. Senatsverwaltung für Bildung, Jugend

10 Die vier anderen savoirs sind savoir comprendre/skills - interpret and relate; savoir apprendre/faire/skills - discover and/or interact; savoir sengager/education; savoir être/ attitudes (vgl. Byram 1997: 34). 
und Sport Berlin 2006) bereits durchgesetzt. Auch widmen sich inzwischen zahlreiche unterrichtspraktische Publikationen dem Thema (für den Französischunterricht vgl. z.B. Vatter/Zapf 2012).

\subsection{Terminologischer Exkurs: Interkulturelle Bildung, interkulturelles Lernen oder interkulturelle Kompetenz?}

Die Einführung des Interkulturalitätsgedankens in den fremdsprachendidaktischen Kontext setzte auch neue terminologische Fragen auf die Tagesordnung. Neben der Schwierigkeit, den Interkulturalitätsbegriff im Spannungsfeld zwischen komplexer Theoriebildung und für den schulischen Unterricht notwendiger Didaktisierung zu modellieren, war auch das Problem zu klären, welches didaktische Leitkonzept sich hierfür am besten eignete - ,Lernen',,Bildung' oder doch ,Kompetenz', das Konzept, das die erziehungswissenschaftliche Fachdiskussion spätestens seit der Jahrtausendwende dominiert? Ohne diese Frage hier beantworten zu wollen, lohnt sich doch ein kurzer Blick auf die semantischen Verschiebungen, welche die Begriffe Lernen, Kompetenz und Bildung in ihren Zusammensetzungen mit dem Interkulturalitätsbegriff erfahren haben.

Für sich allein rücken die Begriffe jeweils unterschiedliche Schwerpunkte in den Zielsetzungen von Schule in den Blick. Der Lernbegriff meint traditionell die Aneignung von Wissen und Fertigkeiten, durchaus auch im Sinne des oben beschriebenen landeskundlichen Wissens. In Abgrenzung zum Bildungsbegriff wird aus informationstheoretischer Perspektive zudem hervorgehoben, dass Lernen zu verstehen ist...

[...] als Prozess der Aufnahme, Aneignung und Verarbeitung neuer Informationen [...], bei dem jedoch der Rahmen, innerhalb dessen die Informationsverarbeitung erfolgt, selber unangetastet bleibt. (Koller 2012: 15)

Der Bildungsbegriff evoziert hingegen eine lange Tradition, die von der griechisch-römischen Antike über das Mittelalter, die Aufklärung sowie über Wilhelm von Humboldt bis in die Gegenwart hinein fortdauert. Humboldt knüpfte an das Erbe des Humanismus an und wandte sich vor allem gegen den Gedanken der Verwertbarkeit des Menschen. Nach Humboldt hat Bildung vielmehr die Aufgabe, der Persönlichkeitsentfaltung jedes einzelnen Menschen Vorrang vor der Berufsausbildung zu geben. Hierfür ist „[...] Freiheit die erste, und unerlassliche Bedingung"(Humboldt 1960-1981, Bd. I: 64; vgl. Koller 2012: 11; Gudjons 2006: 89f.). In der Idee der Entfaltung als Prozess, für den zwar günstige Bedingungen geschaffen werden können, der sich aber nicht steuern oder vorhersagen lässt, wird auch eine Abgrenzung zum Erziehungsbegriff deutlich, der stärker von der Formbarkeit des 
Individuums ausgeht und der in benachbarten Bildungsdiskursen eine zentrale Rolle spielt. ${ }^{11}$ Außerdem wird häufig darauf hingewiesen, dass es sich nur dann um Bildungsprozesse handle, wenn nicht nur das Verstehen von Information selbst, sondern auch der ursprüngliche Rahmen des Verstehens erweitert wird (vgl. Koller 2012: 15).

Der Kompetenzbegriff schließlich hebt erstens darauf ab, dass Lernprozesse nicht mehr im Hinblick auf die Inhalte, durch welche sie angestoßen werden, sondern stärker im Licht ihrer Ergebnisse betrachtet werden sollen. Es geht daher weniger um den Input als um den Output, der beobachtbar, evaluierbar und idealerweise auch quantifizierbar sein soll. Zweitens betont der Kompetenzbegriff die Verbindung von Wissen und Können. Durch diese auf die Anwendung von Kenntnissen ausgerichtete Dimension erhält der Kompetenzbegriff einen handlungsorientierten Charakter (vgl. Weinert 2001: 27f; Europarat 2001: 21; Bonnet/Breidbach 2013: 22f.).

Im Gegensatz zu seiner Bedeutung in den allgemeinen Erziehungswissenschaften nimmt der Begriff der ,interkulturellen Bildung' in der aktuellen fremdsprachendidaktischen Debatte eher eine Randposition ein. Die Begriffe ,interkulturelles Lernen' und ,interkulturelle Kompetenz' sind in der aktuellen Fremdsprachendidaktik jedoch geradezu allgegenwärtig. Auch wenn die Terminologie nicht immer trennscharf verwendet wird, scheint sich doch eine Unterscheidung durchzusetzen, die sich in dem Begriffspaar ,Prozess' vs. ,Ziel ${ }^{c}$ zusammenfassen lässt. Diese Unterscheidung geht zurück auf einen Beitrag von Evelyn Röttger (1996: 157): „Interkulturelles Lernen ist als ein Prozeß zu verstehen, der mit dem Ziel in Gang gesetzt werden soll, interkulturelle Kompetenz(en) zu schaffen." So greift beispielsweise Daniela Caspari (2008: 20) zustimmend auf Röttgers Unterscheidung zurück. Die griffige Formel interkulturelles Lernen $=$ Prozess, interkulturelle Kompetenz $=$ Ziel stößt jedoch auch auf Kritik. Lutz Küster etwa befürchtet eine unzulässige Reduzierung des Interkulturalitätsgedankens, wenn, wie im genannten Beitrag von Evelyn Röttger (1996: 157), interkulturelle Kompetenz als Fähigkeit zur erfolgreichen Lösung von Problemen im Sinne einer Suche nach Konsens beschrieben wird, in Röttgers Formulierung als „Handlungskompetenz zur Herstellung von Gemeinsamkeit“ (vgl. Küster 2010: 40). Hier steht das Ziel im Vordergrund, Kommunikation auf der Grundlage von interkultureller Kompetenz möglichst effizient zu gestalten. Andere Aspekte kommen dabei aber, wie Küster hervorhebt, zu kurz:

11 Vgl. engl. education, frz. éducation, span. educación, etc. Zum Erziehungsbegriff vgl. einführend Koller 2004: 48-69. 
Von ausschlaggebender Bedeutung für interkulturell reflektiertes Verhalten sind hingegen in erster Linie persönlichkeitsbezogene Faktoren wie Neugier auf andere Menschen, Empathiefähigkeit, Selbstkenntnis und cultural awareness. (ebd., Hervorhebung im Original)

Folgende Beobachtung scheint mir in der hier nur kurz angerissenen terminologischen Diskussion um ,interkulturelles Lernen' vs. ,interkulturelle Kompetenz bemerkenswert: Der Lernbegriff wird für sich allein meist mit dem Erwerb von Kenntnissen und Fähigkeiten assoziiert und verweist auf einen (Ziel-)Zustand, in welchem diese in Form von Wissen verfügbar sind. Interkulturelles Lernen wird hingegen als angemessener Terminus für einen Vorgang empfunden, dessen Prozesshaftigkeit, Unabgeschlossenheit und Reflexivität unterstrichen werden soll. Mit dem Kompetenzbegriff verhält es sich umgekehrt: Kompetenz allein wird meist als mentale Disposition modelliert, die sich als Verbindung zwischen Wissen und Können auszeichnet. Sie umfasst zudem die Fähigkeit und Bereitschaft, dieses Wissen und Können anzuwenden. Hierzu sind bestimmte Einstellungen und Haltungen notwendig, zumindest in der inzwischen klassischen Definition von Franz E. Weinert (2001: 27f.):

Dabei versteht man unter Kompetenzen die bei Individuen verfügbaren oder durch sie erlernbaren kognitiven Fähigkeiten und Fertigkeiten, um bestimmte Probleme zu lösen, sowie die damit verbundenen motivationalen, volitionalen und sozialen Bereitschaften und Fähigkeiten, um die Problemlösungen in variablen Situationen erfolgreich und verantwortungsvoll nutzen zu können.

Obwohl der Kompetenzbegriff also zumindest in der stark rezipierten Weinert'schen Definition deutlich weiter gefasst ist als der Lernbegriff, wird er in Kombination mit dem Interkulturalitätsbegriff in vielen Beiträgen als verkürzend empfunden - der Lernbegriff hingegen nicht. Dieser scheinbare Widerspruch lässt sich auflösen, wenn man den Blick auf einen anderen Aspekt der Semantik des Kompetenzbegriffs richtet. Nicht eng vs. weit bzw. Wissen vs. Wissen + Können + Haltung, sondern zwei weitere Dimensionen führen immer wieder zu der Feststellung, dass ,interkulturelle Kompetenz' einen problematischen Terminus darstelle. Zum einen ist dies die Messbarkeit, welche der Kompetenzbegriff nahelegt, und zum anderen der mit ihm verknüpfte Effizienzgedanke („Problemlösungen in variablen Situationen erfolgreich und verantwortungsvoll nutzen zu können“, s. o.). Die bildungspolitischen Diskurse und strukturellen Entscheidungen der letzten Jahre haben besonders diese Aspekte betont, teilweise in starker Verkürzung des bei Weinert weit gefassten Kompetenzbegriffs. In Zusammenhang mit dem Lernbegriff hingegen werden die Fragen nach Effizienz und Messbarkeit in der aktuellen Diskussion deutlich weniger häufig gestellt. Somit wird verständlich, 
wenn Küster (2010: 40f.) seine Überlegungen zur Frage einer angemessenen Terminologie wie folgt zusammenfasst:

Wenn ich hier am Begriff, interkulturelles Lernen' festhalte, so deshalb, weil er am breitesten verwendet wird und daher alle genannten Facetten mit transportiert. Mit anderen Worten, mir ist ein Verständnis interkulturellen Lernens wichtig, das gleichermaßen die Ebenen der Kenntnisse, der Haltungen und der Handlungen einbezieht. Da diese Lernprozesse weder direkt beobachtbar noch direkt steuerbar sind, mag die Rede über interkulturelles Lernen vielfach spekulativ erscheinen. Dieser Umstand sagt hingegen nichts über die Bedeutung des Ziels aus.

\subsection{Unbehagen angesichts des Interkulturalitätsbegriffs in der Fremdsprachendidaktik}

Während manche Verzögerungen, Inkongruenzen und Terminologiefragen im Rahmen der Übernahme des „chronisch vieldeutigen Kulturbegriffs" (Reckwitz 2004: 2) in die Fremdsprachendidaktik in einer Übergangsphase als normaler Prozess der innerdisziplinären Konzeptbildung gesehen werden können, stellt sich aus heutiger Sicht, nach gut 20 Jahren intensiver Forschungsaktivität, die Frage nach einer Zwischenbilanz. Inwiefern sind die Unklarheiten und Widersprüche, welche die zügige Übernahme des Interkulturalitätsbegriffs in Theoriebildung, Forschungspraxis, administrativen Dokumenten und unterrichtspraktischen Vorschlägen verursacht hat, inzwischen ausgeräumt?

Für Küster betreffen die Schwierigkeiten, denen sich die Fremdsprachendidaktik in diesem Zusammenhang weiterhin stellen muss, zwei wichtige Aspekte. Einerseits müsse immer wieder neu auf die Verwendung eines zeitgemäßen Kulturbegriffs geachtet werden, andererseits müsse, wie die oben zitierte Passage zeigt (vgl. Küster 2010: 40f.), dieser Begriff auf Grundlage eines passenden didaktischen Leitkonzeptes in den Kontext des Lehrens und Lernens fremder Sprachen überführt werden. Ähnlich wie Küster warnt auch Claus Altmayer regelmäßig davor, auf veraltete Kulturkonzepte zurückzugreifen. Er stellt der interkulturell ausgerichteten Fremdsprachendidaktik ein denkbar schlechtes Zeugnis aus, wenn er schreibt:

Die Herausbildung eines kulturwissenschaftlichen Forschungsparadigmas innerhalb der Fremdsprachenwissenschaften steht, aller [sic] Bemühungen zum Trotz, noch sehr am Anfang. Vor allem ist es bisher nicht gelungen, die zu Recht differenzierteren Theoriekonzepte praktisch fruchtbar zu machen, sei es nun unterrichtspraktisch oder sei es forschungspraktisch. (Altmayer 2009: 124)

Altmayer hält es insbesondere für bedenklich, dass kulturwissenschaftliche Konzepte bisher nur schleppend oder gar nicht erschlossen worden seien. Auch 
auf Grundlage einer eigenen Pilotstudie zu kulturellen ${ }^{12}$ Lernprozessen konstatiert er, durchaus selbstkritisch, in Bezug auf eine interkulturell ausgerichtete Sprachdidaktik vorwiegend „Probleme und offene Fragen“ (ebd.: 136). Es sei zu befürchten, dass die Fremdsprachendidaktik weiterhin auf essentialistische Kulturkonzepte zurückgreifen könnte, wie sie etwa in den Arbeiten des niederländischen Kulturwissenschaftlers Geert Hofstede und des deutschen Psychologen Alexander Thomas zu finden seien:

Beide Ansätze gehen von der impliziten Vorstellung aus, wonach ,Kulturen' im Sinne von ,Nationalkulturen' in sich abgeschlossene und nach innen weit gehend homogene Einheiten sind, über die sich allgemeine Aussagen nach dem Muster ,Amerikaner empfinden es als ihre Pflicht...' oder ,Für Deutsche gilt die Regel...' [...] aufstellen lassen. Die alltägliche Erfahrung, dass nicht alle Amerikaner bzw. alle Deutschen gleich sind, wird mit dem Hinweis auf eine allerdings nicht genau qualifizierte, Mehrheit' oder mit der Rede von einer gewissen ,Tendenz' o.ä. abgetan. [...] [D]as ,Erlernen` des von Hofstede und Thomas angebotenen kulturellen, Wissens' führt tatsächlich nur zur Verfestigung bestehender stereotypischer Denk- und Wahrnehmungsweisen und ist daher für jede Art von seriösem ,interkulturellem Lernen` nicht nur völlig unbrauchbar, sondern geradezu schädlich. (Altmayer 2004: 102f.; vgl. Volkmann 2010: 83; Thomas 1996: 112)

In Übereinstimmung mit Altmayer formuliert auch Gerhard Bach die Einschätzung, dass fachdidaktische Ansätze zum interkulturellen Lernen und unterrichtspraktische Vorschläge für ihre Umsetzung hinter den Konzepten der Kulturwissenschaften zurückbleiben. Die Lücke, die sich aus seiner Sicht auftut zwischen der Fachliteratur zum interkulturellen Lernen und der Art und Weise, wie dieses Lernen bei seinen eigenen Studierenden stattfindet - oder eben nicht stattfindet -, erzeuge bei ihm gar ein allgemeines Unbehagen. Besonders stark empfinde er dieses Unbehagen, wenn differenzierte theoretische Ansätze in idealtypischen didaktischen Inszenierungen (in einem von ihm zitierten Beispiel geht es um einen E-Mail-Tandem-Kurs) mit mutmaßlich offenen und toleranten Teilnehmern umgesetzt werden (in seinem Beispiel mit französischen und amerikanischen Studierenden) - und es statt zum erhofften interkulturellen Lernen zum Zusammenbruch der Kommunikation kommt (vgl. Bach 2010: 24-26). In den einleitenden Bemerkungen zu seinem Beitrag, in dem er einen solchen „communication breakdown“ (ebd.) schildert, betont Bach (2010: 17) daher:

This paper raises more questions than it provides answers. It reflects [...] a general unease on my part with a number of pedagogical paradigms abounding in the current

12 Ich deute die Vermeidung der gängigen Vorsilbe inter- bei Altmayer als das Bemühen um eine Terminologie, welche dichotomische Vorstellungen von Kultur möglichst vermeiden soll. 
discourse on foreign language didactics. This unease mainly stems from a disparity in what I read in the critical literature on intercultural learning and how I have observed such intercultural learning to occur in the classroom with my own university students or not occur, or to occur with rather unexpected results.

Es lässt sich daher festhalten, dass die seit etwa 20 Jahren betriebene Modellierung und Anwendung des Interkulturalitätsbegriffs zumindest von manchen Vertretern der romanistischen, anglistischen und DaF-/DaZ-Didaktik bis heute als unbefriedigend eingeschätzt werden. Ebenso deutlich wie die Vorschläge auf der Theorieebene werden dabei Beispiele für die Anwendung des Interkulturalitätsbegriffes in Forschungs- und Unterrichtspraxis kritisiert. Oft kreist diese Kritik um einen zentralen Aspekt, und zwar, etwa in den bereits genannten Beiträgen von Altmayer und Bach, um den Umstand, dass Konzeptionen von Kultur zum Einsatz kommen, die aus kulturwissenschaftlicher Sicht als überholt und aus pädagogischer Sicht als kontraproduktiv anzusehen sind. Aus dieser Diskrepanz entsteht bei Bach der bereits zitierte „,general unease“, ein Gefühl, das ich mit Unbehagen übersetze und mit ihm teile. ${ }^{13}$

Während auf die Notwendigkeit, in der interkulturellen Fremdsprachendidaktik einen zeitgemäßen Kulturbegriff zu verwenden, in der Literatur seit Einführung des Konzeptes durchaus regelmäßig hingewiesen wird, ist dagegen ein zweiter Aspekt, den ich im folgenden Abschnitt umreißen möchte, bisher wenig diskutiert worden. ${ }^{14}$

\subsection{Unbehagen angesichts kulturrelativistischer Tendenzen in der Fremdsprachendidaktik}

In der Fachliteratur und in administrativen Leitdokumenten herrscht großes Einvernehmen darüber, dass es eines der Hauptanliegen interkultureller Fremdsprachendidaktik sein soll, Lernende in die Lage zu versetzen, das Eigene zu hinterfragen und dem Fremden aufgeschlossen, neugierig und tolerant zu begegnen. ${ }^{15}$ So heißt es etwa im GeR im einleitenden Kapitel, unter Bezugnahme auf die Empfehlung R (98) 6 des Ministerkomitees des Europarats (vgl. Council of Europe 1982), es solle politisches Ziel für die fremden Sprachen sein, „[...]

13 Nicht gemeint ist im Rahmen der hier ausgeführten Überlegungen das von Sigmund Freud (2004 [1930]) beschriebene „Unbehagen in der Kultur“, das sich nach Freud aus der gesellschaftlich notwendigen Triebunterdrückung speise.

14 Eine Zusammenstellung dieser und anderer ungelöster Fragen der interkulturellen Didaktik findet sich bei Rathje 2006.

15 Zur Problematik der Dichotomie des,Eigenen` und,Fremden'vgl. Kap. 2.1.2. und 3.2.5. 
durch effektivere internationale Kommunikation gegenseitiges Verständnis und Toleranz sowie die Achtung von Identitäten und von kultureller Vielfalt zu fördern" (Europarat 2001: 16). Eine andere Stelle im GeR nennt als Bestandteile interkultureller Kompetenz bestimmte Einstellungen, unter anderem die „Bereitschaft, die eigene kulturelle Sichtweise und das eigene kulturelle Wertesystem zu relativieren" (ebd.: 107). Keine Weltsicht, wird sinngemäß immer wieder betont, könne für sich einen alleinigen Wahrheitsanspruch erheben, sondern es gehe im Gegenteil darum zu lernen, eine jeweils andere Weltsicht in ihrer Andersheit anzuerkennen und von ihr zu lernen.

Worte wie diese können mit breiter Zustimmung rechnen, und ohne Zweifel ist zu begrüßen, dass in Zeiten, in denen das Modell einer offenen, demokratischen Gesellschaft durch Nationalismus, Rassismus und religiösen Fanatismus bedroht wird, ein weitgehender Konsens darüber herrscht, dass Werte wie Toleranz, Offenheit und Wertschätzung von Vielfalt zu den wichtigsten Anliegen des Bildungswesens gehören sollen. Ansätze für (Inter-)Kulturelle Kompetenz integrieren diese Werte daher in ihre Zielkataloge und müssen kaum mit Widerspruch rechnen. Neben der Bedeutung dieser Werte für plurale Gesellschaften könnte jedoch auch eine besondere Eigenschaft des Kulturbegriffs selbst für den breiten Konsens sorgen. Auf diese haben etwa die Soziologen Niklas Luhmann (vgl. Luhmann 1997: 398) und in seiner Nachfolge Dirk Baecker (2001: 51) warnend hingewiesen:

Schlimm ist der Kulturbegriff, weil er seine eigene Operation verheimlicht und an die Stelle eines Wissens um die Kontingenz die Emphase für sich selbst setzt. Kultur ist das Bedeutende, das Wichtige, das Unverzichtbare, ja sogar, Gipfel der Verheimlichung, das Notwendige schlechthin.

Diese „Emphase für sich selbst“, die Selbstimmunisierung der Rede von Kultur gegen eine kritische Reflexion ihrer jeweiligen Prämissen und Konsequenzen, ist auch für Wortneuschöpfungen wie interkulturelle Kompetenz, cultural awareness oder cultural competence zu befürchten. Für cultural competence etwa stellen die amerikanischen Expertinnen für Sozialarbeit Yvonne Johnson und Shari Munch (2009: 220) in blumiger Sprache den Befund, dass eine grundlegende Diskussion nicht erwünscht zu sein scheint:

What could possibly be amiss with the idea of cultural competence (CC), that is, social workers' possession of „a knowledge base of their clients' cultures“ and ability to provide „services that are sensitive to clients' cultures“ [...]? After all, CC sounds as inviting and benign as an Indian samosa, an Irish scone, or American apple pie.

Das Problem verschärft sich bei der Rede von interkultureller Kompetenz insofern, als sie in der Regel weitere, ihrerseits ähnlich selbst-affirmative Begriffe einschließt. Offen, lernbereit, tolerant - wer möchte das nicht sein? Was aber 
ist etwa mit ,Toleranz' genau gemeint? Welche Haltung und welches Verhalten sind angemessen, wenn sich aus dem Aufeinandertreffen unterschiedlicher Weltsichten nicht nur Irritationen, sondern handfeste Konflikte ergeben? Was, wenn es nicht nur keine einvernehmliche Lösung gibt, sondern wenn zudem eine Entscheidung notwendig wird, weil sich die Geltungsansprüche dieser Weltsichten überschneiden und in ihren Forderungen widersprechen? Gibt es vielleicht sogar Situationen, in denen Toleranz im Sinne von Duldung einer abweichenden Weltsicht (und Duldung des aus ihr sich ergebenden Handelns) nicht nur nicht angebracht, sondern ethisch rundheraus inakzeptabel ist? Genügt es dann ebenso, offen, lernbereit und tolerant zu sein? Wann schlägt diese Haltung in Gleichgültigkeit um? Fast ein wenig verschämt wird die Problematik im GeR erwähnt, allerdings lediglich in Form einer offenen Frage:

[Die Entwicklung einer interkulturellen Persönlichkeit als Erziehungsziel] wirft wichtige ethische und pädagogische Fragen auf, etwa: [...] Wie kann Kulturrelativismus mit ethischer und moralischer Integrität in Einklang gebracht werden? (Europarat 2001: 107)

Es zeigt sich, dass gerade Begriffe, die als ethisch und moralisch unbedenklich gelten, im Konfliktfall erheblichen Diskussionsbedarf erzeugen. Am Beispiel der ,Toleranz' lässt sich besonders gut nachvollziehen, dass die Klärung eines Begriffs unabdingbar ist, wenn das Ziel lautet, mit seiner Hilfe soziale und politische Realität zu beschreiben und zu gestalten, und nicht, fromme Wünsche zu formulieren. Wie verbreitet diese Wünsche sind, fasst der Philosoph Rainer Forst (2003: 12) in seiner Studie zum Toleranzbegriff pointiert zusammen: „[... Konflikte, die sich als nicht lösbar herausstellen, gehören offenbar ebenso zum menschlichen Zusammenleben wie der Wunsch, es möge sie nicht geben.“

Wie positioniert sich nun die interkulturelle Fremdsprachendidaktik zu solchen Konflikten, die sich oft an inkommensurablen Weltsichten entzünden? Welche Antworten bietet sie, wenn es um mehr geht als um die Frage, ob man sich mit Handschlag, Schulterklopfen oder Wangenkuss begrüßt? Wie sind Konflikte zu bewerten, bei denen es darum geht, ob Menschen ein Recht auf körperliche Unversehrtheit haben - ohne Wenn und Aber, auch wenn da die,Kultur', in die sie hineingeboren wurden, ziemlich weit gefasste Ausnahmen vorsieht? Das Problem ist in der aktuellen fachdidaktischen Diskussion eigentümlich unterrepräsentiert. Anstatt sich ihm zu stellen, scheint in den Beiträgen zur Inter- und Multikulturalität ein unreflektierter Umgang mit allgemein konsensfähigen Begriffen zu überwiegen, welche die Welt gleichsam in ein sanftes Licht tauchen. Es dominiert der Eindruck, dass sich critical incidents, Konflikte also, die aus dem Aufeinandertreffen unterschiedlicher Weltdeutungen entstehen, in der Regel zur Zufriedenheit aller Beteiligten auflösen lassen. Dafür scheint nur das richtige Maß an interkultureller 
Kompetenz gebraucht zu werden, das heißt Offenheit, Toleranz, Empathie und die Bereitschaft, die eigene ethnozentrische Sichtweise zu relativieren.

Wie schwierig es jedoch oft ist, unterschiedliche Weltsichten zu versöhnen, und wie schnell der Toleranzbegriff an seine Grenzen stoßen kann, möchte ich an einem kurzen Beispiel illustrieren. In der Erzählung The discipline des afrokanadischen Autors Austin Clarke wird ein in Kanada lebender Einwanderer aus Barbados beschuldigt, er habe seinen 13jährigen Sohn zusammengeschlagen. Eine Lehrerin des Jungen erfährt von dem Übergriff und erstattet Anzeige gegen den Vater. Dieser gibt den Gewaltausbruch unumwunden zu. Er habe, wie er seiner Anwältin erklärt er, seinen Sohn lediglich , disziplinieren` wollen:

„You struck him with your fist. You smashed his ribs.“ - „I disciplined him.“ - „You didn’t discipline him. You assaulted him.“ - „I disciplined him.“ (Clarke 2003: 3)

Es kommt zu einer Gerichtsverhandlung, in deren Verlauf eine Sozialarbeiterin, welche sich mit den Verhältnissen im Herkunftsland des Angeklagten beschäftigt hat, ihre Sicht der Lage vorträgt. Sie sagt aus, die Gewaltbereitschaft des Vaters sei durch das kulturelle Erbe der Sklaverei zu erklären, unter der Barbados in der Vergangenheit in besonderem Maße gelitten habe. Der Angeklagte protestiert heftig gegen diese Erklärung. Anstatt aber eine Gelegenheit zu bekommen, seine Sicht der Dinge selbst darzustellen, wird er unverzüglich aus dem Gerichtssaal verwiesen. Für das Verprügeln seines Sohnes wird er zu 5 Monaten Gefängnis verurteilt.

Dem Vater bleibt vor Gericht das Sprechen untersagt. Durch die Erzählung erfährt der Leser jedoch mehr über die Hintergründe, und zwar durch die Stimme des Vaters selbst, der als Ich-Erzähler die Ereignisse zu Hause und vor Gericht sowie seine Gedanken und Gefühle schildert (vgl. ebd.: 1-21). In seiner Darstellung liegen die wahren Gründe für die Tat nicht in der Geschichte der Sklaverei. Vielmehr führt er als Erzähler verschiedene andere Motive für die Tat an, aus denen sich drei Rechtfertigungsmuster für den Übergriff herausarbeiten lassen: erstens die seinem Verständnis nach selbstverständliche Notwendigkeit, die eigenen Kinder zu ,disziplinieren'; zweitens die Frustration eines Mannes, der zeit seines Lebens von starken Frauenfiguren dominiert wurde (in Barbados von der eigenen Großmutter, in Kanada an seiner Arbeitsstelle von einer Vorgesetzten sowie im Prozess von seiner Anwältin und von einer Gefängnispsychologin) und wenigstens zu Hause das Recht haben müsse, ohne weitere Einmischung sein Kind zu ,disziplinieren'; drittens begründet der Erzähler sein Handeln mehrfach mit Verweis auf die Bibel. ${ }^{16}$

16 In der Tat weist die Bibel zahlreiche Passagen auf, auf deren Grundlage sich ,Züchtigung' als Mittel der Erziehung rechtfertigen lässt, und zwar bis hin zur Todesstrafe 
Aus der Sicht interkultureller Fremdsprachendidaktik wäre nun folgende Frage an Austin Clarkes Erzählung zu stellen: Liegt im Konflikt zwischen den Vertretern des kanadischen Staates und dem namenlosen Einwanderer aus Barbados ein critical incident vor, ein Zusammentreffen unterschiedlicher, Kulturen oder, Weltsichten'? Lässt sich der Konflikt daher lösen (oder zumindest besser lösen), wenn beide Seiten kulturell kompetent handeln und im Geiste der Toleranz aufeinander zugehen? Lässt sich aus der Position der Stärke, welche die Vertreter des kanadischen Staates durch ihre institutionelle Macht und ihren höheren Bildungsgrad einnehmen, vielleicht sogar eine besonders große Verpflichtung herleiten, ihre Weltsicht im Geiste interkultureller Kompetenz zu relativieren? Fehlt dem Gericht möglicherweise die „Bereitschaft, die eigene kulturelle Sichtweise und das eigene kulturelle Wertesystem zu relativieren" (Europarat 2001: 107), und handelt es sich daher um ein Urteil, das zwar rechtmäßig, aber nicht gerecht ist? Muss sich das Gericht daher Ethnozentrismus vorwerfen lassen, da es die eigenen moralischen und juristischen Prinzipien ohne Rücksicht auf die Herkunft und kulturelle Prägung des Angeklagten anwendet? ${ }^{17}$

Zusätzlich zu dem Unbehagen, das die starke Verbreitung nationalstaatlicher, essentialisierender Kulturvorstellungen in der Fremdsprachendidaktik bei mir auslöst, empfinde daher ein Zweites. Es speist sich aus dem Eindruck, dass die interkulturell ausgerichtete Fremdsprachendidaktik in Bezug auf sogenannte interkulturelle Begegnungen stark auf die Erzeugung von Konsens und Harmonie ausgerichtet ist. Die konflikt- und machttheoretischen Prämissen und Konsequenzen einer solchen Haltung scheinen dabei aber nicht oder zumindest nicht in der gebotenen Gründlichkeit reflektiert zu werden.

\subsection{Arbeitshypothese und Forschungsfragen}

Im Licht der bis zu dieser Stelle entwickelten Überlegungen kann das oben formulierte doppelte Unbehagen, das ich in Bezug auf die interkulturelle Fremdsprachendidaktik empfinde, als sachlich begründet angenommen werden. Zwei Theoriedefizite konnten vorläufig belegt werden. Sie ergeben sich direkt aus der Bezugnahme auf Kulturverständnisse, welche aus der Sicht zeitgenössischer kulturwissenschaftlicher Theorien als problematisch einzuschätzen sind.

(vgl. EKD 1992: 246 = 5. Mose 21, 18-21). Zu den möglichen Folgen der sogenannten ,schwarzen Pädagogik‘ aus psychoanalytischer Sicht vgl. Miller 2004.

17 Genau dies suggeriert Lothar Bredella in einem Beitrag, in dem ich auf Clarkes Erzählung gestoßen bin (vgl. Bredella 2001: 14). Die demokratietheoretischen Implikationen dieser Auffassung von Ethnozentrismus werden in Kapitel 3.2.5. diskutiert. 
Aus den auf diese Weise festgestellten Defiziten ergibt sich das Forschungsanliegen, dem ich in dieser Arbeit nachgehen möchte. Es lässt sich in der folgenden Form als Arbeitshypothese formulieren:

Interkulturalität ist als Zielkonstrukt des Fremdsprachenunterrichts zu überdenken, weil der Kulturbegriff erstens einen Rückgriff auf überholte Kulturverständnisse, zweitens einen unreflektierten Umgang mit dem Dilemma von Universalismus und Kulturrelativismus begünstigt.

Aus der Hypothese generiere ich folgende Forschungsfragen:

- Forschungsfrage 1: Wie sind ausgewählte Ansätze interkultureller Fremdsprachendidaktik hinsichtlich verschiedener Kulturverständnisse zu beurteilen?

- Forschungsfrage 2: Wie sind ausgewählte Ansätze interkultureller Fremdsprachendidaktik hinsichtlich des Dilemmas von Universalismus und Kulturrelativismus zu beurteilen?

- Forschungsfrage 3: Wie könnte ein Zielkonstrukt für den Fremdsprachenunterricht beschaffen sein, das sowohl ein zeitgemäßes Kulturverständnis als auch einen reflektierten Umgang mit dem Dilemma von Universalismus und Kulturrelativismus anbahnt?

\subsection{Methodisches Vorgehen}

Nachdem die Problemlage umrissen und die daraus sich ergebenden Forschungsfragen formuliert sind, soll nun das methodologische Vorgehen bei der Bearbeitung dieser Fragen dargelegt werden.

Für die Bearbeitung von Forschungsfrage 1 erfolgt zunächst eine Darstellung verschiedener Kulturbegriffe (Kap. 2.1.). Diese stützt sich auf die Arbeiten des Kulturwissenschaftlers Andreas Reckwitz, der ein äußerst unübersichtliches Begriffsfeld in insgesamt nur vier Kategorien eingeteilt hat. Dabei beurteilt er die Vielfalt existierender Kulturverständnisse im Hinblick darauf, in welchem Maße sie die Kontingenz kultureller Phänomene jeweils sichtbar machen oder verschleiern. Dieser Ansatz ist im Rahmen der hier bearbeiteten Fragestellung hilfreich, weil sich auch die Probleme der interkulturell ausgerichteten fremdsprachendidaktischen Beiträge häufig auf das Grundproblem der Verschleierung von Kontingenz zurückführen lassen. Da Reckwitz' Einteilung verschiedener Kulturverständnisse sich in weiten Teilen als gut begründet und nachvollziehbar zeigt, genügt für die Bearbeitung der Forschungsfragen eine beschreibende Zusammenfassung seines Ansatzes. Lediglich vereinzelt ist eine kritische Diskussion notwendig (vgl. z.B. Kap. 2.1.3.). 
Neben der Erschließung des Begriffsfeldes ,Kultur` unter Rückgriff auf Reckwitz erfolgt zudem eine Erörterung der von Wolfgang Welsch modellierten sogenannten Transkulturalität (Kap. 2.1.5.). Es erscheint für diese Arbeit unabdingbar, diesen Theorieansatz darzustellen und zu diskutieren, denn dieser war und ist in der fremdsprachendidaktischen Diskussion vereinzelt für eine Lösung der bekannten Probleme der interkulturell ausgerichteten Fremdsprachendidaktik im Gespräch.

Auch Forschungsfrage 2 kann nur auf der Grundlage ausführlicher theoretischer Überlegungen bearbeitet werden. Hierbei gehe ich von der Beobachtung aus, dass in der Fremdsprachendidaktik häufig die Einnahme einer kulturrelativistischen Position als selbstevident vorausgesetzt wird. Eine solche Position hat jedoch nicht nur eine normative Seite, die durch die hier entwickelten Überlegungen reflexiv zugänglich gemacht werden soll. Sie wirft auch verschiedene Probleme auf, die ausführlich dargestellt und diskutiert werden. Dabei handelt es sich um Selbstwidersprüche und Fehlschlüsse (Kap. 2.2.2.), historisch-philosophische (Kap. 2.2.3.), rechtlich-politische (Kap. 2.2.4.) sowie bildungs- und demokratietheoretische (Kap. 2.2.5.) Probleme.

Das Dilemma von Universalismus und Kulturrelativismus ist bislang in der Fremdsprachendidaktik und in der allgemeinen Erziehungswissenschaft unterrepräsentiert, jedoch nicht unbekannt. Den bislang am ausführlichsten ausgearbeiteten Lösungsansatz stellt Wolfgang Niekes Theorieentwurf des Aufgeklärten Eurozentrismus dar. Dieser wird daher ebenfalls dargestellt und diskutiert (Kap. 2.2.6.).

Vor diesem theoretischen Hintergrund werden in Kapitel 3 ausgewählte Theorieansätze $\mathrm{zu}$ interkulturellem Lernen und interkultureller Kompetenz dargestellt und im Licht der Forschungsfragen 1 und 2 diskutiert. Dabei handelt es sich um insgesamt vier Theorien. Die erste hier besprochene Theorie ist die Didaktik des Fremdverstehens, die im Gießener Graduiertenkolleg entwickelt wurde und von dort einen erheblichen Einfluss auf die hiesige fremdsprachendidaktische Forschungslandschaft entfalten konnte (Kap. 3.2.). Der zweite hier diskutierte Theorieansatz, Claires Kramschs Thirdness, ist in deutschsprachigen Kontexten ebenfalls stark rezipiert worden, wenn auch nicht in einem vergleichbaren Ausmaß wie die Didaktik des Fremdverstehens. Er ist Gegenstand von Kap. 3.3. Weniger bekannt ist dagegen der ebenfalls von Claire Kramsch entwickelte Theorieansatz der Symbolic Competence. Er wird in Kap. 3.4. dennoch diskutiert, da Kramsch ihn explizit in Abgrenzung von unterkomplexen Kulturverständnissen der interkulturell ausgerichteten Fremdsprachendidaktik formuliert hat. Es ist daher zu prüfen, inwieweit der Ansatz möglicherweise 
bereits eine Lösung für die hier diskutierte Problemstellung darstellt. Beim vierten Theorieansatz handelt es sich um Michael Byrams Theorieansatz der Intercultural Communicative Competence (Kap. 3.5.). Er darf in der Diskussion verschiedener Ansätze zum interkulturellen Lernen und zu interkultureller Kompetenz nicht fehlen, da er weitgehend in den GeR übernommen wurde und auf diesem Weg Eingang in zahlreiche verbindliche nationale Curricula gefunden hat.

Alle genannten Theorieansätze werden zunächst ausführlich dargestellt und anschließend im Licht der Forschungsfragen 1 und 2 kritisch gewürdigt. Das Vorgehen wurde gewählt, da es im Sinne guter wissenschaftlicher Praxis unabdingbar ist, zunächst die jeweils eigene Rezeption fremder Beiträge in der gebotenen Ausführlichkeit offenzulegen, bevor man sie kritisch diskutiert.

Die Ergebnisse dieser Analyse werden in Kap. 3.6. zusammengefasst. Ich komme dort zu dem Schluss, dass die eingangs festgestellten Defizite der interkulturellen Fremdsprachendidaktik - die Verwendung problematischer Kulturverständnisse einerseits, der nicht oder nicht ausreichend reflektierte Umgang mit dem Dilemma von Universalismus und Kulturrelativismus andererseits - in den untersuchten Theorieansätzen nicht gelöst werden.

Im daran anschließenden theoriebildenden Teil dieser Arbeit versuche ich, Forschungsfrage $3 \mathrm{zu}$ beantworten, indem ich in Kapitel 4 einen eigenen Theorieansatz entwickle. Er wird mit dieser Arbeit als Alternative zu gängigen, in Anlehnung an die Interkulturalität modellierten Zielkonstrukten des Fremdsprachenunterrichts vorgeschlagen. Für dieses Vorhaben lag es nahe, den Ansatz nicht auf den Kulturbegriff aufzubauen, denn bereits vorliegende Versuche, die theoretischen Probleme interkulturell ausgerichteter Ansätze mit Hilfe neuer Verständnisse von Kultur und Interkulturalität zu lösen, reproduzieren diese Probleme (vgl. insbesondere Kap. 2.1.5. und 3.4.). Dagegen erschien ein anderer Begriff, ,Diskurs', aus zwei Gründen als vielversprechend: Erstens ist er in hohem Maße anschlussfähig an ein sogenanntes kulturwissenschaftliches Kulturverständnis (vgl. Kap. 2.1.4.); zweitens hat er das Potential zur Aufdeckung von Machtverhältnissen und könnte somit das Dilemma von Universalismus und Kulturrelativismus reflexiv zugänglich machen.

Da für den Diskursbegriff ähnlich wie für den Kulturbegriff verschiedene Verständnisse in Umlauf sind, erfolgt ebenfalls zunächst eine Begriffsklärung (vgl. Kap. 4.2.2. und 4.2.3.). Anschließend wird das Potential des Diskursbegriffs für das hier verfolgte Forschungsanliegen diskutiert (vgl. Kap. 4.2.4.).

Für die Übertragung des Diskursbegriffs in fremdsprachendidaktische Kontexte schien der aktuell dominierende Kompetenzbegriff problematisch, denn 
dieser legt die Möglichkeit der Stufung und Evaluation nahe. Dies würde fast zwangsläufig zu Komplexitätsreduktionen führen, ein Problem, das man an bisherigen Versuchen zur Stufung und Evaluation interkultureller Kompetenz anschaulich nachvollziehen kann (vgl. dazu kritisch Byram 2009). Die Verwendung des Kompetenzbegriffs hätte somit das in dieser Arbeit verfolgte Anliegen potentiell unterlaufen. Insofern lag es nahe, an einen bestehenden sprachdidaktischen Theorieansatz anzuknüpfen, dessen Kerngedanke darin besteht, unterschiedliche Dimensionen von Sprache reflexiv zugänglich zu machen: die sogenannte language awareness. Sie wird zunächst rekonstruiert (vgl. Kap. 4.3.2.). Anschließend wird auch ihr Potential für das hier bearbeitete Forschungsanliegen diskutiert (vgl. Kap. 4.3.3.). Da sich der Anschluss an die language awareness-Tradition als zumindest vorläufig tragfähig erweist, nenne ich den in dieser Arbeit entwickelten Theorieansatz Fremdsprachliche Diskursbewussheit.

Gegen die sogenannte Kompetenzorientierung wird häufig kritisch eingewandt, dass sie auf Kosten wichtiger anderer Dimensionen des Fremdsprachenunterrichts durchgesetzt werde, etwa seiner literarisch-ästhetischen (vgl. Küster 2003b; Bonnet/Breidbach 2013) oder auch seiner reflexiven Dimension (vgl. Breidbach 2007 für den bilingualen Sachfachunterricht). Diese und andere Dimensionen spielen für Ansätze einer fremdsprachlichen Bildung eine zentrale Rolle. Der in dieser Arbeit vorgeschlagene reflexive Zugang zu und Umgang mit Sprache als Diskurs könnte möglicherweise ebenfalls einen Beitrag leisten, dass der Bildungsauftrag des Fremdsprachenunterrichts (wieder) erfüllt wird. In Kap. 4.4. soll daher das Verhältnis von Fremdsprachlicher Diskursbewusstheit und Bildung erschlossen werden. Dabei stütze ich mich auf die Arbeiten des Erziehungswissenschaftlers Hans-Christoph Koller. Seine bildungstheoretischen Beiträge sind für die vorliegende Arbeit vielversprechend, weil er Bildungsprozesse als Transformationen von Welt- und Selbstverhältnissen modelliert. Solche Transformationen können nach Koller dann angestoßen werden, wenn Menschen Fremdheits- oder Differenzerfahrungen machen. $\mathrm{Da}$ besonders die Auseinandersetzung mit fremden (auch: fremdsprachigen) Diskursen solche Differenzerfahrungen auslösen können, ergeben sich mögliche Schnittmengen der Fremdsprachlichen Diskursbewusstheit mit Kollers Theorieansatz. Er könnte sich daher als sehr anregend erweisen, wenn die Anschlussfähigkeit der Fremdsprachlichen Diskursbewusstheit an bildungstheoretische Diskurse zur Diskussion steht (Kap. 4.4.3.).

Auch wenn die vorliegende Arbeit in erster Linie einen Beitrag zur fremdsprachendidaktischen Theoriebildung darstellt, steht dennoch die Frage nach der unterrichtlichen Implementierung dieser Überlegungen im Raum. Hierfür werden abschließend Prinzipien für den Fremdsprachenunterricht formuliert, 
deren Beachtung zur Anbahnung Fremdsprachlicher Diskursbewusstheit führen kann (Kap. 4.5.). Inwiefern diese empiriefähig ist, bleibt noch zu beantworten. Einige grundsätzliche Anmerkungen zur empirischen Erschließung von Bewusstheitsphänomenen finden sich in Kap. 4.3.2.

Die hier dargelegten Überlegungen stellen einen Versuch dar, das gewählte methodische Vorgehen und die Entscheidung für bestimmte Theorien zu begründen und zu reflektieren. Solche Entscheidungen bringen es immer mit sich, dass andere, möglicherweise ähnlich ergiebige Theorieansätze nicht oder nur marginal berücksichtigt werden können. Für die vorliegende Arbeit trifft dies besonders auf die sogenannte literacy und die darauf aufbauende Didaktik der multiliteracies zu, die in englischsprachigen Diskursen aktuell eine zentrale Rolle spielen (vgl. The New London Group 1996; Cope/Calantzis 2010). Sie werden seit einigen Jahren auch in der deutschsprachigen Fremdsprachendidaktik rezipiert und weiterentwickelt (vgl. einführend Elsner/Küster/Viebrock 2007). Es erschien jedoch ergiebiger, das hier entwickelte Konstrukt in die Tradition der language awareness/Sprachbewusstheit zu stellen, da diese im deutschsprachigen Kontext insgesamt anschlussfähiger sein dürfte als die Theorie der (multi-)literacies. Zahlreiche Aspekte der language awareness finden sich in ähnlicher Form aber auch in verschiedenen Arbeiten zu den (multi-)literacies.

Abschließend ist anzumerken, dass ein Theorieansatz wie die hier entwickelte Fremdsprachliche Diskursbewusstheit eine bestimmte Art der Sprachverwendung darstellt, die einen überindividuellen Geltungsanspruch erhebt. Es handelt sich mit anderen Worten ebenfalls um einen Diskurs. Dieser soll helfen, Probleme sichtbar zu machen, die bislang nicht oder nicht in ausreichendem Maße reflexiv erschlossen waren. In jedem Fall gelten dabei jedoch die von Georg Auernheimer (2002: 94) treffend formulierten Einschränkungen zur Theoriebildung:

Es geht, wenn wir über wissenschaftliche Konzepte verhandeln, um Konstrukte und deren Brauchbarkeit und - wahrscheinlich überflüssig zu sagen - nicht um Abbilder der Realität. Dabei ist davon auszugehen, dass jedes Konstrukt bestimmte Fragen zulässt oder sogar herausfordert und Fragen verhindern kann.

In der vorliegenden Arbeit wird Fremdsprachliche Diskursbewusstheit als ein solches Konstrukt entworfen. Die Brauchbarkeit dieses Konstruktes wird erst im Licht zukünftiger Diskussionen und Forschungsbeiträge beurteilt werden können.

Für die Bearbeitung der Forschungsfragen ist es notwendig, im Lauf der Arbeit verschiedene komplexe Begriffe ausführlich zu diskutieren. Hierbei operiere ich wiederholt mit zwei ebenfalls komplexen Begriffen, ,Macht' und ,Universalismus, 
die jedoch nicht in der gleichen Ausführlichkeit hergeleitet und erörtert werden. Sie sollen dennoch kurz definiert werden.

Die bekannteste Definition von, Macht' stammt aus der Feder des Soziologen Max Weber: „Macht bedeutet jede Chance, innerhalb einer sozialen Beziehung den eigenen Willen auch gegen Widerstreben durchzusetzen, gleichviel worauf diese Chance beruht" (Weber 1980 [1922]: 28). ,Macht' lässt sich diskurstheoretisch reformulieren als jede Chance, die von einem selbst als richtig oder wahr angenommenen Diskurse und Praxen durchzusetzen (vgl. Kap. 4.2.4.). Dieses Verständnis liegt der vorliegenden Arbeit zugrunde.

Der zweite Begriff, Universalismus, wird häufig als problematisch wahrgenommen. ${ }^{18}$ Dies hat mit den zahlreichen Verbrechen zu tun, die beklagenswerterweise im Namen von Prinzipien mit universellem Geltungsanspruch begangen wurden. Es ist kein Zufall, dass gerade in der Anthropologie der Gegenentwurf zum Universalismus entstanden ist, der Kulturrelativismus. Schließlich hatten Vertreter_innen dieser wissenschaftlichen Disziplin nicht unerheblich an der Rechtfertigung kolonialer Unterdrückung mitgewirkt.

Nach dem 2. Weltkrieg setzte sich ausgehend von der Philosophie und der Soziologie eine Denkrichtung durch, die heute meist als Postmodernismus bezeichnet wird. Ihr Kern besteht ebenfalls in der Ablehnung universell gültiger Deutungsmuster. Sowohl Kulturrelativismus als auch Postmodernismus kommen jedoch ihrerseits nicht ohne Setzungen aus, die als „wahr“ bzw. „universell gültig“ angenommen müssen, z.B. „die Pluralität von Diskursen ist wünschenswert" oder „alle Kulturen sollen toleriert werden“. Diese Problematik wird in Kap. 2.2.2. ausführlich erörtert.

Wenn ich im Rahmen dieser Arbeit von Universalismus spreche, dann tue ich das auf der Basis einer Haltung, welche die eigenen Setzungen erstens als solche anerkennt und sie zweitens nicht als selbstevident voraussetzt, sondern sie offen legt und reflexiv zugänglich macht. Eine nähere Betrachtung zeigt, dass ein solcher reflexiver Universalismus relativistische Anteile enthält, und dass kein Relativismus ohne universalistische Setzungen auskommt (vgl. Kap. 2.2.2.). Ein solcher Ansatz trägt möglicherweise dazu bei, dass die häufig zu beobachtende dichotomische Gegenüberstellung von Universalismus und (Kultur-)Relativismus in Frage gestellt werden kann.

18 Zum Phänomen des Universalismus vgl. einführend das Kapitel mit diesem Titel in Mende (2011: 26-37). 
Jochen Plikat - 978-3-631-70364-9

Downloaded from PubFactory at 01/11/2019 10:12:35AM

via free access 


\section{Kapitel 2: Kulturwissenschaftliche Grundlagen}

\subsection{Zur Frage der Kulturbegriffe}

Die Feststellung, dass der Kulturbegriff sich immer wieder als „schwer zu fassen“ und ,äußerst vieldeutig“ (Nünning 2009: 1) erweist, ist in den Humanwissenschaften zeitgleich mit der Karriere des Begriffs zu einem Gemeinplatz geworden. Für den Literatur- und Kulturwissenschaftler Wolfgang Müller-Funk (2001: 718) etwa gehört Kultur zu den „Plastikworte[n]“, und er weist darauf hin, dass der Begriff seine Karriere gerade der aus dieser Unschärfe sich speisenden „affirmativen Kraft“ (ebd.) zu verdanken habe. Lapidar stellt er fest:

Der kulturtheoretische Diskurs operiert ganz offensichtlich mit verschiedenen Bedeutungen des neuen Leitbegriffs, und man tut gut daran nachzufragen, wie Kultur im konkreten Fall jeweils gemeint sei. (ebd.).

Für Niklas Luhmann (1997: 398) handelt es sich beim Kulturbegriff gar um nichts weniger als „[...] einen der schlimmsten Begriffe, die je gebildet worden sind." Unabhängig davon, ob man sich dieser Einschätzung anschließt oder nicht - fest steht, dass bereits in einer 1952 zusammengestellten Übersicht 164 Definitionen von Culture zu finden sind (vgl. Kroeber/Kluckhohn 1952). In der Zwischenzeit sind so viele hinzugekommen, dass eine erschöpfende Darstellung heute kaum mehr möglich scheint.

Auch in der Fremdsprachendidaktik ist bereits in zahlreichen Beiträgen die Frage diskutiert worden, ob der Kulturbegriff überhaupt eine zentrale Rolle spielen sollte, und wenn ja, was denn unter Kultur zu verstehen sei. Am ausführlichsten wurde das Problem Ende der 1990er-Jahre in der Kontroverse Edmondson/ House vs. Hu erörtert. Während Willis J. Edmondson und Juliane House für einen vollständigen Verzicht auf den Kulturbegriff plädierten, argumentierte Adelheid Hu dafür, ihn beizubehalten, allerdings unter bestimmten, eng gesteckten Voraussetzungen (zusammenfassend vgl. Hu 1999). Die Entscheidung ist bekanntermaßen zugunsten des Kulturbegriffs ausgefallen, wie die prominente Rolle der Interkulturalität in maßgeblichen administrativen Dokumenten auf europäischer, nationaler und länderspezifischer Ebene zeigt (vgl. Europarat 2001; KMK 2003; Senatsverwaltung für Bildung, Jugend und Sport Berlin 2006). Auch weiterhin wird jedoch die Problematik thematisiert, dass der Fremdsprachenunterricht sich auf ein Leitkonzept stützt, für dessen Kern - gemeint ist ,Kultur ${ }^{\text {- }}$ so stark voneinander abweichende Definitionen in Umlauf sind. Dabei wird insbesondere auf die Gefahr hingewiesen, dass der Rückgriff auf einen überholten Kulturbegriff 
leicht zu homogenisierenden, essentialistischen Denkschemata führen könne (vgl. Kap. 2.1.2.). Dies würde, so die Kritik, eines der zentralen Anliegen der interkulturellen Didaktik konterkarieren, nämlich die Überwindung von Stereotypen und Vorurteilen. Daher sei die Arbeit mit einem ,kulturwissenschaftlichen' Kulturbegriff empfehlenswert (vgl. Küster 2005; Altmayer 2006).

Was ist nun unter einem solchen kulturwissenschaftlichen Kulturbegriff zu verstehen, und worin liegt sein Potential für die Begriffsklärung in der Fremdsprachendidaktik? Für die Beantwortung dieser Frage liegt ein Blick in das kulturwissenschaftliche Forschungsprogramm nahe, für das er entwickelt wurde. Dieses Forschungsprogramm besteht nach Andreas Reckwitz, der für seine Ausarbeitung wichtige Impulse gegeben hat, zunächst einmal in der Aufgabe, den eigenen Geltungsbereich abzustecken (vgl. Reckwitz 2004: 1). Dazu gehöre, den Kulturbegriff zu definieren und ihn dabei gleichzeitig, so Reckwitz, möglichst weit zu fassen. Kultur solle prinzipiell alle Bereiche des menschlichen Lebens umschließen, also nicht mehr, wie in der Alltagssprache weiterhin sehr häufig zu beobachten, lediglich bestimmte ethnisch-geographische (,deutsche Kultur, ,Latino-Kultur' usw.) oder gesellschaftliche Bereiche (,Kulturmanagement', ,Kulturprogramm 'usw.). Mit einem solchen weit gefassten Kulturbegriff wird der Versuch unternommen, menschliches Denken und Verhalten in allen denkbaren Ausprägungen als kulturell determiniert zu erklären. Für die Kulturwissenschaft als Disziplin hat das weitreichende Konsequenzen. Indem sie Kultur über bestehende akademische Fachgrenzen hinweg zur zentralen, für alle humanwissenschaftlichen Fächer verbindlichen Bezugsgröße erhebt, emanzipiert sie sich von ihrem Status als Subdisziplin (Kulturgeschichte, Kultursoziologie, Kulturanthropologie, etc.) zu einer Metadisziplin:

[...] nicht eine Partialperspektive, sondern eine Totalperspektive ,Kultur ' wird im kulturwissenschaftlichen Forschungsprogramm eröffnet. Jeder Gegenstand der Geistesund Sozialwissenschaften kann und soll nun als kulturelles Phänomen rekonstruiert werden: ökonomisch-technische Praktiken ebenso wie Politik und Staat, die Sozialstruktur ebenso wie Familie oder Geschlechter, die modernen ebenso wie die vormodernen Gesellschaften, die Natur so wie der Affekthaushalt. (Reckwitz 2004: 1) ${ }^{19}$

19 Einige Bedenken zu einer so weit gefassten Disziplin, die zudem den Anspruch erhebt, die Krise der Geisteswissenschaften zu überwinden, formuliert Hartmut Böhme (1996). Er äußert gar die Befürchtung, dass „[...] die Zauberformel von der ,Kulturwissenschaft' ein postmodernes Balg ist, das substituthaft an die Leerstelle tritt, die durch das Verblassen des Humboldtschen Bildungskonzeptes entstanden ist" (ebd.: 65). Luhmann (1995: 8) erinnert daran, „[...] daß man der Frage weiter nachgehen sollte, 
Neben der Formulierung und Durchsetzung dieses weiten Kulturbegriffs und des aus ihm ableitbaren umfassenden Geltungsanspruchs besteht nach Reckwitz ein zweites zentrales Anliegen der Kulturwissenschaft darin, die Kontingenz menschlichen Denkens, Fühlens und Handelns sichtbar zu machen. Dabei muss beachtet werden, dass die Semantik des Kontingenzbegriffs je nach Kontext variiert. Etymologisch lässt er sich vom lateinischen contingere (sich berühren, zusammenfallen) herleiten. Dabei bleibt offen, in welchem logischen Zusammenhang dieses Zusammenfallen zu sehen ist. In der Psychologie steht Kontingenz für das nicht-zufällige Zusammenfallen von Ereignissen, für ihr kausales oder als zumindest als kausal wahrgenommenes Verbundensein. Als kontingent werden somit zwei Ereignisse bezeichnet, für die ein "Zusammenhang im Auftreten“ (Koch 2008: 369), eine „unmittelbare und erfassbare Beziehung“ (Watzlawick 2007: 58f.) vorliegt. In der Philosophie und Soziologie hingegen ist die Semantik des Begriffs eine andere. Als kontingent werden hier nicht-notwendige Ereignisse bezeichnet, Ereignisse also, die auf eine bestimmte Weise eintreten, aber auch anders eintreten könnten. In der Sprache der formalen Logik wird Kontingenz in diesem zweiten Sinne definiert als "gleichzeitige[r] Ausschluss von Notwendigkeit und Unmöglichkeit“ (Baraldi et al. 1997: 37). ${ }^{20}$ In Bezug auf kulturelle Phänomene eröffnet dieses Verständnis von Kontingenz eine neue Perspektive. Menschliches Denken, Fühlen und Handeln wird nun in seinem jeweiligen Kontext gerade nicht mehr als notwendig gedeutet. Vielmehr lautet die Prämisse, dass diese Notwendigkeit eine Fiktion darstelle, die es radikal zu hinterfragen gelte. Legt man menschlichem Denken, Fühlen und Handeln diesen soziologischen Kontingenzbegriff zugrunde, schärft sich daher der Blick für deren „Nicht-Notwendigkeit und Historizität“" (Reckwitz 2004: 2), und es ergeben sich Spielräume für die Transformation kultureller Phänomene.

Ein Problem kultureller Praktiken, aber auch zahlreicher Forschungsdiskurse, welche sich diesen Praktiken als kulturellen Phänomenen widmen, besteht nun in der Tendenz, diese von Reckwitz und in seiner Folge auch von mir angenommene Nicht-Notwendigkeit nicht nur nicht offenzulegen, sondern sie im Gegenteil zu verschleiern, sie zu ,invisibilisieren“ (ebd.). Auch Dirk Baecker (2001:51) hat in diesem Zusammenhang in einer eingangs bereits zitierten Formulierung

was eigentlich geschieht, wenn wichtige Bereiche gesellschaftlicher Kommunikation, inklusive Religion und Philosophie, als Kultur registriert werden."

20 Eine zentrale Rolle spielt der Kontingenzbegriff auch in der Systemtheorie Luhmann'scher Prägung. Selektionen, die psychische und soziale Systeme vornehmen, sind nach Luhmann immer kontingent, d. h. nicht-notwendig (vgl. Baraldi et al. 1997: 37-39). 
auf die Risiken hingewiesen, welche eine unreflektierte Verwendung des Kulturbegriffs berge: „Kultur ist das Bedeutende, das Wichtige, das Unverzichtbare, ja sogar, Gipfel der Verheimlichung, das Notwendige schlechthin."

Die Rede über Kultur läuft also Gefahr, an entscheidenden Stellen blinde Flecken zu produzieren, nämlich dort, wo es um die Frage geht, ob Phänomene notwendigerweise so sind, wie sie sind - und nicht anders. Geht man von einer solchen Notwendigkeit aus, treten an die Stelle der prinzipiellen Hinterfragbarkeit von Phänomenen fast zwangsläufig Erklärungsmuster wie Schicksal, Vorsehung, historische Notwendigkeit, Weltgeist, Nationalcharakter, Vernunft, gesunder Menschenverstand, die in der postmodernen Philosophie allesamt als kulturell geprägt und historischen Transformationen unterworfen dekonstruiert wurden (vgl. Foucault 1969, 2007 [1966]; zum Vernunftbegriff vgl. Welsch 1995).

Der Grad an Offenlegung bzw. Verdeckung (Invisibilisierung) von Kontingenz kann nun verwendet werden, um die Vielzahl der bekannten Kulturbegriffe aus einer kulturwissenschaftlichen Perspektive zu klassifizieren. ${ }^{21}$ Wie bereits angedeutet muss man sich dabei auf eine Prämisse einlassen, die in der Annahme der Kontingenz aller Phänomene des menschlichen Denkens, Fühlens und Handelns - inklusive sprachlichen Handelns - besteht. Diese Position ist erkenntnistheoretisch im Bereich des Konstruktivismus und in der Ablehnung ontologischer Positionen zu verorten.

Auch wenn die fremdsprachendidaktische Diskussion in den vergangenen Jahren Impulse aus der Kulturwissenschaften verstärkt aufgenommen hat, ist doch der Kontingenzbegriff bisher wenig beachtet worden. Eine Begriffsklärung des Kulturbegriffs auf seiner Grundlage scheint daher im Rahmen der vorliegenden Arbeit und im Licht meiner Fragestellung sinnvoll. So lässt sich überprüfen, ob sich das eingangs formulierte Unbehagen (vgl. Kap. 1.6. und 1.7.) in Bezug auf einflussreiche Ansätze der interkulturellen Fremdsprachendidaktik als begründet zeigt. Weiterhin könnte die Begriffsklärung in Anlehnung an Reckwitz auch über diese Arbeit hinaus für die fremdsprachendidaktische Diskussion von Interesse sein. Sie erlaubt es, ein zentrales und häufig kritisiertes Problem der interkulturellen Fremdsprachendidaktik in den Blick zu nehmen, nämlich die Vorstellung, dass bestimmte Arten des Sprechens und Handelns als Ausdruck von typischen, meist national spezifischen „Kulturstandards“ zu verstehen seien. ${ }^{22}$

21 Eine übersichtliche Darstellung wichtiger Kulturbegriffe in ihrem jeweiligen theoretischen Kontext bietet Müller-Funk (2010).

$22 \mathrm{Zu}$ den sogenannten „Kulturstandards“vgl. Thomas 1996: 112. 
Reckwitz hat durch das Einnehmen der Kontingenzperspektive vier Kategorien von Kulturbegriffen ermittelt, über die ich im Folgenden einen kurzen Überblick gebe. Dabei handelt es sich um den normativen Kulturbegriff, den totalitätsorientierten Kulturbegriff, den differenzierungstheoretischen Kulturbegriff sowie den bedeutungs- und wissensorientierten Kulturbegriff. ${ }^{23}$ In den folgenden Abschnitten werden diese überblicksartig rekonstruiert.

\subsubsection{Der normative Kulturbegriff}

Der normative Kulturbegriff entsteht im Kontext der Aufklärung und ist bis heute in der Alltagssprache zu finden. ${ }^{24}$ Kultur ist in diesem Sinne als Vorstellung davon zu verstehen, wie das Leben idealerweise sein soll. Kultiviert ist, wer sein Leben in einer Art und Weise führt, die als erstrebens- und nachahmenswert gedacht wird. Eine beispielhafte Definition dieses Kulturverständnisses stammt aus der Feder des Germanisten und Lexikographen Johann Christoph Adelung. Er umschreibt Kultur mit den folgenden Worten:

[...] die Veredlung oder Verfeinerung der gesammten Geistes- und Leibeskräfte eines Menschen oder eines Volkes, so daß dieses Wort so wohl die Aufklärung, die Veredelung des Verstandes durch Befreyung von Vorurtheilen, als auch die Politur, die Veredlung und Verfeinerung der Sitten, unter sich begreift. (Adelung 2001 [1793-1801]: 11421)

Schon in der Antike wurde Kultur definiert als das menschliche Bemühen, die Natur zu verbessern. Adelungs Kulturbegriff schließt an diese traditionelle Dichotomie von Natur vs. Kultur an. Im Sprachgebrauch der Antike wurde jedoch stets näher bestimmt, auf welche Bereiche sich das Verbessern und Pflegen (colere) bezog, etwa auf den Ackerbau, die Religion oder auch die individuelle Persönlichkeit (agri cultura, cultus deorum, animi cultura). Bei Adelung fallen im Vergleich dazu zwei wichtige Neuerungen auf. Kultur bezieht sich hier bereits auf die Gesamtheit eines, Volkes. Die Eingrenzung auf partielle, näher definierte Bereiche des antiken Verständnisses von cultura entfällt. ${ }^{25}$ Was genau unter einem Volk zu verstehen sei, bleibt bezeichnenderweise offen, etwa, ob seine Grenzen entlang geografischer, ethnischer, sprachlicher, politischer, religiöser oder

23 Reckwitz richtet seine Analyse auf neuzeitliche Kulturbegriffe. Zur historischen Semantik des Kulturbegriffs (von lat. colere - bebauen, pflegen) vgl. Böhme 1996.

24 Ich stütze die Rekonstruktion der verschiedenen Kulturbegriffe vorwiegend auf die Arbeiten von Reckwitz 2000: 64-90 und 2004.

25 Die erste Verwendung des Kulturbegriffs als Kollektivsingular findet sich Ende des 17. Jahrhunderts bei dem deutschen Naturrechtsphilosophen Samuel von Pufendorf (vgl. Rauhut 1953: 82ff.). 
anderer Grenzen verlaufen sollen. Zweitens wird der Kulturbegriff mit einem aufklärerischen Moment ausgestattet. Der Kant'sche Leitspruch sapere aude, der zum Motto der Aufklärung werden sollte, wird hier auch für den Kulturbegriff relevant: Kultiviert ist, wer seine Urteile zunächst einmal als Vorurteile sieht und sie einer Überprüfung durch die Vernunft unterzieht.

Immanuel Kant (1991 [1784]: 44) bringt wenige Jahre später einen weiteren Aspekt in die Diskussion um den Kulturbegriff ein: den der Moral. Dieser erlaubt es ihm, den (deutschen) Kulturbegriff gegen den Begriff der Zivilisation abzugrenzen, der zeitgleich vor allem in Frankreich und England (civilisation, civilization) zu einem Leitbegriff geworden ist. Zivilisation steht nach Kant für die äußerliche (und damit als oberflächlich kritisierbare) Verfeinerung der Sitten. Erst die Moral erlaube auch die innere Kultiviertheit. Zivilisation ist daher ohne Moral denkbar, Kultur jedoch nicht. Moral und Kultur gehören für Kant untrennbar zusammen. Er nimmt diese Begriffsdefinition auch mit dem Ziel vor, die gesellschaftlichen Umstände im ausgehenden 18. Jahrhundert zu kritisieren. Diesen fehle es in erster Linie an Moral:

Wir sind im hohen Grade durch Kunst und Wissenschaft kultiviert. Wir sind zivilisiert, bis zum Überlästigen, zu allerlei gesellschaftlicher Artigkeit und Anständigkeit. Aber, uns für schon moralisiert zu halten, daran fehlt noch sehr viel. Denn die Idee der Moralität gehört noch zur Kultur; der Gebrauch dieser Idee aber, welcher nur auf das Sittenähnliche in der Ehrliebe und der äußeren Anständigkeit hinausläuft, macht bloß die Zivilisierung aus. (ebd.)

Kant führt hierdurch neben der Dichotomie ,kultiviert' vs. ,nicht kultiviert' die neue Unterscheidung, kultiviert' vs., zivilisiert' ein. Wie Adelung legt er dem Kulturbegriff das Ideal der bürgerlichen (sprich: aufgeklärten, vernünftigen, moralischen) Lebensart zugrunde. Zusätzlich erhält der Kulturbegriff bei Kant eine klar adelskritische Konnotation.

Wie ist nun der normative Kulturbegriff aus der Kontingenzperspektive zu bewerten? Einerseits lässt sich feststellen, dass in einem normativen Kulturverständnis Kultur als prinzipiell veränderbar und daher als kontingent angenommen wird. Sowohl auf individueller als auch auf kollektiver Ebene scheint es möglich, das Denken und Handeln zu verbessern und zu verfeinern. Andererseits wird Kontingenz als Eigenschaft von Kultur jedoch auch verschleiert, da als Entwicklungsrichtung die von der Aufklärung vorgegebene empfohlen wird, was bedeutet, sich an der Vernunft zu orientieren. Im Rahmen eines normativen Kulturverständnisses ist daher die ideale Umsetzung einer ,vernünftigen' Kultur, und damit von Kultur überhaupt, die bürgerliche Gesellschaft (vgl. Reckwitz 2004: 4f.). 


\subsubsection{Der totalitätsorientierte Kulturbegriff}

Während der normative Kulturbegriff maßgeblich von den Autoren der Aufklärung geprägt wurde, hat der totalitätsorientierte Kulturbegriff seinen Ursprung in der deutschen Romantik, deren Vertreter sich für die Besonderheiten fremder Völker zu interessieren beginnen. Im Gegensatz zum normativen Kulturbegriff mit seiner Orientierung an einer idealen Lebensform, der bürgerlichen Kultur, ist nun von Kulturen im Plural die Rede. Wenn aber nicht mehr nur die eine Kultur als Ideal existiert, sondern vielmehr das Nebeneinander einer Vielzahl von Kulturen eingeräumt wird, eröffnet sich ein interessantes Feld für deren vergleichende Betrachtung und Erforschung. ${ }^{26}$ Die Vertreter eines totalitätsorientierten Kulturverständnisses gehen davon aus, dass Kulturen jeweils ein organisches Ganzes darstellen. Kulturen sind, in einer Metapher Johann Gottfried Herders, Kugeln, die von anderen Kugeln abgrenzbar sind. ${ }^{27}$ An dem Umstand, dass Herder sowohl in Zusammenhang mit ,Kulturen' als auch in Zusammenhang mit ,Nationen' die Kugelmetapher verwendet, lässt sich ablesen, dass er beide Begriffe implizit gleichsetzt: „[...] jede Nation hat ihren Mittelpunkt der Glückseligkeit in sich, wie jede Kugel ihren Schwerpunkt“ (Herder 1820 [1774], Bd. 2: 264; vgl. Reckwitz 2004: 6). Nach innen sind diese Gebilde nicht statisch zu denken, sondern durchaus dynamisch. Sie können und müssen sich im Laufe der Geschichte entwickeln, so wie ein einzelner Mensch sich über die Zeit seines Lebens entwickelt und zur Reife gelangt. Herder (1841 [1784], Bd. 2: 133f.) bringt diese Vorstellung auf den Punkt, wenn er schreibt:

Die Cultur eines Volkes ist die Blüte seines Daseins, mit welcher es sich zwar angenehm, aber hinfällig offenbaret. Wie der Mensch, der auf die Welt kommt, nichts weiß; er muß, was er wissen will, lernen: so lernt ein rohes Volk durch Übung für sich oder durch Umgang von andern. Nun hat aber jede Art der menschlichen Kenntnisse ihren eigenen Kreis, d.i. ihre Natur, Zeit, Stelle und Lebensperiode; [...]

Dieses Kulturverständnis ist Ende des 19. Jahrhunderts wegweisend für die Entstehung der Anthropologie als Disziplin, die sich der wissenschaftlichen Beschreibung von Gemeinschaften verschreibt. Wie stark der totalitätsorientierte

26 In manchen Klassifikationen von Kulturbegriffen werden der normative und der totalitätsorientierte Kulturbegriff zusammengefasst, so z. B. bei Wolfgang Welsch, der beide auf Pufendorf (vgl. Rauhut 1953: 82ff.) zurückführt und als „das traditionelle Konzept der Einzelkulturen“ (Welsch 1999: 45-49) bezeichnet.

27 Herders Kugelmetapher schwingt im Deutschen bis heute in der Rede von ,Kulturkreisen' nach, einer häufigen Übersetzung des englischen Begriffs ,civilizations' im Plural (vgl. Huntington 1993: 24). 
Kulturbegriff der Romantik die Anthropologie Boas'scher Prägung beeinflusst hat, lässt sich an folgender Passage aus der Feder seiner Schülerin, der Amerikanerin Ruth Benedict (1989 [1934]: 2f.), ablesen:

The life-history of the individual is first and foremost an accomodation to the patterns and standards traditionally handed down in his community. From the moment of his birth the customs into which he is born shape his experience and behavior. By the time he can talk, he is the little creature of his culture, and by the time he is grown and able to take part in its activities, its habits are his habits, its beliefs his beliefs, its impossibilities his impossibilities. Every child that is born into his group will share them with him, and no child born into one on the opposite side of the globe can ever achieve the thousandth part.

Ähnlich wie Herders Kulturen sind Benedicts „communities“ klar voneinander abgrenzbar. Im Vergleich zu Herder ist jedoch bei Benedict die Einheit stiftende Kraft von Kultur innerhalb einer solchen Gruppe als noch größer einzuschätzen. Das Individuum scheint vollständig determiniert durch seine Zugehörigkeit zu einer Kultur. Seine Bestimmung ist das Aufgehen im Kollektiv. Ist die kulturelle Prägung einmal erfolgt, gibt es kein Zurück. Vor allem in Bezug auf die Möglichkeit des Fremdverstehens (vgl. Kap. 3.2.) legt der totalitätsorientierte Kulturbegriff eine pessimistische Sicht nahe: Nicht einmal der ,tausendste Teil ' (s. o.) einer fremden Kultur sei für Außenstehende zugänglich.

Der totalitätsorientierte Kulturbegriff spielt bis heute in der Alltagssprache eine wichtige Rolle. Gleichzeitig entfaltet er aber auch in aktuellen wissenschaftlichen Diskussionen weiterhin eine enorme Wirkung. Sehr kontrovers werden etwa bis heute die Thesen des amerikanischen Politikwissenschaftlers Samuel P. Huntington diskutiert, der den totalitätsorientierten Kulturbegriff in seinem 1993 erschienenen Aufsatz The clash of civilizations? auf eine neue Ebene hebt. Huntington nimmt dort nicht mehr einzelne Gruppen („communities“, s. o.), Ethnien oder geografische Räume in den Blick. Vielmehr unternimmt er den Versuch, die Weltbevölkerung insgesamt in sechs Großgruppen einzuteilen, die er civilizations nennt. Ins Deutsche wird der Begriff meist übersetzt mit ,Kulturräumen', ,Kulturkreisen` oder schlicht ,Kulturen'. An ihren Grenzen entlang, so Huntingtons zentrale These, werden sich in Zukunft die heftigsten geopolitischen Konflikte entzünden. Civilizations definiert Huntington (1993: 23f.) wie folgt:

What do we mean when we talk of a civilization? A civilization is a cultural entity. Villages, regions, ethnic groups, nationalities, religious groups, all have distinct cultures at different levels of cultural heterogeneity. The culture of a village in southern Italy may be different from that of a village in northern Italy, but both will share in a common Italian culture that distinguishes them from German villages. European communities, in turn, 
will share cultural features that distinguish them from Arab or Chinese communities. Arabs, Chinese and Westerners, however, are not part of any broader cultural entity. They constitute civilizations.

In der drei Jahre später zu einem Buch ausgearbeiteten Form des Essays findet sich eine Weltkarte, auf der die Kulturräume der Welt nach dem Fall des Ostblocks eingezeichnet sind (Huntington 1996: 26f.). Wie oben zu sehen ist, wird der Begriff der civilization bei Huntington auf der Grundlage eines totalitätsorientierten Kulturbegriffs definiert, nämlich als Bündel von Einzelkulturen. Was aber ist eine Kultur? Nachdem über ca. 2/3 des Essays hinweg als bekannt vorausgesetzt wird, was denn unter Kultur zu verstehen sei, findet sich schließlich in einem Nebensatz, dass damit „basic beliefs and values" (Huntington 1993: 40) gemeint sind. Folgt man Huntingtons Definition, dann teilen Angehörige derselben Kultur diese grundlegenden Einstellungen und Werte. Diese machen also das aus, was etwa Italiener, Deutsche, Chinesen oder Araber untereinander verbindet.

Wie ist nun ein solcher Kulturbegriff im Hinblick auf die Offenlegung bzw. Verschleierung von Kontingenz zu bewerten? Zunächst lässt sich feststellen, dass der totalitätsorientierte Kulturbegriff, wie er sich von Herder über Benedict bis zu Huntington rekonstruieren lässt, stärker als der normative Kulturbegriff auf die Anerkennung von Kontingenz ausgerichtet ist, würdigt er doch die Existenz verschiedener, prinzipiell gleichwertiger Kulturen. In der Fixierung des Blicks auf Kollektive ist jedoch auch ein Moment enthalten, das Kontingenz in erheblichem Maße reduziert. Kulturen bzw. Kulturräume werden als „idealerweise nach innen homogen und nach außen geschlossen" (Reckwitz 2004: 6) modelliert. Individuen können der Kultur, in die sie hineingeboren werden, eindeutig zugeordnet werden. Die Anerkennung von Kontingenz zwischen Kulturen wird somit erreicht um den Preis der Reduktion von Kontingenz innerhalb von Kulturen (vgl. ebd.: 5).

Angesichts der zunehmenden globalen Vernetzung scheint ein solcher Kulturbegriff aus heutiger Sicht insofern besonders problematisch, als er im Inneren von Gesellschaften wenig Raum für Heterogenität bietet. Der Mensch scheint weitgehend, wenn nicht gar vollständig festgelegt auf die Lebensweise, die innerhalb seiner Gruppe von Generation zu Generation weitergereicht wird. Sein Denken, Fühlen und Handeln sind damit gerade nicht kontingent, nicht ,nicht-notwendig', sondern im Gegenteil notwendig und im Rahmen des jeweiligen Bezugssystems vorab festgelegt. Wolfgang Welsch (1999: 47-49) hat darauf hingewiesen, dass das Konzept der Einzelkulturen „[... nicht nur deskriptiv 
falsch, sondern auch normativ gefährlich und unhaltbar [... “ ${ }^{\text {sei. }}{ }^{28}$ Ein Begriff aber, der mit einem deskriptiven Anspruch auftritt, gleichzeitig jedoch über ein starkes normatives Potential verfügt, kann besonders leicht zur Verschleierung von Kontingenz führen (vgl. Breidbach 2007: 225ff.).

Neben der Verschleierung des inhärenten normativen Moments ist der totalitätsorientierte Kulturbegriff auch aus ethischer Sicht problematisch. Die Möglichkeit des Verstehens zwischen den Angehörigen verschiedener Kulturen geht gegen Null: Sie können, so behauptet zumindest Benedict (s. o.), nicht einmal ein Tausendstel der Lebenswelt des Anderen nachvollziehen. Denkt man dieses Nicht-Verstehen konsequent zu Ende, scheinen kriegerische Konflikte unvermeidlich. Besonders gefährlich kann ein solcher Kulturbegriff werden, wenn er als Grundlage für die Analyse politischer Konflikte dient, und wenn diese Analyse dann zur Gestaltung praktischer Politik herangezogen wird. Dies gilt etwa für die Arbeiten Huntingtons, der neben seiner wissenschaftlichen Tätigkeit auch das amerikanische Außenministerium berät. Vor diesem Hintergrund ist seine Einschätzung „Islam has bloody borders“ (1993: 35) nur eines von zahlreichen Beispielen aus einem Essay, der zur Schaffung der Wirklichkeit beigetragen haben dürfte, die er lediglich zu beschreiben vorgibt. ${ }^{29}$

Herders Kulturbegriff enthält, sowohl in der ursprünglichen Formulierung als auch in der zugespitzten Fassung wie etwa bei Benedict, einen weiteren Aspekt, welcher die Wahrnehmung von Kontingenz noch weiter reduziert. Er modelliert Kulturen als einer organischen Entwicklung unterworfen, als Kreisläufe, die, ähnlich wie der Mensch, „Lebensperioden“ (Herder (1841 [1784], Bd. 2: 134) kennen. Dies suggeriert, dass sich jede Kultur auf einer bestimmten Entwicklungsstufe befinde. Zu einem beliebigen Zeitpunkt ist sie dieser Auffassung nach in den Kreislauf aus Geburt, Wachstum, Blüte, Reife, Verfall und Tod eingebunden. Es ist ihr also eine Entwicklungsrichtung vorgegeben. Aus der Kontingenzperspektive betrachtet verfügt der totalitätsorientierte Kulturbegriff daher über eine Schnittmenge mit dem normativen Kulturbegriff. Zwar ist nun nicht mehr die bürgerliche Kultur anzustreben, aber es herrscht doch die Vorstellung eines kulturspezifischen Idealzustandes, dem sich die jeweilige Kultur annähern, den sie erreichen, von dem sie sich auf dem Weg zu ihrem Untergang aber auch wieder entfernen kann.

28 Eine detaillierte Diskussion des von Welsch entwickelten Konzeptes der Transkulturalität erfolgt in Kapitel 2.1.5.

$29 \mathrm{Zu}$ einer ähnlichen kritischen Einschätzung von Huntingtons Essay kommen auch Andreas Bonnet und Stephan Breidbach (2007: 257). 
Abschließend noch einige Bemerkungen zu Huntingtons Versuch, die Welt in kulturell mehr oder weniger homogene Großräume einzuteilen. Folgt man seiner Argumentation, sind Menschen qua Geburt und Sozialisation auf ihre civilization kulturell festgelegt. Zwar vergrößert sich der Spielraum für Diversität und damit Kontingenz - durch die Ausweitung des Kulturbegriffs von Einzelkulturen auf Kulturräume oder -kreise. Die Grundproblematik, die sich bereits bei Herder und Benedict zeigen lässt, löst jedoch auch Huntington keineswegs. Es bleibt dabei, dass die Zugehörigkeit etwa zum westlichen, arabischen oder chinesischen Kulturkreis nicht weiter transzendiert werden kann. Die Vision einer universellen menschlichen Gemeinschaft, in der Konflikte mit gewaltfreien Mitteln gelöst werden und in der bestimmte unveräußerliche Rechte für alle Menschen gelten, der Grundgedanke der Vereinten Nationen, wird stillschweigend ad acta gelegt.

Ein Kulturbegriff, wie ihn Huntington seinen Überlegungen zugrunde legt, kann es nicht leisten, Kontingenzen des menschlichen Fühlens, Denkens und Verhaltens offenzulegen. Vielmehr scheint es geradezu eine nationalkulturelle Essenz zu geben, die dazu führt, dass, um bei Huntingtons oben zitiertem Beispiel zu bleiben, die ,Kultur' eines Dorfes in Südtirol der eines anderen auf Sizilien mehr ähnelt als etwa der eines Dorfes in Bayern. Dasselbe gilt auf einer höheren Ebene für die Zugehörigkeit zu Kulturkreisen, etwa zum europäischen oder arabischen. Stephan Breidbach (2007) hat nachgezeichnet, wie im 19. und 20. Jahrhundert individuelle Identitäten in "nationalen Kollektivsubjekten“ (ebd.: 222) aufgingen. In einem zweiten Schritt, so Breidbach weiter, wurde der totalitätsorientierte Kulturbegriff „,vom emanzipativen Leitbild zum politischen Programm“ (ebd.: 225). Huntingtons Essay kann als Versuch gelesen werden, dasselbe auf der transnationalen Ebene der civilizations zu vollziehen.

\subsubsection{Der differenzierungstheoretische Kulturbegriff}

Der vor allem in der systemtheoretisch ausgerichteten Soziologie entwickelte differenzierungstheoretische Kulturbegriff unterscheidet sich in mehrfacher Hinsicht von den bisher vorgestellten, dem normativen und dem totalitätsorientierten. Dies zeigt sich bereits an einer von Talcott Parsons und Gerald M. Platt (1990: 21) in ihrer Studie über Die amerikanische Universität formulierten Definition:

Kultur besteht aus kodifizierten Systemen sinntragender Symbole und aus jenen Aspekten von Handeln, die sich unmittelbar auf Fragen der Sinnhaftigkeit dieser Symbole beziehen. Kultur umfaßt daher Glaubenssysteme, Aussagen kognitiven Gehalts wie auch expressive Symbole und die Codes, die ihnen Bedeutung geben. 
Hier kündigt sich die Konzentration des Kulturbegriffs auf die Sinnzuschreibungen in Bezug auf Handlungen und Symbole an, welche für den bedeutungsund wissensorientierten Kulturbegriff zentral sein werden. Der Geltungsbereich dieses auf den ersten Blick weiten Kulturbegriffs wird jedoch an anderer Stelle deutlich eingeschränkt.

Zum einen betrifft diese Einschränkung den Untersuchungsgegenstand. Parsons und Platt verstehen Kultur nicht im Hinblick auf alle Bereiche einer Gesellschaft, sondern als eines von vier gesellschaftlichen Teilsystemen. Sie definieren Kultur als „Treuhandsubsystem“, das von „Ökonomie“,„Politbereich“ und „gesellschaftliche[r] Gemeinschaft" abzugrenzen sei (vgl. ebd.: 33). Zur Kultur gehört im differenzierungstheoretischen Sinn beispielsweise das akademische System, das zu sehen sei als „[...] Teil des Treuhandsubsystems einer Gesellschaft, jenes Subsystems, das eine engere Verbindung zu kulturellen Bezügen aufweist als jedes der drei übrigen Subsysteme“ (ebd.). Es zeichne sich dadurch aus, dass es „[...] als Treuhänder der kognitiven Kultur und der damit verbundenen Interessen [wirke]“ (ebd.). Kultur meint also nicht mehr die gesellschaftliche Gesamtheit einer geografisch und politisch meist klar abgrenzbaren Gruppe, sondern der Begriff bezieht sich nunmehr lediglich auf einen Teilbereich innerhalb einer solchen Gruppe. Die Kultursoziologie engt ihren Blick damit ein auf das „[...] gesellschaftliche Handlungsfeld, in dem die Produktion, Verteilung und Verwaltung von ,Weltdeutungen' intellektueller, künstlerischer, religiöser oder massenmedialer Art stattfindet" (Reckwitz 2000: 79). Dies erinnert an die Ausrichtung des normativen Kulturbegriffs auf die bürgerliche Kultur. Allerdings ist jetzt nicht mehr die Lebensweise einer bürgerlichen Schicht selbst von Interesse, sondern es wird vielmehr das soziale System in den Blick genommen, welches einem vorwiegend bürgerlichen Publikum Sinnsysteme zur Verfügung stellt und diese verwaltet.

Eine zweite Einschränkung erfährt der differenzierungstheoretische Kulturbegriff durch die Einnahme einer strikt funktionalistischen Perspektive. So werden etwa bildende Kunst, Literatur oder Wissenschaft nicht mehr als Ausdruck von Kultur, sondern als soziale Subsysteme, als spezialisierte Teilbereiche von Kultur verstanden. Jedes der verschiedenen Subsysteme von Kultur wird in diesem Sinne interpretiert als „[... [ spezialisiertes soziales System, das zum Bestand der modernen Gesellschaft bestimmte funktionale Leistungen erbringt" (Reckwitz 2004: 6). Damit wird nachvollziehbar, dass sich die Fragestellungen der Kultursoziologie im Vergleich etwa zur Anthropologie deutlich verschieben. Kultur wird nicht mehr modelliert als Gegenstand, dessen Beschreibung Generalisierungen über eine bestimmte Gruppe erlauben, etwa in Bezug auf die 
,Mentalität' ihrer Mitglieder. Vielmehr stellt sich nun in erster Linie die Frage nach der Funktion von Kultur als Teilsystem einer Gesellschaft, das sich auf die Beschäftigung mit und auf die Hervorbringung von Sinnsystemen spezialisiert hat. Aus systemtheoretischer Sicht ist dabei von besonderem Interesse, auf welche Art und Weise diese Sinnsysteme die Reproduktion ihrer selbst und der Gesellschaft insgesamt sicherstellen.

Ein weiteres wichtiges Merkmal des differenzierungstheoretischen Kulturbegriffs liegt in einer konsequent deskriptiven Haltung. Dieser Aspekt steht in Kontinuität zum totalitätsorientierten Kulturverständnis, stellt jedoch einen weiteren Unterschied im Vergleich zum normativen Kulturverständnis dar.

Zusammenfassend lässt sich festhalten, dass der Übergang vom normativen zum totalitätsorientierten Kulturbegriff eine radikale Ausweitung seiner Semantik darstellte, während der differenzierungstheoretische Kulturbegriff eine doppelte Eingrenzung vollzieht. Diese Eingrenzung ist erstens eine stratifikatorische, da nunmehr nur noch jene Sinnsysteme von Interesse sind, die überwiegend für ein bürgerliches Publikum produziert und von diesem rezipiert werden. Die zweite Eingrenzung ist eine funktionalistische, das heißt, Kultur ist von Interesse als soziales System, dessen Funktion darin besteht, sich selbst zu reproduzieren (vgl. Reckwitz 2004: 6), und das bestimmte Funktionen für die Selbstreproduktion einer Gesellschaft insgesamt übernimmt.

Gegen einen differenzierungstheoretischen Kulturbegriff lassen sich mehrere Vorbehalte formulieren. Aus der Kontingenzperspektive erhebt Reckwitz (ebd.) folgenden Einwand:

In seiner differenzierungstheoretischen Version verliert der Kulturbegriff [mit der Ausrichtung auf die Funktion eines, Treuhändersystems'] weitgehend seine - in der normativen und totalitätsorientierten Variante eingeschränkt vorhandene - Konnotation eines Indikators von Kontingenz der Lebensformen und sein Anregungspotential zum ,Vergleich' von unterschiedlichen Lebensweisen.

Gegen diese Kritik lässt sich zweierlei einwenden. Auch wenn der Begriff in der Tat eine Engführung auf ein gesellschaftliches Teilsystem vornimmt, so wird diese Eingrenzung des Forschungsgegenstandes doch offengelegt und begründet. Reckwitz klärt nicht, inwiefern diese Eingrenzung des Gegenstandes zwangsläufig auch zu einer Einschränkung des Potentials für die Offenlegung von Kontingenz bedeutet. Im Gegenteil, die konsequent deskriptive Ausrichtung und die Verortung in der Systemtheorie legt nahe, dass der differenzierungstheoretische Kulturbegriff für die Offenlegung von Kontingenzen - innerhalb des ,Treuhän-

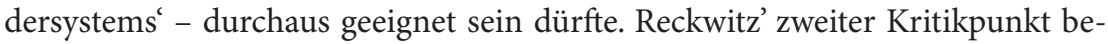
zieht sich nicht mehr auf den Aspekt der Kontingenz, sondern vielmehr auf die 
Frage, ob ein differenzierungstheoretischer Kulturbegriff für Vergleiche geeignet sei. Reckwitz verneint dies, ohne seine Einschätzung argumentativ zu untermauern. Gerade die Analyse von Teilsystemen könnte jedoch für Vergleiche geeignet sein, auch und gerade im Hinblick auf ihre Kontingenzen.

Die Schwächen des differenzierungstheoretischen Kulturbegriffs scheinen daher kaum im Bereich der Invisibilisierung von Kontingenzen zu liegen. Stichhaltiger lässt sich im Hinblick auf die Gültigkeit seiner Prämissen argumentieren. Bereits zeitlich parallel zur Ausarbeitung des differenzierungstheoretischen Kulturbegriffs finden sich etwa innerhalb der Soziologie Stimmen, die einer Einengung seines Geltungsbereichs auf den intellektuellen, künstlerischen und religiösen Bereich widersprechen. Wie Reckwitz unterstreicht, hat der differenzierungstheoretische Kulturbegriff nach der hier beschriebenen engen Fassung insbesondere im Kontext der Postmodernismus-Diskussion seit den achtziger Jahren auch eine erhebliche Ausweitung erfahren. So stellt etwa Fredric Jameson (1992: 48) fest:

[...] the dissolution of an autonomous sphere of culture is rather to be imagined in terms of an explosion: a prodigious expansion of culture throughout the social realm, to the point at which everything in our social life - from economic value and state power to practices and to the very structure of the psyche itself - can be said to have become ,cultural' in some original and yet untheorized sense.

Diese Entwicklung lasse sich beispielsweise an den Ästhetisierungstendenzen der Alltagskultur festmachen (vgl. Reckwitz 2000: 83). Sie stellt die Engführung in Frage, die der differenzierungstheoretische Kulturbegriff vorzunehmen versucht.

Auch im Hinblick auf einen weiteren Aspekt lässt sich die Frage stellen, inwieweit ein eng gefasster differenzierungstheoretischer Kulturbegriff in der Lage ist, eine sich dynamisch entwickelnde Realität zu beschreiben. So sieht etwa Friedrich Tenbruck (1990: 17ff.; vgl. Reckwitz 2000: 80) Kultur ebenfalls in einem differenzierungstheoretischen Sinn als Bereich, in dem Spezialisten die Produktion von Sinnsystemen repräsentativ verwalten. Reckwitz (2000: 80) hält daher in Anlehnung an Tenbruck fest, dass einem solchen Kulturverständnis eine „Asymmetrie zwischen modernen Kulturproduzenten und Kulturkonsumenten" zugrunde liege. Es fußt somit auf der Voraussetzung, dass sich die Gesellschaft tendenziell trennscharf in ,Sender' (Wissenschaftler, Journalisten, etc.) und ,Empfänger` einteilen lässt. Diese Voraussetzung war auch lange gegeben, da die Produktion und massenmediale Verbreitung von ,Weltdeutungen im Zeitalter des Buchs, der Zeitung, des Radios und des Fernsehens in der Tat einer kleinen gesellschaftlichen Gruppe vorbehalten war. Bekanntlich führten 
technische Innovationen in der letzten Dekade des 20. Jahrhunderts aber zu einem Umbruch, der diese Voraussetzungen radikal in Frage stellte.

Die digitalen Medien haben inzwischen praktisch alle Lebensbereiche erreicht und zum Teil erheblich verändert. Aus medientheoretischer Sicht sehen manche die entscheidende Neuerung nun gerade in der Aufhebung der zuvor gültigen Asymmetrie zwischen Produzenten und Konsumenten von Inhalten. Im Gegensatz zu anderen Medien, allen voran Radio und Fernsehen, war das World Wide Web jedoch von Beginn an so konzipiert, dass jedes angeschlossene Gerät nicht nur empfangen, sondern auch senden konnte. Insofern hat mit der technischen Infrastruktur des digitalen Zeitalters in der Tat eine neue Ära begonnen. Während zuvor wenige Sender mit Millionen von Empfängern kommunizierten (one-tomany), ist heute prinzipiell jeder Internetnutzer in der Lage, Inhalte nicht nur zu empfangen, sondern auch selbst für eine potentiell millionenstarkes Publikum zu produzieren (many-to-many). Zwar waren die technischen Hürden zu Beginn des Internetzeitalters hierfür noch recht hoch. Heute werden jedoch keine speziellen Kenntnisse mehr benötigt, um in einem Forum einen Kommentar zu posten, um ein Blog einzurichten, um eine Kurznachricht ( $t$ weet) abzusetzen, um in einem sozialen Netzwerk ein Foto zu posten oder um ein Video, hochzuladen. Diese seit 8-10 Jahren typischen Publikationsformen haben die Utopie der Bereitstellung von Inhalten nicht mehr durch einige wenige, sondern durch theoretisch alle Mitglieder einer Gesellschaft verwirklicht. Sie sind in kürzester Zeit so populär geworden, dass der Unterschied zu den frühen Jahren des Internet als eine Art Paradigmenwechsel empfunden wird, für den sich die Bezeichnung Web 2.0 durchgesetzt hat. Der alte, von Bertolt Brecht zwischen 1927 und 1932 als Radiotheorie formulierte Traum (vgl. Brecht 1990), mit Empfangsgeräten auch senden zu können, den Hans Magnus Enzensberger (1970) zu einer Medientheorie weiterentwickelte, ist somit längst zum Alltag der digitalen Gesellschaft geworden. Der Medienwissenschaftler Stefan Münker (2009: 129) notiert hierzu:

Wenn aber die Bereiche des traditionellen Journalismus und der im Internet entstehenden vernetzten Informationsökonomie sich zu vermischen beginnen und nicht länger strikt getrennt werden können - dann ist die strukturelle Konsequenz für die Form von Öffentlichkeit, welche der Journalismus gemeinhin repräsentiert, deutlich: Die durch journalistische Beiträge konstituierte kritische Öffentlichkeit ist dann eben auch nicht länger als eine von der Zivilgesellschaft institutionell getrennte Sphäre zu beschreiben; sie ist selbst Teil von ihr.

Ein soziologischer Kulturbegriff, der auf eine gewisse Trennschärfe zwischen den ,Produzenten' und den ,Konsumenten' von Weltdeutungen angewiesen ist, erscheint angesichts dieser Entwicklungen als problematisch. Seine Voraussetzungen 
sind empirisch nicht mehr gegeben, und damit dürfte sein Nutzen für die Beschreibung von Gesellschaften nur noch gering sein.

\subsubsection{Der bedeutungs- und wissensorientierte Kulturbegriff}

Den vierten Kulturbegriff bezeichnet Reckwitz in seiner Klassifikation als ,bedeutungs- und wissensorientiert'. Dieser wird bisweilen auch als ,semiotischer oder, leicht tautologisch, als ,kulturwissenschaftlicher ${ }^{`}$ Kulturbegriff bezeichnet. Er lässt sich zurückführen auf Ernst Cassirers Feststellung, dass der Mensch die Welt nur als ,Bedeutungswelt' wahrzunehmen in der Lage sei:

Die Zweiteilung: Symbol oder Gegenstand erweist sich auch hier als unmöglich, da die schärfere Analyse uns lehrt, daß eben die Funktion des Symbolischen es ist, die die Vorbedingung für alles Erfassen von,Gegenständen`oder Sachverhalten ist. (Cassirer 1994 [1942]: 31; vgl. Reckwitz 2004: 7)

Der Mensch ist nach Cassirer ohne Unterlass damit beschäftigt, über die Sinne auf ihn einströmende Informationen zu bedeutungsvollen Einheiten zu verknüpfen. Im Umkehrschluss bedeutet dies, dass Sinn nicht ontologisch vorhanden ist, sondern vom Individuum erst hervorgebracht wird, ein Vorgang, der meist unbewusst auf der Grundlage kulturell vorgegebener Skripts abläuft. Prinzipiell kann dieser Prozess jedoch auch bewusst erfolgen. Daraus ergibt sich die Perspektive, dass automatisch ablaufende Sinnzuschreibungen durchbrochen und neue, außerhalb der vorgegebenen Skripts liegende vorgenommen werden können.

Reckwitz macht vier kulturtheoretische Strömungen aus, welche an Cassirers Überlegungen anschließen und die Kulturwissenschaft nachhaltig beeinflusst haben: Phänomenologie und Hermeneutik, Strukturalismus und Semiotik, Pragmatismus sowie Sprachspielphilosophie (vgl. ebd.).

Die Vorstellung einer Notwendigkeit oder Natürlichkeit menschlichen Denkens, Fühlens und Handelns in bestimmten Situationen wird durch einen solchen bedeutungs- und wissensorientierten Kulturbegriff grundlegend angezweifelt. Er überwindet die Defizite des normativen Kulturbegriffs (bürgerliche Kultur als Idealzustand), des totalitätsorientierten Kulturbegriffs (Kulturen als nach innen homogene und nach außen abgrenzbare,Kugeln') und des differenzierungstheoretischen Kulturbegriffs (Kultur als soziales Treuhandsystem mit der Funktion, sich selbst zu reproduzieren), indem er die Kontingenz menschlicher Sinnzuschreibungen offenlegt, anstatt sie zu verschleiern.

Erst die modernen Kulturtheorien, die sich aus diesen vier verschiedenen theoretischen Quellen speisen, vermögen damit die Implikation der Kontingenz menschlicher Lebensformen, die im Kulturbegriff von Anfang an angelegt war, zu radikalisieren. (ebd.) 
Die erkenntnisthoretische Positionierung des bedeutungs- und wissensorientierten Kulturbegriffs hat höchst relevante machttheoretische Implikationen. Reckwitz (ebd.: 8) hebt in diesem Zusammenhang hervor:

Entscheidend ist nun die Einsicht, dass sämtliche Komplexe von Praktiken der Vergangenheit und Gegenwart - vom archaischen Ritus bis zur modernen Naturwissenschaft - erst vor dem Hintergrund der jeweiligen, sehr spezifischen Sinnhorizonte und Bedeutungscodes möglich sind, ,normal' und ,rational' werden oder gar als ,notwendig und ,natürlich` erscheinen.

Gerade der Verweis auf den Rationalitätsbegriff ist hier von Interesse, da er die Vorstellung in Zweifel zieht, es lasse sich eine universell gültige Vernunft formulieren (vgl. hierzu die historische Analyse des Vernunftbegriffs von Welsch 1995). Vielmehr erscheint auch Vernunft als lediglich in einem bestimmten kulturellen Kontext gültig und ist daher als, kontingent' anzusehen.

Mit dem kulturwissenschaftlichen Kulturbegriff, auf den in der fremdsprachendidaktischen Diskussion häufig Bezug genommen wird, ist also ein bedeutungs- und wissensorientierter Kulturbegriff gemeint. Kultur wird in diesem Sinne definiert als...

[...] die impliziten, in der Regel nicht bewussten symbolischen Ordnungen, kulturellen Codes und Sinnhorizonte [...], die in unterschiedlichsten menschlichen Praktiken -verschiedener Zeiten und Räume - zum Ausdruck kommen und diese ermöglichen. (Reckwitz 2004: 2)

Bevor ich die Überlegungen zur Klassifizierung der Kulturbegriffe aus der Kontingenzperspektive zusammenfasse, folgt zunächst ein Exkurs auf die so genannte, Transkulturalität؛.

\subsubsection{Exkurs: Das Konzept der, Transkulturalität}

Mit dem von Wolfgang Welsch geprägten Begriff der Transkulturalität liegt ein weiterer Kulturbegriff vor, der ebenfalls als bedeutungs- und wissensorientierten Kulturverständnissen einzuordnen ist. Dieser Begriff verdient im Rahmen der vorliegenden Arbeit aus zwei Gründen Beachtung. Erstens widmet sich Welsch konsequent der Problematik, die aus der offenen oder uneingestandenen Verwendung eines normativen bzw. totalitätsorientierten Kulturbegriffs entsteht, aus der Vorstellung also, es gebe homogene und abgrenzbare Einzelkulturen. Zweitens wurde das Konzept Transkulturalität in der fremdsprachendidaktischen Diskussion bereits mehrfach rezipiert (vgl. u. a. Küster 2003a, Breidbach 2003). Hierbei wurde mit dem Begriff die Hoffnung verbunden, er könne einen Ausweg aus den Schwierigkeiten bieten, mit denen man sich in der fremdsprachendidaktischen 
Theoriebildung, Forschung und Unterrichtspraxis in Zusammenhang mit der Interkulturalität konfrontiert sah. Ich möchte im Folgenden die Grundzüge des Transkulturalitätsbegriffs vorstellen und im Rahmen einer kritischen Würdigung diskutieren, ob er vielleicht erneut als Alternative für den in der Fremdsprachendidaktik fest etablierten Interkulturalitätsbegriff in Betracht gezogen werden sollte.

Welsch geht in den beiden Aufsätzen, in denen er den Begriff in die Debatte einführt (vgl. Welsch 1994, 1999), von der Einschätzung aus, dass die seinerzeit dominierenden Kulturbegriffe auf der Vorstellung von homogenen Einzelkulturen basieren. Die Hauptquelle dieser Vorstellung sieht er in den Arbeiten Johann Gottfried Herders. Vor allem mit seiner Metapher von Kulturen als ,Kugeln' habe Herder der Vorstellung zum Durchbruch verholfen, dass Kulturen nach innen homogen und nach außen abgrenzbar seien. Diese Vorstellung sei aber, so Welsch, weder empirisch verwendbar noch normativ vertretbar, ein Einwand, den er ausführlich argumentativ untermauert. Das Hauptargument lautet, dass sich moderne Gesellschaften durch eine hohe Ausdifferenzierung der sozialen Funktionen und durch eine eng damit zusammenhängende Pluralität der Lebensweisen auszeichnen. Welsch unterstreicht daher, erstens, dass die Vorstellung von homogenen Einzelkulturen nicht (mehr) zu gebrauchen sei, denn es sei nicht zu vermeiden, dass auch rein deskriptive Herangehensweisen durch die Verwendung eines veralteten Kulturkonzeptes immer ein stark normatives Moment aufwiesen. Das heißt, dass ein an den Vorstellungen Herders angelehnter Kulturbegriff die Wirklichkeit, die er zu beschreiben vorgibt, zumindest teilweise erst erzeugt. ${ }^{30}$ Ein zweites Problem liegt nach Welsch in dem Umstand, dass das Konzept der Einzelkulturen auf der Vorstellung aufbaue, dass Kultur und Ethnie einander entsprächen. Nicht nur die deutsche Geschichte des 20. Jahrhunderts habe jedoch gezeigt, dass „[...] solch völkische Definitionen hochgradig fiktiv [sind] und [...] krampfhaft gegen die historische Evidenz von Mischungen durchgesetzt werden [müssen]“ (Welsch 1999: 48).

Neben der Einschätzung, dass das Konzept der Einzelkulturen als begriffliches Werkzeug für die Beschreibung und Analyse von Gesellschaften unbrauchbar sei, führt Welsch auch ein gewichtiges ethisches Argument an, das insbesondere bei der Selbstbeschreibung von Gemeinschaften zu berücksichtigen sei. Die

30 Auf das normative Potential eines essentialisierenden Kulturbegriffs wurde bereits oben in Zusammenhang mit den Arbeiten Huntingtons hingewiesen (vgl. Kap. 2.1.2.). Auch Welsch (1999: 55) unterstreicht, dass Kulturbegriffe niemals rein beschreibend sind, sondern dass sie wie andere „operative Begriffe [...] Einfluß auf ihren Gegenstand" haben. 
meist unbewusste normative Dimension des Konzeptes von Einzelkulturen führe dazu, dass Kulturen eine Tendenz entwickelten, sich nach innen zu homogenisieren und nach außen abzuschotten. Auch diese Aspekte seien direkt auf das Herder'sche Kulturverständnis zurückzuführen. Es sei sogar zu befürchten, dass die Kombination aus „Kugelprämisse plus Reinheitsgebot“ $\mathrm{zu}$ „kulturellem Rassismus“ (ebd.: 48) führe.

Welsch diskutiert auf dieser Grundlage die Frage, inwieweit die Konzepte ,Multikulturalität ' bzw. ,Interkulturalität' die umrissenen Probleme möglicherweise lösen können. Die beiden in der zweiten Hälfte des 20. Jahrhunderts entwickelten Ansätze verfolgen ja das Anliegen, einerseits die verstärkte ethnische und kulturelle Durchmischung der modernen Gesellschaften nach innen, andererseits ihre zunehmende internationale Verflechtung nach außen mit einem angemessenen Kulturverständnis abzubilden und zu gestalten. In Bezug auf beide fällt Welschs Urteil jedoch negativ aus, denn er hält sie für ungeeignet, um die von ihm aufgeworfene Problemlage deskriptiv angemessen und ethisch vertretbar zu lösen. Hierfür werden folgende Gründe genannt:

Der Ansatz der Multikulturalität sei zwar ein gut gemeinter Versuch, der empirisch beobachtbaren Vielfalt unterschiedlicher Lebensarten gerecht zu werden. Allerdings baue das Konzept der Multikulturalität ebenfalls auf Herders Vorstellung von klar abgrenzbaren Einzelkulturen auf. Es verlagere lediglich die Probleme, die sich aus der Existenz unterschiedlicher Kulturen ergeben, von außen in Gesellschaften hinein, ohne sie zu lösen. Dadurch entstehe sogar die Gefahr, dass unbeabsichtigterweise Tendenzen gefördert werden, die „[...] unter Berufung auf kulturelle Identität (ein Konstrukt, das man meist aus den Imaginationen eines Vorgestern gewinnt) zu Ghettoisierung und Kulturfundamentalismus führen“" (ebd.: 49).

Als ähnlich problematisch schätzt Welsch auch das Konzept der Interkulturalität ein. Zwar gebe es etwa in der interkulturellen Philosophie oder der interkulturellen Pädagogik durchaus ein Bewusstsein für das Konfliktpotential, das sich aus der Vorstellung von nebeneinander existierenden Einzelkulturen ergibt. Allerdings sei der Ansatz, diese Konflikte durch einen interkulturellen Dialog zu lösen, zum Scheitern verurteilt. Das Grundproblem liege, so Welsch, wiederum in Herders Kulturverständnis, und es gehe darum, sich diesem zu stellen: „Solange man die Primärthese von der Insel- oder Kugelverfassung der Kulturen mitmacht, werden diese Folgeprobleme nicht lösbar sein“ (ebd.: 50).

Es macht somit aus der Sicht Welschs kaum einen Unterschied, ob man sich mit dem Ansatz der Interkulturalität den Grenzlinien zwischen Gesellschaften oder mit dem Ansatz der Multikulturalität den Grenzlinien innerhalb von Gesellschaften widmet. Beide Ansätze führen nach Welschs Auffassung gleichermaßen 
in die Irre, da sie auf Herders Kugelmetapher aufbauten. Diese liefere ein falsches Bild von aktuellen Gesellschaften, die sich ja gerade nicht durch Homogenität auszeichneten, eine Eigenschaft, welche die Kugelmetapher suggeriert, sondern ihr herausragendes Merkmal sei vielmehr das einer zunehmenden „Hybridisierung" (ebd.: 52).

Die Annahme der Hybridität von Kulturen stellt einen zentralen Aspekt der Transkulturalität dar. Wenn innere Homogenität und äußere Abgrenzbarkeit Fiktionen sind, die ein zeitgemäßes Kulturverständnis überwinden muss, könnte die Metapher der Hybridität hierbei wertvolle Dienste leisten. Der Begriff hybrida wurde ursprünglich im Lateinischen als griechisches Fremdwort mit der deutlich negativ konnotierten Bedeutung, Mischling' oder ,Bastard' verwendet. In der Gegenwart hat er Einzug in die verschiedensten Wissensbereiche gehalten und steht nun frei von negativen Konnotationen für Phänomene, die sich durch Kombination oder Mischung auszeichnen (z.B. Hybridfahrzeuge: Kombination aus Verbrennungs- und Elektromotor). Hybridität ist jedoch auch in den Human- und Kulturwissenschaften zu einem geläufigen Begriff geworden. Welsch verwendet ihn in der Bedeutung einer gegenseitigen Durchdringung und Durchmischung von Phänomenen, die vormals bestimmten Einzelkulturen zugeordnet werden konnten. Die immer leichtere weltweite Verfügbarkeit von Waren, Dienstleistungen und Informationen treibe diese Hybridisierung in einem unumkehrbaren Prozess immer mehr voran. Dabei gehe es durchaus nicht nur um eine zunehmende Amerikanisierung der ganzen Welt, um „Coca-Cola, McDonald's oder CNN“ (ebd.: 52), sondern die Hybridisierung laufe auf allen Ebenen und in alle Richtungen ab, mit dem Ergebnis, dass „[u]nsere Kulturen [...] weitgehend durch Mischungen und Durchdringungen gekennzeichnet [sind]“ (ebd.: 51). Damit verschwimmen auch, so Welsch weiter, die Grenzen zwischen Eigenem und Fremdem: ${ }^{31}$

Daher gibt es nichts schlechthin Fremdes mehr. Alles ist in innerer oder äußerer Reichweite. Und ebenso wenig gibt es noch schlechthin Eigenes. Authentizität ist Folklore geworden, ist simulierte Eigenheit für andere, zu denen der Einheimische längst selbst gehört. Umgekehrt kann Fremdes ganz selbstverständlich für Eigenes gehalten werden. Im Innenverhältnis einer Kultur - zwischen ihren diversen Lebensformen - existieren heute ebenso viele Fremdheiten wie in ihrem Außenverhältnis zu anderen Kulturen. Anders gesagt: Die Trennschärfe zwischen Eigenkultur und Fremdkultur ist dahin. (ebd.: 52)

31 Aus dieser Auflösung der Grenzen entstehen Probleme, welche auch die interkulturelle Fremdsprachendidaktik bereits beschäftigten, als Welsch das Konzept der Transkulturalität vorstellte (vgl. Kap. 3.2.). 
Laut Welsch lässt sich, parallel zur kulturellen Hybridisierung auf der Makroebene der Gesellschaften, das Phänomen der Transkulturalität auch auf der Mikroebene der Individuen beobachten. Es sei falsch, Gesellschaften als kulturell homogene ,Kugeln' zu beschreiben, und ebenso falsch sei es, die Identität eines Individuums als auf eine bestimmte eindeutige Weise kulturell geprägt anzunehmen, nur weil es einer bestimmten Nationalität angehöre. Diese Vorstellung hält Welsch für „töricht und gefährlich“ (ebd.: 53), und er erinnert in diesem Zusammenhang an die in den Grundrechten vieler Staaten garantierte „Entklammerung von staatsbürgerlicher und persönlicher beziehungsweise kultureller Identität“ (ebd.).

Neben der Metapher der Hybridität, die Welsch für Kulturen als sich durchdringende und überlappende Bedeutungsstrukturen vorschlägt, bringt er eine zweite Metapher für Kulturen ins Gespräch, nämlich die der transkulturellen Netze (ebd.: 59). Sie erlaubt es ihm, Kulturen als „aus unterschiedlichen Fäden zusammengesetzt und auf unterschiedliche Weise gewebt" (ebd.: 59) zu modellieren. Die Netzmetapher ermöglicht es gleichzeitig, eine mögliche Kritik am Transkulturalitätskonzept schon im Vorfeld zu entkräften, nach der das Konzept der Transkulturalität die Entwicklung einer globalen Einheitskultur fördere. Welsch hält dem entgegen, dass es keineswegs darum gehe, die „Heraufkunft einer uniformen Weltzivilisation“ (ebd.: 58) gutzuheißen. Vielmehr seien Kulturen auch in seinem Modell weiterhin unterscheidbar. Allerdings sei es in der Lage, die Fiktion der klaren Grenzen zwischen,Kugeln' zu überwinden, die sich allenfalls berühren und aneinander stoßen können, und an ihren Platz das Bild miteinander verflochtener Netze zu setzen, das die gegenseitige Beeinflussung und Durchdringung von Kulturen wesentlich treffender zum Ausdruck bringe. Differenzen, die wir gemäß „unseren Intuitionen von kultureller Vielfalt“ (ebd.: 58) wahrnehmen, seien nun nicht mehr zwischen Kugeln, sondern „zwischen unterschiedlichen Netzversionen“ (ebd.: 59) zu suchen, und immer gebe es neben Unterschieden auch Gemeinsamkeiten zwischen einigen Fäden.

Philosophisch bindet Welsch das Konzept der Transkulturalität an Ludwig Wittgensteins Sprachphilosophie an. Nach Wittgenstein finde menschliches Leben immer auf einem „Sockel aus Selbstverständlichkeiten“ (ebd.: 57) statt. Die Rezeption von Wittgensteins Philosophie helfe nun dabei, diesen Sockel als solchen zu erkennen, seine Bestandteile als hybrid und verflochten zu reflektieren, nicht zuletzt auch mit dem Ziel, diese in Frage zu stellen. Zudem orientiere sich Wittgensteins Philosophie konsequent am pragmatischen Gelingen einzelner Interaktionen. Dieses Gelingen werde wahrscheinlicher, wenn man jeden Sockel von Selbstverständlichkeiten nicht als monolithischen Block wahrnehme, 
sondern in seiner Zusammensetzung aus verschiedensten Anteilen. Daraus ergebe sich zudem der Vorteil, dass sich neben Differenzen zwischen Kulturen immer auch Gemeinsamkeiten finden ließen. Die Anlehnung an Wittgenstein ergänzt Welsch um eine ausdrückliche Abgrenzung von der Hermeneutik. Sie komme „mit ihrer Annahme völliger Fremdheit des Anderen auf der einen Seite und der mißlichen Aneignungsdialektik des Verstehens auf der anderen Seite" (ebd.: 58) an die pragmatische Ausrichtung der Wittgenstein'schen Philosophie nicht heran.

Präzisierend ist noch zu ergänzen, dass Welsch, wie er in einer Fußnote klarstellt, die Vorsilbe trans- einerseits in der hier umrissenen Bedeutung verstanden wissen möchte, als Ausdruck des Anliegens also, auf die Auflösung bisheriger Grenzen zwischen Kulturen hinzuweisen und ihre gegenseitige Durchdringung und Überlappung zu betonen. Darüber hinaus deutet Welsch an, dass transzukünftig auch im Sinne von jenseits von interpretiert werden könnte. Transkulturalität wäre daher nicht mehr nur zu verstehen als durch traditionelle Kulturgrenzen hindurchgehend, sondern auch als jenseits traditioneller Kulturverständnisse (vgl. ebd.: 66).

In der Fremdsprachendidaktik wurde der Transkulturalitätsbegriff bisher am ausführlichsten in Zusammenhang mit Johannes Eckerths und Michael Wendts konstruktivistischem Vorstoß rezipiert. In einem von den beiden herausgegebenen Sammelband mit dem Titel Interkulturelles und transkulturelles Lernen im Fremdsprachenunterricht bringt etwa Stephan Breidbach (2003: 219-234) den Begriff aufgrund seines Potentials für eine Überwindung simplifizierender Vorstellungen des Eigenen und Fremden als „Paradigma für den bilingualen Sachfachunterricht" ins Spiel. Auch in seinem Entwurf einer Didaktik für den bilingualen Sachfachunterricht greift Breidbach (2007: 234-237) den Begriff noch einmal auf, um die Problematik des Festhaltens an der Nation als kulturellem Bezugsrahmen herauszuarbeiten, und reiht sich damit wie Welsch in die Reihe der Kritiker des totalitätsorientierten Kulturbegriffs ein. Die diesem eigene Gleichsetzung von Kultur und Nation sei, so Breidbach (ebd.: 236), „,sowohl unterkomplex [...] als auch wirklichkeitsfremd."

Auch Lutz Küster greift den Transkulturalitätsbegriff in seinen Schriften mehrfach auf, am ausführlichsten in einem Beitrag zum genannten Sammelband von Eckerth und Wendt, in dem er den Implikationen der unterschiedlichen Termini ,Interkulturalität' und ,Transkulturalität' nachgeht. Küster (2003a: 49) kommt zu der vorsichtig optimistischen Einschätzung, dass der Begriff für die fremdsprachendidaktische Diskussion insofern von Nutzen sein könnte, als er 
„auf die vielfältigen Brüche und Überlappungen hybrider Strukturen“ aufmerksam mache:

Im Sinne des von Welsch (1996) vertretenen Prinzips, radikaler Unordentlichkeit' denke ich, dass der (wiederentdeckte) Begriff der Transkulturalität am fruchtbarsten ist, wenn er selbst transversal verwendet wird. (ebd.)

Dagegen steht Lothar Bredella dem Konzept der Transkulturalität, mit dem er sich in zwei Beiträgen ausführlich beschäftigt (vgl. Bredella 2010b, 2012), betont kritisch gegenüber. Eine detaillierte Auseinandersetzung mit Bredellas Argumentation würde an dieser Stelle vom Thema wegführen. Es sei jedoch darauf hingewiesen, dass er Welschs Aussagen systematisch zuspitzt, um sie umso wirkungsvoller verwerfen zu können, während er die vielfach vorgetragenen konzeptuellen Probleme der interkulturellen Didaktik, insbesondere in Bezug auf die Dichotomie des Eigenen und Fremden, systematisch herunterspielt.

Es lässt sich festhalten, dass der Begriff der Transkulturalität in der fremdsprachendidaktischen Diskussion der letzten zehn Jahre punktuell auftaucht, dass jedoch eine breite Rezeption bisher nicht erfolgt ist. ${ }^{32}$ Es ist müßig, über Gründe für diesen eher verhaltenen Widerhall zu spekulieren. Ich möchte mich abschließend vielmehr der Frage widmen, inwiefern das Potential der Transkulturalität bisher vielleicht nicht ausreichend erkannt wurde und ob der Begriff daher zumindest in der Fremdsprachendidaktik eine Renaissance verdient hätte.

Wie eingangs dargestellt, geht Welsch von der Problemstellung aus, dass ,unsere geläufigen Kulturbegriffe" (Welsch 1999: 45) - gemeint ist der Stand von 1999 - ihrem Gegenstand nicht mehr angemessen seien, denn „[... zeitgenössische Kulturen scheinen eine andere Verfassung angenommen zu haben, als unsere Kulturbegriffe noch immer behaupten oder suggerieren“ (ebd.). Um diese Einschätzung zu begründen, arbeitet Welsch auf sehr plausible Weise die Probleme heraus, die sich aus der Verwendung von in Herders Tradition stehenden Kulturverständnissen ergeben. Diese fasst er als „das traditionelle Konzept der Einzelkulturen“ (ebd.) zusammen. Es lohnt sich, die Gedankenführung der einleitenden Passage näher zu betrachten. Während zu Beginn noch die Rede von „unsere[n] geläufigen Kulturbegriffe[n]“ ist (ebd.), heißt es wenige Zeilen später nur noch „unsere Kulturbegriffe“ (ebd.). Diese sind für Welsch gleichbedeutend mit den „herkömmlichen Kulturbegriffen“ (ebd., Hervorhebungen J. P.). Es erfolgt also eine Gleichsetzung geläufiger Kulturbegriffe mit dem traditionellen, Herder'schen, totalitätsorientierten Kulturbegriff, und diese Gleichsetzung ist

32 Einen neuen Vorstoß hat unlängst Daniel Reimann (2014) unternommen (vgl. Plikat 2015). 
für große Bereiche der Alltagssprache sicher zulässig. Insofern ist die Problemstellung für diesen Bereich zutreffend, und teilweise verfolgt Welsch in der Tat die Absicht, durch einen neuen alltagssprachlichen Kulturbegriff auch Laien eine differenziertere Perspektive auf kulturelle Phänomene zu ermöglichen. Zwar möchte er seinen Vorschlag nicht mit einem normativen, aber doch zumindest mit einem „rekommendativen“ (ebd.: 61) Anspruch verstanden wissen.

Gleichzeitig ist Transkulturalität allerdings auch als Vorschlag für verschiedene wissenschaftliche Diskurse zu verstehen. Darauf weist etwa die Tatsache hin, dass Welsch den Begriff seit 1992 in den Fachpublikationen verschiedener humanwissenschaftlicher Disziplinen vorgestellt hat (v.a. Philosophie, Soziologie und Kulturwissenschaften, genaue Angaben vgl. Welsch 1999: 62) und er sich somit an ein Fachpublikum richtet. Es verwundert daher, dass Welsch in seinem Versuch, „eine neue Konzeptualisierung von ,Kultur` zu erarbeiten“ (ebd.: 45), die Tatsache einer ausgesprochen produktiven und differenzierten kulturwissenschaftlichen Theoriebildung (vgl. Müller-Funk 2010) nur am Rande erwähnt. So ist etwa der Rekurs auf Wittgenstein keine Neuheit, sondern gilt bereits um die Jahrtausendwende als eine der Hauptsäulen eines bedeutungs- und wissensorientierten Kulturbegriffs (vgl. Reckwitz 2000: 89f.). Hier hätte es sich vermutlich gelohnt, die Anschlussfähigkeit des Transkulturalitätsbegriffs an damals bereits vorliegende neuere Kulturverständnisse herauszuarbeiten. Die Problemstellung, mit der Welsch sich beschäftigt, ist daher zumindest in Bezug auf wissenschaftliche Diskurse als deutlich weniger brisant einzuschätzen, als er dies darstellt.

Von deutlich größerer Bedeutung erscheint mir jedoch die Frage nach der Stimmigkeit des Konzeptes selbst. Wie bereits dargelegt, liegt der Kern von Welschs Kulturbegriff in dem Vorschlag, bei der Rede von Kultur immer die Vorsilbe trans- zu verwenden. Auf diese Weise soll, erstens, die Hybridität, Überlappung und gegenseitige Durchdringung kultureller Phänomene betont werden, und darauf aufbauend soll Transkulturalität, zweitens, im Sinne einer vollständigen Überwindung traditioneller Kulturbegriffe verstanden werden. In Bezug auf diese beiden Anliegen scheint das Konzept zunächst einmal plausibel.

Transkulturalität lässt sich jedoch, drittens, noch in einer weiteren Bedeutung verstehen, auf die Welsch selbst nicht hinweist. Damit ist gemeint, dass transkulturell im Sinne von gemischt oder hybrid nicht nur kulturelle Phänomene selbst sind, sondern auch die wissenschaftliche und alltagssprachliche Rede über diese Phänomene. Wie in Kapitel 2.1. deutlich wird, weisen nur wenige Begriffe eine ähnlich komplexe Semantik wie der Kulturbegriff auf. Dieser Umstand ergibt sich aus seiner im Deutschen seit gut 250 Jahren andauernden Begriffsgeschichte, die in Wissenschafts- und Alltagssprache parallel lief und sich durch 
zahlreiche gegenseitige Beeinflussungen und Durchdringungen auszeichnet. $\mathrm{Zu}$ ebenso intensiven Durchmischungen und Überlappungen kam es dabei auch zwischen verschiedenen wissenschaftlichen Definitionsversuchen. Ansätze, den Kulturbegriff wissenschaftlich handhabbar zu machen, lassen sich insofern auch immer als Versuche verstehen, seine Semantik in Abgrenzung zu jeweils gängigen alltagssprachlichen und/oder anderen wissenschaftlichen Konzepten zu definieren (vgl. Kroeber/Kluckhohn 1952). So wie kulturelle Phänomene immer quer zu traditionellen Grenzen zwischen Kulturen liegen, liegt auch die Semantik der Rede über Kultur daher immer quer oder transversal zu traditionellen Grenzen zwischen wissenschaftlichen Disziplinen und anderen Diskursgemeinschaften. Welschs Beiträge zum Begriff der Transkulturalität sind daher insofern bis heute mit Gewinn zu lesen, als er in ihnen einerseits mit sehr klaren Worten auf die Problematik des Konzeptes der Einzelkulturen hinweist und den Versuch unternimmt, die Durchmischung, Überlappung und Hybridität kultureller Phänomene in einen neuen Terminus zu gießen. Darüber hinaus lässt sich der von ihm herausgearbeitete Grundgedanke der Hybridität und Transversalität von Kulturen mit einigem Erkenntnisgewinn auch auf den Kulturbegriff selbst anwenden, der sich immer wieder als hybrides Konzept mit zahlreichen sich überlappenden Bedeutungsfäden aus alltags- und wissenschaftssprachlichen Diskursen zeigt (vgl. Welsch 2010).

In Bezug auf die Ansätze der Multikulturalität und Interkulturalität teile ich Welschs Einschätzung, dass sie sich mit der Lösung von Problemen auseinandersetzen, die bei näherer Betrachtung als Folgeprobleme eines auf Herder rückführbaren und in mehrerlei Hinsicht problematischen Kulturkonzeptes zu sehen sind (vgl. hierzu ausführlich Kap. 2.1.2.). Transkulturalität wäre diesen Begriffen daher vorzuziehen. Es stellt sich jedoch auch für diesen Begriff die Frage, ob er sein Hauptanliegen einlösen kann. Sicher ist die Metapher eines Bedeutungsnetzes mit offenen Rändern der einer Kugel vorzuziehen, die über eine glatte Oberfläche verfügt und sich an anderen Kugeln stößt. Ich halte jedoch auch den Begriff der Transkulturalität für problematisch, und zwar im Hinblick auf einen entscheidenden Aspekt.

Es stellt sich das Problem, dass bei der Rede von ,Kultur' auch eine noch so treffende Vorsilbe die latent immer wirksame Kraft traditioneller Kulturverständnisse, die es ja eigentlich zu überwinden gilt, möglicherweise nicht aufheben kann. Dies gilt vor allem für alltagssprachliche Kontexte, in denen sich das totalitätsorientierte Kulturverständnis besonders stark durchgesetzt hat. Für die Fremdsprachendidaktik ist dieses Problem insofern äußerst relevant, als die Ebene der wissenschaftlichen Begriffsbildung mit hohem Abstraktionsgrad 
sowohl auf der Ebene der Aus- und -fortbildung von Lehrkräften auf einem mittleren Abstraktionsniveau zugänglich gemacht werden muss als auch auf einem niedrigen Abstraktionsniveau für die Arbeit mit Lernenden einsetzbar sein sollte. Es ist aber zu befürchten, dass sich als Folge der hierfür notwendigen didaktischen Reduktionen die alltagssprachlichen Konnotationen des Kulturbegriffs durchsetzen und die von Welsch entwickelte differenzierte Semantik der Vorsilbe trans- überlagern könnten. Grünewald, Küster und Lüning (2011) bringen diese Problematik in Zusammenhang mit dem Interkulturalitätsbegriff auf den Punkt. Für diesen wurde in der fachdidaktischen Diskussion bereits vielfach darauf hingewiesen, dass er auf ein kulturwissenschaftliches Kulturverständnis aufbauen solle. Angesichts der Komplexität und des hohen Abstraktionsgrades dieses Verständnisses schlagen die genannten Autoren allerdings vor, dass für das interkulturelle Lernen in der Schule im Sinne einer didaktischen Progression „zunächst vereinfachende, homogenisierende Vorstellungen zunehmend hinterfragt, relativiert und ausdifferenziert werden" (Grünewald et al. 2011: 52). Aus kulturtheoretischer Perspektive bedeutet dies jedoch, mit der Reflexion über Kultur auf Grundlage eines totalitätsorientierten Kulturbegriffs zu beginnen und erst allmählich den Übergang zu einem kulturwissenschaftlich orientierten Kulturbegriff anzustreben. Mit anderen Worten, die für das interkulturelle Lernen notwendige didaktische Reduktion lässt sich nur durch den temporären Rückgriff auf ein Kulturverständnis bewerkstelligen, das allgemein auch in den Augen der zitierten Autoren - als veraltet und äußerst problematisch gilt. Die gleiche Schwierigkeit sehe ich jedoch auch für kulturelles Lernen auf der Grundlage von Welschs Konzept der Transkulturalität. Auch wenn mir bisher keine methodischen Ansätze für transkulturelles Lernen bekannt sind, so ist doch zu befürchten, dass sie ähnlich wie Ansätze zum interkulturellen Lernen zumindest anfänglich den Rückgriff auf ein homogenisierendes Kulturverständnis nicht werden vermeiden können. ${ }^{33}$

Aus didaktischen, pädagogischen und wissenschaftspropädeutischen Gründen wäre dagegen die Arbeit mit einem Begriff sinnvoll, der didaktisch reduzierbar ist, ohne dabei fast zwangsläufig in eine reduktionistische Falle zu führen. Ein solcher Begriff müsste dabei jedoch an aktuelle kulturwissenschaftliche Positionen und Begriffe anschlussfähig sein. Er dürfte zudem keine Tendenz zur Verschleierung von Kontingenz aufweisen, wie sie für traditionelle Kulturbegriffe herausgearbeitet

33 Ein forschungspraktischer Beitrag von Rainer Kokemohr, den Hans-Christoph Koller (2012: 163) analysiert, zeigt, dass das Konzept der Transkulturalität nicht nur durch didaktische Reduktionen zu Rückgriffen auf traditionelle Kulturverständnisse führen kann. 
werden konnte. Meiner Einschätzung nach erfüllt der Diskursbegriff diese Kriterien und stellt damit eine vielversprechende Alternative zum Kulturbegriff dar (vgl. Kap. 4.2.). Ich halte die bisherigen Versuche, die vom Kulturbegriff verursachten Probleme mit neuen Kulturbegriffen zu lösen, zumindest im Kontext des Fremdsprachenunterrichts für Quellen neuer Probleme. ${ }^{34}$ Die Frage, ob eine Renaissance des Transkulturalitätsbegriffs die Fremdsprachendidaktik voranbringen würde, würde ich daher mit Nein beantworten.

\subsubsection{Kulturbegriffe: Zusammenfassung}

Die Überlegungen zu den Kulturbegriffen haben gezeigt, dass es sich in jedem Fall lohnt nachzufragen, was genau gemeint ist, wenn die Rede von Kultur ist. Die hier zugrunde gelegte Reckwitz’sche Klassifizierung geht von der Grundannahme aus, dass menschliches Denken, Fühlen und Handeln kontingent, d. h. nicht-notwendig ist. Mit anderen Worten bedeutet dies, dass Individuen in jeder Situation prinzipiell die Möglichkeit zugestanden wird, anders zu denken, zu fühlen oder zu handeln, als dies in ihrem jeweiligen Lebenskontext als ,normal gilt. Aus einer solchen Sicht ergeben sich für die Individuen einerseits erhebliche Spielräume für Alternativen innerhalb gegebener Bedingungen, andererseits aber auch die Möglichkeit der allmählichen Veränderung dieser Bedingungen selbst.

Ausgehend von der Kontingenzprämisse verfolgt die Kulturwissenschaft das Anliegen, einen bedeutungs- und wissensorientierten Kulturbegriff zu entwickeln und innerhalb ihres Forschungsprogramms auf dieser theoretischen Grundlage „[...] die impliziten, in der Regel nicht bewussten symbolischen Ordnungen, kulturellen Codes und Sinnhorizonte [...]“ (Reckwitz 2004: 2) zu beschreiben. Als erfolgreich im Sinne der theoretischen Vorüberlegungen kann dieses Unterfangen also nur gelten, wenn es gelingt, die angenommene Kontingenz sichtbar zu machen, anstatt sie zu verschleiern.

Bezüglich ihrer Tendenz zur Verschleierung von Kontingenz schließe ich mich bei zwei der vier hier vorgestellten Kulturbegriffe Reckwitz’ Einschätzung an. Der normative Kulturbegriff invisibilisiert Kontingenz insofern, als er eine bürgerliche, vernünftige Lebensweise als Ideal setzt. Diese Vorstellung wirkt bis heute vielfach fort, etwa in der Forderung, bestimmte Werke der bürgerlichen Literatur als Teil eines Bildungskanons in schulischen Lektüreplänen beizubehalten.

34 Breidbach (2007: 231) kommt in Bezug auf Kulturverständnisse, die statt Nationalkulturen ,Kulturkreise in den Blick nehmen, zu einer ähnlichen Einschätzung. 
Die Tendenz zur Verschleierung von Kontingenz lässt sich ebenfalls für den totalitätsorientierten Kulturbegriff belegen, der noch stärker in alltagssprachlichen, aber auch wissenschaftlichen Diskursen der Gegenwart nachwirkt. Seine radikalste Ausprägung fand dieser Kulturbegriff in der amerikanischen Anthropologie unter den Nachfolgern von Franz Boas (vgl. Kap. 2.2.1.). Der totalitätsorientierte Kulturbegriff beruht auf der Grundannahme, dass Kulturen nach innen homogen und nach außen abgrenzbar sind. Wer einer bestimmten Kultur angehört, so die These, teilt zwangsläufig bestimmte grundlegende Glaubenssätze und Werte mit allen anderen Angehörigen dieser Kultur. Angesichts gesellschaftlicher Diversität in den modernen Flächenstaaten ist die Homogenitätshypothese jedoch unbrauchbar geworden. Dennoch spielt der totalitätsorientierte Kulturbegriff weiterhin eine wichtige Rolle in der Forderung nach der Multikulturalität von Gesellschaften. Daraus ergeben sich politische Implikationen, die ohne Zweifel problematisch sind (vgl. Kap. 2.1.5.) und von denen im folgenden Kapitel noch ausführlich die Rede sein wird.

Der Multikulturalismus stellt sich dem Befund der kulturellen Durchmischung moderner Gesellschaften. Eine wichtige Rolle spielen dabei Migrationsprozesse: Heute bewohnen meist Menschen unterschiedlicher Herkunft gemeinsam ein Staatsgebiet. Der Multikulturalismus verlagert daher die Diversität zwischen geografisch und meist auch politisch abgegrenzten Kulturen ins Innere der geografisch-politischen Einheiten. Dabei wird empfohlen, die jeweiligen Eigenheiten der ,Herkunftskultur' zu pflegen und zu schützen, gleichzeitig jedoch auch die Integration in die ,aufnehmende Kultur ${ }^{`}$ zu fördern - eine im Kern paradoxe Forderung. ${ }^{35}$ In Bezug auf den totalitätsorientierten Kulturbegriff bleibt zunächst festzuhalten, dass er sowohl der Vorstellung zugrunde liegt, es gebe nach innen homogene und nach außen abgrenzbare Kulturen, als auch der Vorstellung, plurale Gesellschaften bestünden in ihrem Inneren aus (wiederum homogenen und voneinander abgrenzbaren) Kulturen. In beiden Fällen teile ich Reckwitz’ Einschätzung, dass die Kontingenz kultureller Phänomene auf dieser begrifflichen Grundlage eher verschleiert als sichtbar gemacht wird.

Die Kontingenz kultureller Phänomene spielt im differenzierungstheoretischen Kulturbegriff durch seine feste Verankerung in der Systemtheorie eine wichtige Rolle. Zu deren Grundannahmen gehört, dass Selektionen wie etwa die Entscheidung dafür, etwas Bestimmtes zu sagen, immer kontingent sind. Es könnte also immer auch etwas Anderes (oder Nichts) gesagt werden. Zudem

35 In dieser Hinsicht war Claude Lévi-Strauss (1987 [1952]: 75) gedanklich konsequenter (vgl. Kap. 2.2.4.). 
versteht sich die Systemtheorie als radikal deskriptive Wissenschaft. Jegliche normative Tendenz ist ihr, zumindest in ihrem Selbstverständnis, fremd. Wie ich herauszuarbeiten versucht habe, liegt die Problematik des differenzierungstheoretischen Kulturbegriffs daher weniger in der Verschleierung von Kontingenz als in der radikalen Einschränkung des Forschungsgegenstandes. Als ,kulturell ${ }^{\circ}$ werden in diesem Paradigma nur noch solche Phänomene verstanden, die in einem bestimmten gesellschaftlichen Subsystem auftreten. Diese Engführung ist allerdings in Zeiten der demokratischen Öffnung von Diskursgemeinschaften, wenn also die öffentliche Kommunikation durch Weblogs und andere many-tomany-Formate ergänzt wird, kaum noch plausibel.

In Bezug auf die vier Kategorien von Kulturbegriffen fällt auf, dass sowohl der normative, der totalitätsorientierte als auch der differenzierungstheoretische Kulturbegriff Einzug in die Alltagssprache gehalten haben. Andererseits werden gerade jene Phänomene, die in einem bedeutungs- und wissensorientierten Kulturverständnis eindeutig als kulturell bezeichnet werden, etwa Mathematik oder Ökonomie, im Alltagsverständnis meist nicht dieser Kategorie zugeordnet. Bei der Arbeit mit dem Kulturbegriff sieht man sich daher mit der eigentümlichen Situation konfrontiert, dass er einerseits sowohl in der Alltagssprache als auch in der Sprache der Wissenschaft fest verankert und äußerst gebräuchlich ist. Dabei scheinen jedoch alltagssprachlich eben jene Bedeutungen zu dominieren, die sich aus wissenschaftlicher Sicht für die deskriptive Verwendung als äußerst problematisch gezeigt haben und zudem oft ein starkes, meist unreflektiertes normatives Moment in sich tragen.

Auf dieser Grundlage werde ich in Kapitel 3 der Frage nachgehen, welche Kulturbegriffe sich in der Fremdsprachendidaktik finden. Sind sie eher Kontingenz verschleiernd oder machen Sie Kontingenz transparent? Orientieren sie sich an einem normativen, totalitätsorientierten oder differenzierungstheoretischen Kulturverständnis, oder gelingt es ihnen, die kulturwissenschaftliche Theoriebildung zu rezipieren und zu einem für die Fremdsprachendidaktik fruchtbaren Konzept von Kultur und Interkulturalität weiterzuentwickeln?

\subsection{Zum Dilemma von Universalismus und Kulturrelativismus}

Im voranstehenden Kapitel habe ich versucht, die in der einschlägigen Literatur häufig erwähnte Vieldeutigkeit des Kulturbegriffs herauszuarbeiten und handhabbar zu machen. Hierbei hat sich die von Andreas Reckwitz vorgeschlagene ,Kontingenzperspektive' insofern als fruchtbar gezeigt, als sie nicht nur ein überzeugendes Klassifizierungssystem für die Vielzahl bekannter Kulturverständnisse bereitstellt, sondern es auch ermöglicht, einen zeitgemäßen, 
,kulturwissenschaftlichen' Kulturbegriff zu formulieren. Für den fremdsprachendidaktischen Kontext ist diese Begriffsklärung insofern relevant, als sich in den vergangenen beiden Jahrzehnten eine deutliche Ausrichtung auf Interkulturalitätskonzepte durchgesetzt hat und somit die Frage nach dem jeweils zugrunde liegenden Kulturverständnis von fundamentaler Bedeutung ist. Im Rahmen dieser Arbeit ist die Begriffsklärung darüber hinaus von besonderem Interesse, da auf ihrer Grundlage der Frage nachgegangen werden soll, inwieweit die von mir wahrgenommene und bisweilen auch in der Fachliteratur monierte Diskrepanz zwischen kulturwissenschaftlicher Begriffsbildung und interkulturell ausgerichteten fremdsprachendidaktischen Theorieentwürfen belegt werden kann. Dies werde ich in Kapitel 3 versuchen, indem ich ausgewählte Beiträge auf diese Diskrepanz hin kritisch durchsehe.

Ich möchte mich nun einer zweiten Frage zuwenden, welche für die interkulturelle Fremdsprachendidaktik meiner Einschätzung nach ebenso relevant ist, überraschenderweise jedoch auf allen Ebenen der Fachbeiträge unterrepräsentiert ist. In dieser Hinsicht unterscheidet sie sich von der Frage nach dem Kulturbegriff, die ja in den fachdidaktischen Diskursen zumindest auf der akademischen Ebene thematisiert wurde und wird. Diese nächste Frage stellt die zweite Quelle des Unbehagens dar, das mich in Zusammenhang mit dem Interkulturalitätsbegriff mit großer Regelmäßigkeit überkommt (vgl. Kap. 1.7.). Sie lautet: Wie ist mit Konflikten umzugehen, die sich aus dem Kontakt einander fremder Lebensweisen und Wertvorstellungen ergeben können? Diese Frage scheint in Texten zur interkulturellen Didaktik entweder keine Rolle zu spielen, oder den Lesern wird eine Antwort im Sinne eines kulturrelativistisch inspirierten „Konsensualismus“ (vgl. Mall 1997: 78f.) nahegelegt, ohne dass dies in angemessener Weise offengelegt und reflektiert würde. Unter Konsensualismus verstehe ich die Auffassung, dass alle Konflikte grundsätzlich ein Kompromisspotential aufweisen und daher prinzipiell in gegenseitigem Einverständnis beigelegt werden können. Diese Auffassung führt jedoch zu verschiedenen Problemen, unter anderem dazu, dass in Konflikten, in denen keine Konsenslösung gefunden wird, der majoritären oder anderweitig dominierenden Seite häufig Intoleranz und/oder Ethnozentrismus (vgl. Bredella 2001: 14) unterstellt wird: Sie könnte ja, so der vermutlich zugrunde liegende Gedankengang, eher eine Konsenslösung ermöglichen als die minoritäre oder unterlegene Seite. Diese konflikttheoretische Position des Konsensualismus ist in kulturtheoretischer Perspektive dem Kulturrelativismus zuzuordnen. Dabei wird davon ausgegangen, dass Konflikte nicht im Licht transkulturell bzw. universell gültiger Normen betrachtet, beurteilt und möglicherweise beigelegt werden können. 
Normen seien vielmehr stets einzelkulturell geprägt, universelle Normen wie die Menschenrechte existierten daher nicht, ihre Durchsetzung habe keine Legitimationsgrundlage (vgl. The Executive Board 1947).

Wie mit Konflikten umzugehen ist, die aus inkommensurablen ${ }^{36}$ Lebensweisen und Wertvorstellungen (,Kulturen' - ich bevorzuge die Termini Diskurse und Praktiken, vgl. Kap. 4.2.) entstehen, bleibt dabei jedoch eine offene Frage. Wie bereits in Kapitel 1.7. am Beispiel der Erzählung von Austin Clarke angedeutet, können sich aus dieser Haltung erhebliche erkenntnistheoretische, ethisch-moralische und rechtlich-politische Verstrickungen ergeben. Zudem ist zu befürchten, dass eine unreflektierte und affirmative Einnahme einer kulturrelativistischen Position in Bezug auf Machtstrukturen in ähnlicher Weise invisibilisierend wirken kann, wie dies für überholte Kulturverständnisse in Bezug auf die Kontingenz kultureller Phänomene bereits herausgearbeitet wurde. Da kaum zu bestreiten sein dürfte, dass die kulturelle Heterogenität moderner Gesellschaften zunimmt, treten diese Konflikte keineswegs nur im Weltmaßstab auf, sondern haben auch für das Zusammenleben in pluralen Gesellschaften erhebliche Relevanz. ${ }^{37}$

Ich vertrete daher den Standpunkt, dass eine interkulturelle Didaktik, die mehr als wohlklingende Bildungsrhetorik sein möchte, auch Antworten auf die Frage nach dem Umgang mit Konflikten bereitstellen sollte, die aus Fremdheitserfahrungen entstehen können. Verweise auf Offenheit und Empathie sowie der Appell an die Bereitschaft, die eigene Weltsicht zu relativieren, genügen nicht, so wünschenswert diese Haltungen grundsätzlich auch sein mögen. In Bezug auf den Machtaspekt lässt sich für die interkulturelle Didaktik daher das Problem

36 Es wurde verschiedentlich zu Recht darauf hingewiesen, dass ,Kulturen' niemals gänzlich kommensurabel oder inkommensurabel sind (vgl. z.B. Mall 1997: 88). In der Sprache der Hermeneutik lautet derselbe Hinweis, dass Horizonte niemals komplett different sind, aber auch niemals vollständig verschmelzen (vgl. Antor 2007: 119).

37 Die Linguistin Anna Pavlenko hat am 10. Mai 2014 an der Humboldt-Universität zu Berlin im Rahmen eines Vortrags mit dem Titel „Superdiversity - and why it isn't“ darauf hingewiesen, dass neben der Zunahme an Diversität in manchen Weltgegenden auch gegenläufige Trends belegt werden können. Dies gelte z.B. für die Staaten auf dem Gebiet des ehemaligen Jugoslawien, wo in den vergangenen Jahren ,ethnische Homogenisierungen zu verzeichnen waren. Pavlenko warnte in diesem Zusammenhang davor, Entwicklungen in den westlichen Industrienationen unhinterfragt auf den Rest der Welt zu übertragen. Auch wenn dem Einwand grundsätzlich zuzustimmen ist, so kann doch einschränkend erwidert werden, dass die digitale Medienrevolution das,Fremde` in praktisch allen Gegenden der Welt jederzeit zugänglich gemacht hat und zu tendenziell zunehmender Diversität führen dürfte. 
festhalten, dass ihre liberalen Grundanliegen, die im Wesentlichen in der Wertschätzung und Förderung kultureller Diversität liegen, für die Legitimierung und Durchsetzung antiliberaler Positionen missbraucht werden können. Kritik droht zu verstummen, wenn Individuen oder Gruppen ihre Machtansprüche zum Bestandteil einer bestimmten Kultur erklären (vgl. Preuß 1998). Trotz ihrer Brisanz scheint diese Problemlage in den fremdsprachendidaktischen Texten, die sich mit dem Interkulturalitätsbegriff beschäftigen, auffallend unterrepräsentiert. Ein kulturrelativistischer Standpunkt scheint meist selbstevident, die Empfehlung lautet schlicht, sich in allen Situationen „situationsangemessen“ (KMK 2012: 21) zu verhalten. ${ }^{38}$ Was dies im Umgang mit antiliberalen Positionen bedeuten könnte, deren Verfechter_innen sich möglicherweise auf eine zu respektierende kulturelle Differenz berufen, wird meist nur angedeutet und nicht in der gebotenen Ausführlichkeit reflektiert. Dieses Defizit möchte ich in den folgenden Abschnitten anhand einiger Beispiele aufzeigen. Ich beginne mit einem Dokument, welches das Lehren und Lernen fremder Sprachen nach der Jahrtausendwende wie kaum ein zweites geprägt haben dürfte.

Unter den administrativen Dokumenten zum Fremdsprachenunterricht nimmt der Gemeinsame europäische Referenzrahmen für Sprachen (GeR) seit seiner Veröffentlichung 2001 eine Sonderstellung ein, diente und dient er doch als Vorlage für verbindliche nationale und länderspezifische Curricula, für Verfahren der Leistungsfeststellung, für die Aus- und Fortbildung von Lehrkräften sowie für eine Vielzahl an Unterrichtsmaterialien. ${ }^{39}$ Innerhalb des GeR wiederum nimmt die interkulturelle Kompetenz eine wichtige Position ein. So berufen sich die Autoren in der Einleitung explizit auf den „interkulturellen Ansatz“ (Europarat 2001: 14), und im selben Abschnitt finden sich zahlreiche weitere Verweise auf kulturelle Aspekte des Fremdsprachenlernens (vgl. ebd.: 14-16). Zwar findet sich im GeR kein eigenes Kapitel zum Thema interkulturelle Kompetenz, es werden aber in den Abschnitten über „Allgemeine Kompetenzen“ (ebd.: 103) vier der fünf auf Michael Byram zurückgehenden Dimensionen interkulturellen Lernens entfaltet. ${ }^{40}$ So groß also die Rolle des interkulturellen Ansatzes im GeR ist, so klein ist der Stellenwert, welcher dem Dilemma zwischen Kulturrelativismus und Universalismus zukommt. Nach meinen Recherchen findet es sich im

38 Zur Problematik der „Angemessenheit“ (appropriateness) vgl. Fairclough 1992c.

39 Es wird häufig übersehen, dass der GeR lediglich rekommendativen Charakter hat. Seine breite Rezeption in der gesamten EU hat ihm jedoch de facto einen normsetzenden Status verschafft.

$40 \mathrm{Im}$ GeR werden savoir, savoir-faire, savoir-être und savoir-apprendre in jeweils eigenen Unterkapiteln behandelt (vgl. Europarat 2001: 103-109). 
GeR an genau einer Stelle, und zwar in Form einer Frage. Diese weist auf die möglichen Probleme des Interkulturalitätsbegriffs hin, ohne jedoch Ansätze für eine Antwort anzubieten: „Wie kann Kulturrelativismus mit ethischer und moralischer Integrität in Einklang gebracht werden?" (ebd.: 107) Die Frage macht deutlich, dass sich auch die Autor_innen des GeR der Tatsache bewusst waren, dass in ,interkulturellen' Situationen Konflikte entstehen können, die sich nicht von einem ethisch neutralen Standpunkt aus lösen lassen und bei denen kein middle ground für eine Konsenslösung gefunden werden kann. Sie versäumten es jedoch, mögliche ethische Normen für Lösungsansätze offenzulegen und zu reflektieren, etwa im Hinblick auf die Frage, ob diese individuell, gruppenspezifisch oder universell zu konzipieren wären. Es bleibt daher dem/der LeserIn überlassen zu interpretieren, was „ethische und moralische Integrität“ im Sinne des GeR bedeutet. Bezüglich des in der Erzählung von Clarke (2003) aufgeworfenen Problems etwa wäre zu fragen, ob die Ablehnung von Gewalt als Mittel der Erziehung einen universellen Wert darstellt, der im Sinne dieser Integrität zu verteidigen wäre, oder ob die Ablehnung von Gewalt zu Erziehungszwecken vielmehr als Teil einer spezifischen Kultur, vermutlich der,westlichen', zu sehen wäre und daher zur Disposition stünde.

Auch auf der Ebene der fremdsprachendidaktischen Theoriebildung wird das Problem des Umgangs mit Konflikten nur sehr vereinzelt diskutiert. In ungewöhnlicher Ausführlichkeit widmet sich Küster (2003b: 165-173) in seiner Habilitationsschrift zum Konzept der Pluralen Bildung dem Dilemma zwischen Universalismus und Kulturrelativismus. Für den Bildungskontext bringt er es mit folgenden Worten auf den Punkt:

Eine (interkulturelle) Pädagogik, die allerdings konsequent kulturalistisch dächte, müsste zugleich das Fundament, welches die Normativität ihrer Zielsetzungen begründen könnte, aufgeben. (ebd.: 169)

Als mögliche Auswege aus diesem Dilemma diskutiert Küster die Positionen Annedore Prengels, Michele Borrellis, Reinhard Schilmöllers und Wolfgang Niekes. Diese müssen jedoch, wie Küster herausarbeitet, entweder ihren Gültigkeitsbereich einschränken (Prengel) oder nicht begründbare Setzungen vornehmen. Für Borrelli sei dies die „einheitsstiftende Kraft der Vernunft“ (ebd.: 172), für Schilmöller dagegen die antike Vorstellung vom „richtigen, gelingenden Leben“ (ebd.: 170). In beiden Fällen handelt es sich also um Setzungen, die mit dem Vorwurf rechnen müssen, dass es sich bei ihnen um spezifisch europäische Vorstellungen ohne universelle Gültigkeit handle. Inwiefern das vierte von Küster erwähnte Konzept als Ansatz zur Versöhnung von Kulturrelativismus und Universalismus gangbar ist, der auf den Erziehungswissenschaftler Wolfgang Nieke 
(2008: 236f. und passim) zurückgehende „aufgeklärte Eurozentrismus“, wird in Kap. 2.2.6. ausführlich diskutiert.

Neben Küster geht auch Laurenz Volkmann auf das Problem ein. Mit ungewöhnlich klaren Worten thematisiert er es in seiner Fachdidaktik, die den Kulturbegriff im Titel trägt (Fachdidaktik Englisch: Kultur und Sprache, vgl. Volkmann 2010: 186-189). Er schreibt:

Wenn wir die Irritationen des Alltags verlassen und in den Bereich der interkulturellen Leitkonzepte gehen, so stellen sich Fragen nach den Grenzen der Toleranz und Akzeptanz noch deutlicher. Ist der Kulturrelativismus wirklich eine akzeptable Maxime? Sollten Lehrende demnach Empathie und Identifikationsangebote liefern in Bereichen von höchst fragwürdigen Fremd-, Alternativ- und Subkulturen, wie beispielsweise den Azteken, der Mafia oder den Neonazis? Wie steht es mit den,Zumutbarkeitsgrenzen 'bei Fragen der von Eltern arrangierten Ehen, der Verschleierung von Frauen, dem indischen Kastensystem, amerikanischen oder muslimischen Auswüchsen des Fundamentalismus, den in vielen Gesellschaften offensichtlichen sozialen Ungerechtigkeitsstrukturen? (ebd.: 188)

Auch wenn es schwierig sein dürfte, „Irritationen des Alltags“ vom „Bereich der interkulturellen Leitkonzepte“ zu unterscheiden, die ja die Ursache dieser Irritationen sind, ist doch die Deutlichkeit bemerkenswert, mit der Volkmann das Problem anspricht. Die Grenzen der interkulturellen Toleranz zieht er da, wo man sich mit „intolerante[m] Verhalten“ (ebd.: 189) konfrontiert sieht. Allerdings ist auch der Toleranzbegriff für eine normative Setzung wenig geeignet, da er ausgesprochen vieldeutig ist und für die Duldung von Traditionen (wie z.B. den von Volkmann genannten arrangierten Ehen) angeführt werden kann. Diese können durchaus auch im Gegensatz zu individuellen Rechten stehen, wie sie aus den allgemeinen Menschenrechten abgeleitet werden (vgl. Bielefeldt 1996). Bezeichnenderweise fordern in Konfliktfällen häufig beide Seiten von der jeweils anderen Seite, mehr Toleranz zu üben. ${ }^{41}$

Schärfere Konturen nimmt die Grenzziehung dagegen bei Heinz Antor (2007: 121) an, den Volkmann zustimmend anführt:

Wo also die Menschenrechte, die Freiheit, das Recht auf freie Meinungsäußerung und auf Unversehrtheit oder das Existenzrecht des anderen geleugnet werden, wäre es falsch verstandene liberale Toleranz, diese Haltung als verständliche Positionalität zu akzeptieren, die eben aus einem anderen kulturellen Horizont heraus bedingt sei.

41 Vgl. Forst 2003: 709ff. Forst erläutert dort am Beispiel des sogenannten „Kruzifix-Urteils“ den Konflikt um verschiedene Toleranzverständnisse. 
Die Mehrzahl der Beiträge zur interkulturellen Didaktik schweigen jedoch zum Dilemma zwischen Universalismus und Kulturrelativismus oder belassen es bei Hinweisen auf Modelle der allgemeinen interkulturellen Didaktik. Als ein Beispiel sei hier das gestufte Modell für interkulturelle Kompetenz von Milton Bennett genannt, das etwa Adelheid Hu (2008) als mögliche Referenz für die Fremdsprachendidaktik anführt. In Bennetts Modell wird auf einer sechsstufigen Skala die Leugnung der Existenz (denial) fremdkultureller Deutungsmuster als niedrigste, ihre Integration als höchste Stufe interkultureller Sensibilität angeführt (vgl. Bennett 1986: 182). Problematisch ist dabei allerdings, dass diese höchste Stufe (VI) mit dem ethnorelativistischen Standpunkt gleichgesetzt wird. ${ }^{42}$ Diese Setzung kann jedoch selbst dann problematisch sein, wenn man den ohnehin umstrittenen Begriff der ,Ethnie' durch den Kulturbegriff ersetzt. Wer bestimmte Werte für universell gültig hält, erreicht auf Bennetts Skala lediglich Stufe III oder IV. Die zum Teil erheblichen ethischen Probleme, die sich aus der Forderung nach der anscheinend ungefilterten Integration fremdkultureller Haltungen ergibt, werden von Bennett lapidar mit dem Verweis auf William G. Perrys „,ethical scheme“ or some other meta-ethical model“ (ebd.: 193) abgehandelt. Auch Perrys Individualethik kommt jedoch nicht ohne eine universalistische Setzung aus. Diese zu akzeptieren ist in seinem Entwicklungsmodell Voraussetzung dafür, dass ein Student Stufe 5 (von insgesamt 9 möglichen) erreichen kann: „The student perceives all knowledge and values (including authority's) as contextual and relativistic [...]“ (Perry 1970: 9). Somit könnte eine Schülerin/ein Schüler nach Bennetts Modell maximal eine der Stufen III oder IV erreichen, sobald sie/er die von Bennett selbst empfohlene Individualethik Perrys als universell gültig annimmt. Auch Michael Byram (2009: 218f.) weist in seiner Diskussion verschiedener Modelle zur Evaluation interkultureller Kompetenz auf diese Schwäche in Bennetts Modell hin:

In the six stages of Bennett's model which appears to be descriptive, there is an implicit prescription that people should move towards the final stage of integration' and the ethno-relativism which this represents. Ethno-relativism is valued more highly than ethno-centrism as a self-evident, good' [...] Someone who believes that there are universal values would be deemed to fail on this relativist criterion.

Hingegen wird in Bennetts Modell die Möglichkeit nicht in Erwägung gezogen, dass interkulturelle Sensibilität sich auch dadurch auszeichnen könnte, bestimmte

42 Die theoretischen Probleme des Kulturrelativismus werden ausführlich in Kap. 2.2. diskutiert. In der von Bennett verwendeten Terminologie führt der Begriff, Ethnie` zu zusätzlichen Schwierigkeiten. 
Weltsichten nicht zu integrieren - etwa, weil durch sie bestimmte Gruppen von Menschen aus ethnischen, religiösen, sexuellen oder geschlechtsspezifischen Gründen nicht respektiert, sondern systematisch diskriminiert werden.

Der Eindruck, dass das Dilemma von Universalismus und Kulturrelativismus in der fremdsprachendidaktischen Literatur bisher nicht in ausreichendem Maße reflektiert wurde und im Zweifelsfall ein relativistischer Standpunkt auf selbstevidente Weise zu gelten scheint, bestätigt sich somit in der von mir gesichteten Literatur, insbesondere im GeR. Daher sollen im nächsten Schritt die theoretischen Grundlagen erarbeitet werden, auf denen anschließend ausgewählte Ansätze zur interkulturellen Fremdsprachendidaktik in Bezug auf das Dilemma von Universalismus und Kulturrelativismus analysiert werden. Hierfür möchte ich in einem ersten Schritt die Entstehung des Kulturrelativismus umreißen und seine wichtigsten Grundannahmen darstellen. Zweitens möchte ich seine internen Widersprüche und Fehlschlüsse thematisieren und ihn, drittens, einer mehrperspektivischen Kritik unterziehen. Schließlich erfolgt, viertens, die Vorstellung und Diskussion eines Ansatzes zur Lösung des Dilemmas von Kulturrelativismus und Universalismus, des sogenannten , aufgeklärten Eurozentrismus' von Wolfgang Nieke.

\subsubsection{Kulturrelativismus als Reaktion auf Rassismus und Kolonialismus}

Der Kulturrelativismus entstand zu Beginn des 20. Jahrhunderts in der nordamerikanischen Anthropologie. In dieser Disziplin dominierte im ausgehenden 19. Jahrhundert der sogenannte ,Evolutionismus. Er basierte auf den Arbeiten von Lewis Henry Morgan, der drei Stufen der zivilisatorischen Entwicklung definierte: Wildheit, Barbarei und, als höchste Stufe, Zivilisation (vgl. Moore 2009: 21). Diese Stufen müssen, so Morgans Überzeugung, alle Kulturen durchlaufen. Nach Morgan entwickeln sich die Herrschaftssysteme verschiedener Kulturen dabei in diesem Stufenmodell stets von anfangs matriarchalen hin zu patriarchalen Strukturen.

Der deutschstämmige Anthropologe Franz Boas stellte diese Theorie Ende des 19. Jahrhunderts auf Grundlage seiner Forschungsaufenthalte bei den Inuit in Frage. Nicht nur seine Beobachtungen von Mischformen zwischen Matriarchat und Patriarchat widersprachen dem Evolutionismus Morgans. Boas traf auch auf eine Komplexität gesellschaftlicher Strukturen, die es nach Morgans Theorie in einer Jäger- und Sammler-Gesellschaft nicht hätte geben dürfen. Dies galt etwa für den Brauch des Potlatsch (vgl. Boas 1888: 635f.). ${ }^{43}$ Boas (1963 [1911]: 30f,

43 Unter Potlatsch versteht man Geschenke, welche die Funktion haben, innerhalb und außerhalb von Stämmen Reichtum und Überlegenheit zu demonstrieren. Gleichzeitig 
238-242) zog daher das bis dahin gängige Konzept der, Rasse für die Forschung insgesamt in Zweifel.

Auf Grundlage seiner Feldstudien entwickelte Boas eine neue theoretische Basis für die anthropologische Forschung, die allgemein als ,Kulturrelativismus‘ bezeichnet wird. Ihr Kern liegt in der Forderung, dass Kulturen nicht anhand einer vorab festgelegten Entwicklungsskala beschrieben werden dürfen, da dies zu deskriptiven Fehlern führe. Zudem sei die Beurteilung mit Hilfe externer Maßstäbe, wie etwa anhand der europäischen und nordamerikanischen Vorstellung von Zivilisation, äußerst problematisch. Vielmehr sei es die Aufgabe der Anthropologie, Kulturen möglichst präzise und unvoreingenommen zu analysieren und zu beschreiben. Dies sei nur auf Grundlage der Annahme möglich, dass Kulturen jeweils eigenständige und in sich stimmige Systeme sind (vgl. Stocking 1989: 66f.).

Entscheidend sind an dieser Stelle drei Feststellungen. Erstens hatte der Kulturrelativismus zunächst einen rein deskriptiven Anspruch. Er wollte normative und teleologische Vorstellungen von kulturellem Wandel ausdrücklich überwinden und der Anthropologie einen möglichst unvoreingenommenen Blick auf das Fremde ermöglichen. Boas warnte vor einer unreflektierten Verwendung des Begriffs ,Rasse" und kritisierte insbesondere die Gleichsetzung von ,Rasse und ,Nation', die er bereits in der ersten Dekade des 20. Jahrhunderts in Deutschland mit Sorge beobachtete (vgl. Boas 1963 [1911]: 226ff.). Zweitens handelt es sich beim Kulturrelativismus ursprünglich um einen entschieden liberal-emanzipatorischen Ansatz. Dieser richtete sich im Zeitalter des Imperialismus gegen eine Anthropologie, welche leicht instrumentalisiert werden konnte, um die Überlegenheit der,westlichen' Kultur zu begründen und damit die Dominanz der Kolonialmächte zu legitimieren. Diese hatten ja angeblich die höchste Stufe der Entwicklung - die (westliche) Zivilisation - bereits erreicht. Drittens, ebenfalls in Abgrenzung zum Evolutionismus, betont der Kulturrelativismus unter Rückgriff auf den Herder'schen Kulturbegriff (vgl. Kap. 2.1.2.) als Arbeitshypothese die grundsätzliche Verschiedenheit von Kulturen (vgl. Boas 1963 [1911]: 149). Auch dies diente zunächst einem liberal-emanzipatorischen Anliegen, nämlich der Vermeidung einer unreflektierten Übertragung kulturell geprägter Vorstellungen (z.B. über ,zivilisiertes' Leben) auf die untersuchten Kulturen. Boas konnte durch

wird die Akkumulation von Gütern in den Händen Einzelner verhindert. Da diese Schenkungen bisweilen zu einem regelrechten „Wettschenken“ und zur Zerstörung der Existenzgrundlage ganzer Stämme führten, war der Potlatsch in Kanada zwischen 1884 und 1951 verboten. Boas sprach sich bereits in dem genannten Beitrag von 1888 gegen dieses Verbot aus. 
seine Forschungen, aber auch durch seine Lehrtätigkeit sowie durch seine Arbeit für die American Anthropological Association (AAA) den Kulturrelativismus als zentrales Paradigma der anthropologischen Forschung etablieren. Zu seinen Schülern zählten u. a. Alfred Louis Kroeber, Margaret Mead, Melville J. Herskovits und Ruth Benedict, welche in seiner Nachfolge den Kulturrelativismus fortführten und die Anthropologie in der ersten Hälfte des 20. Jahrhunderts entscheidend prägten. Nach dem 2. Weltkrieg arbeiteten u.a. Claude Lévi-Strauss und Clifford Geertz in der Boas'schen Tradition.

Eine für die hier geführte Diskussion entscheidende Weiterentwicklung des Kulturrelativismus vollzog die Boas-Schülerin Ruth Benedict. Vor allem ihr Buch Patterns of Culture (1989 [1934]) ist von besonderem Interesse, weil es nicht nur zur Standardlektüre der anthropologischen Institute an amerikanischen Universitäten avancierte, sondern auch weit über die Grenzen der Anthropologie hinaus rezipiert wurde. Dies führte zu einer Popularisierung der kulturrelativistischen Grundgedanken, die bis heute nachwirkt. Ich beziehe die nachfolgenden Überlegungen zum Kulturrelativismus daher vorwiegend auf dieses Werk, beachte jedoch auch verschiedene Beiträge der anderen genannten Vertreter des Fachs.

Ebenso wie für Boas besteht für Ruth Benedict das Hauptproblem der anthropologischen Forschung zu Beginn des 20. Jahrhunderts im Konzept der Rasse. In strikter Ablehnung des Rassebegriffs fordert auch sie, Kultur zur zentralen Bezugsgröße für die Erklärung menschlicher Phänomene zu erheben. Dabei greift sie auf ein Kulturverständnis zurück, das in der von Herder geprägten Tradition steht, in der Kulturen als voneinander getrennte ,Kugeln' oder ,Inseln' gesehen werden (vgl. Kap. 2.1.2.) Um dieses Kulturverständnis zu illustrieren, zitiert sie in Patterns of Culture ein Gespräch mit Chief Ramon, einem Häuptling der DiggerIndianer: „,In the beginning, ' he said, ,God gave to every people a cup, a cup of clay, and from this cup they drank their life." (Benedict 1989 [1934]: 21) Dieses Gefäß (сup), aus dem jedes Mitglied einer Kultur sein Leben trinke, sei durch die Ankunft des weißen Mannes zu Bruch gegangen: „, [...] Our cup is broken now. It has passed away. “ (ebd.: 22) Benedict führt die Metapher weiter, indem sie den von Chief Ramon beklagten Verlust der ursprünglichen kulturellen Einheit mit folgenden Worten paraphrasiert:

There were other cups of living left, and they held perhaps the same water, but the loss was irreparable. It was no matter of tinkering with an addition here, lopping off something there. The modelling had been fundamental, it was somehow all of a piece. It had been their own. (ebd.)

Benedict tritt hier, ganz in der Tradition Herders, für ein essentialistisches und holistisches Kulturkonzept ein, in dem sich die Besonderheiten von Kulturen aus 
dem jeweils charakteristischen und einzigartigen Zusammenspiel ihrer Bestandteile ergeben. Dabei entstehe Besonderes, denn die Qualität des Ganzen transzendiere die Summe seiner Bestandteile. Entscheidend sei das Zusammenspiel der Teile im System. Der Blick auf isolierte Phänomene führe daher zwangsläufig in die Irre. Genau wie es leicht passieren könne, dass man etwa bei der Analyse der chemischen Bestandteile von Schießpulver zwar jedes Element verstehe, ohne jedoch deren Zusammenspiel zu erfassen, könne man die einzelnen Merkmale einer Kultur untersuchen, dabei jedoch die Besonderheit des Musters (pattern) übersehen (vgl. ebd.: 46f.):

The whole, as modern science is insisting in many fields, is not merely the sum of all its parts, but the result of a unique arrangement and interrelation of the parts that has brought about a new entity. (ebd.: 47)

Individuen werden nach Benedict durch ihre Zugehörigkeit zu einem solchen Ganzen (entity) - zu ihrer Kultur - bestimmt. Die kulturelle Prägung, die jeder Mensch durch seine jeweilige Umgebung erfahre, lege sein Denken, Fühlen und Handeln fest. In aller Deutlichkeit stellt sie unter Rückgriff auf den Ganzheitsbegriff der Gestaltpsychologie fest: „The whole determines its parts, not only their relation, but their very nature" (Benedict 1989 [1934]: 52). Das Ganze und seine Bestandteile stehen dabei in einer engen, unauflösbaren gegenseitigen Abhängigkeit. Benedicts gestaltpsychologisch inspirierter kultureller Determinismus könnte kaum in schärferem Gegensatz zu den Überzeugungen ihres Lehrers stehen, der stets die Individualität jedes Angehörigen einer Gruppe betonte:

Our tendency to evaluate an individual according to the picture that we form of the class to which we assign him, although he may not feel any inner connection with that class, is a survival of primitive forms of thought. The characteristics of the members of the class are highly variable and the type that we construct from the most frequent characteristics supposed to belong to the class is never more than an abstraction hardly ever realized in a single individual, often not even a result of observation, but an often heard tradition that determines our judgement. (Boas 1963 [1911]: 241f.)

Die Auffassung einer radikalen Differenz von Kulturen, die sich aus einem jeweils einzigartigen Zusammenspiel (pattern) ableiten lässt, findet sich bereits bei Boas - allerdings lediglich als forschungsmethodologische Hypothese. Entscheidend ist bei Benedict nun der Schritt von dieser Hypothese hin zur radikalen Differenz von Kulturen als einem ontologischen Axiom (vgl. Eriksen/Stjernfelt 2012: 108f.). Aus der Forderung, dass alle Kulturen so untersucht werden sollen, als seien sie radikal verschieden, wurde das Axiom, dass alle Kulturen radikal verschieden sind. Dieser Gedanke wurde schließlich in einer normativen Wendung noch einen Schritt weiter geführt. Kulturrelativismus bedeutet in diesem Sinn, 
dass alle Kulturen nicht nur verschieden sind, sondern es auch sein sollen. Diese Weiterentwicklung zu normativen Vorstellungen führt nun auch zu wertenden Aussagen über den Zustand verschiedener Kulturen - ein klarer Gegensatz zu Boas' deskriptivem Ansatz. Dies lässt sich etwa an Benedicts Ausführungen zu ihrer Beobachtung ablesen, dass verschiedene Kulturen in unterschiedlichem Maße als harmonisches Ganzes erschienen und daher über ein unterschiedlich hohes Maß an Integration verfügten. Unter Integration versteht Benedict zweierlei. Erstens steht Integration für die Fähigkeit einer Kultur, ein konsistentes, d. h. vor allem widerspruchsfreies und ausbalanciertes Muster zu erzeugen („a balanced and rhythmic pattern", Benedict 1989 [1934]: 223). Zweitens meint Integration die vollständige Selbstbezogenheit und Abgeschlossenheit einer Kultur. Diesen Idealzustand haben manche Kulturen nach Benedict noch nicht erreicht, andere hingegen bereits verloren. Die normative Dimension von Benedicts Kulturbegriff lässt sich nun unter anderem daran ablesen, dass die Aufnahme von Einflüssen anderer Kulturen durchgehend als Zustand des Mangels, eben als „lack of integration“ beschrieben wird (vgl. ebd.: 223, 224, 225, 226). Dies gelte etwa für die von ihr untersuchten Stämme im Inneren von British Columbia:

[Those tribes] have incorporated traits from all the surrounding civilizations. They have taken their patterns for the manipulation of wealth from one culture area, parts of their religious practices from another, contradictory bits from still another. Their mythology is a hodge-podge of uncoordinated accounts of culture heroes out of three different myth-cycles represented in areas around them. Yet in spite of such extreme hospitality to the institutions of others, their culture gives an impression of extreme poverty. Nothing is carried far enough to give body to the culture. (ebd.: 224)

Benedicts normative Prämisse, dass Kulturen ihre Eigenheiten gegen fremde Einflüsse bewahren sollten, lässt sich auch daran belegen, dass sie zwei Hauptursachen dafür vermutet, wenn eine Kultur sich als „wahrhaft verwirrt“ („genuinely disoriented“, ebd.: 226) zeige. Dies könne vermutlich, so ihre Hypothese, entweder auf eine besondere Konfliktlage oder aber auf eine besondere Offenheit für fremde kulturelle Einflüsse zurückgeführt werden („facile hospitality to new influences", ebd.: 226).

Auf Grundlage der Arbeiten von Boas und Benedict lassen sich daher zwei Ausprägungen von Kulturrelativismus unterscheiden: eine deskriptive und, wissenschaftshistorisch gesehen eine Weiterentwicklung, eine normative. ${ }^{44}$ Ich

44 Melford E. Spiro macht in einem Beitrag für die AAA als dritte Form einen epistemologischen Relativismus aus (vgl. Spiro 1986: 259-263). Dieser lässt sich jedoch auch als Spielart des deskriptiven Relativismus interpretieren. 
beziehe die weiteren Ausführungen auf den normativen Kulturrelativismus, der sich vor allem in den Arbeiten der Schüler_innen von Franz Boas findet. Hierfür fasse ich zunächst die wichtigsten Prämissen des Kulturrelativismus überblicksartig zusammen. Dabei stütze ich mich auf die vorwiegend kritischen Beiträge von Paul F. Schmidt (1955), Melford E. Spiro (1986), Ram A. Mall (1999) sowie von Jens Martin Eriksen und Frederik Stjernfelt (2008: 130-139). ${ }^{45}$

$\mathrm{Zu}$ unterstreichen ist, dass der Kulturrelativismus bzw. der normative Kulturrelativismus in Reinform vermutlich von niemandem vertreten wird, ebenso wenig wie es die Anthropologie mit einer einheitlichen theoretischen Ausrichtung gibt. Vielmehr handelt es sich selbstredend auch bei der Anthropologie um eine wissenschaftliche Disziplin mit theoretischen Strömungen und Gegenströmungen, so dass die hier zu Diskussionszwecken zusammengefassten Prämissen nur ein partielles, möglicherweise zugespitztes Bild darstellen. ${ }^{46}$ Es handelt sich jedoch insofern nicht um marginale Positionen, als sie sich auf Beiträge einflussreicher, bis heute stark wahrgenommener Vertreter_innen des Fachs zurückführen lassen. Zudem sind sie von Interesse, da sie außerhalb der Disziplingrenzen rezipiert wurden. Hierbei waren verschiedene Faktoren im Spiel. So wurde etwa Ruth Benedicts Essay Patterns of culture zu einem Klassiker der Anthropologie und entfaltete als solcher auch eine erhebliche Außenwirkung. Teilweise spielte auch der Einfluss auf Institutionen eine Rolle, den Vertreter des normativen Kulturrelativismus bei der Verbreitung ihrer Positionen geltend machen konnten, wie etwa im Falle von Melville Herskovits und der AAA (American Association of Anthropologists) oder im Falle von Claude Lévi-Strauss und der UNESCO.

Die erste Prämisse des Kulturrelativismus lautet, dass unterschiedliche Kulturen (Denk-, Glaubens- und Wertsysteme) existieren und dass ,Kultur', nicht ,Rasse', die zentrale Bezugskategorie der anthropologischen Forschung darstellen soll (vgl. Tilg 2009: 87).

Die zweite Prämisse besteht in der Auffassung, dass Kulturen inkommensurable Ganzheiten darstellen. (Benedict 1989 [1934]: 22f.) Sie lässt sich auf den Kulturbegriff Johann Gottfried Herders zurückführen (vgl. Kap. 2.1.2.). Dieses Kulturverständnis wird häufig als Insel- oder Kugelmodell (vgl. Welsch 1999: 50), bisweilen auch als Containermodell (vgl. Mende 2011:39) bezeichnet.

Die dritte Prämisse liegt in der Überzeugung, dass Menschen auf das Denkens-, Glaubens- und Wertesystem ihrer jeweiligen Kultur festgelegt sind und

45 Soweit sie mir zugänglich sind, belege ich alle Prämissen mit Originalquellen.

$46 \mathrm{Zu}$ einem explizit postmodernen Kulturverständnis in der Anthropologie vgl. zusammenfassend Mende 2011:39f. 
daher nicht in der Lage sind, es zu transzendieren (Benedict 1989 [1934]: 3). Dies bedeutet, dass Kultur als deterministisch angenommen wird: „[...] human beings do not function outside the societies of which they form a part" (The Executive Board 1947: 539).

Die vierte Prämisse betrifft den Bereich ethisch begründeter Entscheidungen. Sie lautet, dass Normen immer kulturspezifisch sind und es daher keine transoder pankulturell gültigen Normen geben könne:

Standards and values are relative to the culture from which they derive so that any attempt to formulate postulates that grow out of the beliefs or moral codes of one culture must to that extent detract from the applicability of any Declaration of Human Rights to mankind as a whole. (ebd.: 542, Hervorhebung im Original)

Die fünfte Prämisse ist eine forschungsmethodologische: Anthropologische Forschung solle möglichst neutral und objektiv, d. h. vor allem unter Ausklammerung der unvermeidlich vorhandenen kulturellen Prägung des Forschers/der Forscherin erfolgen: ${ }^{47}$ "The fieldworker must be faithfully objective" (Benedict 1989 [1934]: 229).

Die sechste Prämisse, die auch in der interkulturell ausgerichteten Fremdsprachendidaktik stark rezipiert wurde, lautet, dass der Stand der kulturellen Entwicklung die Sprache präge: „[...] the form of language will be molded by the state of culture [...]" (Boas 1963 [1911]: 198). Sie wurde in den 1930er Jahren durch die Arbeiten der Ethnolinguisten Edward Sapir und Benjamin Lee Whorf hinsichtlich der Beziehung von Ursache und Wirkung insofern modifiziert, als nun nicht mehr von einer unidirektionalen Wirkung, sondern von einer engen wechselseitigen Abhängigkeit zwischen Sprache und Denken und somit auch zwischen Sprache und Kultur ausgegangen wurde (vgl. Pelz 1996: 34-36).

Die siebte Prämisse besteht in der Überzeugung, dass mangels transkultureller Bewertungskriterien alle Kulturen als gleich wertvoll anzusehen seien, und in der Forderung, sie aus diesem Grund nicht nur zu tolerieren, sondern in ihrer Besonderheit zu respektieren: „Respect for differences between cultures is validated by the scientific fact that no technique of qualitatively evaluating cultures has been discovered“ (The Executive Board 1947: 542).

Die achte Prämisse lautet, dass die kulturelle Prägung von Wissenschaftlern und von Disziplinen dazu führe, dass die Anthropologie - wie im übrigen jede andere Disziplin - im Grunde Ethno-Wissenschaft sei: „[...] our own constructions of

47 Punkt 5. macht deutlich, dass auch der deskriptive Kulturrelativismus eine normative Seite hat, nämlich insofern, als er der anthropologischen Forschung eine bestimmte Methodologie empfiehlt (vgl. Schmidt 1955: 790). 
other people's constructions of what they and their compatriots are up to [...]" (Geertz 1973: 9).

Die neunte Prämisse besteht in der Überzeugung, dass die Reinheit von Kulturen der Kulturmischung vorzuziehen sei. (Benedict 1989 [1934]: 224). Angesichts schnell zunehmender globaler kultureller Verflechtungen befürchtet Lévi Strauss 1951 gar die Entstehung einer europäisch-nordamerikanischen Einheits(misch)kultur. In seinem für die UNESCO verfassten Essay Race et histoire notiert er:

[...] la civilisation implique la coexistence de cultures offrant entre elles le maximum de diversité, et consiste même en cette coexistence. La civilisation mondiale ne saurait être autre chose que la coalition, à léchelle mondiale, de cultures préservant chacune son originalité. (Lévi-Strauss 1987 [1952]: 77)

In den folgenden Abschnitten werde ich den Kulturrelativismus in der hier skizzierten, normativen Form einer Kritik aus mehreren Perspektiven unterziehen. Zunächst zeige ich einige Fehlschlüsse und Selbstwidersprüche der kulturrelativistischen Prämissen auf. Anschließend führe ich verschiedene historisch-philosophische, rechtsphilosophische, praktisch-politische sowie demokratie- und bildungstheoretische Einwände an. Dabei wird in der Form \#1-\#9 auf die hier aufgeführten neun Prämissen verwiesen.

Für das in dieser Arbeit verfolgte Anliegen genügt eine verkürzte Diskussion des Dilemmas zwischen Universalismus und Kulturrelativismus. Hierdurch soll in erster Linie die Frage beantwortet werden können, inwiefern einflussreiche Beiträge zur interkulturellen Fremdsprachendidaktik eine unreflektierte Rezeption kulturrelativistischer Positionen aufweisen. Meine Hypothese lautet, dass manche dieser Positionen nicht nur dem schulischen Erziehungsauftrag mit den Eckpfeilern Menschenrechte, Demokratie und Rechtsstaatlichkeit (vgl. Council of Europe 2010), sondern auch den Grundanliegen der interkulturellen Didaktik selbst widersprechen können.

\subsubsection{Selbstwidersprüche und Fehlschlüsse des Kulturrelativismus}

Um die dichotomische Gegenüberstellung von Kulturen zu ermöglichen, ist der Kulturrelativismus auf einen Kulturbegriff angewiesen, der auf Herders holistische Kulturvorstellungen zurückgeführt werden kann. (\#1, \#2). Dieser totalitätsorientierte Kulturbegriff wird jedoch von der kulturwissenschaftlichen Forschung als äußerst problematisch eingeschätzt. Da dies bereits diskutiert wurde (vgl. Kap. 2.1.2.), seien an dieser Stelle lediglich zwei weitere Argumente angeführt, welche die anthropologische Forschung besonders betreffen: ein theoretisches und ein empirisches. 
Aus theoretischer Sicht lässt sich folgende Argumentation vorbringen. Ein totalitätsorientierter Kulturbegriff schließt verschiedene Domänen menschlicher Gesellschaften ein, z.B. ihr Wirtschaftssystem, ihre Wissenschaft, Religion, Familienbeziehungen, Staatsform, Musik, bildende Kunst, etc. - „the whole fabric" (Benedict 1989 [1934]: 22). Damit trennscharfe Grenzen zwischen Bündeln dieser Domänen - ,Kulturen' - gezogen werden könnten, dürfte keine dieser Domänen einen transkulturellen bzw. universellen Geltungsanspruch erheben. Dieser universelle Geltungsanspruch ist jedoch verschiedenen Denk- und Glaubenssystemen inhärent, etwa der Wissenschaft und den monotheistischen Religionen. Die Konstruktion binärer Differenzen (Kultur A vs. Kultur B) schließt sich also selbst aus, wenn ,Kultur ' Denk- und Glaubens(sub)systeme einschließt, die sich als universell verstehen.

Auch aus empirischer Sicht lässt sich der totalitätsorientierte Kulturbegriff kritisieren. Die gegenseitige Beeinflussung und Durchdringung von Lebensweisen und Glaubenssystemen ist eine unbestrittene historische Tatsache. So lassen sich z.B. zahlreiche Götter, die im klassischen Griechenland verehrt wurden, auf Gottheiten zurückführen, die schon wesentlich früher in Kleinasien und Ägypten verehrt wurden. Ebenso wird angenommen, dass etwa der Jesus- und Marienkult des Christentums von der schon früher praktizierten Verehrung bestimmter vorderasiatischer und nordafrikanischer Gottheiten beeinflusst sind. Der biblische Monotheismus konnte dem Ägyptologen und Religionswissenschaftler Jan Assmann (2003: 19-21, 54-59 und passim) zufolge gedeihen, weil König Echnaton im 14. Jahrhundert v. Chr. mit seiner religiösen Reform hierfür die Grundlagen bereitet hatte. Die bereits zitierten Worte, mit denen Benedict (1989 [1934]: 224) die Mythologie einiger Stämme in British Columbia beschreibt („Their mythology is a hodge-podge of uncoordinated accounts of culture heroes out of three different myth-cycles represented in areas around them."), ließen sich daher ebenso auf das antike Griechenland oder auf den christlich geprägten Okzident anwenden. Eine wertende Beurteilung dieser Verflechtung ist nur durch externe, universelle Kriterien möglich - etwa, wie Benedict dies tut, durch den Grad an Integration, über den eine Kultur verfügt. Nur so kann sie begründen, warum die Offenheit für kulturelle Einflüsse in manchen Fällen als „Mischmasch“ (hodgepodge) zu sehen ist, in anderen jedoch nicht. Eine wertende Beschreibung auf Grundlage eines universellen Kriteriums wie der nach Benedict wünschenswerten ,Integration' stünde jedoch in Widerspruch zur Prämisse, nach der jede Wertung auf Grundlage kulturspezifischer Vorstellungen erfolgt (\#3). Die Annahme, die mit dem totalitätsorientierten Kulturbegriff einhergeht, es gebe so etwas wie einen ,Idealzustand', einen ,reinen', ,ursprünglichen` oder, integrierten 
Zustand, hat daher zur Folge, dass der Kulturrelativismus entweder die Realität von Kulturmischungen ignorieren, einen bestimmten historischen Status einer Gemeinschaft ohne weitere Begründung als Idealzustand setzen oder eine seiner eigenen Prämissen (\#4) missachten muss.

Das holistische Kulturverständnis des Kulturrelativismus hat auch erhebliche Auswirkungen auf die Frage, ob Fremdverstehen prinzipiell möglich ist, oder ob Menschen vielmehr zum Ethnozentrismus verdammt sind. Akzeptiert man die Prämisse der ontologischen Einzigartigkeit von Kulturen (\#1) und kombiniert sie mit der des kulturellen Determinismus (\#3), folgt daraus zwingend, dass Ethnozentrismus unvermeidlich ist und nicht überwunden werden kann. Ein Verstehen fremder Kulturen, wie es etwa die Anthropologie als Disziplin anstrebt, wäre daher prinzipiell unmöglich, da es zwangsläufig immer auf Grundlage der (nicht überwindbaren) eigenen kulturellen Prägung des Forschers bzw. der Forscherin erfolgen müsste. Schließlich ist auch er bzw. sie in seiner bzw. ihrer jeweiligen Weltsicht gefangen und kann daher nicht wissen, ob er bzw. sie mit seiner Interpretation, wirklich` versteht oder möglicherweise einer vollständigen Selbsttäuschung erliegt. Dieses Dilemma wurde auch innerhalb der Anthropologie diskutiert:

[...] with the expected result: an explosion of debates as to whether particular analyses (which come in the form of taxonomies, paradigms, tables, trees, and other ingenuities) reflect what the natives, really' think or are merely clever simulations, logically equivalent but substantively different. (Geertz 1973: 11)

Geertz hat als Ausweg aus diesem Forschungsdilemma den Ansatz der ,Dichten Beschreibung' (Thick description, vgl. Geertz 1973) entwickelt, bei der an die Stelle des Verstehens das Konzept der Interpretation gesetzt wird. Er knüpft damit an die traditionelle Dichotomie zwischen Naturwissenschaften (,verstehen') und Geisteswissenschaften (,interpretieren') an (vgl. Spiro 1986: 263, 282). Auch durch dichte Beschreibung entkommt man dem Dilemma jedoch nicht, das sich für anthropologische Forschung aus der Prämisse der kulturellen Gebundenheit von Erkenntnis ergibt. Entweder ist diese nur im Kontext der jeweiligen kulturellen Prägung möglich, so dass auch Anthropolog_innen selbst dieser Einschränkung unterworfen sind. Dies würde bedeuten, dass sie fremde Kulturen nicht nur nicht verstehen könnten, sondern dass sie ihr Verständnis (bzw. Fehlverständnis) dieser fremden Kulturen auch nur innerhalb ihrer eigenen Kultur mitteilen könnten. Dieselbe Einschränkung gilt auch für Interpretation als eine (ihrerseits ebenfalls kulturell geprägte) Form der Annäherung an Verstehen. Nimmt man die kulturrelativistische Annahme von der kulturellen Prägung jedes Verstehens und Interpretierens ernst, könnte daher jedes anthropologische Forschungsergebnis über 
eine bestimmte Kultur von einem Angehörigen dieser Kultur als erstens sachlich falsch und zweitens in ungültigen Begriffen gefasst zurückgewiesen werden. Dies gilt auch für allgemein gültig angenommene Prämissen wie z.B. \#2. Die Anthropologie würde sich somit ihre eigene Arbeitsgrundlage entziehen, da sie über ,fremde' Kulturen nur noch innerhalb des jeweils, eigenen' kulturellen Kontextes gültige (und verständliche) Aussagen machen könnte.

Laut Spencer (1989) treibt Geertz' Ansatz der Thick description diese Problematik insofern auf die Spitze, als sie auch die intrakulturelle Nachvollziehbarkeit erschwere. An dem für Geertz charakteristischen literarischen Stil kritisiert er, dass der Leser die subjektive Interpretation des Forschers übernehmen müsse, ohne selbst die Möglichkeit zu bekommen, die empirischen Grundlagen dieser Interpretation nachzuvollziehen und aus ihnen gegebenenfalls abweichende Schlüsse zu ziehen:

A good anthropologist will also allow his or her readers to assess the differences between the two or three versions, differences which we can expect to correspond to the different purposes and positions of the explicators. Indeed, in skilled hands, these differences can become the centre of the whole analysis. But this is what Geertz refuses us. In his ethnographic writings, especially those from the mid-1960s onward, there is less and less space allowed for readers to agree or disagree or make their own connexions. His characteristic strategy is to seize on a metaphor $[\ldots]$ and then sustain it through flashes of description, before climaxing in a kind of adjectival blizzard. (ebd.: 147f.)

Der nächste Einwand gegen den Kulturrelativismus betrifft die Idee der Toleranz. Vom kulturrelativistischen Standpunkt aus ist das ,echte 'Verstehen einer fremden Kultur ausgeschlossen. Dennoch, so die Argumentation, sei aus der prinzipiellen Differenz zwischen Kulturen für die Individuen aller Kulturen die Einsicht zu gewinnen, dass andere Kulturen für ihre Angehörigen den selben Wert haben müssen wie die jeweils eigene für einen selbst:

No man can thoroughly participate in any culture unless he has been brought up and has lived according to its forms, but he can grant to other cultures the same significance to their participants which he recognizes in his own. (Benedict 1989 [1934]: 37)

Auch der Vorstand der American Anthropological Association folgt dieser Argumentation: „The individual realizes his personality through his culture, hence respect for individual differences entails a respect for cultural differences" (The Executive Board 1947: 541,vgl.\#7). Es handelt sich hier um ein anschauliches Beispiel für den naturalistischen Fehlschluss. Dieser besteht darin, dass von einem Sein auf ein Sollen geschlossen wird. Aus der Beobachtung, dass unterschiedliche Kulturen existieren, wird gefolgert, dass sie existieren sollen, und daher, dass sie gegenseitig Respekt bzw. Toleranz üben sollen („grant to other cultures the 
same significance“, s. o. Benedict bzw. „respect for cultural differences“, s. o. The Executive Board). Eine frühe Beschreibung dieses logischen Fehlers findet sich am Ende des ersten Teils von David Humes 1738 erschienenem Werk A Treatise of Human Nature in der berühmten Sein-Sollens-Passage:

In every system of morality, which I have hitherto met with, I have always remarked, that the author proceeds for some time in the ordinary way of reasoning, and establishes the being of a God, or makes observations concerning human affairs; when of a sudden I am surprised to find, that instead of the usual copulations of propositions, is, and is not, I meet with no proposition that is not connected with an ought, or an ought not. (Zit. nach Oettingen-Wallerstein 2008: 14, Hervorhebungen im Original)

Wenn sich das Gebot der Toleranz jedoch nicht aus der Existenz unterschiedlicher Kulturen logisch folgern lässt, handelt es sich um eine Setzung in Form eines universellen Wertes. Darin liegt jedoch erneut ein Selbstwiderspruch, denn die Ablehnung universell gültiger Werte ist eine der Grundannahmen des Kulturrelativismus (vgl. \#4). Die Existenz universeller Werte wird somit bestritten, gleichzeitig wird jedoch Toleranz als universeller Wert postuliert:

Ohne die universalistische Voraussetzung, ein Recht auf kulturelle Selbstgestaltung nicht nur für sich, sondern auch für alle anderen Kulturen und Lebenswelten zu fordern, müsste sich jeder kulturelle Partikularismus argumentativ selbst widerlegen. (Göller 2003: 130)

Der Kulturrelativismus bleibt daher eine Antwort auf die Frage schuldig, wie ein universalistisches Prinzip wie Toleranz, welches sich ganz offensichtlich nicht von alleine weltweit behauptet, erstens zu legitimieren und zweitens durchzusetzen ist.

\subsubsection{Historisch-philosophische Einwände gegen den Kulturrelativismus}

Eine der Kernaussagen des normativen Kulturrelativismus lautet, dass es keine universellen Werte und Normen geben könne (\#4). Werte seien immer kulturgebunden und hätten daher auch nur für die Kultur Gültigkeit, in deren Kontext sie formuliert werden. Kritik an der universalistischen Forderung nach der Durchsetzung von Menschenrechten wird daher häufig in Form von Argumenten vorgetragen, welche auf kulturrelativistische Prämissen rückführbar sind. So verfasste der Vorstand der American Anthropological Association 1947 unter Federführung von Melville J. Herskovits einen Protestbrief an die Menschenrechtskommission der Vereinten Nationen, in dem das Vorhaben, eine allgemeine Erklärung von Menschenrechten zu verabschieden, scharf kritisiert wurde 
(vgl. The Executive Board 1947). Ich diskutiere in den folgenden Abschnitten einige der häufigsten Argumente gegen den Anspruch der Menschenrechte auf universelle Gültigkeit.

Die erste und vielleicht am häufigsten aufgegriffene Kritik gegen die Menschenrechte lautet, sie seien, christlich-abendländische 'bzw. ,europäische 'Werte und dürften deswegen keine universelle Gültigkeit beanspruchen (\#4). Es handle sich bei ihnen um Werte, deren Wurzeln klar in der europäischen Aufklärung liegen. Besonders die der europäischen Tradition entstammende Betonung der Rechte des Individuums seien für manche Kulturen problematisch. So verlange etwa die chinesische Kultur in gleichem Maße die Berücksichtigung der Rechte des Kollektivs bzw. des Staates. Wenn daher eine weltweite Beachtung der Menschenrechte gefordert werde, sei dies Symptom einer imperialistischen Grundhaltung. So schreibt der Philosoph Werner Becker (1982: 295f.):

Vor allem im Weltmaßstab ist überhaupt nicht einzusehen, warum Staatsmodelle nur als gerechtfertigt sollen gelten können, die sich an den Grundwerten des europäisch-nordamerikanischen Liberalismus orientieren. [...] Es drückt sich darin - wie übrigens auch in der weltumspannenden liberalistischen Forderung nach individuellen Menschenrechten und Staatskonzeptionen, die sie zu verwirklichen gestatten -, eine Art kultureller Imperialismus des staatsphilosophischen Denkens der Europäer aus.

Dagegen ist, erstens, aus philosophischer Perspektive einzuwenden, dass die Herkunft einer Aussage keine Aussage über ihre Gültigkeit zulässt. ${ }^{48}$ Die Kritik, es handle sich bei den individuellen Menschenrechten um eine europäische Erfindung, stellt daher ein Scheinargument dar. Zweitens kann das Argument auch gewendet und zu seiner eigenen Widerlegung eingesetzt werden. Menschenrechte als spezifisch abendländisch zu bezeichnen könnte als Versuch gesehen werden, diese zu vereinnahmen, ganz als wäre allein dieser Teil der Welt in der Lage Rechte zu formulieren, mit denen Individuen die Ansprüche von Kollektiven abwehren können. Man könnte darin eine besonders subtile Art imperialistischen Dominanzstrebens sehen: Indem die Gültigkeit des die Rechte von Individuen betonenden europäisch-nordamerikanischen staatsphilosophischen Denkens auf diese Weltregionen beschränkt wird, perpetuiert sich möglicherweise deren historisch gegebene Dominanz.

Ein weiterer Einwand lässt sich an dem Befund festmachen, dass nicht nur der ,Westen' die Menschenrechte zu vereinnahmen versucht. Auch außerhalb Europas gab es Versuche, die Menschenrechte aus den je eigenen kulturellen

48 Eine analoge Struktur weist das argumentum ad hominem auf, das in der Rhetorik als klassisches Scheinargument gilt. 
Wurzeln herzuleiten. Der Islamrat für Europa etwa veröffentlichte nach einem Treffen 1981 in Kairo eine Erklärung, in deren Präambel die Menschenrechte als ursprünglich islamisches Gedankengut dargestellt werden (vgl. Bielefeldt 1997: 262). Die „Erklärung der Menschenrechte im Islam“, die 1990 ebenfalls in Kairo von den Außenministern verschiedener arabischer Staaten vorgelegt wurde, verfolgte eine andere Stoßrichtung. Sie stellten den Versuch dar, die Menschenrechte für den spezifischen islamischen Kontext zu formulieren (vgl. ebd.). An beiden Dokumenten ist problematisch, dass sie mehrfach auf den Koran verweisen - im ersten Fall zur Herleitung der universellen Menschenrechte aus den Ursprüngen des Islam, im zweiten Fall zu ihrer Einschränkung für den Islam. Beide Ansätze stehen in Widerspruch zu der Idee, Menschenrechte mit universeller Gültigkeit und gerade nicht mit Verweis auf eine bestimmte religiöse Tradition zu formulieren.

Die häufig vorgenommene Einordnung der Menschenrechte in eine, jüdischchristliche 'Tradition ist dabei ebenso problematisch. Heiner Bielefeldt weist auf den Umstand hin, dass die Menschenrechte keine eindeutig jüdisch-christliche Tradition vorweisen können: „Die Idee allgemeiner Menschenrechte taucht weder in der jüdisch-christlichen Bibel noch in der antiken Philosophie oder im römischen Recht auf“ (Bielefeldt 1995: 99). Vielmehr mussten sie gegen den teilweise massiven Widerstand der Kirchen durchgesetzt werden. Das Menschenrecht auf Religionsfreiheit etwa wurde von der katholischen Kirche erst 1965 auf dem Zweiten Vatikanischen Konzil uneingeschränkt anerkannt (vgl. ebd.). Noch deutlicher kritisieren Eriksen und Stjernfelt (2012: 291) die Rede von den Ursprüngen der Aufklärung und damit auch der Menschenrechte im Christentum:

But even if certain aspects of Christianity have been able to support Enlightenment, there are as many or more aspects which pull in the opposite direction: intolerance of anything but orthodox belief, persecution of heretics, inquisition, clerical hierarchy, the constant interference of the Church in politics and other secular matters, the claim for revealed knowledge over experience and the ensuing anti-scientific stance, vast wars of religion, and severe strictures against free speech.

In jedem Fall ist eine Vereinnahmung der Menschenrechte abzulehnen, egal ob dies unter europäischer, christlicher, islamischer oder sonstiger Flagge geschieht. Jeder Begründungsversuch auf der Grundlage religiöser Texte oder spezifischer Traditionen wird unweigerlich die angestrebte weltweite Akzeptanz unterminieren. Insbesondere die Behauptung, bei den Menschenrechten handle es sich um ,christlich-abendländische', europäische' oder ,westliche 'Werte, kann daher als gewollter oder ungewollter Vereinnahmungsversuch gesehen werden, der seinerseits als eurozentrisch zurückgewiesen werden kann. 
Die Rede vom europäischen Ursprung der Menschenrechte ist darüber hinaus insofern problematisch, als sie einen linearen Fortschritt suggeriert, ganz als wären die Menschenrechte in den Wurzeln der westlichen Zivilisation gewissermaßen von Beginn an angelegt. In dieser Argumentationslinie wäre es als natürliche, organische Entwicklung anzusehen, dass sich die Menschenrechte in den westlichen Staaten durchgesetzt haben. Diese Narration ignoriert den historisch bedeutsamen Umstand, dass sich die Menschenrechte vor allem in Zeiten von Mondernisierungskrisen herausgebildet haben, und zwar als Abwehrrechte gegen staatliche Bevormundung, wirtschaftliche Ausbeutung oder religiösen Fundamentalismus. Dass sie in der aktuell gültigen Form festgelegt sind, wäre in diesem Sinne kein ,natürlicher' Prozess, durch den die westliche Kultur gewissermaßen zu ihrer höchsten Blüte gelangte, sondern es handelte sich um eine historische Kontingenz. Einerseits belegt dies die Tatsache, dass die Menschenrechte keineswegs von selbst entstanden, sondern dass sie erkämpft wurden, meist unter dem Eindruck von millionenfachem Leid und Tod, wie sie etwa die Religionskriege in Europa hervorbrachten. Andererseits ist auch der Umstand zu berücksichtigen, dass neuere Modernisierungskrisen - wie etwa die aktuell viel diskutierte Überwachung der digitalen Kommunikation durch weltweit tätige Geheimdienste - vor dem Hintergrund der Menschenrechte neu zu bewerten sind (vgl. Bielefeldt 1996). ${ }^{49}$

Gerade das letzte Beispiel zeigt, dass die Menschenrechte keineswegs einseitig der Durchsetzung der Machtinteressen westlicher Staten im Sinne des von Becker vermuteten „kulturellen Imperialismus“ (s. o.) dienen, sondern dass sie im Gegenteil die Kritik an Machtmissbrauch erst ermöglichen. So lautet Artikel 12 der Allgemeinen Erklärung der Menschenrechte:

No one shall be subjected to arbitrary interference with his privacy, family, home or correspondence, nor to attacks upon his honour and reputation. Everyone has the right to the protection of the law against such interference or attacks. (UN General Assembly 1948)

Es handelt sich daher bei den Menschenrechten weder um eine spezifische und nur hier gültige Erfindung Europas oder Nordamerikas, noch können die westlichen Staaten für sich beanspruchen, sie ein für allemal verwirklicht zu haben. Vielmehr geht es um den Schutz des Individuums im Spannungsfeld zwischen

49 Mit erstaunlichem Weitblick weist Heiner Bielefeldt bereits 1995 auf die Notwendigkeit hin, dass „[...] dem Recht auf Datenschutz bzw. informationelle Selbstbestimmung allmählich die Qualität eines neuen Menschenrechtsstandards zuwächst“" (Bielefeldt 1995: 103). 
Individuum und Kollektiv, der immer wieder neu ausgehandelt, legitimiert und durchgesetzt werden muss.

Die Formulierung von Abwehrrechten des Individuums gegen Übergriffe durch staatliche, wirtschaftliche oder religiöse Institutionen sind nicht nur kein ,natürliches' Ergebnis der kulturellen Entwicklung Europas, sie sind zudem nicht einmal eine europäische Besonderheit. Zwar wurden sie in der gegenwärtig gültigen Form in diesem Kontext formuliert. Gleichzeitig lassen sich jedoch auch in zahlreichen Texten etwa der konfuzianischen, islamischen und buddhistischen Tradition Ansätze der Formulierung solcher Rechte belegen (vgl. Huxoll 1999: 68f; Bielefeldt 1995: 100f.). Dies gilt insbesondere für den Konfuzianismus, der häufig als das asiatische Gegenmodell zum westlichen Individualismus angeführt wird. In der Tat betont eine Form des Konfuzianismus, auf die sich etwa der chinesische Staat der Gegenwart beruft, die Rechte des Kollektivs vor denen des Individuums (,Staatskonfuzianismus'). In ebenso alten chinesischen Texten lässt sich jedoch auch eine andere Linie des Konfuzianismus nachweisen, welche in völliger Übereinstimmung mit der neuzeitlichen Menschenrechtsidee die Abwehrrechte des Individuums betont. Man könnte daher ebenso argumentieren, dass der Grundgedanke, das Individuum ins Zentrum von universellen Rechten zu stellen, einen ursprünglich nicht-westlichen Kern aufweise. Beim Staatskonfuzianismus, der oft als repräsentativ für asiatisches Denken in Kollektiven angeführt wird, handelt es sich daher lediglich um eine Ausprägung asiatischer Philosophie. Daneben findet sich der klassische Konfuzianismus als zweite Traditionslinie, aus der sich individuelle Menschenrechte herleiten lassen (vgl. Göller 2003: 129f.).

Umgekehrt lässt sich anführen, dass auch im Westen philosophische Ansätze entwickelt wurden und eine enorme Verbreitung erfahren haben, welche die Rechte des Kollektivs vor denen des Individuums betonen, etwa der Marxismus. Sein europäischer Ursprung war kein Hindernis für eine starke weltweite Rezeption, u. a. auch in asiatischen Staaten wie China.

Kritik gegen universell gültige Menschenrechte tritt auch häufig in Form von Kritik gegen den größeren Kontext auf, aus dem sie in der heutigen kodifizierten Form hervorgingen: den der Aufklärung. In dieser Argumentationslinie wird ,Vernunft' als ein ebenso europäisches Projekt dargestellt wie die Aufklärung und die auf ihrer Grundlage erfolgte Formulierung universeller Menschenrechte. Vernunft wird in dieser Form der Kritik daher wie die Menschenrechte unter den Verdacht gestellt, in Wirklichkeit ein Instrument des westlichen Kulturimperialismus zu sein, und wie die Menschenrechte wäre Vernunft daher auf den spezifischen Geltungsbereich zu beschränken, dem sie entstammt. Wie bei den Menschenrechten lässt sich auch hier einwenden, dass die Bezeichnung des Vernunftbegriffs 
als europäisch problematisch ist, und zwar unabhängig davon, ob dies mit dem Ziel der Infragestellung seiner Gültigkeit oder mit dem Ziel der Affirmation und Vereinnahmung geschieht. Wenn unter Vernunft kritisches „Selbstdenken“ (Bielefeldt 1997: 261) zu verstehen ist, dann lassen sich auch hierfür in zahlreichen Traditionen Belege finden. So hat etwa der arabische Philosoph und Arzt Ibn Ruschd (Averroes) im 12. Jahrhundert den Versuch einer vernunftbasierten islamischen Aufklärung unternommen (vgl. Turki 1996). Auch in der buddhistischen Tradition finden sich Texte, welche für das Ideal der Vernunft im Sinne eines kritischen Widerstreits von Positionen und Argumenten eintreten. Das folgende Fragment scheint sogar nichts anderes zu beschreiben als die rationale Rede im Sinne der von Habermas (1971: 137) geprägten Idee der idealen Sprechsituation. In der erhaltenen Form im 4. oder 5. Jahrhundert n. Chr. in der sogenannten Milindapañha überliefert (Teil 2, „Diskussion nach Art eines Weisen“- 2.1.3. Vìmamsanapañho), einem Text der buddhistischen Tradition, handelt es sich um ein Gespräch zwischen dem buddhistischen Mönch Nâgasena und dem griechischen König Menandros, das der Legende nach um 120 v. Chr. stattgefunden haben soll:

Der König sprach: „Ehrwürdiger Nâgasena, wirst du noch weiter mit mir diskutieren?“ - „Wenn du, großer König, in der Sprache eines Gelehrten diskutieren wirst, dann werde ich mit dir diskutieren. Wenn du aber in der Sprache des Königs diskutieren wirst, dann werde ich nicht mit dir diskutieren.“ - „Wie, ehrwürdiger Nâgasena, diskutieren denn die Weisen?“ - „Bei einer Diskussion unter Weisen, großer König, findet ein Aufwinden und ein Abwinden statt, ein Überzeugen und ein Zugestehen; eine Unterscheidung und eine Gegenunterscheidung wird gemacht. Und doch geraten die Weisen nicht darüber in Zorn. So, großer König, diskutieren die Weisen miteinander.“ - „Wie aber, Ehrwürdiger, diskutieren die Könige?“ - „Wenn Könige während einer Diskussion eine Behauptung aufstellen und irgendeiner diese Behauptung widerlegt, dann geben sie den Befehl, diesen Menschen mit Strafe zu belegen. Auf diese Weise, großer König, diskutieren Könige." (Zit. nach Mall 1999: 133)

Habermas' (1971: 137) ideale Sprechsituation weist eine geradezu frappierende Ähnlichkeit zu dieser „Sprache eines Gelehrten“ der Milindapañha auf:

Die ideale Sprechsituation schließt systematische Verzerrung der Kommunikation aus. Nur dann herrscht ausschließlich der zwanglose Zwang des besseren Argumentes, der die methodische Überprüfung von Behauptungen sachverständig zum Zuge kommen läßt und die Entscheidung praktischer Fragen rational motivieren kann.

Auch in außereuropäischen Traditionslinien lassen sich also Ansätze finden, bei denen versucht wird, den Gebrauch der Vernunft und, oft in engem Zusammenhang, die individuellen Rechte von Menschen (als vernunftbegabten Wesen) mit einem universellen Geltungsanspruch zu beschreiben. Zusammenfassend lässt sich daher festhalten, dass es sich weder bei den Menschenrechten noch bei der 
Aufklärung mit dem für sie zentralen Vernunftbegriff um exklusiv abendländische, europäische oder gar christlich-jüdische Ideen handelt. Der indische Philosoph Ram A. Mall schlägt daher vor, eine interkulturelle Philosophie ins Leben zu rufen. Eine solche Philosophie müsse zum Ziel haben, „[...] weder ihre kulturelle Bedingtheit noch ihre völlige kulturelle Unabhängigkeit einseitig zu betonen" (Mall 1999: 141). Auf diese Weise leite die...

[...] interkulturelle Orientierung eine kopernikanische Wende ein, indem sie alle Kulturen, Philosophien, Religionen und Weltanschauungen um die eine wahre Sonne der Menschenrechtsidee kreisen läßt. Dies hat zur Folge, daß nicht nur dem Eurozentrismus, sondern dem Zentrismus schlechthin eine Absage erteilt wird. (ebd.: 141f.)

Eine solche Philosophie solle sich nach Malls Auffassung die „These von der orthaften Ortlosigkeit der Menschenrechte" (ebd.: 142) zu eigen machen.

Ich stimme Mall in Bezug auf die Notwendigkeit einer solchen „ortlosen“, inter- oder transkulturellen Begründung der Menschenrechte ohne Einschränkung zu. In einem Punkt teile ich seine Einschätzung jedoch nicht: Eine universelle Menschrechtsidee, so Mall weiter, „[...] schadet keinem und hilft uns allen“ (ebd.). In einer Zeit, in der offensichtlich kein Mangel an philosophischen, religiösen und politischen Strömungen besteht, denen die Idee universeller Menschenrechte den Boden entziehen würde, scheinen hier Zweifel angebracht. Der universelle Geltungsanspruch der Menschenrechte schadet diesen Strömungen durchaus, und von ihren Anhänger_innen ist mit massivem Widerstand zu rechnen. Dabei werden sie ohne Zweifel auch auf die hier vorgestellten und diskutierten kulturrelativistischen Argumentationsmuster zurückgreifen.

\subsubsection{Rechtlich-politische Einwände gegen den Kulturrelativismus}

Im vorherigen Kapitel habe ich versucht, einige Probleme des normativen Kulturrelativismus aufzuzeigen. Hierfür habe ich verschiedene Kritikpunkte diskutiert, die gegen universalistisch inspirierte Anliegen wie die Allgemeine Erklärung der Menschenrechte der Vereinten Nationen vorgebracht werden. Dabei ging es mir darum, die Problematik zweier besonders häufig angeführter Argumentationslinien herauszuarbeiten: Erstens, dass es sich bei ihnen um europäische bzw. christlich-abendländische Werte handle, die deswegen als eurozentrisch abzulehnen seien, und zweitens, dass sie in der Tradition oder den ,Wurzeln des Abendlandes - und nur dort - angelegt seien. ${ }^{50}$ Gegen beide Standpunkte

50 Die Metapher der,Wurzeln' ist ohnehin problematisch, da sie suggeriert, dass sich bestimmte Prinzipien einer Kultur auf, natürliche 'Weise herausgebildet haben - in anderen Kulturen aber nicht, weswegen man ihre Einhaltung dort auch nicht einfordern 
konnten aus historisch-philosophischer Perspektive gewichtige Gegenargumente gefunden werden.

Ich möchte diese allgemeinen Überlegungen zu einer universellen, oder zumindest weit über europäische Geistestraditionen hinausgehenden, Menschenrechtsidee jetzt an einer anderen Stelle fortsetzen: dem Prinzip der Rechtsstaatlichkeit. Während in den allgemeinen Menschenrechten versucht wird, bestimmte Rechte zu formulieren, die allen Menschen als Menschen zustehen, regelt das Prinzip der Rechtsstaatlichkeit vorwiegend das Verhältnis von Staaten zu ihren Angehörigen als Bürgern (vgl. Sandkühler 1996: 132; Preuß 1998: 61). Menschenrechte und Rechtsstaatlichkeit verweisen dabei in mehrfacher Hinsicht aufeinander.

Erstens ist der Anspruch von Bürgern auf rechtsstaatliche Verfahren in der Präambel der Allgemeinen Erklärung der Menschenrechte enthalten:

[...] it is essential, if man is not to be compelled to have recourse, as a last resort, to rebellion against tyranny and oppression, that human rights should be protected by the rule of law. (UN General Assembly 1948: Preamble)

Dieser Passage liegt die Überlegung zu Grunde, dass die allgemeinen Menschenrechte von einer Absichtserklärung auf internationaler Ebene auf der Ebene der Nationalstaaten in Bürgerrechte übersetzt, gesetzlich festgeschrieben und somit einklagbar gemacht werden müssen. Die Einhaltung dieser Prinzipien muss für jede denkbare Konfliktpartei verbindlich sein: für Privatpersonen ebenso wie für die Vertreter religiöser Gruppen, für Wirtschaftsunternehmen ebenso wie für den Staat und seine Vertreter selbst. So wie die allgemeinen Menschenrechte von den Unterschieden zwischen Menschen - etwa in Bezug auf ihre Zugehörigkeit zu unterschiedlichen Kulturen oder Staaten - auf einen gemeinsamen Kern abstrahieren und damit das Prinzip der Gleichheit als Menschen anstreben, so abstrahieren Rechtsstaaten von den (ökonomischen, sozialen, kulturellen, weltanschaulichen, geschlechtsspezifischen, etc.) Unterschieden zwischen ihren Bürgern mit dem Ziel ihrer „durch Recht garantierten Gleichheit“ (Preuß 1998: 61, Hervorhebung im Original).

Zweitens stellen allein die Rechtssysteme moderner Nationalstaaten die Instrumente zur Verfügung, mit denen Auseinandersetzungen zwischen Individuen, zwischen Individuen und Gruppen sowie auch zwischen Gruppen gewaltfrei und unter Achtung der allgemeinen Menschenrechte ausgetragen werden können. Sie werden als die wichtigsten Garanten für die tatsächliche Durchsetzung von

könne. Die Rede von den kulturellen Wurzeln wäre daher in der Klassifizierung nach Reckwitz (vgl. Kap. 2.1.) einem totalitätsorientierten Kulturverständnis zuzuordnen. 
Menschenrechten als individuelle Abwehrrechte gesehen - auch und gerade gegen Übergriffe des Staates.

Drittens sind aktuell 193 Mitgliedsstaaten seit ihrem Beitritt zu den UN dazu verpflichtet, ihre Rechtssysteme in Übereinstimmung mit den Menschenrechten zu konzipieren bzw. zu überarbeiten. Zum einen bieten diese daher eine national wie transnational gültige Richtschnur für Entscheidungen in Konflikten, die sowohl zwischen Individuen als auch zwischen Individuen und Gruppen entstehen. Zum anderen ermöglichen die Menschenrechte, dass in Rechtsstaaten Konflikte „Zwischen richtigen und unrichtigen Versionen von Recht“ (Sandkühler 1996: 127) sowie zwischen Recht und politischer Herrschaft (vgl. ebd.) auf die Tagesordnung gesetzt und beigelegt werden können, und zwar im Abgleich mit ihren Verfassungen, die ebenfalls vor dem Hintergrund der allgemeinen Menschenrechte legitimierungsbedürftig sind. Sandkühler (ebd.: 126) weist in diesem Zusammenhang auf den wenig bekannten Umstand hin, dass das Verfassungsprinzip in (damals noch: West-)Deutschland erst nach dem zweiten Weltkrieg eingeführt wurde:

Die Bindung der Gesetzgebung an die Verfassung galt in den Vereinigten Staaten schon 1803; in Deutschland wurde sie erst mit dem Grundgesetz 1949 eingeführt; dieser Paradigmenwechsel ist nichts Selbstverständliches.

Entscheidend an diesem Paradigmenwechsel ist der Umstand, dass die politische Herrschaft durch Gesetze nun selbst in die Lage geriet, rational begründet werden zu müssen. Rational begründet heißt in erster Linie, dass sie in Übereinstimmung mit den jeweiligen Verfassungen - im Falle Deutschlands mit dem Grundgesetz - stehen müssen. Es können jedoch auch Änderungen an Verfassungen selbst notwendig werden, falls sich herausstellt, dass Teile von ihnen im Widerspruch zu allgemeinen Menschenrechten stehen:

Das Recht hat diese Grundnorm, die Basis seiner Moralität und Rationalität, nicht in dieser oder jener privaten Welt- und Rechtsanschauung, sondern allein in den Menschenrechten, deren praktische Wirklichkeit zu garantieren seine Aufgabe ist. (ebd.: 122)

Es besteht damit eine enge gegenseitige Abhängigkeit zwischen den allgemeinen Menschenrechten und dem Prinzip der Rechtsstaatlichkeit: Die Menschenrechte sind auf gesetzgebende, rechtsprechende und ausführende Gewalten angewiesen, die ihre Einhaltung garantieren, und umgekehrt beziehen rechtsstaatliche Strukturen einen Teil ihrer Legitimation aus eben dieser Aufgabe.

Wie bereits erwähnt, abstrahieren die Menschenrechte von den politischen, kulturellen, religiösen und sozialen Unterschieden zwischen Individuen und betonen ihre Gleichheit als Menschen. Dementsprechend abstrahieren Rechtsstaaten von 
den vielfältigen Unterschieden zwischen Individuen und garantieren ihre rechtliche Gleichheit als Bürger, ein Prinzip, das in der Formel der „Gleichheit vor dem Gesetz" seinen Ausdruck findet. ${ }^{51}$ Wie ebenfalls bereits argumentiert wurde, legen einige der Grundannahmen des Kulturrelativismus (\#4,\#7) eine Kritik an der Idee universeller Menschenrechte nahe (vgl. The Executive Board 1947). Angesichts der engen Verflechtung der allgemeinen Menschenrechte mit dem Prinzip der Rechtsstaatlichkeit stellt sich daher die Frage, inwieweit ein kulturrelativistischer Standpunkt auch zu diesem in Widerspruch steht. Diese Frage hat in den vergangenen Jahrzehnten erhöhte Relevanz bekommen, da durch zunehmende Migrationsbewegungen immer mehr Menschen unterschiedlicher kultureller Prägung in nationalen und, wie im Falle der EU, supranationalen Rechtsgebieten zusammenleben. In zunehmendem Maße wurde daher die Frage virulent, wie Minderheiten in demokratische Gesellschaften integriert werden bzw. sich integrieren konnten, denn alle Bürger_innen sollten in den vollen Genuss der ihnen zustehenden Bürgerrechte kommen. Dabei stellte sich jedoch das Problem, dass diese Integration möglicherweise nur dann zu verwirklichen wäre, wenn die Mitglieder dieser Minderheiten ihre traditionelle Lebensweise zumindest teilweise aufgaben, und es stellte sich in gleichem Maße für indigene (,nationale') Minderheiten wie für Minderheiten, die sich durch Migrationsbewegungen gebildet hatten.

In der kulturrelativistisch geprägten Tradition der amerikanischen Anthropologie galt als ausgemacht, dass jede Lebensweise, jede Kultur, besonderen Schutz verdiene und in ihrer ,ursprünglichen' Form Bestand haben solle. Im Zusammenhang mit dem Umgang mit Minderheiten stellte sich nun die Frage, inwieweit sich dieses kulturrelativistische Prinzip verwenden ließ, um die Benachteiligung einzelner Gruppen in modernen pluralen Gesellschaften zu überwinden. Hierfür wurden unter dem Namen des Multikulturalismus Ansätze entwickelt, die in der Regel konkrete Vorschläge für die rechtliche Sonderstellung von Minoritäten unterbreiteten und daher weniger forschungsbezogene als vielmehr praktisch-politische Problemstellungen in den Blick nahmen.

Auch wenn Multikulturalismustheorien durchgehend das liberale Anliegen der Schaffung größerer sozialer Gerechtigkeit unterstellt werden kann, bestand jedoch von Beginn an die Gefahr, dass sie in Widerspruch zu Theorien des liberalen Rechtsstaats geraten könnten, deren Kernanliegen ebenfalls in der Konzeption eines für alle Bürger gerechten Staates besteht. Dies gilt etwa für die Liberalismustheorie von John Rawls, für den ein möglichst gerechter Staat so zu konzipieren ist, dass er einer Vielzahl verschiedener Vorstellungen von einem

51 Für die Bundesrepublik Deutschland vgl. Art. 3 Abs. 1 GG. 
guten und vernünftigen Leben die Entfaltung ermöglicht. Hierfür müsse dieser Staat eine Gesellschaft im Sinne einer „political conception of justice“ (Rawls 1993: 14) wohlgeordnet gestalten. Justice und Fairness sieht Rawls vor allem dann gewährleistet, wenn der Staat keine systematischen Ungleichheiten schaffe, sondern diese nur zulasse, wenn sie an gesellschaftliche Positionen geknüpft sind, die allen zugänglich sind („fair equality of opportunity“, ebd.: 291). Kulturelle Differenzen zwischen den Mitgliedern einer solchen Gesellschaft werden von Rawls (ebd.) explizit als Grundlage für politische Ungleichheit ausgeschlossen: "Comprehensive doctrines of all kinds - religious, philosophical, and moral belong to what we may call the ,background culture' of civil society."

Konzepte des Multikulturalismus, welche auf Grundlage der erkenntnis- und wissenschaftstheoretischen Überlegungen des Kulturrelativismus die Forderung nach politischen Differenzen zwischen Bürgern ableiten, stehen daher potentiell im Widerspruch zu liberalen Staatstheorien wie der von Rawls. Da der Multikulturalismus an die Prämissen des Kulturrelativismus anschließt, gilt, dass Einwände gegen den politischen Multikulturalismus auch den Kulturrelativismus betreffen. Ich möchte die Diskussion des Kulturrelativismus daher in den folgenden Abschnitten mit einigen Überlegungen zum Konflikt zwischen dem Prinzip des Multikulturalismus und dem liberalen rechtsstaatlichen Prinzip der Gleichheit vor dem Gesetz fortführen. Diese Ausführungen beziehe ich erstens auf die Multikulturalismus-Beiträge von Will Kymlicka (Multicultural Citizenship, 1985 sowie Multicultural Odysseys, 2007). Die Arbeiten Kymlickas sind hier von besonderem Interesse, weil er sich angesichts der bekannten antiliberalen Kehrseiten des Multikulturalismus explizit dem Anliegen verschrieb, eine liberale Multikulturalismustheorie zu entwerfen. Zweitens beziehe ich mich auf Einwände gegen den Multikulturalismus, die von Ulrich Preuß (1998) sowie von Jens-Martin Eriksen und Frederik Stjernfelt (2012) formuliert wurden. Drittens beziehe ich mich auf die Arbeiten von John Rawls (1971, 1993), der als einer der wichtigsten Theoretiker des Liberalismus im 20. Jahrhundert gilt (vgl. Schaal/ Heidenreich 2006: 98-115). Schließlich versuche ich an drei Beispielen zu illustrieren, wie problematisch die Umsetzung multikulturalistischer Theorie in der Praxis sein kann.

Der Multikulturalismus vertritt das Grundanliegen, in den zeitgenössischen Nationalstaaten, die sich unter anderem bedingt durch Migrationsprozesse als zunehmend vielfältig zeigen, die kulturellen Besonderheiten von gesellschaftlichen Teilgruppen zu bewahren. Er wendet sich explizit gegen die etwa für das historische Selbstverständnis der USA als Einwanderernation zentrale Idee des melting pot, eines Topfs, in dem verschiedene kulturelle Einflüsse zu einem neuen 
Ganzen verschmelzen. Als Gegenentwurf wird das Prinzip der salad bowl (vgl. Chua 2009) vorgeschlagen, einer Salatschüssel also, in der die einzelnen ,Zutaten nicht verschmelzen, sondern als voneinander getrennte Einheiten identifizierbar bleiben sollen..$^{52}$ Die Grundlagen dieser Idee der Bewahrung kultureller Grenzen wurden, wie bereits ausgeführt wurde, in der amerikanischen Anthropologie der ersten Hälfte des 20. Jahrhunderts entwickelt. Nach dem 2. Weltkrieg wurde die Tradition unter anderem von Claude Lévi-Strauss fortgeführt, dem vermutlich prominentesten Anthropologen des 20. Jahrhunderts. Auch abseits von Fachkontexten argumentierte er angesichts der globalen Tendenz zu inter- und intranationalen kulturellen Hybridisierungen, Vermischungen und Verflechtungen für eine konsequente Bewahrung kultureller Unterschiede. Seine Beiträge bekamen dadurch besonderes politisches Gewicht, dass sie durch die UNESCO verbreitet wurden (vgl. Lévi-Strauss 1987 [1952], 2001). Lévi-Strauss setzte sich für die Bewahrung klar voneinander unterscheidbarer Kulturen ein. Dass diese voneinander lernten - und sich somit unweigerlich annäherten - sei nur um den Preis der Aufgabe ihrer jeweiligen Originalität zu bekommen und daher zu vermeiden:

Loriginalité et la nature irremplaçables de ces styles de vie ou, comme disent les AngloSaxons, de ces patterns ne sont pas niables, mais comme ils représentent autant de choix exclusifs on aperçoit mal comment une civilisation pourrait espérer profiter du style de vie d'une autre, à moins de renoncer à être elle-même. (Lévi-Strauss 1987 [1952]: 75, Hervorhebung im Original)

Während sich Lévi-Strauss hier stärker mit dem Problem der Koexistenz verschiedener geographisch getrennter Kulturen befasst, überträgt der kanadische Philosoph Will Kymlicka den von Lévi-Strauss explizit auch im Hinblick auf politische Entscheidungen überarbeiteten Kulturrelativismus auf die seit den späten 1980er-Jahren stark diskutierte Frage nach dem Zusammenleben von Gruppen, die sich den selben geographischen Raum teilen. In Multicultural Citizenship (1995) und Multicultural Odysseys (2007) versucht er die theoretischen Grundlagen zu konzipieren, durch welche die geforderte Bewahrung der Substanz (substance, vgl. Lévi-Strauss 1987 [1952]: 76) und Anerkennung (recognition, vgl. Taylor 2011) kultureller Unterschiede in pluralen Gesellschaften ernst genommen und rechtlich verankert werden könnten. Kymlicka nennt diese Form des Kulturalismus targeted multiculturalism, wobei „targeted“ für die Idee steht, Minderheiten gezielt mit Sonderrechten auszustatten. Zu diesen Sonderrechten sollen unter anderem Rechte zur Selbstverwaltung, polyethnische Rechte sowie

52 Chua sieht in der salad bowl das Geheimnis der Leistungsfähigkeit der USA und die Grundlage ihrer weltweiten Dominanz als ,Hyperpower. 
spezielle Repräsentationsrechte gehören („Self-government rights“, „polyethnic rights“, ,,special rights of group representation“, Kymlicka 2007: 27-31; vgl. Eriksen/Stjernfelt 2012: 171ff.).

Wenn einzelne Gruppen mit Sonderrechten ausgestattet werden, stellt sich jedoch unmittelbar die Frage, wie eine solche Gruppe vom Rest der Bevölkerung abzugrenzen ist. ${ }^{53}$ Sind bei der Definition einer kulturellen Gruppe ethnische, religiöse, sprachliche, ökonomische oder andere Kriterien anzuwenden? Genügt jeweils ein Kriterium, oder muss ein ganzes Bündel erfüllt sein, damit eine Gruppe in den Genuss von Sonderrechten kommt? Wie sehen die politischen Prozesse aus, die zu einer Anerkennung als Minderheit führen? Wer spricht für eine Gruppe, und wie werden die „leaders of minorities“ (Kymlicka 2007: 93) innerhalb der verschiedenen Gruppen bestimmt? (vgl. Eriksen/Stjernfelt 2012: 185) Kymlicka stellt sich diesen Fragen, die auch eine betont machtbezogene Seite haben, bedauerlicherweise nicht. Gerade diese wäre jedoch von einem explizit politischen Multikulturalismuskonzept zu erwarten, da andernfalls eine Invisibilisierung von Machtstrukturen kaum zu vermeiden ist.

Das hier aufgeworfene Problem kann als Abgrenzungsproblem bezeichnet werden. Es lautet: Wenn zwischen Bevölkerungsteilen ,kulturelle Grenzen verlaufen, anhand derer nach innen tendenziell homogene Gruppen definiert werden können, wo genau sind diese Grenzen zu ziehen? Es stellt sich für Multikulturalismustheorien, wenn es um die Frage nach Sonderrechten von Minderheiten geht. Es stellt sich aber gleichermaßen für die interkulturelle Didaktik, deren theoretisches Kernproblem lautet, wann überhaupt eine interkulturelle Situation vorliegt (vgl. Rathje 2006: 8; Hu 1999: 297f.). Wie stark sich pluralistische Gesellschaften in - möglicherweise voneinander abzugrenzende - kleine und kleinste Gruppen ausdifferenzieren, hat Hans Magnus Enzensberger (1988: 264f.) für die Bundesrepublik als „durchschnittliche Exotik des Alltags“ in humoristischer Zuspitzung formuliert:

Niederbayrische Marktflecken, Dörfer in der Eifel, Kleinstädte in Holstein bevölkern sich mit Figuren, von denen noch vor dreißig Jahren niemand sich etwas träumen ließ. Also golfspielende Metzger, aus Thailand importierte Ehefrauen, V-Männer mit Schrebergärten, türkische Mullahs, Apothekerinnen in Nicaragua-Komitees, mercedesfahrende Landstreicher, Autonome mit Bio-Gärten, waffensammelnde Finanzbeamte, pfauenzüchtende Kleinbauern, militante Lesbierinnen, tamilische Eisverkäufer, Altphilologen im Warentermingeschäft, Söldner auf Heimaturlaub, extremistische Tierschützer, Kokaindealer mit Bräunungsstudios, Dominas mit Kunden aus dem höheren

53 Dies verweist auf das in den Kapiteln 2.1. ausführlich entfaltete Problem unterschiedlicher Kulturverständnisse. 
Management, Computer-Freaks, die zwischen kalifornischen Datenbanken und hessischen Naturschutzparks pendeln, Schreiner, die goldene Türen nach Saudi-Arabien liefern, Kunstfälscher, Karl-May-Forscher, Bodyguards, Jazz-Experten, Sterbehelfer und Porno-Produzenten.

In Kapitel 2.1. wurde für ein Kulturverständnis argumentiert, das Kontingenzen offen legt und dabei sowohl der inneren Heterogenität als auch den unscharfen Übergängen zwischen Gruppen Rechnung trägt. Dieselben Argumente gelten nun auch für Multikulturalismustheorien. Jede Theorie, welche auf eine Festlegung kultureller Großgruppen angewiesen ist, läuft Gefahr, mit Kulturverständnissen zu operieren, welche in der kulturwissenschaftlichen Theoriebildung als problematisch gelten.

Das Vorhaben, gesellschaftliche Untergruppen mit einer je eigenen ,Kultur zu definieren, beruht auf der Vorstellung relativ deutlicher, großer Unterschiede. Doch selbst wenn sich auf dieser Grundlage Gruppen mit vergleichsweise hoher interner kultureller Homogenität definieren ließen, bestünde das nächste Problem in der Fraktionenbildung. Es äußert sich darin, dass sich innerhalb von Gruppen entlang kleinster Unterschiede plötzlich tiefe Gräben auftun können, ein Phänomen, das Sigmund Freud (2004 [1930]: 79) als „Narzissmus der kleinen Differenzen“ bezeichnete, eine „[...] bequeme und relativ harmlose Befriedigung der Aggressionsneigung, durch die den Mitgliedern der Gemeinschaft das $\mathrm{Zu}$ sammenhalten erleichtert wird“ (ebd.). Diese kleinen Unterschiede scheinen aus der Außenperspektive manchmal vernachlässigbar, können aus der Innenperspektive der betroffenen Gruppe aber identitätsstiftende Bedeutung erlangen. Ulrich Preuß (1998: 62) hat genau diese Prozesse im Sinn, wenn er schreibt: „Je mehr die kulturellen Eigenarten und Besonderheiten schrumpfen, desto stärker werden kulturelle Identität und sozialer Zusammenhalt betont.“

Die Frage nach verschiedenen Kulturverständnissen mag in Bezug auf die Anthropologie ein wissenschaftliches, in Bezug auf die interkulturelle Didaktik als bildungstheoretisches erscheinen. In Zusammenhang mit Multikulturalismustheorien wird jedoch auch ihre politische Brisanz deutlich. Selbst wenn man Kymlickas Argumentation folgt und bestimmten Großgruppen Sonderrechte einräumt, ergibt sich aus dem ungelösten Abgrenzungsproblem die Schwierigkeit, dass nach der Aufgabe des Prinzips der Gleichheit vor dem Gesetz keine rationalen Begründungen mehr bereitstehen werden, mit denen diese Sonderrechte kleinen und kleinsten Gruppen verwehrt werden könnten. Somit ist zu befürchten, dass das Anliegen, durch Sonderrechte für Gruppen größere Gerechtigkeit zu schaffen, in der Schaffung neuer Ungerechtigkeit enden kann. 
Neben der Frage nach dem Kulturbegriff und dem damit eng zusammenhängenden Abgrenzungsproblem stellt sich eine weitere, auf das Kymlickas Theorieentwurf ebenfalls keine Antwort bietet. Welche politischen Prozesse sind denkbar, um zu entscheiden, dass eine Gruppe den Anspruch auf kulturelle Differenz erheben und damit die von Kymlicka formulierten Gruppenrechte geltend machen kann? Die Ausblendung der machtbezogenen Aspekte einer Gesellschaftstheorie legt die Befürchtung nahe, dass die Gewährung der in ihr geforderten Gruppenrechte - so man dies für wünschenswert hält - nicht in einem demokratischen, fairen und nachvollziehbaren Prozess erfolgen könnte, sondern dass vielmehr jene Gruppen bevorzugt werden könnten, welche diese Rechte politisch effektiv und möglicherweise unter Androhung von Druckmitteln bis hin zu Gewalt durchzusetzen bereit wären. Eriksen und Stjernfelt (2012: 190) bemerken hierzu treffend:

In the absence of criteria for applying, targeted' multiculturalism to a specific demand on behalf of a cultural group, how can it be avoided that it is merely the group which lobbies the best or shouts most loudly which achieves to be ,targeted'? Or, even worse, how can it be avoided that it is the group that best manages to employ threats or acts of violence which is awarded with special rights? Kymlicka is very far from solving such problems with ,targeted' multiculturalism. The lack of criteria for what counts as a proper target is almost complete.

Für die hier geführte Diskussion sind schließlich Kymlickas Bemerkungen zu den Grenzen von Gruppenrechten interessant, die sich in den Schlusspassagen von Multicultural citizenship finden. Diese seien dort zu ziehen, wo entweder die Freiheit anderer Gruppen oder die Freiheit einzelner Mitglieder innerhalb von Gruppen in Frage gestellt werde:

It is equally important to stress the limits on such rights. In particular, I have argued that they must respect two constraints: minority rights should not allow one group to dominate other groups; and they should not enable a group to oppress its own members. In other words, liberals should seek to ensure that there is equality between groups, and freedom and equality within groups. (Kymlicka 1995: 194, Hervorhebungen im Original)

Kymlicka formuliert hier einen klassisch liberalen Standpunkt. Allerdings bleibt offen, wie die Garantie kultureller Sonderrechte für Gruppen sowie die Garantie individueller Freiheitsrechte für ihre Mitglieder gleichzeitig verwirklicht werden können. Dies dürfte insbesondere dann schwierig sein, wenn eine Gruppe sich darüber definiert, dass bestimmte individuelle Freiheitsrechte ihrer Mitglieder eingeschränkt werden (z.B. in Bezug auf die Wahl des Ehepartners, auf die Religion, auf Diskriminierungen aus Gründen des Geschlechts oder der sexuellen Orientierung, auf Gewalt als Mittel der Erziehung, etc.). Wenn dagegen im Sinne 
des liberalen Multikulturalismus gefordert wird, dass eine Gruppe eben diese möglicherweise Identität stiftenden - kulturellen Besonderheiten aufgeben müsse, ist kaum noch ein Unterschied zu den Grundsätzen klassisch liberaler Staatstheorie erkennbar.

Wie ich versucht habe darzulegen, beruhen zentrale Forderungen des Multikulturalismus auf veralteten Kulturverständnissen und sind zudem mit dem rechtsstaatlichen Prinzip der Gleichheit vor dem Gesetz unvereinbar. Dennoch lassen sich auf der Ebene größerer und einflussreicherer gesellschaftlicher Gruppen bereits in der Gegenwart Beispiele finden, bei denen aus Rücksicht auf religiöse, ethnische oder kulturelle Differenzen Sonderrechte eingeräumt werden. Ich möchte nach den oben entwickelten theoretischen Überlegungen daher an drei aktuellen Beispielen die praktische Problematik der Gewährung von kulturell legitimierten Sonderrechten, der Kernforderung von Kymlickas Multikulturalismustheorie, illustrieren. Dabei handelt es sich um je ein Beispiel aus Großbritannien, ein Beispiel aus Malaysia sowie ein Beispiel aus Deutschland.

In Großbritannien gilt seit 1973 eine allgemeine Helmpflicht für Motorradfahrer. Ausgenommen hiervon ist allerdings die religiöse Minderheit der Sikhs. Ihnen wird in der 1976 verabschiedeten sogenannten Motor-Cycle Crashhelmets (Religious Exemption) Bill (vgl. House of Lords 1976) gestattet, ohne Helm Motorrad zu fahren. In der Debatte, die dieser Ausnahmeregelung vorausging, führten ihre Befürworter zwei Hauptargumente an. Erstens würde die Helmpflicht die Angehörigen der Sikh-Religion zwingen, entweder auf die Nutzung von Motorrädern oder auf das Tragen des traditionellen Turbans (Dastar) und damit auf einen integralen Bestandteil ihres religiösen Glaubens zu verzichten. Dies sei in einer liberalen Gesellschaft eine unzumutbare Benachteiligung. Das zweite, vermutlich entscheidende Argument lautete, dass die Sikhs in den britischen Streitkräften im 2. Weltkrieg wertvolle Dienste geleistet hätten. Da die britische Gesellschaft nichts einzuwenden hatte, als Sikhs mit einem Turban statt einem Stahlhelm an militärischen Schlachten teilnahmen, so müsste sie ihnen nun auch gestatten, mit einem Turban Motorrad zu fahren, was ja wesentlich weniger riskant sei. Gegner des Gesetzes wie Lord Monson argumentierten jedoch, dass zwischen einem religiösen Brauch (custom) und einer religiösen Pflicht (obligation) unterschieden werden müsse, und das Tragen des Turbans sei möglicherweise lediglich ein nicht verbindlicher Brauch. Einen solchen zur Begründung eines Sonderrechts heranzuziehen, würde möglicherweise zu Forderungen nach weiteren Sonderrechten führen:

Granting exemption in respect of what I hold to be a religious custom rather than a religious obligation could lead to demands for exemptions on the grounds of religious 
obligations of a less innocuous nature. I am thinking of the possible demand for the right to carry the $\operatorname{kirpan}^{54}[\ldots]$. (House of Lords 1976: \$1164)

Das zweite Gegenargument lautete, dass die an sich zu begrüßende Liberalisierung einer Vorschrift zu Unzufriedenheit unter allen anderen Motorradfahrern und möglicherweise sogar zu Spannungen zwischen Bevölkerungsgruppen führen könnte:

[...] I believe it is incumbent upon me to scrutinise legislation of this kind carefully to see that the rest of us are not inadvertently put at a disadvantage by what may superficially appear to be innocuous and, indeed, welcome legislation in so far as it is of liberalising nature. [...] I wonder whether it might not cause resentment among the majority of motor-cyclists, who are not Sikhs, and perhaps thereby contribute to a worsening of community relations, which I am sure noble Lords would agree would be highly undesirable. (ebd.)

Trotz dieser Einwände wurde das Gesetz verabschiedet und trat im November 1976 in Kraft. Was manche als glorreiche Stunde liberaler Gesetzgebung sahen (in den Worten des Abgeordneten Sidney Bidwell „The Turban Victory“), sahen andere als Aufgabe des Prinzips der Gleichheit vor dem Gesetz und damit als Ungerechtigkeit. Wie stark diese Ungerechtigkeit von manchen empfunden wurde, zeigt der Fall des britischen Mathematiklehrers und Weltkriegsveteranen Fred Hill. Von Beginn an ein Gegner der Helmpflicht, weigerte er sich seit dem Inkrafttreten der Ausnahmeregelung für Sikhs 1976 bis zu seinem Tod 1984 beharrlich, auf dem Motorrad einen Helm zu tragen. Sämtliche deswegen verhängten Bußgeldbescheide ignorierte er, wofür im Laufe der Jahre insgesamt 31 Gefängnisstrafen gegen ihn verhängt wurden (vgl. Hardy 2013).

Das Beispiel mag noch vergleichsweise harmlos erscheinen, handelt es sich bei Motorradfahrern doch um erwachsene Menschen, die durch ihre Weigerung, einen Helm zu tragen, niemanden außer sich selbst in Gefahr bringen. Von Vertretern eines radikalen Liberalismus wie dem Abgeordneten Enoch Powell wurde daher argumentiert, die Entscheidung über das Tragen eines Helms falle in den Bereich der persönlichen Risikoabwägung, jede gesetzliche Verpflichtung stelle daher ohnehin einen unangemessenen Übergriff dar.

Als zweites Beispiel für den Konflikt zwischen dem Prinzip der Gleichheit vor dem Gesetz und der Gewährung von Gruppenrechten möchte ich den Fall der Malaiin Lina Joy schildern. Malaysia versteht sich seit der Gründung des aktuellen Staates als multikulturell. Ethnisch setzt sich die Bevölkerung mehrheitlich

54 Krummdolch der Sikhs, der aus religiösen und zeremoniellen Gründen getragen wird. 
aus Malai_innen zusammen (sogenannte Bumiputera, $67 \%$ ). ${ }^{55}$ An zweiter Stelle folgen Chines_innen (24\%), an dritter Inder_innen (7\%) und an vierter Stelle ,Andere' (Others, $2 \%){ }^{56}$ Die Religionszugehörigkeiten verlaufen weitgehend entlang dieser ethnischen Grenzen. So bekennt sich die Mehrheit der Bumipute$r a$ zum Islam, während in den anderen Bevölkerungsgruppen andere Religionen dominieren (Buddhismus, Hinduismus, Christentum und Sikh-Religion).

In der Verfassung Malaysias ist die Zugehörigkeit zu einer Religion von der Zugehörigkeit zu einer ethnischen Gruppe entkoppelt. Allen Malai_innen wird in Art. 11, Abs. (1) ausdrücklich Religionsfreiheit garantiert: „Every person has the right to profess and practise his religion [...]" (Government of Malaysia 2009). Zwar wird das religiöse Bekenntnis in den Personalausweis eingetragen. Aus Art. 11 der Verfassung lässt sich jedoch das Recht ableiten, eine Glaubensgemeinschaft zu verlassen, einer anderen beizutreten (oder nicht) und dies auch entsprechend in den Ausweispapieren ändern zu lassen. Von genau diesem Recht wollte die Malaiin Lina Joy 1999 Gebrauch machen. Ihre Konversion vom Islam zum Christentum und auch ihre Namensänderung in Azlina Jailani verliefen unproblematisch. Als sie jedoch aus ihrem Ausweis den Eintrag über ihre frühere Religionszugehörigkeit entfernen lassen wollte, wurde ihr dieses Ansinnen von den zivilen Behörden verweigert, solange sie keine entsprechende Erlaubnis eines islamischen Gerichts vorlegen könne. Begründet wurde diese Entscheidung mit einem 1988 in Kraft getretenen Verfassungszusatz (Act A704), welcher den zivilen Gerichten verbietet, in Fällen zu entscheiden, für die Scharia-Gerichte (Syariah courts) zuständig sind: „The courts referred to in Clause (1) [the High Courts of Malaysia] shall have no jurisdiction in respect of any matter within the jurisdiction of the Syariah courts" (Government of Malaysia 2009: Art. 121, (1A)). Lina Joy alias Azlina Jailani weigerte sich jedoch, ein solches Gericht anzurufen, da sie deren Zuständigkeit in ihrem Fall - sie war ja bereits zum Christentum konvertiert - nicht anerkannte. Zudem ist Apostasie im islamischen Recht nicht vorgesehen. Es ergab sich also eine Art Pattsituation: Die zivilen Gerichte verwiesen die Klägerin an ein Religionsgericht. Sie bestand jedoch mit Verweis auf die malaiische Verfassung auf eine Entscheidung durch ein ziviles Gericht

55 Es ist zu betonen, dass der Begriff der,Ethnie ähnlich problematisch ist wie jener der ,Rasse. Da er jedoch in zahlreichen Staaten zur Kategorienbildung eingesetzt wird und damit Realitäten erzeugt, verwende ich ihn hier. Zu diesen Staaten zählen u.a. auch die USA, wo im Zensus ethnische Kategorien wie caucasian, african-american, asian-american und hispanic erhoben werden.

56 Stand: 2010. Die Ergebnisse des damals erhobenen Zensus sind auf der neuen Webseite des malaiischen Amtes für Statistik inzwischen nicht mehr abrufbar (Stand: Juni 2015). 
und bezweifelte zudem jede Zuständigkeit eines islamischen Gerichts für sie als bekennende Christin. Lina Joys Antrag wurde in allen Instanzen abgelehnt, bis schließlich der Oberste Gerichtshof Malaysias am 30. Mai 2007 alle vorherigen Urteile bestätigte und damit auch die Aufmerksamkeit der internationalen Presse auf sich zog. ${ }^{57}$

Artikel 121 der malaiischen Verfassung kann als Beispiel gelten, die von Kymlicka geforderten „self-government rights“ (Kymlicka 2007: 27f.) zu verwirklichen. Der Fall zeigt jedoch, wie das Sonderrecht einer Gruppe, das im geschilderten Fall darin besteht, ihren Mitgliedern den Austritt aus der Gruppe zu verweigern, das in der Verfassung garantierte Recht auf Religionsfreiheit aushöhlen und damit das Prinzip der Gleichheit vor dem Gesetz verletzen kann.

Etwas anders ist das dritte Problem gelagert, das 2012 über Monate hinweg in der deutschen Öffentlichkeit diskutiert wurde. Dabei ging es um die Frage, ob die Beschneidung von Jungen aus religiösen Gründen mit dem in Deutschland grundgesetzlich garantierten Recht auf körperliche Unversehrtheit vereinbar sei (vgl. Art. 2, Abs. 2 GG). Das Landgericht Köln hatte in einem Fall die im Islam und im Judentum gängige Praxis der Beschneidung als Körperverletzung gewertet und damit einen Präzedenzfall geschaffen, der eine seit Jahrzehnten geduldete religiös motivierte Tradition auf die politische Tagesordnung setzte (vgl. LG Köln, Urt. vom 07.05.2012 - 151 Ns 169/11). Das Urteil sorgte für teils heftige Kritik. Unter anderem wurden Parallelen zur Judenverfolgung im Nationalsozialismus gezogen. So kommentierte der Jurist, Schriftsteller und Journalist Maximilian Steinbeis (2012) in seinem Blog:

Wenn dieses Urteil richtig wäre, dann müssten ausgerechnet deutsche Staatsanwälte als einzige auf der ganzen Welt, wenn ich nicht irre - Juden verfolgen, weil sie tun, was Juden tun.

Angesichts der Brisanz des Themas beschäftigte sich der Deutsche Ethikrat mit den Konflikt zwischen Art. 2, Abs. 2 und Art. 4, Abs. 1 und 2 GG (Religionsfreiheit). Seine noch im Herbst des selben Jahres ausgesprochene Empfehlung lautete, für Beschneidungen folgende Mindeststandards zu etablieren:

1. umfassende Aufklärung und Einwilligung der Sorgeberechtigten 2. qualifizierte Schmerzbehandlung 3. fachgerechte Durchführung des Eingriffs sowie 4. Anerkennung eines entwicklungsabhängigen Vetorechts des betroffenen Jungen. (Deutscher Ethikrat 2012)

57 Vgl. Perlez 2006; Kauffmann 2007. Amnesty International erwähnt im Länderkurzbericht 8/2008 diesen und andere Fälle von Konflikten zwischen staatlicher und religiöser Gerichtsbarkeit in Malaysia (vgl. Amnesty International 2008). 
Am 12.12.2012 verabschiedete der Deutsche Bundestag ein Gesetz, das als $₫$ 1631d ins Bürgerliche Gesetzbuch aufgenommen wurde:

Beschneidung des männlichen Kindes:

(1) Die Personensorge umfasst auch das Recht, in eine medizinisch nicht erforderliche Beschneidung des nicht einsichts- und urteilsfähigen männlichen Kindes einzuwilligen, wenn diese nach den Regeln der ärztlichen Kunst durchgeführt werden soll. Dies gilt nicht, wenn durch die Beschneidung auch unter Berücksichtigung ihres Zwecks das Kindeswohl gefährdet wird.

(2) In den ersten sechs Monaten nach der Geburt des Kindes dürfen auch von einer Religionsgesellschaft dazu vorgesehene Personen Beschneidungen gemäß Absatz 1 durchführen, wenn sie dafür besonders ausgebildet und, ohne Arzt zu sein, für die Durchführung der Beschneidung vergleichbar befähigt sind.

Die Neuregelung wurde von vielen Kommentatoren als kluger Kompromiss eingeschätzt. In der Tat ist zu betonen, dass durch die gesetzlich vorgeschriebene Beachtung der „Regeln der ärztlichen Kunst“ (ebd.) in Zukunft bei Beschneidungen seltener medizinische Komplikationen auftreten dürften. Meiner Einschätzung nach wurde der grundlegende Konflikt zwischen einer religiösen Praxis und dem grundgesetzlich verbrieften Recht auf körperliche Unversehrtheit durch die neue gesetzliche Regelung jedoch nicht auf zufriedenstellende Weise gelöst. Erstens ist die Empfehlung des Ethikrates, dem betroffenen Jungen ausdrücklich ein Vetorecht einzuräumen, nicht aufgegriffen worden. Der Gesetzgeber begründet diese Entscheidung im Kommentar zum Gesetz mit der Argumentation, dass das Gesetz ja gerade die Beschneidung für Jungen regle, die von diesem Vetorecht noch keinen Gebrauch machen können, da sie „[...] noch nicht in der Lage sind, Wesen, Bedeutung und Tragweite des [...] Eingriffs in ihre körperliche Unversehrtheit zu erfassen“ (vgl. Deutscher Bundestag 2012: 18). Zweitens wird Art. 4 GG von Verfassungsrechtlern meist als „im höchsten Maße auf das Individuum bezogene Recht" (Krüper 2012: 549, Hervorhebung im Original) interpretiert. Im vorliegenden Fall wird jedoch eben dieses individuelle Recht im Sinne einer durch die Eltern vertretenen Gruppe ausgelegt, so dass ein anderes individuelles Recht straffrei gebrochen werden kann: das des Individuums auf körperliche Unversehrtheit. Neben dieser Umdeutung des individuellen Rechtes der Religionsfreiheit in ein Gruppenrecht wird, drittens, möglicherweise ein weiteres Verfassungsprinzip verletzt, das Diskriminierungsverbot. Es lautet:

(1) Alle Menschen sind vor dem Gesetz gleich. [...] (3) Niemand darf wegen seines Geschlechtes, seiner Abstammung, seiner Rasse, seiner Sprache, seiner Heimat und Herkunft, seines Glaubens, seiner religiösen oder politischen Anschauungen benachteiligt oder bevorzugt werden. Niemand darf wegen seiner Behinderung benachteiligt werden. (Art. 3, Abs. 1,3 GG) 
Die Beschneidung von Mädchen verursacht bekanntermaßen wesentlich gravierendere medizinische Folgen als die von Jungen, ein Umstand, der auch im Kommentar zu $\$ 1631 d$ BGB hervorgehoben wird (vgl. Deutscher Bundestag 2012: 13f.). Die Beschneidung von Mädchen wird dort daher richtigerweise als „Ausdruck tief verwurzelter Ungleichheit der Geschlechter und eine extreme Form der Diskriminierung von Frauen" (ebd.) gewertet. Inwiefern die Beschneidung von Jungen jedoch keinen solchen „Ausdruck von tief verwurzelter Ungleichheit der Geschlechter" darstellt, wird weder im Gesetzestext noch im begleitend veröffentlichten Kommentar deutlich. Sowohl bei der Beschneidung von Mädchen als auch bei der Beschneidung von Jungen handelt es sich um religiös motivierte, medizinisch jedoch nicht indizierte Eingriffe. Die Vereinbarkeit von $\$ 1631$ d BGB, welche die Beschneidung von Jungen gestattet, mit dem in Art. 3, Abs. 3 des Grundgesetzes in klaren Worten formulierten Diskriminierungsverbot bleibt daher eine offene Frage.

Die hier diskutierten Defizite von Kymlickas Multikulturalismustheorie sowie die vorgestellten Beispiele zeigen, dass die Übernahme kulturrelativistischer Positionen allen guten Absichten zum Trotz zu erheblichen Konflikten mit auf liberalen Staats- und Gesellschaftstheorien basierenden Verfassungsprinzipien führen können. Im nächsten Kapitel möchte ich herausarbeiten, aus welchen Gründen der Kulturrelativismus nicht nur aus solchen rechtlich-politischen, sondern auch aus bildungs- und demokratietheoretische Erwägungen bedenklich sein könnte.

\subsubsection{Bildungs- und demokratietheoretische Einwände gegen den Kulturrelativismus}

Ich den letzten beiden Kapiteln habe ich versucht, die Problematik einer kulturrelativistischen Standpunktes aus zwei Perspektiven herauszuarbeiten. Hierfür habe ich zunächst historisch-philosophische Einwände gegen den Kulturrelativismus entfaltet. In einem zweiten Schritt habe ich eine Parallele zwischen Kulturrelativismus und Multikulturalismus gezogen und beispielhaft an den Vorschlägen Will Kymlickas die Widersprüche zwischen einer Multikulturalismustheorie und dem liberalen Rechtsstaatsprinzip der Gleichheit vor dem Gesetz herausgearbeitet. Ich möchte nun eine dritte Perspektive öffnen und am Beispiel Deutschlands der Frage nachgehen, inwiefern eine konsequente Anwendung kulturrelativistischer Prinzipien auf das öffentliche Schulwesen demokratischer Staaten problematisch sein kann. ${ }^{58}$

58 Ich stütze diese Überlegungen vorwiegend auf einen Beitrag, den Axel Honneth, Direktor des Frankfurter Instituts für Sozialforschung, auf dem 23. Kongress der Deutschen Gesellschaft für Erziehungswissenschaft gehalten hat (vgl. Honneth 2013). 
Grundsätzlich gilt für den deutschen Staat und damit auch für staatliche Schulen das Prinzip der religiös-weltanschaulichen Neutralität (vgl. Schlaich 1972; Huster/Brugger 1997). Aus dieser Neutralität ergibt sich ein Verbot jeglicher Missionierung der Lernenden für einen bestimmten religiösen Glauben. Auch einseitige politische Einflussnahme ist nicht gestattet. Hierfür wurde 1976 im sogenannten ,Beutelsbacher Konsens' (vgl. Bundeszentrale für politische Bildung 2011) der Begriff des, Überwältigungsverbotes' geprägt, der nicht nur für die Fächer der politischen Bildung, sondern für alle Schulfächer relevant ist. Lehrkräfte sind ausdrücklich angehalten, einseitige Beeinflussungen zu vermeiden und für das Ziel einer mündigen Urteilsbildung eine Vielfalt an religiösen bzw. weltanschaulichen sowie politischen Überzeugungen zu Wort kommen zu lassen.

Einem Fremdsprachenunterricht, der das Prinzip der Interkulturalität ins Zentrum seiner Bemühungen stellt, kommt hierbei eine wichtige Rolle zu. Es wird empfohlen, Lernenden die sogenannten Zielsprachenländer in ihrer kulturellen Vielfalt zugänglich zu machen, etwa indem verschiedene weltliche und religiöse Bräuche und Feste, kulinarische Vorlieben, musikalische Traditionen etc. thematisiert werden (vgl. Senatsverwaltung für Bildung, Jugend und Sport Berlin 2006: 30). In einem kulturwissenschaftlich geprägten Verständnis umfasst ,Kultur' jedoch wesentlich mehr als diese Bereiche. Vielmehr wird Kultur als "Totalperspektive“ (Reckwitz 2004: 1) gefordert:

[Unter Kultur sind] die impliziten, in der Regel nicht bewussten symbolischen Ordnungen, kulturellen Codes und Sinnhorizonte [zu verstehen] [...], die in unterschiedlichsten menschlichen Praktiken - verschiedener Zeiten und Räume - zum Ausdruck kommen und diese ermöglichen. (ebd.: 2)

$\mathrm{Zu}$ diesen symbolischen Ordnungen wären selbstverständlich auch die Bereiche Politik und Religion mit ihren Konsequenzen für ethische Fragestellungen zu zählen. Diese Aspekte dürften keineswegs nur marginale Bedeutung haben. So unterstreicht etwa Michael Byram (2009: 219), dass interkulturelle Kompetenz immer auch in Bezug auf die zugrunde liegenden Wertvorstellungen modelliert werden müsse, insbesondere dann, wenn diese Kompetenz auch in die Leistungsbewertung einfließen soll:

If someone were to be assessed as being, non-judgmental' or accepting ,a non-universality of cultural values', this is a values position itself. Someone who believes that there are universal values would be deemed to fail on this relativist criterion.

Somit stellt sich die Frage, inwieweit der staatlich organisierte interkulturelle Fremdsprachenunterricht das Recht und die Aufgabe hat, ,kulturelle‘ Prinzipien 
wie Demokratie, Einhaltung der Menschenrechte und Rechtsstaatlichkeit zu vermitteln, wenn damit potentiell die Vielfalt der im Klassenzimmer akzeptierten Lebensweisen und Weltanschauungen (,Kulturen') eingeschränkt wird. Ich entwickle in den folgenden Abschnitten zwei Argumente, die dafür sprechen, die Prinzipien des demokratischen Rechtsstaates trotz möglicher kulturrelativistisch begründeter Kritik durchzusetzen und sie explizit als Auftrag des staatlichen Bildungswesens zu belassen und zu stärken. Es handelt sich um ein bildungstheoretisches und ein demokratietheoretisches Argument.

Das bildungstheoretische Argument lässt sich ausgehend von den aktuellen Tendenzen entwickeln, die darauf hindeuten, dass die Inhalte schulischen Lernens in zunehmendem Maße auf eine spätere wirtschaftliche Verwertbarkeit befragt und entsprechend umgestaltet werden sollen. Diese Tendenzen lassen sich etwa daran festmachen, dass in Analogie zu Leistungsindizes von Unternehmen verstärkt auch in Schulen und Universitäten die Frage nach dem Output gestellt wird. Zur Ermittlung dieses Outputs gewinnen Testverfahren an Bedeutung, die Vergleiche auf der Grundlage quantitativer Daten ermöglichen. ${ }^{59}$ Diese Daten dienen als Grundlage für unterschiedlichste Zwecke, unter anderem dafür, Ranglisten für Schulen und Universitäten zu erstellen. Sie liefern betriebswirtschaftlich handhabbare Kriterien, anhand derer etwa über die Zuweisung (oder Kürzung) von Mitteln an Institutionen entschieden werden kann. Aber auch auf der Ebene der Evaluation von Mitarbeiter_innen kommen verstärkt quantitative Verfahren zum Einsatz, etwa dann, wenn Professor_innen in Abhängigkeit von der Zahl ihrer Publikationen oder der Höhe der von ihnen eingeworbenen Drittmittel beurteilt werden. ${ }^{60}$

Kritiker sehen diese Entwicklung jedoch als äußerst problematisch. Sie befürchten, dass durch die Übertragung betriebswirtschaftlicher Prinzipien auf Bildungseinrichtungen eine Vielzahl an negativen Auswirkungen eintreten könnte. Zu diesen zählen u.a. die Förderung von Konkurrenz statt Kooperation sowie die Verdrängung von Wissen, das sich nicht quantifizieren lässt (vgl.

59 Der Philosoph Konrad Paul Liessmann hat mit seiner Theorie der Unbildung 2006 einen Essay vorgelegt, der sich kritisch mit den negativen Auswirkungen dieses Trends auf die Bildungslandschaft auseinandersetzt.

60 In deutschen Hochschulen wurde dieses Prinzip als sogenannte, Leistungsorientierte Mittelvergabe، (LOM) eingeführt. Dazu kritisch Münch (2009: 113ff.). Auch Liessmann (2006: 84) warnt eindringlich vor dem Trend zur vollständigen quantitativen Erfassung von Bildungseinrichtungen: „Je mehr an einer Universität oder Schule von Qualitätssicherung die Rede ist, desto weniger geht es um Qualitäten, sondern einzig darum, Qualitäten in Quantitäten aufzulösen.“ 
Münch 2009: 93ff.). Dies könnte eine grundlegende Umgestaltung der Bildungslandschaft nach sich ziehen:

Das heißt, dass Wissen dominant als eine ökonomische Ressource verstanden wird. [...] Die konsequente Umsetzung dieser Perspektive bedeutet, dass der Staat seine Aufgabe weniger in der öffentlich-rechtlichen Organisation und Kontrolle von Bildung und Forschung hat und mehr in der Einrichtung und Regulierung von Märkten für Bildung und Forschung [...]. (ebd.: 23)

Diese Ökonomisierung von Bildung widerspricht allerdings dem neuhumanistischen Bildungsverständnis in der Tradition Kants und Humboldts, in dem sich auch der Fremdsprachenunterricht lange sah. Nach diesem Verständnis sollte über Bildungsprozesse gerade nicht im Licht ihrer wirtschaftlichen Verwertbarkeit entschieden werden, und entsprechend sollten sie nicht nach rein ökonomischen Gesichtspunkten organisiert werden. Für sprachliche Bildung, die eine tragende Säule der Humboldt'schen Bildungstheorie darstellt, galt dies in besonderem Maße (vgl. Küster 2003b: 136). Vielmehr sind in diesem Verständnis von Bildung zwei andere Anliegen zu betonen.

Das eine Anliegen ist ein (neu-)humanistisches. Es steht dafür, den Blick weniger auf den quantifizierbaren und ökonomisch verwertbaren Output als auf das Individuum zu richten. Bildungsprozesse zu fördern bedeutet in diesem Sinne in erster Linie, Menschen, v.a. jungen Menschen zu ermöglichen, ihre individuellen Anlagen in möglichst hohem Maße zu entfalten. ${ }^{61}$

Das zweite Argument, welches Kritiker der Ökonomisierung von Bildungsprozessen anführen, ist ein republikanisches. Aus dieser Perspektive wird die Einschätzung betont, dass die Entfaltung des Individuums nicht nur in der Tradition des Humanismus geboten sei, sondern auch eine wichtige politische Dimension habe. Bildung solle es allen Mitgliedern einer Gesellschaft ermöglichen, ihre staatsbürgerlichen Rechte in möglichst hohem Maße wahrzunehmen und sich als "Gleiche unter Gleichen an der republikanischen Gesetzgebung" (Honneth 2013: 49) zu beteiligen (vgl. Hentig 2004: 75; Rawls 1993: 199f.; Küster 2003b: 142).

Es ist nun zu befürchten, dass mit der Ökonomisierung von Bildungsprozessen auch ihre Ent-Politisierung einhergeht, denn politische und ethisch-moralische Fragestellungen sind nicht quantifizierbar und zudem für eine wirtschaftliche Verwertung irrelevant, ja stehen ihr potentiell im Weg. Bildungseinrichtungen, die einer ökonomischen Logik unterworfen werden, hätten nicht mehr das Ziel, Bürger zu erziehen, die ihre Möglichkeiten möglichst breit entfalten können und

61 Zum Bildungsbegriff vgl. Kapitel 4.4.2. 
die dadurch in hohem Maße in der Lage wären, sich als soziale Wesen zu begreifen, gesellschaftliche Entscheidungsprozesse zu reflektieren und sich an ihnen zu beteiligen. Vielmehr hätte eine ökonomisierte Bildung nur noch die Aufgabe der „,...] Produktion und Reproduktion von Humankapital, das Rendite erwirtschaften soll“ (Münch 2009: 30).

Die Tendenz zur Aufweichung des humanistischen und republikanischen Auftrags von Bildungseinrichtungen könnte jedoch neben dem Bestreben, sie ökonomischen Diskursen zu unterwerfen, noch einen weiteren Grund haben. $\mathrm{Zu}$ Recht wird ja gefordert, auch in Form von verbindlichen schulrechtlichen und curricularen Vorgaben, kulturelle Vielfalt im Klassenzimmer nicht nur zu dulden, sondern ausdrücklich als Bereicherung wahrzunehmen und zu fördern. Dabei stellt sich jedoch die Frage, inwiefern dies auch für Haltungen und Weltansichten gilt, die im Gegensatz zu den Prinzipien eines liberalen Bildungswesens - im Kern Menschenrechte, Demokratie und Rechtsstaatlichkeit - stehen. Axel Honneth (2013: 47) erinnert in diesem Zusammenhang an das Kant'sche Modell einer republikanischen Schule und schreibt:

Das Recht der Eltern, ihren Kindern die je eigenen, partikularen Wertüberzeugungen zu vermitteln, musste an der Pforte der Schule gebrochen werden, damit den Zöglingen durch die Einübung von reflexiven Verhaltensweisen der Weg zur Teilnahme an der öffentlichen Willensbildung geebnet werden konnte.

Aus kulturrelativistischer Sicht wäre dieser Standpunkt jedoch selbst als kulturgebunden zu kritisieren. Wenn keine Kultur und damit auch nicht die, westliche bzw. ,europäische ${ }^{62}$ mit ihrer Orientierung an Menschenrechten, Demokratie und Rechtsstaatlichkeit einen Geltungsanspruch erheben kann, dann scheint es angemessen, diese Prinzipien jederzeit zur Disposition zu stellen:

[...] ja es kann sogar sein, dass es sich bei dieser zweiten theoretischen Verschiebung um die unbeabsichtigte Konsequenz der insgesamt gutgemeinten Absicht handelt, den in unseren Gesellschaften wachsenden Pluralismus der ethnischen und religiösen Kulturen durch eine Unterstreichung der strikten Unparteilichkeit des staatlich organisierten Unterrichts Rechnung zu tragen. (ebd.: 46)

Ein dem Bildungsgedanken mit seiner Betonung der humanistischen und republikanischen Anliegen von Schule verpflichteter Unterricht kann daher nicht umhin, der - ich betone es einmal mehr: prinzipiell äußerst wünschenswerten Toleranz und Förderung kultureller Vielfalt Grenzen zu setzen. Diese liegen dort,

62 Zur Kritik an der Vereinnahmung universalistischer Prinzipien als „westlich“ bzw. „europäisch“vgl. Kap. 2.2.3. sowie Bielefeldt 1997: 259-261. 
wo seine eigenen Voraussetzungen, nämlich Menschenrechte, Demokratie und Rechtsstaatlichkeit, in Frage gestellt werden.

Eng verwoben mit diesen Grenzen eines kulturrelativistischen Standpunktes aus bildungstheoretischen Überlegungen heraus ist, zweitens, eine demokratietheoretische Argumentationslinie. Die Frage lautet hier, inwieweit demokratische Gesellschaften das Recht haben, für ,ihre eigenen kulturellen und moralischen Bestandsvoraussetzungen" (Honneth 2013: 43) zu sorgen, oder inwieweit sie sich in Bezug auf unterschiedliche kulturelle Normvorstellungen vielmehr auf eine strikte Neutralität zurückziehen müssen. Letzteres legt wiederum eine konsequente Anwendung der kulturrelativistischen Prinzipien auf den Kontext der Schule nahe.

[...] so entsteht unmerklich jene diffuse Gemengelage von Falschem und Richtigem, aus der heraus plötzlich jede Art von Parteilichkeit des schulischen Unterrichts als gleichermaßen problematisch oder verwerflich gelten muss; das Gebot staatlicher Neutralität wird folgerichtig nun bis zu dem Punkt ausgedehnt, an dem selbst die Idee der demokratischen Erziehung ihre normative Selbstverständlichkeit verliert. (ebd.: 47)

Diese Auslegung der weltanschaulichen Neutralität von Schule wäre in letzter Konsequenz nur um den Preis zu haben, dass auch solchen Lernenden argumentativ wenig entgegenzusetzen wäre, die mit Verweis auf einen jeweils differenten kulturellen Hintergrund rassistische, sexistische oder religiös-fundamentalistische Positionen vertreten. Lehrkräfte dürften sich konsequenterweise nicht mehr als Vertreter des demokratischen Rechtsstaats sehen, sondern hätten den Auftrag, in der Schule die jeweiligen kulturell geprägten Ansichten der Eltern weiterzugeben oder zumindest bei deren Entfaltung nicht im Wege zu stehen (vgl. ebd.: 48). Honneth hält diese Tendenz für problematisch, da eine demokratischen Prinzipien verpflichtete staatliche Bildung geradezu das einzige Instrument darstelle, um die Existenzbedingungen demokratischer Gesellschaften immer wieder neu hervorzubringen. Mit der Verpflichtung zu strikter, kultureller' Neutralität entfalle daher auch das Recht des Staates, eine allgemeine Schulpflicht einzufordern und durchzusetzen. Schulen verlören ihre legitimatorische Grundlage, wenn man ihnen den demokratischen Auftrag entziehe: „[...] insofern ist der Konflikt um das staatliche Schulsystem [...] immer auch ein Kampf um die Zukunftsfähigkeit von Demokratien“ (ebd. 2013: 48).

Honneths Überlegungen machen deutlich, dass die Frage der kulturellen das heißt auch: weltanschaulichen - Voraussetzungen schulischer Bildung nicht mit einem unreflektierten Verweis auf, Neutralität ' gelöst werden kann. Es ergibt sich vielmehr das Dilemma, dass Schulen entweder liberale Werte vertreten und gegebenenfalls auch durchsetzen müssen, womit sie sich aus der Perspektive 
des Kulturrelativismus dem Vorwurf aussetzen würden, keine wahre kulturelle Pluralität zu dulden; oder sie müssen eben diese Werte aufgeben und damit die Legitimationsgrundlage ihrer eigenen Existenz zu Disposition stellen. In strikt kulturrelativistischer Perspektive könnte keines der beiden Modelle zur Legitimation einer allgemeinen Schulpflicht Geltungsanspruch erheben, auch nicht, wie Honneth schreibt, das den demokratischen Prinzipien verpflichtete. ${ }^{63}$

Das Problem führt zurück zum hier diskutierten Ausgangsdilemma zwischen Universalismus und Kulturrelativismus. Der Mangel an einer Normativität, die einen Anspruch auf kulturelle Neutralität bzw. universelle Gültigkeit erheben und sich somit gegen Kritik - auch: kulturrelativistisch inspirierte Kritik - schützen könnte, bleibt bestehen.

\subsection{6 ,Aufgeklärter Eurozentrismus` als Versuch der Versöhnung von Universalismus und Kulturrelativismus}

Die bislang vermutlich gründlichste Aufarbeitung des Dilemmas, welches der Konflikt zwischen Kulturrelativismus und Universalismus für Bildungkontexte darstellt, hat 2000 der Erziehungswissenschaftler Wolfgang Nieke vorgelegt. ${ }^{64}$ Ich möchte Niekes Vorschlag zur Lösung des Konfliktes zunächst darstellen und in einem zweiten Schritt diskutieren, inwiefern er tragfähig und somit auch für eine interkulturell ausgerichtete Fremdsprachendidaktik von Interesse ist.

Nieke bezieht sich im Gegensatz zu den oben entwickelten Überlegungen nicht auf einen normativen Kulturrelativismus, sondern auf eine Ausprägung, bei der die normativen Annahmen der anthropologischen Wissenschaftstradition relativiert werden. Der Hauptunterschied zwischen diesen beiden Ausprägungen des Kulturrelativismus lässt sich wie folgt formulieren: Im ersten Fall wird davon ausgegangen, dass es keine universell gültige Norm geben kann. Im zweiten Fall wird angenommen, dass eine universell gültige Norm zwar prinzipiell möglich ist, dass diese aber bisher nicht gefunden wurde. Nieke (2008: 146) nennt diese Position daher ,agnostizistischen' Kulturrelativismus. ${ }^{65}$ Das Grundproblem in Bezug auf Konflikte, die sich aus unterschiedlichen kulturellen Standpunkten

63 In Deutschland ist die Frage, ob die allgemeine Schulpflicht den religiösen Überzeugungen von Eltern ggf. nachzuordnen ist, mit dem Beschluss 1 BvR 436/03 des Bundesverfassungsgerichts vom 29.4.2003 erneut verneint worden.

64 Ich beziehe mich hier auf die überarbeitete 3. Auflage von 2008.

65 Der Begriff ist an die philosophische Tradition des Agnostizismus angelehnt, in der die Frage nach der Existenz Gottes für nicht beantwortbar bzw. nicht erkennbar (grch. a-gnoein: nicht wissen) gehalten wird. 
ergeben, ist jedoch das gleiche. Nieke (ebd.: 206) formuliert es mit folgenden Worten:

Es sollte deutlich geworden sein, dass eine Position des agnostizistischen Kulturrelativismus, wie sie in der Diskussion über die politische Zielsetzung einer multikulturellen Gesellschaft und einer darauf bezogenen Interkulturellen Erziehung und Bildung oft vertreten wird, im praktischen Umgang der Menschen miteinander auf Dauer nicht haltbar, nicht lebbar und praktizierbar ist.

Wenn aber Kulturrelativismus in der Interkulturellen Erziehung und Bildung, das heißt auch in einer auf deren Prinzipien basierenden Fremdsprachendidaktik, nicht vertretbar ist, ergibt sich die Frage, wie der für das Zusammenleben offensichtliche Bedarf an politischen und ethischen Normen gedeckt werden kann, ohne dass man die sogenannten europäischen oder westlichen Werte als universell annehmen und sich somit dem Vorwurf des Eurozentrismus aussetzen muss. ${ }^{66}$ Nach Nieke ist eine solche eurozentrische Haltung vor allem dann problematisch, wenn „explizit oder implizit von der Selbstverständlichkeit und Plausibilität inhaltlicher Setzungen“" (ebd.: 237) ausgegangen werde. Umgekehrt sei bereits die Einsicht, dass jeder universalistische Ausweg aus dem Kulturrelativismus eurozentrisch sei, eine "qualitative Veränderung“ (ebd.) zum Positiven. Für diese „Einsicht in die Unvermeidlichkeit der Eingebundenheit in die eigenen kulturellen Hintergründe und Untergründe“ (ebd.) prägt Nieke den Begriff des „aufgeklärten Eurozentrismus“ (ebd.). Als erster Bestandteil dieses Konzeptes lässt sich die Bewusstheit der eigenen kulturell geprägten Perspektive festhalten.

Aus dieser Bewusstheit ergebe sich, zweitens, die Fähigkeit, „[...] den anderen ein größeres Recht auf ihren Weg, die Welt zu sehen und zu bewerten [...] “ (ebd.: 238) einzuräumen, mit anderen Worten, mehr Toleranz zu zeigen. Eine solche ihrer eigenen kulturellen Prägung bewusste und daher tolerante Haltung könne im Konfliktfall, drittens, „auf die klärende Kraft vernünftiger Verständigung hoffen“ (ebd.), ein Vorgehen, das "selbstverständlich wiederum eurozentrisch“ (ebd.) sei.

Die wichtigsten Elemente des aufgeklärten Eurozentrismus stellen somit Bewusstheit, Toleranz und Vernunft dar. Was aber bedeutet, Vernunft' in diesem Zusammenhang, ein Begriff, der historisch eng mit der Aufklärung verknüpft ist? Nieke thematisiert das Problem, dass der Vernunftbegriff, dem selbst das

66 Dies setzt voraus, dass man die zur Debatte stehenden Werte wie Menschenrechte und Demokratie als „aus der Denktradition der nordwesteuropäischen Kulturen“ (Nieke 2008: 237) stammend annimmt, eine Haltung, deren Problematik in Kapitel 2.2.3. erörtert wurde. 
europäische Erbe anhaftet, nicht ohne weiteres als Ausweg aus dem Eurozentrismus herangezogen werden kann. Als mögliche Lösung schlägt er die „situative Begrenzung von Geltungen" (ebd.: 238, Hervorhebung im Original) vor, die auch für den Vernunftbegriff gelten müsste. Hierdurch sei zu erzielen, dass bestimmte „Weltdeutungen und Normgeltungen [...] nicht mit dem Anspruch auf Universalität“ (ebd.) aufträten, sondern „nur für die Lebenswelt, zu der sie gehören“ (ebd.: 240) Gültigkeit reklamieren könnten. Damit ist in erster Linie eine Trennung von privaten und öffentlichen Lebenswelten gemeint:

Es müsste dann zum vernünftigen Umgang mit den Konflikten gehören, dass die dadurch entstehende Befremdung, dass in anderen Privatwelten andere Deutungsmuster und Normen in Geltung sind als in meiner eigenen, ertragen werden muss. (ebd.)

Nieke räumt allerdings ein, dass diese Haltung für die „öffentlichen Anteile von Lebenswelt" (ebd.) schwierig umzusetzen sei. Er schlägt daher vor, Konflikte, die kulturbedingt sind und den öffentlichen Bereich betreffen, durch sogenannte ,Diskurse‘ bzw. ,virtuelle Diskurse‘ zu lösen. Den Diskursbegriff stützt Nieke auf die Überlegungen Karl-Otto Apels, die auch Habermas’ Diskursverständnis beeinflusst haben. Unter,Diskurs' ist in diesem Sinne ein Gespräch zu verstehen, in dem die Gesprächspartner die Ebene der Kommunikation verlassen, um die Grundlagen dieser Kommunikation zu klären. ${ }^{67}$ Idealerweise sind alle Machtstrukturen zwischen den an einem solchen Gespräch beteiligten Personen aufgehoben, und es herrscht lediglich der "Zwanglose Zwang des besseren Arguments“ (Habermas 1971: 137).

Entscheidend ist für Nieke in einem solchen Diskurs zur Klärung interkultureller Konflikte nun, dass alle Positionen gleichermaßen Ausdruck finden: "In Diskursen ist sicherzustellen, dass alle Beteiligten gleichberechtigt zu Wort kommen und ihre Argumente ernstgenommen werden“" (Nieke 2008: 244). Um die Benachteiligung einzelner Positionen zu verhindern, weil sein Vertreter bzw. seine Vertreterin abwesend ist oder seine bzw. ihre Sprachkenntnisse nicht ausreichen, können diese auch durch einen Stellvertreter bzw. eine Stellvertreterin zu Wort kommen. In diesem Fall spricht Nieke von einem „virtuellen Diskurs“ (vgl. ebd.: 240ff.).

Am Beispiel eines Konfliktes aus dem schulischen Kontext spielt Nieke nun durch $^{68}$, wie ein interkultureller Konflikt mit Hilfe eines Diskurses beigelegt

67 Zum Habermas'schen Diskursverständnis vgl. Kap. 4.2.2.

68 Das Beispiel ist kein empirisch dokumentierter Einzelfall, sondern ein frei nacherzählter, in Lehrerfortbildungen in Nordrhein-Westfalen anscheinend „oft berichteter Konflikt“" (Nieke 2008: 245. Vgl. ebd.: 91, 241, 245f.). 
werden könne. Dabei geht es um ein türkischstämmiges Mädchen, dessen Lehrerinnen es wegen guter schulischer Leistungen auf eine weiterführende Schule schicken möchten. Der Vater widersetzt sich diesem Vorhaben mit dem Argument, dass eine baldige Rückkehr in die Türkei und eine Verheiratung des Mädchens geplant sei. Durch einen Diskurs, wie ihn Nieke vorschlägt, wären nun beide Parteien angehalten, ihre Argumentationsgrundlagen offenzulegen, im geschilderten Fall die Lehrerinnen und der Vater.

Nieke entfaltet anschließend, in welcher Weise sich der Diskurs entwickeln könnte. Besonders interessant sind hierbei die Letztbegründungen der beteiligten Konfliktparteien. Die Lehrerinnen würden, so Niekes Vermutung, ihr Eintreten für die Gleichberechtigung des Mädchens vermutlich mit einem Verweis auf die Menschenrechte begründen: „[...] sie zogen ${ }^{69}$ dann aber die Menschenrechte heran und hier das Recht auf Gleichheit aller Individuen“" (ebd.: 246). Der Vater hingegen würde religiöse Überzeugungen anführen:

Der Vater entgegnete: Wie willst du mir etwas über meine Religion sagen können, wo du doch gar nicht die Sprache gelernt hast, in der die heiligen Schriften geschrieben sind und allein verstanden werden können? Er kann nach seinem Verständnis seiner Religion nicht akzeptieren, dass eine Ungläubige etwas Richtiges über seine Religion sagen kann, was seiner eigenen Überzeugung zuwiderläuft. (ebd.: 247)

Der tieferen Ursachen des Konfliktes liegen also in dem von Nieke geschilderten Beispiel in normativen Setzungen, die nicht weiter begründet werden können. Welchen Ausweg aus diesem Konflikt schlägt Nieke nun im Rahmen des von ihm entwickelten Vorschlags eines ,aufgeklärten Eurozentrismus' vor? Erneut wird hier das Prinzip der oben bereits erwähnten „situativen Begrenzung von Geltung" angeführt. Während die situative Begrenzung zunächst zwischen öffentlich vs. privat vorgenommen wird, wird sie jetzt auf territorialer und verfassungsrechtlicher Grundlage präzisiert. Nieke räumt ein, dass diese Argumentation zunächst „nichts anderes als die Durchsetzung der nordwesteuropazentrischen Vorstellung von Individualität und Gleichheit“ (ebd.: 249) sei. Sie sei aber gegen den „Vorwurf des Eurozentrismus“ (ebd.) zu schützen, da es sich um die für alle gültige verfassungsmäßige Grundlage des Zusammenlebens handle:

Moderne Staaten verdanken ihren Bestand und ihre Stabilität nach innen formalen, in Rechtsform gegossenen Regelungen des Zusammenlebens von Individuen, denen weitreichende inhaltliche Freiheiten zugestanden werden, deren Grenzen jeweils durch berechtigte Interessen anderer definiert sind. Wer in einem solchen Staat seinen Wohnsitz

69 Nieke verwendet den Indikativ, obwohl der geschilderte Fall lediglich nacherzählt wird. Ebenso in der nächsten zitierten Passage, „entgegnete“, „kann“. 
nimmt, muss sich diesen Regelungen unterordnen, unbeschadet ob er sie inhaltlich voll teilen kann oder nicht. Ohne eine solche, auch erzwingbare, Zustimmung zu den Grundregelungen des Zusammenlebens wäre dies ständig gefährdet.

$\mathrm{Zu}$ diesen Grundregelungen gehört auch die Respektierung des gesatzten Rechts, also all der Regelungen, die auf dem Weg einer Legitimation durch Verfahren, also durch Beschlussfassung der Legislative zustande gekommen sind - und dies wiederum unabhängig davon, ob die Richtigkeit dieser Regelungen akzeptiert wird oder nicht. (ebd.)

In letzter Konsequenz müsse ein Vater, der dies nicht akzeptieren könne, sein Leben in einem solchen Staat aufgeben und ihn mit seiner Familie verlassen:

Wenn der Vater eine solche situative Begrenzung der Geltung seiner Weltdeutung ganz unerträglich findet, bleibt ihm keine andere Möglichkeit, als in einem Staat seinen Wohnsitz zu nehmen, in dem diese Weltdeutung unangefochten in Geltung bleiben kann. (ebd.: 249f.)

Ich möchte in den folgenden Abschnitten erörtern, inwiefern Niekes Vorschlag eine gangbare Lösung für den Konflikt zwischen Universalismus und Kulturrelativismus darstellt und damit auch für eine interkulturell ausgerichtete Fremdsprachendidaktik, die solche Konflikte zur Kenntnis nimmt, von Interesse wäre. Dies wäre dann der Fall, wenn der Vorschlag lediglich Setzungen vornähme, welche von verschiedenen realistischerweise denkbaren ,kulturellen' Standpunkten aus ohne die Anwendung von Zwang akzeptiert würden.

Zunächst ist hervorzuheben, dass die Bearbeitung von Konflikten durch Diskurse, wie sie Nieke vorschlägt, und die mit ihnen einhergehende Offenlegung der jeweiligen Argumentationsgrundlagen und Setzungen in der Tat entscheidend scheint, wenn man das Habermas'sche Ideal des herrschaftsfreien Diskurses anstrebt. Zwar dürfte auch dies nicht immer zu einem Kompromiss oder einer gütlichen Einigung führen. Jedes andere Vorgehen stünde jedoch unter dem doppelten Verdacht, sowohl die eigenen Beweggründe verschleiern zu wollen, als auch dem Anderen die Fähigkeit abzusprechen, den eigenen Standpunkt im Sinne interkultureller Verständigung zu relativieren. Allerdings endet jede rationale Argumentation an Setzungen, die als Werte oder ,Letztbegründungen bezeichnet werden. Welsch (1995: 726) stellt in seiner historischen Analyse des Vernunftbegriffs in diesem Zusammenhang klar:

Begründungen fußen letztlich stets auf solchem, was nicht mehr infolge von Herleitung oder Beweis, sondern nur noch auf andere Weise für begründet gilt - etwa, indem es einleuchtet oder indem es mit anderen Annahmen konkordant ist oder indem es sich durch seine Folgen empfiehlt oder indem es in der Reflexion jeder Befragung standhält.

In dem von Nieke geschilderten Fall wären diese Letztbegründungen auf der einen Seite die,Menschenrechte` sowie das, Recht auf freie Entfaltung der Persönlichkeit', 
auf der anderen Seite ,Gottes Wille` bzw. familiäre Traditionen`. Entscheidend ist nun, dass auf dieser Grundlage beide Seiten für sich reklamieren könnten, ,vernünftig' zu argumentieren, da sie dies in Übereinstimmung mit den jeweils eigenen Werten tun. Diese Werte stellen aber Letztbegründungen bzw. Setzungen dar, welche von manchen Standpunkten aus vermutlich nur unter Anwendung von Zwang akzeptiert würden. Der Vernunftbegriff fällt damit als zwangloser Ausweg aus dem Dilemma zwischen Universalismus und Kulturrelativismus weg, ein Schluss, den auch Nieke (2008: 248, Hervorhebung im Original) selbst zieht:

Mit der Erklärung Hier stehe ich und kann nicht anders endet die Argumentationskette in einem Diskurs und damit auch die Möglichkeit, diese Position für die anderen Diskursteilnehmer verständlich und nachvollziehbar zu machen.

Nieke bringt als zweiten Ansatz für eine Lösung des Dilemmas die „situative Begrenzung von Geltung" ins Gespräch, die zum einen zwischen den Sphären privat vs. öffentlich, zum anderen zwischen verschiedenen Rechtsgebieten verlaufen könnte. $\mathrm{Zu}$ der Dichotomie privat vs. öffentlich ist anzumerken, dass die Möglichkeit, im privaten Bereich unterschiedliche Wertvorstellungen und Lebensentwürfe zu verwirklichen, keine Besonderheit von Niekes aufgeklärtem Eurozentrismus, sondern ein Grundprinzip liberaler Rechtsstaaten darstellt. So gelten etwa sexuelle Handlungen unter der Voraussetzung, dass alle Beteiligten volljährig sind und in keiner Weise unter Zwang stehen, in Deutschland als Privatangelegenheit. Auf dieser Grundlage wurde in Deutschland 1994 der berüchtigte $₫ 175$ des Strafgesetzbuchs endgültig gestrichen, der bis dahin sexuelle Handlungen zwischen gleichgeschlechtlichen Partnerinnen und Partnern unter Strafe stellte.

Die Begrenzung der Geltung von Normen auf bestimmte Lebensbereiche kann zudem insofern kritisiert werden, als die Unterscheidung zwischen privaten und öffentlichen Sphären des Lebens keineswegs als kulturneutral gelten kann, sondern vielmehr mit anderen Modellen konkurriert, welche diese Trennung ablehnen - auch und besonders in den Bereichen Sexualität und Religion, die in liberalen Rechtsstaaten ausdrücklich als privat gelten. Insofern ist die von Nieke vorgeschlagene situative Begrenzung der Geltungsbereiche von Normen in privat und öffentlich eine kulturgebundene Setzung und somit ebenfalls kein Ausweg aus dem Dilemma zwischen Universalismus und Kulturrelativismus.

Die situative Begrenzung der Geltungsbereiche von Normen nach territorialen Kriterien stellt das dritte Element dar, welches nach Nieke ein Vermittlungspotential aufweist. Die Einwände müssen hier am deutlichsten formuliert werden. Ansätze interkultureller Verständigung zeichnen sich dadurch aus, dass sie Modelle entwickeln, nach denen Konflikte, die aus kulturgebundenen Wertvorstellungen 
entstehen, im Spannungsfeld zwischen Universalismus und Kulturrelativismus im Geist der Einsicht beigelegt werden. Modelle, die hierbei auf Zwang oder Androhung von Zwang zurückgreifen, können mit Sicherheit nicht als Ansätze im Geiste des „Zwanglosen Zwangs des besseren Arguments“ (Habermas 1971: 137) gelten. Ich kann mir nur schwer vorstellen, dass die Empfehlung, jemand solle „[...] in einem Staat seinen Wohnsitz zu nehmen, in dem diese Weltdeutung unangefochten in Geltung bleiben kann" (Nieke 2008: 249f.), von allen Seiten als das ,bessere Argument' akzeptiert wird. Vielmehr halte ich die Idee, Wertekonflikte durch Exilierung der Angehörigen von Minderheiten zu lösen, für eine weder wünschenswerte noch gangbare Lösung für das Dilemma zwischen Universalismus und Kulturrelativismus. Ich schätze das Potential von Niekes Konzept des ,aufgeklärten Eurozentrismus' daher für die hier diskutierten Problemfelder des interkulturell ausgerichteten Fremdsprachenunterrichts als gering ein.

Zum Dilemma von Universalismus und Kulturrelativismus lässt sich somit als Zwischenergebnis festhalten, dass es sich dabei um eine oft vernachlässigtes Grundproblem der interkulturellen Pädagogik und Didaktik handelt. Am Aufgeklärten Eurozentrismus, einem Ansatz, der sich diesem Dilemma stellt, wurde herausgearbeitet, dass er ,interkulturelle' Konflikte entweder durch die Unterscheidung von Geltungsbereichen - öffentlich vs. privat - zu lösen versucht, oder durch die Anregung, die betroffenen Personen mögen das Land verlassen. Dabei handelt es sich einerseits um einen Gemeinplatz liberalen Staatsdenkens, andererseits um einen Vorschlag, der für die Ausgestaltung pluraler Gesellschaften weder wünschenswert noch gangbar erscheint. Somit bietet Nieke keinen überzeugenden Ansatz für eine Lösung des Dilemmas.

Dessen Pointe liegt nun gerade in dem Umstand, dass sowohl universalistische als auch kulturrelativistische Positionen auf nicht hintergehbare universalistische Setzungen angewiesen sind. Unabhängig davon, welche Haltung man persönlich einnimmt - in keinem Fall scheint es befriedigend, die eine oder andere Position unreflektiert zu vertreten. Dies würde unweigerlich zu Invisibilisierungen von Kontingenzen und Machtverhältnissen führen, wie sie von Andreas Reckwitz für verschiedene Kulturverständnisse herausgearbeitet wurden (vgl. Kap. 2.1.). Vielleicht sollten Universalismus und Kulturrelativismus daher nicht als unversöhnliche Gegensätze, sondern als gleichermaßen notwendige Prinzipien gesehen werden. Diese könnten als wechselseitige Korrektive funktionieren, wenn sie reflexiv aufeinander angewandt werden. Hierbei wäre allerdings die - ihrerseits universalistische - Voraussetzung zu beachten, dass diese Korrekturen durch diskursive Aushandlungen vorgenommen werden sollen. 
Die hier vorgeschlagene Orientierung an Menschenrechten, Rechtsstaatlichkeit und Demokratie (vgl. Council of Europe 2010) stellt somit keine letztgültige universalistische Setzung dar. Vielmehr handelt es sich um einen vielversprechenden Vorschlag, der jedoch seinerseits der Aushandlung bedarf und jederzeit auch eingesetzt werden kann, um gesellschaftliche und machtpolitische Verhältnisse in Europa zu hinterfragen.

Auf der Grundlage dieser Überlegungen werden in den nun folgenden Kapiteln wichtige Ansätze interkultureller Fremdsprachendidaktik im Licht der Forschungsfragen 1 und 2 diskutiert. 


\section{Kapitel 3: Ansätze interkultureller Fremdsprachendidaktik in der Diskussion}

\subsection{Einleitende Überlegungen}

Im vorhergehenden Kapitel wurde der Versuch unternommen, zwei Problembereiche zu umreißen, die für die interkulturelle Fremdsprachendidaktik ebenso relevant wie ungelöst sind: das Problem der Kulturverständnisse und das Dilemma von Universalismus und Kulturrelativismus. In Folgenden soll nun untersucht werden, wie einflussreiche Ansätze interkultureller Fremdsprachendidaktik in Bezug auf diese Problembereiche einzuschätzen sind. Auf diese Weise sollen die Forschungsfragen 1 und 2 bearbeitet werden.

Aus der Fülle an Publikationen zum Thema wurden insgesamt vier Ansätze für eine ausführliche Analyse ausgewählt. Als Auswahlkriterien spielten dabei ihr jeweiliger Einfluss auf die fremdsprachendidaktische Diskussion in Europa und in Deutschland sowie ihre Relevanz für die hier diskutierten Problemstellungen eine Rolle (vgl. Kap. 1.9.). Die Wahl fiel erstens auf die im Umfeld des Gießener Graduiertenkollegs entwickelte Didaktik der Fremdverstehens und dabei insbesondere auf die Arbeiten Lothar Bredellas; zweitens auf Claire Kramschs Konzept der Thirdness; drittens auf das ebenfalls von Kramsch entwickelte Konzept der Symbolic Competence; viertens auf Michael Byrams Konzeption der Intercultural Communicative Competence.

Die hier durchgeführte Analyse beschränkt sich auf Beiträge zur fremdsprachendidaktischen Theoriebildung, denn es ist davon auszugehen, dass sowohl Dokumente verschiedener bildungsadministrativer Ebenen (z.B. der GeR, nationale Bildungsstandards oder im Falle Deutschlands länderspezifische Curricula) als auch Unterrichtsmaterialien auf diesen Beiträgen fußen. Es handelt sich bei ihnen somit um abgeleitete Texte. Wie sehr dies zutrifft, ist besonders deutlich am GeR zu sehen. Die dort zu findende Beschreibung interkultureller Kompetenz deckt sich weitgehend mit Byrams Ansatz der Intercultural Communicative Competence. Probleme der Theorieebene sind daher in erster Linie auf dieser Ebene zu identifizieren und in einem zweiten Schritt ebenfalls auf dieser Ebene zu lösen. 


\subsection{Vom Verstehen zur Verständigung: Der hermeneutische Ansatz des Gießener Kollegs}

\subsubsection{Problemstellung der Didaktik des Fremdverstehens}

Unternimmt man den Versuch, fremdsprachliches Lernen interkulturell auszurichten, so liegt eine Auseinandersetzung mit dem Begriffspaar ,Eigenes'vs. ,Fremdes`sehr nahe. Dabei stellen sich zunächst mehrere grundlegende erkenntnistheoretische, mithin philosophische Fragen: Wie lässt sich das Eigene vom Fremden unterscheiden, und zwar sowohl auf individueller Ebene als auch auf der Ebene von Gruppen? Sind wir als Menschen in der Lage, Fremdes, wirklich ' zu verstehen, oder sehen wir es doch immer wieder nur durch die Brille des Eigenen? Ist Fremdverstehen also möglich, und wenn ja, unter welchen Bedingungen? Im gleichen Zusammenhang stellen sich auch pädagogische und didaktische Fragen. Vorausgesetzt, Fremdverstehen ist möglich - inwieweit ist es auch lehr- und lernbar? Wie genau müssen didaktische Inszenierungen aussehen, die Fremdverstehen erfolgreich anbahnen? Und schließlich: Welche Rolle spielt sprachliches Lernen in diesem Kontext?

Für Lothar Bredella und Herbert Christ waren diese Fragen, die um das Problem kreisen, wie Fremdverstehen definiert und sinnvoll in den Fremdsprachenunterricht integriert werden könnte, so zentral, dass sie sie ins Zentrum ihrer Forschung stellten. Sie gründeten 1991 das Gießener Graduiertenkolleg „Didaktik des Fremdverstehens" und leiteten es gemeinsam bis 2000. Nach Christs Emeritierung leitete Bredella das Kolleg noch bis 2003, nun in Zusammenarbeit mit Michael Legutke. Aus der Arbeit im Kolleg sind neben zahlreichen Forschungsarbeiten (u.a. Schinschke 1995, Bechtel 2003) auch mehrere Sammelbände hervorgegangen (vgl. Bredella/Christ 1995, Bredella/Delanoy 1999, Bredella et al. 2000), sodass das Kolleg für die Dauer seines Bestandes und darüber hinaus die fremdsprachendidaktische Diskussion in Deutschland maßgeblich beeinflussen konnte. Auch wenn der Name Lothar Bredella natürlich nicht exklusiv für die Positionen des Kollegs steht, fassen die Schriften, für die er alleine oder als CoAutor zeichnete, die Arbeit in Gießen doch gut zusammen. Es scheint deswegen legitim, sich in der Rekonstruktion und Diskussion der Didaktik des Fremdverstehens vorwiegend auf Bredella als deren herausragenden Impulsgeber und Vertreter zu beziehen. Ich stütze meine Analyse daher vorwiegend auf eine Auswahl seiner Schriften. ${ }^{70}$

70 Vgl. Bredella 1994, 1999, 2000, 2001, 2007, 2010a, 2010b, 2012 sowie Bredella et. al. 2000 . 
Wie stellt sich die Problemlage dar, welche im Zentrum der Arbeit im Gießener Kolleg steht? Bredella zufolge hat sich die Frage nach dem Umgang mit dem Fremden seit dem Zweiten Weltkrieg und in zunehmendem Maße seit der Öffnung der Grenzen Osteuropas grundlegend verändert. Arbeits- und Flüchtlingsmigration haben in den Industrienationen multikulturelle Gesellschaften entstehen lassen, in denen Menschen unterschiedlichster ethnischer Herkunft, Religion und Lebensweise zusammenleben. Angesichts dieser Entwicklung habe sich auch das Leitbild des prototypischen Fremdsprachenschülers geändert. Die Fremdsprachendidaktik hatte ab der kommunikativen Wende bis in die späten 1980er-Jahre den Touristen im Blick, der ein Hotelzimmer reservieren, ein Auto mieten oder eine Mahlzeit bestellen möchte. Etwa seit Beginn der 1990er-Jahre orientierte sie sich jedoch zunehmend auch am (zukünftigen) Migranten, der sich frei auf einem europäischen oder gar weltweiten Arbeitsmarkt bewegt und einen komplexen Alltag bewältigen muss (vgl. Bredella 1999: 93-97). Aber unabhängig davon, ob der/dem Lernenden das Fremde nur auf Urlaubsreisen oder auch im Alltag begegne, bleibe die grundlegende Frage zunächst unbeantwortet: Lässt sich das Fremde überhaupt verstehen, ohne es am Eigenen zu messen und so in eine ethnozentristische oder gar rassistische Falle zu tappen? Denn zumindest was den Ethnozentrismus angehe, ließen sich in der deutschen Erziehungswissenschaft prominente Stimmen finden, welche diese Frage klar verneinen würden. So zitiert Bredella etwa Meinert A. Meyer, der die Möglichkeit des Fremdverstehens grundlegend anzweifle, wenn er die „prinzipiell nicht aufhebbare Andersartigkeit des Anderen“ hervorhebe (Meyer 1993: 135, vgl. Bredella 1999: 99). Hat Meyer nun Recht - was der Didaktik des Fremdverstehens von Anfang an ein enges Korsett anlegen würde? Bredella gibt sich mit Meyers Befund zunächst einmal nicht zufrieden und macht sich in benachbarten Disziplinen auf die Suche, in denen die Dichotomie des Eigenen und Fremden bereits ausführlich diskutiert wurde. Welche Ansätze finden sich dort? Und können sie für die wichtige Frage nach dem Eigenen und Fremden in der Fremdsprachendidaktik möglicherweise fruchtbar gemacht werden? Bredella diskutiert in diesem Zusammenhang Beiträge aus der Anthropologie, Sozialwissenschaft und aus der Psychoanalyse.

In einem ersten Schritt fasse ich Bredellas Rezeption dieser in verschiedenen Disziplinen entwickelten Ansätze zusammen. Da mir diese Rezeption nicht immer gelungen erscheint, beschäftige ich mich anschließend in einem Exkurs kritisch mit der Art und Weise, wie Bredella verschiedene Beiträge aus benachbarten Disziplinen für die Fremdsprachendidaktik verarbeitet. Anschließend stelle ich den Lösungsansatz vor, den Bredella und andere für das Dilemma von 
Eigenem und Fremdem im Gießener Kolleg entwickelt und als „Didaktik des Fremdverstehens“ bekannt gemacht haben. Schließlich diskutiere ich die „Didaktik des Fremdverstehens“ im Licht meiner Forschungsfragen.

\subsubsection{Von Lothar Bredella diskutierte Ansätze zur Dichotomie des Eigenen und Fremden}

Wie bereits in Kapitel 2.2.1. dargestellt wurde, finden sich wichtige Anregungen zum Problem des Fremdverstehens in der Anthropologie. Die Beiträge eines ihrer prominentesten Vertreter, Claude Lévi-Strauss, wurden auch von Bredella rezipiert. In Bezug auf die entscheidende Frage, ob Ethnozentrismus grundsätzlich überwunden werden kann, habe Lévi Strauss festgestellt, so Bredella, dass „[...] die meisten Kulturen der Welt ethnozentrisch seien [...]“ (Bredella 2001: 11). In der Tat lässt sich in Race et culture, einem grundlegenden Essay von LéviStrauss, diese Einschätzung finden: „Tantôt chaque culture s'affirme comme la seule véritable et digne d'être vécue; elle ignore les autres, les nie même en tant que cultures" (Lévi-Strauss 2001: 131f.). ${ }^{71}$ Diese Aufwertung der eigenen Kultur auf Kosten einer fremden sei sogar, so resümiert Bredella den Standpunkt von Lévi-Strauss, die Voraussetzung dafür, dass Menschen die eigene Kultur schätzen und sich mit ihr identifizieren können (vgl. Bredella 2001: 11).

Stellt der Ethnozentrismus also ein universales Phänomen dar und ist daher der Versuch, durch das Lernen fremder Sprachen einen ethnozentrischen Standpunkt zu überwinden, von vornherein zum Scheitern verurteilt? Bredella führt neben dem Anthropologen Lévi-Strauss weitere Autoren an, welche die Möglichkeit des Fremdverstehens grundsätzlich in Zweifel ziehen. Unter ihnen ragt Edward Said heraus, der 1978 mit Orientalism eine Arbeit vorgelegt hat, welche die vermutlich radikalste Kritik an den westlichen Orient-Studien als Disziplin und damit an ihrem Versuch des Fremdverstehens darstellt. Das Buch des palästinensisch-amerikanischen Literaturwissenschaftlers, der aus einer christlichen Familie stammte und in Kairo aufwuchs, wurde breit rezipiert und erhielt Lob von einflussreichen Stimmen wie Michel Foucault, auf dessen Diskursbegriff es fußt. Es löste jedoch auch eine überaus kontroverse Debatte aus, die bis heute anhält. ${ }^{72}$

71 Ich zitiere aus dem französischen Original des Essays. Bredella bezieht sich auf die englische Übersetzung von Joachim Neugroschel und Phoebe Hoss (vgl. Lévi-Strauss 1985: 3ff.). Das einschränkende „tantôt“ ist dort korrekt mit „sometimes“ übersetzt (vgl. ebd.: 7).

72 Unter anderem wird kritisiert, dass er lediglich Literatur berücksichtigt habe, die seine These stützte. Eine ausführliche Kritik von Orientalism findet sich in Warraq 2007. 
Saids Grundthese lautet, dass die wissenschaftliche Beschäftigung mit dem Orient im Grunde der Versuch sei, diesen zu unterwerfen. Der Westen habe durch die Erzeugung eines wissenschaftlichen Diskurses seine Denkweise zum Maßstab und damit zu einem Werkzeug zur Ausübung von Macht erhoben. Das Verstehen sei lediglich ein Vorwand, um die beforschte Kultur - in diesem Fall den, Orient ${ }^{\prime}-$ zu dominieren bzw. bestehende politische Dominanz akademisch zu unterfüttern. Jeder Europäer oder Amerikaner, der den Orient beforscht habe, habe dies im Wissen um die Macht des eigenen Herkunftslandes getan, und dies habe seinen Blick einseitig beeinflusst:

For if it is true that no production of knowledge in the human sciences can ever ignore or disclaim its author's involvement as a human subject in his own circumstances, then it must also be true that for a European or American studying the Orient there can be no disclaiming the main circumstances of his actuality: that he comes up against the Orient as a European or American first, as an individual second. (Said 2003 [1978]: 11, Hervorhebung im Original)

Unter diesen Voraussetzungen wurde nach Said ein Diskurs generiert, der in verschiedenen Formen repräsentiert sei, der jedoch immer zu einem asymmetrischen Machtverhältnis führe:

[...] Orientalism can be discussed and analyzed as the corporate institution for dealing with the Orient - dealing with it by making statements about it, authorizing views of it, describing it, by teaching it, settling it, ruling over it: in short, Orientalism as a Western style for dominating, restructuring, and having authority over the Orient. (ebd.: 3)

Der Orient als solcher existiere gar nicht, sondern er sei eine Projektionsfläche des Westens, der vom Westen konstruierte prototypische Andere. Das Wissen über diesen Anderen werde einerseits gebraucht, um ihn zu beherrschen, andererseits aber auch, um die eigene Identität zu festigen:

[This book] also tries to show that European culture gained in strength and identity by setting itself off against the Orient as a sort of surrogate and even underground self. (ebd.)

Die vermutlich am schärfsten formulierte Kritik an der Vorstellung, (Fremd-) Verstehen, Forschung und Produktion von Wissen werde von edlen Motiven angetrieben, findet sich bei Michel Foucault, auf den Bredella ebenfalls eingeht. Während es Said weniger um eine Fundamentalkritik an der Möglichkeit des Fremdverstehens als um die Diskussion eines bestimmten Fachdiskurses zu einer bestimmten Zeit in einem bestimmten historischen Kontext geht, ist Foucaults Standpunkt radikaler. Nach Foucault (1971b: 170; vgl. Bredella 1994: 22) 
ist die eigentliche Motivation des Wissen-Wollens nicht Wissen, sondern Macht, und dabei werde immer Ungerechtigkeit erzeugt:

L'analyse historique de ce grand vouloir-savoir qui parcourt l'humanité fait donc apparaître à la fois qu'il n'y a pas de connaissance qui ne repose sur l'injustice (qu'il n'y a donc pas, dans la connaissance même, un droit à la vérité ou un fondement du vrai) et que l'instinct de connaissance est mauvais (qu'il y a en lui quelque chose de meurtrier, et qu'il ne peut, qu'il ne veut rien pour le bonheur des hommes).

Während laut Bredella Lévi-Strauss und in deutlich stärkerem Maße Said Fremdverstehen für schwierig und selten, aber prinzipiell möglich halten, scheint es bei Foucault geradezu ausgeschlossen.

Ähnlich wie Foucault bezweifelt auch der deutsche Anthropologe Hans-Peter Duerr die Möglichkeit des Fremdverstehens. Anders als für Foucault liegt für Duerr das Problem jedoch nicht in den Intentionen der Suche nach Wissen. Vielmehr hält er Verstehen ohne,Nostrifizierung', d. h. ohne Überführung in die Kategorien der eigenen Verstehensmodi, für kaum möglich. Verstehen bedeutet nach Duerr (1978:152; vgl. Bredella 1994: 23) oft, sich etwas ,anzueignen', und dies geschehe durch die Überführung in die eigenen Denkschemata - ein Problem, das er auch unter Anthropologen ausmacht:

Das Fremde wird ,entfremdet' wird heimisch gemacht und dadurch neutralisiert. Verstanden ist etwas dann, wenn [...] es eingeordnet ist in das, was wir zum Bereich unserer eigenen Kultur rechnen.

Bredella fasst die Konsequenz dieser Denkweise bündig zusammen, wenn er schreibt:

Das bedeutet schließlich, [...] daß nur Afro-Amerikaner Afro-Amerikaner - und wir können hinzufügen -, nur Deutsche Deutsche verstehen können. Eine solche Auffassung ist jedoch letztlich inhuman, weil sie unsere gemeinsame menschliche Erfahrung ignoriert und den Anderen ausgrenzt. (Bredella 1994: 24)

Dennoch räumt Bredella ein, dass die Überwindung des Ethnozentrismus eine große Herausforderung darstellt. Wie haben sich die interkulturell ausgerichtete Erziehungswissenschaft und Fremdsprachendidaktik bisher zu diesem Problem positioniert? Eine von Bredella diskutierte Haltung besteht darin, in einem ethnozentrisch gefärbten Fremdverstehen nicht ein unvermeidliches Übel, sondern ein wünschenswertes Ziel zu sehen. Schließlich bedeutet die Relativierung der eigenen Weltsicht immer auch die zumindest partielle Preisgabe der eigenen Identität. Manche Pädagogen sehen aber im genauen Gegenteil das Ziel erzieherischen Handelns. Aus dem Feld der Erziehungswissenschaft führt Bredella als einen Vertreter dieser Ansicht Meinert A. Meyer (1992: 16; vgl. Bredella 1999: 98) 
an, der empfohlen habe, beim interkulturellen Lernen „[...] mit sich und seiner kulturellen Herkunft identisch zu bleiben." Auch in der Fremdsprachendidaktik findet Bredella Vertreter dieser Position, etwa bei Diethelm Knauf, der gefordert hat, man solle in der Auseinandersetzung mit dem Fremden doch „[...] in kritischer Distanz und bei klarem Verstand mit seiner kulturellen Herkunft identisch [...] bleiben“" (Knauf 1996: 44, vgl. Bredella 2001: 11, 1999: 98). Beide Autoren befürworten laut Bredella also einen Umgang mit dem Fremden, dessen Ziel die Festigung der eigenen Identität ist. Dies bedeutet jedoch, sich Ethnozentrismus geradezu auf die Fahnen zu schreiben.

Bei Meyer kommt noch ein zweiter interessanter Aspekt hinzu: die Anerkennung einer unüberwindlichen Differenz zwischen dem Eigenen und Fremden sei sogar Voraussetzung dafür, dass beim Lernen einer Fremdsprache von ,Bildung' gesprochen werden könne:

Fremdsprachenunterricht ist bildend, wenn die fremden Sprachen so vermittelt werden, daß die Schüler die in ihnen artikulierte, fremdsprachige, Weltansicht' erfahren können, und wenn ihnen dabei ermöglicht wird, die prinzipiell nicht aufhebbare Andersartigkeit der Anderen zu erfahren. (Meyer 1993: 135; vgl. Bredella 1999: 99)

Bredella kritisiert diese Haltung als deterministisch: Sie bedeute, dass man als Mensch ein für allemal auf die kulturelle Prägung festgelegt ist, die man in der frühen Kindheit erfahren hat, und dem Fremdsprachenunterricht falle lediglich die Aufgabe zu, diese Prägung in der Beschäftigung mit einer fremden Sprache und in Abgrenzung zu der in ihr transportierten Weltansicht zu vertiefen (vgl. Bredella 1999: 98-102). Bredella verweist hingegen darauf, dass Identitäten dynamisch seien und sich in einem vielfältigen Wechselspiel verschiedener Einflüsse herausbildeten. Meyers und Knaufs Position hält Bredella nicht zuletzt aus ethischer Sicht für nicht vertretbar:

Wenn wir uns auf die Situation des Migranten [... besinnen, dann kann es nicht nur darum gehen, daß wir Andere auf ihre unaufhebbare Andersheit festlegen, sondern ihnen Raum geben für neue Bestimmungen des Eigenen und Fremden. (ebd.: 99)

Indirekt wirft Bredella (ebd.: 100) der von Meyer vertretenen Haltung sogar rassistische Tendenzen vor, wenn er unter Rückgriff auf Pierre-André Taguieff daran erinnert, dass...

[...] früher Rassisten Menschen auf ihre Rasse festgelegt haben und daß sie heute, da der Rassismus nicht mehr legitimierbar ist, Menschen auf ihre Kultur festlegen. In beiden Fällen handelt es sich um einen Reduktionismus, der die Freiheit des Einzelnen auf Selbstbestimmung ignoriert [...]. 
Bredella selbst weist hier also darauf hin, dass der Kulturbegriff mit Vorsicht zu verwenden sei, denn im Umgang mit der Dichotomie des Eigenen und Fremden führe er leicht dazu, dass man in homogenisierende Zuschreibungen abgleite.

Mit der Psychoanalyse stellt Bredella eine weitere, gänzlich andere Herangehensweise an die Problematik des Fremdverstehens vor. Während die Anthropologie Differenz und damit Fremdheit meist entweder zwischen geografisch getrennten Kulturen ausmacht oder zumindest zwischen Individuen, die vielleicht denselben Lebensraum teilen, dabei aber unterschiedlichen ethnischen oder kulturellen Gruppen angehören, weist die Psychoanalyse im Anschluss an Sigmund Freud darauf hin, dass jedem Menschen Teile seiner eigenen Persönlichkeit fremd sein können. Diese Anerkennung fremder Anteile in uns selbst mag individuell zunächst eine verstörende Erkenntnis sein. Gleichzeitig stelle sie aber möglicherweise eine große Chance dar, so Bredella, und zwar nicht nur insofern, als sie eine bessere Kenntnis des Selbst ermögliche, sondern auch, weil sie einen Ausweg aus einer essentialistischen Wahrnehmung des Eigenen und Fremden weise. Mit Julia Kristeva führt Bredella die wohl prominenteste Vertreterin einer psychoanalytisch fundierten Literatur- und Kulturwissenschaft an. Der eben skizzierte Umgang mit dem Eigenen und Fremden findet sich in ihrem Buch mit dem programmatischen Titel Étrangers à nous mêmes (1988). Kristeva plädiert dort dafür, den Gegensatz zwischen Eigenem und Fremdem zu überwinden, indem man anerkennt, dass man auch Teile der eigenen Persönlichkeit als fremd erleben kann. Dies öffne den Weg dafür, sich selbst, in einem zweiten Schritt aber auch den Anderen besser zu verstehen, und dies könne sogar so weit führen, dass sich Fremdheitserfahrungen insgesamt auflösten:

Étrangement, létranger nous habite : il est la face cachée de notre identité, l'espace qui ruine notre demeure, le temps où s'abîment l'entente et la sympathie. De le reconnaitre en nous, nous nous épargnons de le détester en lui-même. Symptôme qui rend précisément le ,nous' problématique, peut-être impossible, létranger commence lorsque surgit la conscience de ma différence et s'achève lorsque nous nous reconnaissons tous étrangers, rebelles aux liens et aux communautés. (Kristeva 1988: 9)

Kristevas Vorschlag zum Umgang mit dem Fremden, der sich von den oben zusammengefassten Ansätzen aus Anthropologie und Sozialwissenschaft radikal unterscheidet, überzeugt jedoch aus Bredellas Sicht ebenfalls nicht. Er sieht in ihm eine übertriebene Aufwertung des Fremden, eine „Glorifizierung“ (Bredella 2001: 12), die eine doppelte Gefahr darstelle, nämlich „[...] dass man einerseits verkennt, was den Fremden angetan wird, und dass man andererseits die Erfahrung der Assimilation von vornherein als Verrat brandmarkt [...]“ (ebd.). 
Als Zwischenfazit lässt sich festhalten, dass Bredella einen ausgeprägt interdisziplinären Blick auf die Dichotomie von Eigenem und Fremdem wirft und so eine sehr differenzierte Darstellung der Problemlage erreicht. Dabei warnt er insbesondere vor einem unreflektierten ethnozentrischen Denken. Gleichzeitig hält er es für problematisch, das Fremde lediglich zur Konsolidierung des Eigenen zu betrachten. Zudem sei ohnehin jede Form von essentialistischen Identitätszuschreibungen zu vermeiden, da immer neu bestimmt werden müsse, was unter Eigenem und Fremdem überhaupt zu verstehen sei. Man müsse vielmehr jedem Menschen die Freiheit zugestehen, sich selbst zu verorten. Der Wunsch nach kultureller Homogenität weise sogar Parallelen zu jenem nach rassischer Reinheit auf (vgl. Bredella 1999: 100). Auch die Psychoanalyse weise keinen gangbaren Weg, um die Dichotomie des Eigenen und Fremden zu überwinden. Allerdings lehnt Bredella auch die Ansicht ab, Fremdverstehen sei grundsätzlich unmöglich.

Bevor ich nachzeichne, welchen Ausweg aus dieser Problemlage die „Didaktik des Fremdverstehens" vorschlägt, möchte ich jedoch in einem kurzen Exkurs einen anderen Aspekt in Bredellas Beiträgen thematisieren. Dabei geht es um die Frage, inwiefern er verschiedene wissenschaftliche Positionen auf nachvollziehbare und im jeweiligen Kontext stimmige Weise verarbeitet.

\subsubsection{Exkurs: Diskussion der von Bredella referierten Ansätze}

Die Wiedergabe fremder Forschungspositionen zu einem gewählten Thema stellt ohne Zweifel einen wichtigen Teilbereich wissenschaftlichen Schreibens dar. Bei der Durchsicht von Lothar Bredellas Schriften fällt auf, dass er dieser Aufgabe ausführlich, unter Beachtung vielfältiger Forschungsrichtungen und mit einer belebenden Lust an der Zuspitzung und der Kontroverse nachkommt (vgl. Bredella 2010b). Gleichwohl stellt sich die Frage, inwiefern es bei Zuspitzungen bleibt, inwiefern jedoch in Bredellas Schriften wissenschaftliche Positionen Dritter unkenntlich gemacht oder gar in ihr Gegenteil verkehrt werden. Ich stelle im Folgenden zwei Beispiele dieser im Hinblick auf gute wissenschaftliche Praxis problematischen Arbeitsweise dar.

Eine für den interkulturellen Fremdsprachenunterricht hoch relevante Disziplin ist die Anthropologie, eine Wissenschaft, die gewissermaßen ihre raison dêtre auf der Annahme gründet, dass das Fremde detailliert und (möglichst) objektiv beschrieben und auf dieser Grundlage bis zu einem gewissen Grad auch verstanden werden kann. Wie steht nun diese Disziplin, für die Fremdverstehen gewissermaßen das Kerngeschäft darstellt, zum Problem des Ethnozentrismus? Bredella greift die Frage anhand der von Lévi-Strauss vertretenen Positionen auf. So zitiert er etwa eine Passage aus der Feder von Lévi-Strauss als Beispiel für 
„Auffassungen [...], die den Ethnozentrismus rechtfertigen“ (Bredella 2001: 11). Dabei führt er das oben bereits wiedergegebene Zitat von Lévi-Strauss als Beleg für die Einschätzung an, dass ein ethnozentrischer Umgang mit dem Fremden für „die meisten Kulturen in der Welt“ (Bredella 2001: 11) üblich sei. Er scheint direkt im Anschluss den Kontext des Zitates und damit Lévi-Strauss' Haltung zu resümieren, wenn er schreibt:

Das Unverständnis für fremde Kulturen ist nach Lévi-Strauss notwendige Voraussetzung dafür, sich mit der eigenen Kultur zu identifizieren und sich von anderen Kulturen abzugrenzen. (ebd.)

Der zitierte Satz aus Race et culture lässt sich in dieser Form jedoch nicht zusammenfassen - Lévi-Strauss behauptet nicht, dass die meisten Kulturen ethnozentrisch seien, sondern lediglich, dass sich dies manchmal („tantôt“, Lévi Strauss 2001: 131) manifestiere. Eine genaue Lektüre der von Bredella zitierten Passage zeigt zudem, dass Lévi-Strauss seine Einschätzung über die Verbreitung des Ethnozentrismus noch weiter relativiert, indem er betont, dass Ethnozentrismus, gepaart mit Verachtung oder gar Dehumanisierung des Anderen, insbesondere bei ,primitiven' Völkern sehr verbreitet sei:

La plupart des peuples que nous appelons primitifs se désignent eux-mêmes d'un nom qui signifie, les vrais', les bons', les excellents', ou bien tout simplement, les hommes'; et ils appliquent aux autres des qualificatifs qui leur dénie la condition humaine, comme ,singes de terre' ou ,œufs de pou'. (ebd.)

Die Überwindung von Ethnozentrismus zeichnet sich damit zunächst als eine zivilisatorische Errungenschaft ab. Lévi-Strauss relativiert jedoch auch dies, wenn er, weiterhin in Bezug auf, primitive ' Völker, fortfährt:

Mais on connait aussi une autre attitude, qui est complémentaire de la précédente plutôt qu'elle ne la contredit, et selon laquelle l'étranger jouit du prestige de l'exotisme et incarne la chance, offerte par sa présence, délargir les liens sociaux. [...] Tant que les cultures se tiennent simplement pour diverses, elles peuvent donc, soit volontairement s'ignorer, soit se considérer comme des partenaires en vue d'un dialogue désiré. Dans l'un et l'autre cas, elles se menacent et s'attaquent parfois, mais sans mettre vraiment en péril leurs existences respectives. La situation devient toute différente quand, à la notion d'une diversité reconnue de part et d'autre, se substitue chez l'une d'elle le sentiment de sa supériorité fondé sur l'inégalité des rapports de force, et que la reconnaissance positive ou négative de la diversité des cultures fait place à l'affirmation de leur inégalité. (ebd.: 133f.)

Die Verbreitung des Ethnozentrismus als Geringschätzung anderer Kulturen wird bei Lévi-Strauss also mehrfach eingeschränkt: erstens in zeitlicher Hinsicht („tantôt“); zweitens sei er häufig, aber beileibe nicht immer bei indigenen Völkern anzutreffen. Vielmehr sei bisweilen auch eine Einstellung zu beobachten, 
bei der alles Fremde bewundert wird. Drittens vertritt Lévi-Strauss ebenfalls nicht, wie von Bredella behauptet, die Ansicht, mit dem Eigenen könne man sich nur bei gleichzeitiger Geringschätzung des Fremden identifizieren. Zwar nennt er als eine mögliche Haltung die von Bredella aufgegriffene, nämlich die, bei welcher der Blick auf eine fremde Kultur von oben herab in der Gewissheit der eigenen Überlegenheit erfolgt. Lévi-Strauss führt jedoch noch drei weitere mögliche Konstellationen an. Deren erste ist ebenfalls asymmetrisch, allerdings unter umgekehrten Vorzeichen. Sie zeichnet sich, wie bereits erwähnt, durch Bewunderung für das Fremde aus, dem Exotismus und Prestige zugeschrieben werden. Darüber hinaus lassen sich nach Lévi-Strauss zwei weitere, symmetrische Verhältnisse beobachten. Zum einen gebe es die wertfreie Kenntnisnahme der Existenz des jeweils Anderen, allerdings ohne Interesse an einer Aufnahme oder Vertiefung von Beziehungen. Zum anderen bestehe eine weitere Konstellation in der Anerkennung der Unterschiede bei gleichzeitigem beidseitigem Wunsch nach Dialog und gegenseitiger Bereicherung.

Lévi-Strauss' wissenschaftliches Werk wurde durchaus kontrovers diskutiert. Jacques Derrida etwa hat ihm einen „Ethnozentrismus, der als Anti-Ethnozentrismus gedacht wird“ (zit. nach Voss 2009) vorgeworfen. ${ }^{73}$ Ihn als Vertreter der Einschätzung in Anspruch zu nehmen, dass es gar nicht zu vermeiden sei, dem Ethnozentrismus zu verfallen, wenn man sich mit eigenen Kultur identifizieren möchte, ist zumindest eine gewagte Zuspitzung. Die Behauptung, dass sich LéviStrauss „zum Ethnozentrismus [bekennt]“ (Bredella 2001: 11), ist nicht haltbar.

Neben der Überwindung des Ethnozentrismus geht es im Kontext der interkulturellen Didaktik auch immer wieder um die Frage, welche Konsequenzen Differenzerfahrungen in Bezug auf die eigene Identität haben bzw. haben sollen. Sollen Fremdheitserfahrungen dazu dienen, die eigene Identität zu stabilisieren, oder sollen sie vielmehr helfen, Identität als zeitgebundenes, fließendes Konstrukt zu erkennen, das immer neu hinterfragt werden muss? Wäre es daher sinnvoll Lernende zu ermuntern, im Umgang mit Differenz einerseits sich selbst zu finden, aber auch, darin eine Chance zur Veränderung wahrzunehmen?

Die Frage kehrt auch in Lothar Bredellas Schriften mit großer Regelmäßigkeit wieder. Wiederum vermutlich mit dem Ziel, die eigene Position deutlicher herauszuarbeiten - ein an sich völlig legitimes Anliegen -, grenzt Bredella sich von der Ansicht ab, „als Lern- und Erziehungsziel des Fremdsprachenunterrichts die Bewahrung der eigenen Identität" (Bredella 1999: 98) festzulegen. Als Vertreter dieser Position führt er zum einen, wie in Kap. 3.2.1. erwähnt, den

73 Zur Diskussion dieser Kritik vgl. ebd. 
Erziehungswissenschaftler Meinert A. Meyer an, zum anderen den Englischdidaktiker Diethelm Knauf. Während Meyer in der Tat mit Konzeptionen von Kultur und Identität arbeitet, die tendenziell statisch sind, und dabei die Affirmation des Eigenen empfiehlt (vgl. Meyer 1992: 16), ist die Grundaussage von Diethelm Knaufs Arbeit eine ganz andere (vgl. Knauf 1996). Dennoch wird er von Bredella zusammen mit Meyer als Vertreter ein und derselben Haltung genannt. Recht ausführlich zitiert Bredella aus Knaufs Dissertation mit dem Titel Cultural Studies im Englischunterricht:

Ich plädiere also nicht für die Aufgabe der eigenen kulturellen Herkunft [sic] sondern gerade für die Bewußtmachung derselben, die immer auch interkulturelle Momente beinhaltet, denn keine Kultur ist regional, geschlechtsmäßig, ethnisch, sozial, generationsmäßig etc. homogen. (Knauf 1996: 44; vgl. Bredella 1999: 98)

Zum einen lässt sich somit festhalten, dass Knauf in Bezug auf Kulturkonzepte jeglichen Homogenitätsvorstellungen eine klare Absage erteilt, was ihn zunächst von Meyer unterscheidet und mit Bredella verbindet. Ganz ähnlich positioniert sich Bredella (1999: 101), wenn er hervorhebt, ...

[...] daß es sich bei dem Verhältnis von Eigenem und Fremdem nicht um eine ontologische, sondern um eine relationale Kategorie handelt. Oft sind Unterschiede zwischen Menschen ein- und derselben Kultur gravierender als die zwischen Menschen verschiedener Kulturen.

Zum anderen ist zu unterstreichen, dass Knauf sich auf den Seiten, aus denen Bredella zitiert, sogar ausdrücklich von Meyers Definition interkultureller Kompetenz distanziert - genau wie Bredella selbst. Wenn Knauf (1994: 96) in Anlehnung an die Cultural Studies betont, bei der Förderung interkultureller Kompetenz sei auch „die Veränderung der eigenkulturellen Wertkodices, Rollen und Verhaltensweisen" zu beachten, befindet er sich nicht nur exakt auf einer Linie mit neueren Ansätzen, welche die Notwendigkeit hervorheben, beim interkulturellen Lernen das Eigene und Fremde als komplexe, relational zu verstehende Kategorien zu begreifen und in der Auseinandersetzung mit ihnen der Reflexivität eine zentrale Rolle zuzuweisen (vgl. Holzbrecher 2010). Es lässt sich auch kaum ein Unterschied zu grundlegenden Auffassungen aus dem Feld der Didaktik des Fremdverstehens erkennen. Es erstaunt daher, dass Bredella behauptet, es gehe Knauf darum, „Grenzen klarer zu bestimmen“ (Bredella 2001: 11). Das Gegenteil ist der Fall: Knauf problematisiert in Anlehnung an Werner Hüllen ausdrücklich jene Grenzziehungen, welche zur Unterscheidung von intrakultureller und interkultureller Kommunikation überhaupt erst vorgenommen werden müssen (vgl. Knauf 1996: 45; zur Abgrenzungsproblematik vgl. Rathje 2006: 7f.). 
Wie sehr Knaufs Ansichten über interkulturelles Lernen mit denen Bredellas kompatibel sind, lässt sich auch an folgender Passage aus Bredellas grundlegendem Beitrag Zielsetzungen interkulturellen Fremdsprachenunterrichts belegen:

Das Einnehmen einer Innenperspektive ist ein fachliches Ziel. [...] Es ist aber auch ein allgemeines Erziehungsziel. Wir erfahren damit eine Bereicherung unserer begrenzten

Sichtweisen und gewinnen Distanz zu uns selbst. (Bredella 1999: 114)

Knaufs oben zitiertes Plädoyer für „Veränderung der eigenkulturellen Wertkodices, Rollen und Verhaltensweisen" als Ziel interkultureller Didaktik ist somit an Bredellas Ansatz nahtlos anschlussfähig. Wenn Bredella Knaufs Ansatz verwirft, mag das effektvoll sein - gerecht wird er ihm damit nicht. Bredella fasst Knaufs Standpunkt mit folgenden Worten zusammen: „Fremdsprachliches und fremdkulturelles Lernen dienen dann nicht dazu, Grenzen zu überschreiten, sondern Grenzen klarer zu bestimmen“ (Bredella 2001: 11). Auf welcher Grundlage Bredella zu dieser Einschätzung kommt, ist nicht nachvollziehbar.

Eine gründliche kritische Durchsicht von Lothar Bredellas Schriften steht noch aus und ist nicht der Gegenstand dieser Arbeit. Die genannten Beispiele zeigen jedoch, dass sich hier ein möglicherweise interessantes Feld auftut. Unabhängig von der vereinzelt problematischen Darstellung fremder Forschungspositionen möchte ich nun jedoch die von Bredella entscheidend geprägte Didaktik des Fremdverstehens darstellen und diskutieren.

\subsubsection{Grundzüge der Didaktik des Fremdverstehens}

Wenn man das Verstehen des Fremden grundsätzlich für möglich hält, stellt sich die Anschlussfrage, wie es sich beschreiben lässt. Entscheidend ist nach Bredella, das Fremde nie als absolute, sondern immer als relationale Kategorie zu einem Eigenen zu verstehen (vgl. Bredella 1999: 101). Stets müsse auch definiert und reflektiert werden, was das Eigene sei, wenn man über das Fremde sprechen und sich diesem verstehend annähern möchte. Bei dieser Standortbestimmung müsse man jedoch vermeiden, das Eigene und das Fremde zu essentialisieren (vgl. Bredella 2010a: 10), es also als homogen und unveränderlich wahrzunehmen, und man müsse immer bedenken, dass häufig die „Unterschiede zwischen Menschen ein- und derselben Kultur gravierender als die zwischen Menschen verschiedener Kulturen" sein können (Bredella 1999: 101). Wie Bredella neben vielen anderen Beispielen am Fall des chinesisch-amerikanischen Autors Eric Liu erläutert, sei die Rede vom chinesischen (amerikanischen, deutschen, etc.) ,Wesen' unter anderem deshalb gefährlich, weil sie schnell zu rassistischen Denkmustern führe, insbesondere dann, wenn das Eigene als „Maßstab für die Beurteilung des Fremden“ (Bredella 2001: 10) herangezogen werde. Dies sei 
besonders problematisch, wenn der ethnische und kulturelle Hintergrund von Einwanderern dazu diene, sie aus der aufnehmenden Gesellschaft auszuschließen (vgl. ebd.).

Bredella unterstreicht, dass in der - meist gut gemeinten - an Einwanderer gerichteten Ermunterung, ihre Kultur zu bewahren, die Falle des Rassismus lauere. Das Konzept ,Rasse` sei zwar heute meist durch das Konzept ,Kultur' ersetzt, strukturell gehe es aber in beiden Fällen darum, Menschen auf ihre Herkunft festzulegen, und möglicherweise auch darum, sie auf diesem Weg auszugrenzen (vgl. ebd.: 11).

Welche Chancen bietet nun der Fremdsprachenunterricht für das Fremdverstehen, worin liegt sein Potential für die Überwindung der Dichotomie zwischen Eigenem und Fremdem? Folgt man Duerrs oben zitierter Sicht, nach der dem Verstehen immer eine ,Nostrifizierung' vorausgeht, dann müsste man konsequenterweise auch bezweifeln, dass eine fremde Sprache verstanden werden kann. Die Annahme, dass lediglich durch die Übersetzung in die Muttersprache Verstehen möglich ist, wäre naheliegend. Das wäre aber ebenso die Illusion, echten' Verstehens wie der - angeblich ebenfalls zum Scheitern verurteilte - Versuch, eine fremde Kultur zu verstehen.

Bredella vertritt einen entgegengesetzten Standpunkt. Gerade in der Tatsache, dass die Annäherung an das Fremde im Medium einer fremden Sprache geschieht, sieht er eine besondere Stärke des Fremdsprachenunterrichts. Dieser erlaube es, ja erzwinge sogar, dass wir das Eigene - in jedem Fall die eigene Sprache hinter uns lassen: „Die fremde Sprache können wir uns jedoch nur aneignen, indem wir uns an sie anpassen" (ebd.: 12). Dies erstrecke sich ebenso auf den Bereich der Kultur:

Was wir über das Sprachenlernen gesagt haben, gilt auch für das Verstehen fremder Kulturen. Demnach können wir, entgegen Saids Ausführungen, fremde Kulturen in ihrer Andersheit verstehen. (ebd.)

Bredella greift zur Diskussion dieses entscheidenden Problems auf einen Beitrag des Philosophen Frithjof Rodi mit dem Titel Zur Metaphorik der Aneignung zurück (vgl. Rodi 1967). Rodi arbeitet dort die Dialektik des Begriffs heraus, die darin besteht, dass der Prozess der An-Eignung einerseits als „Besitzergreifung“ (ebd.: 435) vonstatten gehen kann, andererseits aber auch als Anpassung an das Fremde. Wenn Verstehen aber als Besitzergreifung abläuft, entsteht für Bredella die Gefahr, ...

[...] daß wir das Fremde auf das Eigene reduzieren, aber die Betonung der Inkommensurabilität der eigenen und der fremden Kultur verkennt nicht nur, wie Kulturen durch Interpretationen zustandekommen und sich ständig verändern, sondern führt auch zu 
einem Essentialismus, der die Fremden ausgrenzt, weil sie uns und wir ihnen immer fremd bleiben müssen. Aber die Erfahrung zeigt, daß wir Fremdsprachen und die Fremden unsere Sprache lernen können, so daß wir miteinander einen Dialog führen können. (Bredella 1994: 28f, Hervorhebung J. P.)]

In Bezug auf die zentrale Frage, ob ein Verstehen über kulturelle Grenzen hinweg jenseits von Ethnozentrismus grundsätzlich möglich ist, lässt sich Bredellas Argumentation somit wie folgt zusammenfassen:

1. Lernen und verstehen heißt, sich aneignen'

2. ,Sich aneignen' kann heißen, von etwas Besitz zu ergreifen. Es kann aber auch heißen, sich auf das Fremde einzulassen, selbst ein Stück weit Teil des Fremden zu werden.

3. Eine fremde Sprache kann man lernen, verstehen, man kann sie sich aneignen, man lässt sich also auf sie ein, wird ein Teil von ihr.

4. Für das Verstehen fremder Sprachen und fremder Kulturen gelten die gleichen Voraussetzungen.

5. Da fremde Sprachen lern- und verstehbar sind, gilt dies also auch für fremde Kulturen.

Das Verstehen einer fremden Kultur ist nach Bredella also möglich, weil auch das Verstehen einer fremden Sprache möglich ist. Es ist zudem insofern wünschenswert, als es hilft, die Beschränktheit und Provinzialität der eigenen Weltsicht zu überwinden.

Wie lässt sich jedoch das Dilemma des Fremdverstehens auflösen, das nach Bredella darin besteht, dass es im Spannungsfeld zwischen Ethnozentrismus auf der einen Seite und Glorifizierung des Fremden auf der anderen Seite stattfindet? Wie lassen sich „[...] gerade nicht die Phänomene der fremden Kultur unter die eigenen Deutungsschemata und Wertmaßstäbe subsumieren, sondern die der fremden Kultur rekonstruieren.“, wie Bredella (2001: 12) in Anlehnung an Clifford Geertz und Oswald Schwemmer formuliert? Im Gießener Kolleg wurde hierfür das Konzept des Dialogs (auch: Vermittlung, Dialektik) zwischen Außen- und Innenperspektive entwickelt (vgl. Bredella 1999: 111-114; Bredella et al. 2000: XIXff.; Bredella 2001: 12f; Bredella 2010a: XXIIf.). Der Begriff des Dialogs sei, so Bredella, zentral, um das Verhältnis zwischen dem ,Ich` und dem ,Anderen` zu verstehen. Unter Rückgriff auf Michail Bachtin ${ }^{74}$ und Michael

74 In der englischsprachigen Literatur dominiert die Schreibung Mikhail Bakhtin, seltener Mihail Bahtin. Die im Deutschen übliche Transliteration mit „ch“ gibt die Lautung im Russischen am besten wieder (stimmloser velarer Frikativlaut, kyrillischer Buchstabe „cha“, geschrieben „x“). 
Holquist betont er, dass sich das Ich erst im Dialog mit dem Anderen konstituieren könne: Alterität sei die Bedingung von Identität. Erst der Blick von außen, mit den Augen des Anderen, erlaube es, dass wir uns selbst verstehen, und nur so sei die Herausbildung einer Identität möglich:

For in order to see ourselves, we must appropriate the vision of others. [...] it is only the other's categories that will let me be an object for my own perception. I see my self as I conceive others might see me. In order to forge a self, I must go outside. ${ }^{75}$ (Holquist 1990: 28; vgl. Bredella 2010a: XXIIf.)

In diesem Sinne bestehe das Ziel des interkulturellen Fremdsprachenunterrichts darin, den Dialog zwischen dem Ich und dem Anderen, zwischen dem Eigenen und Fremden in Gang zu setzen. Der Prozess der Erkenntnisgewinnung in der Auseinandersetzung mit dem Fremden erfolge grob in drei Schritten, die auch ein methodisches Vorgehen nahelegten (vgl. Bredella et al. 2000: XLI): Die Annäherung an das Fremde erfolge üblicherweise (1) von einer Außenperspektive aus. Entscheidend sei nun, sich (2) auch auf die Innenperspektive des Fremden einzulassen, um so die Gefahr des Ethnozentrismus zu überwinden. Schließlich komme es (3) darauf an, beide Perspektiven kritisch zu konfrontieren, und in der „Spannung zwischen Innen- und Außenperspektive“ könne sich „reflektiertes interkulturelles Verstehen [vollziehen]“ (Bredella 2001: 12). Den Begriff der Außenperspektive differenziert Bredella in Anlehnung an diesen Dreischritt aus, bleibt dem Modell aber treu, wenn er das Verstehen im Licht des eigenen Vorverständnisses als „Außenperspektive I“, das durch die zeitweise Übernahme der (fremdkulturellen) Innenperspektive aktualisierte Verstehen als „Außenperspektive II“ definiert (Bredella 2007: 24). Eben diese Vermittlung von Innen- und Außenperspektive durch Ingangsetzung eines konstruktiven Dialogs zwischen Innen- und Außenperspektive ist nach Auffassung Bredellas der Kern des interkulturellen Fremdsprachenlehrens und -lernens (vgl. Bredella 1999: 111).

Im Spannungsfeld zwischen Innen- und Außenperspektive lässt sich auch der Unterschied herausarbeiten, der nach Bredella zwischen, Verstehen' und, Verständigung' liegt. Bredella verteidigt ja die Möglichkeit, eine fremdkulturelle Innenperspektive einzunehmen, gegen zahlreiche Einwände (s. o.). Wenn dies gelinge und der Perspektivenwechsel vollzogen werde, könne von, Verstehen' gesprochen werden (vgl. Bredella 1999: 112)., Verständigung ' hingegen gehe noch einen Schritt weiter: Sie liege dann vor, wenn es zu einem Vermittlung zwischen

75 Mit dem Anschluss an Bachtins Dialogismus positioniert sich Bredella gegen alle Ausprägungen radikal-konstruktivistischen Denkens, denen er vorwirft, sie seien „monologisch“ (Bredella 2010a: XXIII). 
Innen- und Außenperspektive komme. Verständigung in diesem Sinne bedeute jedoch keineswegs, dass stets ein Konsens erzielt werden müsse. Zentral sei vielmehr die grundsätzliche Bereitschaft zum Dialog, die Anerkennung fremder Sichtweisen als prinzipiell gleichwertig und die Bereitschaft, den eigenen Standpunkt in Frage zu stellen (vgl. Bredella et al. 2000: XXVIIIf; Bredella 1999: 113). Teil von Verständigung könne also durchaus sein, den Dissens herauszuarbeiten und sich darauf zu einigen, dass man sich uneinig ist („we agree that we disagree“, Bredella et al. 2000: XXIX) - eine Haltung, durch welche im Fremdsprachenunterricht allgemeine Erziehungsziele wie „Kritikfähigkeit, Toleranz, Metakommunikation und Verständigung" (Bredella 1999: 114) verfolgt werden könnten.

\subsubsection{Die Didaktik des Fremdverstehens im Licht der Forschungsfragen}

In den folgenden Abschnitten sollen die Grundlagen der Didaktik des Fremdverstehens, wie sie oben dargestellt wurden, im Licht der beiden ersten Forschungsfragen diskutiert werden. Dabei führe ich einerseits Passagen aus Beiträgen zur Didaktik des Fremdverstehens an, in denen explizit thematisiert wird, welches Kulturverständnis diesem Ansatz zugrunde liegt bzw. wie sich die Autoren zum Dilemma von Universalismus und Kulturrelativismus selbst verorten. Andererseits beziehe ich mich auf Beispiele, welche zur Illustration der Didaktik des Fremdverstehens angeführt werden, und versuche zu ermitteln, welches Kulturverständnis bzw. welche Haltung zum Dilemma zwischen Universalismus und Kulturrelativismus dort jeweils implizit zugrunde liegt.

Wie oben gezeigt wurde, stellt die Frage nach der grundsätzlichen Möglichkeit von Fremdverstehen eine Kernfrage der Didaktik des Fremdverstehens dar. Das Anliegen besteht darin, einen dritten Standpunkt zwischen dem Eigenen und dem Fremden zu finden. Hierdurch soll zwischen zwei Extremen vermittelt werden, die als, Ethnozentrismus' auf der einen Seite und,vollständige Identifikation mit dem Fremden' beschrieben werden können. Dieser dritte Standpunkt komme durch das Prinzip der Dialogizität zustande und ermögliche Verständigung.

Die Didaktik des Fremdverstehens bewegt sich somit in großer Nähe zum Verstehensmodell der literarischen Hermeneutik, deren zentraler Begriff der Horizont ist. Mit Horizont sind die Bedingungen gemeint, unter denen jeder Verstehensprozess stattfindet, in den Worten Hans-Georg Gadamers (1975: 286) der „[...] Gesichtskreis, der all das umfaßt und umschließt, was von einem Punkte aus sichtbar ist." Jedes literarische Werk entstehe unter der Wirkung eines je eigenen Horizonts, und daher gehe es beim literarischen Verstehensprozess darum, die hermeneutische Differenz zwischen verschiedenen Horizonten zu überbrücken, 
und zwar dem des Lesers und dem des Werks. Durch die Verschmelzung dieser Horizonte komme der Verstehensprozess voran. Dieser sei aber stets vorläufig und unabschließbar. Vielmehr entstehe durch jedes Verstehen ein neuer Horizont und damit die Grundlage für immer neue Verstehensprozesse. Diese vollziehen sich wiederum in der Überbrückung der hermeneutischen Differenz zwischen verschiedenen Horizonten, so dass ein hermeneutischer Zirkel entstehe.

In der Didaktik des Fremdverstehens wird der Verstehensprozess bei kultureller Fremdheit nun als strukturgleich zum Verstehensprozess modelliert, der in jeder Auseinandersetzung mit einem literarischen und daher ebenfalls fremden Werk zu durchlaufen ist. Der erkenntnistheoretische Nachweis jedoch, dass auch kulturelle Fremdheit (in der Sprache der Hermeneutik: die hermeneutische Differenz) prinzipiell überbrückbar und Verstehen somit möglich ist, wird, wie oben dargestellt, in Analogie zur Möglichkeit erbracht, dass Menschen eine fremde Sprache lernen und verstehen können. Dies bedeutet jedoch, dass Sprache und Kultur implizit gleichgesetzt werden. Eine solche Gleichsetzung ist aber im Sinne eines bedeutungs- und wissensorientierten Kulturverständnisses problematisch, da es auf ein totalitätsorientiertes Kulturverständnis mit der Tendenz zur Gleichsetzung von Nation, Sprache und Kultur hindeutet. Von einem solchen Kulturverständnis distanziert sich Bredella jedoch mehrfach mit Nachdruck (Bredella et al. 2000: XIII-XIX, Bredella 2010a: 136f.).

Die häufig auf Humboldt sowie auf Sapir und Whorf zurückgeführte Vorstellung der Verknüpfung einer Sprache mit einem bestimmten Weltbild lehnt er entschieden $\mathrm{ab}$ und erinnert daran, dass die These zumindest von Whorf präzisiert worden sei. Dieser habe betont, dass das Weltbild, das eine bestimmte Sprache transportiere, sowohl durch Reflexion als auch durch das Erlernen einer fremden Sprache durchbrochen werden könne, eine Einschätzung, der sich Bredella ausdrücklich anschließt (vgl. Bredella 1999: 87). Zudem belege die postkoloniale Literatur, dass man mit einer Sprache verschiedene Weltbilder zum Ausdruck bringen könne. Autoren wie Chinua Achebe bewiesen, dass man die Sprache der Besatzer auch gegen diese wenden könne. Wenn gegen Autoren, die in der Sprache der früheren Kolonialherren schreiben, manchmal der Vorwurf des Verrats erhoben werde, sei dies daher nicht gerechtfertigt (vgl. ebd.: 88).

Ebenso deutlich wie Vorstellung von sprachlichem Determinismus kritisiert Bredella (ebd.: 91) die Vorstellung von kulturellem Determinismus:

Kultur determiniert nicht das Handeln der Menschen, sondern schafft für sie nur einen Rahmen, in dem sie handeln. Es ist eine Schwäche des interkulturellen Lernens, daß es oft den Eindruck vermittelt, als bräuchte man nur über Gewohnheiten, Werte und 
Einstellungen der fremden Kultur Bescheid wissen, um die Menschen dieser Kultur zu verstehen.

Menschen hätten vielmehr die Fähigkeit, sich reflexiv, kreativ und kritisch von ihrer eigenen Kultur zu distanzieren und seien daher nicht auf ein bestimmtes Denken oder Handeln festgelegt (vgl. ebd.).

Zusammenfassend lässt sich also festhalten, dass die Didaktik des Fremdverstehens sich explizit auf ein Kulturverständnis beruft, in dem Sprache und Kultur sich nicht gegenseitig determinieren, sondern in einem historisch gewachsenen dialektischen Abhängigkeitsverhältnis stehen (vgl. Bredella et al. 2000: XVII). Darüber hinaus erteilt Bredella auch Vorstellungen von intrakultureller Homogenität eine entschiedene Absage. Unter Berufung auf Hans Joas, Hans-Georg Gadamer, Günter Figal und Ram A. Mall unterstreicht er die Möglichkeit von Differenzerfahrungen innerhalb einer Kultur und betont, „[...] dass wir mit Menschen anderer Kulturen mehr gemeinsam haben können, als mit Menschen aus der eigenen Kultur [...]“, und dass dies eine „Grundeinsicht der interkulturellen Kompetenz" sei (Bredella 2010a: 137). Sprachen und Kulturen eröffneten und erweiterten für Individuen Spielräume des Denkens und Handelns. Dies sei ein Prozess, der neben Bereicherungen durchaus auch Herausforderungen bereithalte (vgl. ebd.: XXIXf.).

Die explizit erläuterten Grundlagen der Didaktik des Fremdverstehens sind somit nah an einem bedeutungs- und wissensorientierten Kulturverständnis zu verorten, bei dem Kultur als ein vielschichtiges, heterogenes Phänomen angenommen wird (vgl. Kap. 2.1.4.). Das angeführte erkenntnistheoretische Argument, dass das Verstehen einer fremden Kultur prinzipiell möglich sei, da auch das Verstehen einer fremden Sprache möglich sei, wird durch ein solches Kulturverständnis jedoch unterlaufen. Nur wenn man von einem totalitätsorientierten Kulturverständnis mit einer Entsprechung von Sprache und Kultur ausgeht, kann man diesen Analogieschluss ziehen und aus der Möglichkeit, eine Sprache $\mathrm{zu}$ verstehen, die Möglichkeit ableiten, eine Kultur zu verstehen (vgl. Bredella 2001: 12). Wenn man dagegen von einem bedeutungs- und wissensorientierten Kulturverständnis ausgeht, ist dies nicht zulässig. Bredella ist daher auf den zumindest temporären Rückgriff auf ein totalitätsorientiertes Kulturverständnis angewiesen, auch wenn in seinen Ausführungen ansonsten ein bedeutungs- und wissensorientiertes Kulturverständnis dominiert.

Auf welches Kulturverständnis wird nun implizit in den Beispielen zurückgegriffen, mit denen die Didaktik des Fremdverstehens illustriert wird? Bredella führt in einer Publikation die Autobiographie Lost in Translation von Eva Hoffmann an, in dem die Autorin ihre Erfahrungen als polnische Immigrantin im 
Kanada der 1950er-Jahre verarbeitet (vgl. Bredella 1999: 95). ${ }^{76}$ Hoffmann beschreibt und reflektiert dort ihre Erlebnisse als 13-jähriges, frisch im neuen Land angekommenes Mädchen. Hierbei wird sie in verschiedenen Situationen darauf aufmerksam, dass die semantischen Grenzen in ihrer Erstsprache Polnisch und im Englischen unterschiedlich verlaufen. So bemerkt sie etwa am Beispiel ,friendship' vs. ,acquaintance', dass ,friendship' weiter gefasst zu sein scheint als die polnische Entsprechung. Auch Gesten, so Hoffman, würden in Kanada ganz anders interpretiert als in Polen. Für Peggy, Evas kanadische Freundin, sei etwa das freundschaftlich gemeinte Unterhaken des Arms beim gemeinsamen Spaziergang eine peinliche Angelegenheit („,an embarrassment“, zit. nach Bredella 1999: 96). Auch das kanadische ,dating` wird von Eva als von den Gepflogenheiten in Polen abweichend wahrgenommen. Die Differenz in diesem Bereich empfinde sie gar so stark, dass sie das, dating', so Bredella (ebd.), ,[...] mit den Augen eines Anthropologen betrachtet.“

Die wenigen bei Bredella aufgeführten Beispiele genügen um deutlich zu machen, dass Peggy und Eva in Hoffmans Autobiographie als Vertreterinnen von Sprache A (Englisch) und Kultur A (Kanada/Nordamerika) bzw. Sprache B (Polnisch) und Kultur B (Polen) dargestellt werden. Dieser Interpretation von Evas Fremdheitserfahrungen schließt sich Bredella vorbehaltlos an. So gibt er erklärend zu Protokoll:

Es wird in der nordamerikanischen Kultur erwartet, daß man Menschen mit positiven Adjektiven und Substantiven beschreibt. Das hat zur Folge, daß ,kindliness' und ,kindness' im Englischen einen ganz anderen Stellenwert als die entsprechenden Worte im Polnischen besitzen und auf eine andere kulturelle Logik verweisen. (ebd.: 95)

Die Möglichkeit, dass die Autorin selbst Stereotypen sowohl über ,die polnische als auch über ,die kanadisch/nordamerikanische' Kultur (re-)konstruiert, wird von Bredella nicht reflektiert. Der zeitliche Abstand der Autorin zum erzählten Geschehen und ihre inzwischen erfolgte Hochschulbildung erinnern jedoch daran, dass auch autobiographisches Schreiben als Fiktionalisierung von realen Erlebnissen zu lesen ist. Zumindest als Möglichkeit sollte daher in Betracht gezogen werden, dass Eva Hoffmans Erinnerungen von einem totalitätsorientierten Kulturverständnis beeinflusst sein könnten. Auf diese Möglichkeit deutet eine weitere Passage aus Lost in Translation hin, die von Bredella (1999: 96) ebenfalls zitiert wird:

76 Eva Hoffmanns autobiographisches Werk ist nicht zu verwechseln mit dem unter dem gleichen Titel bekannten Film von Sofia Coppola (2003). 
Cultural distances are different, I later learn in a sociology class, but I know it already. I learn restraint from Penny, who looks offended when I shake her by the arm in excitement, as if my gesture had been one of aggression instead of friendliness. (Hoffman 1990: 146)

Kennt die 13jährige Eva wirklich schon die wahren Gründe für Peggys irritierende Reaktion, oder handelt es sich um einen Erklärungsansatz, mit dem Hoffman einem Fremdheitserlebnis ihrer Jugend nach vielen Jahren Sinn verleiht, indem sie es als kulturell bedingt interpretiert? Bredella weist unter Rückgriff auf Gertrud Nunner-Winkler selbst auf das Phänomen des kategorialen Denkens hin, das als Grundprinzip menschlicher Kognition gilt. Es zeichnet sich nach Nunner-Winkler durch die Hauptmerkmale Generalisierbarkeit, Essentialismus und Beständigkeit aus (vgl. Bredella 1999: 109). Bredella kommt daher zu der Einschätzung, dass „Kategorisieren und Stereotypisieren unvermeidlich“ (ebd.) seien. Vielleicht beruhen auch die Jugenderinnerungen Eva Hoffmans auf diesem Phänomen? Bredella warnt zu Recht vor der „Überzeugungskraft des kategorialen Denkens“ und betont, dass hierbei „sprachliches und interkulturelles Lernen eine wichtige Aufgabe" hätten (ebd.). Seine eigene Interpretation der von Eva Hoffman geschilderten Erlebnisse als Immigrantin in Kanada bleibt jedoch an eben jener entscheidenden Stelle blind, wo es darum geht, die von der Autorin vorgenommenen Kategorisierungen und Stereotypisierungen von Fremdheitserlebnissen kritisch zu reflektieren. ${ }^{77}$

Eine solche Reflexion könnte verschiedene Aspekte in den Blick nehmen: Inwiefern werden eine 13-jährige Polin und ihre kanadische Freundin in Hoffmans Autobiographie als Repräsentantinnen der polnischen bzw. kanadischen Kultur dargestellt? Inwiefern erfolgt eine Gleichsetzung von polnischer Sprache und polnischer Kultur einerseits, von englischer Sprache und kanadisch/nordamerikanischer Kultur andererseits? Inwiefern können Heranwachsende auch in ihrer ,eigenen' Kultur starke Fremdheitserlebnisse haben? Inwiefern sind die Erlebnisse von Eva daher möglicherweise nicht durch kulturelle Differenz, sondern aus der Spannung zwischen individuellen Vorstellungen und gesellschaftlichen Normen zu erklären, mit denen sich jeder Teenager und jede Teenagerin auseinandersetzen muss? Inwiefern ergeben sich die Irritationen zwischen Eva und Peggy vielleicht aus unterschiedlich ausgeprägten Persönlichkeitsmerkmalen wie Extra- bzw. Introversion?

77 Bredella greift seine Interpretation von Hoffmans Autobiographie in einer späteren Publikation (2010b: 26) noch einmal auf und bekräftigt sie mit Nachdruck. 
Bredella interpretiert Evas Schwierigkeiten in Kanada jedoch in Anlehnung an Hoffman durchgehend als „Spannungen zwischen der nordamerikanischen und der polnischen Kultur" (ebd.: 95) und somit als Beispiele für interkulturelle Fremdheitserfahrungen. Bredellas Interpretation von Eva Hoffmans Autobiographie Lost in Translation zeigt daher meiner Einschätzung nach auf sehr anschauliche Weise, wie Denken in den Kategorien der Interkulturalität zum Rückgriff auf ein nationalkulturelles Kulturverständnis und damit im Sinne von Reckwitz $\mathrm{zu}$ einer Invisibilisierung von Kontingenzen führen kann. Diese Nationalkulturen scheinen sich durch eine Art Essenz auszuzeichnen, der man auf die Spur kommen kann, wenn man auch populärkulturelle Artefakte in den Blick nimmt. Für England ist dies die Englishness, zumindest in der Darstellung von Bredella, Meißner, Nünning und Rösler (2001: XLIII, Hervorhebungen im Original):

Um etwa Einblick in jene mentalen und sozialen Traditionen zu gewinnen, die für ein Verständnis von Englishness grundlegend sind, eignen sich etwa die Filme von Monty Python, soap operas wie Coronation Street oder die ,Hofberichterstattung ' über das fröhliche Treiben der Windsors besser als die meisten Werke der highbrow literature.

Eva und Peggy werden in dieser Perspektive zu Vertreterinnen der ,Polishness und der,Canadianness', so dass Bredellas Interpretation nur noch wenige Merkmale eines bedeutungs- und wissensorientierten Kulturverständnisses aufweist und eher auf ein totalitätsorientiertes Kulturverständnis zurückgeführt werden kann. Kontingenzen im Verhalten der literarischen Figuren werden hierdurch eher invisibilisiert als offengelegt.

Wenden wir uns der zweiten Frage zu, jener nach der Einnahme eines kulturrelativistischen Standpunktes. Hierbei ist zunächst hervorzuheben, dass Bredella einen radikalen erkenntnistheoretischen Relativismus entschieden ablehnt. Seinen diesbezüglichen Standpunkt hat er ausführlich und mit Nachdruck herausgearbeitet (vgl. Bredella 1994, 2010a: XVII-XXII; Bredella et al. 2000: XIII-XIX). Auch das Problem des ethischen Relativismus, der sich aus einem kulturrelativistischen Standpunkt ergibt, wird von Bredella und anderen Mitgliedern des Gießener Kollegs thematisiert, wenn auch wesentlich weniger ausführlich. So erwähnen Bredella, Meißner, Nünning und Rösler in der Einleitung zum Sammelband Wie ist Fremdverstehen lehr- und lernbar? in einem Abschnitt über den „Dialog zwischen Außen- und Innenperspektive“ (Bredella et al. 2000: XXIIIf.) ein Beispiel, in dem ein solcher Dialog an eine Grenze stoßen kann:

Stellen wir uns vor, dass in einer traditionellen Gesellschaft einer jungen Frau vorgeworfen wird, sie habe die Ehre ihrer Familie verletzt, weil sie sich allein mit einem Mann in einem Zimmer aufgehalten habe und daher geächtet werden muss. Werden wir uns an der Verurteilung dieser Frau beteiligen, weil alle Werte kulturbedingt und alle Kulturen 
gleichwertig sind? [...] Sicherlich liegt in dem Beharren auf der eigenen Auffassung die Gefahr des Ethnozentrismus, aber andererseits erscheint es in manchen Fällen auch notwendig zu sein, an unserer Auffassung festzuhalten, um unsere Selbstachtung nicht zu verlieren. (ebd.: XXIV)

In deutlicheren Worten werden in einem anderen Beitrag die Grenzen des ethischen Relativismus genannt. Unter strikter Ablehnung einer von Hillis Miller formulierten radikal relativistischen Position vertritt Bredella (1994: 27) dort darauf hin, dass ein solcher Standpunkt nicht einmal die Beurteilung von Rassismus oder Völkermord erlaube:

Wenn nur die Entscheidung ethisch ist, die keine ethischen Entscheidungen fällt, dann bedeutet dies, daß wir einen Rassisten wegen seines inhumanen Verhaltens nicht verurteilen dürfen, weil unser ethisches Verhalten genauso grundlos ist wie das seinige, mit dem er andere diskriminiert, und daß wir, indem wir sein Verhalten kritisieren, das praktizieren, was wir an ihm kritisieren, nämlich intolerant zu sein.

Ein solcher Relativismus sei keine Grundlage, „[...] um interkulturelles Verstehen und Zusammenleben zu ermöglichen“" (ebd.).

Auch einige Bemerkungen zum Thema Toleranz sind in diesem Zusammenhang von Interesse. Sie finden sich in einem Abschnitt, in dem Bredella (1999: 102) das Verhältnis von "sprachlichen Lern- und allgemeinen Erziehungszielen“ erörtert. Er unterstreicht dort in Anlehnung an Werner Becker, dass Toleranz keineswegs die Aufgabe jeder ethischen Norm bedeute. Um Toleranz handle es sich vielmehr dann, wenn Verhalten nach einer abweichenden Norm als solches erkannt, jedoch ausgehalten werde. Dennoch müsse dann „[... i im einzelnen erörtert werden [...], wo die Grenzen der Toleranz liegen“ (ebd.: 104).

Die angeführten Passagen zeigen, dass das Problem des ethischen Relativismus innerhalb der Didaktik des Fremdverstehens durchaus thematisiert wurde. Es ist jedoch eine eigentümliche Scheu davor zu spüren, in Betracht kommende ethische Normen beim Namen zu nennen, wie sie z.B. in der Allgemeinen Erklärung der Menschenrechte der Vereinten Nationen zu finden sind..$^{78}$ Über die Gründe hierfür lässt sich nur spekulieren. Es könnte zumindest eine Rolle spielen, dass die Menschenrechte, wie in Kapitel 2.2.3. ausführlich dargestellt, aus kulturrelativistischer Sicht häufig als ethno- bzw. eurozentrisch kritisiert werden. Zwar werden einzelne Konflikte, die sich aus inkommensurablen Weltsichten ergeben können, vereinzelt genannt, wie etwa die Frage, ob Frauen diskriminiert werden dürfen oder nicht, ob Rassismus und Völkermord zulässig sind oder nicht, etc. Welche normativen Setzungen es erlauben, in diesen Fällen einen

78 Eine Ausnahme stellt ein Beitrag Franz-Joseph Meißners (1999) dar. 
ethisch vertretbaren Standpunkt zu finden, bleibt jedoch eigentümlich vage. Es scheint entweder selbstevident zu sein, welche Normen in Frage kommen, damit „im einzelnen erörtert werden“ (Bredella 1999: 104) kann, wo die Grenzen der Toleranz liegen. Bisweilen werden solche Normen aber auch als Teil der „unserer Auffassung" (Bredella et al. 2000: XXIV) schlicht vorausgesetzt. Diese Formulierung ist in doppelter Hinsicht problematisch: Wenn es um die entscheidende Frage der Akzeptanz der Menschenrechte geht, unterstellt sie Lernenden entweder eine kulturelle Homogenität, oder es wird suggeriert, dass diese als selbstevidente Grundlage „unserer Auffassung“ zu übernehmen sei. In beiden Fällen besteht die Gefahr, dass Machtstrukturen, welche der Legitimierung und Durchsetzung der Menschenrechte (oder ihrer Missachtung) zugrunde liegen, nicht offengelegt und reflektiert, sondern invisibilisiert werden.

Neben den genannten Passagen, die sich explizit dem Dilemma zwischen Universalismus und Kulturrelativismus widmen, möchte ich abschließend ein weiteres literarisches Beispiel diskutieren, bei dem dieser Konflikt augenfällig wird. Bredella verwendet es zur Illustration der „Dialektik von Eigenem und Fremdem beim interkulturellen Verstehen" (vgl. Bredella 2001). Dabei handelt es sich um die Erzählung The discipline des aus Barbados stammenden, seit 1955 in Kanada lebenden Schriftstellers Austin Clarke (vgl. Clarke 2003). Da sie bereits in Kapitel 1.7. zusammengefasst wurde, gehe ich nun direkt der Frage nach, welches Kulturverständnis Bredellas Interpretation zugrunde liegt und inwiefern diese in Bezug auf das Dilemma zwischen Universalismus und Kulturrelativismus verortet werden kann. Gerade für den zweiten Aspekt ist Clarkes Erzählung möglicherweise besonders aufschlussreich, da in ihr ein Jugendlicher von seinem Vater brutal verprügelt wird. Zumindest eines der Themen der Erzählung ist somit das Problem von Gewalt als Mittel der Erziehung. Dem liegt die Frage zugrunde, inwieweit das Recht des Jugendlichen auf körperliche Unversehrtheit verletzt wurde, ein Recht, das in den Artikeln 3 („Everyone has the right to life, liberty and security of person.“) und 5 („No one shall be subjected to torture or to cruel, inhuman or degrading treatment or punishment.") der Allgemeinen Erklärung der Menschenrechte als universell angenommen wird (UN General Assembly 1948).

Bredella berichtet, dass die Lektüre der Erzählung immer wieder zu erheblichen Irritationen unter seinen Studierenden geführt habe. Diese befürchteten, dass das Verhalten des Vaters legitimiert werden soll. Bredella (2001: 14) argumentiert jedoch, dass es bei der Lektüre von Clarkes Erzählung keineswegs darum gehe, das Verhalten des Vaters zu rechtfertigen, sondern vielmehr darum, „die Innenperspektive des Erzählers einzunehmen“. Genau in diesem Punkt versagten nach Bredellas Einschätzung die am Prozess beteiligten Personen: „Aber 
weder Rechtsanwältin noch Sozialarbeiterin und Richter lassen sich auf das, was er sagt, ein, sondern beurteilen ihn nach ihren jeweiligen Außenperspektiven“" (ebd.). Dies sei, so deutet Bredella zumindest an, Ausdruck von Ethnozentrismus:

Aber es ist fraglich, ob diese Gesellschaft, die ihn zu einer Gefängnisstrafe von sechs Monaten verurteilt, um ihre Werte zu verteidigen, wirklich, zivilisiert' ist und ob sie nicht bei der Verurteilung des Angeklagten ethnozentrisch handelt. (ebd.)

Implizit werden somit der Richter, die Sozialarbeiterin und sogar die Anwältin zu Vertretern von Kultur A (Kanada/Nordamerika), die allesamt in einem ethnozentrischen Denken verhaftet sind und in Ermangelung der Fähigkeit, echtes Fremdverstehen zu zeigen, den Vertreter von Kultur B (Barbados) aburteilen. Ich teile Bredellas Einschätzung in Bezug auf ethnozentrisches Denken der, Gesellschaft' zwar nicht; zumindest aus den Äußerungen der Sozialarbeiterin spricht jedoch ein totalitätsorientiertes Kulturverständnis. Diese kann ohne Zweifel zu ethnozentrischem Denken führen. Die Absicht der Sozialarbeiterin ist jedoch das genaue Gegenteil: „I would recommend a light sentence, under the circumstances, Your Honour" (vgl. Clarke 2003: 16). Sie plädiert also dafür, den kulturellen Hintergrund des Angeklagten als mildernden Umstand geltend zu machen. Einzig aus einer Äußerung des Richters spricht offener Ethnozentrismus: „They must be taught a lesson, that they're not back in the West Indies" (ebd.). Hier deutet sich an, dass der Angeklagte auf Grundlage seines kulturellen Hintergrundes mit einem besonders strengen Strafmaß rechnen muss. Beide Standpunkte stehen im Widerspruch zum Prinzip der Gleichheit vor dem Gesetz.

Dagegen bleibt die Anwältin mit ihrer Weigerung, mit einer kulturalistischen Argumentation mildernde Umstände für ihren Mandanten zu erwirken, nicht nur dem Prinzip der Gleichheit vor dem Gesetz treu. Vielmehr weigert sie sich auch, das Verhalten ihres Mandanten als kulturell determiniert zu interpretieren und gibt ihm damit einen Teil jener Individualität zurück, die ihm im Prozess sowohl vom Richter als auch von der Sozialarbeiterin verweigert wird. Bezeichnenderweise ist es deren Aussage als Expertin, die den wütenden Protest des Angeklagten verursacht. Hintergrund der Tat sei die „predisposition for cultural violence among West Indian parents“ (ebd.: 14), und diese sei historisch auf die Sklaverei zurückzuführen.

Die Erklärungen des Angeklagten, die sich aus den Dialogen außerhalb der Gerichtsverhandlung sowie aus seinen Erzählerkommentaren ergeben, kreisen um andere Themen: um die Selbstverständlichkeit von körperlichen Strafen in seiner eigenen Kindheit, um seine Frustrationen im Umgang mit verschiedenen, von ihm immer wieder als dominant erlebten Frauen sowie um die Aussagen der Bibel, die sein Verhalten gegenüber dem Sohn aus seiner Sicht eindeutig 
legitimierten. Diese Erklärungen geben dem Erzähler die Individualität, die ihm im Gerichtsprozess verweigert wird. In Bredellas Beitrag finden sie jedoch mit Ausnahme der „Fürsorge und Strenge“ der Großmutter (ebd.: 13) keine Erwähnung.

Dreh- und Angelpunkt in Bredellas Argumentation ist der angebliche Mangel an Fremdverstehen, den das kanadische Gericht im Umgang mit einem Immigranten an den Tag legt. Möglicherweise kommt er nur zu diesem Ergebnis, weil er die geschilderte Begebenheit als interkulturellen Konflikt deutet. Blendet man jedoch die Herkunft des Vaters bei der Interpretation der Erzählung aus, bietet sich ein anderes Bild. Man sieht einen Mann, der auf der Grundlage religiöser und durch persönliche Erfahrung geprägter Vorstellungen über seine väterlichen Rechte in Konflikt mit dem Gesetz gerät. Die Art, wie der Justizapparat mit ihm umgeht, empfindet er als ent-individualisierend. Als wäre er ein Laubblatt oder eine störende Bananenschale („I was a dried fallen leaf that had to be raked away [...] Or a piece of banana skin kicked out of the way [...]", Clarke 2003: 15), fühlt er sich zum Objekt einer gut geölten Maschine degradiert, die mit großer Effizienz für Ordnung sorgt. Zwar kennt er, im Gegensatz zu Josef K., Kafkas Protagonist in Der Prozess, den Grund der Anklage. Dennoch hat sein Erlebnis insofern kafkaeske Züge, als er die Anklage für ungerechtfertigt hält und daher nicht versteht, was mit ihm geschieht. Vielmehr hält er sein Verhalten unangefochten für legitim. Dies gibt er zumindest nach der Verhandlung im Gespräch mit einer Psychiaterin zu Protokoll:

,The system has done you harm, hasn't it?

I nod.

[...]

,If your son left potato chips on the couch or on the carpet again, would you knock him down? You would knock him down again with your fist, wouldn't you?

I nod. (ebd.: 16)

Die Pointe an Clarkes Erzählung liegt aus meiner Sicht gerade darin, dass sie eine interkulturelle Deutung unterläuft. Vielmehr bietet sie Lesern verschiedene Diskurse an (kulturalistisch, juristisch, religiös, alltagsbezogen, medizinisch/ psychiatrisch, feministisch ${ }^{79}$ ), mit denen sich die brutale ,Disziplinierung des Jugendlichen deuten ließe. Keiner der in Frage kommenden Diskurse bietet jedoch eine hinreichende, zufriedenstellende Erklärung für das Verhalten des Vaters. Vielmehr erzeugen all diese Diskurse neue Leerstellen, die den Leser und

79 Die Erzählung wurde zuerst 1985 in einer Sammlung mit dem Titel When women rule veröffentlicht. 
die Leserin ähnlich verstört zurücklassen wie den Protagonisten selbst. ${ }^{80}$ Bredella versäumt es, die verschiedenen Lesarten auszuloten, die sich im Anschluss an verschiedene Diskurse ergeben. Auf der Suche nach „kreativen Antworten, die das Fremde und Eigene überschreiten" (Bredella 2001: 14), übersieht er nicht nur, dass in Clarkes Erzählung vielfältige Diskurse angeboten und doch verworfen werden. Er übersieht auch, dass menschliches Verhalten manchmal Fragen aufwirft, auf die es keine Antworten gibt.

Der Aufschrei, den die kulturalistische Festlegung durch die Sozialarbeiterin beim Protagonisten von The discipline auslöst, könnte auch als Protest des Autors dagegen gelesen werden, dass sein Werk bis heute meist aus kulturalistischer Perspektive gelesen wird: als postkoloniale Literatur.

Die ethische und machtbezogene Dimension der Erzählung wird in Bredellas Beitrag nicht reflektiert, was einer Invisibilisierung gleichkommt. Zwar räumt Bredella ein, dass die Einwände seiner Studierenden gegen das Einfühlen in die Innenperspektive eines Vaters, der seinen Sohn krankenhausreif geschlagen hat, „nicht ungerechtfertigt" (ebd.: 14) seien. Eine Analyse der komplexen Diskursstruktur der Erzählung bleibt jedoch aus. Bredella empfiehlt lediglich, nach einer kreativen Antwort zu suchen, die ,über unsere Auffassungen als auch die des Textes hinausgeht" (ebd.). Möglicherweise zeigt jedoch gerade die Schwierigkeit, für Clarkes Erzählung eine solche Antwort zu finden, nicht nur die Grenzen der Didaktik des Fremdverstehens, sondern jeder Form hermeneutischen Verstehens.

\subsection{Interkulturalität als, Dritter Ort': Claire Kramschs Konstrukt der, Thirdness'}

\subsubsection{Problemstellung der, Thirdness}

Wie Lothar Bredella stellt sich auch Claire Kramsch der Frage nach einer sinnvollen Modellierung des Verstehens kultureller Differenz im Kontext des Lehrens und Lernens fremder Sprachen. Die Eckdaten ihrer Biographie verweisen auf eine Vielfalt sprachlicher und kultureller Einflüsse. Geboren 1935 als Tochter eines französischen Vaters und einer polnisch-ungarischen Mutter, die einer jüdischen Familie entstammte und zum Katholizismus konvertierte, wächst Kramsch in Reims auf und studiert in Paris Germanistik. Nach ihrer Emigration in die USA zeigt sie ab 1963 intensive Lehr- und Publikationstätigkeiten,

80 Insofern handelt es sich um keine Bildungs-Erzählung, eine Eigenschaft, die The discipline mit Jeffrey Eugenides' Roman The virgin suicides teilt.Vgl. Kap. 4.4.2. und Koller 2012: 170-184. 
zunächst in Cambridge/Massachusetts, ab 1990 dann in Berkeley/Kalifornien. In Bezug auf die Diskussion im deutschsprachigen Raum ist insbesondere zu erwähnen, dass Kramsch als Germanistin nicht nur interessiert und in der Lage ist, diese zu rezipieren, sondern sich auch mit Beiträgen in Deutsch und Englisch aktiv an dieser Diskussion beteiligt. ${ }^{81}$ Ähnlich wie die Mitglieder des Gießener Graduiertenkollegs bemüht sie sich Mitte der 1990er-Jahre, den Kulturbegriff in den Fokus der fremdsprachendidaktischen Forschung zu rücken (vgl. Kramsch 1995: 59). Aus ihrer Sicht kann deren hermeneutischer Ansatz die Problemlage jedoch nicht ausreichend klären.

Für die Fremdsprachendidaktik schätzt Kramsch die Frage nach dem Verhältnis von Sprache und Kultur Mitte der 1990er-Jahre vor allem aus zwei Gründen als besonders dringlich ein. Der erste Grund liegt darin, dass sich aus Sicht und zum Bedauern der Autorin in der Fremdsprachendidaktik seit den 1960er-Jahren die Linguistik, nicht die Anthropologie als Bezugswissenschaft auf breiter Front durchgesetzt hat. Dies habe zu einer Konzeption von Kommunikation geführt, die den erfolgreichen und möglichst reibungslosen Austausch von Information zwischen Individuen ins Zentrum der Aufmerksamkeit gerückt habe (vgl. Kramsch 1999: 42). In ihrem Kern sei diese Sicht auf Sprache und Fremdsprachen, so Kramsch weiter, ...

[...] infused with a Western ideology, based on the enlightened belief in the democratizing value of symmetrical, unlimited turns-at-talk between like-minded speakers and hearers in free information exchanges, irrespective of their cultural backgrounds. (ebd.)

Der Seitenhieb auf Jürgen Habermas' Überlegungen zu einem herrschaftsfreien Diskurs (vgl. Habermas 1971: 137) ist nicht zu übersehen, auch wenn Kramsch ihn hier nicht expliziert. ${ }^{82}$ Aus ihrer Sicht handelt es sich um einen in die Irre führenden, ideologischen Standpunkt, dieses Konstrukt als Standard für Kommunikationssituationen anzunehmen, umso mehr, wenn es um Sprecher mit unterschiedlichen Muttersprachen gehe.

81 Ihr hier diskutierter Beitrag von 1995 etwa erschien in einem von Lothar Bredella herausgegebenen Sammelband.

82 Andere beschäftigen sich ausführlicher mit Habermas als Ideengeber für das Konzept der kommunikativen Kompetenz. So hatte etwa für Claus Gnutzmann Habermas’ „mit Blick auf eine gesellschaftliche Utopie“ (Gnutzmann 1997: 227) entwickelte Theorie einen zwiespältigen Einfluss auf die Fremdsprachendidaktik. Diese Einschätzung teilt auch Barbara Schmenk (2005: 66), wenn sie schreibt: „Diese ,Sozialblindheit‘ des Kompetenzbegriffs Chomskys wird nun bei Habermas noch überhöht, indem sie zu einer gesellschaftlichen Sozialromantik gesteigert wird.“ 
Zwar liegen Mitte der 1990er-Jahre bereits erste Vorschläge zur Modellierung von interkultureller Kompetenz in der Fremdsprachendidaktik vor. Diese sind laut Kramsch jedoch nicht überzeugend. So kritisiert sie etwa an den Arbeiten von Geneviève Zarate und Michael Byram, diese blieben einem strukturalistischen Paradigma verhaftet, welches das Eigene und Fremde starrer und homogener konzipiere, als dies in Wirklichkeit der Fall sei (vgl. Kramsch 1999: 43). Besonders problematisch sei der Ansatz, interkulturelle Kommunikation als Streben nach Konsens zu entwerfen - und, wie man ergänzen darf, damit dem Habermas'schen Ideal zu folgen (vgl. ebd.). Zudem vermerkt Kramsch (1995: 58), der Begriff ,interkulturell“ sei insofern problematisch, als er meist im Sinne der „kulturellen Merkmale von Durchschnittsbürgern in Nationalstaaten“ verstanden werde.

Es gibt für Kramsch jedoch noch einen zweiten Grund, warum die Fremdsprachendidaktik das Lernziel ,kommunikative Kompetenz überwinden und sich mit dem Kulturbegriff eingehender beschäftigen solle, und zwar die zunehmende ethnisch-kulturelle Durchmischung der westlichen Gesellschaften. Aus dieser sozialen Diversität erwachsen laut Kramsch Konflikte, zu deren Lösung die Politik von der Fremdsprachendidaktik einen Beitrag erwarte. Zudem sei auch im internationalen Kontext die Notwendigkeit stark gewachsen, „[...] mit Menschen zu verhandeln, deren Art zu sprechen, zu denken und zu handeln sich von der eigenen unterscheidet [...]“ (ebd.: 51).

Die Notwendigkeit, innerhalb von Gruppen mit Diversität umzugehen, nehmen verschiedene Multikulturalismustheorien in den Blick. Kramsch gibt jedoch zu bedenken, dass vor allem in den Vereinigten Staaten das Bestreben, die kulturelle Vielfalt in Klassenzimmern zu würdigen, dazu geführt habe, dass Differenzen betont, Gemeinsamkeiten von Lernenden jedoch vernachlässigt worden seien. Zwar komme der multikulturellen Pädagogik das Verdienst zu, auch in der Fremdsprachendidaktik den Blick für soziale, ethnische und geschlechtsspezifischen Diversität geschärft zu haben. Allerdings sei man dabei zumindest in den USA über das Ziel hinausgeschossen:

Die kulturelle Verschiedenartigkeit innerhalb der USA wird in der amerikanischen Schulbildung dermaßen betont, daß allzuoft vergessen wird, welche gemeinsamen nationalen Eigenschaften US-Amerikaner eigentlich haben, die sie möglicherweise von Bürgern anderer Länder unterscheiden. (Kramsch 1995: 60)

Somit haben laut Kramsch weder Interkulturalitäts- noch Multikulturalitätskonzepte befriedigende Antworten auf die von ihr umrissene Problemlage zu bieten, zumindest nicht jene, die bis Ende der 1990er-Jahre vorliegen. Kramsch entwickelt ausgehend von diesem Problemaufriss nun ihrerseits einen Vorschlag, 
mit dem sie versucht, die bis dahin dominierenden dichotomischen (oder auch ,dyadischen') Ansätze von interkultureller Kompetenz zu überwinden. Dabei rückt sie den Grundgedanken der, Drittheit' ins Zentrum ihrer Überlegungen. In einem ersten Entwurf von 1995 spricht sie von einem „dritten Ort“ (Kramsch 1995: 62), wobei sie sich vorwiegend auf den Kulturtheoretiker Homi Bhabha bezieht. In einem zweiten, stärker ausdifferenzierten Vorschlag integriert sie zudem die Arbeiten des Semiotikers Charles Peirce sowie des Philosophen und Literaturkritikers Michail Bachtin, der seinerseits Homi Bhabha stark beeinflusste. 1999 prägt sie für diesen Ansatz den Begriff Thirdness: The Intercultural Stance. So lautet auch der Titel des Beitrags, auf den ich die hier vorgestellten Überlegungen vorwiegend stütze.

Ich fasse in den folgenden Abschnitten zunächst einige von Kramschs grundlegenden Überlegungen zu den Problemfeldern Sprache und Kultur zusammen. Anschließend umreiße ich die Anregungen, die sie aus den Arbeiten von Peirce, Bachtin und Bhabha für ihr Konzept der Thirdness bezieht. Auf dieser Grundlage diskutiere ich dieses im Licht meiner beiden ersten Forschungsfragen. ${ }^{83}$ Neben Kramschs theoretischen Ausführungen ist für die hier vorgenommene Analyse auch eine Fallstudie von Interesse, an der sie ihr Verständnis von Thirdness illustriert. Dabei handelt es sich um die Analyse einer Diskussion zum Thema „Ausländerfeindlichkeit in Germany“" (vgl. Kramsch 1999: 48-58).

\subsubsection{Grundzüge der, Thirdness}

Ähnlich wie die Vertreter des Gießener Graduiertenkollegs thematisiert auch Kramsch wiederholt die grundlegende Frage nach dem Verhältnis von Sprache und Kultur. Sie kritisiert dabei in ähnlicher Weise Kulturverständnisse, bei denen von einer homogenen Einheit von Nation, Sprache und Kultur ausgegangen wird. Diese Vorstellungen seien, so Kramsch, eine zentrale Schwäche etwa strukturalistischer Ansätze, die von klareren Grenzziehungen, größerer Gleichheit und Symmetrie zwischen Kulturen sowie von größerer Homogenität innerhalb von Kulturen ausgingen, als es der Wirklichkeit entspreche (vgl. Kramsch 1999: 43). Unter Bezugnahme auf Beiträge aus der Semiotik vertritt Kramsch vielmehr die Position, dass Bedeutung nicht durch eine Kultur oder Sprache festgelegt sei, sondern im Spannungsfeld zwischen situationellen Gegebenheiten und kulturell zur Verfügung stehenden Sinnangeboten in konkreten Interaktionen immer neu ausgehandelt werde. Dabei gehe man davon aus, dass von den Sprecher_innen jeweils sowohl die eigene Identität als auch die Identität des Interaktionspartners

83 Die Analyse erfolgt auf Grundlage von Kramsch 1995, 1998 und 1999. 
einkalkuliert werden, um auf Grundlage angenommener geteilter Bedeutungen mit Hilfe von Sprache zu kooperieren („conversational co-operation“, Kramsch 1998: 35). Sprache zu verwenden bedeutet somit nach Kramsch nicht nur, kulturell gegebene Bedeutungsstrukturen zu reproduzieren, sondern auch, diese aktiv zu gestalten: „The system of signs that constitute culture is actively constructed through the verbal actions taken by sign-makers in interaction with one another" (ebd.). Auch auf die Sapir-Whorf-Hypothese geht Kramsch in diesem Zusammenhang ein. Sie unterstreicht, dass heute niemand mehr den sprachlichen Determinismus einer starken Version der Hypothese ernst nehmen könne (vgl. ebd.: 13), und vertritt vielmehr den Standpunkt einer schwachen Version, bei der von „cultural differences in the semantic associations evoked by seemingly common concepts" (ebd.) ausgegangen werde. Das heißt, dass die kulturell vermittelten Konnotationen den Sprechern einer Sprache eine bestimmte Weltsicht nahelegen, ohne sie auf diese festzulegen.

Mögliche kulturelle Einflüsse auf die Erzeugung von Bedeutung durch Sprache sieht Kramsch auf drei Ebenen: auf einer universalen, auf einer nationalen sowie auf einer regionalen Ebene (vgl. Kramsch 1995: 54ff.). Während sie universale und nationale Konzeptionen von Kultur für problematisch hält, begrüßt sie die im Zuge der kommunikativen Wende erfolgte Ausrichtung des Sprachunterrichts auf "lokale Verbindungen zwischen Sprache und Kultur“ (ebd.: 56). Dies habe den Sprachunterricht demokratisiert und dafür gesorgt, dass allmählich ein Kulturverständnis in den Unterricht Einzug gehalten habe, bei dem „Kultur als die Worte und Handlungen alltäglicher Menschen im alltäglichen Leben“ (ebd.) gesehen werde. Kramsch weist in diesem Zusammenhang auch auf die Verschleierung des Zusammenhangs zwischen Sprache und Macht hin. So habe die strukturalistisch beeinflusste Sprachdidaktik interkulturelle Konflikte vorwiegend als Probleme gesehen, die es durch rationales Sprechen zwischen rationalen Erwachsenen zu lösen galt (vgl. Kramsch 1999: 43), dabei jedoch die Möglichkeit außer Acht gelassen, dass Konflikte auch nicht lösbar sein können: „Yet, as we know, consensus might not be possible, or indeed, desirable, if there is no commensurable ground between members of different social groups" (ebd.). Sie sieht jedoch weder in universalistischen noch in kulturrelativistischen Lösungsansätzen vielversprechende Auswege aus den Dilemmata, die aufgrund von inkommensurablen Bedeutungssystemen entstehen. In beiden Fällen bestehe die Gefahr, dass Machtverhältnisse verschleiert würden. So hält sie etwa an Taylors multikulturalistischem Ansatz der „Politics of recognition“ (vgl. Kramsch 1998: 82f; Taylor 2011) für problematisch, dass er auf einen „common purpose“ bzw. ein „common good“ (Kramsch 1998: 82) angewiesen sei. Diese könnten jedoch 
nicht vorausgesetzt werden, und somit bestehe die Gefahr, dass unterschiedliche Ansichten darüber, was denn unter „common good“ zu verstehen sei, eingeebnet würden (vgl. ebd.). Für Kramsch ist vielmehr die Bereitschaft entscheidend, Differenzen über diese Fragen auszuhalten („[... a willingness to accept that our horizons might be displaced as we attempt to understand the other.", ebd.: 83). Dagegen könne eine Politik, die das Ziel der multikulturellen Harmonie verfolge, gravierende Nebenwirkungen haben:

National governments that promote multicultural, multiracial harmony like Singapore or the US, one could argue, in fact enhance ethnic separateness by constantly drawing attention to ,racial ${ }^{c}$ and ,ethnic identities. Such distinctions might be bolstered by religion. (ebd.)

Vor dem Hintergrund dieser Überlegungen entfaltet Kramsch ihren Ansatz für einen zeitgemäßen Sprach- und Kulturunterricht. Dabei stellt sie den Begriff der Thirdness in den Mittelpunkt. Thirdness wurde zu Beginn des 20. Jahrhunderts als semiotisches Konzept von Charles Peirce ${ }^{84}$ geprägt. Kramsch (1999: 44) zufolge unterscheidet Peirce drei „modes of being“: Firstness ist in diesem Modell die unmittelbare Bewusstwerdung von aufgenommener Information, Secondness meint die Reaktion auf diese Information und die Interaktion mit Anderen, Thirdness schließlich öffnet eine diachrone Achse und ermöglicht die Wahrnehmung von Kontinuität, die Identifikation von Mustern und deren Generalisierung. Entscheidend für das Konzept der Thirdness ist nun die Annahme, dass Zeichen (signs) niemals isoliert Bedeutung (meaning) erzeugen können, sondern dass dies ausschließlich unter Rückgriff auf und in Relation zu anderen Zeichen möglich ist. Indem Zeichen wiederholt dieselbe Bedeutung zugeschrieben bekommen, entwickelten sich Konventionen: „[Signs and symbols] create paths of expectations that are shared among members of the same signifying community and that allow them to anticipate future events" (ebd.). Die Notwendigkeit, die Bedeutung von Zeichen in einem gegebenen Kontext immer wieder zu aktualisieren, erlaube dabei auch die Umdeutung jener Bedeutungen, die zu fester Tradition geworden seien. Die Möglichkeit hierzu eröffne sich in besonderem Maße im Kontakt mit anderen Kulturen:

They are constantly resemioticized by outsiders who have come in, by insiders who have gone out and come into contact with other cultures, other experiences, and who

84 Kramsch zitiert lediglich Homi Bhabha aus den Originalbeiträgen, bei Peirce und Bachtin stützt sie sich auf die Rezeption durch John K. Sheriff (1994) bzw. Michael Holquist (1990). 
now give different meaning to the traditional signs used in their original community. (Kramsch 1999: 45)

Neben dem auf Peirce zurückgehenden Thirdness-Begriff ist für Kramsch, zweitens, Michail Bachtins Dialogismus von entscheidender Bedeutung. Bachtin weist darauf hin, dass der Einzelne seine Identität nur in Abhängigkeit von einem Anderen - und in Abgrenzung zu diesem - festzulegen in der Lage sei. Zentral ist dabei der Gedanke, dass Identität nicht außerhalb des Dialogs existiert und diesem vorausgeht, sondern dass sie erst in der Kommunikation durch und in Sprache konstruiert wird, und zwar als Antwort (response) auf tatsächliche oder antizipierte Äußerungen des Anderen. Die Beziehung zum Anderen, die sich daraus ergibt, ist nicht nur auf der synchronen, sondern auch auf der diachronen, historischen Achse zu denken. Ähnlich wie bei Peirce entsteht auf der zeitlichen Achse die Möglichkeit zur Veränderung und damit zur Freiheit, und genau darin liegt wiederum die ,Drittheit' (Thirdness) des Dialogs. (vgl. Kramsch 1999: 45-46)

Unter den drei Theoretikern, auf die sich Claire Kramsch beruft, betont schließlich Homi Bhabha am stärksten den Kulturbegriff. ${ }^{85}$ Während Peirce und Bachtin noch abstrakt von Thirdness sprechen, findet sich bei Bhabha die räumliche Metapher des Third Space, die auch für Claire Kramsch zentral werden soll. Für Bhabha ergibt sich die Bedeutung des Kulturbegriffs aus der Kommunikation selbst, denn diese könne nicht als reiner Informationsaustausch modelliert werden, sondern sei immer angewiesen auf Interpretation - und somit kulturell geprägt. Der dritte Ort besteht nun nach Bhabha in der Position, die ein Sprecher einnimmt, wenn er sich äußert. Dabei beziehe er sich stets gleichzeitig auf die Welt außerhalb seiner selbst, konstruiere in diesem Akt aber auch den eigenen Standpunkt und somit die eigene Identität jeweils neu:

For Bhabha, this ,third space' defines the position of the speaker of an utterance who both refers to events in the outside world and, in so doing, constitutes him/herself as subject of enunciation. (ebd.: 47).

Während kultureller Wandel bei Peirce und Bachtin auf der diachronen Achse entsteht, ist er bei Bhabha bereits in der - synchronen - Vielfalt der Stimmen angelegt, in die jeder Sprecher das eigene Sprechen einschreibt:

85 Im Unterschied zu Peirce (1839-1914) und Bachtin (1895-1975) kann Bhabha $\left({ }^{\star} 1949\right)$ bereits die gesellschaftlichen Veränderungen in seine Theorie einarbeiten, die in einer globalisierten Welt zu beobachten sind. 
It is that Third Space, though unrepresentable in itself, which constitutes the discursive conditions of enunciation that ensure that the meaning and symbols of culture have no primordial unity or fixity; [...]. (Bhabha 1994: 37).

Es fällt auf, dass sowohl bei Peirce als auch bei Bachtin und Bhabha die Möglichkeit von Bedeutungswandel und damit von kulturellem Wandel in die jeweiligen Modelle für die Erzeugung von Bedeutung integriert ist. Dies verweist auf die auch von Kramsch vertretene Auffassung von Kultur als heterogenes, dynamisches System von Bedeutungen, bei dem Sprache eine zentrale Rolle spielt. Sprecher_innen greifen die kulturell vorgegebenen Bedeutungen nicht nur auf, sondern gestalten Sprache und Kultur mit, indem sie eine Sprache nutzen.

Nach dieser kurzen Bestandsaufnahme erfolgt in den folgenden Abschnitten eine Diskussion von Kramschs Konzept der Thirdness im Licht der ersten Forschungsfrage.

\subsection{3 ,Thirdness' im Licht der Forschungsfragen}

Aus den bisherigen Ausführungen wird schnell deutlich, dass Kramschs theoretische Überlegungen zunächst eindeutig einem bedeutungs- und wissensorientierten Kulturverständnis zuzuordnen sind. Die von Peirce, Bachtin und Bhabha übernommenen Konzepte von Thirdness verweisen auf die Dynamik der Prozesse, die sich für sprachlich-kulturelle Bedeutungssysteme sowohl aus individuellen Interaktionen als auch aus der diachronen Dimension von Sprache ergeben. Da Kramsch ihre Vorstellung von Thirdness in enger Anlehnung an diese Theorieentwürfe modelliert, lässt sie wenig Raum für Kulturverständnisse, bei denen Kulturen als tendenziell statische, homogene und voneinander abgrenzbare Einheiten gesehen werden. Indem sie so ihr Konzept ausdrücklich semiotisch fundiert, unterstreicht sie, dass Bedeutung zwar einerseits sozial vermittelt wird, andererseits jedoch auch auf individueller Ebene immer wieder neu erzeugt wird und somit als veränderbar anzusehen ist. Hierdurch schärft sie den Blick für die in einem kulturwissenschaftlichen Kulturverständnis zentrale Kontingenz kultureller Phänomene.

Trotz aller Bemühungen um ein bedeutungs- und wissensorientiertes Kulturverständnis können manche Formulierungen in Kramschs Beiträgen jedoch auch im Sinne eines totalitätsorientierten Kulturverständnisses mit seiner Tendenz zur Gleichsetzung von Sprache und Kultur und zur Invisibilisierung von Kontingenz gedeutet werden. So erwähnt Kramsch (1995: 63) in Bezug auf das Lesen fremdsprachlicher Texte etwa die „herkömmliche Lesart des Muttersprachlers“. Sie suggeriert mit dieser Formulierung, dass Muttersprachler neben einer gemeinsamen Sprache auch eine gemeinsame Kultur teilen, die zu einer 
bestimmten „herkömmlichen“ Lesart von Texten führt. Dies widerspricht der von ihr selbst wiederholt vertretenen Sicht, dass die Gleichsetzung von Sprache, Nation und Kultur eine ideologische Vorstellung darstelle, die für den Fremdsprachenunterricht keine Rolle mehr spielen solle (vgl. Kramsch 1998: 74f.).

In einem zweiten Beispiel wird ein Kulturverständnis, das Nation, Sprache und Kultur gleichsetzt, noch deutlicher sichtbar. In einem Kapitel über „Communities of language users" (vgl. ebd.: 6ff.) hebt Kramsch hervor, dass neben Sprachgemeinschaften („speech communities“, ebd.: 6) auch Diskursgemeinschaften („discourse communities“, ebd.) existierten, und illustriert diese Aussage anschließend an einem Beispiel:

For instance, Americans have been socialized into responding, Thank you' to any compliment, as if they were acknowledging a friendly gift: ,I like your sweater! ' -, Oh, thank you!' The French, who tend to perceive such a compliment as an intrusion into their privacy, would rather downplay the compliment and minimize its value: , Oh really? It's already quite old!' The reactions of both groups are based on the differing values given to compliments in both cultures, and on the differing degrees of embarrassment caused by personal comments. (ebd.: 7)

Diese Überlegungen, in denen implizit ,Diskursgemeinschaft' mit ,Nation gleichgesetzt wird, weisen eine geradezu erstaunliche Nähe zu den sogenannten ,Kulturstandards' der interkulturellen Psychologie auf (vgl. Thomas 1996). Diese sind jedoch mit einem bedeutungs- und wissensorientierten, die Heterogenität und Dynamik von Kulturen betonenden Kulturverständnis nur schwer zu vereinbaren. Vielmehr dürften gerade die ,Kulturstandards' zu jener Stereotypenbildung beitragen, deren Überwindung ein zentrales Anliegen des interkulturellen Fremdsprachenunterrichts darstellt. Aus diesem Grund notiert etwa Claus Altmayer (2004: 102f, vgl. Kap. 1.6.), die Kulturstandards nach Thomas seien „[...] für jede Art von seriösem ,interkulturellem Lernen' nicht nur völlig unbrauchbar, sondern geradezu schädlich."

Neben diesen lediglich punktuell erfolgenden Rückgriffen auf ein totalitätsorientiertes Kulturverständnis sehe ich jedoch das Hauptproblem von Kramschs Ansatz im Begriff der Thirdness selbst. Problematisch ist dieser Begriff insofern, als er eine ,Firstness' und eine ,Secondness' suggeriert, die leicht mit Vorstellungen von ,Kultur A` vs. ,Kultur B` und damit dem totalitätsorientierten Kulturverständnis assoziiert werden können - genau mit jenem Kulturverständnis also, das es zu überwinden gilt. Zwar entwirft Kramsch ihr Konzept in völliger Übereinstimmung mit ihren theoretischen Überlegungen zu den Themen Kultur und Sprache als dynamische und heterogene, soziale und individuelle Phänomene. Hierdurch stellt sie klar, dass sie unter Thirdness ein fragiles, flüchtiges 
Konstrukt versteht, das lediglich vorübergehend entsteht, wenn interkulturelle Begegnungen stattfinden, als ,trialectic of the individual, the social, and the relational“ (Kramsch 1999: 57). Die „Überzeugungskraft des kategorialen Denkens“ (Bredella 1999: 109) könnte jedoch auch bei der abstrakt gedachten Thirdness zur Vorstellung von einem konkreten, dritten Ort' führen. Es ist daher zu befürchten, dass es in der Rezeption von Kramschs Konzept zu einer Umdeutung im Sinne eines totalitätsorientierten Kulturverständnisses kommt. Lernende könnten Thirdness als Standpunkt missverstehen, den sie als Vertreter_innen von Kultur und Sprache A in der Auseinandersetzung mit Kultur und Sprache B einnehmen können, um von dort aus die Perspektiven A und B zu koordinieren. ${ }^{86}$ Dies wird umso wahrscheinlicher, wenn der fremdsprachliche Klassenraum selbst zu diesem inter-kulturellen, dritten Ort erklärt wird. ${ }^{87}$ Somit könnte die Rezeption von Kramschs Thirdness, der, Third domain' oder der, intercultural stance' leicht zu den reduktionistischen Denkschemata führen, die in Zusammenhang mit dem Kulturbegriff bereits hinlänglich bekannt sind und deren Überwindung vielfach angemahnt wird (vgl. Kap. 1.6.). Ähnlich wie beim Begriff der Interkulturalität ist daher zu befürchten, dass auch die Thirdness zur Entstehung der Probleme beiträgt, die sie lösen möchte.

Die Frage nach dem Kulturverständnis, welches der Thirdness zugrunde liegt, möchte ich auch auf der Grundlage eines Fallbeispiels diskutieren, mit dem Kramsch ihr Konzept illustriert. Dabei handelt es sich um eine Diskussion, die 1993 von Lehrkräften im Rahmen einer von Kramsch (1999: 48) als „trilingual, tricultural“ beschriebenen Lehrerfortbildung geführt wurde. Die Hauptteilnehmer der Diskussion sind Lehrkräfte verschiedener Fächer und Herkunft: Dieter, „a left-wing West German social democrat and teacher of English“, Donna, „an American teacher of German in the US“, Pierre, ,a French teacher of English in France“, sowie Uwe und Dagmar, „East German teachers of English and French“ (ebd.: 51f.). Gegenstand der Diskussion ist ein Ansteckbutton, den Dieters Lernende entworfen haben. Dieter präsentiert diesen der Runde und empfiehlt ihn als authentisches Material für den Deutschunterricht in Frankreich oder den

86 Bach (2010: 26) befürchtet dies insbesondere, wenn man nicht mit Kramschs abstrakten Begriffen wie Thirdness oder Third domain operiert, sondern zur Metapher der,Brücke zwischen zwei Kulturen' greift, wie dies etwa Gerhard Fischer (1994, vgl. Bach 2010) tut.

87 Bredella et al. (2000: XXX) tun dies zustimmend in Bezug auf Kramsch (1995). Sie unterstellen ihr dabei aber eine Position, die sie so nicht vertritt. Vielmehr plädiert sie im zitierten Beitrag dafür, diesen Ort als „den neu entstehenden, sich verändernden dritten Ort im Sprachlerner/in selbst“ zu sehen (ebd.: 62). 
USA. Der Button stellt das Zifferblatt einer Uhr dar, deren Zeiger auf fünf vor zwölf stehen. In der Mitte des Zifferblatts ist ein großes Hakenkreuz zu sehen.

Die Grafik löst eine hitzige Diskussion um die Frage aus, ob die symbolhafte Warnung vor dem Neonazismus mit der gebotenen Eindeutigkeit dargestellt wird. Für Dieter stellt die von seinen Lernenden angefertigte Grafik eindeutig eine eindringliche Warnung vor den Gefahren eines aufkeimenden Neonazismus dar und ist daher aus seiner Sicht gut für die pädagogische Arbeit geeignet. Für Donna dagegen ist die unveränderte Darstellung des Hakenkreuzes - es ist weder zerbrochen noch durchgestrichen - so problematisch (,appalling“, ebd.: 50), dass sie den Button keinesfalls im Unterricht einsetzen würde.

Kramsch analysiert dieses interessante Beispiel für Bedeutungsaushandlung ausführlich und aus mehreren Perspektiven, und zwar aus semiotischer (vgl. ebd.: 51-53), dialogischer (vgl. ebd.: 53-55) und diskurstheoretischer (vgl. ebd.: 55-57) Perspektive. Dabei berücksichtigt sie einerseits die verschiedenen, aus ihrer Sicht jeweils kulturell geprägten Standpunkte, die von den Diskussionsteilnehmer_innen vertreten werden. Zudem bezieht sie auch die jeweilige Sprachwahl in ihre Interpretation mit ein, da in der Diskussion zwischen Deutsch, Englisch und Französisch gewechselt wird. Kramsch kann so einerseits auf überzeugende Weise die subtilen Bedeutungsverschiebungen herausarbeiten, welche die Diskussionsteilnehmer_innen in Bezug auf die symbolische Darstellung eines politischen Statements vornehmen, und andererseits verdeutlichen, wie sie sich dabei jeweils in Bezug auf verschiedene Diskurse positionieren. Die Teilnehmer_innen stoßen dabei durchaus auch auf Grenzen der Verständigung, ein Vorgang, den sie jedoch ebenfalls zu reflektieren und zu akzeptieren in der Lage sind (vgl. ebd.: 56).

Entscheidend für die hier diskutierte Fragestellung ist nun, inwieweit die Identifikation mit verschiedenen Diskursen in Kramschs Interpretation auf kontingente Weise erfolgt und daher mit einem bedeutungs- und wissensorientierten Kulturverständnis kompatibel wäre, oder inwieweit die beteiligten Lehrkräfte in Kramschs Interpretation auf ihre jeweilige Herkunft festgelegt sind. Sagen sie das, was sie sagen, weil sie aus Ostdeutschland, Westdeutschland, Frankreich oder den USA stammen? Dies würde auf ein deterministisches, tendenziell totalitätsorientiertes Kulturverständnis hindeuten.

Zunächst möchte ich hervorheben, dass ich Kramschs Einschätzung in einem wichtigen Punkt teile. Aus dem Gesprächsprotokoll wird deutlich, dass die Teilnehmer_innen im Lauf der Diskussion verschiedene Perspektiven erkennen, aus denen der Ansteckbutton gedeutet werden kann, und sie gestehen ihren Gesprächspartner_innen zu, diese einzunehmen. Interessant ist in diesem 
Zusammenhang jedoch, mit welchen Worten Kramsch den Verlauf der Diskussion zusammenfasst:

Their delicate manoeuvers to show each other solidarity and personal investment $[\ldots]$ show a willingness to continue to relate to one another, not because of a common ground, which they can have no hope of achieving given their incommensurable histories, but because of a growing awareness that there is always yet an-Other [sic] perspective to dualistic confrontations. (ebd.: 57, Hervorhebung J. P.)

Entscheidend scheint mir hier, dass es nicht Diskurse sind, zwischen denen kein "common ground“ gefunden werden kann und die somit unvereinbar (inkommensurabel) sind. Es scheint auch für Menschen unterschiedlicher kultureller Prägung unmöglich, einen solchen „common ground“ zu finden, und die Erklärung hierfür liegt laut Kramsch in ihren „incommensurable histories“. Mit anderen Worten: Das Individuum trifft keine rationale Entscheidung zwischen unterschiedlichen Bedeutungen, wenn verschiedene Diskurse im Widerstreit zueinander stehen, und es erzeugt auch keine neuen Bedeutungen. Es ist vielmehr festgelegt durch seine jeweilig geografisch-kulturelle Prägung.

Auf ein solches deterministisches Kulturverständnis deutet auch die Interpretation eines kurzen Wortwechsels hin, der sich zwischen Uwe und Claudia, einer weiteren Diskussionsteilnehmerin, abspielt. Dabei geht es um die unterschiedliche Wahrnehmung des Hakenkreuz-Symbols in Deutschland und in den USA (vgl. ebd.: 56). Kramsch deutet diesen Wortwechsel wie folgt:

We have here an interesting German-German dialogue across two irreducible historical and geographical frontiers, and between two incommensurable perceptions or ,Wahrnehmungen' of fascism, that of an East German living now in a unified Germany, that of a West German living now in the United States. These, Wahrnehmungen' have over time been either stigmatized or, indeed, made taboo, i.e., they have been pretty much removed from rational public discourse. (ebd.)

Kramsch sieht hier inkommensurable Wahrnehmungen, obwohl meiner Einschätzung nach das Gegenteil vorliegt: Die Teilnehmer_innen erkennen im Dialog, dass ihre jeweilige Wahrnehmung subjektiv ist, arbeiten gemeinsam die voneinander abweichenden Grundlagen ihrer jeweiligen Bedeutungszuschreibungen heraus, und reflektieren diesen Prozess. Sie führen damit auf beeindruckende Weise vor, dass sie gerade nicht auf ihre jeweilige historisch geprägte Wahrnehmung festgelegt sind, sondern dass sie diese zu überarbeiten bereit und in der Lage sind. Bezeichnenderweise schwenken Uwe und Dagmar, die ostdeutschen Englischlehrkräfte, auf die Linie Dieters, des westdeutschen Englischlehrers, ein, obwohl es sich doch laut Kramsch ebenfalls um Menschen mit „incommensurable perceptions" handeln müsste. 
An anderer Stelle hingegen räumt Kramsch einer Teilnehmerin durchaus die Freiheit ein, sich in Bezug auf verschiedene Diskurse frei zu positionieren:

By teaching German in the United States, Donna is in an eminently mediating position, an intercultural position par excellence. She, like many other language teachers, has had to decide where she stands vis a vis the taboos and stigmata attached to the German language, and how to talk or not to talk about them in an American context. (ebd.: 53)

In Bezug auf das Fallbeispiel, das Kramsch zur Illustration der Thirdness analysiert, zeigt sich somit kein einheitliches Bild. Meist erfolgt die Interpretation in Übereinstimmung mit den theoretischen Überlegungen zum Verhältnis von Sprache und Kultur, das heißt den Teilnehmer_innen wird die Fähigkeit zugestanden, ihre jeweilige kulturelle Prägung zu überwinden. Bisweilen scheinen die Beiträge der Diskussionsteilnehmer_innen jedoch auch vollständig durch ihre jeweilige ,Kultur' determiniert zu sein. Sie sprechen gleichermaßen als Repräsentant_innen von Kultur A (Ostdeutschland), Kultur B (Westdeutschland), Kultur C (Frankreich) oder Kultur D (USA), und als solche ist es ihnen verwehrt, einen „common ground“ zu finden. Ein solches Kulturverständnis entfernt sich jedoch wieder von den von Kramsch selbst entwickelten, sehr überzeugenden kulturtheoretischen Überlegungen.

Weniger ausführlich als ihr Kulturverständnis thematisiert Kramsch in ihren Beiträgen zur Thirdness die Probleme, die sich für den interkulturellen Fremdsprachenunterricht aus dem Dilemma zwischen Universalismus und Kulturrelativismus ergeben können. Dennoch wirft sie die hierfür zentrale Frage nach dem Umgang mit - auch durch Sprache erzeugten und weitergegebenen - Machtstrukturen auf und vertritt die Ansicht, dass diese durch universalistische wie kulturrelativistische Positionen gleichermaßen verschleiert werden können. Dabei ist es ihr ein Anliegen darauf hinzuweisen, dass die Durchsetzung sprachlicher Homogenität in Nationalstaaten eine Form von imperialistischem Machtmissbrauch darstelle, der zu einem Verlust an Diversität führe. Diese Diversität stelle einen Reichtum dar, den es zu erhalten gelte, „[...] because each language provides a uniquely communal, and uniquely individual, means by which human beings apprehend the world and one another" (Kramsch 1998: 77). Gleichzeitig warnt sie jedoch auch vor einer Fixierung der inter- bzw. multikulturell ausgerichteten (Bildungs-)Politik auf die Bewahrung sprachlich-kultureller Diversität und sieht vor allem für die Vereinigten Staaten die Gefahr, dass auf diese Weise sprachliche, ethnische, religiöse und soziale Grenzen vertieft statt abgebaut werden, wodurch neue Formen von Diskriminierungen entstehen könnten (vgl. Kramsch 1995: 59). 
Kramsch nimmt somit einen Standpunkt ein, mit dem sie sich von Universalismus und Kulturrelativismus gleichermaßen zu distanzieren versucht. Es liegt jedoch auf der Hand, dass sich das Dilemma von Universalismus und Kulturrelativismus bei ethischen Konflikten auf diese Weise nicht lösen lässt. Meiner Einschätzung nach lassen sich Kramschs Beiträge in dieser Hinsicht eher einem moderat relativistischen Standpunkt zuordnen, dessen Konsequenzen jedoch nicht ausbuchstabiert werden. So betont Kramsch (1999: 43) zwar, dass eine dialogische Vermittlung zwischen den Mitgliedern verschiedener sozialer Gruppen manchmal schlicht unmöglich sei (,,if there is no commensurable ground between members of different social groups") und distanziert sich damit von der unreflektierten Konsensorientierung, die aus vielen Beiträgen zum interkulturellen Lernen spricht (vgl. Kap. 1.7.). Wie jedoch solche nicht lösbaren Konflikte reflektiert und bearbeitet werden können, bleibt auch bei Kramsch eine offene Frage.

In Bezug auf das wichtige Erziehungsziel des Aushaltens von Differenz sollte berücksichtigt werden, dass man sich im Konfliktfall nicht immer auf eine Position des Aushaltens im Sinne von Untätigkeit und schon gar nicht auf eine ethisch „neutrale“ Position zurückziehen kann. So betont etwa Wolfgang Nieke (2008: 241, Hervorhebung im Original) zu Recht:

Der Konflikt entsteht daraus, dass es widersprüchliche, aber jeweils verbindliche Handlungsanweisungen für dieselbe Situation gibt. Da man in einer Situation nicht nicht handeln kann, muss entschieden werden; denn auch ein Nichthandeln ist ein Handeln. Die Entscheidung für die eine oder die andere Seite verletzt die Selbstverständlichkeiten, Wertüberzeugungen, Heiligkeiten der je anderen Seite. Manchmal lassen sich Auswege finden, in denen die Handlungsvorschriften beider Seiten aufgehoben werden können. In anderen Fällen gelingt dies nicht, und dann muss man zur Entscheidung für die eine oder die andere Richtung kommen.

Zusammenfassend lässt sich daher festhalten, dass die Frage, nach welchen ethischen Maßstäben eine solche Entscheidung im Konfliktfall zu treffen wäre, auch in den hier ausgewerteten Beiträgen zur Thirdness nicht überzeugend beantwortet wird. Die äquidistante Position, die Kramsch zu universalistischen wie kulturrelativistischen Positionen einzunehmen versucht, könnte sich im Konfliktfall als zumindest moderat kulturrelativistisch herausstellen. In Bezug auf den Umgang mit Konflikten, die eine ethische Dimension aufweisen, bietet der Ansatz der Thirdness daher kaum Orientierung.

Im Rahmen der hier diskutierten Fragestellung verdient ein weiterer Ansatz Beachtung, den Kramsch seit der Jahrtausendwende in mehreren Beiträgen als Autorin und Co-Autorin entworfen hat und den sie symbolic competence nennt. Um ihn geht es in den folgenden Abschnitten. 


\subsection{Umgang mit Komplexität und Mehrdeutigkeit: Claire Kramschs ,symbolic competence}

\subsubsection{Problemstellung der, symbolic competence}

Die bisher diskutierten Ansätze für eine interkulturelle Fremdsprachendidaktik die Didaktik des Fremdverstehens des Gießener Graduiertenkollegs sowie Claire Kramschs Konzept der Thirdness - verfolgen beide das Anliegen, Interkulturalität unter Rückgriff auf einen zeitgemäßen Kulturbegriff zu modellieren. Wie gezeigt werden konnte, ist jedoch keiner der Ansätze frei von essentialistischen und dichotomischen Vorstellungen, die auf ein totalitätsorientiertes Kulturverständnis verweisen. Besonders in der Anwendung der theoretischen Überlegungen auf literarische oder empirisch erhobene Texte wird bisweilen auf Kategorien zurückgegriffen, in denen die fiktiven oder realen Personen, um die es jeweils geht, in ihrem jeweiligen Denken und Verhalten auf ihre geografisch-politische Herkunft oder auf ihre Zugehörigkeit zu einer Gruppe kulturell festgelegt werden. Dies ist in der Didaktik des Fremdverstehens häufiger und deutlicher zu beobachten als in den Beiträgen zur Thirdness. Bei diesen Beispielen kategorialen Denkens steht die Gefahr des Reduktionismus und Determinismus im Raum. Menschen werden auf diese Art leicht auf, typische' Merkmale im Sinne der sogenannten ,Kulturstandards' reduziert, welche Erklärungen für ihr Denken und Verhalten bereitstellen (vgl. Thomas 1996). Umgekehrt wird Verhalten, das für Mitglieder einer Gruppe als ,typisch' gilt, verstärkt wahrgenommen, so dass sich der Kreislauf der durch den Bestätigungsfehler (confirmation bias) befeuerten Stereotypenbildung schließt.

In diesem Kapitel möchte ich nun mit der symbolic competence ein weiteres Konzept vorstellen und diskutieren, das ebenfalls von Claire Kramsch maßgeblich geprägt wurde ${ }^{88}$ Es hat meiner Einschätzung nach aus zwei Gründen das Potential, nicht zu den Rückgriffen auf veraltete Kulturverständnisse zu führen. Der eine Grund, warum mich Kramschs neuerer Ansatz im Rahmen dieser Arbeit interessiert, liegt darin, dass in ihm nicht mehr der Kulturbegriff im Zentrum steht. Dies könnte ein entscheidender Vorteil sein, denn möglicherweise ist gerade die Mehrdeutigkeit des Kulturbegriffs (vgl. Kap. 2.1.) eine wichtige Ursache dafür, dass die Probleme der Theoriebildung, die mit seiner Hilfe gelöst werden sollen, sich immer wieder neu stellen. Ein zweiter Grund, die symbolic competence hier

88 Die folgenden Ausführungen stützen sich auf zwei Beiträge von 2006 und 2009, deren einzige Autorin Kramsch ist, sowie auf zwei weitere Beiträge, die sie 2008 in Zusammenarbeit mit Michael Chad Wellmon bzw. Anne Whiteside publiziert hat. 
zu diskutieren, liegt in dem Umstand, dass für sie der Diskursbegriff eine wichtige Rolle spielt. Da ich den Diskursbegriff selbst ins Zentrum des hier entwickelten Zielkonstruktes stelle (vgl. Kap. 4.2.), soll geklärt werden, inwieweit symbolic competence möglicherweise bereits eine tragfähige Lösung für die Probleme der interkulturellen Fremdsprachendidaktik bietet, die den Ausgangspunkt dieser Arbeit darstellen. Kramsch bewegt sich zwar auch in ihren neueren Beiträgen weiterhin innerhalb des interkulturellen Paradigmas ${ }^{89}$, aber der Schwerpunkt ihrer Aufmerksamkeit ist nun auf zwei Begriffe gerichtet, welche das Potential haben, die oben geschilderten Schwachpunkte anderer Ansätze (zu denen auch ihr eigener der Thirdness gehört) zu überwinden: auf den Komplexitätsbegriff und auf den Symbolbegriff. Kramsch geht in ihren Überlegungen zur symbolic competence von den Defiziten aus, die sie auch nach der Jahrtausendwende in einem weiterhin auf dem kommunikativen Ansatz basierenden Fremdsprachenunterricht sieht. Die Problemstellung ähnelt somit jener, mit der sie sich bereits im Kontext der Thirdness auseinandersetzte (vgl. Kap. 3.3.1.).

Der kommunikativen Fremdsprachendidaktik Hymes'scher Prägung kommt Kramsch zufolge das wichtige Verdienst zu, zwei aus ihrer Sicht unerfreuliche Traditionslinien der Fremdsprachendidaktik überwunden zu haben. Diese bestanden einerseits in einer Fixierung auf grammatische Strukturen, die in dekontextualisierten Einheiten analysiert und memorisiert wurden, und andererseits in einem behavioristisch inspirierten Vorgehen, welches auf eine möglichst fehlerfreie Imitation vorgegebener sprachlicher Muster baute. Diese Ansätze erfüllten, so Kramsch, die Bedürfnisse einer Ideologie, die davon ausging, dass Wissen vorgefertigt in Texten zu finden war. Zur Erschließung dieses Wissens sei es daher je nach methodischem Ansatz lediglich darum gegangen, die richtigen Texte korrekt $\mathrm{zu}$ interpretieren und sie sich gegebenenfalls einzuprägen (vgl. Kramsch 2006: 249). Kommunikatives Fremdsprachenlernen habe daher nicht nur aus didaktischer Sicht eine wichtige Neuerung im Vergleich zur GrammatikÜbersetzungs-Methode oder der audiolingualen und audiovisuellen Fremdsprachendidaktik dargestellt, sondern es habe auch geholfen, eine demokratische Lernkultur zu etablieren. Die Lernenden sollten nun lernen, eine Fremdsprache als Kommunikationsmedium zu sehen, welches nur in seinem spezifischen sozialen Kontext zu verstehen war und welches sogar das Potential hatte, dem Sprecher, beispielsweise einem Migranten, Zugang zu einer bis dahin verschlossenen sozialen Gruppe zu ermöglichen (vgl. ebd.). Allerdings seien auch zunehmend

89 Dies geht etwa aus dem Titel eines 2009 veröffentlichten Beitrags hervor: Discourse, the symbolic dimension of Intercultural Competence. 
Defizite des communicative language teaching zu verzeichnen. Erstens wurde die kommunikative Didaktik Kramschs Einschätzung nach immer stärker auf den Bereich der Mündlichkeit reduziert („reduced to its spoken modality“, ebd.: 250). Zudem habe sie sich von den ursprünglichen Zielen, die um die Förderung von Demokratie und sozialer Gerechtigkeit kreisten, wieder entfernt und sich in zunehmendem Maße auf Aspekte der Funktionalität, Effizienz und Messbarkeit ausgerichtet:

In the educational world, communication has been slowly resignified to mean the ability to exchange information speedily and effectively and to solve problems, complete assigned tasks, and produce measurable results. (ebd.)

Die Fixierung auf die Lösung von kommunikativen Aufgaben habe dazu geführt, dass heutzutage viel zu selten Sinn und Zweck der Aufgaben selbst hinterfragt werde: „What often needs to be negotiated nowadays is not how to achieve the task, but the nature and the purpose of the task itself" (ebd.). In einer zunehmend komplexen Welt sei es zudem nicht mehr angemessen, kommunikative Kompetenz als Fähigkeit zu modellieren, die ein Tourist benötigt, um in einem kulturell homogenen fremden Land mit den dort anzutreffenden Muttersprachlern erfolgreich Informationen auszutauschen. Vielmehr müsse Fremdsprachenunterricht Lernende in die Lage versetzen, den Vorgang der Erzeugung von Information und der Aushandlung von Bedeutung zu durchschauen: „Today it is not sufficient for learners to know how to communicate meanings; they have to understand the practice of meaning making itself" (ebd.: 251).

Neben der kommunikativen Didaktik schätzt Kramsch auch die intercultural communicative competence als problematisch ein, wie sie etwa von Michael Byram oder Geneviève Zarate modelliert wird (vgl. Kramsch 2009: 116f.). ${ }^{90}$ Beide verharrten, so Kramsch, in einer strukturalistischen Auffassung von Sprache (vgl. ebd.: 116) und vernachlässigten zudem deren diskursive Dimension (vgl. ebd.: 117), womit vor allem machtbezogene Aspekte gemeint sind.

\subsubsection{Gründzüge der,symbolic competence}

Kramsch und ihre Co-Autoren Wellmon und Whiteside begegnen diesen Defizitbeobachtungen mit einem Konstrukt, das sich auf drei theoretischen Strömungen bezieht. Diese sind erstens die postmoderne Soziolinguistik, die mit dem Begriff der Ökologie arbeitet. Dabei gehe es darum, so Kramsch in Anlehnung an Jay L. Lemke und Jan Blommaert, ein Ereignis in seinem vollständigen

90 Das Konzept Byrams wird in Kap. 3.5. vorgestellt und diskutiert. 
ökologischen Kontext zu verstehen („in its total ecological context“, Kramsch 2009: 114). Die zweite Strömung ist die Komplexitätstheorie (complexity theory) in ihrer Anwendung auf fremdsprachliches Lernen, wie sie von Diane LarsenFreeman und Lynne Cameron vorgenommen wurde. Die Komplexitätstheorie beruht laut Kramsch ihrerseits auf dem Dialogismus Bachtins, den sie als dritte Strömung für die symbolic competence rezipiert (vgl. ebd.). ${ }^{91}$

Als drei Merkmale von symbolic competence nennt Kramsch (2006: 251) in einem frühen Entwurf „Production of Complexity“,,"Tolerance of Ambiguity“ und „Form as Meaning“. Ich stütze meine Darstellung und Diskussion auf eine zweite Fassung der symbolic competence, die sich in drei späteren Publikationen findet (vgl. Kramsch/Wellmon 2008: 219f.; Kramsch/Whiteside 2008: 659f.; Kramsch 2009: 115f.). Abgesehen von unterschiedlichen kurzen Beispielen zu Illustrationszwecken werden dort jeweils in gleichem Wortlaut insgesamt fünf Merkmale von symbolic competence erläutert. Auch wenn die symbolic competence somit eine Entwicklung durchlaufen hat, weisen doch sowohl die Problemstellung als auch die Theorien, die zu ihrer Lösung herangezogen wurden, in allen genannten Publikationen große Schnittmengen auf.

Das erste Merkmal der symbolic competence ist die Wahrnehmung der Relativität des Selbst und des Anderen („Relativity of Self and Other“, Kramsch 2009: 115). Das Ich sei nicht einheitlich, sondern multipel („the I is not unitary, but multiple“, ebd.). In jedem Diskurs (hier im Sinne von,Gespräch', vgl. Kap. 4.2.2.) sei daher immer eine Vielfalt an Stimmen zu hören. Durch einen Beobachter (etwa in Gestalt eines Forschers, der ein Gesprächsprotokoll analysiert) kommen, so Kramsch, neue Standpunkte bzw. Stimmen hinzu, die bei der Interpretation (bzw. der Interpretation der Interpretation) berücksichtigt werden müssen.

Beim zweiten Merkmal geht es darum, in Diskursen zeitliche Rahmen („time scales“, ebd.) wahrzunehmen. Diskurse seien keine synchronen Gebilde, sondern setzten sich, so Kramsch in Anlehnung an Blommaert, aus verschiedenen Zeitebenen zusammen. Hierfür verwendet sie Blommaerts Begriff der layered simultaneity. Das Wirken unterschiedlicher Zeitebenen im Diskurs sei den Teilnehmern teils bewusst, teils nicht bewusst (vgl. ebd.).

Das dritte, eng mit den unterschiedlichen Zeitebenen zusammenhängende Merkmal von symbolic competence bezeichnet Kramsch als Emergentismus („emergentism“, ebd.). Darunter verstehe man die in der Soziolinguistik vertretene Annahme, dass Bedeutung nicht als feste Struktur in den Köpfen der Sprecher existiere, sondern im Moment der Sprachverwendung durch die Aktualisierung

91 Bachtin Dialogismus spielte bereits für die Thirdness eine zentrale Rolle (vgl. Kap. 3.3.2.). 
diskursiver Strukturen emergiere, indem semiotische Gleichzeitigkeiten erzeugt werden („semiotic simultaneity“, ebd.).

Das vierte Merkmal sieht Kramsch in der Unabschließbarkeit („unfinalizability“, ebd.: 116) diskursiver Ereignisse. Hierzu gehöre auch, dass an einem Gespräch nicht nur die direkt involvierten Personen beteiligt seien, sondern indirekt auch jene, die man sich lediglich vorstelle oder an die man sich erinnere (vgl. ebd.). Jedes Gespräch ist somit die Fortsetzung anderer Gespräche, und jedes Gespräch kann an anderer Stelle aufgegriffen und fortgesetzt werden.

Einzelne Gespräche sollten daher nach Kramsch nicht als abgeschlossene Ereignisse, sondern als Fraktale („fractals“, ebd.) gesehen werden, als Bruchstücke großer Muster, die durch diese Fraktale konstituiert werden. ${ }^{92}$ Diese Annahme stellt das fünfte und letzte Merkmal der symbolic competence dar.

Kramsch und Whiteside (2008: 667) formulieren auf dieser Grundlage folgende Definition für symbolic competence:

Symbolic competence could thus be defined as the ability to shape the multilingual game in which one invests - the ability to manipulate the conventional categories and societal norms of truthfulness, legitimacy, seriousness, originality - and to reframe human thought and action.

Hervorzuheben ist das hier genannte Konzept des Framing bzw. Reframing, das auch in anderen Kontexten geläufig ist, etwa der Psychologie bzw. Psychotherapie, dem Coaching, der Politikwissenschaft, der Wirtschaftswissenschaft und dem Marketing. Ich werde es im folgenden Kapitel in der Diskussion einer Fallanalyse wieder aufgreifen, mit der Kramsch (2009: 108-112) die symbolic competence ausführlich illustriert und in der es eine wichtige Rolle spielt. Zunächst sollen jedoch Kramschs theoretische Überlegungen zur symbolic competence im Licht der Forschungsfragen diskutiert werden..$^{93}$

92 Kramsch verwendet hier den Begriff fractals in einem anderen als dem üblichen Wortsinn. Dieser bezieht sich in der Regel auf mathematische Modelle oder auf in der Natur vorkommende Strukturen, welche in unendlichen rekursiven Schleifen Muster erzeugen. Diese Muster sind in jedem Betrachtungsmaßstab identisch oder annähernd identisch.

93 Kramsch geht auch der Anschlussfähigkeit nach, welche die symbolic competence an den deutschen Bildungsbegriff einerseits (vgl. Kramsch/Wellmon 2008: 221-223) sowie an Byrams 5 savoirs andererseits (vgl. Kramsch 2009: 116f.) aufweist. Dies wiederzugeben würde an dieser Stelle jedoch von der hier diskutierten Fragestellung wegführen. 


\subsubsection{Symbolic competence' im Licht der Forschungsfragen}

Claire Kramsch entfaltet für die symbolic competence theoretische Strömungen der Semiotik, der Soziolinguistik und Diskurstheorie noch deutlicher, als sie dies für das Konzept der Thirdness bereits getan hatte. Auch die Wahl des Namens überzeugt. Während Thirdness noch im Sinne einer naiven Inter-Kulturalität als Standpunkt zwischen Kultur A und Kultur B (miss-)verstanden werden konnte (vgl. Kap. 3.3.3.), unterstreicht im neuen Konzept schon der Name die theoretischen Grundlagen, auf denen es beruht. Symbolic competence wird durch die Merkmale Relativity of Self and Other, Time scales, Emergentism, Unfinalizability und Fractals (vgl. Kramsch 2009: 115f.) in einer Weise modelliert, welche totalitätsorientierten Kulturverständnissen allgemein, insbesondere jedoch jeglichen homogenisierenden Gleichsetzungen von Kultur, Sprache und Nation diametral entgegensteht. Kramsch beruft sich vielmehr auf ein Verständnis von Kultur, durch das sie Generalisierungen und Simplifizierungen konsequent zu vermeiden versucht. Mit den Begriffen der Ökologie und Komplexität betont sie zudem die Dynamik jener Prozesse, die bei der Erzeugung von Bedeutung ablaufen. Implizit wird somit auch die Kontingenz dieser Phänomene verdeutlicht. Die theoretischen Ausführungen, durch die interkulturelle Kompetenz als symbolic competence modelliert wird, beruhen daher auf einem Kulturverständnis, das sich im Sinne der Kategorienbildung nach Reckwitz eindeutig als bedeutungsund wissensorientiert klassifizieren lässt.

Das Dilemma von Universalismus und Kulturrelativismus wird hingegen nicht ausführlich thematisiert, ähnlich, wie dies auch in den Beiträgen zur Thirdness festzustellen war. Zwar hebt Kramsch mehrfach hervor, dass Ansätze der kommunikativen und interkulturellen Didaktik es ihrer Einschätzung nach bislang versäumt haben, Sprache konsequent als Diskurs zu betrachten, und daran sei insbesondere die Vernachlässigung der Frage nach den in und durch Sprache erzeugten Machtstrukturen problematisch (vgl. Kramsch 2006: 252; Kramsch 2009: 114). Wie genau die Offenlegung von Machtstrukturen im Einzelnen verlaufen und welcher Umgang mit Konfliktsituationen ratsam sein könnte, wird jedoch nicht thematisiert.

Das Kernanliegen von symbolic competence besteht darin, Lernende in die Lage zu versetzen, das komplexe Spiel sprachlicher Bedeutungserzeugung zu durchschauen und für ihre Zwecke aktiv zu beeinflussen: „[...] the ability to manipulate the conventional categories [...] and to reframe human thought and action" (Kramsch/Whiteside 2008: 667). Die ethische Dimension eines solchen Umgangs mit Sprache als Diskurs wird jedoch konsequent ausgeblendet. Erziehungsziele wie etwa jene, die in einem Sammelband zur interkulturellen 
Kompetenz vertreten werden, in dem auch ihr jüngster Beitrag zur symbolic competence erschienen ist (vgl. Hu/Byram 2009), schließt Kramsch (2009: 107) gar ausdrücklich aus dem Aufgabenfeld des Fremdsprachenunterrichts aus: "Language teachers teach language, not ethics or psychology."

An anderen Stellen scheint dagegen auch symbolic competence über eine ethische Dimension zu verfügen. Diese sei jedoch, so Kramsch, im Gegensatz zu den von Byram und Zarate vertretenen moralischen und politischen Vorstellungen allein aus der soziolinguistischen Theorie zu legitimieren:

It [symbolic competence] seeks to locate morals, politics and symbolic power in discourse itself, whether the linguistic code is the native or the foreign language. (ebd.: 117)

Hierbei kontrastiert sie Byrams savoir s'engager, das sie, wie auch die anderen savoirs, als „collection of stable knowledges“ (ebd.: 118) darstellt, mit dem Begriff der savviness, das sie als "combination of knowledge, experience and judgment“ (ebd.) beschreibt. Die Umrisse einer Ethik, auf deren Grundlage eine solche Urteilsfähigkeit angebahnt werden könnte, bleiben zumindest in den theoretischen Ausführungen zur symbolic competence jedoch ausgesprochen unscharf. Symbolic competence kann somit in Bezug auf das Dilemma zwischen Universalismus und Kulturrelativismus vorläufig einem relativistischen Standpunkt zugeordnet werden.

Eine deutlichere Antwort insbesondere auf die zweite Forschungsfrage erhoffe ich mir von einem Fallbeispiel, mit dem Kramsch illustriert, was genau unter symbolic competence zu verstehen sei. Ich fasse es in den folgenden Abschnitten zusammen, um auf dieser Grundlage die beiden Forschungsfragen erneut zu diskutieren.

Hintergrund des von Kramsch analysierten Fallbeispiels ist ein Besuch des damaligen Papstes Benedikt XVI. im April 2008 in den USA. In einer Predigt vor amerikanischen Bischöfen sprach Benedikt damals einige aus seiner Sicht problematische Entwicklungen in der amerikanischen Gesellschaft an. Unter anderem warnte er dabei vor den Einflüssen von Säkularismus und Materialismus:

While it is true that this country is marked by a genuinely religious spirit, the subtle influence of secularism can nevertheless color the way people allow their faith to influence their behavior. Is it consistent to profess our beliefs in church on Sunday, and then during the week to promote business practices or medical procedures contrary to those beliefs? [...] Any tendency to treat religion as a private matter must be resisted. [...] For an affluent society, a further obstacle to an encounter with the living God lies in the subtle influence of materialism [...]. (The Holy See 2008)

Über den Besuch des Papstes wurde in den amerikanischen Medien ausführlich berichtet, so etwa durch den Fernsehsender PBS (Public Broadcasting Service), ein 
Sender, der sich von der Vielzahl privater Fernsehstationen insofern unterscheidet, als er als das amerikanische Pendant zum deutschen öffentlich-rechtlichen Fernsehen gelten kann. Am 17. April 2008 strahlte PBS eine aus zwei Teilen bestehende Sendung über den Besuch Benedikts XVI. aus. Deren erster Teil führt im Format einer Dokumentation von ca. 8 Minuten Länge in das Thema ein. Im Anschluss folgt ein Studiogespräch von ca. 9 Minuten Länge, das der PBS-Moderator Joffrey Brown mit zwei Gästen führt, den katholischen Priestern Joseph Fessio und Tom Reese. ${ }^{94}$ Kramsch wählt eine Passage aus diesem Studiogespräch, in dem sie einen „critical incident“ (Kramsch 2009: 110) sieht, für eine ausführliche Analyse aus, um so ihr Verständnis von symbolic competence zu veranschaulichen. Von besonderem Interesse ist dabei für Kramsch die Bitte des Moderators an seine beiden Studiogäste, die oben zitierte Warnung des Papstes von den Einflüssen von Säkularismus und Materialismus näher zu erläutern (vgl. ebd.: 109). Father Reese kommt dieser Bitte mit folgenden Worten nach:

Well, what I think he's saying is he recognizes how important freedom is to the American people. The pope is for freedom, he loves our freedoms. But he talks about ... that with freedom comes responsibility, [...]. (Public Broadcasting Service 2008; vgl. Kramsch 2009: 109)

Die Machtdimension von Diskursen zeigt sich für Kramsch nun anschaulich in dem Umstand, dass das Gespräch im Studio im Grunde ein Gespräch zwischen Institutionen sei. Diese Institutionen seien einerseits die katholische Kirche, andererseits die globale Supermacht Amerika. Der Moderator und seine Gäste seien lediglich als deren Stellvertreter für deren Stimmen („actors in the studio“, ebd.: 110) anzusehen.

Ähnlich wie in der Gesprächsanalyse zur Illustration der Thirdness (vgl. Kap. 3.3.3.) werden anschließend auch in diesem Fallbeispiel die Bedeutungskonstruktionen nachgezeichnet, welche die Sprecher im Laufe der Studiodiskussion vornehmen. Hierbei interessiert sich Kramsch in besonderem Maße dafür, auf welche Weise parallel zu den Bedeutungen auch Identitäten konstruiert werden. Kramsch zufolge positioniert sich etwa der Moderator durch die Art der Formulierung einer an seine Gäste gerichtete Frage als US-Amerikaner außerhalb der katholischen Welt: „He [the Pope] knows the culture of the United States. What is he saying?" (ebd.: 109)

Wie in den beiden oben zitierten Passagen zu sehen ist, werden „secularism“ und „materialism“, die Schlüsselbegriffe der päpstlichen Rede, auf diese Frage

94 Die Sendung ist sowohl als Video-Stream als auch als Transkript im Internet abrufbar, vgl. Public Broadcasting Service 2008. 
hin von einem der katholischen Priester in "freedom“ und „responsibility“ umgedeutet. Auf diese Weise wird aus einer recht deutlichen Kritik, deren Hintergrund die 2007 maßgeblich von der Wall Street verursachte und zum Zeitpunkt des Papst-Besuchs weiter andauernde Finanz- und Wirtschaftskrise sein dürfte, eine grundsätzliche Zustimmung zum amerikanischen way of life („,...] he loves our freedoms.", ebd.). Für Kramsch stellt dies eine sprachliche und diplomatische Glanzleistung dar, ganz im Sinne der von ihr umrissenen Kompetenz: „[...] symbolic competence was displayed by all three interlocutors as they negotiated the sensitive interpretation of the Pope's statement" (ebd.: 113). Zwar ist auch Kramsch der Ansicht, dass Father Reese die Aussage des Papstes in ihr exaktes Gegenteil umdeutet („[...] ends up reaffirming precisely what Benedict XVI was excoriating.", ebd.: 112). Dies ist seiner symbolic competence jedoch offensichtlich nicht abträglich.

Ich stimme Kramsch insofern zu, als es den katholischen Priestern gelingt, der Kritik des Papstes jede Spitze zu nehmen und en passant den Katholizismus als hoch kompatibel mit einer liberalen Marktwirtschaft nach US-amerikanischem Modell darzustellen. Man könnte Father Reese und Father Fessio in diesem Sinne auch als ausgezeichnete Referenten für Öffentlichkeitsarbeit, mit anderen Worten als spin doctors ansehen. Die Kunst des reframing beherrschen sie ohne Zweifel virtuos. Es stellt sich jedoch die Frage, inwiefern auch Jeffrey Brown symbolically competent gehandelt hat. Hierfür ist die Begründung von Interesse, mit der Kramsch die rhetorische Volte der katholischen Priester für angemessen erklärt. Säkularismus und Materialismus, so Kramsch, seien für das amerikanische Publikum unverständliche bzw. missverständliche Begriffe. Die meisten Amerikaner assoziierten mit ihnen atheistische Länder und kommunistische Regimes („[...] usually associated with atheist countries and communist regimes like that of the Soviet Union.“, ebd.). Um dieses Missverständnis auszuräumen und einen "common symbolic ground for mutual understanding" (ebd.: 114) zu schaffen, sei eine Übersetzung in eine Ausdrucksweise notwendig, die dem Publikum leichter zugänglich sei:

By doing this, he [Father Reese] translated the foreign lexicon of ,secular materialism into the familiar lexicon of ,freedom and responsibility - a way of speaking that Americans can readily recognize. [...] In essence, the Catholic priest rephrases the message of the Gospel into an American message, in which democracy itself has become the national religion. (ebd.: 112)

Diese Interpretation ist aus meiner Sicht in zwei wichtigen Aspekten zu kritisieren. Erstens halte ich die Umdeutung, die ,Übersetzung' des Begriffs Säkularismus in der hier vorgenommenen Weise für keineswegs notwendig oder zulässig, 
sondern für ausgesprochen problematisch. Es stellt sich vielmehr die Frage, inwieweit Säkularismus in der kollektiven Vorstellungswelt der Amerikaner (vorausgesetzt, eine solche existiert) wirklich vorwiegend mit den negativ besetzten Begriffen Atheismus und Kommunismus assoziiert wird. Und selbst wenn dies so wäre, böte das Stichwort Säkularismus dem Moderator eine ausgezeichnete Gelegenheit für eine kritische Nachfrage. Im Gegensatz zu Kramschs Darstellung handelt es sich bei Säkularismus keineswegs um einen un-amerikanischen Wert, sondern ganz im Gegenteil um ein fundamentales Prinzip des Staatsverständnisses der Vereinigten Staaten. Es findet sich im ersten Verfassungszusatz von 1791.

Thomas Jefferson, dritter Präsident der USA und leidenschaftlicher Verfechter des Säkularismus, verstand darunter die Errichtung einer Trennwand zwischen Kirche und Staat, „a wall of separation between Church \& State ${ }^{“ 95}$ Dieses Verständnis von Säkularismus ist keineswegs überholt. Vielmehr wird der Begriff ,secularism' üblicherweise in genau jenem Sinne definiert, der an Jeffersons Diktum anschlussfähig ist, und zwar als ,the belief that religion should not be involved with the ordinary social and political activities of a country" (Cambridge Dictionary Online o. J.). In der politischen Domäne ist der Begriff durchaus üblich. So verwendet etwa die Organisation Americans United for the separation of church and state den Begriff, secular' bis heute unter Berufung auf Jeffersons Definition (vgl. AU o. J.).

Säkularismus ist nicht nur ein Grundpfeiler der Verfassung der Vereinigten Staaten, sondern gehört allgemein zu den Kernforderungen liberaler Demokratietheorien, wie z.B. jener von John Rawls (vgl. Rawls 1993: 175). Indem Reese den Begriff des Säkularismus vom Tisch wischt und behauptet, es sei eigentlich um Freiheit und Verantwortung gegangen, entschärft er gekonnt die Kritik des Papstes an der amerikanischen Gesellschaft. Dabei geht es meiner Auffassung nach im Kern darum, die Grenze zwischen Religion und Staat in Frage zu stellen, um den Einfluss der katholischen Lehre im Alltag zu erhöhen. Dies ist nicht überraschend, im Gegenteil: Der Versuch, den eigenen politischen und gesellschaftlichen Einfluss zu erhöhen, liegt in der Logik einer sich als universal verstehenden Religion. Genau hier liegt auch die Machtdimension des Fernsehgesprächs über die Papst-Rede, das Kramsch analysiert, und hier liegt der zweite zu kritisierende Aspekt an Kramschs Interpretation. ${ }^{96}$

95 Die Formulierung stammt aus einem Brief, den Jefferson 1802 an die Baptistengemeinde von Danbury schickte, vgl. The Library of Congress 1998.

96 Gegen die hier vorgenommene Analyse ließe sich einwenden, der Papst habe mit „secularism“ nicht die Trennung von Kirche und Staat, sondern die Ablehnung von 
Symbolic competence bedeutet nach Kramschs Definition, menschliches Denken und Handeln „neu zu rahmen“ (to reframe), und wie aus der oben wiedergegebenen Passage ersichtlich ist, gelingt dies den katholischen Priestern im Studiogespräch ausgezeichnet. Weniger kompetent ist jedoch der Auftritt des Moderators Brown, der lediglich als Stichwortgeber für seine Gäste auftritt. Er könnte die Gelegenheit nutzen, um an den Stellenwert des Säkularismus in der Verfassung der USA zu erinnern und somit wie seine Gäste das mehrsprachige Spiel formen, an dem er beteiligt ist („[...] to shape the multilingual game in which one invests [...]", Kramsch/Whiteside 2008: 667). Stattdessen bietet er seinen Gästen auf unkritische Weise eine Plattform für deren Sprachspiel, das darin besteht, eine katholische Ethik als durch und durch kompatibel mit dem american way of life darzustellen.

Die Mahnungen des Papstes könnten auch als Widerstreit von Diskursen mit sich überschneidenden Geltungsansprüchen gedeutet werden, und zwar zwischen dem Diskurs der liberalen Staatstheorie, auf dem die Verfassung der Vereinigten Staaten beruht, und dem der katholischen Ethik. Somit läge ein gutes Beispiel für einen Widerstreit (différend) im Sinne Lyotards vor (vgl. Kap. 4.2.4.). Weder der PBS-Moderator noch Kramsch erkennen jedoch die Unvereinbarkeit dieser Diskurse. Statt sie zu benennen und auszuhalten, wird der Konflikt im Sinne der katholischen Ethik aufgelöst. In Kramschs Interpretation des Gesprächs auf Grundlage der symbolic competence wird daher dessen Machtdimension nicht offengelegt. Somit löst Kramsch einen zentralen Aspekt der theoretischen Konzeption von symbolic competence in ihrem Fallbeispiel nicht ein.

Den Grund hierfür vermute ich in dem Umstand, dass Kramsch auch ihr neues Konzept innerhalb des interkulturellen Paradigmas entwirft. Zwar weist sie in ihren theoretischen Überlegungen zur symbolic competence mehrfach auf die Bedeutung hin, welche Diskursen in diesem Konstrukt zukommen solle. Es finden sich jedoch ebenfalls mehrere Passagen, die darauf hindeuten, dass insbesondere in der Anwendung auf das besprochene Fallbeispiel weniger der Diskursbegriff als der Kulturbegriff eine erkenntnisleitende Rolle spielt. So deutet sie das analysierte Fernsehgespräch mit einen Kernbegriff der interkulturellen Didaktik als interkulturellen „critical incident“ (Kramsch 2009: 108; vgl. Byram

jedem Transzendenz-Bezug menschlichen Lebens gemeint, ein Leben „etsi Deus non daretur (als ob es Gott nicht gäbe)“ (vgl. Innovative Media 2008). Diese Mahnung wäre jedoch ausgerechnet in Bezug auf die USA überraschend, erzielt doch die amerikanische Bevölkerung in Umfragen zur Religiosität regelmäßig Spitzenwerte unter den Industrienationen. In jedem Fall ist jedoch die „Übersetzung“ durch Father Reese problematisch. 
2004: 301). Den Gesprächsteilnehmern scheint in diesem Licht die Rolle zuzukommen, zwischen Kultur A (politische und wirtschaftliche Weltmacht USA) und Kultur B (religiöse Weltmacht katholische Kirche) zu vermitteln: „[...] they had to finesse a response between two potential rival powers, Washington and the Vatican" (Kramsch 2009: 110). Ihre eigene Rolle sieht Kramsch in der Deutung des Gesprächs als Fernsehzuschauerin, die auf interkulturelle Lücken („,intercultural gaps“, ebd.: 113) besonders aufmerksam achte - auch dies ein Hinweis darauf, dass Kramsch sich in ihrer Analyse stärker an Kulturen als an Diskursen orientiert.

Entscheidend ist in diesem Zusammenhang, dass der Papst als nach katholischem Dogma unfehlbares Oberhaupt der katholischen Kirche vermutlich durchaus den Anspruch erheben würde, für eine homogene Institution zu sprechen. Es kann daher durchaus angemessen sein, den Katholizismus zumindest hypothetisch als einheitliche Kultur zu betrachten, die in ihrem Selbstverständnis mehr auf die Beilegung als auf die Pflege und das Aushalten von internem Dissens ausgerichtet ist, obwohl selbstverständlich auch innerhalb der katholischen Kirche abweichende Positionen auftreten. Für die amerikanische Kultur gelten hingegen ganz andere Bedingungen. Wenn die Aufgabe des Moderators Jeffrey Braun darin besteht, wie Kramsch es formuliert, als eine Art Bauchredner die Position des Fernsehpublikums zu vertreten („He had to ventriloquate, so to speak, questions that many American sponsors and taxpayers would be likely to ask.", ebd.: 110), so ist die Frage angemessen, wie gut er diese Aufgabe erfüllt. Wahrscheinlich tut er dies aus der Sicht eines Teils der Zuschauer gut; ebenso wahrscheinlich ist jedoch, dass sich ein anderer Teil von Brown ausgesprochen schlecht vertreten fühlt.

Die Worte des Papstes, mit denen Säkularismus als schleichende Gefahr dargestellt wird („the subtle influence of secularism“, s. o.), lässt Brown unkommentiert stehen, statt auf die Schlüsselrolle des Säkularismus in der Verfassung der USA hinzuweisen. Ähnlich untätig bleibt Brown in Bezug auf die Umdeutung der Papst-Rede in ein Plädoyer für „freedom and responsibility“ durch die anwesenden Priester.

Zusammenfassend lässt sich somit festhalten, dass die Fallanalyse, mit der Kramsch das Konzept der symbolic competence illustriert, deutlich hinter den von ihr formulierten theoretischen Ansprüchen an dieses Konzept zurückbleibt. Dies gilt einerseits im Hinblick auf das von Kramsch in ihren theoretischen Überlegungen vertretene bedeutungs- und wissensorientierte Kulturverständnis. Die Kultur des demokratischen und pluralen Nationalstaates USA wird der Kultur des streng hierarchischen und auf Einheit ausgerichteten Katholizismus 
gegenübergestellt. Die Kultur der USA wird damit selbst homogenisiert, was Kramschs Überlegungen in die Nähe eines totalitätsorientierten Kulturverständnisses rückt.

In Bezug auf die Machtdimension ist festzuhalten, dass nicht hinterfragt wird, auf welche Weise den inkommensurablen Diskursen „katholische Ethik“ vs. „säkulare Demokratie“ in der analysierten Diskussion Geltung verschafft wird bzw. nicht verschafft wird. Stattdessen scheint sich der Konflikt in den Begriffen ,freedom and responsibility' aufzulösen. Bereits in den 1990er-Jahren hatte Kramsch kritisiert, dass in Entwürfen zur interkulturellen Kompetenz Konflikte häufig als Probleme gesehen wurden, die es lediglich im Sinne einer universellen Rationalität zu lösen galt:

Cross-cultural communication has mostly been viewed as a problem-to-be-solved', a struggle on the way to reaching consensus through rational talk between rationallyminded adults. (Kramsch 1999: 43)

Die Analyse in diesem Kapitel zeigt jedoch, dass sich auch für das Konzept der symbolic competence solche konsensualistischen Grundannahmen belegen lassen. Wie das Konzept der Thirdness bleibt es ebenfalls hinter dem Anspruch zurück, die Vorstellung von homogenen Kulturen zu überwinden. Das Vorhaben, in Bezug auf die Offenlegung diskursiv erzeugter Machtstrukturen neue Wege zu gehen, wird ebenfalls nicht eingelöst. Inwiefern dies Fremdsprachenlehrkräfte und ihren Lernenden leisten können, ist mehr als fraglich, wenn es selbst einer in Theoriefragen ausgewiesenen Expertin wie Claire Kramsch nicht gelingt, ihre eigenen Gedanken mit der gebotenen Konsequenz zur Anwendung zu bringen.

\subsection{Schwerpunkte interkultureller Kompetenz: Michael Byrams fünf, savoirs ${ }^{6}$}

\subsubsection{Problemstellung der ,Intercultural communicative competence}

Um Interkulturalität geht es auch bei dem vierten Konstrukt, das im Rahmen dieser Arbeit diskutiert werden soll. Dabei handelt es sich um die sogenannte Intercultural Communicative Competence (ICC) von Michael Byram. Dieses Kompetenzmodell ist im Rahmen dieser Arbeit insofern von Interesse, als es in leicht veränderter Form in den GeR übernommen wurde (vgl. Europarat 2001: 103-109). Da der GeR seit seiner Veröffentlichung zu dem Leitdokument für den Fremdsprachenunterricht in Europa geworden ist, dürfte die ICC von allen hier diskutierten Konstrukten zur interkulturellen Fremdsprachendidaktik am stärksten rezipiert worden sein. 
Byram (1997: 1f.) geht von der Annahme aus, dass interkulturelle Begegnungen in zwei grundsätzlich zu unterscheidenden Kontexten stattfinden, dem der Urlaubsreise und dem der Migration. Die Bedürfnisse von Touristen (bzw. von Menschen, die mit Touristen zu tun haben) und von Migranten (bzw. von Menschen, die mit Migranten zu tun haben) seien dabei jeweils andere. Der Tourist sei lediglich in kurze interkulturelle Begegnungen verwickelt. Der Migrant hingegen - Byram spricht vom „sojourner“ (ebd.: 1) - hält sich lange im fremden Land auf. Zwar handle es sich weder beim Tourismus noch bei der Migration um grundsätzlich neue Phänomene. Da jedoch beides in der zweiten Hälfte des 20. Jahrhunderts massiv zugenommen habe, könne man inzwischen von einem veränderten Zustand der Welt („,condition of the world“, ebd.) sprechen. Neu sei an diesem Zustand vor allem, so Byram, dass nun nicht mehr nur Angehörige von Eliten wie Diplomaten und Geschäftsleute mit den Mitgliedern anderer Gruppen in Kontakt treten, sondern dass alle Mitglieder von sprachlichen und kulturellen Gruppen dazu ermutigt werden (vgl. ebd.). Dabei seien es weniger die kurzen touristischen Kontakte als vor allem die länger andauernden Begegnungen im Kontext von Migration, welche große Herausforderungen an alle Beteiligten stellten:

$[\ldots]$ it is the sojourner who produces effects on a society which challenge its unquestioned and unconscious beliefs, behaviours and meanings, and whose own beliefs, behaviours and meanings are in turn challenged and expected to change. (ebd.)

Diese Herausforderungen seien so hoch, dass sie besondere Anstrengungen von Bildungssystemen erforderlich machten, um zukünftige Migranten angemessen auf ihre Aufenthalte vorzubereiten:

For the qualities of the sojourner, which run counter to the many influences creating a sense of loyalty and group identity, are seldom acquired without help, are seldom learnt without teaching. (ebd.: 2)

Vor diesem Hintergrund werde die Notwendigkeit ersichtlich, ein deskriptives, detailliertes und verständliches Modell für die Anbahnung jener Eigenschaften zu entwickeln, die man in interkulturellen Situationen benötige (vgl. ebd.: 5).

Byram möchte mit seinem Kompetenzmodell jedoch nicht nur wichtige Elemente interkulturellen Lernens benennen, sondern auch eine Grundlage bereitstellen, um diese zu beurteilen („evaluate and assess“, ebd.: 2) ${ }^{97}$ Dies sei aus zwei

97 Ausführliche Überlegungen in Bezug auf evaluation and assessment interkultureller Kompetenzen finden sich in Byram (2009). Schröder (2012: 37) begrüßt in Bezug auf die Bildungsstandards von 2012 die Entwicklung von Standards für Sprachbewusstheit 
Gründen erforderlich. Einerseits könnte Schülern als zukünftigen Migranten auf diese Weise schriftlich bestätigt werden, dass sie über interkulturelle Kompetenz verfügten („[...] providing them with certification of their capacities [...]“, ebd.), und ein solcher Nachweis könne die Integration in eine aufnehmende Gesellschaft erleichtern („[... gain acceptance as sojourners in another society“, ebd.). Andererseits könnten dann Institutionen, welchen die Vermittlung dieser Kompetenzen obliege, ihrerseits im Hinblick auf die Erfüllung dieser Aufgabe bewertet werden:

Educational institutions therefore have a responsibility, and a need to demonstrate their ability to fulfil it, to show they are accountable. Evaluation of their general efficacy, and assessment of the individuals in their charge are part of that accountability [...]. (ebd.)

Ein wichtiger Aspekt für das Verständnis von Byrams Modell liegt darüber hinaus in dem Umstand, dass er von komplexen, aber gleichzeitig günstigen Bedingungen für interkulturelle Kommunikation ausgeht:

This $[\ldots]$ is intended to be a comprehensive and rich description of what is required in the most complex and also the most favourable circumstances of intercultural communication. (ebd.: 5)

Zusammenfassend lässt sich somit festhalten, dass Byrams Modellierung interkultureller Kompetenz in erster Linie die Bedürfnisse zukünftiger Migrant_innen in den Blick nimmt, für die er das Leitbild des intercultural speaker (vgl. ebd.: 31ff.) entwirft. Dieser soll auf Grundlage des Modells bereits im schulischen Fremdsprachenunterricht den Umgang mit Fremdheit unter den komplexen, jedoch prinzipiell günstigen Bedingungen erlernen können, die ihn in einer aufnehmenden Gesellschaft erwarten. Darüber hinaus soll das Modell eine Beurteilung sowohl der Lernenden als auch der jeweiligen Institution und ihrer Vertreter erlauben.

\subsubsection{Grundzüge der,Intercultural communicative competence}

Das Konstrukt der Intercultural communicative competence setzt sich aus vier Teilkompetenzen zusammen: aus linguistic competence, sociolinguistic competence, discourse competence und intercultural competence (vgl. Byram 1997: 73). Die ersten drei der genannten Teilkompetenzen werden von Byram in Anlehnung an Jan Ate van Ek jeweils kurz definiert (vgl. ebd.: 48), jedoch nicht ausführlich diskutiert. Im

und Sprachlernkompetenz, Aspekte schulischen Lernens, die seiner Einschätzung nach nicht messbar sind, sondern „[...] aufgrund von Lehrer-Expertise begutachtet werden müssen." 
Zentrum seiner Überlegungen steht dagegen die vierte Teilkompetenz, intercultural competence. Diese wird in insgesamt fünf Schwerpunkte (auch: Faktoren) aufgefächert, die sogenannten savoirs, für welche die jeweils anzustrebenden Zielvorgaben ausführlich erläutert werden: savoirs, savoir comprendre, savoir être, savoir apprendre/faire und savoir s'engager (vgl. Byram 1997: 34, 73 und passim). ${ }^{98}$

Unter dem ersten Kompetenzschwerpunkt, savoirs („knowledge“, vgl. ebd.: 58ff.), sind nach Byram Wissensbereiche über soziale Gruppen, über ihre Produkte und Praktiken zu verstehen, jeweils im eigenen Herkunftsland und in dem des Gesprächspartners: „Knowledge: of social groups and their products and practices in one's own and in one's interlocutors country [...]" (ebd., Hervorhebung im Original). Dieses Wissen weist große Überschneidungen mit den Inhalten der traditionellen Landeskunde auf (vgl. Kap. 1.1.) und wird in deutschsprachigen Kontexten häufig als „soziokulturelles Orientierungswissen“ bezeichnet (vgl. KMK 2003: 8). Mit savoirs ist u.a. das Wissen über historische Ereignisse und ihre Bedeutung für die jeweilige nationale Identität, über Traditionen historischer Erinnerung, über Wahrnehmungstraditionen in Bezug auf geographische Räume, über Sozialisationsprozesse und deren Institutionen und über Konventionen des persönlichen Umgangs gemeint (vgl. Byram 1997: 60). Dabei fällt auf, dass für savoirs nicht nur verschiedene Wissensbereiche eine Rolle spielen, etwa über die Wahrnehmung geographischer Räume innerhalb eines anderen Landes, sondern auch, wie diese Wahrnehmung einerseits von verschiedenen sozialen Gruppen und Minderheiten dieses Landes, andererseits im Herkunftsland des intercultural speaker und drittens gegebenenfalls auch von Menschen aus weiteren Ländern wahrgenommen wird:

The intercultural speaker knows about perceptions of regions and regional identities, of language varieties [...], of markers of internal and external borders and frontiers, and how these are perceived by others. (ebd.: 59f, Hervorhebung J. P.)

Für interkulturelle Kompetenz ist es somit nach Byram neben der Kenntnis verschiedener Wissens- bzw. Wahrnehmungssysteme ebenfalls von Bedeutung, die „Wahrnehmung der Wahrnehmung" zu kennen, mit anderen Worten, diese Wissens- bzw. Wahrnehmungssysteme in einer interkulturellen Begegnung miteinander abgleichen und ihre Relevanz für die gegebene Situation einschätzen zu können.

Der zweite Kompetenzschwerpunkt, savoir comprendre („Skills of interpreting and relating", ebd.: 61), steht für die Fähigkeit, Bezüge zwischen Dokumenten und Ereignissen der fremden und eigenen Kultur herstellen zu können. Der

98 Die Reihenfolge stellt weder bei Byram noch in der hier zu findenden Zusammenfassung eine Priorisierung dar. Besonderes Gewicht hat für Byram lediglich der Schwerpunkt savoir s'engager. 
intercultural speaker solle in der Lage sein, die kulturelle (möglicherweise auch ethnozentrische) Geprägtheit von Deutungen zu erkennen, diese als Quellen von Missverständnissen aufzudecken und in Konflikten, die sich aus sich widersprechenden Deutungen ergeben können, zu vermitteln. Dabei soll er insbesondere auch unausgesprochene Prämissen berücksichtigen können (vgl. ebd.: 61). Savoir comprendre bedeutet nach Byram jedoch auch, unüberbrückbare Differenzen als solche zu erkennen: ,The intercultural speaker [...] can help interlocutors to identify common ground and unresolvable difference" (ebd.).

Unter savoir être („,attitudes“, ebd.: 57), dem dritten Kompetenzschwerpunkt, versteht Byram eine offene Haltung im Sinne einer Bereitschaft, sich auf Fremdheitserfahrungen einzulassen. Es sei wichtig, Fremden und Fremdem auf Augenhöhe zu begegnen, dabei die eigenen Überzeugungen zeitweise außer Kraft zu setzen und gleichzeitig fremde Überzeugungen zeitweise als gültig anzunehmen $(,[\ldots]$ readiness to suspend disbelief about other cultures and belief about one's own. “, ebd.). Savoir être schließt dabei neben verbalen auch non-verbale Aspekte ein, etwa die Offenheit im Umgang mit fremder Mimik und Gestik. Dies bedeutet, dass der intercultural speaker sich an die Erwartungen anpassen soll, die eine aufnehmende Gruppe in Bezug auf das Verhalten von Fremden hat:

The intercultural speaker notes and adopts the behaviours specific to a social group in a way which they and the members of that group consider to be appropriate for an outsider [...]. (ebd.: 58)

Der vierte Kompetenzschwerpunkt, savoir apprendre/faire („Skills of discovery and interaction", ebd.: 61), steht für die Fähigkeit, sich neues Wissen über eine Kultur anzueignen. Ebenso ist eine Handlungsfähigkeit gemeint, bei der in interkulturellen Begegnungen unter Zeitdruck die verschiedenen Schwerpunkte von intercultural competence zum Einsatz kommen (ebd.). Dies betrifft nicht nur Situationen, in die der intercultural speaker unmittelbar involviert ist, sondern ist auch gefragt, wenn er zwischen Gesprächspartnern aus der eigenen und fremden Kultur vermitteln soll:

The intercultural speaker can identify and estimate the significance of misunderstandings and dysfunctions in a particular situation and is able to decide on and carry out appropriate intervention, without disrupting interaction and to the mutual satisfaction of the interlocutors. (ebd.: 63)

Unter savoir s'engager („Critical cultural awareness/political education“, ebd.) schließlich, dem fünften Kompetenzschwerpunkt, versteht Byram eine allgemeine Kritikfähigkeit in Bezug auf Phänomene der eigenen und fremden Kultur. Diese Kritikfähigkeit solle sich expliziter Kriterien auf der Grundlage von Handlungen 
und Dokumenten der eigenen und fremden Kultur bedienen. Mit savoir s'engager ist ausdrücklich auch die Fähigkeit gemeint, explizite oder implizite Wertvorstellungen zu erkennen und diese in einem kritischen Urteil zu berücksichtigen. Byram entwirft diesen Kompetenzschwerpunkt in Anlehnung an das Konzept der politischen Bildung aus dem deutschsprachigen Kontext. In Bezug auf den Begriff der political education unterstreicht er daher, dass es sich um eine direkte Übersetzung aus dem Deutschen handle, denn im Englischen werde der Terminus mit Indoktrinierung in Verbindung gebracht und sei somit negativ konnotiert. Gemeint sei jedoch eine demokratische Erziehung im Sinne einer „education for citizenship“ oder einer „education for democracy“ der britischen bzw. US-amerikanischen Tradition (vgl. ebd.: 55).

Die Anbahnung dieser fünf Kompetenzschwerpunkte interkulturellen Lernens ist für Byram ausdrücklich eine Aufgabe von Bildungseinrichtungen. Sie müsse vorwiegend unter Anleitung einer Lehrkraft stattfinden, und zwar sowohl an schulischen als auch an außerschulischen Orten. Wichtige weitere Lernorte seien jedoch auch jene, an denen Lernende interkulturelle Kompetenzen unabhängig von der Schule erwerben und erproben können. Diese Art des Lernens müsse vor allem auch nach Ende der Schulzeit fortgesetzt werden (vgl. ebd.: 65-70, 73). Die Grundlagen müssten jedoch bereits in der Schule in Form von generalisierbaren Kompetenzen systematisch gelegt werden:

This in turn suggests a classroom methodology which allows learners to acquire explicitly the underlying principles of the skills and knowledge they are taught, and the means of generalising them to new experience. (ebd.: 69)

Unabhängig davon, an welchen Orten dieser Kompetenzerwerb tatsächlich stattfindet, werden die Kompetenzschwerpunkte in Form einer Grafik metaphorisch zusammengeführt. In ihr werden die savoirs als Fäden dargestellt, aus deren Verflechtung interkulturelle Kompetenz entsteht (vgl. ebd.: 73).

\subsection{3 ,Intercultural communicative competence' im Licht der Forschungsfragen}

In den folgenden Abschnitten möchte ich zunächst kurz Byrams Entscheidung erörtern, die Kompetenzschwerpunkte interkulturellen Lernens als savoirs zu modellieren. Anschließend erfolgt eine Diskussion des Modells im Licht der Forschungsfragen 1 und 2.

Das französische Lemma savoir, das in der Beschreibung der Kompetenzschwerpunkte interkulturellen Lernens eine Schlüsselrolle spielt, kann bekanntlich sowohl als Substantiv als auch als Verb verwendet werden. Zwischen den beiden 
Verwendungen ergeben sich interessante semantische Nuancen. Als Substantiv steht savoir für einen strukturierten Vorrat an Informationen, der einerseits in der Welt, andererseits im Gehirn eines Individuums vorhanden sein kann - Wissen. Als Verb drückt savoir dagegen den Zustand aus, in dem ein Mensch über diese strukturierten Informationen verfügen kann, in dem er oder sie also etwas, weiß: Wird das Verb in einer perfektivischen Zeitform verwendet (z.B. il a su), kann savoir darüber hinaus eine incohative Bedeutung annehmen, die sich mit, anfangen, etwas zu wissen' umschreiben lässt. Da diese Bedeutung im Deutschen nicht grammatikalisiert ist, wird sie meist durch ein anderes Lexem ausgedrückt, im genannten Fall mit,erfahren'.

In der dreifachen Bedeutung als externer oder interner Wissensvorrat, als mentaler Zustand sowie als Prozess, der zu diesem Zustand führt, erschöpft sich die Semantik von savoir jedoch noch nicht. Wenn savoir mit einem anderen Verb kombiniert wird, steht es für die Fähigkeit zu handeln, mit anderen Worten für ein ,Können'. Es fällt auf, dass dies auf vier der fünf savoirs zutrifft: savoir comprendre, savoir être, savoir apprendre/faire und savoir s'engager. Auch hier ist jedoch noch eine Besonderheit hervorzuheben, denn das Verb être fällt seinerseits gewissermaßen aus der Reihe, weil es kein Handeln, sondern einen Zustand, ein ,Sein' im Sinne einer Haltung beschreibt.

Byrams Überlegungen fußen dabei auf einem Kompetenzverständnis, das er ausdrücklich weit fasst:

It will have been evident in earlier chapters that I have used the term, competence' in a sense derived from Chomsky and Hymes and my definition of intercultural competence includes knowledge, attitudes and skills. (Byram 1997: 72)99

Da Byram die Kompetenzschwerpunkte interkulturellen Lernens in diesem Sinne, d. h. als ein in hohem Maße interdependentes Geflecht aus Wissen, Haltung und Können darstellen möchte, erscheint mir seine Entscheidung, sie als savoirs zu beschreiben, als außerordentlich geglückte und elegante Lösung. Die schillernde Semantik der verschiedenen savoirs zeigt sich auch darin, dass die Rezeption zumindest in den nicht-romanischen Sprachen meist über die französischen Termini des Originals erfolgt, da Übersetzungen die ursprünglichen Bedeutungen nur näherungsweise zum Ausdruck bringen könnten (vgl. Europarat 2001: 103-109).

99 Ein ähnlich weites Kompetenzverständnis findet sich auch in Franz E. Weinerts Definition, welche für die deutschsprachige Diskussion um den Kompetenzbegriff zentrale Bedeutung erlangte. Vgl. Weinert 2001: 27f. 
Ich möchte Byrams Ausführungen zur intercultural competence nun im Licht der Forschungsfragen 1 und 2 diskutieren. In Bezug auf das zugrunde liegende Kulturverständnis ist zunächst festzuhalten, dass Byram diese Frage deutlich weniger ausführlich thematisiert, als dies Lothar Bredella und Claire Kramsch tun (vgl. Kap. 3.2.-3.4.). Die fast durchgehende Gleichsetzung von Nationalstaat (country), Sprache und Kultur, die zu einer dichotomischen Gegenüberstellung von Nationalkulturen führen kann, wird jedoch in einer kurzen Passage problematisiert. Byram (1997: 39ff.) vertritt dort die Ansicht, dass angesichts der großen Zahl an unterschiedlichen Kulturverständnissen im Kontext des Fremdsprachenunterrichts ein Kulturverständnis angebracht sei, das den Bedürfnissen von Lehrkräften gerecht werde. Ein solches Kulturverständnis könne von den Einstellungen und dem Wissen ausgehen, welches die Mitglieder einer Gruppe kraft ihrer Zugehörigkeit zu dieser Gruppe teilten („[...] the beliefs and knowledge which members of a social group share by virtue of their membership.", ebd.: 39). Gleichzeitig weist Byram jedoch auf die Gefahr hin, dass seine Ausführungen zur interkulturellen Kompetenz im Sinne homogener Nationalkulturen missverstanden werden könnten:

We have to be aware of the dangers of presenting, a culture' as if it were unchanging over time or as if there were only one set of beliefs, meanings and behaviours in any given country. (ebd.)

Vielmehr sei auch zu berücksichtigen, dass Menschen auf individuelle Weise Wissen und Einstellungen in Interaktionen einbringen. Ihnen die ,Kultur' der Mehrheitsgesellschaft zu unterstellen könne sogar rundheraus schädlich sein, wenn sie sich eben dieser Mehrheitsgesellschaft gar nicht zugehörig fühlten (vgl. ebd.).

Unter Bezugnahme auf einige von John Gullov Christensen (vgl. Byram 1997: 40) formulierte Einwände gegen die Gleichsetzung von Nation und Kultur setzt sich Byram anschließend mit der für Modelle interkulturellen Lernens entscheidenden Frage auseinander, inwieweit überhaupt von einem grundsätzlichen Unterschied zwischen interkultureller und intrakultureller (im Sinne von internationaler bzw. intranationaler) kommunikativer Kompetenz ausgegangen werden kann (zum Abgrenzungsproblem vgl. u.a. Rathje 2006: 8; Hu 1996). Trotz der bekannten Einwände lege eine sozialpsychologische und linguistische Perspektive jedoch nahe, so Byram, dass Fremdsprachlichkeit ein zentrales Kriterium darstelle, auf dessen Grundlage Menschen zwischen interkultureller und intrakultureller Kommunikation unterschieden: „[...] the subjective experience [...] distinguishes significantly between inter-cultural/ country and intra-cultural/country communication" (Byram 1997: 41). Dabei 
sei von Bedeutung, dass Sprecher einer Fremdsprache sich im Umgang mit Muttersprachlern oft machtlos fühlten („[...] a degree of powerlessness vis à vis a native speaker.", ebd., Hervorhebung im Original). Byram kommt daher zu der Einschätzung, dass für Begegnungen, bei denen nationale und sprachliche Grenzen überschritten werden, eine besondere sozio-kulturelle Kompetenz notwendig sei, die sich von jener unterscheide, die man für Begegnungen innerhalb dieser Grenzen benötige (vgl. ebd.).

Es wird deutlich, dass Byram seinem Modell interkultureller Kompetenz auf ein Kulturverständnis aufbaut, bei dem Sprache, Nation und Kultur weitgehend gleichgesetzt werden. Im Licht der von Reckwitz formulierten Kategorien wäre es zu den totalitätsorientierten Kulturverständnissen zu zählen. Dies ist, wie in Kapitel 2.1.2. ausführlich dargestellt wurde, insofern problematisch, als die Kontingenz kultureller Phänomene hierdurch tendenziell invisibilisiert wird. Auch wenn Lehrkräfte laut Byram ein Bedürfnis nach einem solchen Kulturverständnis haben mögen (vgl. ebd.: 39), sagt dies wenig über seine Leistungsfähigkeit in Bezug auf die Erfassung sprachlicher und kultureller Realitäten in einer zunehmend komplexen Welt aus. So können etwa regionale Identitäten stark ausgeprägt sein, auch innerhalb Europas mit seinen vergleichsweise starken nationalstaatlichen Traditionen. Man denke etwa an die Unterschiede zwischen Nord- und Süditalien oder zwischen Bayern, Friesland und Baden. Eine regionale Identität kann durch eine regionale Sprache noch erheblich verstärkt werden. In der Gegenwart wäre dies in Frankreich für viele Bewohner Korsikas, der Provence und der Bretagne zutreffend, in Spanien für viele Bewohner Kataloniens, Galiciens und das Baskenlandes. Dies zeigt, dass der Normalfall in Europa nicht nationalsprachlich-kulturelle Homogenität, sondern regionale Heterogenität ist. Für die in Deutschland wichtigsten Schulfremdsprachen Englisch, Französisch und Spanisch gilt zudem, dass diese in vielen ehemaligen Kolonien der jeweiligen Mutterländer bis heute Verkehrs- oder Nationalsprachen sind und - insbesondere das Englische - eine enorme Bedeutung als internationale linguae francae haben. Sie mit nationalstaatlich verorteten Bedeutungssystemen zu koppeln ist somit sowohl sowohl in intranationaler als auch in internationaler Perspektive kaum vertretbar. Die weltweit als lingua franca verwendete Form des Englischen wird aus diesem Grund bisweilen auch halb scherzhaft Globish genannt.

Nicht nur in Bezug auf Bevölkerungsgruppen ist die Gleichsetzung geographisch-politischer mit sprachlichen und kulturellen Grenzen als zunehmend problematisch anzusehen. Auch in individuellen Identitätskonstruktionen werden die für ein totalitätsorientiertes Kulturverständnis charakteristischen Grenzziehungen entlang Nation, Sprache und (National-)Kultur von einer Vielzahl 
weiterer kultureller Systeme überlagert, von Bedeutungsnetzen also, die eine mindestens ebenso wichtige identitätsstiftende Funktion haben können. Wer zwischen Menschen mit gleicher Staatszugehörigkeit und/oder gleicher Muttersprache auch eine kulturelle Gleichheit herleitet, die größer ist als zwischen Menschen mit unterschiedlicher Staatszugehörigkeit und/oder Muttersprache, kann daher leicht in stereotypisierende, potentiell diskriminierende Denkmuster verfallen. Diese Argumente überwiegen meiner Einschätzung nach im Vergleich zu den von Byram angenommenen Vorteilen, die das Modell der intercultural competence für Lernende und Lehrkräfte durch die vorläufige Gleichsetzung von Nation, Sprache und Kultur bieten könnte (vgl. ebd.).

Auch wenn Byram in Zusammenhang mit dem seinem Modell zugrunde liegenden Kulturverständnis mehrfach vor Simplifizierungen und Stereotypisierungen warnt, stellt sich dennoch die Frage, inwieweit diese Warnungen auch in der Rezeption des Modells Gehör finden. Es ist zu befürchten, dass ein solches Modell gegen die Absichten seines Verfassers eben jene Kategorien bereitstellen könnte, auf denen nationalkulturelle Stereotypisierungen beruhen, und dass diese durch die „Überzeugungskraft kategorialen Denkens“ (Bredella 1999: 109) trotz aller Warnungen für die gegenseitige Wahrnehmung von Interaktionspartnern auf dysfunktionale Weise prägend sein könnten.

In Übereinstimmung mit dem zugrunde liegenden Kulturverständnis zielt Byrams Modell auf Fremdheitserfahrungen ab, die aus Begegnungen zwischen Einheimischen mit auf die eine oder andere Weise von einem geographisch-politischen Außen hinzugekommenen Menschen (Touristen oder Migranten) entstehen. Entsprechend wird von diesen erwartet, sich in Bezug auf die kulturellen Standards der aufnehmenden Gruppe angemessen zu verhalten („appropriate for an outsider“, Byram 1997: 58). Es stellt sich jedoch die Frage, inwieweit diese Empfehlung für die Fremdheitserfahrungen innerhalb pluraler, demokratischer Einwanderungsgesellschaften aufrecht erhalten werden kann. So zeigen etwa die Migrationsbewegungen, die in den vergangenen Jahrzehnten in die EU und innerhalb der EU zu verzeichnen waren, dass sich die Fragen interkulturellen Zusammenlebens keineswegs nur für begrenzte Zeitspannen („during a period of residence“, ebd.), sondern dauerhaft stellen. Für viele Migrant_innen ist die Übersiedelung in das aufnehmende Land definitiv. Sie heiraten, gründen Familien, beantragen vielleicht die Staatsbürgerschaft. Der intercultural speaker im Sinne eines „sojourner“ (ebd.: 1) erscheint vor dem komplexen Hintergrund pluraler Einwanderungsgesellschaften als Bezugsgröße nicht mehr geeignet.

$\mathrm{Da}$ in Byrams Modell von tendenziell homogenen Gesellschaften (bzw. gesellschaftlichen Teilgruppen, vgl. Byram 1997: 54f.) ausgegangen wird, wäre mit 
Fremdheit dann zu rechnen, wenn sich Mitglieder unterschiedlicher Gesellschaften bzw. gesellschaftlicher Teilgruppen begegnen. Dieses Konzept von Fremdheit ist jedoch nur unter der Voraussetzung stimmig, dass Individuen einerseits mit ihrer Gruppe, andererseits mit sich selbst identisch sind. Hierdurch bleiben jedoch solche Fremdheitserfahrungen potentiell unberücksichtigt, die einerseits zwischen Angehörigen derselben Gruppe (,intrakulturell'), andererseits in Individuen selbst (,intraindividuell') entstehen können. Auf sozialer wie individueller Ebene bleibt hierdurch wenig Raum für komplexe, multiple, widersprüchliche, sich verändernde Gruppen- und Einzelidentitäten. Von eben solchen Identitäten ist jedoch aus Sicht der zeitgenössischen Identitätsforschung in postmodernen Gesellschaften auszugehen (vgl. Küster 2003b: 154).

Ich komme zur zweiten Forschungsfrage. Hier ist zunächst zu betonen, dass Byram (1997: 43) den Kompetenzschwerpunkt des savoir s'engager als education im Sinne politischer Bildung versteht und dieser in seinem Modell eine wichtige Rolle zuweist: „In the model proposed here, I want to focus on political education as a part of general education because it has a particular relationship with ICC." Auch die Anordnung der savoirs in einer tabellarischen Übersicht verdeutlicht die zentrale Rolle der politischen Bildung: Savoir s'engager bildet dort das Zentrum, um welches die anderen vier Schwerpunkte angeordnet sind (vgl. ebd.: 34). Byram lässt somit keinen Zweifel daran, dass interkulturelle Kompetenz auch eine politische und kulturkritische Seite hat („critical cultural awareness“, ebd.), die ihrerseits nicht ohne eine ethische Verankerung vorstellbar sind.

Wie zeigt sich diese politisch-ethische Dimension der intercultural competence nun in Bezug auf das Dilemma von Universalismus und Kulturrelativismus? Byram (ebd.: 44f.) schlägt hier einen auf den Menschenrechten basierenden Standpunkt vor, was zunächst auf eine universalistische Ausrichtung des Modells deutet:

Taking international standards of human rights as the base-line for evaluation is not of course a ready-made solution to the question of what standpoint should or could be recommended, since interpretations of human rights differ, but it provides a starting point for those teachers who feel that they need to offer their learners a rational approach to evaluations of the value systems of other cultures. This is particularly important for those who teach languages from societies with very different moral and ethical traditions, with respect to the treatment of women or children, for example. ${ }^{100}[\ldots]$ A human rights standpoint offers a rationale for handling strong emotional responses.

100 Die Problematik der hier zugrunde liegenden Gleichsetzung von Gesellschaft bzw. Nation, Sprache und Kultur wird in den folgenden Abschnitten nicht weiter problematisiert, da sie bereits oben diskutiert wurde. 
Es fällt jedoch auf, dass die Empfehlung in derselben Passage relativiert wird. Internationale Menschenrechtsstandards werden laut Byram unterschiedlich interpretiert, und diese Unterschiede lassen sich vermutlich auf differierende kulturelle Wertesysteme zurückführen. Hierbei handelt es sich jedoch um ein klassisches kulturrelativistisch inspiriertes Argument. Es legt die Frage nahe, welchen Nutzen internationale Menschenrechtsstandards haben, wenn es am Ende doch von kulturspezifischen Interpretationen abhängt, ob Menschen beispielsweise Schutz vor Folter oder vor Verfolgung auf Grundlage ihrer Religion, Hautfarbe oder sexuellen Orientierung genießen sollten (vgl. UN General Assembly 1948: Art. 2 und 5).

Auch die Verknüpfung des Menschenrechtsstandpunktes mit einer (vermutlich als universell angenommenen) Vernunft, die Byram vornimmt („a rational approach“, „a rationale for handling strong emotional responses“, s. o.), dürfte das Problem nicht lösen, da mit unterschiedlichen, jeweils einen Gültigkeitsanspruch erhebenden Rationalitäten zu rechnen ist (vgl. Welsch 1995).

Während in der zitierten Passage mit den genannten Einschränkungen eine Empfehlung für die Menschenrechte ausgesprochen wird, erscheinen diese an anderer Stelle als austauschbar mit anderen normativen Bezugssystemen:

The intercultural speaker is aware of their own ideological perspectives and values (,human rights'; socialist; liberal; Moslem; Christian etc.) and evaluates documents or events with explicit reference to them. (Byram 1997: 64)

Dabei bleibt jedoch offen, welche Ausprägungen der jeweiligen Perspektive akzeptabel wäre, damit von einem intercultural speaker die Rede sein kann. Verfügt beispielsweise ein Katholik über interkulturelle Kompetenz, der im Grunde seines Herzens überzeugt ist, dass jede Form von Sexualität außerhalb der Ehe gegen die Würde der beteiligten Personen verstößt (vgl. Der Heilige Stuhl 1997, Art. 2353), solange er sich der kulturellen Geprägtheit dieser Überzeugung bewusst ist und er andere Auffassungen als prinzipiell gleichberechtigt akzeptiert? Dies würde ihn zwangsläufig zu einem liberalen Katholiken machen. Allgemein würde dies im Analogieschluss bedeuten, dass ein intercultural speaker zwar ein bestimmtes Wertesystem für sich als gültig annehmen darf, aber jeweils nur in einer liberalen Auslegung. Die für den intercultural speaker geforderten Prinzipien der Reflexivität und Offenheit beinhalten somit unhintergehbare Normen, für die eine interkulturelle Gültigkeit angenommen werden muss.

Ich teile Byrams Einschätzung, dass das Erkennen und Aushalten von Differenz ein wichtiges Bildungsanliegen darstellen sollten („The intercultural speaker [...] can help interlocutors to identify common ground and unresolvable difference.", ebd.: 61). Manche Differenzen können jedoch zu erheblichen Konflikten führen, 
etwa, weil sie mit verbindlichen Rechtsnormen kollidieren (vgl. Kap. 2.2.4.). In solchen Konflikten genügt Erkennen und Aushalten nicht, „[...] denn auch ein Nichthandeln ist ein Handeln“ (Nieke 2008: 241). Ein Modell interkultureller Kompetenz, das für solche Konflikte keine handlungsleitenden Prinzipien anbietet, ist zu kritisieren, da es an einer entscheidenden Stelle einen blinden Fleck aufweist.

Beachtung verdient auch die Frage, welche Rolle der jeweilige Kontext für politische Bildung als Teil des fremdsprachlichen Lernens spielen sollte. Byram vertritt hier den Standpunkt, dass beim Unterrichten westeuropäischer Sprachen (er nennt die Beispiele Spanisch, Französisch, Deutsch, Englisch, Niederländisch) in Westeuropa die Konfrontation mit radikaler Differenz kaum gegeben sei, so dass sich ein unpolitischer Fremdsprachenunterricht eher rechtfertigen lasse (vgl. Byram 1997: 45). In Zusammenhang mit außereuropäischen Sprachen wie dem Arabischen oder Chinesischen müssten sich die Lernenden jedoch auch mit ganz anderen als den ihnen vertrauten Gesellschaftsmodellen auseinandersetzen. Deshalb sollten politisch relevante Themen wie soziale Ungleichheit Gegenstand des Unterrichts dieser Sprachen sein, um die Lernenden für diese Phänomene sowohl in der Zielkultur als auch in der Ausgangskultur zu sensibilisieren:

[...] a realistic representation in teaching materials of the country in question can and should soon introduce learners to different social groups, including those of low status and disadvantage. This can problematise a society's treatment of all its social groups, and through a reflexive methodology, raise questions about each learner's own society and its attitude to disadvantaged groups. (ebd.)

Es fällt auf, dass diese Forderung auf einer Prämisse beruht. Sie lautet, dass die Benachteiligung sozialer Gruppen ein Problem aller Gesellschaften darstellt, das thematisiert (und nach Möglichkeit gelöst) werden sollte. Diese Prämisse wäre jedoch mit bestimmten Gesellschaftsmodellen inkommensurabel, wie z.B. dem indischen Kastensystem. Sie stellt somit eine universalistische Setzung dar, die ich zwar teile, die jedoch als solche offengelegt werden müsste.

Problematisch ist auch, dass Byram in der zitierten Passage von relativer kultureller Homogenität innerhalb der europäischen Sprachen und innerhalb einer europäischen Schülerschaft ausgeht, eine Annahme, die durch steigende gesellschaftliche Pluralität immer weniger gültig sein dürfte. Darüber hinaus stellt sich die Frage, inwiefern gesellschaftliche Prinzipien wie die Menschenrechte, Demokratie und Rechtsstaatlichkeit, deren Vermittlung Auftrag öffentlicher Schulen ist, allein deswegen als gegeben angenommen werden können, weil Lernende in einem bestimmten Land wohnen oder eine bestimmte Muttersprache sprechen (vgl. Honneth 2013 und Kap. 2.2.5.). 
Ich beende an dieser Stelle die Diskussion von Byrams Modell interkultureller Kompetenz. Anwendungen des Modells auf literarische oder empirisch erhobene Texte, wie ich sie für Bredellas und Kramschs Modelle in den Kapiteln 3.2.-3.4. erörtert habe, lassen sich in diesem Fall nicht diskutieren, da sich Byram in der hier besprochenen Veröffentlichung auf theoretische Überlegungen beschränkt. Eine Ausnahme bilden lediglich seine Überlegungen zur Curriculumsgestaltung, die er am Beispiel des Französischunterrichts an der amerikanischen Ostküste veranschaulicht (vgl. Byram 1997: 81-86). Dieses Beispiel wird in Übereinstimmung mit dem der intercultural competence zugrunde liegenden Kulturverständnis entwickelt. Der in Zusammenhang mit der hier geführten Diskussion besonders relevante Schwerpunkt des savoir s'engager wird dabei nicht weiter problematisiert. Eine separate Diskussion des Beispiels ist daher nicht erforderlich.

Zusammenfassend lässt sich festhalten, dass Byrams Modellierung der Schwerpunkte interkultureller Kompetenz in Form von savoirs als ausgesprochen differenziert und elegant zeigt. Sie beruht jedoch auf einem totalitätsorientierten, mit der Gleichsetzung von Nation, Sprache und Kultur operierenden Kulturverständnis. Ein solches Kulturverständnis kann die Pluralität der meisten zeitgenössischen Gesellschaften nicht in angemessener Weise erfassen (vgl. Welsch 1994, 1999). Aus pädagogischer Sicht ist zu befürchten, dass die von Byram in Bezug auf dieses Kulturverständnis selbst formulierten Vorbehalte von dessen Tendenz zur Förderung homogenisierender und dichotomisierender Denkschemata überlagert werden.

Das Dilemma von Universalismus und Kulturrelativismus zeigt sich in Byrams Modell in Gestalt einer äußerst vorsichtig formulierten Empfehlung für einen Menschenrechtsstandpunkt. Es weist somit tendenziell universalistische Züge auf. Daneben wird jedoch auch ein kulturrelativistischer Standpunkt vertreten. Dessen universalistische Prämissen (vgl. Kap. 2.2.2.) werden jedoch nicht reflektiert. Die für eine intercultural competence im Sinne Byrams unhintergehbaren normativen Setzungen werden daher nicht ausreichend offengelegt, so dass die Frage im Raum steht, inwiefern das Modell für die Offenlegung von Machtstrukturen geeignet oder eher zu deren Verschleierung beiträgt. Dies könnte sich gerade für den Umgang mit Konfliktsituationen als erhebliche Schwäche erweisen.

Es sei in diesem Zusammenhang daran erinnert, dass Byram für sein Modell interkultureller Kompetenz von grundsätzlich günstigen Bedingungen ausgeht („[...] the most favourable circumstances of intercultural communication.", Byram 1997: 5). Dabei bleibt offen, woran genau günstige Bedingungen zu erkennen sind und inwiefern sie einen Bedarf an spezifischen interkulturellen Kompetenzen erzeugen. Gerhard Bach (2010: 24, vgl. Kap. 1.6.) hat in einem bereits angeführten Beispiel verdeutlicht, dass auch unter sehr günstigen Rahmenbedingungen mit 
dem Zusammenbruch der Kommunikation zu rechnen ist, und hat auf dieser Grundlage einige Defizite der interkulturellen Didaktik benannt. Eine Schlussfolgerung, die sich aus seinen Überlegungen ableiten lässt, lautet, dass bisherige Modelle interkultureller Kompetenz die Möglichkeit von Konflikten bereits unter günstigen Bedingungen unzureichend berücksichtigen. Unter ungünstigen Bedingungen dürften sich diese Defizite der interkulturellen Didaktik besonders deutlich zeigen. Das heißt, dass eben jene Bedingungen, in denen interkulturelle Kompetenzen in besonderem Maße gefragt sein könnten, nicht antizipiert werden, und dies scheint auch für Byrams Modell einer intercultural competence zu gelten. Zwar legt er in seinem Modell besonderen Wert auf den Kompetenzschwerpunkt der politischen Bildung, des savoir s'engager. Die dafür erforderliche Ausrichtung an universellen Werten, wie sie in den Menschenrechten und den aus ihnen abgeleiteten demokratischen Prinzipien zu finden sind, hätte jedoch meiner Einschätzung nach mit größerer Deutlichkeit formuliert werden können. ${ }^{101}$ Dies hätte zwar die Probleme des zugrunde liegenden Kulturverständnisses nicht gelöst, aber doch zumindest den Schwerpunkt des savoir s'engager in eindeutiger Weise ethisch verortet.

Wie bereits eingangs erwähnt, wurden die savoirs in den Katalog allgemeiner Kompetenzen des GeR übernommen und haben somit eine erhebliche Verbreitung erfahren (vgl. Europarat 2001: 103-109). Das Problem der ethischpolitischen Dimension interkultureller Kompetenz wurde dabei auf ganz eigene Weise gelöst: Der Schwerpunkt savoir s'engager taucht im GeR schlicht nicht auf (vgl. Plikat 2016).

\subsection{Fazit: Problemfelder der interkulturellen Fremdsprachendidaktik}

In der Analyse verschiedener Ansätze zur interkulturellen Fremdsprachendidaktik konnte die Arbeitshypothese bestätigt werden, dass diese in mindestens zweierlei Hinsicht problematisch sind: einerseits in ihrer Tendenz zu homogenisierenden, dichotomisierenden und damit Kontingenzen invisibilisierenden Kulturverständnissen (Forschungsfrage 1); andererseits in der Tendenz zur Vernachlässigung von Fragen, die sich aus dem Dilemma von Universalismus und Kulturrelativismus ergeben. Dies kann, wie gezeigt werden konnte, zu einer Invisibilisierung der Machtdimension von Konflikten führen (Forschungsfrage 2).

101 Für mehr Klarheit sorgt hier eine spätere vertiefte Auseinandersetzung mit verschiedenen Konzepten zur Rolle demokratischer Prinzipien in der schulischen Bildung. Vgl. Byram 2008. 
Diese Problemlage ist für das Lernen fremder Sprachen als interkulturelles Lernen aus mindestens zwei Gründen hoch relevant. Erstens fördern überholte Kulturverständnisse das Denken in Auto- und Heterostereotypen. Eine interkulturelle Didaktik, die mit diesen Kulturverständnissen arbeitet, unterläuft somit ihre eigene Zielsetzung. Zweitens wird den Lernenden durch die Setzung eines kulturrelativistischen Standpunktes als Norm die Möglichkeit vorenthalten, „interkulturelle“ Kompetenz gezielt für Konfliktsituationen aufzubauen, für jene Situationen also, in denen sie diese Kompetenz in besonderem Maße benötigen werden. Somit ergibt sich die paradoxe Situation, dass einflussreiche Ansätze interkultureller Fremdsprachendidaktik ihr Kernanliegen, das des Umgangs mit Differenz, auf doppelte Weise nicht einlösen: einerseits, indem sie mit problematischen Kulturverständnissen operieren; andererseits, indem sie das Bekenntnis zu grundlegenden Prinzipien des Zusammenlebens - Menschenrechte, Demokratie und Rechtsstaat - verweigern.

Beide Problembereiche hängen, so scheint es, eng mit der Verwendung des Begriffs ,Kultur' zusammen. Dieser führt, wie gezeigt werden konnte, immer wieder zum Rückgriff auf unterkomplexe Kulturverständnisse, und zwar selbst bei jenen Experten, die sich die Entwicklung einer komplexen Auffassung von Interkulturalität zum Ziel gesetzt haben. Zudem legt er einen Kulturrelativismus nahe, der einen kritischen Umgang mit ,Kultur' (im Sinne etwa einer critical cultural awareness) nicht nur nicht fördert, sondern konterkariert.

Bei aller Kritik sind jedoch auch die Verdienste des cultural turn in der Fremdsprachendidaktik zu nennen. Interkulturalität als Zielkonstrukt fremdsprachlichen Lernens hat dazu geführt, dass frühere landeskundliche Ansätze hinterfragt und allmählich durch komplexere Ansätze ersetzt wurden. So betonen alle gängigen Modellierungen interkultureller Kompetenz im Unterschied zu traditionell landeskundlichen Ansätzen nicht nur die Bedeutung soziokulturellen Orientierungswissens, sondern auch der affektiven und verhaltensbezogenen Dimensionen des Umgangs mit Differenz. Die Verwendung überholter Kulturverständnisse haben sie zwar nicht wirksam eindämmen können, aber sie haben sehr wohl dazu beigetragen, dass diese zumindest als problematisch wahrgenommen werden.

In den folgenden Kapiteln wird versucht, einen alternativen Theorieansatz zu entwickeln. Dieser soll sowohl kulturelles Lernen im Sinne eines komplexen kulturwissenschaftlichen Kulturverständnisses fördern also auch das Dilemma von Universalismus und Kulturrelativismus reflexiv zugänglich machen. Dieser Ansatz wird, so die Konsequenz aus den bis zu dieser Stelle entfalteten Überlegungen, ohne den Kulturbegriff auskommen müssen. 


\section{Kapitel 4: Theoriebildung: Umrisse des Konstruktes ,Fremdsprachliche Diskursbewusstheit ${ }^{\text {}}$}

\subsection{Einleitende Überlegungen}

Die bis zu dieser Stelle ausgeführten Überlegungen und Analysen haben gezeigt, dass die auf den Interkulturalitätsbegriff ausgerichtete Fremdsprachendidaktik dazu neigt, zwei Probleme zu vernachlässigen: Erstens sind häufig Kulturverständnisse festzustellen, die aus der Sicht kulturwissenschaftlicher Theoriebildung als nicht mehr zeitgemäß gelten müssen. Zweitens wird in der Regel ein kulturrelativistischer Standpunkt empfohlen, der nicht nur Machtstrukturen ausblendet, sondern auch erhebliche ethische Probleme aufwirft und nicht zuletzt in Widerspruch zum Erziehungsauftrag der demokratischen Schule steht.

Die von Dirk Baecker (2001: 51) geäußerte Befürchtung, dass der Kulturbegriff zur Selbst-Affirmation, zur „Emphase für sich selbst“ neigen kann, hat sich somit bei der Analyse verschiedener Theorieansätze aus dem Bereich der interkulturellen Fremdsprachendidaktik bestätigt. Es zeigt sich, dass seine Verwendung immer wieder zu Invisibilisierungen seiner Prämissen und Konsequenzen führt - teilweise sogar gegen die erklärte Absicht der Autor_innen, die den Kulturbegriff ins Zentrum ihrer Überlegungen stellen. Angesichts dieser Problemlage scheint das Unbehagen, das ich zu Beginn dieser Arbeit im Anschluss an eine Formulierung Gerhard Bachs zum Ausdruck gebracht habe, durchaus begründet, so dass der Bedarf nach einer Alternative zum Zielkonstrukt „Interkulturelle Kompetenz" als gegeben angenommen werden kann. Welche Anforderungen müsste ein solches Konstrukt erfüllen? Auf Grundlage der bisher ausgeführten Überlegungen lassen sich folgende Aspekte vorläufig festhalten: Es müsste...

... den Kulturbegriff selbst vermeiden, da dieser vermutlich zu den genannten Problemen zurückführen würde; es müsste gleichzeitig jedoch an „kulturwissenschaftliche“ Kulturkonzepte anschlussfähig sein und diese bei den Lernenden anbahnen.

... auf einer konzeptuellen Ebene angesiedelt sein, auf der verschiedene Arten des Sprechens und Handelns als überindividuelle und damit soziale Phänomene befragt werden können. 
... die gesellschaftliche und (macht-)politische Dimension von (Fremd-)Sprache in den Blick nehmen.

... sich dem allgemeinen Trend der Stufung und Quantifizierung von Bildungsprozessen entziehen, da diese zu Komplexitätsreduktion und Entpolitisierung führen können.

... prinzipiell empiriefähig sein.

... sich den Herausforderungen (fremd-)sprachlichen Lernens in der Vielzahl von Genres, Medien und Modi stellen, mit denen Lernende im globalisierten digitalen Zeitalter täglich umgehen.

... an den für eine fächerübergreifende Perspektive und für übergeordnete Bildungsziele vor allem in der deutschsprachige Diskussion weiterhin relevanten Bildungsbegriff anschlussfähig sein.

Für die Umsetzung dieses Vorhabens zur fremdsprachendidaktischen Theoriebildung erscheinen drei Theorieansätze als vielversprechend:

1. Die auf der Diskurstheorie Foucault'scher Prägung basierenden Arbeiten Norman Faircloughs zum Verhältnis von Sprache und Macht.

2. Das Konzept der Sprachbewusstheit (language awareness), das für den deutschsprachigen Kontext v.a. durch die Arbeiten Dieter Wolffs, Claus Gnutzmanns und Steffi Morkötters rezipiert wurde.

3. Die Bildungstheorie des Erziehungswissenschaftlers Hans-Christoph Koller, der den Gedanken der Transformation ins Zentrum seiner Überlegungen stellt.

Auf ihrer Grundlage soll Forschungsfrage 3 beantwortet werden.

Die genannten theoretischen Ansätze, die für das Konzept der Fremdsprachlichen Diskursbewusstheit erschlossen werden sollen, verfügen, ähnlich wie der Kulturbegriff, über vielfältige und komplexe Traditionen. Dies gilt in besonderem Maße für den Bildungsbegriff, der seit gut 200 Jahren in der deutschsprachigen Diskussion eine phasenweise zentrale Rolle spielte, und zwar - eine weitere Parallele zum Kulturbegriff - sowohl in der Alltagssprache als auch in Fachkontexten. Der Diskursbegriff verfügt ebenfalls über eine vielfältige Begriffsgeschichte. Das Ziel dieser Arbeit besteht jedoch nicht darin, die historische Semantik der Begriffe vollständig zu entfalten. Dies wäre zumindest für den Kulturbegriff und den Diskursbegriff jeweils ein separates Forschungsvorhaben. Ich beschränke mich daher auf jene Aspekte, die mir für das Konstrukt fruchtbar erscheinen, das auszuarbeiten Ziel dieser Arbeit ist. Eine solche Beschränkung trägt natürlich immer auch subjektive Züge, und dies in doppelter Hinsicht:

Erstens bedeutet eine Entscheidung für die Aufnahme bestimmter theoretischer Ansätze gleichzeitig eine (teilweise) Abgrenzung nach außen gegen andere, bei denen sich eine ebenso ausführliche Rezeption vermutlich gelohnt 
hätte. Hierzu zählen im Bereich der Fremdsprachendidaktik unter anderem die Konzepte der Pluralen Bildung von Lutz Küster (2003b), das Konzept der Reflexiven Bildung von Stephan Breidbach (2007) sowie verschiedene Arbeiten von Wolfgang Hallet zur Intertextualität und Interdiskursivität (2002, 2007, 2008). Hierbei ist die Schwerpunktsetzung jedoch jeweils eine andere: Sowohl Hallet als auch Küster haben die literarische Bildung im Fremdsprachenunterricht ins Zentrum ihrer Überlegungen gestellt, während Breidbach die Grundzüge einer Didaktik für den bilingualen Sachfachunterricht vorgelegt hat. Die Untersuchung der Anschlussfähigkeit des Konzeptes der Fremdsprachlichen Diskursbewusstheit mit den genannten Ansätzen, die sich als ausgesprochen anregend für die vorliegende Arbeit erwiesen haben, wäre jedoch Gegenstand weiterer Forschung. Außerhalb des deutschsprachigen Raums wäre etwa das Konzept der responsabilité épistémologique zu nennen, wie es von Jean-Paul Narcy-Combes $(2010,2013)$ vertreten wird.

Zweitens erfordert die Rezeption einer bestimmten Theorie immer auch eine Schwerpunktsetzung und damit eine (teilweise) Abgrenzung nach innen, die reflektiert erfolgen sollte, aber ebenfalls unvermeidlich subjektive Züge trägt. Innerhalb der Bildungstheorie etwa hätte eine ausführliche Rezeption der Humboldt'schen sprachphilosophischen Arbeiten sich mit Sicherheit als ergiebig erwiesen. Ebenso hätten die Arbeiten des Philosophen Jean-François Lyotard oder des Erziehungswissenschaftlers Helmut Peukert eine ausführlichere Darstellung und Diskussion verdient, als dies im hier gegebenen Rahmen möglich ist. Humboldt, Lyotard und Peukert haben jedoch das Werk Hans-Christoph Kollers entscheidend geprägt und zumindest indirekt auch diese Arbeit beeinflusst.

Ein theoretisches Konzept wie die hier entwickelte Fremdsprachliche Diskursbewusstheit stellt in diesem Sinne selbst einen Diskurs dar, der wie alle Diskurse entsteht, indem andere Diskurse ausgewählt, gewichtet, verbunden und transformiert werden. Ich versuche in den folgenden Kapiteln, diesen Prozess so differenziert und transparent wie möglich darzustellen und verweise an den gegebenen Stellen auf ausführlichere Darstellungen der theoretischen Überlegungen, auf denen diese Arbeit beruht. Dabei gehe ich jeweils in einem dreischrittigen Verfahren vor. Zunächst umreiße ich die Problemstellung, mit der sich das vorgestellte theoretische Konzept befasst. Anschließend stelle ich das rezipierte Konzept selbst vor, um so mein eigenes Verständnis zu resümieren und offenzulegen. Schließlich diskutiere ich es im Hinblick auf das Potential für den Theorieansatz, der hier ausgearbeitet wird, die Fremdsprachliche Diskursbewusstheit. 


\subsection{Zum Diskursbegriff}

\subsubsection{Vorüberlegungen zum Diskursbegriff}

Diskurs: Modewort aus der akademischen Welt. „Diskurs“ wurde aus der modernen französischen Philosophie ins Deutsche eingeführt und bedeutet, dass die Art, wie man einen gesellschaftlichen Gegenstand begrifflich fasst oder über ihn spricht, auch die Wirklichkeit prägt. Im heutigen Gebrauch schwingt nur noch vage etwas Philosophisches mit, weil Diskurs nur noch im Sinne von „öffentliches Reden“ verwendet wird. „Wir brauchen einen öffentlichen Diskurs über unsere Werte“, lautet eine beliebte Forderung, die nichts anderes bedeutet als: „Wir sollten öffentlich über unsere Werte reden“. Aber so einfach mag man es nicht sagen, es könnte ja auf Anhieb verstanden werden. (Kirchhoff/Krämer 2010: 54)

Bei der Arbeit an einem fremdsprachendidaktischen Zielkonstrukt, das eine Alternative zum Kulturbegriff mit seiner Tendenz zur Selbst-Affirmation, zur Invisibilisierung von Kontingenzen und Machtstrukturen sowie zur homogenisierenden Wahrnehmung von Gruppen bieten soll, stößt man unweigerlich auf den Diskursbegriff. Handelt es sich bei ihm wirklich nur, wie die zitierten Autoren behaupten, um eine akademische Nebelkerze? Das Zitat macht zumindest darauf aufmerksam, dass sich die alltagssprachliche Rezeption des Diskursbegriffs im Deutschen in zweierlei Hinsicht von der des Kulturbegriffs unterscheidet. Erstens fiel sie deutlich schwächer aus als die des Kulturbegriffs - der Diskursbegriff wird weiterhin vorwiegend als „der akademischen Welt“ zugehörig wahrgenommen. Zweitens wird der Diskursbegriff in nicht-akademischen Kontexten anscheinend bisweilen verdächtigt, nicht für neue Einsichten zu sorgen, sondern lediglich banale Vorgänge in eine beeindruckende Sprache zu kleiden. Dieser Verdacht dürfte gegen den Kulturbegriff kaum jemals formuliert werden, denn er ist in der Alltagssprache so allgegenwärtig, dass er jeden Nutzen für intellektuelle Spreizungen verloren haben dürfte.

Die Frage, inwieweit ein Begriff wie Diskurs, der im Deutschen weiterhin als vorwiegend wissenschaftlich konnotiert ist, als Leitbegriff für die Fremdsprachendidaktik geeignet ist, wird noch zu erörtern sein (vgl. Kap. 4.2.4.). Die Behauptung jedoch, es handle sich bei ihm lediglich um eine gedrechselte Bezeichnung für eine öffentliche Diskussion über ein bestimmtes Thema, kann mit Verweis auf die Arbeiten Michel Foucaults entschieden zurückgewiesen werden. Der Kern von Foucaults Diskursbegriffs liegt nämlich genau in der ersten der oben genannten Bedeutungen, die „im heutigen Gebrauch“ angeblich kaum noch eine Rolle spielt und die darauf abzielt, die prägende Kraft der Sprache auf unsere Wahrnehmung der Wirklichkeit offenzulegen. Kaum jemand dürfte bezweifeln, dass mit dieser Ausprägung des Diskursbegriffs ein neues 
Analysewerkzeug entwickelt wurde, welches die verschiedensten humanwissenschaftlichen Disziplinen in erheblichem Ausmaß geprägt hat. Diese Karriere des Begriffs scheint durchaus gerechtfertigt: Erst mit Hilfe des Diskursbegriffs wurde es möglich zu reflektieren, wie sehr wir uns in sprachlich, diskursiv gesteckten Grenzen bewegen, wenn wir denken und sprechen. Foucault und andere haben mit Hilfe des Diskursbegriffs verschiedene Grenzziehungen offengelegt, an denen wir uns auf selbstverständliche Weise orientieren, wenn wir etwa eine vordergründig so offensichtliche Unterscheidung wie die zwischen Wahnsinn und Vernunft treffen (vgl. Foucault 1972). Im Anschluss an diese Überlegungen lässt sich auf eine radikal neue Weise nachvollziehen, was genau abläuft, wenn wir etwas scheinbar Banales tun wie beispielsweise „öffentlich über unsere Werte reden“: Die Regeln des Diskurses, so zeigt Foucault, legen fest, was zu diesem Thema gesagt werden kann und was nicht, wer sprechen darf und wer nicht, wem zugehört wird und wem nicht.

,Diskurs' ist heute neben ,Kultur' ein Kernbegriff unter anderem der Soziologie, der Linguistik, der Literaturwissenschaft oder der Bildungstheorie. Obwohl es sich dabei ohne Ausnahme um wichtige Bezugswissenschaften der Fremdsprachendidaktik handelt, rezipierte diese jedoch eigentümlicherweise vorwiegend den Kulturbegriff, und zwar auf allen Ebenen: auf der Ebene der akademischen Diskussion ebenso wie auf der Ebene der administrativen und curricularen Vorgaben sowie auf der Ebene der Lehr- und Lernmaterialien. Während der cultural turn der Humanwissenschaften also auch in der Fremdsprachendidaktik - mehr oder weniger fundiert - vollzogen wurde, verursachte der vermutlich ebenso wichtige discursive turn in der Fremdsprachendidaktik einen vergleichsweise geringen Widerhall. Wolfgang Hallet (2008: 77) beklagte in diesem Zusammenhang noch vor wenigen Jahren, dass der Diskursbegriff in einem Großteil der fremdsprachendidaktischen Diskussion über einen „Non-Status“verfüge.

Seither sind erste Tendenzen erkennbar, dass neben dem Kulturbegriff allmählich auch der Diskursbegriff berücksichtigt wird. So findet er etwa in den Bildungsstandards für den Mittleren Schulabschluss von 2003 lediglich eine einzige Erwähnung (vgl. KMK 2003: 73), in den Abiturstandards (vgl. KMK 2012) taucht er dagegen bereits an 26 Stellen auf. Zum Vergleich: der Suchbegriff, Kultur' liefert im Dokument von 200348 Treffer, im Dokument von 2012334 Treffer. Mit anderen Worten: Das Verhältnis der Erwähnungen von,Diskurs` und, Kultur und ihrer Zusammensetzungen hat sich in zwei vergleichbaren Dokumenten der KMK zwischen 2003 und 2012 von 1:48 auf ca. 1:12 verschoben.

Dieser Aufmerksamkeitsschub dürfte in besonderem Maße von der CLILDidaktik ausgegangen sein. In ihrem Rahmen wurde in den letzten Jahren von 
verschiedenen Autoren auf die Bedeutung sogenannter ,Diskursfunktionen' für das sachfachliche Lernen in einer Fremdsprache verwiesen (vgl. u.a. Zydatiß 2007: 440, 447). Wie in allen Bezugswissenschaften, die sich mit ,Diskurs' auseinandersetzen, finden sich jedoch auch in der Fremdsprachendidaktik sehr unterschiedliche Verständnisse des Begriffs. Dies ist nicht weiter überraschend, wenn man bedenkt, dass discours bereits lange vor Foucault im Französischen als Bezeichnung für eine längere, zusammenhängende Rede oder einen Vortrag diente und zunächst in die Linguistik übernommen wurde. Foucaults Diskurskonzeption hebt sich hiervon deutlich ab; auch seine Verwendung des Terminus ist jedoch nicht immer klar. Vielmehr prägte er in seinem überaus reichen und sich über die Jahre entwickelnden Werk mindestens drei verschiedene Bedeutungen von ,Diskurs. Er selbst gibt zu Protokoll, nicht immer für eine schärfere Konturierung des Begriffs gesorgt zu haben:

Enfin au lieu de resserrer peu à peu la signification si flottante du mot, discours, je crois bien en avoir multiplié le sens: tantôt domaine général de tous les énoncés, tantôt groupe individualisable d'énoncés, tantôt pratique réglée rendant compte d’un certain nombre d'énoncés. (Foucault 1969: 106)

Ebenso wenig, wie es also den Diskursbegriff oder den Foucault'schen Diskursbegriff gibt, lässt sich in der Fremdsprachendidaktik eine einheitliche Verwendung des Terminus feststellen. Vermutlich ist daher eine gründliche Begriffsklärung vonnöten, wenn die Rolle des Diskursbegriffs in der Fremdsprachendidaktik weiter zunehmen sollte. Dies fordert etwa Wolfgang Hallet (2008: 78, Hervorhebung im Original), wenn er schreibt:

Andererseits ist es natürlich Aufgabe des disziplinären und transdisziplinären fachdidaktischen Diskurses, unabhängig vom oder auch gegenläufig zum politischen mainstream solche Konzepte und eine darauf gründende Terminologie zu entwickeln, welche die Aufgaben des Fremdsprachenunterrichts in den globalisierten, diversifizierten und digitalisierten Kommunikationsgesellschaften des 21. Jahrhunderts am besten erfassen können. Der Begriff des Diskurses [...] ist dazu nicht bloß außerordentlich geeignet, sondern unabdingbar.

Ich verstehe das hier verfolgte Anliegen, ein Konzept fremdsprachlicher Diskursbewusstheit zu umreißen, durchaus im Sinne dieses von Hallet festgestellten Theoriedefizits. Für eine vorläufige Begriffsklärung orientiere ich mich dabei an dem bereits genannten Beitrag Hallets (2008), der unter Rückgriff auf Hans-Eberhard Piepho nicht nur für die Aufwertung des Diskursbegriffs in der Fremdsprachendidaktik insgesamt plädiert, sondern bei dieser Gelegenheit auch vorgeschlagen hat, zwischen drei Diskursbegriffen zu unterscheiden. Ich versuche auf den folgenden Seiten, verschiedene Diskursbegriffe in Anlehnung an 
diese Kategorien zu rekonstruieren. Bei den drei zu unterscheidenden Diskursverständnissen handelt es sich erstens um das linguistische Diskursverständnis, zweitens um das sozialphilosophische (Foucault'sche) Diskursverständnis, die beide bereits erwähnt wurden, und drittens um das kommunikationstheoretische (Habermas'sche) Diskursverständnis. Dieses wurde besonders im Deutschen in die gehobene Alltagssprache übernommen und dürfte im Eingangszitat gemeint sein.

Ziel der folgenden Überlegungen ist zu klären, was genau unter diesen Diskurskonzeptionen jeweils zu verstehen ist, inwieweit sie bereits in die fremdsprachendidaktische Diskussion übernommen wurden und worin ihr Potential für den hier zu entwickelnden Ansatz der fremdsprachlichen Diskursbewusstheit liegt.

\subsubsection{Klärung des Diskursbegriffs}

Das erste, linguistische Diskursverständnis liegt selbst in zahlreichen Ausprägungen vor (vgl. Bluhm et al. 2000). Von diesen möchte ich im Folgenden zwei aufgreifen, die textlinguistische und die funktional-pragmatische. Die textlinguistische Konzeption verdient hier eine Erwähnung, weil sie am Anfang der erstaunlichen Karriere des Diskursbegriffs in der zweiten Hälfte des 20. Jahrhunderts steht. Die funktional-pragmatische Konzeption ist von Interesse, da sie in der allgemeinpädagogischen Forschung rezipiert wurde.

Der textlinguistische Diskursbegriff geht von der Beobachtung aus, dass Sprachproduktion durch die Verkettung sprachlicher Zeichen zu sinnvollen Einheiten nach bestimmten Regeln abläuft. Im Gegensatz zur deskriptiven Grammatik der traditionellen Linguistik wird jedoch nicht mehr nur gefragt, wie sich diese Verkettungsregeln auf der Phonem-, Morphem- und Wortebene beschreiben lassen. Vielmehr wird der Blick nun auch auf die nächsthöhere Ebene gerichtet, um auch die Verkettungsregeln von Sätzen erforschen zu können. Diese Ebene wird diskursive Ebene genannt, und die linguistischen Verfahren, bei denen Sprache auf dieser Ebene untersucht wird, stellen daher eine Ausprägung der unter dem Begriff Diskursanalyse versammelten sprachwissenschaftlichen Forschungsrichtungen dar.

Wenn man die Struktur von Texten oberhalb der syntaktischen Ebene in den Blick nimmt (vgl. Harris 1952), lassen sich Regeln beobachten, nach denen bestimmte Genres typischerweise aufgebaut sind. Die Offenlegung dieser Regeln verfolgte etwa Roland Barthes (1966) mit seinem Verfahren zur Analyse der narrativen Struktur von Erzählungen, wobei er unter einer ,Erzählung' ganz allgemein die sprachliche Darstellung einer Abfolge von Ereignissen verstand. Auf 
dieser Grundlage war es ihm möglich, in einer Anschlusspublikation die (bis dahin scheinbar offensichtliche) Grenzziehung zwischen fiktionalen und historiografischen Texten in Frage zu stellen (vgl. Barthes 1967).

Neben der textlinguistischen Ausprägung lässt sich ein zweiter Bedeutungsstrang des linguistischen Diskursbegriffs rekonstruieren, den man als funktionalpragmatisch bezeichnen kann. Hierbei wird die ursprüngliche Bedeutung von discours im Französischen im Sinne von ,Rede` oder, Gespräch 'betont. ,Diskurs steht hier für die mündliche Sprachverwendung, die räumlich und zeitlich gebunden ist und bei welcher daher Adressat(en) und Kontext unmittelbar präsent sind. Diese Einengung des Diskursbegriffs ermöglicht eine klare Abgrenzung zwischen ,Diskurs' und ,Text'.,Diskurs' steht in diesem Verständnis für den flüchtigen, vergänglichen mündlichen Sprachgebrauch, ,Text‘ bezeichnet dagegen den konservierten mündlichen Sprachgebrauch - als Tonbandaufzeichnung, Transkript, Protokoll, usw. ${ }^{102}$ So definiert der Linguist Hartmut Haberland (1999: 912, 914) unter Rückgriff auf Bronisław Malinowski und Konrad Ehlich:

This means that text is what happens to discourse if or when it is taken out of the immediate context of its production, whether written down, recorded, quoted or remembered. [...] Text is transportable, but discourse is not. [...] Discourse vanishes the moment it has happened; it can be recalled but not called back. [...] A text is a thing that can be in different places and at different times; discourse is an event that has only one here and now.

Hier wird die Unmittelbarkeit mündlicher Sprachverwendung betont, die bedinge, dass die Zweckhaftigkeit, die im Akt des Sprechens gegeben sei, bei der Aufzeichnung verloren gehe. ,Diskurs' ist in diesem Sinne eben wegen seiner Flüchtigkeit nicht analysierbar, ,Text ${ }^{`}$ hingegen schon, so dass Diskursanalyse eigentlich nur als Textanalyse umgesetzt werden kann (vgl. ebd.: 914). Es wird deutlich, dass ,Diskurs' in der ersten, textlinguistischen Bedeutung sehr nah am Textbegriff zu verorten ist. In der funktional-pragmatischen Linie hingegen steht ,Diskurs' häufig quasi-synonym für, Gespräch'.

Eine wichtige Rolle spielt nun der funktional-pragmatische Diskursbegriff in der Unterrichtsforschung, etwa in den Arbeiten Michael Becker-Mrotzecks, der seine Fassung der Diskursanalyse im Kern als „die linguistische Untersuchung

102 Dieser eng gefasste Textbegriff unterscheidet sich deutlich von der weiten Konzeption, die etwa von Doris Bachmann-Medick (2004) vertreten wird und auch in fremdsprachendidaktischen Beiträgen aufgegriffen wurde. Sie schlägt vor, „Kultur“ im Anschluss an Geertz als Gewebe von Bedeutungen und damit insgesamt als „Text“ zu interpretieren. Zur Kritik an Bachmann-Medick vgl. Ort 2008: 34. 
mündlicher Kommunikation generell“ (Weber/Becker-Mrotzeck 2012: 1) konzipiert. Hierbei beruft er sich auf drei theoretische Ansätze: erstens auf die Sprechakttheorie nach John L. Austin und John Searle sowie ihre Weiterentwicklung zur funktionalen Pragmatik durch Konrad Ehlich, zweitens auf die Sprachtheorie Karl Bühlers, ebenfalls in einer Weiterentwicklung durch Ehlich (vgl. ebd.: 2), und drittens auf eine Theorie, welche den Blick auch auf die gesellschaftliche Ebene richtet. In ihr werden Sprechakte als Vorgänge gesehen, bei denen sozial vorgegebene Bedürfnisse durch sprachliches Handeln von einem Bedürfnis (Defizienz) in einen Zustand der Befriedigung (Suffizienz) überführt werden:

In short, the fundamental aim of Functional Pragmatics is to analyze language as a sociohistorically developed action form that mediates between a speaker (S) and a hearer $(\mathrm{H})$, and achieves - with respect to constellations in the actants' action space (Rehbein 1977) - a transformation of deficiency into sufficiency with respect to a system of societally elaborated needs. (Redder 2008: 136, zit. nach Weber/Becker-Mrotzeck 2012: 3)

Im linguistischen Verständnis steht,Diskurs' somit entweder für jene Strukturen, welche durch die regelhafte Verknüpfung von Sätzen gebildet werden, oder er steht für situations-, kontext- und adressatengebundene mündliche Sprachverwendung, aus deren Aufzeichnungen sich typische Muster rekonstruieren lassen. Beide Ansätze wurden verwendet, um Genres wie die politische Rede, den wissenschaftlicher Vortrag, den Dialog zwischen Arzt und Patient, das Unterrichtsgespräch, etc. anhand ihrer, diskursiven' Merkmale zu beschreiben. Dabei lassen linguistische Diskursverständnisse die grundlegende Vorstellung meist unangetastet, dass es sich bei Sprache um ein Medium handle, mit dem Individuen in tendenziell autonomer und bewusster Weise Zwecke verfolgen. Unter anderem in diesem Aspekt unterscheiden sie sich grundlegend vom sozialphilosophischen Diskursbegriff, der in erheblichem Maße von Michel Foucault geprägt wurde. Ich möchte im Folgenden dieses zweite Verständnis von,Diskurs' umreißen.

Eine einfache Frage, die sich für eine Annäherung an Foucaults Diskursbegriff eignet, lautet: Wer spricht? (Vgl. Sarasin 2006: 117ff.) In der Tradition des Humanismus ist die Antwort eindeutig: Das Individuum spricht, es bedient sich des Mediums Sprache, um seine Bedürfnisse zu artikulieren, um sich mit seinen Mitmenschen auszutauschen und um sie zu beeinflussen. Sprache ist in diesem Sinne das Vehikel, mit dem das bewusste - seit Sigmund Freud auch das unbewusste, triebhafte - Innere artikuliert werden kann. Foucault stellt diese Vorstellung in seinem Werk radikal zur Disposition. Seine These lautet, dass das Individuum die Sprache zwar spricht, aber gleichzeitig wird es auch von ihr gesprochen - in einem Maße, welche seine Autonomie nachhaltig in Frage stellt. Sprache steht damit nicht 
mehr einfach als neutrales Werkzeug zur Verfügung. Vielmehr ist sie nach Foucault auf eine ganz bestimmte Art vorstrukturiert. Bei diesen Strukturen handelt es sich um fest gefügte, historisch tradierte Sprachverwendungen, und eben diese nennt Foucault ,Diskurse. Sie entstehen an Themen entlang, und auf Diskurse als thematisch strukturierte Konfigurationen - nicht auf Sprache an sich - richtet er sein Interesse. Ein solches Sprachverständnis lässt wenig Raum für einen sprachlichen Realismus, für die Vorstellung also, dass Sprache eine objektiv vorhandene Realität einfach nur abbilde. Die Benennung von Dingen erfolgt nach Foucault vielmehr angeleitet von diskursiven Regeln, und das Anliegen der Diskursanalyse besteht eben darin, diese Regeln offenzulegen:

[...] je voudrais montrer sur des exemples précis, qu’en analysant les discours eux-mêmes, on voit se desserrer l'étreinte apparemment si forte des mots et des choses, et se dégager un ensemble de règles propres à la pratique discursive. (Foucault 1969: 66)

Nicht nur Wörter und Dinge verhielten sich zueinander nach den Regeln von Diskursen, sondern dies gelte auch auf einer höheren Ebene. So seien etwa wissenschaftliche Fachdisziplinen oder Unterscheidungen wie jene zwischen Wahnsinn und Vernunft ebenfalls an Diskursgrenzen entlang organisiert, und bekanntlich hat Foucault in einem seiner Hauptwerke die Geschichte des Wahnsinns als Geschichte von Diskursen über den Wahnsinn rekonstruiert (vgl. Foucault 1972). Vor diesem Hintergrund wird deutlich, dass der französische Titel der Antrittsvorlesung Foucaults am Collège de France - Lordre du discours (1971a) - mehrdeutig zu verstehen ist. Erstens ist die Ordnung der Diskurse selbst gemeint, die Art und Weise also, in der Sprache als geregeltes Sprechen in festen Formationen strukturiert ist. Zweitens geht es um die Ordnung der Welt, der ,Dinge' (choses), welche dem Menschen nicht, an sich', sondern immer nur in Abhängigkeit von diskursiven Strukturen zugänglich seien. Drittens schließlich steht ordre auch für den Befehl, womit die normative Kraft verdeutlicht wird, die, zumindest nach Ansicht Foucaults, von Diskursen ausgeht. ${ }^{103}$

Zur Illustration dieses Aspekts zitiert Foucault im Vorwort zu Les mots et les choses (2007 [1966]) eine von Jorge Luis Borges fingierte chinesische Enzyklopädie, in der die Tierwelt nach überraschenden Kategorien eingeteilt seien:

En sus remotas páginas está escrito que los animales se dividen en (a) pertenecientes al Emperador, (b) embalsamados, (c) amaestrados, (d) lechones, (e) sirenas, (f) fabulosos, (g) perros sueltos, (h) incluidos en esta clasificación, (i) que se agitan como locos,

103 Die Dopeldeutigkeit von frz. „ordre“ geht in der gängigen deutschen Übersetzung des Titels, Die Ordnung der Dinge, verloren. 
(j) innumerables, (k) dibujados con un pincel finísimo de pelo de camello, (1) etcétera, (m) que acaban de romper el jarrón, (n) que de lejos parecen moscas. (Borges 1996: 166f.) ${ }^{104}$

Foucault vertritt den Standpunkt, dass Diskurse das Denken und Sprechen eines Menschen bereits durchdrungen haben, noch ehe er selbst das erste Wort artikuliert. Diskurse prägten aber nicht nur, wie von einer Sache gesprochen werden kann, sondern auch, $o b$ dies überhaupt möglich sei. Dies zu regeln ist nach Foucault eine wichtige Funktion von Experten, die sich entlang diskursiver Grenzen in Fachdisziplinen organisieren, sowie die Funktion der in Analogie zu diesen Disziplinen aufgebauten gesellschaftlichen Institutionen wie Universitäten, Kliniken, Kirchen oder Justiz: Sie wachten darüber, wer auf welche Art und Weise über welche Themen sprechen dürfe, wem zugehört werde und wem nicht.

Die Aufgabe von Erziehungssystemen in Gesellschaften bestehe nun darin, den Zugang zu Diskursen und damit zu Fachdisziplinen und Institutionen zu öffnen und zu regulieren. Mit Blick auf das Individuum erfüllten sie damit zwei konträre Funktionen, nämlich einerseits die aufklärerisch-emanzipatorische Funktion der Ermöglichung von Partizipation, andererseits jedoch auch eine regulierende, bereits vorhandene Machtstrukturen reproduzierende Funktion:

Léducation a beau être, de droit, l'instrument grâce auquel tout individu, dans une société comme la nôtre, peut avoir accès à n'importe quel discours, on sait bien qu'elle suit dans sa distribution, dans ce qu'elle permet et dans ce qu'elle empêche, les lignes qui sont marquées par les distances, les oppositions et les luttes sociales. Tout sytème d'éducation est une manière politique de maintenir ou de modifier l'appropriation des discours, avec les savoirs et les pouvoirs qu'ils emportent avec eux. (Foucault 1971a: 45f.) ${ }^{105}$

All dies läuft nach Foucault in der Regel unbewusst, gewissermaßen hinter dem Rücken derjenigen ab, die sich der Sprache lediglich zu bedienen glauben. Ein zentrales Problem angesichts dieses Befundes lautet nun, dass Diskurse nach Foucault niemals direkt für eine Analyse greifbar sind. Vielmehr entziehen sie sich, wirken im Verborgenen, und müssen daher gewissermaßen in Detektivarbeit rekonstruiert werden. ${ }^{106}$ Das Anliegen der Diskursanalyse besteht daher darin,

104 Das Zitat zeigt auch Foucaults schalkhafte, humoristische Seite.

105 Auch wenn Foucault selbst den zentralen Begriff der Aufklärung - Vernunft - in seinen Studien über den Wahnsinn in Frage stellt, kann doch auch sein Denken insofern als zutiefst aufklärerisch gelten, als es vernunftgeleitet, machtkritisch, emanzipatorisch und reflexiv ist. Zu Foucaults Verhältnis zur Epoche der Aufklärung vgl. Schneider 1999.

106 Eine wichtige Inspiration für Foucaults Diskursanalyse waren die Arbeiten des französischen Anatomen Xavier Bichat (vgl. Sarasin 2006: 68f.). Foucault rückte seine Arbeit als Diskursanalytiker auch in die Nähe der Genforschung: Beide Disziplinen 
durch die Offenlegung diskursiver Strukturen diese überhaupt erst zugänglich, bewusst und damit kritisierbar zu machen. Foucault hält dies im Grunde nur in der Retrospektive für möglich, wenn die zahllosen Spuren rekonstruiert werden, die ein Diskurs v.a. in Form von schriftlichen Texten hinterlassen hat.

Das Objekt der Forschung stellt nun ein Korpus aus Texten dar, das zum Zweck der Diskursanalyse zusammengestellt und in Verbindung mit dem Ort des jeweiligen diskursiven Ereignisses, den Mechanismen der Wiederholung und Einschreibung sowie den Grenzen der jeweiligen diskursiven Formation analysiert wird (vgl. Sarasin 1996: 143f.). Die Gesamtheit dieser Elemente bildet in Foucaults Terminologie ein Archiv. ${ }^{107}$ Die Arbeit des Diskursanalytikers ähnelt damit der eines Archäologen, worauf der programmatische Titel von L'archéologie du savoir (1969) hindeutet.

Bei der Diskursanalyse geht es nun darum, auf verschiedenen Ebenen die Grenzziehungen sichtbar zu machen, aus deren Zusammenspiel ,Kultur', aber auch kultureller Wandel entsteht. Auf der Makroebene der Denksysteme, die historische Epochen prägen, spielt nach Foucault für das Abendland gerade die Grenzziehung zwischen Wahnsinn und Vernunft eine Schlüsselrolle. Grenzziehungen lassen sich nach Foucault jedoch nicht nur an den sprachlichen Manifestationen von Diskursen belegen, sondern finden auch in Institutionen einen materielle Entsprechung:

Les grands hospices, les maisons d'internement, œuvres de religion et d'ordre public, de secours et de punition, de charité et de prévoyance gouvernementale sont un fait de l'âge classique: aussi universels que lui et presque contemporains de sa naissance. (Foucault 1972: 64)

Somit lässt sich festhalten, dass Diskurse im Foucault'schen Sinne drei verschiedene Seiten aufweisen, welche jeweils aufeinander verweisen: die Seite der mentalen und sprachlichen Strukturen, womit bestimmte Formen des Denkens und Sprechens gemeint sind; die Seite der sozialen Praxis im Sinne von Handlungen, welche in den mental und sprachlich vorgegebenen Strukturen vollzogen

bemühten sich, die Mechanismen eines versteckt wirkenden Programms offenzulegen (vgl. Sarasin 2009).

107 An Edward Saids auf Foucaults Diskurstheorie basierender Studie der Orientwissenschaften im 19. Jahrhundert ist u.a. zu kritisieren, dass sie die deutschen Beiträge zum, Orient-Diskurs' nicht verarbeitete (vgl. Said 2003 [1978]: 2). Das Beispiel zeigt, dass eine begründete und transparente Textauswahl auch in der Diskursanalyse ein zentrales Kriterium für gute wissenschaftliche Praxis darstellt. Mit anderen Worten: Hinter der selektiven Auswahl von Texten lauert auch für Foucault-Nachfolger der Bestätigungsfehler. 
werden; schließlich die materiale Seite, d. h. die physischen Manifestationen von Diskursen, zu denen etwa Denkmäler, Werkzeuge, Maschinen, bestimmte Kleidungsstile, Form und Ausstattung von Gebäuden usw. gehören. ${ }^{108}$

Mentale und sprachliche, soziale sowie materiale Strukturen sind nach Foucault diskursive Strukturen, und diese sind niemals naturgegeben oder unschuldig, sondern sie konfigurieren gesellschaftliche Machtstrukturen und werden gleichzeitig von diesen rekonfiguriert. Diskurstheorie im Sinne Foucaults bedeutet damit auch die Analyse von Macht. In Bezug auf die Geschichtsschreibung etwa bedeutet dies die Ablösung von Vorstellungen, welche Geschichte als zielgerichtetes Fortschreiten im marxistischen Sinn verstehen. Auch andere Ansätze wie etwa jener, in dem Geschichte im Sinne der berühmten Formulierung Leopold von Rankes als wahrheitsgetreuer Bericht davon, „wie es eigentlich gewesen“ ist (zit. nach Baberowski 2005: 66) dargestellt wird, sind im Licht der Foucault'schen Diskurstheorie nicht mehr zu halten. Vielmehr wäre die Geschichte von Gesellschaften aus diskursanalytischer Perspektive neu zu schreiben. Als ein Beispiel sei hier der Holocaust genannt: Es lässt sich rekonstruieren, dass der Diskurs der Körperhygiene, welcher sich im 19. Jahrhundert in einer sprunghaften Zunahme an populärwissenschaftlichen Publikationen zum Thema manifestiert, eine entscheidende Rolle für das Konzept der Rassenhygiene der Nationalsozialisten und damit für den Holocaust gespielt hat. Erst der Hygienediskurs, so die These des diskursanalytisch arbeitenden Historikers Philipp Sarasin (1996: 158, Hervorhebung im Original), habe den Boden für ein bis dahin nicht artikulierbares und damit nicht vorstellbares Verbrechen bereitet:

Teile dieser hygienischen und bakteriologischen Diskurse haben solange Denkweisen geformt, bis auch Unaussprechliches, diese Taten konkreter Täter, an den Rand des Denkbaren gerieten: Die schaurigste interdiskursive Metaphorik des 20. Jahrhunderts ist schließlich jene des ,desinfizierenden' Gases, das aus einer ,Dusche` strömt.

Die Geschichte von Diskursen ist dabei im Sinne Foucaults immer auch als Geschichte von Machtstrukturen zu verstehen. Macht ist jedoch nicht nur wie im genannten Beispiel als Dominanz einer Gruppe über eine andere zu verstehen, und sie ist in nur seltenen Fällen einfach etwas, was manche besitzen oder ausüben und andere nicht. Vielmehr handelt es sich für Foucault (1997: 26) bei Macht um ein latentes, dabei jedoch allgegenwärtiges Phänomen, das Individuen einerseits konstituiert, das jedoch andererseits in Diskursen durch sie hindurchfließt:

108 Zur Disziplinierung des Körpers in Schulen, Kasernen und Gefängnissen vgl. Foucault 2006 [1975]: 159-199. 
[...] ne pas prendre le pouvoir comme un phénomène de domination massif et homogène - domination d'un individu sur les autres, d'un groupe sur les autres, d'une classe sur les autres -; bien avoir à l'esprit que le pouvoir, sauf à le considérer de très haut et de très loin, n'est pas quelque chose qui se partage entre ceux qui l'ont et qui le détiennent exclusivement, et puis ceux qui ne l'ont pas et qui le subissent. Le pouvoir, je crois, doit être analysé comme quelque chose qui circule, ou plutôt comme quelque chose qui ne fonctionne qu'en chaîne. Il n'est jamais localisé ici ou là, il n'est jamais entre les mains de certains, il n'est jamais approprié comme une richesse ou un bien. Le pouvoir fonctionne. Le pouvoir s'exerce en réseau et, sur ce réseau, non seulement les individus circulent, mais ils sont toujours en position de subir et aussi d'exercer ce pouvoir. Ils ne sont jamais la cible inerte ou consentante du pouvoir, ils en sont toujours les relais.

Macht ist damit in der mental-sprachlichen, sozialen und materialen Seite von Diskursen allgegenwärtig. Sie ist es in der Sprache, der Schule, der Forschung oder der Stadtplanung ebenso wie in scheinbar so individuellen oder gar intimen Bereichen wie der Familie, der Mode oder der Sexualität. Gerade dann, wenn wir uns besonders privat und individuell zu verhalten glauben - man denke an Foucaults Schlüsselthema Sexualität -, tun wir dies möglicherweise entlang diskursiver Grenzen, die zuvor von anderen abgesteckt wurden.

Zum Foucault'schen Diskursbegriff ist abschließend noch hervorzuheben, dass mindestens zwei Ebenen von Diskursen zu unterscheiden sind: Einerseits verwendet Foucault den Begriff als Kollektivsingular, der das dominierende Denk- und Erkenntnissystem einer Epoche bezeichnet und den bis dahin gängigen Begriff episteme ablöst. Andererseits steht ,Diskurs' für eine thematisch angeordnete Summe von Aussagen (énoncés), so dass sich etwa Diskurse der Weiblichkeit und Heterosexualität (vgl. Mills 2007: 93ff.), ökonomische Diskurse (vgl. Díaz-Bone/Krell 2009), Diskurse der Erziehung (éducation, vgl. Foucault 1971a: 45f.), Orient-Diskurse (vgl. Said 2003 [1978]), juristische Diskurse (vgl. Foucault 2006 [1975], Vernunft-Diskurse (vgl. Welsch 1995), der Diskurs der Beichte (vgl. Mills 2007: 86-92), der Diskurs des Thatcherismus (vgl. Fairclough 1989: 169-196), der bereits genannte Hygiene-Diskurs (vgl. Sarasin 1996) usw. rekonstruieren lassen. Solche Diskurse können in Konkurrenz zueinander geraten, etwa dann, wenn ökonomische Diskurse auf Universitäten übertragen werden und dort ehemals erkenntnis- und entscheidungsleitende bildungstheoretische Diskurse in die Defensive drängen (vgl. Liessmann 2006; Wodak 2009). ${ }^{109}$

Für einen kurzen Überblick über verschiedene Diskursverständnisse sind im Rahmen dieser Arbeit auch die Arbeiten des britischen Linguisten Norman Fairclough von Interesse, weil ihm ein diskursanalytisch inspirierter Blick auf

109 Zum Widerstreit von Diskursen vgl. die Bemerkungen zu Lyotard in Kapitel 4.2.4. 
Sprache insbesondere im Hinblick auf Bildungsprozesse ein Anliegen war (vgl. Fairclough 1989: 233-247). Wie für Foucault spielt auch für Fairclough die Frage der sprachlichen Codierung von Macht eine Schlüsselrolle. Macht wird nach Faircloughs Überzeugung in alltäglichen Kontexten vor allem in Form von gesellschaftlichen Normen ausgeübt. Solche Normen oder Konventionen seien das Ergebnis vergangener und aktueller Machtkämpfe (vgl. ebd.: 2). Konventionen seien von besonderem Interesse, weil Machtstrukturen sich in modernen Gesellschaften weniger durch Zwang äußerten als durch die Schaffung von Konsens, und hierfür sei Sprache das wichtigste Instrument und der wichtigste Austragungsort: „[...] [domination] works, as I have been arguing increasingly through 'consent' rather than 'coercion', through ideology, and through language" (ebd.: 233). Um diese meist unbewussten sprachlich codierten Dominanz- und Machtstrukturen offenzulegen, lohne es sich insbesondere, solche Normvorstellungen in den Blick zu nehmen, die weitgehend als ,selbstverständlich 'oder ,dem gesunden Menschenverstand entsprechend' gelten („common-sense-assumptions“, ebd.: 2). Diese unbewussten Strukturen sind für Fairclough Ideologien (ebd.). Macht bestehe nun gerade darin, solche „common-sense-assumptions“ durchzusetzen und auf diesem Weg gesellschaftliche Homogenität herzustellen (vgl. ebd.: 22).

Mit der Annahme der ideologischen Natur von Sprache begründet Fairclough die Forderung, dass kritische Sprachbetrachtung, für die er den Begriff Critical language study (CLS) prägt, eines der Hauptanliegen sämtlicher sozialwissenschaftlicher Fächer („one of the major themes of modern social science“, ebd.: 3) sein solle. Einen besonderen Mangel an sprachkritischen Inhalten diagnostiziert er darüber hinaus der schulischen (Sprach-)Bildung, ein Bereich, für welchen er das Zielkonstrukt einer Critical language awareness (CLA) vorschlägt. ${ }^{110}$ Diesen Mangel hält er insofern für gravierend, als den Lernenden auf diese Weise die Möglichkeit der demokratischen Partizipation vorenthalten werde, denn bei CLA handle es sich um nichts weniger als um ein „prerequisite for effective democratic citizenship" (Fairclough 1992c: 3). Einer kritischen Linguistik falle daher die Aufgabe zu, im Sinne der CLS sprachkritisch zu forschen, und dem Erziehungssystem obliege es, diese Ansätze in Form von CLA in den Schulen zu implementieren:

110 Hintergrund dieser Begriffswahl ist die in Kap. 4.3.2. beschriebene, zeitgleich in Großbritannien stattfindende Entwicklung von awareness-Ansätzen. Vgl. den von Fairclough (1992c) moderierten Sammelband zum Thema. 
If power relations are indeed increasingly coming to be exercised implicitly in language, and if language practices are indeed coming to be consciously controlled and inculcated, then a linguistics which contents itself with describing language practices without trying to explain them, and relate them to the social and power relations which underlie them, seems to be missing an important point. And a language education focused upon training in language skills, without a critical component, would seem to be failing in its responsibility to learners. People cannot be effective citizens in a democratic society if their education cuts them off from critical consciousness of key elements within their physical or social environment. If we are committed to education establishing resources for citizenship, critical awareness of the language practices of one's speech community is an entitlement. (ebd.: 6)

Ein kritischer Umgang mit Sprache sei auch deswegen von entscheidender Bedeutung, weil, so Fairclough, ein Trennung zwischen,Sprache` und,Gesellschaft gar nicht möglich sei. Vielmehr sei jedes sprachliche Handeln gesellschaftliches Handeln:

My view is that there is no external relationship ,between' language and society, but an internal and dialectical relationship. Language is a part of society; linguistic phenomena are social phenomena of a special sort, and social phenomena are (in part) linguistic phenomena. (Fairclough 1989: 23, Hervorhebung im Original)

Mit seiner Sicht auf Sprache als, Diskurs', als Ort der Encodierung und Ausübung von Macht, stellt sich Fairclough explizit in die Tradition Foucaults (vgl. ebd.: 12; Fairclough 1992a: 37-61). ${ }^{111} \mathrm{Im}$ Gegensatz zu diesem ist für Fairclough mit ,Diskurs' jedoch nicht vorwiegend die verborgene Struktur ,hinter' der Sprache gemeint, sondern Sprache als ,social practice‘ ist Diskurs (Fairclough 1989: 22). Ein weiterer Unterschied besteht darin, dass das Individuum nach Auffassung Faircloughs in deutlich geringerem Maße dem Diskurs ausgeliefert ist als nach Auffassung Foucaults. Fairclough betont explizit, dass er das Verhältnis zwischen Diskurs und Individuum bzw. zwischen Diskurs und Gesellschaft für ein dialektisches hält. Zwar sei jeder Mensch in die vorgegebenen diskursiven Strukturen verwoben. Sozialer Wandel („social change“, vgl. Fairclough 1992a) sei aber dennoch möglich und könne durchaus von Individuen oder Gruppen aktiv herbeigeführt werden:

Foucault's insistence upon the subject as an effect of discursive formations has a heavily structuralist flavour which excludes active social agency in any meaningful sense. This is unsatisfactory, [...]. [...] subjects are ideologically positioned, but they are also capable

111 Fairclough (1989: 12f.) würdigt explizit die Beiträge von Foucault und Habermas, kritisiert jedoch deren aus seiner Sicht mangelnde Operationalisierbarkeit: „they remain theoretical“ (ebd.: 13). 
of acting creatively to make their own connections between the diverse practices and ideologies to which they are exposed, and to restructure positioning practices and structures. The balance between the subject as ideological 'effect', and the subject as active agent, is a variable which depends upon social conditions such as the relative stability of relations of domination. (ebd.: 45,91 )

Fairclough schlägt nun vor, den Diskursbegriff auf drei Ebenen zu verwenden. Jeder Diskursebene entspricht dabei eine Ebene sozialen Handelns. Auf der ersten Ebene finden sich Diskurse („actual discourses“) als tatsächlicher Sprachgebrauch, als ,actual talk or writing“, und diesem Sprachgebrauch entsprechen jeweils konkrete soziale Handlungen („actual practices“, Fairclough 1989: 29). Hierzu zählt etwa das tatsächlich stattfindende Gespräch zwischen Arzt und Patient und die parallel dazu ablaufende Untersuchung, die tatsächlich stattfindende Vorlesung an einer Universität und die damit verbundenen Rituale, etc. Auf der zweiten Ebene siedelt Fairclough „types of discourse“ an, denen „types of practice" entsprechen: das Arzt-Patient-Gespräch als bestimmten Regeln unterworfene Kommunikationsform, die Vorlesung als Form der universitären Lehre, und die jeweils entsprechenden typischen Handlungsformen. ${ }^{112}$ Auf der dritten Ebene schließlich findet sich der jeweilige „order of discourse“ - damit sind, um bei den Beispielen zu bleiben, etwa der medizinische oder der wissenschaftliche Diskurs insgesamt gemeint. Die Trennung in "Sprachgebrauch“ und „soziale Handlung" ist auf dieser Ebene weniger trennscharf: der "order of discourse“ stellt sich vielmehr als ein Teilbereich des „social order“ dar: „What I shall call an order of discourse is really a social order looked at from a specifically discoursal perspective $[\ldots]^{\text {“ }}$ (ebd.).

Es wird deutlich, dass Faircloughs Diskursverständnis damit sowohl linguistische als auch sozialphilosophische Ansätze umschließt. Bevor ich mich jedoch der Diskussion um die mögliche Bedeutung der vorgestellten Diskurskonzeptionen für die hier zu entwickelnde Theorie Fremdsprachlicher Diskursbewusstheit widme, möchte ich ein weiteres Diskursverständnis umreißen, das die Semantik des Begriffs im Deutschen stark geprägt hat und das vor allem mit dem Namen Jürgen Habermas in Verbindung steht.

,Diskurs', das zeigt das Eingangszitat zu diesem Kapitel, wird im deutschen Alltagsgebrauch häufig mit der Bedeutung, öffentliches Gespräch oder Debatte über ein bestimmtes Thema' in Verbindung gebracht. Dieses Diskursverständnis geht maßgeblich auf die Theorie kommunikativen Handelns von Jürgen Habermas

112 Wenn keine Verwechslungsgefahr besteht, spricht Fairclough auch auf dieser Ebene bisweilen einfach von „discourse“. Vgl. Fairclough 1989:29. 
(1988b [1981]) zurück. In seiner Kommunikations- und Gesellschaftstheorie unterscheidet er zwischen ,Kommunikation' und ,Diskurs. Kommunikatives Handeln stellt nach Habermas gewissermaßen den Normalfall des Sprachgebrauchs dar, wenn es also darum geht, das Einverständnis (,Konsens') über etwas herzustellen oder zu erneuern (vgl. ebd.: 38f; Ott 2000: 387). Um einen ,Diskurs (auch: Argumentation) handle es sich hingegen dann, wenn die Kommunikation gestört ist und kein Einverständnis hergestellt werden kann (,Dissens', vgl. Habermas 1988b [1981]: 38) und daher die Grundlagen der Kommunikation selbst thematisiert und argumentativ geklärt werden müssen:

Das Medium, in dem diese negativen Erfahrungen produktiv verarbeitet werden können, ist der theoretische Diskurs, also die Form der Argumentation, in der kontroverse Wahrheitsansprüche zum Thema gemacht werden. (ebd.: 39, Hervorhebungen im Original)

Diskurse sind daher in einer von Habermas (1984: 500) selbst gewählten Metapher „Inseln im Meer der Praxis“ alltäglicher Kommunikation. Sie treten immer dann hervor, wenn geltende Machtverhältnisse zumindest temporär suspendiert werden und Kommunikationspartner sich mit Hilfe von Argumenten über die bis dahin unausgesprochenen Prämissen ihrer Kommunikation austauschen. Sowohl Habermas' Kommunikations- als auch sein Diskursbegriff sind daher prinzipiell konsensorientiert: Konsens ist das Ziel von Kommunikation und, sollte diese scheitern, das Ziel von Diskursen. Mit anderen Worten: Diskurse werden geführt, um den reibungslosen Ablauf von Kommunikation (wieder) herzustellen. Dabei spielt Vernunft eine zentrale Rolle, denn am Ende setzt sich nach Habermas (1984: 161, Hervorhebung im Original) das „,bessere Argument“ kraft seiner Rationalität durch:

Die Konsensustheorie der Wahrheit beansprucht, den eigentümlich zwanglosen Zwang des besseren Argumentes durch formale Eigenschaften des Diskurses zu erklären und nicht durch etwas, das entweder, wie die logische Konsistenz von Sätzen, dem Argumentationszusammenhang zugrundeliegt oder, wie die Evidenz von Erfahrungen, von außen gleichsam in die Argumentation eindringt. Der Ausgang eines Diskurses kann weder durch logischen noch durch empirischen Zwang allein entschieden werden, sondern durch die ,Kraft des besseren Argumentes. Diese Kraft nennen wir rationale Motivation.

Habermas' Verständnisse von ,Wahrheit' und ,Rationalität' wurden vielfach kritisiert (vgl. z.B. Freundlieb 1975). Diese Kritik ist auch in Zusammenhang mit der Frage zu berücksichtigen, inwieweit der Habermas'sche Diskursbegriff für eine Theorie Fremdsprachlicher Diskursbewusstheit ergiebig sein könnte (vgl. Kap. 4.2.4.). Ich möchte zunächst jedoch der Frage nachgehen, welche der hier umrissenen Diskursverständnisse aktuellen fremdsprachendidaktischen Publikationen zugrunde liegen. 


\subsubsection{Zur Verwendung des Diskursbegriffs in fremdsprachendidaktischen Beiträgen}

Wie in den einleitenden Bemerkungen zu diesem Kapitel erwähnt, ist der Diskursbegriff in fremdsprachendidaktischen Diskussionen im Vergleich zum Kulturbegriff bislang unterrepräsentiert. Gleichwohl wurde er in der Vergangenheit verschiedentlich aufgegriffen, wobei ein Schwerpunkt in verschiedenen Beiträgen zur Didaktik des bilingualen bzw. CLIL-Unterrichts zu liegen scheint. ${ }^{113}$

So arbeitet etwa Wolfgang Zydatiß (2007: 447) in seiner empirischen Studie der Deutsch-Englischen Züge in Berlin (DEZIBEL) mit dem Konzept der „(akademischen) Diskursfunktionen“. Darunter versteht er die „gemeinsame Schnittmenge von Inhalt, Denken und Sprache“ (ebd.: 440, 447). Gleichbedeutende Begriffe seien „academic language functions“ sowie „micro genres“ (ebd.). Das zugrunde liegende Diskursverständnis wird nicht explizit geklärt, dürfte jedoch im (text-)linguistischen Bereich liegen. ,Diskurs' scheint für einen spezifischen Sprachgebrauch zu stehen, durch den sich disziplinspezifische Genres herausbilden. Der Reiz der ,Diskursfunktionen', die sich auf dieser Grundlage formulieren lassen, liegt für Zydatiß in der „Operationalisierbarkeit der verschiedenen Kategorien über verschiedene Ausdrucksmittel“ (ebd.), ein sowohl aus empirischer als auch aus unterrichtspraktischer Sicht vielversprechender Befund. Die Kategorien des akademischen Diskurses sind nach Zydatiß „Beschreibung“, „Erklärung" und „Bewertung" (ebd.: 448), denen eine Vielzahl unterschiedlicher Redemittel zugeordnet werden, u.a. „naming things, people“ (Beschreibung), „drawing conclusions“ (Erklärung) und „expressing and justifying preferences, attitudes or choices" (Bewertung) (ebd.).

Daneben finden sich in der genannten Studie auch Verwendungen des Diskursbegriffs, welche eher auf eine funktional-pragmatische Bedeutung verweisen. So schreibt Zydatiß (ebd.: 440, Hervorhebung J. P.):

Das inhaltlich-linguistische Substrat des Sachfachunterrichts ist in aller Regel eine Material- oder Textsorte, die es im Sinne einer bestimmten Aufgabe zu verstehen, zu interpretieren, zu reflektieren oder zu bewerten gilt, was immer auch sprachproduktive,

113 Ich gehe an dieser Stelle nicht auf das von Hans-Eberhard Piepho Ende der 1970erJahre entwickelte Konzept der ,Diskurstüchtigkeit' ein (vgl. Piepho 1974, 1979), das Wolfgang Hallet (2008) vorgestellt und zur Grundlage eines Plädoyers für eine Aufwertung des Diskursbegriffs in fremdsprachendidaktischen Ansätzen gemacht hat. Es basiert auf einem Habermas'schen Diskursverständnis. Ebenso klammere ich an dieser Stelle Claire Kramschs Überlegungen zur symbolic competence aus, die in Kap. 3.4.3. diskutiert worden sind. 
diskursive Leistungen beinhaltet bzw. freisetzt: im lehrergeleiteten Unterrichtsgespräch und in schülerverantworteten Präsentationen ebenso wie in schriftlichen Lernzielkontrollen und in Klausuren.

In einem weiteren Beitrag von Zydatiß (2010) klingt auch das Habermas'sche Diskursverständnis an, etwa dann, wenn die Rede von „dialogisch-diskursiven Interaktionsstrukturen“ (ebd.: 259) oder von einem „diskursiv-reflektierten“ Sprachgebrauch (ebd.: 263) ist. Ein sozialphilosophisches Diskursverständnis deutet sich insofern an, als auch von „Diskursgemeinschaften“ (Zydatiß 2007: 440) im Sinne akademischer Disziplinen die Rede ist. Die Überschneidung mit Foucault ist jedoch unter anderem insofern als gering einzuschätzen, als die Ausführungen zu den Diskursfunktionen die Möglichkeit einer neutralen, objektiven Beschreibung, Erklärung und Bewertung nicht grundlegend in Frage stellen. Aus Foucault'scher Sicht wäre hier anzumerken, dass ,Beschreiben', ,Erklären und ,Bewerten' ihrerseits Teile eines bestimmten, nicht selbstevidenten und daher legitimierungsbedürftigen Diskurses darstellen, der bestimmte Machtkonstellationen voraussetzt. Zusammenfassend lässt sich festhalten, dass Zydatiß den Diskursbegriff vorwiegend in einem textlinguistischen Sinn sowie, jedoch in geringerem Maße, in einem funktional-pragmatischen Sinn verwendet. Sozialphilosophische und kommunikationstheoretische Diskursverständnisse spielen allenfalls marginal eine Rolle.

Zentral ist der Diskursbegriff für einen Ansatz, der in der language-across-thecurriculum-Bewegung seinen Anfang nahm, von dort in die deutschsprachige Diskussion zur Didaktik des bilingualen Unterrichts übernommen wurde (vgl. Dalton-Puffer 2013: 139) und sich inzwischen auch in allgemein-fremdsprachendidaktischen Ansätzen findet (vgl. Cassany 2007; Hallet 2011a). Diskursive Strukturen finden sich nach diesem Verständnis in Form von linguistischen Mikrofunktionen, denen relativ klar bestimmte „Diskursmarker“ (Dalton-Puffer 2013: 140) zugeordnet werden könnten (z.B. ,Klassifizieren', ,Vergleichen', ,Spekulieren'). Sie finden sich aber auch in Form von Makrofunktionen, deren linguistische Beschreibung nicht immer leicht sei (wie z.B. ,Überzeugen', vgl. ebd.). Sprachliches und inhaltliches Lernen vollziehe sich darüber hinaus auch in „großflächigeren sprachlichen Formen" (ebd.: 142), und hierfür habe sich der Begriff des ,Genres' etabliert. In diesem Sinne wird für den CLIL-Unterricht, aber auch für den regulären Fremdsprachenunterricht immer häufiger dafür plädiert, das Prinzip des, generischen' Lernens zu berücksichtigen, d. h. den Unterricht an Diskursfunktionen und Genres entlang zu orientieren (vgl. Hallet 2011a). Der Begriff des ,Genre' ist dabei zu verstehen als „[...] mehrere prototypische Stadien durchlaufendes, zielgerichtetes Sprachhandeln [...], dem eine (gewöhnlich implizite) 
soziale bzw. kulturelle Übereinkunft zugrunde liegt [...]“ (Dalton-Puffer 2013: 142), oder, in einer Definition Hallets (2011a: 2), „[...] nicht nur als textuelles Muster, sondern als kulturell verfügbare Ressource, mit der in kommunikativen Akten Bedeutung erzeugt wird." Es wird deutlich, dass das Diskursverständnis, auf welchem der Genre-Begriff fußt, ein vorwiegend textlinguistisches ist. ${ }^{114}$

Fremdsprachendidaktische Konzepte, welche mit einem textlinguistisch geprägten Diskursverständnis operieren, können sich auf den GeR berufen, in dem in einem kurzen Abschnitt die sogenannte ,Diskurskompetenz' umrissen wird (vgl. Europarat 2001: 123-125). Diese wird definiert als „[...] die Fähigkeit der Sprachverwendenden/Lernenden, eine Satzsequenz so zu arrangieren, dass kohärente sprachliche Textpassagen entstehen“ (ebd.: 123). Es werden verschiedene Kriterien für „direktes und effizientes Kommunizieren“ (ebd.) aufgelistet (u. a. „thematische Organisation, Kohärenz und Kohäsion“, ebd.), für die im Anschluss Skalen nach den üblichen GeR-Kompetenzstufen zur Verfügung gestellt werden (vgl. ebd.: 125). Auch wenn das Diskursverständnis in Zusammenhang mit der, Diskurskompetenz ' klar textlinguistisch fundiert ist, finden sich im GeR im selben Unterkapitel jedoch auch pragmalinguistische Aspekte. Dies scheint aber weniger an einem funktional-pragmatischen Diskursverständnis zu liegen als an dem Umstand, dass Diskurskompetenz als Teil von allgemeiner gefassten „pragmatischen Kompetenzen“ (ebd.: 123) beschrieben wird. Vor diesem Hintergrund wird nachvollziehbar, dass als Teilaspekte von Diskurskompetenz auch die Aspekte „Flexibilität in Bezug auf die Umstände der Kommunikationssituation“ sowie „Sprecherwechsel“ (ebd.: 123) genannt und ebenfalls in gestuften Skalen operationalisiert werden (vgl. ebd.: 124). Allerdings ist die Skala zum „Sprecherwechsel" bereits in praktisch identischer Form an anderer Stelle des GeR aufgeführt, und zwar unter der Rubrik „Interaktionsstrategien“ (vgl. ebd.: 87-89). Dies macht ebenfalls deutlich, dass das Diskursverständnis, welches der im GeR beschriebenen ,Diskurskompetenz zugrunde liegt, kein funktional-pragmatisches, sondern ein textlinguistisches ist. ${ }^{115}$

114 Lediglich in Hallet (2011b) deutet sich ein sozialphilosophisches Diskursverständnis an, welches er jedoch in anderen Beiträgen deutlicher herausarbeitet.

115 Der Diskursbegriff wird an anderen Stellen des GeR durchaus auch als Synonym von ,Gespräch' und damit in einem klar funktional-pragmatischen Sinne verwendet. Im erwähnten Kapitel zu den Interaktionsstrategien etwa wird auf die Bedeutung des Sprecherwechsels verwiesen, der eingesetzt werde, „um im Diskurs die Initiative zu ergreifen (das Wort ergreifen)" (Europarat 2001: 87, Hervorhebung im Original). 
Bei Helmut Johannes Vollmer hingegen überwiegt die funktional-pragmatische Bedeutung von ,Diskurs. In seinen Ausführungen Zum Aufbau kritischer Diskurskompetenz bei zukünftigen Fremdsprachenlehrern, so der Titel eines Beitrags von 2001, bezieht er sich explizit auf die Pragmalinguistik (vgl. ebd.: 79) sowie auf die Diskursanalyse im Sinne der Analyse „mündlicher wie schriftlicher verbaler Interaktion“ (ebd.: 81). Allerdings versteht Vollmer ,Diskurs' auch im Sinne eines Blicks auf Sprache, welcher Aspekte von Dominanz und Macht berücksichtigt („eine in jedem Diskurs präsente und relevante Triebkraft“, ebd.: 82), so dass sich Überschneidungen mit dem Foucault'schen Diskursverständnis ergeben. Dieser Aspekt von Diskurs scheint für Vollmer jedoch vorwiegend im Hinblick auf „die Nutzung des diskursiven Instrumentariums in [sic] Sinne des Interessen- oder Machtmissbrauchs“ (ebd.) von Bedeutung zu sein und wird nicht weiter vertieft. Insgesamt lässt sich festhalten, dass Vollmers Diskursverständnis zunächst ein im Kern funktional-pragmatisches ist. $\mathrm{Zu}$ späteren Zeitpunkten finden sich jedoch auch Beiträge, in denen Vollmer für das textlinguistische Diskursverständnis in didaktischen Kontexten plädiert, wie es oben in Zusammenhang mit Zydatiß' DEZIBEL-Studie bereits umrissen wurde. Vollmer (2010a: 246) schlägt in diesem Zusammenhang den Begriff der „fachbasierten Diskursfähigkeit" vor.

Eine rein funktional-pragmatisches Diskursverständnis im Sinne der linguistischen Gesprächsanalyse liegt der empirischen Studie zugrunde, die Mark Bechtel mit deutschen und französischen Lernenden zum Sprachenlernen im Tandem durchführte (vgl. Bechtel 2003, 2009). Er beruft sich dabei auf Michael Becker-Mrotzeck sowie auf Klaus Brinker und Sven Sager (vgl. Bechtel 2003: 97-116, 2009: 144).

Andreas Bonnet, Stephan Breidbach und Wolfgang Hallet operieren dagegen in einem Beitrag von 2009 mit einem deutlich weiter gefassten Diskursverständnis. In der dort modellierten, fremdsprachigen reflexiven Diskurskompetenz', das sie als neues Zielkonstrukt für den bilingualen Unterricht vorschlagen, fließen sowohl textlinguistische, funktional-pragmatische als auch sozialphilosophische Diskursverständnisse zusammen:

Einerseits bezeichnet ,Diskurs' die Art und Weise, wie unter bestimmten historischen oder sozialen Bedingungen Bedeutung und damit Wissen konstruiert werden. Andererseits bezeichnet ,Diskurs' kommunikatives Handeln in konkreten Situationen. Diskursfähigkeit besteht also nicht nur darin, in Situationen kommunikativ handeln zu können. Sie bedeutet auch, Herkunft, Perspektive und Zweck von Wissen und Äußerungen zu erkennen. (Bonnet et al. 2009: 177) 
Um die beiden Bedeutungen terminologisch zu unterscheiden, schlagen sie vor, von ,Diskurs' lediglich in der ersten, sozialphilosophischen Bedeutung zu sprechen, im zweiten Fall dagegen die Begriffe „Kommunikation“, „Bedeutungsaushandlung" oder „Interaktion“ (ebd.: 178) zu verwenden. ${ }^{116}$

Ein deutlich sozialphilosophisch geprägtes Diskursverständnis findet sich bei Breidbach (2007), der seinerseits auf bildungstheoretische Entwürfe von Helmut Peukert und Hans-Christoph Koller zurückgreift. Ich deute Breidbachs Verwendungen des Diskursbegriffs in dem Sinne, dass Diskurse einerseits sprachlich und institutionell gefestigte Strukturen meinen, wie sie sich z.B. in den akademischen Disziplinen zeigen. Wie Peukert und Koller stellt dabei auch Breidbach den von François Lyotard geprägten Begriff des „Widerstreits“ von Diskursen in den Mittelpunkt (vgl. ebd.: 266; zur Rezeption Lyotards durch Koller vgl. Kap. 4.4.2.). Andererseits werden auch Redezusammenhänge und Sprechweisen als Diskurse bezeichnet, die unterhalb dieser Abstraktionsebene zu verorten sind. Konkret bedeutet dies, dass innerhalb des fremdsprachendidaktischen Diskurses verschiedene Diskurse zu finden sind, etwa der „Diskurs zur Integration von sachfachlichem und fremdsprachlichem Lernen“" (Breidbach 2007: 154ff.) oder der „Diskurs zur Integration als Formen interkulturellen Lernens“ (ebd.: 158ff.). Auch auf dieser Ebene sei, so Breidbach, auf Pluralität zu achten, auf die „plurale Binnenstruktur einzelner Diskurse“ (ebd.: 161), und auch bei ihnen seien - analog zum Umgang mit verschiedenen Weltzugriffen - die Prinzipien Pluralität und Widerstreit zu berücksichtigen.

Mit einem entschieden sozialphilosophischen Diskursbegriff arbeitet auch Wolfgang Hallet (2007) in einem literaturdidaktischen Beitrag, in diesem Fall unter Rückgriff auf Claire Kramsch (1998). Hallet schlägt vor, die kulturelle Einbettung literarischer Texte nicht im Sinne einer ,annotation culture “ zu thematisieren (vgl. Hallet 2007: 383). Damit meint er die aus seiner Sicht oberflächliche und unzureichende Praxis, Texte in Fußnoten punktuell mit kulturellen Hintergrundinformationen zu garnieren. Vielmehr seien literarische Texte systematisch als komplexe Gewebe zu verstehen, die im Zusammenspiel verschiedener Diskurse entstehen. Am Beispiel des literarischen Textes Minority Report von Philip K. Dick führt er vor, wie bei der Lektüre einer Science-Fiction-Erzählung verschiedene Diskurse zur Interaktion gebracht werden können. Hierfür böten sich etwa zeitgenössische Bürgerrechtsdiskurse, Bürgerrechtsdiskurse aus der Zeit der Veröffentlichung der Erzählung sowie epochenübergreifende

116 Auch hier erfolgt eine terminologische Trennung von Diskurs und Kommunikation, die allerdings nicht mit jener von Habermas zu verwechseln ist. 
verfassungsrechtliche Diskurse an (vgl. ebd.: 393). Die Verbindungen zwischen diesen Diskursen seien, wie Hallet betont, nicht einfach gegeben, sondern sie müssten im Akt des Lesens aktiv hergestellt werden: „They have to be explored, recognized, noticed, and actively made“ (ebd.: 395). Diese Art des Lesens im Sinne einer gezielten und bewussten Herstellung interdiskursiver Verbindungen nennt Hallet „wide reading“ (ebd.).

Zusammenfassend lässt sich festhalten, dass in Beiträgen zur Fremdsprachendidaktik text- und pragmalinguistische Diskurskonzeptionen deutlich überwiegen. Der kommunikationstheoretische Diskursbegriff wird bisweilen aufgegriffen, wenn metakommunikatives und reflektierendes Sprechen gemeint ist, ohne dass er dabei jedoch im Zentrum didaktischer Entwürfe gerückt wird. Sozialphilosophische Diskursverständnisse finden sich dagegen nur in wenigen Beiträgen, insbesondere bei Stephan Breidbach (2007) und Wolfgang Hallet (2007, 2008, 2011b, 2012). Die breite Rezeption eines solchen Diskurs-Begriffs im "fremdsprachendidaktischen mainstream", die Hallet (2008: 77, Hervorhebung im Original) forderte, stellt somit weiterhin ein Desiderat dar.

\subsubsection{Zur Bedeutung des Diskursbegriffs für die Fremdsprachliche Diskursbewusstheit}

In den folgenden Abschnitten werden einige der bis zu dieser Stelle rekonstruierten Aspekte des Diskursbegriffs diskutiert. Hierbei soll es zunächst vor allem um die grundsätzliche Frage gehen, welches Diskursverständnis als Kern des Zielkonstruktes Fremdsprachliche Diskursbewusstheit sinnvoll erscheint. In einem zweiten Schritt soll geklärt werden, welche konzeptuellen und terminologischen Differenzierungen auf dieser Grundlage getroffen werden können.

In den Analysen verschiedener Ansätze interkultureller Didaktik (vgl. Kap. 3) wurden deren Tendenzen zur Invisibilisierung der Machtdimension von Sprache herausgearbeitet. Diese konnten auf die Verwendung des Kulturbegriffs und die ihm eigene Tendenz zur Selbst-Affirmation zurückgeführt werden. SelbstAffirmation bedeutet vor allem, dass Kritik an bestehenden Machtverhältnissen erschwert wird, sobald diese als ,kulturell ${ }^{c}$ und somit per Definition als wertvoll und schützenswert angesehen werden. Es liegt daher nahe, ein Konstrukt, das sich diesem Defizit stellen möchte, auf ein Diskursverständnis zu gründen, das die Machtdimension in den Fokus rückt.

In einigen linguistischen Diskursverständnissen ist eine solche machtkritische Dimension angelegt. Dies gilt insbesondere für textlinguistische Ansätze in der Tradition von Roland Barthes, die es erlauben, auch solche Genres als ,Erzählungen' zu deuten, die einen Wahrheitsanspruch erheben (z.B. Biographien, 
historische Abhandlungen, etc.). ${ }^{117}$ Diese Überlegung zeigt jedoch, dass ein textlinguistisches Diskursverständnis nicht ausreicht, um die Machtdimension von Sprache in all ihren Ausprägungen zu fassen. Es scheint ein Bedarf zu bestehen an einer Theorie, die einen Blick auf jene Mechanismen ermöglicht, die gewissermaßen ,hinter ' der Sprache und somit auch hinter Textgenres als Konventionen von Sprachverwendung wirken.

Das kommunikationstheoretische Diskursverständnis in der Habermas'schen Tradition scheint hierfür noch weniger geeignet. Es verfügt zwar über eine stark ausgeprägte reflexive und damit auch potentiell machtkritische Dimension, da es den Blick dafür schärft, dass Kommunikation scheitern muss, solange die Regeln dieser Kommunikation nicht geklärt sind. Nach Habermas (1971: 137) setzt sich aber bei diesen Klärungen, die er ,Diskurse‘ nennt, der „Zwanglose Zwang des besseren Argumentes“ durch. Die Existenz einer einzigen Rationalität, welche als Grundlage für die Entscheidung über das bessere Argument dienen könnte, muss jedoch in Frage gestellt werden. Vielmehr wird in der Postmoderne von mehreren Rationalitäten ausgegangen, deren Differenzen nicht immer aufgelöst, sondern lediglich offengelegt werden können. Sie sind im Sinne des von Lyotard (1983) beschriebenen, Widerstreits' (différend) auszuhalten. So schreibt Breidbach (2004: 155) in diesem Zusammenhang:

Mit der Rede von der erkenntnistheoretischen Postmoderne ist die wissenschaftstheoretische Einsicht in die Unmöglichkeit abschließbarer und eindeutiger Erkenntnis und vollständiger Wirklichkeitsbeschreibung ebenso in einen Begriff gegossen worden wie das Bewusstsein, Wissens- oder Diskurssysteme auf die ihnen unterliegenden Prämissen und Normen zu befragen, die innerhalb des jeweiligen Diskurses selbst nicht reflektiert werden können und als gültig angenommen werden müssen.

Ein weiteres Defizit im Habermas'schen Diskursverständnis besteht in der Trennung von ,Kommunikation' und ,Diskurs'. Sie suggeriert, dass die Aushandlung von Machtverhältnissen nur dann geschehe, wenn die Interaktionspartner diese explizit thematisierten. Zudem wird davon ausgegangen, dass Diskurse von Kommunikationspartnern geführt werden, die in gleichem Maße zum Sprechen fähig und berechtigt sind. Hierdurch werden jedoch viele Situationen nicht erfasst, beispielsweise jene, in denen die Machtfrage gestellt und vielleicht sogar metakommunikativ thematisiert wird, in denen jedoch keine ideale Kommunikationssituation vorliegt, weil ein großes Hierarchiegefälle zwischen den

117 Vgl. hierzu auch White 1973. Überschneidungen ergeben sich auch mit dem Diskursverständnis Lyotards (1979: 12), der Diskursordnungen als, große Erzählungen ‘ (grands récits) sieht. 
Interaktionspartnern besteht. Lyotard (1983: 24f.) hat darauf aufmerksam gemacht, dass Konsenslösungen, die in solchen Situationen erzielt werden und die laut Habermas angestrebt werden sollten, häufig nichts anderes als die Durchsetzung eines Diskurses auf Kosten eines anderen sind.

Es liegt daher nahe, das hier entwickelte Konstrukt einer fremdsprachlichen Diskursbewusstheit auf ein sozialphilosophisches Diskursverständnis zu stützen, wie es von Foucault begründet und von Fairclough für den Bereich sprachlichen Lernens weiterentwickelt wurde. In diesem Verständnis bildet Macht keinen marginalen, nur in besonderen Situationen zu beachtenden Aspekt von Sprache, sondern steht im Zentrum der Theorie. Es scheint daher unter den hier vorgestellten Diskursverständnissen am besten geeignet, die Tendenzen zur Invisibilisierung von Machtstrukturen, die für die interkulturelle Didaktik herausgearbeitet werden konnten, zu überwinden.

In einem zweiten Schritt ist nun zu klären, welche konzeptuellen und terminologischen Differenzierungen für die Arbeit mit einem sozialphilosophischen Diskursverständnis notwendig sind. Dabei stellt sich auch die Frage, in welchem Verhältnis Sprache als Diskurs zu bestimmten Handlungen steht. Da sowohl diskursive also auch handlungsbezogene Strukturen auf verschiedenen Abstraktionsebenen beobachtet werden können, ist außerdem zu klären, welche Ebenen dabei sinnvollerweise zu berücksichtigen sind. Für eine solche Klärung bietet sich als Grundlage Norman Faircloughs Ebenenmodell von practices und discourses an (vgl. Fairclough 1989: 29), das sowohl die sprachliche Dimension als auch die handlungsbezogene Dimension sozialer Beziehungen erfasst. Fairclough unterscheidet in diesem Modell drei Ebenen sozialer Handlungen, denen drei Ebenen von Diskursen entsprechen. Die Ebenen sind sowohl horizontal als auch vertikal als interdependent zu verstehen:

Tab. 1: Norman Faircloughs Modell von Diskursen und Praxen (Quelle: Fairclough 1989: 29)

\begin{tabular}{|c|c|}
\hline Social order & Order of discourse \\
\hline Types of practice & Types of discourse \\
\hline Actual practices & Actual discourses \\
\hline
\end{tabular}

Ich halte das Modell insofern für zielführend, als es Sprache konsequent als soziales Handeln versteht, gleichzeitig jedoch auch die diskursiven Vernetzungen nicht-sprachlichen Handelns aufzeigt. Dennoch schlage ich vor, es in zweierlei Hinsicht zu modifizieren. Erstens scheint mir ein Vertauschen der beiden Spalten plausibel, um durch die übliche Leserichtung von links nach rechts zu verdeutlichen, dass Diskurse Praxen tendenziell vorgelagert sind. Zweitens 
scheint mir das Einfügen einer zusätzlichen Abstraktionsebene zwischen einzelnen Handlungen bzw. Äußerungen (actual practices, actual discourses) und den Handlungskategorien bzw. Diskurskategorien (types of practice, types of discourse) sinnvoll. ${ }^{118}$ Auf dieser Ebene wären überindividuelle, konventionelle Rede- und Handlungsweisen zu verorten, die um bestimmte Themen angeordnet sind, jedoch zum selben type of discourse bzw. type of practice gehören. Das auf diese Weise modifizierte, erweiterte und in deutsche Terminologie übertragene Modell verschiedener Ebenen des Sprechens und Handelns könnte wie folgt aussehen:

Tab. 2: Erweitertes Modell von Diskursen und Praxen

\begin{tabular}{|l|l|l|}
\hline 1 & $\begin{array}{l}\text { Diskursordnungen (Order of } \\
\text { discourse }{ }^{119} \text { ) } \\
\text { z.B. Menschenrechte, Demokratie, } \\
\text { Rechtsstaatlichkeit, Wissenschaft, } \\
\text { Religion }\end{array}$ & $\begin{array}{l}\text { Soziale Ordnungen (Social order) } \\
\text { z.B. internationale Menschenrechtsgerichte, } \\
\text { Parlamente, Gerichte, Universitäten, staatliches } \\
\text { Schulwesen, religiöse Gemeinschaften }\end{array}$ \\
\hline Diskurskategorien (Types of \\
$\begin{array}{l}\text { discourse) } \\
\text { z.B. Fremdsprachendidaktik, } \\
\text { Rechtswissenschaft, Theologie }\end{array}$ & $\begin{array}{l}\text { Handlungskategorien (Types of practice) } \\
\text { z.B. Abteilungen für Fremdsprachendidaktik } \\
\text { an Universitäten, juristische Fakultäten, } \\
\text { Bistümer, Kirchengemeinden, Schulen }\end{array}$ \\
\hline 3a & $\begin{array}{l}\text { Diskurse (Actual discourses) } \\
\text { z.B. Diskurs der } \\
\text { Kompetenzorientierung, Diskurs } \\
\text { des Strafrechts, Diskurs der } \\
\text { Marienverehrung }\end{array}$ & $\begin{array}{l}\text { Praxen (Actual practices) } \\
\text { z.B. Praxis des kompetenzorientierten } \\
\text { Unterrichts, Strafprozesse, katholische Messen }\end{array}$ \\
\hline 3b & $\begin{array}{l}\text { Äußerungen (Actual discourses) } \\
\text { z.B. ein Unterrichtsentwurf für } \\
\text { eine Stunde zur Förderung der } \\
\text { Schreibkompetenz, ein Gerichtsurteil, } \\
\text { ein Ave Maria }\end{array}$ & $\begin{array}{l}\text { Handlungen (Actual practices) } \\
\text { z.B. eine Unterrichtsstunde zur Förderung } \\
\text { der Schreibkompetenz, die Verkündung eines } \\
\text { Gerichtsurteils, das Niederknien vor einer } \\
\text { Marienfigur }\end{array}$ \\
\hline
\end{tabular}

Auf der Makroebene finden sich die Diskursordnungen (Ebene 1). Dabei handelt es sich um die Bedeutungs- und Wissenssysteme der Makroebene, innerhalb derer Sinn erzeugt wird. Sie finden ihre Entsprechung in sozialen Ordnungen, die in

118 Fairclough (1989: 28) weiß um die Zweideutigkeit von actual practices und actual discourses zwischen individuellem und konventionellem Sprechen bzw. Handeln und begrüßt sie („,a felicitous ambiguity“, ebd.).

119 In Klammern stehen zum Vergleich die von Norman Fairclough vorgeschlagenen Termini. Hierdurch wird verdeutlicht, dass er zwischen den Ebenen $3 \mathrm{a}$ und $3 \mathrm{~b}$ begrifflich nicht unterscheidet. 
Institutionen zum Ausdruck kommen. Mit den Institutionen sind nicht etwa die Gebäude gemeint, in denen diese Institutionen residieren, sondern es geht um die Institutionen als ideelle Gemeinschaften. Innerhalb der Diskursordnungen lassen sich Diskurskategorien (Ebene 2) unterscheiden, z.B. die verschiedenen wissenschaftlichen Disziplinen. Sie finden ihre Entsprechung in Handlungskategorien. Die Diskurskategorien ergeben sich aus einer Vielzahl einzelner Diskurse (Ebene 3a), womit gemeint ist, dass über bestimmte Themen auf eine bestimmte Art und Weise gesprochen wird. Ihnen entsprechen Praxen, d. h. bestimmte Arten sozialer Handlungen. Diskurse und Praxen schließlich entstehen aus einer Vielzahl einzelner Äußerungen bzw. Handlungen (Ebene 3b) und lassen sich aus diesen rekonstruieren.

Aus einer Leserichtung von links nach rechts und von oben nach unten ergibt sich zwischen den Feldern jeweils ein kausaler Zusammenhang: Strafprozesse als juristische Praxis laufen in einer bestimmten Ordnung ab, weil dies in den relevanten Diskursen des Strafrechts so festgelegt ist. Eine Lehrerin äußert sich in einer bestimmten Art und Weise, weil dies den relevanten Diskursen des kompetenzorientierten Unterrichts entspricht.

Das Verhältnis aus Ursache und Wirkung kann jedoch auch umgekehrt gelagert sein, etwa dann, wenn einzelne Äußerungen von Wissenschaftlern allmählich einen neuen Diskurs herausbilden und schließlich zur Bildung einer neuen wissenschaftlichen Disziplin (Diskurskategorie) führen. Ein Beispiel hierfür wäre die Entstehung der Kulturwissenschaften (vgl. Böhme 1996). Die einzelnen Felder des Modells stehen somit in komplexen interdependenten Verhältnissen.

Da in der Postmoderne eine Pluralität von Diskursen philosophisch, ethisch, politisch und auch bildungstheoretisch geboten scheint, wäre Fremdsprachliche Diskursbewusstheit im Anschluss an Lyotard (1983), Küster (2003b), Breidbach (2007) und Koller (2012) darauf auszurichten, auf allen Ebenen Pluralitäten sichtbar zu machen: auf der Ebene der Äußerungen und Handlungen, auf der Ebene der Diskurse und Praxen, auf der Ebene der Diskurs- und Handlungskategorien wie auf der Ebene der Diskursordnungen und sozialen Ordnungen. Pluralität aufzuzeigen heißt jedoch auch, alternative Bedeutungs- und Handlungsoptionen zuzulassen. In kulturwissenschaftlicher Perspektive wäre ein solcher Blick auf Äußerungen und Handlungen somit geeignet, deren Kontingenzen offenzulegen. Das Zielkonstrukt Fremdsprachliche Diskursbewusstheit hätte daher das Potential, ein bedeutungs- und wissenschaftliches Kulturverständnis anzubahnen, ohne dabei mit dem immer wieder zu Missverständnissen führenden Kulturbegriff arbeiten zu müssen. 
Es hätte zudem ein deutlich ausgeprägtes machtkritisches Potential, da es auf jeder Abstraktionsebene von Diskursen und Praxen die Frage nach deren Verhältnis zu anderen Diskursen und Praxen und somit nach deren Legitimation nahe legt. Fremdsprachliche Diskursbewusstheit könnte somit dazu beitragen, dass Macht nicht mehr vorwiegend als zu beseitigendes Übel gesehen wird, als Manipulation und Missbrauch, sondern vielmehr als allgegenwärtiges Phänomen in sozialen Beziehungen, das es zu gestalten gilt. Als Beispiel sei hier das Prinzip der ,Angemessenheit' (,appropriateness') genannt, das in Beiträgen zur interkulturellen Didaktik häufig empfohlen wird (vgl. Europarat 2001: 105; Kramsch 2009: 114; zur Kritik am Begriff der appropriateness aus soziolinguistischer Perspektive vgl. Fairclough 1992c). Dabei wird davon ausgegangen, dass es kulturspezifische Formen der Angemessenheit gebe und dass diese für möglichst reibungslose Kommunikationsabläufe zu beachten seien. Zwar hat Angemessenheit ohne Zweifel eine wichtige beziehungsstiftende und -erhaltende Funktion. Ein diskurstheoretischer Blick ermöglicht es jedoch, die Einforderung eines angemessenen Sprechens und Handelns als subtile Form der Ausübung von Macht zu reflektieren, die zum Erhalt bestehender gesellschaftlicher Verhältnisse beiträgt. Um sozialen Wandel herbeizuführen, muss daher manchmal auf eine Weise gesprochen und gehandelt werden, die von den gesellschaftlich dominierenden Gruppen als ganz und gar unangemessen empfunden wird. Man denke an Menschenrechtsaktivist_innen des 20. Jahrhunderts wie Rosa Parks, Martin Luther King oder Rigoberta Menchú. ${ }^{120}$

In der Bewusstmachung von Diskursen und Praxen könnte somit ein erhebliches Potential für die Befähigung zu gestaltender gesellschaftlicher Teilhabe liegen, zu einer „effective citizenship in the domain of language“ (Fairclough 1992c: 54). Die Tendenz des Kulturbegriffs zur Selbst-Affirmation, zur „Emphase für sich selbst“ (Baecker 2001: 51) könnte durch die Tendenz zur Reflexivität des Diskursbegriffs überwunden werden. Der Fremdsprachenunterricht könnte auf diese Weise einen substantiellen Beitrag zu den allgemeinen Erziehungszielen der demokratischen Schule leisten. Dabei gilt selbstverständlich, dass auch die Rede von ,Demokratie‘ oder der, demokratischen Schule in diskursiven Strukturen stattfindet. Diese müssen immer wieder neu reflexiv zugänglich gemacht werden, damit Machtverhältnisse offengelegt und auf ihre Legitimierung hin befragt werden können.

120 Das hier implizierte Problem der Legitimation von Gewalt kann im Rahmen der vorliegenden Arbeit nur erwähnt, nicht aber in angemessenem Umfang diskutiert werden. In der interkulturellen Didaktik wäre in jedem Fall die systemstabilisierende Funktion der Forderung nach , angemessenem ' Verhalten zu reflektieren. 
Ich möchte in den folgenden Abschnitten einige Fragen diskutieren, die das Konstrukt der Fremdsprachlichen Diskursbewusstheit auf der Grundlage eines sozialphilosophischen Diskursverständnisses aufwirft. Diese Fragen betreffen die Rolle der Fremdsprache, die Anschlussfähigkeit an benachbarte theoretische Konzepte (Kultur, textlinguistisches und kommunikationstheoretisches Diskursverständnis), die Aspekte Kontingenz, Pluralität und Macht sowie das Problem der Empirie.

Im interkulturellen Paradigma wird davon ausgegangen, dass bei der Begegnung zweier Menschen mit unterschiedlicher Muttersprache nicht nur sprachliche, sondern auch kulturelle Fremdheit vorliegt. Dies bedeutet im Umkehrschluss, dass bei Menschen mit derselben Muttersprache von kultureller Nähe auszugehen wäre. Die Gültigkeit dieser Prämisse wurde verschiedentlich angezweifelt (vgl. Kap. 3.2.5.). Dabei wurde argumentiert, dass sich das Problem kultureller Grenzziehungen nicht auf die Grenzen zwischen Sprachsystemen reduzieren lässt (vgl. Hu 1996; Rathje 2006). Das Konstrukt der Fremdsprachlichen Diskursbewusstheit legt nun nahe, die Abgrenzungsproblematik aus einer grundsätzlich anderen Perspektive zu betrachten. Für Differenzerfahrungen wären aus dieser Perspektive nicht mehr die Grenzen zwischen Sprachen und sogenannten (Einzel-)Kulturen entscheidend, sondern vielmehr die Grenzen zwischen Diskursen, Diskurskategorien und Diskursordnungen. Das Entwicklungspotential für den Fremdsprachenunterricht könnte dabei darin liegen, mit den Lernenden nicht mehr dichotomische Vergleiche zwischen Sprachen und ,Kulturen' anzustellen, sondern mit ihnen einzelsprachliche Manifestationen von Diskursen aufzuspüren. Durch eine didaktisch anzubahnende reflexive Brechung könnte dies ein Bewusstsein dafür schaffen, dass das sprachlich Fremde sehr vertraut, das sprachlich Vertraute jedoch sehr fremd sein kann. Auf diese Weise könnte verdeutlicht werden, dass Diskurse nicht auf bestimmte Sprachen, Nationalkulturen oder geographische Räume festgelegt werden können, sondern dass sie diese als transversale Netze überlagern und durchdringen. Fremde Sprachen sind für diese Erkenntnis vermutlich nicht unverzichtbar. Sie können es aber möglicherweise erheblich erleichtern, Diskurse und Praxen gewissermaßen von außen zu betrachten.

Zur Veranschaulichung soll der Umgang mit der Erzählung Crónica de una muerte anunciada von Gabriel García Márquez (2003 [1981]) dienen. Die Handlung der Crónica lässt sich in wenigen Zeilen zusammenfassen: In den 1950erJahren wird in einem kolumbianischen Dorf die Heirat von Ángela Vicario mit Bayardo San Román, einem reichen jungen Mann und Neuling im Dorf, gefeiert. Der Bräutigam bringt die Braut jedoch in der Hochzeitsnacht zum Haus der Eltern zurück. Angeblich ist sie keine Jungfrau mehr. Ángela sagt, der Schuldige 
sei Santiago Nasar, ein arabischstämmiger Viehzüchter und im Dorf beliebter junger Mann. Pedro und Pablo Vicario, die Brüder der verschmähten Braut, machen sich aus diesem Grund in den Morgenstunden in volltrunkenem Zustand direkt von der Hochzeitsfeier aus auf, um den angeblichen Übeltäter zu töten. Sie wollen so die Ehre der Familie wieder herstellen. Auf dem Weg zu seinem Haus erzählen sie aber zahlreichen Dorfbewohnern von ihrem Vorhaben - es scheint geradezu, als wollten sie von dem Mord abgehalten werden. Doch niemand greift ein, und so finden die Vicario-Brüder schließlich den nichtsahnenden Santiago und erstechen ihn. All dies wird in der Erzählung von einem früheren Freund Santiagos geschildert, der 27 Jahre später in sein Heimatdorf zurückkehrt, um die fatalen Ereignisse zu rekonstruieren, die man in heutiger Begrifflichkeit vermutlich als, Ehrenmord' bezeichnen würde.

Für die Arbeit mit der Crónica liegt ein Unterrichtsvorschlag von Catharina Herbst (2004a, 2004b) vor, der auf dem interkulturellen Paradigma basiert. Die Erzählung wird als Möglichkeit gesehen, sich mit der kolumbianischen bzw. der lateinamerikanischen Kultur auseinanderzusetzen. Die Autorin schlägt hierfür zunächst vor, die Erzählung mit Hilfe von textanalytischen und kreativen Verfahren zu erschließen. So sollen sich die Lernenden jeweils eine Haupt- und eine Nebenperson aussuchen, diese während der Lektüre genauer beobachten oder sich ihre Gedanken in bestimmten Situationen vorstellen. Grundgedanke ist dabei, den literarischen Text als „kulturelle[n] Botschafter und Vermittler“ (Herbst 2004b: 95) zu lesen. Die Crónica ermögliche die „Begegnung mit fremdkulturellen Denkmustern“ (ebd.: 95f.), welche der kolumbianischen bzw. lateinamerikanischen Kultur zugeordnet werden. Das Thema der Erzählung - die Einhaltung eines Ehrenkodex - sei bis heute vor allem in Kolumbien von großer Aktualität. Die Erzählung konfrontiere „[...] den westeuropäischen Leser mit von seiner Lebenswelt stark abweichenden Wertvorstellungen“ (ebd.: 97). Herbst entwickelt hierbei viele sinnvolle Vorschläge zur Erarbeitung der Romanhandlung und -figuren, zur Perspektivenübernahme etc. Dabei ist sogar sehr zutreffend die Rede vom „Diskurs von Scham und Ehre“ (vgl. Herbst 2004b: 98), der in der Erzählung $\mathrm{zu}$ beobachten sei. Auch die Reflexion eigener kultureller Vorstellungen werde bei den Lernenden angebahnt (ebd.). Hier bleibt der Vorschlag jedoch sehr vage:

Die Ergebnisse [der Diskussion über Mannespflicht in Fragen der Ehre] werden auf die Lebenswelt der Jugendlichen übertragen, indem darüber diskutiert wird, was die Gesellschaft von Männern / Frauen / Jugendlichen / Ausländern erwartet [...]. (ebd.: 99)

Die Gefahr der Dichotomisierung und Stereotypisierung des, Eigenen' und des ,Fremden' ist hierbei deutlich zu erkennen (vgl. Forschungsfrage 1). Auch der Ausgang der Diskussion scheint beliebig zu sein. Wie sollte die Lehrkraft, wie die 
Lernenden reagieren, falls Einzelne oder sogar eine Mehrheit der Lerngruppe den in der Erzählung dargestellten Mord an Santiago befürworten? Wie wäre mit der Auffassung umzugehen, die Vicario-Brüder hätten nicht nur Santiago, sondern auch ihre Schwester töten müssen, um die Familienehre wieder herzustellen? Hier wird eine tendenziell kulturrelativistische Position erkennbar (vgl. Forschungsfrage 2). Dies heißt selbstverständlich nicht, dass Lehrkräfte einen solchen Diskussionsverlauf zulassen würden. Im Unterrichtsvorschlag selbst sind jedoch keine Ansätze zu erkennen, die sie und die Lernenden bei der Arbeit mit der komplexen Thematik unterstützen würden. Jede Haltung erscheint als legitim, solange diskutiert wird. Zwar ist die Rede von „Zusatzmaterialien“ (ebd.: 97), durch welche die Lernenden mit dem „nötigen kulturellen Hintergrundwissen“ (ebd.) ausgestattet werden sollen. Worin dieses Wissen besteht, bleibt jedoch offen. Konkret wird lediglich auf weitere literarische Texte verwiesen, und zwar auf die Dramen Federico García Lorcas (vgl. ebd.: 100) und auf eine Erzählung von Eduardo Galeano (ebd.: 99), in der ein alternatives Ende der Crónica entworfen wird (vgl. Galeano 1993: 35ff.).

Bei einem Vorschlag mit dem Ziel, Fremdsprachliche Diskursbewusstheit anzubahnen, käme man teilweise vermutlich auf ähnliche methodische Ideen. Mit der Rede von ,Diskursen' statt von ,Kulturen' ließe sich jedoch die Komplexität der Erzählung wesentlich leichter sichtbar machen. Anstatt den Text in einem realistischen Sinn als „kulturelle[n] Botschafter und Vermittler“ (Herbst 2004b: 95) zu deuten, würde ein diskurstheoretischer Ansatz verdeutlichen, dass diese Kulturalität durch ein kunstvolles Verweben von Bedeutungsfäden - Äußerungen entsteht, die über räumliche und zeitliche Grenzen hinweg und durch sie hindurch gesponnen werden. Diese Äußerungen können Bedeutung erzeugen, weil ihnen vorgängige diskursive Strukturen existieren. Die diskursiven Strukturen werden jedoch ihrerseits von den Äußerungen auf subtile Weise re-konfiguriert.

García Márquez gestaltet die Erzählung als Crónica und verortet sie damit in der Geschichtsschreibung. Diese Diskurskategorie legt nahe, dass es sich um eine wahrheitsgemäße Rekonstruktion der Ereignisse handelt. Die Bedingungen hierfür scheinen zunächst günstig zu sein, da zahlreiche Zeugen noch leben und vom Chronisten persönlich befragt werden können. Seine Arbeit stellt somit einen Versuch dar, vergangene Ereignisse in eine sinnvolle Ordnung zu bringen. Eben diesen Versuch lässt García Márquez jedoch systematisch ins Leere laufen. Besonders deutlich wird dies an der Tatsache, dass sich die Zeugenaussagen in vielerlei Hinsicht widersprechen. Dies gilt sogar in Bezug auf das Wetter zum Zeitpunkt des Mordes. Während manche Zeugen behaupten, es habe geregnet, sprechen andere von einem sternklaren Himmel (vgl. García Márquez 2003 
[1981]: 73). Bei einer unterrichtlichen Behandlung würde sich also die Thematisierung historiographischer Diskurse anbieten. Die Erzählung weist darüber hinaus auch zahlreiche Anschlussmöglichkeiten an andere Diskurse auf, etwa an feministische, religiöse, philosophische und juristische. Allgemein lässt sich festhalten, dass Diskurse selten rein einzelsprachlich noch rein einzelfachlich konstruiert sind. Fremdsprachliche Diskursbewusstheit legt somit mehrsprachiges und fächerübergreifendes Lernen als durchgängige Prinzipien nahe, damit Diskurse und Praxen in angemessener Weise rekonstruiert, dekonstruiert und konstruiert werden können.

Ich komme nun zur nächsten Frage, jener nach der Anschlussfähigkeit an benachbarte Konzepte. Fremdsprachliche Diskursbewusstheit wurde in den bisherigen Überlegungen in Abgrenzung einerseits zum Kulturbegriff, andererseits zum textlinguistischen und kommunikationstheoretischen Diskursverständnis entworfen. In einem nächsten Schritt soll nun diskutiert werden, inwiefern hier dennoch Kompatibilitäten vorliegen. Diese Frage ist in Bezug auf den Kulturbegriff leicht zu beantworten. Das Hauptargument dieser Arbeit lautet, dass das seit langem geforderte ,kulturwissenschaftliche, $d$. h. bedeutungs- und wissensorientierte Kulturverständnis im Fremdsprachenunterricht besser angebahnt werden kann, wenn dabei auf den Kulturbegriff verzichtet und stattdessen mit dem sozialphilosophisch zu verstehenden Diskursbegriff gearbeitet wird. Diese Verbindung von Diskurstheorie und kulturellem Lernen ist nicht neu. So schreibt etwa Breidbach (2004: 154, Hervorhebung im Original):

Interkulturelle Erfahrungen im Sachfachunterricht sind grundsätzlich dann denkbar, wenn Diskursgrenzen erreicht oder überschritten werden, entweder durch die Aneignung (fach-)spezifischer Deutungsmuster oder durch den Vergleich zwischen unterschiedlichen spezifischen Deutungsmustern. Insofern stellen wissenschaftliche Disziplinen Modelle von Wirklichkeit bereit, in denen bestimmte Aspekte von Welt thematisiert, aber auch ent-thematisiert werden. Aus diesen Überlegungen erwächst ein Verständnis von Fachunterricht, in dem wissenschaftliche Disziplinen als Kulturen interpretiert werden.

Die von Breidbach vorgeschlagene Gleichsetzung von interkulturellem Lernen mit inter-disziplinärem als inter-diskursivem Lernen wird jedoch durch das Zielkonstrukt Fremdsprachliche Diskursbewusstheit erweitert, vertieft und erhält einen neuen Schwerpunkt, da der Diskursbegriff selbst als zentrales Analysewerkzeug vorgeschlagen wird. Hierdurch könnte die Gefahr von Rückgriffen auf überholte Kulturverständnisse verringert und die Chance auf die Anbahnung eines zeitgemäßen kulturwissenschaftlichen Kulturverständnisses erhöht werden.

Auch in Bezug auf textlinguistische Diskursverständnisse schätze ich die Anschlussfähigkeit der fremdsprachlichen Diskursbewusstheit als hoch ein. Diskurse, 
Diskurskategorien und Diskursordnungen sind Rekonstruktionen auf der Grundlage einzelner Äußerungen. Die Summe dieser Äußerungen nannte Foucault ein Archiv. Sie manifestieren sich in bestimmten Medien, Modi und Genres. Diese Genres oder Diskurse ${ }^{121}$ (im textlinguistischen Sinne) liegen in gewisser Weise quer zu Äußerungen, Diskursen, Diskurskategorien und Diskursordnungen des hier vorgeschlagenen Modells. Die beiden Ansätze stehen somit in keinem Gegensatz, sondern ergänzen sich vielmehr wechselseitig. Aufgrund der oben herausgearbeiteten Vorteile des sozialphilosophischen Diskursverständnisses scheint es jedoch sinnvoll, den Begriff in diesem Sinne zu verwenden. Diskurse im textlinguistischen Sinne hingegen könnten als ,Genres', die Beschäftigung mit diesen Diskursen als ,generisches Lernen ' bezeichnet werden, eine Terminologie, die sich ohnehin aktuell durchzusetzen scheint (vgl. Hallet 2011a, Dalton-Puffer 2013).

In den folgenden Abschnitten soll nun die Frage erörtert werden, wie die eng miteinander verwobenen Aspekte Kontingenz, Pluralität und Macht im Konstrukt fremdsprachlicher Diskursbewusstheit zu verorten sind. Wie oben ausführlich dargestellt hat Andreas Reckwitz auf das Problem der Invisibilisierung von Kontingenzen durch den Kulturbegriff verwiesen. Es hat sich auch in der Analyse von Ansätzen zur interkulturellen Fremdsprachendidaktik an vielen Stellen gezeigt. Das in dieser Arbeit entwickelte Argument lautet, dass ein auf dem Diskursbegriff basierendes Zielkonstrukt hier einen Ausweg anbieten könnte. In den Analysen konnte auch herausgearbeitet werden, dass die interkulturelle Didaktik zu einer kulturrelativistischen Position tendiert, die erhebliche ethischpolitische Probleme aufwerfen kann. Die postmoderne, diskurstheoretisch geprägte Erkenntnistheorie scheint jedoch einen ähnlich gelagerten Diskursrelativismus nahezulegen. Wenn sozusagen alles Diskurs ist und dabei gleichzeitig eine radikale Pluralität empfohlen wird, ergibt sich dann nicht zwangsläufig ein anything goes, ein sowohl erkenntnistheoretisch als auch ethisch radikaler Relativismus als einzig vertretbare, ,postmoderne' Haltung?

Zur Beantwortung der Frage lohnt sich ein Blick in das Werk Jean-François Lyotards, der schon mehrfach zitiert wurde. Auf den ersten Blick scheint dieser einen eben solchen radikalen Relativismus zu empfehlen: Da die ,großen Erzählungen' (grands récits) erkenntnistheoretisch und ethisch nicht mehr vertretbar seien, gehe es darum, Konflikte zwischen Diskursarten als Widerstreit (différend) $\mathrm{zu}$ verstehen und auszuhalten, anstatt sie in einen Rechtsstreit (litige) zu verwandeln und aufzulösen (vgl. Lyotard 1983: 24f.). Es muss, in einer Metapher

121 Joseph Vogl gibt in seiner Lyotard-Übersetzung die französischen Termini genre bzw. genre du discours mit ,Diskursart' wider (vgl. Lyotard 1987: 13). 
Lyotards, gewissermaßen die Existenz verschiedener Diskursinseln ermöglicht werden (ebd.: 190, Hervorhebung im Original):

Chacun des genres de discours serait comme une île; la faculté de juger serait, au moins pour partie, comme un armateur ou comme un amiral qui lancerait d'une île à l'autre des expéditions destinées à présenter à l'une ce quelles ont trouvé (inventé, au vieux sens) dans l'autre, et qui pourrait servir à la première de, comme-si intuition' pour la valider. Cette force d'intervention, guerre ou commerce, n'a pas d'objet, elle n'a pas son île, mais elle exige un milieu, c'est la mer, l'Archepelagos, la mer principale comme se nommait autrefois la mer Egée.

Dieser Forderung ist jedoch nicht selbstevident, sondern an Bedingungen gebunden, die politisch und gesellschaftlich geschaffen werden müssen. Da mit der Gefahr zu rechnen ist, dass eine Insel die Alleinherrschaft im Archipel an sich zu reißen versucht, muss also, wie Lyotard es ja selbst schreibt, gewissermaßen eine Fregatte zwischen den Inseln kreuzen, die eben dies verhindert. Welcher Reeder finanziert und bemannt jedoch diese Fregatte, welcher Admiral führt auf ihr das Kommando? Ist ein hierfür notwendiger ,neutraler' Standpunkt überhaupt denkbar? Dieser innere Widerspruch im Werk Lyotards wurde unlängst von Christian Lavagno (2012: 112f.) in klaren Worten herausgearbeitet:

Es erscheint naiv, darauf zu vertrauen, dass ein Seefahrer, der unweigerlich eigene Interessen verfolgt, in seiner Vermittlungstätigkeit die Autonomie jeder Insel unangetastet lassen könnte. Hinzu kommt noch das Problem, dass - um im Bild zu bleiben - sowohl friedlicher Handel als auch kriegerische Intervention stets einer Basis bedürfen. Der Navigator hat jedoch per definitionem keine eigene Insel; er kommt irgendwie aus dem Nichts und zirkuliert lediglich zwischen den Territorien. [...] Lyotard scheint die Figur des [...] Seefahrers selbst nicht ganz geheuer zu sein. Er beeilt sich, die Figur des Richters nachzuschieben, offenbar um dem Einwand zuvorzukommen, ein Vermittler dürfe nicht durch eigene Interessen in die Konflikte involviert sein. Freilich bleibt auch beim Richter unklar, wo er eigentlich herkommt und was genau sein Status ist. [...] Die Frage stellt sich: wenn der Richter selber nicht Herr über eine Insel ist, sondern rastlos zwischen den Inseln hin- und herfährt, um einerseits legitime Gebietsansprüche abzustecken, andererseits Verbindungen und Übergänge zwischen anerkannten Territorien herzustellen, was unterscheidet seinen Diskurs dann von einem übergeordneten Metadiskurs, wie er vom Modell des Widerstreits gerade ausgeschlossen wird?

Es zeigt sich einmal mehr das Paradox, das bereits mehrfach thematisiert wurde (vgl. Kap. 2.2.2.). Unabhängig davon, ob Relativismus und Pluralität aus der anthropologischen Theorie oder aus dem Theorem des Widerstreits hergeleitet werden: Sie sind auf nicht hintergehbare, universalistische Setzungen angewiesen. Nur bestimmte Leitdiskurse oder, in der hier vorgeschlagenen Terminologie,,Diskursordnungen ' können die gewünschte Relativität und Pluralität 
von Diskursen gewährleisten. Ein besonderer Reiz der diskurstheoretischen Perspektive liegt nun darin, dass sie auch auf sich selbst angewendet werden kann und so die Reflexion dieser Setzungen ermöglicht.

Als Diskursordnungen, welche die u.a. in Lyotards Theorem des Widerstreits geforderte Pluralität gewährleisten können, bieten sich die Menschenrechte, Demokratie, Rechtsstaatlichkeit und Wissenschaft an, da sie selbst auf dem Prinzip der Binnenpluralität beruhen. Sie könnten auch aus postmoderner Perspektive akzeptabel sein, da sie nicht nur die Pluralität von Erkenntnis und Ethik, sondern auch deren Vorläufigkeit betonen. Diese Vorläufigkeit ist wohlgemerkt nicht mit Beliebigkeit zu verwechseln. Sie bedeutet vielmehr, dass Erkenntnis und Ethik kontinuierlich legitimiert und überprüft werden müssen, und zwar sowohl im Hinblick auf innere Widersprüche der als gültig angenommenen Diskursordnungen als auch im Hinblick auf Modernisierungsschübe durch externe „fundamentale Erschütterungen“ (Beck 1993: 15). ${ }^{122}$

Lyotards Forderung nach Pluralität und Widerstreit bezieht sich auf hoher Abstraktionsebene auf ,Diskursarten. Für mindestens ebenso wichtig sind jedoch die Prinzipien Pluralität und Widerstreit auf der Ebene der Diskurse selbst einzuschätzen. Gerade für den Wissenschaftsbetrieb ist dies keine Selbstverständlichkeit. Ein anschauliches Beispiel für den Versuch, eine Diskurshoheit im Grenzbereich zwischen Psychologie und Verhaltensbiologie zu errichten, findet sich in der Diskussion um die Frage, ob das menschliche Gehirn bei der Geburt eine tabula rasa darstellt oder nicht. In den 1970er-Jahren dominierte in akademischen Kreisen der USA die Hypothese, dass dies in der Tat der Fall sei. Kulturelle Einflüsse, Erziehung usw. - nurture - sind dieser Auffassung nach alles, nature ist nichts (vgl. Watson 1925: 104). Dagegen sahen sich die Vertreter_innen eines soziobiologischen Ansatzes, die davon ausgingen, dass das menschliche Gehirn von beiden Faktoren beeinflusst wird, aus einem Zusammenspiel also von nature und nurture, massiven Repressionen der etablierten Meinungsführer, aber auch der sich als politisch, links' verstehenden Studentenschaft ausgesetzt. Sie wurden nicht nur in Rezensionen und Zeitungsessays als, Nazis` beschimpft. Es kam auch zu Störungen ihrer Lehrveranstaltungen und Vorträge bis hin zu körperlichen Übergriffen. 1978 wurde ein Vortrag von Edward O. Wilson, Autor des Buches Sociobiology (1975, vgl. Wilson 2000), in besonders drastischer Form gesprengt: Störer drangen in den Saal ein, hielten diffamierende Transparente

122 Foucault wird bisweilen ein radikal erkenntnisskeptischer Standpunkt unterstellt. Vereinzelt hat er sich jedoch auch explizit gegen einen solchen Standpunkt ausgesprochen (vgl. Sarasin 2006: 114). Zudem müsste ein solcher Standpunkt selbst einen Wahrheitsanspruch erheben und sich somit selbst widersprechen. 
hoch, u.a. mit einem Hakenkreuz, entrissen ihm das Mikrofon und gossen ihm einen Kübel Wasser über den Kopf (vgl. Pinker 2003: 108-115).

Auch in der Politik und den Massenmedien gibt es immer wieder das Phänomen, dass die Pluralität von Diskursen zugunsten eines stark dominierenden Mainstream-Diskurses aufgegeben wird. Ein inzwischen gut erforschtes Beispiel ist das Einschwenken der einflussreichsten US-amerikanischen Medien in den Monaten und Jahren nach den Attentaten des 11. September 2001 auf den von der Bush-Administration geführten Patriotismus-Diskurs (vgl. Bonner 2011). Dies lässt sich u.a. an einer bestimmten Sprachverwendung belegen. Während das sogenannte waterboarding bis 2001 fast immer als Folter (torture) bezeichnet wurde, übernahmen viele Zeitungen ab 2002 von Regierungsstellen verwendete euphemistische Begriffe wie aggressive/harsh/coercive interrogation methods oder spielten das Thema auf andere Weise herunter. ${ }^{123}$

Es handelt sich dabei um klare Beispiele für das Aufgeben der Binnenpluralität innerhalb von Diskurskategorien, in den genannten Fällen der Psychologie und der Verhaltensbiologie bzw. der Massenmedien. Fremdsprachliche Diskursbewusstheit kann möglicherweise dazu beitragen, den Blick für solche Konformisierungsprozesse zu schärfen. Die Beispiele zeigen, dass diese nicht nur, wie von Lyotard gefordert, auf der Ebene der Diskursordnungen und Diskurskategorien zu vermeiden sind, sondern auch auf der Ebene der Diskurse selbst.

Im Bereich der Fremdsprachendidaktik als Diskurskategorie wäre die Dominanz des Empirie-Diskurses zu nennen, welcher sich in den vergangenen 10-15 Jahren in der Bildungsforschung allgemein, aber auch in der fremdsprachendidaktischen Forschung durchgesetzt hat. Empirische fremdsprachendidaktische Forschung basiert auf der oft unausgesprochenen Setzung, dass die relevanten Aspekte fremdsprachlichen Lernens empirisch erfassbar sind. Die Korollare dieser Setzung lauten, dass das empirisch Erfassbare relevant, das empirisch nicht (oder schwer) erfassbare hingegen weniger relevant ist. Von dieser Abwertung sind alle,weichen', schwer messbaren Aspekte von Lernprozessen potentiell betroffen (vgl. Hu/Leupold 2008: 64-74). In diesem Zusammenhang hat Lutz Küster (2010: 40f.) für den Bereich des interkulturellen Lernens implizit vor einer einseitig empirischen Ausrichtung fremdsprachendidaktischer Forschung und vor einer sich daraus ergebenden einseitigen Schwerpunktsetzung gewarnt:

123 Vgl. Desai et. al. 2010. In der Studie wurden die Beiträge in den vier größten Zeitungen des Landes ausgewertet: USA Today, The Wall Street Journal, The New York Times, The Los Angeles Times. 
Da diese Lernprozesse weder direkt beobachtbar noch direkt steuerbar sind, mag die Rede über interkulturelles Lernen vielfach spekulativ erscheinen. Dieser Umstand sagt hingegen nichts über die Bedeutung des Ziels aus.

Dieser Hinweis könnte auch für die Fremdsprachliche Diskursbewusstheit gelten. Das Problem der Empiriefähigkeit des Konstruktes soll jedoch zunächst als offene Frage stehen bleiben, die später noch einmal zu diskutieren sein wird.

Der im Rahmen dieser Arbeit vorgeschlagene Diskursbegriff stellt ein intellektuelles Werkzeug dar, das, so die hier vertretene Position, für die Anbahnung eines kulturwissenschaftlichen Kulturverständnisses besser geeignet sein könnte als der stark alltagssprachlich überlagerte, selbst-affirmative und sloganisierte Kulturbegriff..$^{124}$ Selbstverständlich ist jedoch auch der Diskursbegriff Beschränkungen unterworfen. So stellt er hohe Anforderungen an die Fähigkeit zu abstraktem Denken, welche bei jugendlichen Lernenden nicht vorausgesetzt werden kann und daher allmählich aufgebaut werden muss. Eine weitere Einschränkung des Diskursbegriffs liegt darin, dass er möglicherweise im Laufe der Zeit selbst ähnlichen Verschleifungen und alltagssprachlichen Überformungen ausgesetzt sein wird, wie sie beim Kulturbegriff bereits festzustellen sind. Die wichtigste Beschränkung liegt aber in seiner Reichweite: Auch bei einem diskurstheoretisch geschulten Blick auf Diskurse und Praxen ist zu berücksichtigen, dass menschliches Sprechen und Handeln nicht immer abschließend erklärbar ist. Der postmoderne Zweifel an der vollständigen Wirklichkeitsbeschreibung legt die Vermutung nahe, dass ein , anthropologischer Rest' bleiben wird, der sich jeder Einordnung in Diskurse entzieht.

Im nächsten Schritt soll jedoch nun die Frage im Zentrum stehen, inwieweit die Ausrichtung fremdsprachlichen Lernens auf Diskurse und Praxen als Bewusstheit modelliert werden kann. Hierfür sind zunächst einige grundlegende Überlegungen zum menschlichen Bewusstsein notwendig.

\subsection{Zum Konzept der, language awareness'/Sprachbewusstheit}

\subsubsection{Bewusstsein als philosophisches Rätsel}

Welche denkbare Verbindung besteht zwischen bestimmten Bewegungen bestimmter Atome in meinem Gehirn einerseits, andererseits den für mich ursprünglichen, nicht weiter definirbaren, nicht wegzuleugnenden Thatsachen: ,Ich fühle Schmerz, fühle Lust, fühle warm, fühle kalt; ich schmecke Süsses, rieche Rosenduft, höre Orgelton, sehe Roth, ‘ und der ebenso unmittelbar daraus fliessenden Gewissheit: ,Also bin ich?’ Es ist eben

124 Zur ,Sloganisierung fremdsprachendidaktischer Leitkonzepte vgl. Schmenk 2008. 
durchaus und für immer unbegreiflich, dass es einer Anzahl von Kohlenstoff-, Wasserstoff-, Stickstoff-, Sauerstoff- usw. Atomen nicht sollte gleichgültig sein, wie sie liegen und sich bewegen, wie sie lagen und sich bewegten, wie sie liegen und sich bewegen werden. Es ist in keiner Weise einzusehen, wie aus ihrem Zusammenwirken Bewusstsein entstehen könne. Sollte ihre Lagerungs- und Bewegungsweise ihnen nicht gleichgültig sein, so müsste man sie sich nach Art der Monaden schon einzeln mit Bewusstsein ausgestattet denken. Weder wäre damit das Bewusstsein überhaupt erklärt, noch für die Erklärung des einheitlichen Bewusstseins des Individuums das Mindeste gewonnen. (Du Bois-Reymond 1872: 26)

Einige Konzepte, die in der fremdsprachendidaktischen Diskussion der letzten zwei Jahrzehnte eine Rolle gespielt haben, drehen sich um das Anliegen, die Aufmerksamkeit der Lernenden nicht nur auf das Erreichen kommunikativer Ziele, sondern auch auf Inhalte und Vorgänge des sprachlichen Lernens selbst zu lenken und diese dadurch bewusst zu gestalten. Zu diesen Konzepten zählen in der englischsprachigen Diskussion unter anderem language awareness, language learning awareness, cultural awareness, linguistic awareness, metalinguistic awareness, metalinguistic abilities, linguistic consciousness, knowledge about language, communicative awareness. Diese Begriffe werden im deutschsprachigen Kontext zum Teil beibehalten, zum Teil auch übersetzt und weiterentwickelt, etwa als Sprachbewusstsein, Sprachbewusstheit, Sprachenbewusstheit, Sprachlernbewusstheit, Nachdenken über Sprache, Sprachreflexion und Kommunikationsbewusstheit. Es zeigt sich also eine erhebliche terminologische Vielfalt, die, wie Annelie Knapp (2013: 73f.) anmerkt, angesichts des Facettenreichtums menschlicher Sprache und des Nachdenkens über sie noch erheblich erweitert werden könnte, etwa um „Sprachstrukturbewusstheit, Sprachkönnensbewusstheit, [...] Sprachlernbedarfsbewusstheit, [...] Sprachvariationsbewusstheit, Sprachwahlbewusstheit [...] Sprachwirkungsbewusstheit [...]". Ähnlich wie beim Kulturbegriff, der, wie sich gezeigt hat, erheblichen Diskussionsbedarf erzeugt, dürfte es sich daher auch bei den Begriffen ,Bewusstsein' bzw. ,Bewusstheit' lohnen zu klären, „was jeweils gemeint sei“ (Müller-Funk 2001: 718).

Wie genau Bewusstsein, die Grundlage unseres Eins-Seins in der Welt, entsteht und wie es beschaffen ist, stellt eine der ältesten Fragen der Menschheit dar. Eine intuitive Antwort lautet, dass es sich um eine Art Essenz jedes Menschen handelt, einen Kern, in dem alles Denken, alle Erlebnisse und alle mit ihnen verbundenen Sinneseindrücke und Gefühle gebündelt und verarbeitet werden. Bewusstsein scheint entscheidend dafür, dass Menschen sich über Zeit und Raum hinweg als Einheit erleben können und zu fundamentalen Fähigkeiten wie Lernen und Planung in der Lage sind. Diese Einheit ist auch für den Menschen als 
soziales Wesen unverzichtbar: Nur wenn Andere ihn als mit sich selbst identisch erleben, wird sein Verhalten für sie berechenbar. ${ }^{125}$

Die Antwort vieler Religionen auf die Frage nach dem Ursprung des Bewusstseins lautet bekanntlich, dass es aus einer immateriellen Seele hervorgehe, die den Körper des Menschen bewohne. In der Regel wird diese Seele in einer über den Tod hinaus andauernden Existenz entweder belohnt oder bestraft, meist in Abhängigkeit vom Lebenswandel, dem sie im Diesseits als Bewohnerin eines menschlichen Körpers nachging.

Auch die Philosophie ringt seit Jahrtausenden mit der Frage nach der Herkunft, der Beschaffenheit und dem Funktionieren von ,Bewusstsein'. Tentative Antworten ziehen sich wie ein roter Faden durch die abendländische Geistesgeschichte. Die antike Philosophie beschäftigte sich dabei noch nicht mit dem Bewusstseinsbegriff, sondern mit dem Begriff der ,Seele'. Aristoteles etwa beschreibt sie in seinem Werk Über die Seele (Buch II, Kapitel 1,412 a 27) als prótē entelécheia, als „erste Vollendung“, die ihren Zweck in sich selbst habe (zit. nach Seidl 1995: 62f.). Sie ermögliche es uns, nicht nur die einzelnen Sinneseindrücke (z.B. akustische oder visuelle) wahrzunehmen, sondern dabei auch wahrzunehmen, dass wir wahrnehmen.

In der mittelalterlichen Scholastik gewinnt neben dem Begriff der Seele der des Bewusstseins an Bedeutung. Für Thomas von Aquin war darunter wie für Aristoteles die Wahrnehmung der Wahrnehmung bzw. das Wissen vom Wissen $\mathrm{zu}$ verstehen. In den Quaestiones disputatae de veritate (XVII, a. 1 s. c. 9) schreibt er: „Sed conscientia nominat scientiam cum collatione; dicitur enim conscire, quasi simul scire. Ergo conscientia est scientia actualis. "126 (Zit. nach Fundación Tomás de Aquino 2000-2013) Die Struktur der lateinischen Vorsilbe con- zeigt hierbei, wie tief die von Aristoteles und anderen formulierte Vorstellung vom

125 Anstelle einer einzigen, stabilen Identität wird heute von multiplen Identitäten ausgegangen, welche sich in verschiedenen sozialen Kontexten bilden. Ein schneller sozialer Wandel in postindustriellen Gesellschaften erhöht den individuellen Druck, auf diese Veränderungen zu reagieren, so dass inzwischen auch von fluiden Identitäten gesprochen wird. Dennoch kann das Zusammenleben nur funktionieren, wenn Menschen Identität zumindest unterstellt werden kann. Umgekehrt gilt die Unfähigkeit, sich selbst als eine Person zu erleben, als schwere Persönlichkeitsstörung (dissoziative Identitätsstörung).

126 In der deutschen Übersetzung ist darüber hinaus zwischen einer „[...] rein konstatierende[n] und ein[er] nach Recht und Unrecht beurteilende[n] [... “ (Stein 2008: 460), conscientia' zu unterscheiden. Entsprechend müssen jeweils verschiedene Termini gebraucht werden: ,Bewusstsein` und, Gewissen`. 
Bewusstsein als Denken über das Denken (oder als Wissen - „scientia“ - und gleichzeitiges Wissen, dass man weiß - „quasi simul scire“) in unseren Vorstellungen vom Bewusstseins verwurzelt ist. Auf dem hier von Thomas von Aquin verwendeten lateinischen Nomen conscientia beruhen bekanntlich die Bezeichnungen für Bewusstsein in den romanischen Sprachen (frz. conscience, span. conciencia, usw.), aber auch im Englischen. Für John Locke etwa ist Bewusstsein (consciousness) ähnlich wie bei Aristoteles auf sich selbst gerichtete Wahrnehmung. In seinem Essay An Essay Concerning Human Understanding (1690, Book II, I.19) findet sich folgende Definition: „Consciousness is the perception of what passes in a Man's own mind“ (Zit. nach Fuller et al. 2000: 71).

Immanuel Kant unterscheidet dagegen zwei Arten von Bewusstsein: das ,empirische' und das ,transzendentale‘. Nur wenn ein Mensch über das nach innen, auf sich selbst gerichtete Bewusstsein bereits verfüge, könne er es auch auf außerhalb seiner selbst wahrgenommene Eindrücke richten:

Nun können keine Erkentnisse in uns statt finden, keine Verknüpfung und Einheit derselben unter einander, ohne diejenige Einheit des Bewußtseyns, welche vor allen Datis der Anschauungen vorhergeht, und, worauf in Beziehung, alle Vorstellung von Gegenständen allein möglich ist. Dieses reine ursprüngliche, unwandelbare Bewußtseyn will ich nun die transcendentale Apperception nennen. [...] Alles empirische Bewußtsein hat aber eine notwendige Beziehung auf ein transzendentales (vor aller besonderen Erfahrung vorhergehendes) Bewußtsein, nämlich das Bewußtsein meiner selbst, als die ursprüngliche Apperzeption. (Kant 1781: 107, 117)

Die Frage nach dem Ursprung und dem Sitz beider Arten von Bewusstsein bleibt jedoch zunächst offen ${ }^{127}$, und ob sie jemals zu klären sein wird, hat Leibniz in einem interessanten Gedankenexperiment herausgearbeitet. Hierzu stellte er sich vor, man könne ein menschliches Gehirn so stark vergrößern, dass man darin herumgehen und es wie eine Mühle besichtigen könne. (vgl. Leibniz 1998 [1714]: $\$ 17)$ In diesem Maßstab könne man vielleicht auch genau verstehen, wie alle Einzelteile dieser Maschine funktionieren. Leibniz vermutete jedoch, dass man selbst dann noch immer nicht in der Lage wäre zu sagen, wie genau Bewusstsein entsteht: „Et cela posé, on ne trouuera en la visitant au dedans, qve des pieces qvi se poussent les unes les autres, et jamais de qvoy expliqver une perception" (ebd.). Das Kernproblem eines analytischen Vorgehens liegt also in Anlehnung an Leibniz darin, dass das Ganze, das wir normalerweise als ,Bewusstsein

127 Dass das Bewusstsein eine Funktion des Gehirns ist, kann heute als unstrittig gelten. Daniel Dennett hat dazu angemerkt, dass eine (irgendwann vielleicht mögliche) Transplantation des Gehirns daher die einzige Form der Organspende sei, bei der man lieber der Spender als der Empfänger sein möchte (vgl. Dennett 2002: 25). 
bezeichnen, die Summe seiner Bestandteile zu überragen scheint. Bewusstsein ist daher ,emergent'. In jedem Fall scheinen die einzelnen Funktionen des Gehirns in der Summe etwas qualitativ Neues zu ergeben, das auf dem umgekehrten Weg der Analyse seiner Bestandteile möglicherweise nicht ergründet werden kann. ${ }^{128}$ Der Philosph Peter Bieri weist darauf hin, dass dies ein Rätsel darstelle, das sich von anderen Rätseln unterscheide. Während wir uns bei gewöhnlichen Rätseln ungefähr vorstellen könnten, was als akzeptable Lösung in Frage käme, haben wir, so Bieri, beim Rätsel des Bewusstseins „, [... ] keine Vorstellung davon, was als Lösung, als Verstehen zählen würde“ (Bieri 1994: 180).

Neben Religion und Philosophie beschäftigen sich auch die zeitgenössische Psychologie und die Neurowissenschaften intensiv mit der Frage, wie Bewusstsein entsteht. Sie gehen dabei einen Weg, der stark an Leibniz' Gedankenexperiment erinnert. Bewusstsein, so die Grundannahme, ist im Gegensatz zu den Überzeugungen der meisten Religionen nicht das Produkt einer immateriellen Seele, sondern es entsteht, wie alle anderen psychischen Merkmale des Menschen auch, auf Grundlage von biochemischen Prozessen im Gehirn. Durch die möglichst detaillierte Erforschung der funktionalen Ausdifferenzierung des Gehirns könne man, so die Hoffnung, irgendwann vielleicht verstehen, wie genau das $\mathrm{Zu}$ sammenspiel modelliert werden muss, aus dem das menschliche Bewusstsein entsteht. Vielleicht handelt es sich um ein lokalisierbares, spezialisiertes Modul, ein neuronales Subsystem, das darauf spezialisiert ist, in einem ,cartesianischen Theater ' die Einheit des ,Ich' zu simulieren und so Bewusstsein zu ermöglichen. Wahrscheinlicher scheint jedoch zum jetzigen Forschungsstand, dass Bewusstsein aus dem Zusammenspiel einer Vielzahl beteiligter neuronaler Netzwerke entsteht (vgl. Kiefer 2008: 163-165; Dennett 1991: passim). Aus evolutionsbiologischer Perspektive ist in jedem Fall plausibel, dass es einen evolutionären Vorteil darstellen muss, über ein Bewusstsein zu verfügen, da sich dieses Merkmal andernfalls nicht durchgesetzt hätte.

Die vorläufigen Ergebnisse der Neurowissenschaften und der Psychologie sind von erheblicher Tragweite für das Selbstbild des Menschen. So lässt sich etwa der für das abendländische Denken eminent wichtige cartesianische LeibSeele-Dualismus angesichts einer Fülle empirischer Studien, die diesen Dualismus in Zweifel ziehen, kaum noch vertreten (zusammenfassend vgl. Dennett 1991; Damasio 2007; Kahneman 2012; Gazzaniga 2012), und dies stellt auch jede

128 Leibniz folgerte aus dem Gedankenexperiment, dass das Bewusstsein schon in der „Substance Simple“ (ebd.), also den Bestandteilen der „machine“ enthalten sein müsste: den Monaden (vgl. ebd.). Dadurch wird jedoch das Problem keineswegs gelöst, sondern lediglich auf eine andere Ebene verlagert. 
religiös fundierte theory of mind, die auf der Hypothese einer unsterblichen Seele aufbaut, nachhaltig in Frage. Die Annahmen über das menschliche Bewusstsein sind dabei weit davon entfernt, rein akademische Probleme zu sein. Vielmehr ist es auch politisch hoch relevant, welche Bewusstseinstheorie wir bei der Suche nach Antworten auf wichtige gesellschaftlichen Fragen zugrunde legen. So kommt man etwa bei den Themen Schwangerschaftsabbruch oder Stammzellenforschung zu anderen Ergebnissen, wenn man auf der Grundlage argumentiert, dass im Embryo ab dem Moment des Verschmelzens von Ei- und Samenzelle eine unsterbliche Seele Wohnung nimmt - die aktuelle Position der katholischen Kirche -, als wenn man dies nicht tut. Ebenso wird man Fragen der sozialen Gerechtigkeit anders bewerten, wenn man wie im Hinduismus annimmt, dass der aktuelle gesellschaftliche Status eines Menschen in direktem Zusammenhang mit den guten und schlechten Taten früherer Daseinsformen seiner Seele steht, als wenn man dies bezweifelt. ${ }^{129}$

Es lässt sich festhalten, dass die Vorstellungen der Religionen zu Seele und Bewusstsein heute oft als nicht mehr zufriedenstellend angesehen werden. Gleichzeitig wird die Frage nach der Entstehung des Bewusstseins in den Grenzgebieten zwischen Philosophie, Psychologie und Neurowissenschaft weiterhin äußerst kontrovers diskutiert (vgl. Kiefer 2008). Das „Welträthsel“, als das der Physiologe Du Bois-Reymond es 1872 beschrieb, bleibt in seinem Kern ungelöst.

\subsubsection{Grundzüge des Konstruktes, language awareness`/ Sprachbewusstheit}

Obwohl das Konzept ,Bewusstsein' in Philosophie, Psychologie und Neurowissenschaften bis heute zu kontroversen Diskussionen führt und daher weiterhin als schwer definierbar gelten muss, hat der Begriff und an ihn angelehnte Termini (,Bewusstheit',,Bewusstmachung', etc.) seit Mitte der 1970er-Jahre in verschiedene L1- und L2-Didaktiken Einzug gehalten. Hierbei lassen sich zwei Phasen mit jeweils unterschiedlichen Anliegen und Schwerpunktsetzungen unterscheiden. Ich rekonstruiere in einem ersten Schritt die Entwicklung des awareness-Begriffs, der zunächst vorwiegend im Hinblick auf die Rolle des Englischen im britischen Schulsystem entwickelt wurde. In einem zweiten Schritt stelle ich seine Rezeption und Weiterentwicklung in der deutschsprachigen Debatte dar, die in den frühen 1990er-Jahren einsetzten und bei denen hauptsächlich mit der Übersetzung Bewusstheit gearbeitet wurde. Neben Vorschlägen zur theoretischen

129 Zum Konzept des,Karma', das in praktisch allen Ausprägungen des Hinduismus eine zentrale Rolle spielt, vgl. Glasenapp 1996: 67f. 
Modellierungen stelle ich dabei auch Positionen dar, die sich mit dem Problem der Wirksamkeit von Sprachwissen für Sprachkönnen beschäftigen, und gehe auf einige grundsätzliche Überlegungen zum Problem der Empirie ein. Schließlich erörtere ich das Potential des Bewusstheitsbegriffs für das Konstrukt Fremdsprachliche Diskursbewusstheit.

Eine erste Phase, in der die Frage nach dem Potential des Bewusstseinsbegriffs für schulische Bildung ins Zentrum pädagogischer Diskussionen rückte, lässt sich in Großbritannien ab der zweiten Hälfte der 1970er-Jahre verorten. Ein Reformbedarf entstand damals maßgeblich durch den sogenannten Bullock-Report, eine zwischen 1972 und 1975 erarbeitete Bestandsaufnahme zur Leistungsfähigkeit des britischen Schulsystems im Hinblick auf die Förderung von literacy im Sinne von grundlegenden Lese- und Schreibfertigkeiten im Englischen. Der von der damaligen Bildungsministerin Margaret Thatcher erteilte Auftrag lautete:

To consider in relation to schools: (a) all aspects of teaching the use of English, including reading, writing, and speech; (b) how present practice might be improved and the role that initial and in-service training might play; (c) to what extent arrangements for monitoring the general level of attainment in these skills can be introduced or improved; and to make recommendations. (DES 1975: xxxi)

Das drei Jahre später vorgelegte Ergebnis der Bestandsaufnahme war ernüchternd. Die Autoren konstatierten trotz aller Vorsicht, die bei der Klage um angeblich sinkende Schülerleistungen immer angebracht sei ${ }^{130}$, dass die Kenntnisse im Bereich ,Sprache' deutlich hinter jenen Erwartungen zurückblieben, die weiterführende Bildungseinrichtungen und Arbeitgeber an die Absolvent_innen des britischen Schulsystems stellten:

It may be true that in commerce, industry, and higher education alike comparisons with past standards are misleading, but the clear implication is that standards need to be raised to fulfil the demands that are being made upon them. (Department of Education and Science 1975: 4)

Neben den insgesamt zu niedrigen Leistungen zeichnete sich auf Grundlage der für den Bericht ausgewerteten Studien ein zweiter, für die Autoren ebenfalls besorgniserregender Effekt ab. Anstatt den Einfluss des sozialen Hintergrunds auszugleichen und so ein zentrales Anliegen jedes öffentlichen Schulsystems

130 Klagen über den angeblichen Niedergang der Jugend lassen sich bekanntlich bis in die Antike rekonstruieren. Für die vergangenen Jahrzehnte sind die Arbeiten von James Flynn von Interesse, der in den entwickelten Ländern einen kontinuierlichen Anstieg des durchschnittlichen IQ ausgemacht hat (,Flynn-Effekt'). Vgl. Flynn 2012. 
einzulösen, schienen die britischen Schulen diesen Einfluss zu vertiefen, und dieser Effekt schien sich in den Jahren vor Erhebung der im Bullock-Report berücksichtigten Studien sogar noch verstärkt zu haben:

Secondly the results provide an interesting analysis by social class. It was found that among children with fathers in professional or managerial jobs the average standard had improved, or at least been maintained. But among those with fathers in semi-skilled or unskilled jobs the average performance at 11 was seriously below the standard of the equivalent social group 10 years earlier. (ebd.: 22)

Die Kommission stellte gemäß ihrem Auftrag ans Ende ihres Berichtes eine Liste mit konkreten Empfehlungen zur Verbesserung der dokumentierten Probleme. Gleich zu Beginn dieser 333 (!) Punkte umfassenden Liste wird dazu geraten, Sprachunterricht als schulweite und alle Einzelfächer betreffende Aufgabe zu verstehen:

Each school should have an organised policy for language across the curriculum, establishing every teacher's involvement in language and reading development throughout the years of schooling. (ebd.: 514)

Ein sprachdidaktischer Ansatz, der direkt an die Empfehlungen des Bullock-Berichtes anknüpft, kreist um die sogenannte language awareness, ein Konzept, das maßgeblich durch die Monographie Awareness of language (1984) des Linguisten und Fremdsprachenlehrers Eric Hawkins geprägt wurde. Hawkins geht in ihr von der doppelten Defizitbeobachtung des Bullock-Reports aus, der wie oben beschrieben zu dem Ergebnis gekommen war, dass das britische Schulsystem erstens keine ausreichenden grundlegenden Sprachkenntnisse vermittelte, und dass es zweitens den Zusammenhang zwischen Sprachniveau und sozialer Herkunft nicht ausgleichen konnte. Ein zentrales Desiderat sieht Hawkins daher darin, dass der schulische Unterricht diese und andere Lücken besser als bisher schließen solle. Er meint im Einzelnen die Lücke zwischen Alltags- und Bildungssprache, die Lücke zwischen gesprochener und geschriebener Sprache, die Lücke zwischen Kindern aus verschiedenen sozialen Schichten, die Lücke zwischen Kindern mit und ohne Migrationshintergrund, die Lücke zwischen verschiedenen Bildungseinrichtungen wie Grundschule, Sekundarschule und Universität, die Lücke zwischen verschiedenen Schulfächern und schließlich die Lücke zwischen verschiedenen Aspekten von Sprache:

It [language awareness] also bridges the 'space between' the different aspects of language education (English/foreign language/ethnic minority mother tongues/English as a second language/Latin) which at present are pursued in isolation, with no meeting place for the different teachers, no common vocabulary for discussing language. (Hawkins 1984: 4) 
Das diesen Defiziten zugrunde liegende pädagogische Problem führt Hawkins auf den Umstand zurück, dass Sprecher_innen ihre Muttersprache zunächst einmal als , natürlich` empfinden. In monolingualen Umgebungen entwickeln sie daher, so Hawkins, ohne gezielte Unterstützung weder einen Blick für die Arbitrarität sprachlicher Zeichen (ebd.: 17-19) noch für die sprachliche Verfasstheit menschlichen Wissens und Denkens allgemein. Der monolinguale „linguistic parochialism“ (ebd.: 17) Großbritanniens verhindere entscheidende Fortschritte in der Beherrschung der Muttersprache und führe dazu, dass die Lernenden ihr Entwicklungspotenzial weder in ihrer mündlichen noch in ihrer schriftlichen Sprachverwendung ausschöpften. Hawkins befürchtet zudem, dass der Mangel an gezielter Förderung mutter- und fremdsprachlicher Kenntnisse dazu führen könnte, dass Lernende kaum Toleranz im Umgang mit sprachlichen Minderheiten entwickelten und dass daraus massive gesellschaftliche Verwerfungen entstehen könnten (vgl. ebd.). Da eine solide sprachliche Bildung für den schulischen und damit auch gesellschaftlichen Erfolg, aber auch für das Zusammenleben in einer multiethnischen Gesellschaft entscheidend sei, müsse der Beschäftigung mit Sprache eine prominente Rolle zukommen.

Als Ausweg schlägt Hawkins nun die seit den 1970er-Jahren in Großbritannien vereinzelt erwähnte language awareness als pädagogisches Leitziel und als Kern für ein gesamtschulisches Sprachenkonzept vor („language across the curriculum", vgl. DES 1975: 188-193; Hawkins 1984: 2). ${ }^{131}$ Language awareness wird dabei zunächt ganz einfach definiert als „,...] to challenge pupils to ask questions about language, which so many take for granted“ (ebd.: 4). Diese Fragen seien wohlgemerkt keineswegs nur in Bezug auf grammatische Phänomene zu stellen. Anstelle einer Rückkehr zu traditionellem Grammatikunterricht als Selbstzweck stehe language awareness vielmehr für das Anliegen, den Blick für das Funktionieren von Sprache auf verschiedenen Ebenen zu schärfen:

We are seeking to light fires of curiosity about the central human characteristics of language which will blaze throughout our pupils' lives. [...] Above all we want to make our pupils' contacts with language, both their own and that of their neighbours, richer, more interesting, simply more fun. (ebd.: 6)

Der Hauptteil von Hawkins' Monographie besteht aus Reflexionen, mit denen er bei allen in irgendeiner Weise mit schulischer Bildung befassten Leser_innen, inklusive den Eltern schulpflichtiger Kinder, ein tieferes Verständnis für das Funktionieren von Sprache anbahnen möchte. Insofern handelt es sich bei Awareness

131 Eine der frühesten Erwähnungen von ,metalinguistic awareness' findet sich bei Cummins (1978). 
of language nicht nur um sprachdidaktische Überlegungen zu einem zum damaligen Zeitpunkt vergleichsweise neuen Konzept, sondern auch um ein Lehrbuch, das beim Leser selbst durch Einsicht in Sprache, Sprachen und Sprach(en)lernen language awareness fördern möchte. Wie sehr Hawkins die Verbreitung und praktische Umsetzung seiner Vorschläge am Herzen liegen, zeigen auch die beiden Anhänge, die sich gezielt an Sprachlehrkräfte bzw. an teacher trainers richten: Anhang A (Learning to listen, vgl. ebd.: 189-213) enthält Übungen zur Verbesserung des Hörverstehens im Englischen. In Anhang B finden sich dagegen zwei Vorschläge für Curricula, die eine beispielhafte Umsetzung der Forderung der Bullock-Kommission nach einem gezielten Sprachtraining für angehende Lehrkräfte aller Fächer darstellen und in der Lehrerausbildung direkt eingesetzt werden können (vgl. ebd.: 214-218).

Das breite Echo, das language awareness hervorrief, macht deutlich, dass die von Hawkins und anderen bis Mitte der 1980er-Jahre vorgeschlagenen Definitionen („to ask questions about language“, ebd.: 4; „a person’s sensitivity to and conscious perception of the nature of language and its role in human life", Donmall 1985: 7; „the ability to think about and reflect upon the nature and functions of language“, Pratt/Grieve 1984: 2) ein pädagogisches Kernproblem aufgeworfen hatten, das jedoch noch darauf wartete, linguistisch und sprachdidaktisch ausbuchstabiert und im Licht erster empirischer Studien diskutiert zu werden. Diesen Versuch unternahmen Carl James und Peter Garret in einem Sammelband, den sie 1991 vorlegten. In ihrem einleitenden Beitrag The scope of Language Awareness ist insbesondere die Benennung von fünf Teildomänen hervorzuheben, die nach Auffassung der Autoren zu berücksichtigen seien. Sie sind hier von besonderem Interesse, weil sie für die Rezeption des Konzeptes in der deutschsprachigen Fremdsprachendidaktik eine Schlüsselrolle spielen werden. Dabei handelt es sich um die affektive (affective domain), die soziale (social domain), die politische ('power' domain), die kognitive (cognitive domain) und die performative Domäne (performance domain) (vgl. James/Garrett 1991: 12-20).

Die affektive Domäne bezieht sich auf das Anliegen, Sprache nicht nur kognitiv zu betrachten, sondern auch im Hinblick auf die Emotionen zu befragen, die sie bei der/beim Lernenden hervorruft. ${ }^{132}$ Im Anschluss an Donmall (1985: 7) wird vorgeschlagen, im Umgang mit Sprache „attention, sensitivity, curiosity, interest and aesthetic response" (James/Garrett 1991: 13) zu fördern.

132 Language wird hier im Unterschied zu anderen Passagen vorwiegend mit grammar gleichgesetzt. 
Die soziale Domäne nimmt Bezug auf mögliche soziale Spannungen in multiethnischen und multilingualen Gesellschaften. Language awareness hat nach Auffassung von James und Garrett ein großes Potential, diese Konflikte zu entschärfen und sprachliche Toleranz zu fördern (die Autoren bevorzugen den aus ihrer Sicht positiver konnotierten Begriff endorsement, vgl. ebd.: 14). Sie warnen dabei allerdings davor, Kinder anderer Herkunftssprachen herablassend zu behandeln oder sie bzw. ihre Sprachkenntnisse zum Nutzen der monolingualen Mitschüler_innen zu instrumentalisieren.

Mit der politischen Domäne ist ein Blick auf Sprache gemeint, der Manipulationsversuche offenlegen soll. Unter Rückgriff auf Paulo Freire und Norman Fairclough wird hier das emanzipatorische Potential von language awareness betont. Freire hatte bereits 1972 den Begriff der conscientização geprägt, womit nach Auffassung von James und Garrett „[...] alerting people to the hidden meanings, tacit assumptions and rhetorical traps laid by those who traditionally have most access to the media for verbal communication [...]" (ebd.: 14) gemeint sei. Dies sei besonders im Hinblick auf die Sprache der Politik und der Werbung von Interesse (vgl. ebd., Fairclough 1989: passim).

James' und Garretts Ausführungen zur vierten, der kognitiven Domäne von language awareness stellen ein entschiedenes Plädoyer für Sprachbetrachtung als legitimen Bildungsinhalt sui generis dar:

In the LA [language awareness] definition, language in general and languages in particular are legitimate objects of study, as legitimate as other aspects of our physical or social environment that are studied in disciplines like history, chemistry, biology, etc. (James/ Garrett 1991: 15; das Argument findet sich bereits bei Hawkins 1984: 5f.)

Unter Abgrenzung von behavioristischen Auffassungen vom Sprachenlernen und unter Rückgriff auf Cummins (1978) betonen die Autoren zudem, dass language awareness einen positiven Effekt auf die kognitive Entwicklung haben könne. Dies zeige sich bei zwei Gruppen von Kindern und Jugendlichen, die auf natürliche Weise mit dem Sprechen über Sprache aufwüchsen, nämlich bei solchen, die entweder bilingual sozialisiert seien oder einer gehobenen sozialen Schicht entstammten (vgl. James/Garrett 1991: 16).

Bemerkenswert ist in diesem Zusammenhang, dass James und Garrett auch mit der kognitiven Domäne keineswegs lediglich dekontextualisierte Grammatikanalyse im Sinn haben. Vielmehr schwebt ihnen die Betrachtung von Sprache im Gebrauch vor, „language in use“ (ebd.: 15). Zudem regen sie an, dabei auch die Bedeutung von Genres zu thematisieren: 
[...] writing classes centred on helping pupils to identify the conventional patterns of organisation that we instinctively conform to when we produce instances of genres such as telling a story, applying for a job, writing a laboratory report or consulting a doctor (ebd.)

Sie setzen hiermit schon früh einen Impuls zugunsten von Ansätzen, die in jüngerer Zeit auch in der deutschsprachigen Didaktik als generisches Lernen verstärkt gefordert werden (vgl. Hallet 2011a).

Die performative Domäne schließlich wirft eine Frage auf, die auch in Deutschland für die Legitimierung von language awareness im Kontext der Kompetenzorientierung des Fremdsprachenunterrichts zentral sein wird: Inwiefern lässt sich das aus Sprachbetrachtung gewonnene Wissen auch in ein besseres Sprachkönnen umsetzen? James und Garrett vertreten eine Haltung, die sich einer schwachen interface-position (vgl. Ellis 1997; Pesce 2010: 17-25) zuordnen lässt. Sie betonen dabei insbesondere die Bedeutung differenzierter Rückmeldungen über den eigenen Wissensstand, welche Lernende durch Sprachbetrachtung erhielten. Dies sei eine zentrale Voraussetzung für eine autonome Verbesserung der eigenen sprachlichen Fähigkeiten und damit auch der Performanz, und zwar nicht nur, wie dies in manchen Ansätzen zur language awareness gefordert werde, durch die Bewusstmachung bereits implizit vorhandenen Wissens, sondern auch durch die so erst mögliche Offenlegung von Wissensrückständen:

It follows then that definitions of LA [language awareness] that concentrate on the explicit-making of implicit knowledge are only half-truths: once we realise what we do know, we are able to identify what it is that we need to know. By the same token, realising what we do not know helps us to see what we do know. It is in this way that skills improve when we raise implicit knowledge to awareness. As anyone knows, honest and objective self-evaluation is the key to self-improvement. (James/Garrett 1991: 19)

Allerdings wird auch der große Bedarf an empirischer Forschung zu der Frage hervorgehoben, inwieweit von einer Steigerung der sprachlichen Performanz durch language awareness ausgegangen werden kann. Dieser Zusammenhang müsse bis dahin als Spekulation („conjecture“, ebd.: 20) betrachtet werden. ${ }^{133}$

Mit Beginn der 1990er-Jahre setzt auch in Deutschland die Rezeption der language awareness ein. Obwohl bereits Hawkins ausdrücklich auf die Rolle der Fremdsprachen für die Förderung von language awareness hingewiesen

133 Die englischsprachige Diskussion um language awareness wurde ab 1994 maßgeblich innerhalb der Association for Language Awareness weitergeführt. Der Verband definiert das Konzept heute als „explicit knowledge about language, and conscious perception and sensitivity in language learning, language teaching and language use" (Association for Langauge Awareness 2012). 
hatte, dreht sich die Diskussion in Großbritannien doch vorwiegend um den muttersprachlichen Englischunterricht. In Deutschland wird das Konzept hingegen schon früh auch in fremdsprachendidaktischen Beiträgen aufgegriffen. Wegweisend sind hier die Arbeiten von Dieter Wolff (1993) sowie von Claus Gnutzmann (1997, 2007, 2010a, 2010b). Während in Großbritannien weiterhin die Frage der literacy in der englischen Sprache im Vordergrund steht, dreht sich die deutschsprachige Debatte stärker um Fragen der Mehrsprachigkeit. So argumentiert etwa Wolff aus Sicht der Spracherwerbs- und der Bilingualismusforschung und plädiert dafür, language awareness als ,Sprachbewusstheit' für hiesige fremdsprachendidaktische Diskurse fruchtbar zu machen. ${ }^{134}$ Sprachbewusstheit bedeutet für Wolff dabei in erster Linie Kognitivierung durch Versprachlichung von unbewusstem Wissen. Es habe sich herausgestellt, so Wolff (1993: 511), dass „[...] Sprachlernprozesse eng an kognitive Prozesse gebunden sind, an Generalisierungsprozesse, an Abstraktionsprozesse, an Prozesse des Hypothesenbildens und des Hypothesentestens." Für Sprachbewusstheit schlägt er in Anlehnung an Hawkins (1984) sowie an Pratt und Grieve (1984) folgende Arbeitsdefinition vor:

Unter Sprachbewußtheit (language awareness) soll also im weiteren Kontext die Fähigkeit verstanden werden, die Struktur von Sprache, die psychologischen Prozesse der Sprachbenutzung und die Funktionen von Sprache in der Interaktion bewußt wahrnehmen und darüber reflektieren zu können. (Wolff 1993: 514, Hervorhebung im Original)

Aus den Äußerungen bilingualer Kinder etwa sei zu schließen, dass sie über eine höhere Sprachbewusstheit verfügten (vgl. ebd.: 517-522). Daher sei im Umkehrschluss zu erwarten, dass eine Förderung der Sprachbewusstheit auch zu höherer Sprachkompetenz führe, insbesondere dann, wenn diese Förderung nicht nur in der Muttersprache, sondern auch durch den kontrastiven Vergleich zwischen Mutter- und Fremdsprache(n) erfolge (vgl. ebd.: 511, 514f.). Im Hinblick auf die Förderung von Sprachbewusstheit sei zu bedenken, dass sich diese bei bilingualen Kindern keineswegs auf Sprachstrukturen beschränke, sondern vielmehr „alle Aspekte menschlicher Kommunikation und Interaktion“ (ebd.: 511) betreffe. Wolff betont, dass die klassische Grammatikarbeit des Fremdsprachenunterrichts kaum geeignet sei, Sprachbewusstheit in diesem weiten Sinne zu fördern:

Der Lerner wird häufig in ein Korsett grammatischer Begrifflichkeiten gezwängt, die ihm nicht einsichtig sind, er wird, meist vom Lehrer gesteuert, nur auf bestimmte grammatische Phänomene aufmerksam gemacht, die das jeweilige Lernziel der Unterrichtseinheit sind. (ebd.: 516)

134 Vereinzelt auch „Sprachbewusstsein“, vgl. z. B. Wolff 1993: 511, 518. 
Wolff hofft hingegen, dass durch ein weit angelegtes Verständnis des neuen Konzeptes auch die aus seiner Sicht schädliche Dichotomie zwischen Kommunikation und Sprachbewusstheit überwunden werden kann. In beiden Bereichen könne durch geeignete unterrichtliche Verfahren - gemeint ist vor allem ,experimentierendes, exploratives Lernen" (ebd.: 529) unter Einbeziehung der Muttersprache zu Sprachgebrauch angeregt werden, und zwar einerseits als „Sprachgebrauch in kommunikativen Aktivitäten“, andererseits als „Sprachgebrauch beim Experimentieren und Forschen“. Die Kombination aus so angebahnten „Kommunikationsfähigkeiten“ bzw. „Sprachbewusstheit“ führe schließlich zu „Sprachfähigkeit (Proficiency)“ (vgl. das Modell in Wolff 1993: 528).

Ähnlich wie Wolff sieht auch Claus Gnutzmann zu Beginn der 1990er-Jahre ein deutliches Defizit im Bereich der Sprachbewusstheit. Die Ursache hierfür macht er vor allem in der kommunikativen Wende und in der Vernachlässigung schriftlicher Kompetenzen aus, die er mit ihr verbindet. Zwar sei in der kommunikativen Fremdsprachendidaktik unter dem Einfluss von Habermas und Chomsky eine explizite Abkehr von behavioristischen Einflüssen erfolgt, und hierbei sei auch, ebenfalls im Unterschied zum Primat der Mündlichkeit in behavioristischen Ansätzen, die schriftliche Kompetenz der mündlichen im Prinzip gleichgestellt worden. In der Praxis sei jedoch die Mündlichkeit für das Lernziel ,kommunikative Kompetenz' genauso stark betont worden, wie dies schon in der audiolingualen Methode der Fall gewesen sei:

Trotz dieser völlig unterschiedlichen, ja entgegengesetzten theoretischen Begründungszusammenhänge ist beiden Methoden in ihrer praktischen Anwendung die besondere Betonung des Mündlichen gemeinsam. (Gnutzmann 1997: 227, Hervorhebung im Original)

In Form eines thesenartigen Plädoyers (ebd.: 228) schlägt Gnutzmann vor, den language awareness-Ansatz aus der britischen Diskussion als Nachdenken über Sprache zu übernehmen, um den Begriff auf diese Weise auch im Deutschen „als umfassendes und integratives Lehr- und Lernkonzept“ (ebd.: 232) unter Berücksichtigung von muttersprachlichem und fremdsprachlichem Unterricht möglichst weit zu fassen. Hierbei sollten, so Gnutzmann, die von James und Garrett geprägten fünf Domänen berücksichtigt werden: die affektive, die soziale, die politische, die kognitive und die performative (vgl. ebd.: 232-235; Gnutzmann 2010b: 117f.). ${ }^{135}$

135 Gnutzmann übersetzt domain meist als ,Domäne', vereinzelt auch als ,Dimension` oder,Seité. 
Einen anderes Verständnis von language awareness geht auf Ute Rampillon (1997) zurück. Zwar basieren ihre Überlegungen wie die Gnutzmanns auf der allgemeinen Definition von James und Garrett. Allerdings beschränkt sie sich nicht auf deren fünf Domänen, sondern schlägt vielmehr vor, language awareness als „Metakognitive Reflexionen zum Fremdsprachenlernen“ (Rampillon 1997: 176) zu modellieren. Als deren Bestandteile sollten, so ihr Vorschlag, drei Felder fachdidaktisch in den Blick genommen werden:

Tab. 3: Ute Rampillons Modell von language awareness (Quelle: Rampillon 1997: 176, Hervorhebungen im Original)

\begin{tabular}{|c|c|}
\hline \multicolumn{2}{|c|}{$\begin{array}{l}\text { Language Awareness: } \\
\text { Metakognitive Reflexionen zum Fremdsprachenlernen }\end{array}$} \\
\hline Linguistic awareness & $\begin{array}{l}\text { sprachliche Kenntnisse } \\
\text { sprachliche Fertigkeiten }\end{array}$ \\
\hline Communicative awareness & $\begin{array}{l}\text { Wissen über Funktionsweisen von Sprache: } \\
\text { - Kommmunikationsstrategien } \\
\text { - Strategien der Körpersprache } \\
\text { - Diskursstrategien } \\
\text { - Dominanzstrategien } \\
\text { und die Fertigkeit, diese Strategien zu deuten bzw. } \\
\text { selber anzuwenden. }\end{array}$ \\
\hline learning awareness & $\begin{array}{l}\text { Wissen über Lern-, Denk und Problemlöseprozesse } \\
\text { und die Fertigkeit, diese Strategien zu deuten bzw. } \\
\text { anzuwenden. } \\
\text { - Stützstrategien } \\
\text { - Primärstrategien } \\
\text { - Instruktionsstrategien. }\end{array}$ \\
\hline
\end{tabular}

Es zeigt sich, dass die beiden ersten Felder deutlich an die von James und Garrett aufgestellten fünf Domänen angelehnt sind. Das Feld der learning awareness hingegen richtet die Aufmerksamkeit weniger auf die verschiedenen Facetten von Sprache als vielmehr auf den Vorgang des Lernens einer (fremden) Sprache selbst. Dieser Aspekt, häufig übersetzt mit Sprachlernbewusstheit, wurde in der zweiten Hälfte der 1990er-Jahre von einem Teilaspekt der Sprachbewusstheit zu einem ihr beigeordneten Konzept aufgewertet (vgl. Edmondson 1997; KnappPotthoff 1997).

Ein weiterer Versuch begrifflicher Klärung findet sich bei Steffi Morkötter (2005), die eine der wenigen empirischen Studien zur language awareness vorgelegt hat. Für ihre Untersuchung zu Sprachbewusstheit und Mehrsprachigkeit stützt sie sich auf drei der von James/Garrett formulierten und von Gnutzmann 
rezipierten fünf Domänen, und zwar auf die affektive, die soziale und die politische (vgl. Morkötter 2005: 32). Morkötter entwickelt indes darüber hinaus selbst drei Ebenen von Sprachbewusstheit, die gewissermaßen quer zu diesen Domänen liegen, nämlich erstens „Sprachbewusstheit als ein individuelles dynamisches Gefüge von Kognitionen, Einstellungen und Emotionen einer Person zu Sprache(n) und zum Lernen und Lehren von Sprachen“ (ebd.: 37), zweitens „Sprachbewusstheit als Mittel des Sprachenlernens im Sinne einer Nutzung expliziten Wissens für Sprachgebrauch und -erwerb [...]“ (ebd.) sowie drittens „Sprachbewusstheit als Ziel an sich im Sinne einer Bewusstheit über beispielsweise sprachliche Vielfalt [...]“ (ebd., Hervorhebungen jeweils im Original). Morkötter strebt in ihrer Untersuchung „Einblicke in Kognitionen, Einstellungen und Emotionen" (ebd.: 38) in Bezug auf alle dieser Ebenen von Sprachbewusstheit an, räumt dabei jedoch ein, dass die Erkenntnisse nicht die Sprachbewusstheit selbst, sondern eher die Haltung von Lehrenden und Lernenden $z u$ dem Konzept der Sprachbewusstheit betreffen werden. Die Studie bezieht sich somit nicht auf die Sprachbewusstheit von Lernenden und Lehrkräften, sondern es handelt sich vielmehr um eine Untersuchung der Frage, wie dieses Konzept von diesen jeweils eingeschätzt wird:

Die Untersuchung ist somit auf einer metasprachlichen und metakognitiven Ebene von Language Awareness nach Konzeption a) angesiedelt, d.h. es wird primär auf Sprachbewusstheit und deren Bedeutung für Sprachenlernen und -lehren auf Seiten von Lernern ebenso wie von Lehrern abgehoben. (ebd.: 38)

Auch Küster (2012) sieht im Konzept der language awareness bzw. Sprachbewusstheit ein Potential für den Fremdsprachenunterricht, vor allem in seiner um language learning awareness bzw. ,Sprachlernbewusstheit' im Sinne Rampillons (1997) erweiterten Form. Bei einem weit gefassten Konzept von Sprachbewusstheit sieht er Schnittmengen mit Ansätzen, welche um die Begriffe Reflexivität und Bildung kreisen. Neben dem Einsatz von typischen Reflexionsinstrumenten wie dem Portfolio obliege es jedoch vor allem der Lehrkraft, im Unterrichtsgespräch Gelegenheiten für Metakognitionen zu schaffen:

Wichtiger aber noch als der Einsatz einzelner Instrumente und Verfahren scheint mir zu sein, dass Lehrkräfte das Prinzip der Reflexivität im laufenden Unterrichtsgeschehen immer wieder an geeigneten Stellen im Unterrichtsgespräch zur Geltung bringen, indem sie die Aufmerksamkeit der Lernenden unaufdringlich auf die Metaebene lenken. Erst durch die langfristig angelegten Wiederholungen eines solchen Perspektivenwechsels ist zu erwarten, dass sich auf Seiten der Lernenden eine reflexive Haltung ausbildet, die dann in eine weitgefasste Awareness mündet. (Küster 2012: 94, Hervorhebung im Original) 
Gleichzeitig warnt Küster jedoch davor, dass eine zu starke Betonung von Sprachbewusstheit und Sprachlernbewusstheit dazu führen könnte, „[...] Fremdsprachenlernen als primär mentalen und zugleich linearen Prozess misszuverstehen" (ebd.: 95). Er verweist hierbei auf die Bedeutung sozio-kultureller und emergentistischer Ansätze, die deutlich machten, dass Lernen nicht nur als ein kognitiver Vorgang, sondern auch als „ein in interaktiven Kontexten eingebettetes und komplex-interdependentes soziales Geschehen“ (ebd.: 96) verstanden werden müsse.

Küsters Beitrag verweist auf ein weiteres Problem, das sich zusätzlich zu der Frage nach verschiedenen Modellierungen von language awareness und abgeleiteter Konzepte stellt (zusammenfassend vgl. Hug 2007; Gnutzmann 2007, 2010b; Schmidt 2010). Gemeint ist die Frage, inwieweit Sprachbewusstheit als (explizites) Sprachwissen für (implizites) Sprachkönnen wirksam ist.

Zur Frage der Wirksamkeit von explizitem grammatischem Sprachwissen lassen sich prinzipiell drei Standpunkte unterscheiden (zusammenfassend vgl. Pesce 2010: 17-25). Der erste Standpunkt bezeichnet die Annahme eines starken Wirkzusammenhangs zwischen grammatischem Wissen und sprachlichem Können (strong-interface-position, vgl. Bialystok 1978), der zweite Standpunkt steht für den Zweifel an jeglichem Zusammenhang zwischen diesen beiden Bereichen (non-interface-position, vgl. Krashen 1981: 1-11). Vertreter_innen des dritten Standpunktes (weak-interface-position) gehen davon aus, dass grammatisches Sprachwissen von den Lernenden zwar nicht direkt in Sprachkönnen umgesetzt werden kann, dass es den Lernprozess jedoch zumindest indirekt positiv beeinflusst und beschleunigt:

Explicit knowledge, then, can contribute indirectly to interlanguage development. [...] A corollary of this position is that formal instruction directed at explicit knowledge may have a delayed rather than an immediate impact on the learners' interlanguage. (Ellis 1997: 124)

Zur Untermauerung der Annahme wird der Begriff des noticing ins Spiel gebracht, der entscheidend sei, dass auf Grundlage der bloßen Konfrontation des Schülers mit einem sprachlichen Phänomen (input) auch tatsächliche Verarbeitung (intake) entstehe (vgl. Schmidt 1990).

Beiträge zur Sprachbewusstheit lassen sich nun meist der weak-interfaceposition zuordnen (vgl. Rampillon 1997: 177, 182f; Morkötter 2005: 47; Gnutzmann 2010b: 118). Die Autor_innen verweisen dabei jedoch durchgehend auf die nach wie vor dünne empirische Basis zur Sprachbewusstheit (vgl. James/ Garrett 1991: 18; Wolff 1993: 515; Gnutzmann 1997: 235, 2010b: 118f.), und damit komme ich nach dem Problem der theoretischen Modellierung und dem 
Problem ihrer Wirksamkeit für das Sprachkönnen nun zur Empirie, dem dritten Problembereich der Sprachbewusstheit.

Zwar liegen von Morkötter (2005) und Fehling (2008) erste Studien zu Teilaspekten von Sprachbewusstheit vor, von denen sich manche erhoffen, dass sie den Forschungsbedarf allmählich reduzieren helfen (vgl. Gnutzmann 2010b: 119). Insgesamt muss die empirische Basis jedoch weiterhin als äußerst dünn gelten. Lapidar notiert etwa Jürgen Kurtz (2012: 109) in diesem Zusammenhang:

Auf der Grundlage der gegenwärtig vorliegenden Erkenntnisse und Theorien zum Sprachwissen und zur Sprachenbewusstheit lassen sich noch keine entsprechenden Empfehlungen oder gar Prinzipien für das Lehren und Lernen von Fremdsprachen in der Schule formulieren.

Dieser Mangel an Forschung zu einem seit etwa 20 Jahren vorliegenden Konzept könnte möglicherweise auf einige grundlegende Probleme der empirischen Erfassung mentaler Phänomene zurückzuführen sein, auf die Annelie Knapp in einem aktuellen Beitrag (vgl. Knapp 2013) hinweist. Einerseits ergeben sich diese Probleme aus den hier bereits thematisierten uneinheitlichen Definitionen von language awareness/Sprachbewusstheit und der daraus resultierenden vielfältigen Terminologie. Andererseits könnten grundlegendere Probleme jedoch in der Natur von awareness- bzw. Bewusstseins- und Bewusstheitskonzepten selbst liegen.

Erstens ist awareness als rein mentaler Vorgang auf einer anderen Ebene als funktionale sprachliche Kompetenzen angesiedelt und muss aus diesem Grund als grundsätzlich schwer beobachtbar gelten. Zudem ist fraglich, ob bewusste psychische Vorgänge in jedem Fall versprachlicht werden können, oder ob sie nicht vielmehr, wie Knapp (ebd.: 76) zu bedenken gibt, „von den Betroffenen evtl. auch nicht präzise verbalisierbar" und daher nicht von außen beobachtbar sein können.

Zweitens stellt sich in Abhängigkeit von diesen Überlegungen das Problem der Datenerhebung: Inwiefern lassen gewonnene Daten Aussagen über das Vorhandensein und die Qualität von awareness zu? (vgl. ebd.)

Drittens schließlich stellt sich das Problem, dass awareness möglicherweise erst zum Zeitpunkt der Forschung entsteht, dass also die Datenerhebung selbst erst zu Sprachbewusstheit führt bzw. sie verstärkt (vgl. ebd.). Dieser dritte Aspekt wird nun durch das sogenannte Perspektivenproblem verschärft. Dabei handelt es sich um ein erkenntnistheoretisches Problem in Bezug auf mentale Vorgänge, das darin besteht, dass Bewusstseinsphänomene zunächst einmal ausschließlich aus einer Ich-Perspektive erlebt werden. Diese Perspektive, so das Anliegen jeder Bewusstseinsforschung, soll nun aus der Perspektive einer dritten Person 
wissenschaftlich beschrieben und damit objektiv zugänglich gemacht werden, und zwar möglichst ohne dass dabei „die ,Röte“ des Rots oder das ,Stechen des Schmerzes“ (Kiefer 2008: 156), welche vom jeweiligen Bewusstsein erlebt werden, verloren gehen (vgl. ebd.: 156). ${ }^{136}$ Inwieweit jedoch die Perspektiven der ersten und dritten Person überhaupt zur Deckung zu bringen sind, ist das noch zu klärende „wissenschaftstheoretische Kernproblem der Bewusstseinsforschung" (ebd.).

Jedes weit gefasste Verständnis von Sprachbewusstheit hat sich einem empirischen Zugriff bislang systematisch entzogen. Die genannten erkenntnistheoretischen und forschungsmethodologischen Probleme liefern dafür einen Erklärungsansatz. Sie werden auch in jeder zukünftigen Studie zur Sprachbewusstheit zu berücksichtigen sein. Gleiches gilt auch für noch zu entwickelnde Ansätze zur empirischen Erforschung Fremdsprachlicher Diskursbewusstheit.

\subsubsection{Zur Bedeutung der Sprachbewusstheit für die Fremdsprachliche Diskursbewusstheit}

Ich möchte die Bedeutung von language awareness/Sprachbewusstheit für das Konzept Fremdsprachliche Diskursbewusstheit im Folgenden in Bezug auf drei Probleme diskutieren, welche sich in der Rekonstruktion des Begriffsfeldes gezeigt haben: das Theorieproblem, das Performanzproblem und das Empirieproblem. Darüber hinaus ist auch eine konzeptuelle und begriffliche Klärung von Bewusstsein, Bewusstheit und Bewusstmachung notwendig.

Große Teile des Theorieproblems von language awareness/Sprachbewusstheit können auf die Frage zurückgeführt werden, was unter language/Sprache jeweils $\mathrm{zu}$ verstehen ist. ${ }^{137}$ Hierbei ist zu betonen, dass das Konzept in der Rezeption häufig auf die Betrachtung sprachstruktureller Aspekte verkürzt und in der Folge einseitig mit traditionellem Grammatikunterricht in Verbindung gebracht wurde. Die Autoren der DESI-Studie etwa berufen sich zwar auf die „neuere language awareness-Forschung" (Klieme et al. 2006: 8), beschränken sich jedoch in der Erhebung selbst auf die Fähigkeit zum Monitoring grammatischer und stilistischer Phänomene:

136 Der Philosoph Thomas Nagel hat dieses Problem 1974 in einem Aufsatz mit dem Titel What is it like to be a bat? anschaulich dargestellt.

137 An der Verwendung von language awareness, Sprachbewusstheit oder beiden Begriffen ist abzulesen, ob sich die jeweiligen Überlegungen auf die englischsprachige Diskussion, auf die deutschsprachige Diskussion oder auf auf beide bezieht. 
Konkret sprechen die Testaufgaben drei Arten von sprachlichen Phänomenen an: schwierige, spät und bewusst gelernte sowie durch den Sprachwandel gefährdete grammatische Phänomene (z.B.: Unterscheidung Dativ-/ Akkusativobjekt, Kongruenzen innerhalb eines Satzes - d.h. Übereinstimmungen hinsichtlich Kasus, Genus, Numerus, Person - über einen größeren Fokusbereich hinweg, Gebrauch des Genitivobjekts, Konjunktivformen), - indirekte Rede und Konjunktiv - Aspekte der Stilistik (vor allem häufig auftretende Wortverbindungen [so genannte semantische Kollokationen], Stilverträglichkeit, Stilistik des Konjunktivs 1 und 2). (ebd.: 8f.)

Dagegen wurden die Befürworter von language awareness/Sprachbewusstheit als sprach- und fremdsprachendidaktisches Leitkonzept nicht müde zu betonen, dass ein analytischer Blick auf die formale Seite von Sprache lediglich einen Aspekt bewusstmachender Verfahren darstelle. Dieser habe zwar durchaus seine Berechtigung als Teil sprachlichen Lernens, stehe jedoch neben anderen, ebenso wichtigen Aspekten (vgl. James/Garrett 1991: 12-20).

Es könnte für die Beilegung dieser Diskussion zielführend sein, das Ziel der Bewusstheit statt in Bezug auf ,Sprache' allgemein eher in Bezug auf ,Diskurse' anzubahnen, da der Diskursbegriff spezifischer ist und eine Verkürzung auf die Bedeutung ,Grammatik' kaum zulässt. Für ihn spricht auch, dass er in der hier vorgeschlagenen Bedeutung (vgl. Kap. 4.2.4.) nicht nur die Gesamtheit von language awareness im Sinne von James/Garrett (1991) zu umfassen in der Lage ist, sondern dass er zudem einige der dort genannten Teildimensionen herausgreift und betont. Ein besonderes Gewicht käme durch den Diskursbegriff der politischen bzw. der machtbezogenen Dimension zu. Somit würde jene Dimension von Sprache aufgewertet, die gerade in der deutschsprachigen Debatte um Sprachbewusstheit in der bisherigen Rezeption unterrepräsentiert war. Gnutzmann etwa nennt diese Dimension zwar, allem Anschein nach aber nicht, weil er von ihrer Relevanz überzeugt wäre, sondern eher der vollständigen Wiedergabe der Konzeption nach James/Garrett zuliebe. Er schreibt (1997: 234, Hervorhebungen im Original):

Diese [die politische] Domäne gehörte ursprünglich nicht zum Kernbereich von language awareness. Warum diese Domäne dann doch integriert wurde, ist nicht ganz klar. Nicht unplausibel erscheint jedoch die Hypothese, daß dadurch der Vorwurf an die frühe Phase von language awareness, Schülerinnen und Schüler sprachlich und sozial zu disziplinieren, entkräftet werden sollte. Anders ausgedrückt: die Protagonisten von language awareness hatten Angst, mit dem konservativen Establishment identifiziert zu werden und hofften, auf diese Weise ihre, linken' Kritiker zufriedenzustellen.

Inwieweit diese Hypothese zutrifft, ist schwer zu beurteilen. Zutreffend ist mit Sicherheit, dass das Anliegen der politischen Bildung im Sinne einer allgemeinen Kritikfähigkeit bis in die 1990er Jahre tendenziell von Vertretern des linken 
Spektrums formuliert wurde. Man denke an Theodor W. Adornos Theorie der Halbbildung (2006 [1959]), an Paulo Freires Pädagogik der Unterdrückten (1993) oder an das maßgeblich von Norman Fairclough (1992b) geprägte Konstrukt der critical language awareness. Die Tatsache, dass politische Bildung ein traditionell linkes Anliegen darstellt, sagt allerdings nichts darüber aus, in welchem Maße die politische Dimension bei der Modellierung von language awareness für die Autoren eine Herzensangelegenheit war, in welchem Maße sie jedoch, wie Gnutzmann vermutet, lediglich als Zugeständnis an mögliche linke Kritiker aufgenommen wurde.

Angesichts der entschieden emanzipatorischen Stoßrichtung, die sich bereits bei Hawkins (1984) findet, erscheint mir jedoch die Aussage, die politische Dimension habe ursprünglich nicht zum Kern von language awareness gehört, als nicht zutreffend. So sind etwa die im Bullock-Bericht festgestellten Versäumnisse des britischen Bildungssystems im Ausgleich von sozialen Nachteilen eine eminent politische Problemstellung, und eben deren Lösung stellt von Beginn an eines der Hauptanliegen der language awareness-Bewegung dar (vgl. Kap. 4.3.2.). Hawkins (1984: 64f.) verteidigt zudem die Anbahnung solider Kenntnisse in der Verkehrssprache des jeweiligen Staates ausdrücklich gegen Vorwürfe, dies stelle eine (politische) Manipulation von sprachlichen und kulturellen Minderheiten dar. Vielmehr sieht er die wichtigste Legitimation des Vorhabens, möglichst allen Kindern und Jugendlichen solide Kompetenzen im mündlichen und schriftlichen Gebrauch von Standard English zu vermitteln, darin, ihnen die Teilnahme an gesellschaftlichen Entscheidungsprozessen zu ermöglichen. Sprachliche Bildung ist somit nach Hawkins nicht als Manipulation, sondern im Gegenteil als Erziehung zu Autonomie und somit als Schutz vor Manipulation zu sehen. Den Kritikern des language awareness-Ansatzes wirft er seinerseits vor, lebende Gegenbeweise zu ihren eigenen Thesen zu sein. Sie seien nur deswegen in der Lage, ihre Kritik zu formulieren, weil sie selbst in ihrer Schulzeit eine bildungssprachliche Erziehung genossen hätten:

[...] why, having had the good fortune themselves to acquire the language of education, do they feel justified in arguing that the same opportunity to learn should be denied to the children now in school? (ebd.: 65)

Die Ziele von language awareness gehen jedoch, so Hawkins, über die Bedürfnisse einzelner Lernender hinaus. Diesen zu ermöglichen, ihr Mitbestimmungsrecht in autonomer Weise wahrnehmen zu können, sei eine der wichtigsten Zielsetzungen schulischen Lernens; es sei jedoch gleichzeitig auch eine Grundbedingung für eine demokratische Gesellschaft insgesamt. Der Versuch der Legitimierung von language awareness durch die Ausrichtung an den Zielen eines 
demokratischen öffentlichen Schulwesens wird auch ersichtlich, wenn Hawkins in recht deutlicher Anspielung auf Ivan Illichs 1971 veröffentlichte Streitschrift Deschooling Society (deutsche Ausgabe 2003) das dort vertretene anarchistische Bildungsprogramm mit dem der demokratischen Schule kontrastiert. Kern des Letzteren ist für ihn ein „apprenticeship in autonomy, which is vital for a democracy" (Hawkins 1984: 65, Hervorhebung im Original). Somit wird deutlich, dass die politische Dimension für das Konstrukt der language awareness zentrale Bedeutung hat, und zwar sowohl für die Bedürfnisse der einzelnen Lernenden als auch für den Fortbestand und die Stärkung demokratischer Gesellschaften insgesamt.

Das hier vorgeschlagene Konstrukt Fremdsprachliche Diskursbewusstheit basiert auf einem weit gefassten Verständnis der politischen Dimension von Sprache. Um zu betonen, dass diese Dimension nicht nur den Bereich der (professionellen) Politik, sondern interpersonelle Verhältnisse allgemein betrifft, könnte es sinnvoll sein, von der machtbezogenen Dimension zu sprechen. Diese würde auch die soziale Dimension umfassen. Es wäre daher nicht mehr notwendig, diese Dimension separat auszuweisen, wie es in der Diskussion um language awareness/Sprachbewusstheit üblicherweise geschieht.

Unabhängig davon, ob man Hawkins' Optimismus in Bezug auf das emanzipatorische Potential von language awareness teilt oder ob man mit ihren Kritikern hinter der Aufwertung der (nationalsprachlichen) Schulbildung eine verdeckte Manipulation durch die dominierenden Teile der Gesellschaft vermutet, steht außer Zweifel, dass das Konzept der language awareness zumindest schon zu einem frühen Zeitpunkt über eine deutlich erkennbare politische Dimension verfügte. Eine solide und handhabbare theoretische Modellierung von language awareness war gegen Ende der 1980er-Jahre dennoch dringend notwendig, nicht zuletzt um einer Kritik zu begegnen, deren Vertreter entweder eine Rückkehr zur traditionellen Grammatikanalyse oder Manipulationen im Sinne gesellschaftlich dominanter Gruppen befürchtete - oder beides. Garrett und James füllten diese konzeptionelle Lücke, indem sie language awareness in die oben aufgeführten fünf Dimensionen auffächerten (vgl. James/Garrett 1991: 12-20). Sie legten dadurch die vielleicht wichtigste Grundlage für die weitere Rezeption des Konstruktes, wobei sie in Übereinstimmung mit Hawkins auch und gerade die politische Dimension von Sprache betonten. Der Umstand, dass diese Dimension von language awareness in der deutschsprachigen Rezeption des Konstruktes eine eher marginale Rolle spielt, lässt sich daher aus den für spätere awarenessAnsätze maßgeblichen Schriften von Hawkins, James und Garrett nicht erklären. Ihre Ausführungen sind in dieser Hinsicht deutlich und unmissverständlich. 
Die politische Domäne stellt insofern zunächst kein Problem der anglophonen Theoriebildung dar.

In einer anderen Domäne jedoch könnten die in der ursprünglichen Konzeption von language awareness nicht intendierten Bedeutungs- und Gewichtungsverschiebungen, die in der Rezeption zu erkennen sind, bereits auf der Theorieebene angelegt sein. Hierbei handelt es sich um jene Domäne, bei der es um die Analyse sprachlicher Strukturen gehen soll und die von James und Garrett als cognitive domain bezeichnet wird. Diese Bezeichnung legt die Frage nahe, inwiefern es sich bei der Bewusstmachung der anderen, also der affektiven, sozialen und machtbezogenen Domänen nicht ebenfalls um kognitive Prozesse handelt. ${ }^{138}$ Man könnte daher gegen James' und Garretts Terminus der cognitive domain einwenden, dass dieser nicht nur den Gegenstand dieser Dimension von Bewusstmachung - sprachliche Strukturen - nicht beim Namen nennt, sondern dass er dabei auch suggeriert, dass die Bewusstmachung der anderen Domänen kein kognitiver Vorgang sei. Ich halte jedoch die Bewusstmachung der Mechanismen, auf deren Grundlage Sprache bzw. Diskurs funktioniert, immer für einen kognitiven Prozess. Statt von einer ,kognitiven' Domäne wäre es daher möglicherweise sinnvoll, von einer, sprachstrukturellen' Domäne zu sprechen.

Ein weiteres Problem in der theoretischen Modellierung von language awareness/ Sprachbewusstheit stellt sich in Bezug auf die sogenannte Performanzdomäne. Diese unterscheidet sich insofern von den anderen Domänen, als es bei ihr nicht um einen bestimmten Aspekt von Sprache geht, der zum Gegenstand der Reflexion von Lernenden gemacht werden soll. Die Performanzdomäne steht meinem Verständnis nach vielmehr für die Frage, inwieweit das Zielkonstrukt der language awareness/Sprachbewusstheit eine generelle Wirksamkeit für die Förderung kommunikativer Kompetenzen aufweist. Mit anderen Worten, es geht um das Nachdenken über die Frage, inwieweit das Nachdenken über Sprache einen Mehrwert im Hinblick auf die Ziele des kommunikativen Unterrichts aufweist. Damit befindet sich das Nachdenken über die Performanzdomäne eine Abstraktionsebene über den anderen Domänen. ${ }^{139}$ Zunächst sei daher festgehalten, dass es sinnvoll sein könnte, die Performanzdomäne aus dem Katalog der fünf Domänen von language awareness auszuklammern. Dies hat etwa Silvia Fehling (2008: 104) in ihrer empirischen Studie zur language awareness bei

138 Ich klammere die fünfte Domäne, die Performanzdomäne, an dieser Stelle aus. Sie wird unten gesondert diskutiert.

139 In der Terminologie der Systemtheorie würde man von einer Beobachtung dritter Ordnung sprechen. Vgl. Baraldi et al. 1997: 123; Berghaus 2001: 49. 
bilingual unterrichteten Lernenden getan. Dieses Vorgehen leuchtet ein, denn während sich mit den passenden Instrumenten Daten zur kognitiven (sprachstrukturellen), affektiven, sozialen und politischen (machtbezogenen) Domäne erheben lassen, gilt dies für die Performanzdomäne nicht. Diese lässt sich lediglich als Korrelation zwischen den anderen Dimensionen und gemessener sprachlicher Performanz ausdrücken.

Unabhängig von der Frage, in Bezug auf welche Domänen von Sprache language awareness/Sprachbewusstheit angebahnt werden sollte, herrscht jedoch Einigkeit darüber, dass sie stets mit einem kognitiven Ebenenwechsel verbunden ist. Fremdsprachenunterricht, der sich am Ziel awareness oder,Bewusstheit' orientiert, verschiebt den Fokus von einer möglichst automatisierten, ,unbewussten' kommunikativen Sprachverwendung hin zu einer ,bewussten', analytischen Betrachtung von Sprache in all ihren Facetten, Verwendungs- und Wirkungszusammenhängen. Der Fokus fremdsprachlichen Lernens verschiebt sich somit zumindest zeitweise hin zum „Nachdenken über Sprache“ (Gnutzmann 1997: 228). In dieser Verschiebung sehe ich, wie oben bereits angedeutet, einen kognitiven, in vielerlei Hinsicht metakognitiven Prozess. Es ist daher mit dem Einwand zu rechnen, dass das hier entwickelte Konstrukt Fremdsprachlicher Diskursbewusstheit, das an die Tradition der language awareness anknüpft, einseitig kognitivistisch angelegt sei. Ich versuche, diesen Einwand mit einer dreifachen Argumentation zu entkräften.

Erstens wäre zu hinterfragen, inwiefern die Dichotomie Kognition vs. Emotion (und ggf. auch Volition) im Licht neuropsychologischer Forschung weiterhin aufrecht erhalten werden kann. Vieles deutet darauf hin, dass die Grenzen zwischen diesen Bereichen deutlich fließender sind als bisher angenommen. So konnte in zahlreichen empirischen Studien belegt werden, dass vordergründig bewusste Prozesse oft systematisch auf einer vorbewussten Ebene durch Emotionen beeinflusst werden (vgl. Kahneman 2012: passim). ${ }^{140}$

Zweitens müsste auch eine Didaktik, die auf Emotionen im Sinne einer positiven, motivationssteigernden Einstellung zu fremden Sprachen allgemein, zu Differenzerfahrungen etc. setzt, die hierfür eingesetzten Verfahren offen legen

140 Anstelle von Kognition vs. Emotion könnten die Konzepte System 1 vs. System 2 für zukünftige Forschung von Interesse sein, auch für fremdsprachendidaktische Fragestellungen. Der Psychologe Daniel Kahneman (2012) versteht unter System 1 ein ,schnelles' (unbewusstes, emotional gefärbtes) System, das den Großteil der kognitiven Aktivitäten steuert. Es ist gewissermaßen der in unserem Gehirn eingebaute „Autopilot“. System 2 dagegen meint die ,langsame“ (bewusste, rationale) Kognition. Vgl. auch Damasio 2007 und Ariely 2008. 
und sie für Kritik öffnen. Dies würde jedoch nichts anderes als einen kognitiven Zugriff bedeuten, der auch und vor allem den Lernenden selbst ermöglicht werden müsste. Ihnen diesen zu verwehren würde bedeuten, sie zu Objekten einer Pädagogik zu degradieren, wie sie in Rousseaus Émile entworfen wurde.

Drittens lässt sich die Gefahr, dass in Bewusstmachungsprozessen die affektivemotionale Ebene vernachlässigt wird, bannen, indem emotional-affektive Aspekte systematisch in diese Prozesse eingebunden werden. Dieses Vorgehen ist, wie oben ausgeführt, in der Modellierung von language awareness nach James und Garrett (1991: 12f.) bereits ausdrücklich angelegt. Diese unterstreichen sogar, dass die affektive Seite von Sprachbewusstheit ihrer Einschätzung nach in besonderem Maße beachtet werden sollte. Auch Gnutzmann (1997: 232) betont in direkter Anlehnung an James und Garrett die affektive Dimension. Sie nimmt somit einen festen Platz in der bisherigen theoretischen Modellierung von language awareness/Sprachbewusstheit ein.

Ich habe oben argumentiert, dass ein sozialphilosophisch verstandener Diskursbegriff dazu beitragen könnte, dass die politisch-machtbezogene Dimension von Sprache den Stellenwert bekommt, der ihr in den maßgeblichen Modellierungen von language awareness/Sprachbewusstheit ohnehin beigemessen wird. Ich möchte hier die Position vertreten, dass der Diskursbegriff dieses Potential auch im Hinblick auf die affektive Dimension von Sprache aufweist. Zwar steht die Diskurstheorie als Sprach- und Sozialtheorie in einer vorwiegend kognitivistisch-rationalistischen Tradition. Sie wurde jedoch auch in reflexiver Brechung auf sich selbst angewendet, wodurch die Existenz unterschiedlicher Rationalitäten offengelegt und somit der Geltungsanspruch der Diskurstheorie selbst relativiert werden konnte. Zudem kam es durch diskurstheoretische Arbeiten insbesondere auch in Bezug auf solche Themen zu überraschenden Einsichten, die üblicherweise als rein dem Bereich der Emotionen zugehörig wahrgenommen werden. Dies gilt etwa für die menschliche Sexualität, die, wie die Studien Foucaults zeigen, ebenfalls in erheblichem Maße von Diskursen geprägt ist (vgl. Foucault 1976). Auch andere, anscheinend ebenfalls stark emotional gesteuerte Bereiche menschlichen Denkens und Handelns, etwa die ästhetischen Reaktionen auf literarische oder filmische Werke, lassen sich aus diskurstheoretischer Perspektive reflektieren (vgl. Hallet 2007). Durch einen diskurstheoretisch geprägten Ansatz könnten Lernende daher etwa dafür sensibilisiert werden, welche Rolle gesellschaftliche Normvorstellungen bei der Produktion und Rezeption von Kunstwerken spielen, und inwieweit ihre eigenen subjektiven, ,emotionalen Reaktionen von diesen Normvorstellungen geprägt sind. Das Konstrukt der Diskursbewusstheit könnte daher in erheblichem Maße dazu beitragen, dass neben 
der bisweilen vernachlässigten politischen Dimension von language awareness auch deren affektive Dimension mehr Beachtung erfährt.

Ich komme nach dem Theorieproblem nun auf das zweite Problem von language awareness zu sprechen, das Performanzproblem. Die Performanzdomäne findet sich, wie oben dargestellt, unter den fünf Domänen von language awareness nach James und Garrett. Es scheint sich jedoch um eine Domäne zu handeln, die sich von den anderen Domänen in zweierlei Hinsicht unterscheidet. Erstens betrifft sie das Konzept der language awareness insgesamt und wirft Fragen auf, mit denen sich, wie bereits oben festgestellt wurde, eher die fremdsprachendidaktische Forschung, die Autor_innen curricularer Vorgaben sowie Lehrkräfte, weniger jedoch die Lernenden selbst befassen müssen. Zweitens und in engem Zusammenhang mit dieser Feststellung betrifft die Performanzdomäne die Frage nach der Legitimation von language awareness als Leitkonzept des Fremdsprachenunterrichts. Ich halte daher eine separate Diskussion dieser Domäne für angebracht.

Für ein Verständnis des Performanzproblems ist es entscheidend, den didaktikgeschichtlichen Hintergrund zu berücksichtigen, vor dem das Konzept language awareness entwickelt wurde. Diesen Hintergrund bildet die kommunikative Fremdsprachendidaktik (vgl. Kap. 4.3.2.). Language awareness/Sprachbewusstheit kann und muss daher als Gegenentwurf zu einer Didaktik gesehen werden, welche auf Fähigkeiten bzw. Kompetenzen zur Erreichung von kommunikativen Zielen fokussiert. Dabei erhebt die kommunikative Didaktik für sich den Anspruch, diese Kompetenzen in besonders wirksamer Weise anbahnen zu können. Innerhalb des bis heute weiterhin dominierenden kommunikativen Paradigmas müssen sich konkurrierende Zielkonstrukte daher immer auch der Frage stellen, inwiefern sie die Zielsetzungen der kommunikativen Didaktik zu erreichen in der Lage sind, ein Legitimationsdruck, der auch für Ansätze in der Tradition der Sprachbewusstheit gilt. So räumt etwa Karen Schramm (2012: 201) für die Didaktik des Deutschen als Fremdsprache zwar den prinzipiellen Nutzen metakognitiver Zugänge ein, betont jedoch gleichzeitig die aus ihrer Sicht ungebrochene Bedeutung kommunikativer Kompetenzen, denen diese Metakognition nachzuordnen sei:

Aus dieser Perspektive [angesichts der traditionellen Ausrichtung der DaF-Didaktik auf die Vermittlung deklarativen Wissens] ist vorrangig nach dem Beitrag des lernerseitigen expliziten Sprachwissens nicht als eigenständiges Lernziel, sondern als Mittel zum Zweck der sprachlichen Kompetenzentwicklung zu fragen.

Vorbehalte hinsichtlich der Wirksamkeit und Effizienz von language awareness sind so alt wie das Konstrukt selbst. So notieren James und Garrett (1991: 17) 
bereits zu Beginn der 1990er-Jahre in ihren Überlegungen zur Performanzdomäne einleitend:

This is the most contentious and certainly the most crucial issue in LA philosophy. The issue is whether knowing about language improves one's performance or command of the language; that is, whether analytical knowledge impinges on language behaviour.

Wie oben bereits erwähnt, vertreten sie in der Frage eine vorsichtig formulierte weak-interface-Position, von der sie jedoch einräumen, dass es sich im Grunde um eine Mutmaßung („conjecture“, ebd.: 20) handle. Dabei verweisen sie ausdrücklich auf die ausgesprochen dünnen empirischen Grundlagen zur Frage der Wirksamkeit von language awareness, stimmen jedoch gleichzeitig der grundsätzlichen Notwendigkeit solcher Forschung zu:

What seems to be spectacularly absent is research. Apart from the notable small-scale exception of LA validation reported here by Heap we know of no significant provision of research funding to investigate this crucial and obviously worrying question. (ebd.: 18)

Angesichts dieses Forschungsdefizits versuchen James und Garrett, die Wirksamkeit von language awareness mit einer theoretischen Überlegung plausibel zu machen. Dies tun sie, indem sie eine Defizitsicht auf das Konstrukt formulieren („a deficit view of LA“, ebd.: 19, Hervorhebung im Original). Lernen geschehe immer dann, wenn der/dem Lernenden die Differenz zwischen dem, was er weiß, und dem, was er nicht weiß, bewusst werde, und hierbei könne language awareness einen wichtigen Beitrag leisten: „[...] once we realise what we do know, we are able to identify what it is that we need to know" (ebd.). Auch die neuere Forschung konnte jedoch keinen ursächlichen Zusammenhang zwischen language awareness/Sprachbewusstheit und sprachlicher Performanz herstellen (vgl. Kurtz 2012: 109). ${ }^{141}$

In Bezug auf eine Legitimierung des Zielkonstruktes der fremdsprachlichen Diskursbewusstheit möchte ich das Performanzproblem hier aus zwei Gründen aus einer anderen Perspektive beleuchten. Erstens gilt der empirische Nachweis von direkten Wirkungszusammenhängen in Bildungskontexten aufgrund der Faktorenkomplexion grundsätzlich als äußerst schwierig („a never ending story", Gnutzmann 1997: 235; zur Faktorenkomplexion als Problem der Fremdsprachenerwerbsforschung vgl. Grotjahn 2006: 248, 252f.). Dies gilt auch für den

141 Königs (2010: 327) nennt zwar eine neuere empirische Studie von Haukas 2009 zum L2-Erwerb des Deutschen, diese beziehe sich allerdings lediglich auf die Bewusstmachung sprachlicher Strukturen und des Lernprozesses selbst, d. h. auf eine der fünf Teildimensionen von language awareness sowie auf language learning awareness. 
oft eingeforderten Beleg eines ursächlichen Zusammenhangs zwischen Sprachbewusstheit und Performanz in kommunikativen Situationen. Zweitens, und dies ist aus meiner Sicht das gewichtigere Argument gegen eine utilitaristische Begründung von Bewusstheit, kann der Legitimierungsbedarf im Hinblick auf kommunikative Kompetenz selbst in Frage gestellt bzw. relativiert werden, denn neben dieser können noch zwei weitere, mindestens ebenso relevante Anliegen fremdsprachlichen Lernens formuliert werden.

Dabei handelt es sich einerseits um das propädeutische Anliegen schulischer Bildung, ein Leitziel, das insbesondere in der Sekundarstufe II greift, das jedoch auch in den mittleren und unteren Jahrgängen angebahnt werden muss. Bereits Hawkins (1984: 6) hebt hervor, dass es allgemein als selbstverständliche Aufgabe von Schule angesehen wird, Lernende an Inhalte wissenschaftlicher Disziplinen wie Biologie oder Chemie heranzuführen. In gleichem Maße solle auch die Heranführung an linguistische Fragestellungen bereits in der Schule zu einer Selbstverständlichkeit werden und nicht länger einem ständigen Legitimationsdruck ausgesetzt sein. James und Garrett (1991: 18) vertreten einen ähnlichen Standpunkt, wenn sie schreiben:

$[\ldots]$ the view was cogently expressed [...] that LA [language awareness] needs no justification in terms of improvement in skill, just as biology does not have to prove that it has led to improved crop or stock production. The study of language is patently selfjustifying.

Wenn man zudem davon ausgeht, dass Fachwissenschaften diskursive Systeme darstellen, wird deutlich, dass ein Nachdenken über Diskurse nicht nur in spezifisch linguistische und sozialwissenschaftliche Fragestellungen einführen könnte, sondern auch im Sinne einer reflexiven Wissenschaftspropädeutik ein großes Potential aufweist. ${ }^{142}$

Neben diesen Überlegungen zur Propädeutik lässt sich eine zweite Legitimationsgrundlage für Fremdsprachliche Diskursbewusstheit anführen. Diese Grundlage bildet der allgemeine Erziehungsauftrag der demokratischen Schule (vgl. Kapitel 2.2.5. sowie Honneth 2013). Wenn Schule auf die Teilnahme an politischen Entscheidungsprozessen vorbereiten soll, dann sollte auch der Fremdsprachenunterricht diesen Auftrag ernst nehmen. Wenn man dabei davon ausgeht, dass gesellschaftliche Macht in hohem Maße über diskursiven Sprachgebrauch ausgeübt wird, liegt es für die Anbahnung einer selbstbestimmten Partizipation an dieser Macht nahe, auch im Fremdsprachenunterricht die Funktionsweise von Diskursen zu reflektieren. Die Legitimation Fremdsprachlicher Diskursbewusstheit

142 Zur reflexiven Thematisierung von Wissenschaften vgl. Breidbach 2007: 246ff. 
könnte somit einerseits aus dem propädeutischen, andererseits aus dem emanzipatorischen Potential des Nachdenkens über Diskurse hergeleitet werden.

Ich möchte unterstreichen, dass diese Argumentation die Bedeutung kommunikativer Kompetenzen für den Fremdsprachenunterricht keineswegs grundsätzlich in Abrede stellen soll. Es geht vielmehr darum, deren Rolle als dominierendes oder gar einziges Anliegen fremdsprachlichen Lernens zu hinterfragen. Dabei müssen die Zielsetzungen kommunikativer Didaktik mit dem Leitziel einer fremdsprachlichen Diskursbewusstheit keineswegs kollidieren. Vielmehr können sich äußerst wünschenswerte Synergieeffekte ergeben.

So kann die Kontroversität, die sich aus der Bewusstmachung zueinander im Widerspruch stehender Diskurse und/oder Praxen ergibt, zu außerordentlich starken Kommunikationsanlässen werden. ${ }^{143}$ Dies könnte insbesondere dann gelingen, wenn Bezüge zu den identitätsstiftenden Diskursen und Praxen der Lernenden hergestellt und durch deren Konfrontation mit anderen Diskursen und Praxen Differenzerfahrungen ermöglicht werden. Bewusstheit könnte somit in Form von Kommunikation über die Bedeutungsnetze angebahnt werden, in welche die Lernenden selbst, aber auch relevante Personen aus deren Umfeld (Lehrkräfte, Eltern, Geschwister, Freunde, Nachbarn, etc.) verstrickt sind. Auf diese Weise könnte der Fremdsprachenunterricht kulturelles Lernen im besten kulturwissenschaftlichen Sinne anbahnen.

Mögliche Themen der Bewusstmachung müssten dabei auch jene Bedingungen sein, unter denen schulisches Lernen stattfindet. Das Prinzip der Lernerautonomie könnte auf eine neue Ebene gehoben werden, wenn Lernenden nicht mehr nur in die Entscheidung einbezogen werden, wie sie bestimmte Lern- bzw. Kompetenzziele erreichen können, ein Vorgehen, das Barbara Schmenk (2004: 77) als „Scheinautonomie“ kritisiert. Vielmehr könnten sie auch lernen darüber nachzudenken, wer diese Ziele mit welcher Legitimation und im Rahmen welcher übergeordneten Zielvorgaben festlegt. Dies könnte dazu beitragen, dass Lernenden die Machtdimension von Sprache nicht mehr lediglich in den Kontexten von Politik und Werbung bewusst wird (vgl. Rampillon 1997: 179; Gnutzmann 1997: 234). Mit Hilfe bewusstmachender Verfahren, die um einen sozialphilosophisch verstandenen Diskursbegriff kreisen, ließe sich vielmehr zeigen, dass Macht eine geradezu allgegenwärtige Dimension von Sprache darstellt. ${ }^{144}$ Machtstrukturen wären somit selbstredend auch in allen sozialwissenschaftlichen, linguistischen

143 Auf dieses Potential bewusstmachender Verfahren verweist auch Wolff (1993: 528f.).

144 Vgl. z.B. in Fairclough 1989 die Analysen einer Zeitungsmeldung über einen britischen Soldaten (49-55) sowie eines Textes über das Verhalten, das von Frauen in gynäkologischen Untersuchungen erwartet wird (58-62). 
und sprachdidaktischen Ansätzen aufzuspüren, die sich als sprach- bzw. machtkritisch verstehen und die oft suggerieren, sie betrachteten die Welt von einem neutralen Standpunkt aus.

Mit den bis zu dieser Stelle entwickelten Überlegungen versuche ich zu ergründen, inwiefern es zielführend sein könnte, das hier entwickelte Konstrukt im Anschluss an die Tradition der language awareness/Sprachbewusstheit als Fremdsprachliche Diskursbewusstheit zu modellieren. Es scheint, dass die fünf von James und Garrett (1991) formulierten Domänen von language awareness hierbei auf drei Schlüsseldomänen reduziert werden können:

1. Die affektive Domäne (James/Garrett: affective domain)

2. Die machtbezogene Domäne (James/Garrett: social domain, „power“domain)

3. Die sprachstrukturelle Domäne (James/Garrett: cognitive domain)

Das in diesem Kapitel diskutierte Performanzproblem betraf vor allem die Frage, inwieweit sich die Wirksamkeit von Bewusstheitskonzepten für kommunikative Kompetenzen belegen lässt, um daraus eine Legitimierung dieser Konzepte abzuleiten. Ich habe dabei argumentiert, dass die Anliegen der Wissenschaftspropädeutik und der politischen Bildung als Legitimationsquellen eine ebenso große Beachtung finden sollten. In diesem Licht relativiert sich zumindest ein Teil des dritten Problems, das sich in der Rekonstruktion von language awareness/ Sprachbewusstheit zeigte, des Empirieproblems. Ich gehe der Frage daher nicht weiter nach, inwieweit sich für Bewusstheitskonzepte eine Wirksamkeit hinsichtlich kommunikativer Kompetenzen empirisch belegen lässt. Es wird jedoch noch zu erörtern sein, inwieweit das Konstrukt der fremdsprachlichen Diskursbewusstheit seinerseits empiriefähig ist, eine Frage, deren Grundproblematik ich in Kapitel 4.3.2. in Anlehnung an Knapp (2013) referiert habe. Ich möchte die folgenden Abschnitte vielmehr der konzeptuellen und terminologischen Klärung der Begriffe Bewusstsein, Bewusstheit und Bewusstmachung widmen.

Es wurde schon mehrfach auf die terminologische Vielfalt hingewiesen, die in der deutschsprachigen fremdsprachendidaktischen Diskussion im Zusammenhang mit den Begriffen awareness bzw. Bewusstheit und mit den an sie angelehnten Termini zu beobachten ist (vgl. Küster 2012; Knapp 2013: 65). Diese Vielfalt lässt sich zumindest in Teilen auf die geringe Einheitlichkeit der englischsprachigen Theoriebildung zurückführen, auf deren Grundlage die Begriffe gebildet wurden (vgl. ebd.). Sie dürfte jedoch ebenso mit den offenen konzeptuellen Fragen zusammenhängen, die das menschliche Bewusstsein bis heute aufwirft (vgl. Kap. 4.3.1.). In jedem Fall liegt awareness-Konzepten die Annahme zugrunde, dass Sprache, vor allem Muttersprache, zunächst unbewusst verwendet wird (vgl. Hawkins 1984: 17ff.). Da Sprache jedoch eng mit dem Denken verwoben 
ist, wird befürchtet, dass mit einer solchen unbewussten Sprachverwendung auch ein unbewusstes Denken und Lernen einhergehe. Durch die bewusste Verwendung von Sprache dürfte daher, so die Hoffnung, auch das in ihr sich vollziehende Denken und Lernen zu einem bewussten Prozess werden.

Es ist jedoch fraglich, inwieweit die binäre Opposition zwischen bewusstem und unbewusstem Denken bzw. Sprechen in dieser Form aufrecht erhalten werden kann. Für den Bereich des Lernens einer fremden Sprache ist auf Grundlage der Spracherwerbsforschung anzunehmen, dass bei den mentalen Prozessen, bei denen die Grenze von unbewusster zu bewusster Sprachverwendung überschritten wird, eher von graduellen Übergängen als von einem dichotomischen Gegensatz auszugehen ist (vgl. Gnutzmann 2010a: 17). Unabhängig davon, wie man sich diese Übergänge im Einzelnen vorstellen muss und ob für das Denken ähnlich graduelle Übergänge zwischen Bewusstsein, Vorbewusstsein und Unbewusstsein anzunehmen sind, lässt sich zumindest festhalten, dass die Vorstellung zweier voneinander getrennter mentaler Zustände und Kognitionssysteme durch das Begriffspaar unbewusst vs. bewusst tief in der Sprache und in Alltagsvorstellungen verankert ist.

Vor diesem Hintergrund stellt sich die Frage, inwieweit sich ein Konstrukt wie die hier entwickelte Fremdsprachliche Diskursbewusstheit so modellieren lässt, dass es in schulischen Lernumgebungen angebahnt werden kann. Die hierfür notwendige grundlegende Erschließung neurowissenschaftlicher Konzepte stellt zum jetzigen Zeitpunkt noch ein Forschungsdesiderat dar. ${ }^{145}$ Ich unternehme in den folgenden Abschnitten dennoch den Versuch einer vorläufigen konzeptuellen und terminologischen Klärung. Hierbei lege ich das Konzept des Wissens über Diskurse und Praxen zugrunde, für das ich in Anlehnung an Sigmund Freuds Begrifflichkeit zur Beschreibung des psychischen Apparates vier Ebenen der Verfügbarkeit unterscheide: ${ }^{146}$

- Ebene (1): das Bewusste - vorhandenes, abgerufenes Wissen über Diskurse und Praxen: verbalisiertes Wissen, auf das die Aufmerksamkeit aktuell gerichtet ist.

- Ebene (2): das Vorbewusste - vorhandenes, abrufbares Wissen über Diskurse und Praxen: Wissen, das prinzipiell vorhanden und durch mehr oder weniger große willentliche Anstrengung abrufbar und verbalisierbar ist.

145 Eine praxisorientierte Monographie zum Thema Fremdsprachenunterricht und Neurowissenschaften mit einem Schwerpunkt in der Dramapädagogik hat Michaela Sambanis (2013) vorgelegt.

146 Vgl. Freud 2012 [1912]: 25-36. 
- Ebene (3): das Unbewusste - vorhandenes, nicht abrufbares Wissen über Diskurse und Praxen: Wissen, das prinzipiell vorhanden, jedoch auch durch große willentliche Anstrengung nicht ohne Unterstützung abrufbar oder verbalisierbar ist. ${ }^{147}$

- Ebene (4): nicht vorhandenes, nicht abrufbares Wissen

Diskursbewusstheit kann auf dieser Grundlage definiert werden als quer zu diesen Ebenen liegende, habitualisierte, schwebende Aufmerksamkeit für Diskurse und Praxen. Ein solches Verständnis von Bewusstheit schlagen auch Decke-Cornill und Küster (2015: 205f.) in Anlehnung an Hawkins vor:

Eine unmittelbare Entsprechung des Wortes [awareness] im Deutschen gibt es nicht. Gemeint ist eine Wachheit für bestimmte Zusammenhänge, nicht weit entfernt von dem, was in der Psychoanalyse als „gleichschwebende Aufmerksamkeit“ bezeichnet wird. Sie steht im Gegensatz zur Strukturiertheit und Explizitheit formalisierten Wissens. Während Letztere sich unmittelbar lehren und bewusst lernen lassen, entspricht Erstere eher einer fragenden Grundhaltung, die der Einzelne über eine Veränderung eigener Lernhaltungen und Wirklichkeitsaneignungen erst langsam entwickeln kann.

Knapp (2013: 69) schlägt in Bezug auf das Konzept der (intercultural) communicative awareness ein ähnlich gelagertes Verständnis von awareness vor:

Folglich könnte (intercultural) communicative awareness ganz generell als eine ,HabAcht'-Haltung bzw. eine, Pass immer auf, was in der Interaktion vor sich geht und ob Missverständnisse durch kulturelle Divergenz aufgetreten sein könnten'-Disposition verstanden werden $[\ldots]$.

Fremdsprachendidaktische Verfahren zur Anbahnung Fremdsprachlicher Diskursbewusstheit müssten es in diesem Sinne ermöglichen, dass Lernende sich Wissen über Diskurse und Praxen der Ebenen 4 und 3 erschließen, es für eine begrenzte Zeit auf Ebene 1 vorhalten und es langfristig auf Ebene 2 verankern. ${ }^{148}$

147 Das Unbewusste betrifft in der Psychoanalyse Wissen, das aufgrund von Tabu, Trauma usw. unzugänglich ist. Mit diesem Wissen zu arbeiten fällt in den Aufgabenbereich von Psychologen und Psychiatern. Hier ist dagegen solches Wissen gemeint, das durch bewusstmachende Verfahren im schulischen Unterricht erschlossen und reflektiert werden kann, wie z. B. Normvorstellungen über Geschlechterrollen.

148 In der neuropsychologischen Forschung wird davon ausgegangen, dass Menschen ihr Bewusstsein (Ebene 1) zu einem gegebenen Zeitpunkt auf maximal 7 Informationseinheiten richten können (vgl. Roche 2013: 65). Dies bedeutet, dass auch bei der aufmerksamen, bewussten Beschäftigung mit einem Thema (etwa über die Dauer einer Unterrichtsstunde hinweg) niemals lediglich Ebene 1, sondern immer auch ein zwischen den Ebenen 1 und 2 anzusiedelnder "Zwischenspeicher" involviert ist. Diese Überlegungen verdeutlichen die Anschlussfähigkeit des hier vorgeschlagenen 
Der Terminus ,Bewusstmachung' erscheint dann als zutreffend, wenn Wissen von den Ebenen 4 und 3 auf Ebene 2 unter Einbeziehung von Ebene 1 überführt wird. Hierbei spielt das Medium Sprache eine entscheidende Rolle, und zwar in mehrerlei Hinsicht:

Erstens ist davon auszugehen, dass Wissen nicht ontologisch gegeben, sondern intra- und intersubjektiv konstruiert ist. Der Gebrauch des Mediums Sprache im Fremdsprachenunterricht: der Fremdsprache - ist hierfür unverzichtbar (vgl. Dalton-Puffer 2013: 139; Gnutzmann 2010a: 16). Von bewusstem Lernen wäre in besonderem Maße dann auszugehen, wenn dieser Vorgang selbst reflektiert wird.

Daraus ergibt sich zweitens, dass die Rolle schüleraktivierender Unterrichtsverfahren zu betonen wäre, insbesondere im Hinblick auf die systematische Ermöglichung von Schüler-Schüler-Interaktionen in der Fremdsprache (vgl. Bonnet et al. 2009: 185-187).

Damit Lernende drittens eine Fremdsprachliche Diskursbewusstheit im Sinne der hier entwickelten theoretischen Überlegungen entwickeln können, benötigen sie das dafür notwendige terminologische und konzeptionelle Rüstzeug, und zwar sowohl in Bezug auf die in diesem Kapitel diskutierten Konzepte (Bewusstsein vs. Bewusstheit, etc.) also auch in Bezug auf die im vorhergehenden Kapitel entwickelten diskurstheoretischen Überlegungen.

Als Zwischenfazit lässt sich somit festhalten, dass Fremdsprachliche Diskursbewusstheit anzubahnen wäre, indem Diskurse und Praxen, die sich in fremdsprachigen Umgebungen manifestieren, durch Interaktionen in der Fremdsprache bewusst gemacht und auf ihre affektive, machtbezogene und sprachstrukturelle Dimension reflektiert werden.

Ich habe einen Leitbegriff, der für den deutschsprachigen Kontext von zentraler Bedeutung ist, in der hier geführten Diskussion bislang weitgehend ausgeblendet: Bildung. Ein Zielkonstrukt für die Fremdsprachendidaktik, wie es in dieser Arbeit entwickelt werden soll, ist jedoch auch in Bezug auf allgemeine bildungstheoretische Überlegungen $\mathrm{zu}$ reflektieren. Hierfür bietet sich ein bildungstheoretischer Entwurf an, der von der klassischen Bildungstheorie Humboldts ausgeht, jedoch zahlreiche neuere Ansätze verarbeitet, u.a. das bereits vorgestellte Konzept des Widerstreits von Jean-François Lyotard. Gemeint ist das von Hans-Christoph Koller entwickelte Konzept der transformatorischen Bildung, um das es im folgenden dritten und letzten theoriebildenden Teilkapitel gehen soll.

Ebenenmodells zu den Konzepten Ultrakurzzeitgedächtnis, Kurzzeitgedächtnis und Langzeitgedächtnis (vgl. ebd.), die jedoch gesondert zu erörtern wäre. 


\subsection{Zur Theorie transformatorischer Bildungsprozesse}

\subsubsection{Problemstellung der Theorie transformatorischer Bildungsprozesse}

Der Bildungsbegriff verfügt in der deutschsprachigen Diskussion über eine gut 200jährige Tradition und spielt als Leitkategorie in gesellschaftlichen Debatten bis heute eine wichtige Rolle. Als zentrales Konzept der Erziehungswissenschaften und später der verschiedenen Fachdidaktiken wurde er allerdings seit den 1960er-Jahren auch vielfach in Frage gestellt. Die Hauptargumente, die gegen ,Bildung' vorgebracht wurden und werden, lauten nach Einschätzung des Erziehungswissenschaftler Hans-Christoph Koller, dass es sich erstens um ein veraltetes Konzept handle, das zweitens für eine empirische Erforschung ungeeignet sei (vgl. Koller 2012: 10). Als Alternativen werden von den Kritikern, so Koller, „[...] (vermeintlich) anschlussfähigere Termini wie ,Qualifikation', ,Identität oder ,Autopoiesis" gefordert" (ebd.).

Dieser Liste wäre noch der Terminus ,Kompetenz' hinzuzufügen, der etwa seit der Jahrtausendwende wie kein anderer die pädagogische und didaktische auch: fremdsprachendidaktische - Diskussion prägt, den Koller jedoch an dieser Stelle nicht erörtert. ${ }^{149}$ Gerade in den Fremdsprachendidaktiken wird jedoch auch immer wieder auf den Bildungsbegriff zurückgegriffen, insbesondere dann, wenn es um die Beschreibung von Aspekten geht, die sich der Stufung und Messung entziehen und deswegen oft ,weiche' Kompetenzen genannt werden (vgl. Fäcke 2013). Hierzu zählen etwa der literarisch-ästhetische Bereich (vgl. Küster 2003b) oder die Reflexivität von - sprachlichen und sachfachlichen - Lernprozessen (vgl. Breidbach 2007).

Auch Koller widersetzt sich dem Trend, den Bildungsbegriff aus der Diskussion auszublenden. Er stimmt den Kritikern des Bildungsbegriffs zwar insofern $\mathrm{zu}$, als er ihn ebenfalls für veraltet hält, zumindest teilweise und in seiner klassisch-humanistischen Ausprägung. Im Hinblick auf die Notwendigkeit, dass eine pädagogische Leitkategorie nicht nur theoretisch beschrieben, sondern auch empirisch zugänglich gemacht werden muss, gibt er den Kritikern ebenfalls recht. Beide Probleme hält er jedoch auch auf Grundlage des Bildungsbegriffs für lösbar. Im Anschluss an Wolfgang Klafki und Jörg Ruhloff

149 Ein Überblick über den Diskussionsstand um den Kompetenzbegriff in den Fremdsprachendidaktiken findet sich bei Vollmer 2010b, ein aktueller Problemaufriss in Bezug auf literarisch-ästhetische Bildung bei Bonnet/Breidbach 2013. 
unterstreicht Koller (2012: 10) dabei einen Aspekt, den er für einen entscheidenden Vorteil des Bildungsbegriffs hält:

Zumindest unter den an dieser Debatte Beteiligten herrscht dabei die Einschätzung vor, der Bildungsbegriff sei für die Erziehungswissenschaft insofern unverzichtbar, als er (oder vielleicht genauer: die Bildungstheorie als Teildisziplin) jenen Ort darstellt, an dem über Legitimation, Zielsetzung und Kritik pädagogischen Handelns methodisch reflektiert gestritten werden kann und soll [...].

Die Kraft zur Bündelung einer notwendigen Debatte hat also, folgt man Kollers Argumentation, lediglich der Begriff Bildung, und darin könnte einer der Gründe liegen, warum er in der erziehungswissenschaftlichen Diskussion trotz aller Kritik seit etwa 1990 auch eine „Renaissance“ (ebd.) erlebe.

Kollers bildungstheoretische Überlegungen nehmen ihren Ausgang in der Auseinandersetzung mit einem Denker, der den Bildungsbegriff so entscheidend geprägt hat, dass sein Name bis heute mit ihm untrennbar verbunden ist: Wilhelm von Humboldt. Humboldts Bildungsverständnis beruht auf zwei Grundannahmen. Erstens stellt er in der Tradition des Humanismus den einzelnen Menschen ins Zentrum seiner Überlegungen. Dessen Zweck ist nach Humboldt (1960-1981, Bd. I: 64; vgl. Koller 2012: 11) „[...] die höchste und proportionirlichste Bildung seiner Kräfte zu einem Ganzen. “ Das vornehmste Ziel von Bildung ruht demnach im Menschen selbst, nicht etwa in seiner ökonomischen oder politischen Verwertbarkeit. Damit es zu dieser Bildung im Sinne einer Entfaltung der im Menschen angelegten „Kräfte“ kommen kann, sei jedoch die Auseinandersetzung mit der „Welt“ unabdingbar, in den Worten Humboldts (1960-1981, Bd. I: 235f; vgl. Koller 2012: 11) „[...] die Verknüpfung unsres Ichs mit der Welt zu der allgemeinsten, regesten und freiesten Wechselwirkung."

Die zweite von Humboldts Grundannahmen lautet nun, dass diese Wechselwirkung in erster Linie in Form von Sprache stattfinde, denn sie sei die wichtigste Mittlerin zwischen „Ich“ und „Welt“. Gleichzeitig ist für Humboldts Bildungskonzeption entscheidend, dass diese Vermittlung nicht im Sinne einer objektiven Repräsentation von „Ich“ bzw. „Welt“ erfolgt, sondern dass beide im Prozess der sprachlichen Vermittlung erst hervorgebracht werden. Humboldt (1960-1981, Bd. III: 426; vgl. Koller 2012: 12) nennt Sprache daher „das bildende Organ des Gedanken“. Der Doppelsinn zwischen genitivus subiectivus und genitivus obiectivus ist hier durchaus beabsichtigt. Zum einen ist Sprache das Werkzeug, über das die Gedanken verfügen, um sich selbst auszudrücken. Zum anderen werden die Gedanken selbst durch die Beschaffenheit der Sprache geprägt, derer sie sich lediglich zu bedienen glauben. 
Humboldt formuliert bereits hier Überlegungen, die im 20. Jahrhundert etwa für Ludwig Wittgensteins Sprachphilosophie oder für den Konstruktivismus zentral werden sollten. Auch bei Michel Foucault wird die Idee zentral sein, dass Sprache - bei Foucault: Sprache als Diskurs - keine einfache Abbildfunktion hat:

Tâche qui consiste à ne pas - à ne plus - traiter les discours comme des ensembles de signes (d'éléments signifiants renvoyant à des contenus ou à des représentations) mais comme des pratiques qui forment systematiquement les objets dont ils parlent. (Foucault 1969: 66f.)

Die Gesamtheit eines sprachlich verfassten Ensembles von Gedanken nennt Humboldt „Weltansicht“ (Humboldt 1960-1981, Bd. III: 434; vgl. Koller 2012: 13). Wenn Gedanken aber erst durch Sprache hervorgebracht werden können und Sprache ihrerseits die Beschaffenheit der Gedanken prägt, dann folgt daraus, dass unterschiedliche Sprachen auch unterschiedliche Gedanken hervorbringen. Das gleiche gilt für „Weltansichten“: Da sie in unterschiedlichen Sprachen gefasst sind, müssen sie sich zwangsläufig unterscheiden. Die Auffassung, dass mit jeder Sprache eine andere "Weltansicht“ einhergehe, legt nun im Hinblick auf Bildungsprozesse nahe, dass durch das Erlernen verschiedener Sprachen verschiedene "Weltansichten“ erschlossen werden können. Somit wird nachvollziehbar, warum Sprachen einen zentralen Platz in Humboldts Bildungstheorie einnehmen, denn durch sie werde dem Menschen „[...] der Reichthum der Welt und die Mannigfaltigkeit dessen, was wir in ihr erkennen [...] " (Humboldt 1960-1981, Bd. V: 111; vgl. Koller 2012: 13) erst zugänglich.

Die wichtigsten Anregungen, die Koller aus den bildungs- und sprachtheoretischen Arbeiten Humboldts bezieht, sind nun folgende: ${ }^{150}$

Erstens verdankt er Humboldt die Einsicht, dass „Weltansichten“ sprachlich verfasst sind. Koller fügt dieser Überlegung den Aspekt hinzu, dass für Bildungsprozesse nicht nur die „Weltansicht“ und damit das Verhältnis zur Welt von Interesse ist, sondern ebenso das Verhältnis zu sich selbst, und auch dieses ist damit sprachlich verfasst. Beide Perspektiven fasst er im Anschluss an Rainer Kokemohr in der Formel „Welt- und Selbstverhältnisse“ zusammen (Koller 2012: 16).

Zweitens kann Koller ausgehend von Humboldts und Kokemohrs Überlegungen eine erste Aktualisierung des Bildungsbegriffs formulieren. Während ,Lernen' innerhalb gegebener Welt- und Selbstverhältnisse stattfinde und diese nicht

150 Zu einer ausführlichen Diskussion der Humboldt'schen Sprach- und Bildungstheorie vgl. Koller 1997, 1999: 51-93. 
grundlegend verändere, könne von,Bildung 'nur dann die Rede sein, wenn diese Welt- und Selbstverhältnisse verändert, „transformiert“ werden (ebd.: 15). Diese Überlegung ist entscheidend für das Verständnis von Kollers Theorie transformatorischer Bildung. Er betont, dass er mit ihr nicht nur das Anliegen verfolgt, den traditionellen Bildungsbegriff neu und anders zu konzipieren. Gleichzeitig gehe es darum, Bildung selbst als „Andersdenken oder Anderswerden“ (ebd.: 9, Hervorhebung im Original) zu modellieren.

Wenn im Anschluss an Humboldt festgehalten werden kann, dass Welt- und Selbstverhältnisse sprachlich verfasst sind, und wenn Bildung in der Transformation dieser Welt- und Selbstverhältnisse besteht, dann liegt, so Koller weiter, in der Sprache auch ein vielversprechender Ansatz für die empirische Erforschung von Bildung. Über Sprache könnte der (qualitativ-)empirische Zugang zu jenen psychischen Transformationen möglich sein, die nach Koller Bildungsprozesse ausmachen.

Humboldts Bildungstheorie lässt jedoch aus Kollers Sicht auch einige Fragen offen (vgl. ebd.: 14f.). Die erste dieser Fragen betrifft die Auslöser von Bildungsprozessen. Wie müssen sie beschaffen sein, damit es in der Auseinandersetzung mit der Welt tatsächlich zu einer Transformation der „Weltansichten“ bzw. „Welt- und Selbstverhältnisse“ kommt? Die zweite Frage nimmt den Umstand in den Blick, dass Humboldts Bildungsverständnis möglicherweise von einem zu harmonistischen Verständnis der Differenzen zwischen verschiedenen „Weltansichten" ausgeht. Inwieweit können und sollten diese möglicherweise gar nicht zu einem „Ganzen“ gefügt werden? Bildung bestünde dann vielleicht vielmehr darin, die Differenzen zwischen verschiedenen Weltansichten zu erkennen und auszuhalten, anstatt sie miteinander zu versöhnen. Die dritte Frage an Humboldt betrifft schließlich den Bereich Empirie. Wie genau können Bildungsprozesse einer wissenschaftlichen Erforschung zugänglich gemacht werden?

Auf Grundlage dieser Problemstellung, die sich aus der neuen Lektüre der Humboldt'schen Schriften ergibt, formuliert Koller vier Ansprüche an eine Theorie transformatorischer Bildung (vgl. ebd.: 17f.). Eine solche Theorie müsse, erstens, bei einer Beschreibung der Struktur der Welt- und Selbstverhältnisse ansetzen. Zweitens müsse sie formulieren, welche „Problemlagen und Krisenerfahrungen“ (ebd.) Bildungsprozesse auslösen. Drittens müsse sie genau beschreiben, auf welche Art und Weise die Transformationsprozesse selbst ablaufen. Viertens schließlich müsse sie die Grundlage für eine empirische Erfassung der transformatorischen Bildungsprozesse legen.

Die Auseinandersetzung mit diesen Ansprüchen stellt das Kernanliegen von Kollers Theorieentwurf dar. Dieser steht im Zentrum der folgenden Abschnitte. 


\subsubsection{Grundzüge der Theorie transformatorischer Bildungsprozesse}

Koller entfaltet den Entwurf seiner Theorie transformatorischer Bildungsprozesse in vier Teilen, in denen die Möglichkeiten erörtert werden, die eingangs formulierten Ansprüche an eine solche Theorie einzulösen. Ich stelle diese Überlegungen in den folgenden Abschnitten überblicksartig und in der gebotenen Kürze dar. Im Anschluss an die Darstellung der Theorie transformatorischer Bildungsprozesse wird diese auf ihre Bedeutung für das im Rahmen dieser Arbeit zu entwickelnde Konzept der Fremdsprachlichen Diskursbewusstheit hin diskutiert.

Bezüglich der Strukturen von Welt- und Selbstverhältnissen diskutiert Koller die Gesellschaftstheorie Pierre Bourdieus, das Konzept der narrativen Identität, die strukturale Psychoanalyse nach Jacques Lacan sowie Judith Butlers Konzept der Subjektivation.

Bourdieu widmet sich in seinen soziologischen Studien der Frage nach dem Verhältnis von individuellem Handeln und gesellschaftlichen Vorgaben. ${ }^{151}$ Intuitiv scheint klar zu sein, dass Handeln niemals ganz individuell, aber auch niemals ganz sozial determiniert ist. Wie genau gestaltet sich nun das Verhältnis dieser beiden Pole? Nach Bourdieu spielt sich individuelles Handeln in der Tat innerhalb sozialer Vorgaben ab. Diese determinierten das Handeln zwar nicht, legten aber doch einen Rahmen fest, der einerseits bestimmte Verhaltensweisen ermögliche und andererseits - ein entscheidender Aspekt - bestimmte Alternativen ausschließe. Diesen Rahmen bezeichnet Bourdieu als ,Habitus. Das Habitus-Konzept stellt das gesuchte Bindeglied zwischen individuellem Handeln und gesellschaftlichen Vorgaben dar. Dass diese Vorgaben erfolgreich und zuverlässig, d. h. ohne permanente soziale Kontrolle, eingehalten werden, wird nach Bourdieu dadurch sichergestellt, dass Individuen sie verinnerlichen: „Histoire incorporée, faite nature, et par là oubliée en tant que telle, l'habitus est la présence agissante de tout le passé dont il est le produit [...]" (Bourdieu 1980: 94; vgl. Koller 2012: 25f.). Der Habitus sorge auf diese Weise dafür, dass individuelles Verhalten relativ unabhängig von unmittelbar einwirkenden Faktoren geschehe (indépendance relative, Bourdieu 1980: 94), wodurch Kontinuität entstehe. Zwar sieht auch Bourdieu eine wechselseitige Abhängigkeit zwischen Individuum und

151 Die für das Verständnis der Theorie transformatorischer Bildungsprozesse notwendige Wiedergabe der maßgeblichen Bezugstheorien stützt sich auf Kollers Rezeption, da nur diese für das hier entwickelte Anliegen von Interesse ist. Von Koller angeführte Zitate habe ich im Originalzusammenhang überprüft. 
Gesellschaft - ein Umstand, für den er die Formulierung „strukturiert-strukturierende Struktur" geprägt hat: ${ }^{152}$

Les conditionnements associés à une classe particulière de conditions d'existence produisent de habitus, systèmes de dispositions durables et transposables, structures structurées prédisposées à fonctionner comme structures structurantes,[...]. (ebd.: 88, Hervorhebung im Original)

Im Habituskonzept überwiegt nach Kollers Einschätzung daher die „Trägheit und Veränderungsresistenz" (Koller 2012: 27). Seine Bilanz lautet daher, dass das Habituskonzept in Bezug auf eine Bildungstheorie, die den Aspekt der Transformation in den Mittelpunkt stellt, nur bedingt fruchtbar sei. Wenn Bildung in der Transformation von Welt- und Selbstverhältnissen bestehe, wäre sie vielmehr "mit und gegen Bourdieu“ (ebd.: 28) als "Transformation des jeweiligen Habitus“ (ebd.: 28f, Hervorhebung im Original) zu begreifen. Eine solche Transformation ist jedoch im eher auf Bewahrung ausgerichteten Habituskonzept zunächst einmal nicht vorgesehen. Koller schätzt das Potential des Habitus-Begriffs zudem insofern als begrenzt ein, als Bourdieu auch einen Zusammenhang des Habitus mit dem Kapitalbegriff herstellt. Dies sei zwar im Hinblick auf die Offenlegung von Machtstrukturen, die sich nach Bourdieu durch die Anhäufung von ökonomischem, kulturellem und sozialem Kapital ergeben, von einigem Interesse. Die Überführung der Habitustheorie in eine Theorie transformatorischer Bildung habe aber insofern eine Grenze, als bei Bourdieu kulturelles und soziales Kapital mit ökonomischem Kapital unter einem Aspekt gleichgesetzt werden: Bei allen drei Formen von Kapital gehe es nach Bourdieu vorwiegend um eine (quantitative) Akkumulation mit dem Ziel, die persönliche Machtposition auszubauen. Koller zufolge erschwert aber eben dieser Aspekt in Bourdieus Gesellschaftstheorie den Versuch, soziales und kulturelles Kapital nicht nur im Hinblick auf ihre Quantität, sondern auch im Hinblick auf ihre Qualität und damit auf ihre mögliche Transformation hin zu analysieren (vgl. ebd.: 31 ).

Auf der Suche nach einer angemessenen Beschreibung von Welt- und Selbstverhältnissen nimmt Koller in einem nächsten Schritt den Begriff der Identität in den Blick, in dem er im Unterschied zum Habituskonzept auch für die „individuelle, psychische Seite des Welt- und Selbstbezugs" (ebd.: 34) ein vielversprechendes Potential sieht. Unter Rückgriff auf Klaus Mollenhauer betont

152 In Bezug auf das Verständnis von Kultur findet sich ein ähnlicher Gedanke in der bereits zitierten Metapher von Clifford Geertz (vgl. Kap. 1.2.), der diese als vom Menschen selbst gesponnenes Bedeutungsgewebe definiert hat, in das dieser selbst verstrickt ist. 
Koller, dass Identität eine Fiktion darstelle, bei der es sich im Grunde um eine „Einheit des Vielerlei“ (Mollenhauer 2008: 156; vgl. Koller 2012: 34) handle. ${ }^{153}$ Mollenhauer noch einmal zitierend, hebt Koller hervor, dass „eine so verstandene Identität 'in Fragen der Bildung des Menschen nur als Problem, nicht als Tatsache" zu verstehen sei. (ebd.) So könne weder in diachroner Perspektive, also über den Verlauf einer Biographie hinweg, noch in synchroner Perspektive, also etwa über verschiedene soziale Rollen hinweg, ohne weiteres von Identität ausgegangen werden (vgl. ebd.: 36f.). Wenn Identität aber nicht mehr als selbstverständlich gegebene Einheit einer Persönlichkeit angenommen werden kann, so stellt sich die Frage, wie es dennoch zu der Einheitlichkeit kommt, mit der wir uns selbst und andere wahrnehmen.

Auf der Beobachtung, dass diese Einheitlichkeit anscheinend durch den Vorgang des Erzählens hergestellt werden kann, beruht nun das Konzept der ,narrativen Identität. Koller stützt sich bei der Diskussion dieses Konzeptes vorwiegend auf die Arbeiten Paul Ricœurs und Guy Widdershofens (vgl. ebd.: 36ff.). Deren Kernthese laute, dass die Einheit der Person nicht empirisch vorhanden sei, sondern im Akt des Erzählens immer wieder neu performativ hergestellt werden müsse. Ähnlich wie bei Bourdieu findet sich auch in den Überlegungen zur narrativen Identität die Frage nach dem Zusammenhang zwischen individueller Erfahrung und sozialer Bedingtheit. Mögliche Diskrepanzen zwischen diesen beiden Wirkkräften werden nach Ricœur dadurch bewältigt, dass die individuelle Erzählung nicht frei von Vorgaben erfolge, sondern sich an narratologischen Konventionen orientiere. Zunächst disparate und chaotische Erlebnisse könnten von Menschen so in die Form einer für andere plausiblen Erzählung gebracht und dabei in eine sinnvolle Einheit überführt werden, und eben hierdurch entstehe narrative Identität. ${ }^{154}$ Entscheidend ist dabei, dass der performative Akt des identitätsstiftenden Erzählens nicht nur an andere gerichtet ist, die von der Erzählung überzeugt werden sollen, sondern dass auch der Erzählende selbst gewissermaßen zu seinem eigenen Zuhörer wird. Aus dem Konzept der narrativen Identität folgt daher, dass Ordnung, Sinn und Identität nicht in mehr oder weniger wahrheitsgetreuer Form durch Erzählungen weitergegeben

153 Identität als Einheitlichkeit der individuellen Psyche wird zunehmend auch auf dem Gebiet der Neurowissenschaften in Frage gestellt (vgl. Gazzaniga 2012).

154 Die Ordnung stiftende Funktion jeder Narration wurde u.a. in Byrons Don Juan thematisiert und im Englischen zum geflügelten Wort („Truth is stranger than fiction“.) Spätere humoristische Zuspitzungen werden Mark Twain und Tom Clancy zugeschrieben („The difference between fiction and reality? Fiction has to make sense!"). 
werden, denn dafür müssten sie schon vor dem Akt des Erzählens ontologisch vorhanden sein. Vielmehr entstehen sie erst in diesem Akt des Erzählens - als Narration und Selbst-Narration.

Wenn Bildung in der Transformation von Welt- und Selbstverhältnissen stattfindet, diese jedoch maßgeblich in Form von Narrationen konstituiert sind, dann müssten, so folgert Koller, Narrationen in einer Theorie transformatorischer Bildung eine zentrale Rolle spielen (ebd.: 44). Sie könnten nicht nur wertvolle Hinweise in Bezug auf die Struktur der jeweiligen Welt- und Selbstverhältnisse bereithalten. Vielmehr wäre auch zu vermuten, dass transformatorische Bildungsprozesse zu Bruchstellen in den sozial vorgegebenen Erzähl-Genres führen. Narrationen könnten daher sowohl Hinweise auf Anlässe von Bildungsprozessen liefern als auch, da sie sprachlich verfasst sind, den empirischen $\mathrm{Zu}$ griff ermöglichen. ${ }^{155}$

Auf der Grundlage dieser für Koller zumindest vorläufig zufriedenstellenden Analyse der Struktur von Welt- und Selbstverhältnissen lautet die nächste Frage, der er sich ausführlich widmet, welche Anlässe das Potential haben könnten, deren Transformation auszulösen. Hierfür diskutiert er zwei Ansätze, welche der Vermutung nachgehen, dass hierfür vor allem krisenhafte Erfahrungen in Frage kommen: Günter Bucks Konzept der, negativen Erfahrung und Bernhard Waldenfels' Konzept der ,Erfahrung des Fremden'. Eine weitere Spur, der Koller aus der Suche nach Anlässen für Transformationen nachgeht, ist Jean-François Lyotards Philosophie des Widerstreits, ein Ansatz, den er zuvor bereits in seiner Habilitationsschrift ausführlich und ebenfalls vor dem Hintergrund der Humboldt'schen Bildungstheorie rezipiert und für bildungstheoretische Diskurse fruchtbar gemacht hat (vgl. Koller 1999: 23-49).

Buck entwickelt sein Konzept der negativen Erfahrung auf Grundlage der Hermeneutik, von der er die Position übernimmt, dass menschliche Erfahrung immer vor einem ,Erwartungshorizont' stattfinde. Durch das Vorhandensein eines Horizonts werde Erfahrung erst möglich, und gleichzeitig haben Erfahrungen das Potential, Horizonte zu verändern. Was geschieht aber, wenn sich eine Erfahrung nicht in Erwartungen einfügen lässt, die durch einen vorhandenen und bekannten Horizont gegeben sind? Hierfür prägt Buck den Begriff der ,negativen Erfahrung. Koller (2012: 76) fasst diese Überlegungen Bucks mit den Worten zusammen, dass durch eine solche negative Erfahrung „[...], hinter ${ }^{c}$ dem

155 Da die Überlegungen zur strukturalen Psychoanalyse nach Jaqcques Lacan und zum Konzept der Subjektivation nach Judith Butler in der Theorie transformatorischer Bildungsprozesse lediglich eine marginale Rolle spielen, werden sie hier nicht dargestellt. 
bisherigen, nun negierten Horizont ein neuer Horizont auftaucht, der einen adäquateren Rahmen für das Verständnis des Gegenstandes bietet. “156

Das Potential dieses Ansatzes für eine Theorie transformatorischer Bildung liegt auf der Hand. Koller (2012: 77, Hervorhebung im Original) resümiert:

So könnte man sagen, dass das Welt- und Selbstverhältnis der Subjekte, die einen transformatorischen Bildungsprozess durchlaufen, durch bestimmte Problemlagen negiert, d.h. in Frage gestellt, destabilisiert oder gar völlig außer Kraft gesetzt wird. Und der Transformationsprozess, aus dem neue, zur Problembearbeitung besser geeignete Figuren des Welt- und Selbstverhältnisses hervorgehen, ließe sich mit Buck als Horizontwandel bzw. als zweite, absolute Negation begreifen.

Dies mache vor allem deutlich, dass Bildung in Abgrenzung von Humboldt nicht etwa als harmonischer Vorgang zu begreifen sei, sondern vielmehr als „[...] radikale Infragestellung bisheriger Welt- und Selbstverhältnisse erscheint und somit das Krisenhafte und Riskante an Bildungsprozessen betont wird“ (ebd.: 78).

Ähnlich wie Bucks Konzept der ,negativen Erfahrung' beschäftigt sich auch Waldenfels' Konzept der ,Erfahrung des Fremden' mit der Frage, wie Menschen mit Erfahrungen umgehen, die sich zunächst einmal nicht in ihre bestehenden Welt- und Selbstverhältnisse einordnen lassen. Koller untersucht daher auch diesen Ansatz auf sein mögliches Potential für eine Theorie transformatorischer Bildungsprozesse. Zentral sei dabei der von Waldenfels hervorgehobene Aspekt, dass Fremdheit nie ein absolutes, sondern immer ein relationales Verhältnis darstelle. Das Fremde zeichne sich dadurch aus, dass es eine bedrohliche oder verlockende „Beunruhigung“ (ebd.: 83) auslösen könne. Koller sieht daher in der ,Erfahrung des Fremden' eine „typische Herausforderung für transformatorische Bildungsprozesse" (ebd.: 85). Über Waldenfels hinausgehend und im Anschluss an Julia Kristeva unterstreicht Koller (ebd.: 83, Hervorhebung im Original) zudem, dass Fremdheitserfahrungen sowohl zwischen als auch innerhalb von Individuen auftreten können: „In diesem Sinne lässt sich sagen, dass Fremdes sowohl inter-als auch intrapersonell - und ebenso inter- wie intrakulturell - in Erscheinung treten kann" (vgl. Kap. 3.2.2.).

Der dritte theoretische Ansatz, dem Koller auf der Suche nach Anlässen für transformatorische Bildungsprozesse nachgeht, ist die Diskurstheorie des französischen Philosophen Jean-François Lyotard. Dieser geht in seinen beiden zentralen Schriften Das postmoderne Wissen (La condition postmoderne, 1979) und

156 Zwischen dem Begriff der,Erfahrung ' und dem konstruktivistischen Begriff der,Perturbation' tut sich eine interessante Parallele auf, der Koller jedoch nicht nachgeht. Gleiches gilt für die ,Erfahrung des Fremden' nach Waldenfels (s. u.). 
Der Widerstreit (Le différend, 1983) von der Annahme aus, dass Wahrheit durch die Verkettung von Sätzen nach bestimmten Regeln eines Sprachspiels erzeugt wird. Die höhere Ordnungsebene dieser Sprachspiele nennt Lyotard Diskursart. ${ }^{157}$ Lyotard betont, dass in der Postmoderne eine, große Erzählung, eine MetaDiskursart, die alle anderen Diskursarten zu ordnen in der Lage wäre, nicht mehr gegeben und auch nicht mehr zu vertreten sei. Vielmehr sei von der Existenz verschiedener, prinzipiell gleichwertiger, potentiell inkommensurabler Diskursarten auszugehen. Heutige plurale Gesellschaften müssten sich daher darum bemühen, auch eine Pluralität von Diskursarten anzuerkennen. Den Gegensatz zwischen verschiedenen inkommensurablen Diskursarten nennt Lyotard différend (,Widerstreit'). Statt diesen différend zu akzeptieren und offenzuhalten, werden Konflikte jedoch häufig, so Lyotard, von einem différend in einen litige (,Rechtsstreit') umgewandelt und auf diese Weise beigelegt. Anstelle der ethisch gebotenen Akzeptanz von Pluralität bedeute dies aber, dass sich eine Diskursart auf Kosten anderer Diskursarten durchsetze:

A la différence d'un litige, un différend serait un cas de conflit entre deux parties (au moins) qui ne pourrait pas être tranché équitablement faute d'une règle de jugement applicable aux deux argumentations. (Lyotard 1983: 9)

Für eine Theorie transformatorischer Bildung sind Lyotards Überlegungen nach Kollers Einschätzung von großem Interesse, und zwar nicht, weil sie sich gut integrieren ließen, sondern vielmehr, weil sie eine radikale Herausforderung an bildungstheoretische Diskurse insgesamt darstellten. Da Bildungstheorien ebenfalls Diskursarten seien, lege der Gedanke des Widerstreits zwischen Diskursarten nämlich die Frage nahe, ob nicht auch sie lediglich weitere Sprachspiele darstellten. In diesem Fall seien sie als "große Erzählungen“ zu betrachten, da sie "pädagogisches Wissen und pädagogisches Handeln zu legitimieren versuchen“ (ebd.: 95). In diesem Licht wären auch Bildungsdiskurse, so Koller, konsequent im Hinblick auf die Bewahrung eines différend auszurichten. Hierfür sei eine Neuausrichtung des Bildungsbegriffs in folgendem Sinne notwendig:

Meine bildungstheoretische Schlussfolgerung aus diesen Überlegungen läuft nun auf den Vorschlag hinaus, die ethische Dimension bei Lyotard als Ausgangspunkt für eine Neufassung des Bildungsbegriffs zu nehmen und Bildung als jenen Prozess der Entstehung neuer Sätze und Diskursarten zu begreifen, der zur Anerkennung und zum Offenhalten des Widerstreits erforderlich ist. Auf eine Formel gebracht lässt sich die

157 Es handelt sich jeweils um die höchste Ordnungsebene. In der hier vorgeschlagenen Terminologie wären dies im Anschluss an Foucault und Fairclough Diskursordnungen (vgl. Kap. 4.2.4.). 
Transformation von Welt- und Selbstverhältnissen im Anschluss an Lyotard mithin als ein innovatorisches bzw. paralogisches Sprachgeschehen beschreiben, bei dem neue sprachliche Möglichkeiten ge- oder erfunden werden, um dem Widerstreit der Diskursarten gerecht zu werden. (Koller 2012: 97)

Wenn nun ein Anlass für eine Transformation von Welt- und Selbsthältnissen vorliegt - in der Regel durch eine krisenhafte Erfahrung, die als ,negative Erfahrung', als Fremdheitserfahrung oder als Unvereinbarkeit von Diskursarten beschrieben werden kann -, wie genau entsteht aus dieser Situation etwas Neues? Dieser Frage widmet sich Koller im dritten Teil seiner Überlegungen. Er unterteilt diese im Hinblick auf die Entstehung neuen Wissens, auf die Entstehung neuer Interaktionsstrukturen und auf die Entstehung neuer Lesarten (vgl. ebd.: 101-135). Ich beschränke mich hier auf die Darstellung der Erkenntnisse, die Koller aus dem Werk von Charles Sanders Peirce sowie aus Judith Butlers Konzept der Resignifizierung gewinnt und in seinen Entwurf einer Theorie transformatorischer Bildung integriert.

Neues Wissen entstehe nach Peirce auf drei unterschiedliche Arten: erstens durch Induktion, worunter das Formulieren einer allgemeinen Regel auf Grundlage eines Falls zu verstehen sei; zweitens durch Deduktion, worunter die $\mathrm{Zu}$ ordnung eines Falles zu einer allgemeinen Regel zu verstehen sei (ebd.: 109). Lediglich die dritte Form der Erkenntnisgewinnung bringe jedoch wirklich neues Wissen hervor. Für sie prägt Peirce den Begriff der ,Abduktion' Unter Abduktion versteht Peirce eine „[...] Operation, die eine neue Regel für ein bislang unerklärbares Phänomen findet" (ebd.: 110). Dies ist für Koller im Hinblick auf transformatorische Bildungsprozesse in zweierlei Hinsicht von Interesse: Erstens sei für ihr Zustandekommen auf Grundlage von Abduktionen die „[...] habituelle Bereitschaft [notwendig], eigene Überzeugungen in Frage zu stellen" (ebd.: 111). Zudem sei entscheidend, dass Abduktionen „[...] Spielräume für experimentierendes Handeln benötigen, die frei von rationaler Steuerung und externer Erfolgskontrolle sind“ (ebd.).

Auf der Suche nach einer angemessenen Beschreibung für die Entstehung von Neuem in transformatorischen Bildungsprozessen beschäftigt Koller sich schließlich mit Judith Butlers Konzept der, Resignifizierung. Butler entwickelt es auf der Grundlage von John Langshaw Austins Sprechakttheorie und illustriert es am Beispiel des hasserfüllten Sprechens (hate speech). Sprache hat offensichtlich das Potential, zu erniedrigen und zu verletzen, aber hat sie auch das Potential, so die Ausgangsfrage, sich gegen die Absichten von hasserfülltem Sprechen zur Wehr zu setzen? Im Kontext der Sprechakttheorie stellt sich an dieser Stelle erneut die Frage nach der sozialen Verfasstheit von Diskursen und „[...] nach 
den Bedingungen der Möglichkeit dafür, dass Subjekte innerhalb einer gegebenen gesellschaftlichen und politischen Ordnung verändernd wirksam werden können“ (ebd.: 131). Es ist dieses Potential im Hinblick auf Veränderungen von Konventionen, die Judith Butlers Ansatz für eine Theorie transformatorischer Bildungsprozesse interessant machen. Dessen Potential liegt nach Koller insbesondere darin, dass Butler die performative Wiederholung von Sprechakten hervorhebe. Da solche Wiederholungen prinzipiell auch als Resignifizierung erfolgen können, enthielten sie daher die "Chance einer Transformation“ (ebd.). Solche Transformationen seien etwa dann zu beobachten, wenn diskriminierte Minderheiten abwertende Bezeichnungen mit Stolz verwenden und so deren performative Wirkung umdeuten.

Butlers Konzept der Resignifizierung unterscheidet sich in einem wichtigen Punkt von den bis zu dieser Stelle rezipierten Ansätzen von Buck, Waldenfels, Lyotard und Peirce. Diese hatten Koller zu dem Zwischenergebnis geführt, dass Bildungsprozesse als tendenziell tiefe Brüche in Welt- und Selbstverhältnissen zu modellieren seien, als „Außerkraftsetzen einer Ordnung“ (ebd.: 85), als „absolute Negation“ (ebd.: 77), die durch „Überraschung oder sogar existenzielle Erschütterung" (ebd.: 110) ausgelöst werde. Im Gegensatz dazu lassen sich auf Grundlage von Butlers Überlegungen transformatorische Bildungsprozesse auch als allmähliche, kleinschrittige Vorgänge beschreiben:

Das Neue wäre demzufolge also nicht das ,ganz andere', völlig Unbekannte, Noch-nieDagewesene, sondern vielmehr eine Wiederholung des schon Vorhandenen, die das Wiederholte in einen anderen Kontext versetzt und so in seiner Bedeutung verschiebt. (ebd.: 135)

Hierdurch werde die Entstehung des Neuen „entmystifiziert“ (ebd.), und gleiches gelte für transformatorische Bildungsprozesse, die an das Konzept der Resignifizierung anknüpfen. Das Neue entstehe dabei durch Anregungen aus der „[...] diskursive[n] Außenwelt, die gleichsam die Stichworte liefert, die in den resignifizierenden Praktiken (fehl-)angeeignet werden können“ (ebd.). Ähnlich wie der Ansatz der narrativen Identität weisen auch diese Überlegungen auf Möglichkeiten der empirischen Erforschung transformatorischer Bildungsprozesse hin, die Koller im letzten Teil seines Theorieentwurfes erörtert.

Nachdem die Strukturen von Welt- und Selbstverhältnissen aus Kollers Sicht hinreichend beschrieben und die Anlässe und die möglichen Ergebnisse ihrer Transformation diskutiert sind, münden die Überlegungen zu einer Theorie transformatorischer Bildungsprozesse schließlich in Fragen zur deren empirischer Erforschung. Hierbei befasst er sich zunächst damit, „unterschiedliche Formen pädagogischen Wissens" (ebd.: 141) voneinander abzugrenzen. Im 
Anschluss an einen Vorschlag Peter Vogels unterscheidet er dabei „Empirische Erziehungswissenschaft“, „normatives oder handlungsleitendes Wissen“ sowie "Theoretische Erziehungswissenschaft", eine Wissensform, für die er alternativ die Bezeichnung „Reflexives Wissen“ vorschlägt (vgl. ebd.). Diese Formen des Wissens seien im Sinne Lyotards als unterschiedliche Diskursarten zu verstehen. Daraus folge, dass ihr Verhältnis als das eines Widerstreits aufzufassen und damit möglicherweise nicht auflösbar sei.

Diese Vorüberlegungen zur empirischen Erforschung transformatorischer Bildungsprozesse sind von erheblicher Tragweite für Kollers Theorieentwurf: Zum einen erteilt er mit ihnen jeglicher Vereinnahmung reflexiver Theoriebildung im Hinblick auf ihre (v.a. quantitativ-)empirische Verwertbarkeit eine Absage. Zum anderen macht er damit die Grenzen des eigenen Vorhabens deutlich, denn auch bei der Überführung einer reflexiven Bildungstheorie in eine qualitative Studie solle man nicht den Fehler begehen „[...] so zu tun, als könne sie [...] die soziale Wirklichkeit von Bildung [...] angemessen oder gar vollständig und ohne Rest erfassen“ (ebd.: 147f, Hervorhebung im Original). Hierfür gebe es mindestens zwei Gründe:

Erstens sei auch mit solchen „[...] Aspekte[n] des Bildungsgeschehens [zu rechnen], die sich empirischer Identifizierung möglicherweise völlig entziehen [...] (ebd.: 148), also sowohl einem quantitativen als auch einem qualitativen Zugriff. Zweitens sei zu berücksichtigen, dass „[...] aufgrund der sozialen Normativität und der Adressierungsstruktur jeder Narration lebensgeschichtlichen Erzählungen notwendigerweise entscheidende Momente oder Aspekte ihres Referenten entgehen" (ebd.: 149). Auch empirische Forschung im qualitativen Paradigma produziert demnach unvermeidlicherweise blinde Flecken, weil in Narrationen ebenfalls nur ein ausschnitthaftes Bild entsteht, das - ich ergänze möglicherweise nur partiell ausgewertet wird.

Für den Zugriff auf transformatorische Bildungsprozesse setzt Koller nun im Anschluss an die Arbeiten Rainer Kokemohrs und Winfried Marotzkis auf biographische Verfahren (vgl. ebd.: 154). Für diese empfiehlt er das narrationsanalytische Auswertungsverfahren nach Fritz Schütze, das im Gegensatz zu ähnlichen Vorgehensweisen vor allem den Vorteil aufweise, dass „[...] das erhobene Material [...] in seiner tatsächlichen sequenziellen Struktur ausgewertet" (ebd.: 155) werde. Dieses Verfahren sei noch im Hinblick auf einen wichtigen Aspekt zu erweitern. Während biographische Verfahren lediglich darauf ausgerichtet sind, Prozesse im Rückblick zu rekonstruieren, seien doch potentiell auch solche Bildungsprozesse von Interesse, die sich „[...] in der Erzählgegenwart, also 
während des biographischen Interviews selber vollziehen [...]“ (ebd.: 156, Hervorhebung im Original).

Bei der Auswertung sei im Hinblick auf die Transformationen selbst besonders auf „[...] Brüche und auf die Wahl neuer, bisher nicht realisierter Handlungsmöglichkeiten [...]“ (ebd.: 165) zu achten. Zudem seien auch kleine Änderungen in Welt- und Selbstverhältnissen sichtbar zu machen. Hierfür empfiehlt Koller (ebd.: 165) unter Rückgriff auf Judith Butlers Konzept der Resignifizierung, auch auf feine Bedeutungsverschiebungen zu achten:

Methodisch folgt daraus, dass es darauf ankommt, zu untersuchen, inwiefern Sprecherinnen oder Sprecher in einem jeweils bestimmten Kontext (wie z.B. einem biographischen Interview) kulturell bereitliegende Muster aufgreifen, aber durch die Art und Weise der Kontextualisierung in ihrer Bedeutung verändern und so neue Bedeutungen hervorbringen.

Schließlich sei auch der Rückgriff auf Lyotards Diskursbegriff in methodologischer Hinsicht von Gewinn. Koller grenzt sich hierfür von Kokemohrs Vorgehen bei der empirischen Auswertung einer Diskussion zwischen afrikanischen und europäischen Wissenschaftlern über Rassismus ab. Kokemohr führt dort das Scheitern der Interaktion auf die Fremdheit zwischen den Interaktionspartnern zurück, die sich aus ihrer jeweiligen Herkunft ergebe. Koller schlägt dagegen vor, den Teilnehmern der Diskussion nicht kultur- bzw. herkunftsbedingte Fremdheit, sondern eine gemeinsame Diskursart zu unterstellen: die der wissenschaftlichen Rede. Das Scheitern wäre dann vielmehr auf einen weder von den Beteiligten noch von Kokemohr wahrgenommenes ,etwas “ zurückzuführen, das nur in einer anderen Diskursart überhaupt gesagt werden könnte. Dieses „etwas“ komme „[...] deshalb nur indirekt (etwa in Intonation und Sprechgeschwindigkeit) zum Ausdruck [...]“ (ebd.: 164). Daher führe das Konzept des Widerstreits nach Lyotard zu einem größeren Erkenntnisgewinn, während das von Kokemohr verwendete Konzept der Transkulturalität zumindest in diesem Beispiel eine „[...] kulturalisierende Reduktion der Interaktionspartner auf ihre jeweilige Herkunftskultur [...]“ (ebd.: 163) verursache. ${ }^{158}$

Auch diese Überlegungen spielen für Koller (ebd.: 164) im Hinblick auf die empirische Analyse transformatorischer Bildungsprozesse eine wichtige Rolle:

Die Suche nach Fremdheitserfahrungen in einem empirischen Dokument hätte [...] nicht von personalen Instanzen, sondern von Diskursen auszugehen und danach zu fragen, wo und wie sich in einer Diskursart Fremdes zeigt, indem es sich den Regeln dieser

158 Zum Begriff der Transkulturalität vgl. Kap. 2.1.5. Zur unbeabsichtigten Kulturalisierung vgl. Kap. 3. 
Diskursart entzieht. Auf diese Weise entkäme man der problematischen Tendenz, das Eigene und das Fremde mit personalen Instanzen gleichzusetzen, und wäre in der Lage, auch intrasubjektive bzw. intrakulturelle Fremdheitserfahrungen analysieren zu können.

Die somit gelegten theoretischen Grundlagen einer transformatorischen Bildungstheorie wendet Koller schließlich exemplarisch auf einen Text an. Er wählt zu diesem Zweck jedoch nicht, wie es zu erwarten wäre, empirisch erhobene Daten. Vielmehr entscheidet er sich für eine Analyse des Romans Die Selbstmordschwestern von Jeffrey Eugenides (The Virgin suicides, 1993). Diese Textauswahl ist in doppelter Hinsicht originell: erstens, weil es sich um einen literarischen Text handelt, der, zweitens, gerade nicht als Bildungsroman im Sinne einer erfolgreichen Transformation von Welt- und Selbstverhältnissen gelten kann. Es sind gerade solche gescheiterten Bildungsprozesse, die Koller interessieren, denn sie erfüllen seiner Einschätzung nach in besonderem Maße seine selbst aufgestellt Forderung, dass „[...] die Erforschung transformatorischer Bildungsprozesse selbst einen Bildungsprozess darstellen sollte [...]“ (Koller 2012: 172).

Im Zentrum des Romans stehen fünf Schwestern, die zu Beginn der 1970erJahre in einer amerikanischen Kleinstadt in einer streng religiösen Familie aufwachsen. Sie nehmen sich alle das Leben, zuerst eine der Schwestern, dann, im Abstand von etwa einem Jahr, in einem kollektiven Selbstmord auch die anderen vier Schwestern. Um einen Bildungsroman handelt es sich aus Kollers Sicht nun insofern, als die Handlung aus der Perspektive verschiedener Schulfreunde der Schwestern erzählt wird. Für sie können die Selbstmorde im Sinne der entwickelten theoretischen Grundlagen Bildungsprozesse in Gang setzen, da sie eine radikal neue Erfahrung darstellen und somit eine Transformation der bisherigen Welt- und Selbstverhältnisse erfordern. Genau daran arbeiten sich die Bewohner der Kleinstadt im Laufe des Romans ab. Sie ziehen verschiedene Erklärungsansätze in Betracht, mit deren Hilfe die schrecklichen Ereignisse erklärbar, nachvollziehbar und damit weniger bedrohlich werden könnten. Koller (ebd.: 181) deutet dies als Versuche, die Selbstmorde in bestehende Diskurse zu integrieren:

Die Reihe der diskursiven Ordnungen [...] reicht dabei vom Alltagsbewusstsein, das Selbstmord als eine ansteckende Krankheit auffasst, mit der die Schwestern infiziert worden seien, über religiöse und politische Weltanschauungen bis zu (pseudo-)wissenschaftlichen Diskursen wie der Rede vom wachsenden Stress, dem Adoleszente ausgesetzt seien, oder von der kurz bevorstehenden Entdeckung eines, Gen[s] für Selbstmord $[\ldots]$.

Die Integration der Ereignisse in solche bestehenden Diskurse könnte aus bildungstheoretischer Perspektive als erfolgreiche Transformation von Welt- und Selbstverhältnissen gedeutet werden. Die Pointe des Romans, auch im Hinblick 
auf Kollers Theorieentwurf, liegt nun darin, „[...] dass all diese Erklärungsversuche nicht nur ausführlich referiert, sondern jeweils auch [...] in ihrem Scheitern vorgeführt werden“ (ebd.: 181). Insofern erfüllt Eugenides’ Roman die Anforderung an ein Beispiel für transformatorische Bildungsprozesse und weist gleichzeitig über ein solches hinaus:

Vielleicht $[\ldots]$ besteht Bildung ja weniger in dem abgeschlossenen Vorgang der Ersetzung eines etablierten durch ein neues Welt- und Selbstverhältnis als vielmehr in einem unabschließbaren Prozess der Infragestellung oder Verflüssigung bestehender Ordnungen und eines Anderswerdens mit offenem Ausgang. (ebd.: 169, Hervorhebung im Original)

Somit scheint auch Koller selbst, zumindest jedoch sein Theorieentwurf, eine Transformation durchlaufen zu haben. Koller reformuliert seinen theoretischen Entwurf daher abschließend noch einmal:

Vielleicht wäre Bildung vor diesem Hintergrund nicht mehr zu begreifen als der Prozess einer produktiven Verarbeitung, die das Scheitern bzw. die Negativität überwinden oder ,aufheben' könnte, sondern als eine Art schwer zu beschreibender Doppelbewegung. Diese doppelte Bewegung bestünde darin, einerseits Fremdheitserfahrungen, Scheitern und Negativität als unhintergehbare conditio humana anzuerkennen, sie aber andererseits dennoch als Herausforderung ernst zu nehmen, die uns nötigt, nach einer Antwort zu suchen, die sich nicht auf deren resignierte Hinnahme beschränkt. (ebd.: 184)

In den folgenden Abschnitten ist nun zu erörtern, inwieweit das hier entwickelte Konzept einer fremdsprachlichen Diskursbewusstheit durch Kollers Theorie transformatorischer Bildung erweitert und präzisiert werden kann. Da es sich dabei um eine Theorie handelt, die theoretische Einflüsse aus verschiedenen Disziplinen integriert, bietet es sich an, die Erörterung an diesen Einflüssen entlang aufzubauen.

\subsubsection{Zur Bedeutung der Theorie transformatorischer Bildungsprozesse für die Fremdsprachliche Diskursbewusstheit}

In den folgenden Abschnitten soll die Bedeutung von Kollers oben ausführlich dargestellter Theorie transformatorischer Bildungsprozesse für das hier vorgeschlagene Konstrukt Fremdsprachliche Diskursbewusstheit diskutiert werden. Hierfür werden, erstens, die wichtigsten der von ihm rezipierten theoretischen Grundlagen erörtert. Zweitens soll eine kritische Beleuchtung der von Koller auf dieser Grundlage entwickelten weiterführenden Überlegungen erfolgen.

Ich beginne mit den sprachphilosophischen Überlegungen Wilhelm von Humboldts, bei denen auch Kollers Theorieentwurf ansetzt. Die interkulturell ausgerichtete Fremdsprachendidaktik fußt auf der Prämisse, dass ,(National-) 
Sprache' und ,(National-?)Kultur' dicht vernetzt seien. Hieraus wird abgeleitet, dass immer dann, wenn sprachliche Fremdheit auftritt, auch mit kultureller Fremdheit zu rechnen sei. Solche Fremdheit liege beispielsweise dann vor, wenn eine Person, deren L1 Deutsch ist, mit einer anderen Person interagiert, deren L1 Englisch, Französisch, Spanisch usw. ist. Der zwingende Umkehrschluss dieser Position lautet, dass mit geringerer kultureller Fremdheit zu rechnen wäre, wenn sich zwei Personen mit der gleichen L1 begegnen.

Aus dem Werk Humboldts scheint sich diese Prämisse der interkulturellen Fremdsprachendidaktik zunächst theoretisch begründen zu lassen, denn er schreibt, dass sich aus der Vielfalt der Sprachen zwangsläufig eine „Verschiedenheit der Weltansichten“ (Humboldt 1960-1981, Bd. III: 20; vgl. hierzu auch Koller 2012: 13) ergebe. In jeder dieser Sprachen „[...] [stehen] neue Arten zu denken und empfinden [...] vor uns da" (Humboldt 1960-1981, Bd. V: 111). Humboldt folgert aus dieser Feststellung, dass die Beschäftigung mit fremden Sprachen eine besondere Bedeutung für individuelle Bildungsprozesse habe. Somit scheint sich mit Humboldts Sprachphilosophie die zumindest tendenzielle Gleichsetzung von Sprache und Kultur rechtfertigen zu lassen, mit welcher in der interkulturellen Fremdsprachendidaktik häufig gearbeitet wurde und wird.

Entscheidend ist an dieser Stelle jedoch zu bedenken, dass Humboldts Überlegungen keineswegs bei der oben zitierten Gleichsetzung von (National-)Sprache und (National-)Kultur enden. Er schreibt weiter:

Eine Nation hat freilich im Ganzen dieselbe Sprache, allein schon nicht alle Einzelnen in ihr [...] ganz dieselbe, und geht man noch weiter in das Feinste über, so besitzt wirklich jeder Mensch seine eigne. (Humboldt 1960-1981, Bd. III: 228)

Somit kann mit Humboldt argumentiert werden, dass sprachliche Grenzen und mit ihnen Grenzen zwischen,Weltansichten' - nicht nur zwischen, sondern auch innerhalb von Nationalsprachen verlaufen. Mit kultureller Fremdheit wäre daher nicht nur, und nicht einmal in besonderem Maße, zwischen den Angehörigen von Großgruppen, wie sie Nationen darstellen, sondern auch zwischen Angehörigen von Gruppen innerhalb dieser Nationen und in letzter Konsequenz zwischen allen Menschen zu rechnen. ${ }^{159}$ Das Problem, dass Kulturen, aus deren Aufeinandertreffen interkulturelle Situationen entstehen, hierfür zunächst voneinander abgegrenzt werden müssten, bleibt somit bestehen (vgl. Rathje 2006). Der Versuch, es durch die Gleichsetzung von (National-)Sprache und (National-)

159 Wie in Kap. 3.2.2. ausgeführt, hat Julia Kristeva diesen Gedanken in der Tradition der Psychoanalyse noch einen Schritt weiter geführt und hervorgehoben, dass nicht nur interpersonal, sondern auch intrapersonal mit Fremdheitserfahrungen zu rechnen sei. 
Kultur zu lösen, ist auch im Licht der Humboldt'schen Sprachphilosophie nicht überzeugend. In besonderem Maße gilt dies für die in Deutschland dominierenden Schulfremdsprachen Englisch, Französisch und Spanisch, die bekanntlich nicht mehr nur in den jeweiligen kolonialen Mutternationen, sondern in einer Vielzahl von Staaten Amts- und Verkehrssprachen sind. Mit Humboldt lässt sich somit argumentieren, dass die L1 eines Menschen kaum Information darüber enthält, mit welcher „Weltansicht“ bei ihm oder ihr zu rechnen ist. Der Umgang mit Fremdheit wäre daher nicht mehr vorwiegend im Fremdsprachenunterricht, sondern ebenso in den nicht-fremdsprachlichen Schulfächern anzubahnen, wie z.B. dem Deutsch- oder Geschichtsunterricht, dem Chemie- oder Biologieunterricht.

Wenn „Sprache“ und „Nation“ sich jedoch als unzuverlässige Indikatoren von Fremdheit zeigen, bleibt am anderen Ende der Skala ein extremer Individualismus, auf dessen Grundlage immer von Fremdheit zwischen (individuellen) Weltansichten auszugehen wäre. ${ }^{160}$ Dem würde jedoch die offensichtliche Existenz von Gruppen widersprechen, welche Bedeutungen, „Weltansichten“ teilen. Beispiele hierfür wären Religionen und Konfessionen, politische Parteien und Parteiflügel, wissenschaftliche Disziplinen und Forschungsrichtungen, etc. Es scheint vielversprechend, diese geteilten Bedeutungen nicht an Nationalsprachen oder Staatsangehörigkeiten festzumachen, sondern an Diskursen, an überindividuellen Strukturen der Sprachverwendung und Bedeutungserzeugung. Mit Fremdheit wäre auf dieser Grundlage nicht mehr vorwiegend dann zu rechnen, wenn Angehörige verschiedener Nationalstaaten in verschiedenen Sprachen interagieren, sondern dann, wenn Grenzen zwischen Diskursen überschritten werden. Dieser Vorschlag findet bereits sich in Stephan Breidbachs (2004: 154) Überlegungen zur Didaktik des CLIL-Unterrichts, lässt sich jedoch auf alles sprachliche Lernen und somit auf schulisches und außerschulisches Lernen insgesamt übertragen.

Humboldts Erkenntnis, dass jeder "seine eigne“ Sprache (und folglich auch Weltansicht) hat, ist jedoch nicht nur sprach- und fachdidaktisch, sondern auch ethisch-politisch relevant. Bildungssysteme im Sinne Humboldts müssten jedem und jeder Heranwachsenden ermöglichen, die Prägung durch die Gruppe(n), der bzw. denen er oder sie sich zugehörig fühlt, zu reflektieren und gegebenenfalls zu transformieren. Jede Vereinnahmung des Individuums durch eine Gruppe könnte auf dieser Grundlage hinterfragt werden, unabhängig davon, ob die Gruppe sich

160 Diesen Standpunkt legt etwa der radikale Konstruktivismus nahe. Vgl. v. Glasersfeld/ Köck 2005. 
als ,Familie', ,Gemeinschaft', ,Stamm', ,Volk', ,Nation', oder eben ,Kultur ' versteht. Bereits Humboldts Schriften lassen somit kulturdeterministische Vorstellungen als problematisch erscheinen, wie sie etwa von der Anthropologin Ruth Benedict (1989 [1934]: 2f.) entwickelt wurden (vgl. Kap. 2.2.1.):

By the time he [the individual] can talk, he is the little creature of his culture, and by the time he is grown and able to take part in its activities, its habits are his habits, its beliefs his beliefs, its impossibilities his impossibilities.

Neben seinen sprachphilosophischen Überlegungen spielt in Humboldts Werk auch die Ablehnung eines utilitaristischen, auf die ökonomische Vereinnahmung des Menschen ausgerichteten Bildungsverständnisses eine wichtige Rolle. Er wird daher auch in aktuellen Beiträgen immer wieder als wichtigster Gewährsmann angeführt, wenn „Selbsterkenntnis und Freiheit“ (Liessmann 2006: 56) als letzte Ziele von Bildung in Erinnerung gerufen werden. Im hier ausgeführten erweiterten Sinne können Humboldts sprach- und kulturphilosophische Überlegungen als Ablehnung jeglicher Vereinnahmung des Individuums durch eine Gruppe gedeutet werden, unabhängig davon, ob diese ökonomisch, ethnisch, politisch, religiös, kulturell oder auf andere Weise begründet wird. Diskursbewusstheit wäre daher im Anschluss an Humboldt zu modellieren als der Versuch, Bildungsprozesse durch die Auseinandersetzung mit vielfältigen Diskursen und Praxen anzustoßen, die individuelle Integration oder Ablehnung dieser Diskurse und Praxen zu ermöglichen und dabei dieses Vorgehen selbst offenzulegen und zu reflektieren. Fremdsprachliche Diskursbewusstheit wäre anzubahnen, indem auch die Diskurse und Praxen fremdsprachlicher Kontexte identifiziert und auf ihre Bedeutung für die je eigenen Welt- und Selbstverhältnisse reflektiert werden. Dabei wäre auch die Frage zu stellen, inwieweit Diskurse und Praxen modifiziert werden, wenn sie in den spezifischen strukturellen und historisch-semantischen Gegebenheiten unterschiedlicher Sprachen (re-)konstruiert werden.

Humboldts Sprachphilosophie zeigt sich somit als äußerst anregend für das Konstrukt Fremdsprachliche Diskursbewusstheit. Dieses zeichnet sich jedoch seinerseits als Diskurs ab, der wie seine theoretischen Grundlagen auf nicht hintergehbare Setzungen angewiesen ist. Diese gilt es hier ebenfalls zu reflektieren. Das heißt, wenn, wie hier gefordert wird, Fremdsprachliche Diskursbewusstheit im Anschluss an Humboldt in der Auseinandersetzung mit pluralen, mannigfaltigen Diskursen angebahnt werden soll, dann sind hierfür die politischen und institutionellen Voraussetzungen zu schaffen bzw. zu erhalten. Hierzu gehören Meinungs- und Pressefreiheit, Religionsfreiheit, der freie Zugang zu Information, die Zulassung politischer Parteien, das Verbot von Diskriminierung aufgrund von 
Geschlecht oder sexueller Neigung, etc. ${ }^{161}$ Konkurrierenden Konzeptionen wäre dann eine Absage zu erteilen, wenn sie diese Grundprinzipien der Pluralität ablehnten und lediglich eine bestimmte Weltanschauung zuließen.

Humboldts sprachphilosophische Überlegungen sind darüber hinaus auch für den Aspekt der Bewusstheit aufschlussreich. Wie oben dargestellt, geht Humboldt davon aus, dass Sprache das „,bildende Werkzeug der Gedanken“ darstellt. Dies lässt sich in doppelter Weise verstehen: einerseits, dass Gedanken der Sprache bedürfen, um zu entstehen; andererseits, dass sie die Sprache als Werkzeug verwenden, um sich Ausdruck zu verschaffen. Gleiches gilt für die festen Strukturen, in denen Sprache verwendet wird, die Diskurse. ${ }^{162}$ Fremdsprachliche Diskursbewusstheit wäre somit anzubahnen, indem diese Vorgänge reflexiv zugänglich gemacht werden. Hierfür ist wiederum das Werkzeug Sprache unverzichtbar. Sprache ist demnach als das Werkzeug zu sehen, mit dem Gedanken ausgedrückt werden. Dabei bewegen sich Gedanken immer in vorgegebenen diskursiven Strukturen, werden von diesen geformt, tragen jedoch möglicherweise auch zu deren Transformation bei. Diese Prozesse laufen für Sprecher_innen einer Sprache in der Regel unbewusst ab. Um sie bewusst zu machen, ist wiederum das Werkzeug Sprache unabdingbar, und wiederum ist man dabei auf die Verwendung vorhandener diskursiver Strukturen angewiesen. Man könnte Sprache daher im Anschluss an Humboldt nicht nur als „bildendes Organ der Gedanken“, sondern auch als „bildendes Organ der Bewusstheit“ bezeichnen.

Dies hat offensichtliche didaktische Konsequenzen. Ein Fremdsprachenunterricht, der sich am Zielkonstrukt Fremdsprachliche Diskursbewusstheit orientieren möchte, müsste die Ebene kommunikativer Sprachverwendung regelmäßig verlassen und sich auf die Ebene des Nachdenkens über Diskurse und Praxen begeben. Hierfür müsste er die notwendigen gedanklichen und sprachlichen Werkzeuge bereitstellen und einüben, und er muss diesen Vorgang selbst reflexiv erschließen. Dabei wären mehrere Dimensionen von Diskursen und Praxen in den Blick zu nehmen, wie sie in Kapitel 4.3.3. in Anlehnung an James und Garrett (1991) vorgeschlagen wurden. Neben der sprachstrukturellen Domäne wären insbesondere die affektive Domäne sowie die machtbezogene Domäne zu berücksichtigen.

161 Zur Diskussion möglicher Einwände gegen diese universalistischen Setzungen, die in der Allgemeinen Erklärung der Menschenrechte und nachgeordneten Dokumenten festgehalten sind, vgl. Kap. 2.2.3.

162 Während Foucault, wie oben dargestellt, von einem Primat der Diskurse ausgeht, betont Fairclough das dialektische Verhältnis von Individuum und Diskursen. Vgl. Kap. 4.2.2. 
Im nächsten Schritt soll nun diskutiert werden, welche Bedeutung Bourdieus Habituskonzept für die Fremdsprachliche Diskursbewusstheit haben könnte. Wie oben ausgeführt, formuliert Koller als zentralen Vorbehalt gegen die Verwendung des Habituskonzeptes in einer Theorie transformatorischer Bildungsprozesse, dass dieses tendenziell statisch angelegt sei. Dagegen lässt sich jedoch einwenden, dass auch ein Habitus denkbar ist, der nicht auf Statik, d. h. auf Bewahrung der bestehenden Welt- und Selbstverhältnisse ausgerichtet ist, sondern vielmehr jederzeit deren Transformation in Betracht zieht. Ein solcher, Pluralität zur Kenntnis nehmender und Transformation ermöglichender Habitus wäre sowohl im Sinne transformatorischer Bildungsprozesse als auch im Sinne Fremdsprachlicher Diskursbewusstheit als wünschenswert anzusehen. Er wäre in der reflektierten Auseinandersetzung mit pluralen mutter- und fremdsprachlichen Diskursen und Praxen anzubahnen. Dieses Vorgehen sowie die Bereitschaft, Diskurse und Praxen in die jeweils eigenen Welt- und Selbstverhältnisse zu integrieren (oder dies auf reflektierte Weise nicht zu tun), müsste eingeübt, verstetigt und somit habitualisiert werden. Wenn also mit Habitus im Sinne Bourdieus ein fester Rahmen gemeint ist, der bestimmte Möglichkeiten des Sprechens und Handelns einschließt und andere ausschließt, so könnte man Fremdsprachliche Diskursbewusstheit als Habitus im Sinne eines beweglichen, offenen und transformierbaren Rahmens verstehen.

An dieser Stelle wird jedoch erneut ein Grundwiderspruch deutlich, welcher in Analogie zu dem von Kant (1982 [1803]: 20; vgl. Koller 2004: 38) formulierten Grundproblem jeglicher Erziehung gelagert ist:

Eines der größten Probleme der Erziehung ist, wie man die Unterwerfung unter den gesetzlichen Zwang mit der Fähigkeit, sich seiner Freiheit zu bedienen, vereinigen könne. Denn Zwang ist nötig! Wie kultiviere ich die Freiheit bei dem Zwange? Ich soll meinen Zögling gewöhnen, einen Zwang seiner Freiheit zu dulden, und soll ihn selbst zugleich anführen, seine Freiheit gut zu gebrauchen.

Übertragen auf das Konstrukt Fremdsprachliche Diskursbewusstheit lautet dieser Widerspruch, dass als Norm ein Habitus anzustreben wäre, welcher die Offenheit für Pluralität und die Bereitschaft zur Transformation beinhalten müsste - mit Ausnahme seiner selbst. Nach den Überlegungen zu Humboldts Sprachphilosophie führen somit auch die Überlegungen zu Bourdieus Habitustheorie an einen Punkt, an dem die Notwendigkeit einer normativen Setzung deutlich wird. Den Kern dieser Setzung bildet die Forderung nach einer Pluralität von Diskursen. Sie selbst wäre von der Forderung nach Pluralität notwendigerweise auszunehmen.

Auch wenn sich die Habitustheorie mit den genannten Einschränkungen für das Konstrukt Fremdsprachliche Diskursbewusstheit als anregend zeigt, ist 
in Bezug auf einen anderen, entscheidenden Aspekt jedoch ein wichtiger Unterschied erkennbar. Dieser bezieht sich auf die Frage, inwiefern Diskurse und Praxen bewusst gemacht werden oder nicht. Da Bourdieu unter Habitus eine „[...] einverleibte, zur Natur gewordene und damit als solche vergessene Geschichte [...]" (zit. nach Koller 2012: 25) ${ }^{163}$ versteht, geht sein Habitusverständnis deutlich über das hinaus, was man als gewohnheitsmäßiges, ,habitualisiertes Denken, Sprechen und Handeln beschreiben könnte. Während dieses durchaus bewusst stattfinden kann, ist jenes, das wir uns „einverleibt" und „vergessen“ haben, nicht bewusst. Ein Habitus im Sinne Bourdieus wäre somit nach dem hier vorgeschlagenen Ebenenmodell auf Ebene 3 (vgl. Kap. 4.3.3.) zu verorten. Für die Anbahnung von Diskursbewusstheit müsste es aber gerade darum gehen, die Entstehung, Struktur und Wirkung von Diskursen und Praxen sichtbar zu machen und auf ihre Bedeutung für die jeweiligen Welt- und Selbstverhältnisse zu reflektieren. Wenn Habitus im engeren Sinne daher in einer unbewussten Rezeption und Reproduktion bestimmter Diskurse und Praxen als „strukturiertstrukturierende Strukturen " besteht, so legt das hier vorgeschlagenen Zielkonstrukt Fremdsprachliche Diskursbewusstheit die Überwindung dieses Zustands nahe. Ein Habitus aber, der als solcher offengelegt, reflektiert und somit für eine Transformation erschlossen wird, hört im engeren Sinne von Bourdieus Definition auf, ein solcher zu sein.

Im Anschluss an diese Überlegungen zu Humboldt und Bourdieu soll in den folgenden Abschnitten Judith Butlers Konzept der „Resignifizierung“ erörtert werden. Wie oben ausgeführt, schätzt Koller das Phänomen der Resignifizierung im Hinblick auf die Theorie transformatorischer Bildung in doppelter Hinsicht als bedeutsam ein. Zum einen können Resignifizierungen, so Koller (2012: 165), Hinweise auf Bildungsprozesse enthalten. Darüber hinaus ermögliche Butlers Konzept, Transformationen im Sinne einer „Entstehung von Neuem“ von den hohen Ansprüchen zu befreien, die etwa Waldenfels formuliert hatte, und sie so zu „entmystifizieren“ (ebd.). Aus Butlers Überlegungen werde deutlich, so Kollers Fazit, dass selbst feine Resignifizierungen Ausdruck transformatorischer Bildungsprozesse sein können (vgl. ebd.).

In Bezug auf Fremdsprachliche Diskursbewusstheit lohnt es sich, diesen Gedanken aufgreifen und ihn einen Schritt weiter zu führen. Der erste Aspekt, der in diesem Zusammenhang Erwähnung verdient, besteht in der Feststellung, dass auch feine Differenzen in Diskursen und Praxen Fremdheitserfahrungen

163 „Histoire incorporée, faite nature, et par là oubliée en tant que telle, l'habitus est la présence agissante de tout le passé dont il est le produit [...]“ (Bourdieu 1980: 94). 
auslösen können. Hierfür spricht, dass die Auseinandersetzungen um solche Differenzen oft innerhalb von Diskursgemeinschaften besonders heftig ausgetragen werden - bis hin zum Einsatz von Gewalt. Man denke hier an die Auseinandersetzungen zwischen den Konfessionen der großen Weltreligionen (Katholiken gegen Protestanten, Sunniten gegen Schiiten, etc.), an die ideologischen Grabenkämpfe der politischen Linken (Stalinisten, Trotzkisten, Maoisten, etc.) oder an die Stammeskämpfe, die bis heute große Teile Afrikas und der arabischen Halbinsel in Atem halten. Die Differenzen können so klein sein, dass für Außenstehende oft nur noch mit Mühe nachvollziehbar ist, wie sie zu ernsthaften Konflikten, geschweige denn zu Blutvergießen führen können. Immer und immer wieder zeigt sich, dass ,kulturelle‘ Fremdheit, das heißt Differenzen zwischen unterschiedlichen Diskursen und Praxen, mindestens ebenso häufig innerhalb von wie zwischen Diskursgemeinschaften als gravierend empfunden wird. Gelegenheiten für ,kulturelles' Lernen - und der Bedarf an Toleranz und Empathie - ergeben sich somit nicht nur oder nicht in erster Linie dann, wenn sich die Angehörigen zweier verschiedener Nationalkulturen begegnen. Sie entstehen auch dann, wenn über voneinander abweichende Diskurse und Praxen verhandelt werden muss, ganz unabhängig davon, ob diese verschiedenen Sprachen und Nationen zuzuordnen sind oder nicht. Butlers Konzept der Resiginifizierungen ist für das hier entwickelte Konstrukt insofern von Bedeutung, als es dafür sensibilisiert, dass Differenzen, anders als oft angenommen, innerhalb von Diskursgemeinschaften sehr wohl existieren, und dass sie dort durch feine Bedeutungsverschiebungen jederzeit neu entstehen können.

Der zweite Aspekt von Butlers Konzept der Resignifizierung, der für die Fremdsprachliche Diskursbewusstheit bedeutsam erscheint, liegt in ihrem Potential für die Bewusstmachung verschiedener Dimensionen von Sprache. So kann an dem von ihr gewählten Beispiel der hate speech verdeutlicht werden, welche - in diesem Fall: schlimmen - Auswirkungen Sprache im Bereich der Emotionen haben kann. Gleichzeitig zeigt das Beispiel jedoch auch, dass die Zielscheiben dieser Art des Sprechens keine wehrlosen Opfer sind, sondern dass sie ihrerseits die Möglichkeit haben, neue Bedeutungen zu erzeugen, die zu neuen Diskursen und Praxen führen können. Durch diese Überlegungen gibt Butler dem Individuum zumindest einen Teil der Autonomie zurück, die ihm von der Diskurstheorie Foucault'scher Prägung in Abrede gestellt worden war. Butler verdeutlicht, wie sich mit dem Konzept der Resignifizierung nicht nur die emotionale, sondern auch die machtbezogene Dimension von Sprache reflektieren lässt.

In diesem Zusammenhang scheint es lohnend, noch einmal auf ein oben ausführlich analysiertes Fallbeispiel zurückkommen, mit dem Claire Kramsch 
ihr Konzept einer Symbolic competence illustrierte. In der Analyse konnte gezeigt werden, dass das interkulturelle Paradigma den Blick auf Bedeutungsverschiebungen verstellen kann, wenn man sich auf seiner Grundlage lediglich auf die Suche nach der ,richtigen' Übersetzung begibt. Konkret ging es dabei darum, dass zwei katholische Priester in einer Fernsehsendung die vom damaligen Papst Benedikt XVI. formulierte Kritik am amerikanischen „secularism and materialism“ entschärften, indem sie seine Worte in eine Mahnung für „freedom and responsibility“ übersetzten (vgl. Kap. 3.4.3.). Für Kramsch stellte dies ein gelungenes Beispiel dafür dar, wie ein critical incident durch das Finden einer gemeinsamen Sprache gelöst werden kann, im genannten Fall zwischen den katholischen Priestern einerseits und dem amerikanischen Fernsehmoderator (und dem von ihm vertretenen Publikum) andererseits. Meine Kritik an dieser Lesart lautet, dass sie erstens von einem tendenziell homogenen Publikum ausgeht und zweitens die Machtdimension des Gesprächs vollständig ausblendet.

Im Anschluss an Judith Butler könnte man nun die Äußerungen des Papstes auch als ,Resignifizierung' deuten. Der Begriff secularism, der in der amerikanischen Verfassungsgeschichte fest verankert ist und für eine strikte Trennung von religiösen und politischen Fragen steht, wird von Papst Benedikt XVI. in einer Predigt in einem Atemzug mit materialism genannt, der einseitigen Ausrichtung des Lebens auf die Anhäufung von Reichtum. ${ }^{164}$ Beide stellen in der Überzeugung des Papstes für die Gläubigen eine Gefahr dar. Benedikts Absicht dürfte darin bestehen, die negative Konnotation von materialism auf den Begriff secularism zu übertragen und ihn so in Frage zu stellen. Wenn jedoch Säkularismus als Prinzip aufgeweicht ist, dann stehen religiöse Institutionen wie die katholische Kirche bereit, um ein Mitspracherecht in politischen Fragen einzufordern. Der Papst äußert somit durch die Resignifizierung von secularism eine recht deutliche Kritik an einem dominierenden Diskurs, dem des Säkularismus. Hierdurch bringt er implizit den von ihm vertretenen Diskurs des Katholizismus Gespräch.

Diese Resignifizierung kommentieren die beiden Priester im Studiogespräch nun ihrerseits. Als Grund hierfür kann angenommen werden, dass sie der Kritik des Papstes die Spitze nehmen wollen, um zu vermeiden, dass seine Position in

164 Die realen Defizite in diesem Bereich stehen hier nicht zur Diskussion. So dürfte ein öffentliches Bekenntnis zum Atheismus in den USA bis heute zum Ende jeder nennenswerten politischen Karriere führen. Eine direkte Verwicklung des Staates in die Finanzierung religiöser Institutionen, wie sie z.B. in Deutschland durch den Einzug der „Kirchensteuer“ praktiziert wird, ist in Staaten mit stark ausgeprägtem säkularem Staatsverständnis wie den USA und Frankreich jedoch ausgeschlossen. 
den Medien als unamerikanisch dargestellt wird. ${ }^{165}$ Dies tun sie, indem sie das Begriffspaar „secularism and materialism“, welches eben dies auslösen könnte, durch ein anderes ersetzen, welches deutlich stärker konsensfähig sein dürfte: "freedom and responsibility".

Hier wird deutlich, inwiefern solche Analysen von „Resignifizierungen“ zur Anbahnung Fremdsprachlicher Diskursbewusstheit dienen könnten. Auf das Beispiel bezogen könnte man mit Lernenden also der Frage nachgehen, in welchen historischen, staatsphilosophischen und religiösen Kontexten der Säkularismus-Diskurs entstanden ist, welche Geschichte er durchlaufen hat, welche Rolle er heute im Staatsverständnis der USA und anderer Staaten (z.B. Frankreichs und Deutschlands) spielt, welche Praxen mit ihm in Zusammenhang stehen, usw. Ebenso könnte die Frage gestellt werden, welche Absicht die beiden Priester mit der vollzogenen Umdeutung verfolgt haben könnten, welche Rolle der Moderator dabei spielte, wem in der Sendung Redezeit eingeräumt wurde und wem nicht, etc. ${ }^{166}$ Ein solches Vorgehen würde wesentlich detailliertere Analysen ermöglichen, als wenn Akteure schlicht als Vertreter von Kultur A (des Katholizismus) und Kultur B (der USA) interpretiert werden, die lediglich eine gemeinsame Sprache finden müssen, um sich zu verständigen. Hierdurch könnten kulturalistische Zuschreibungen vermieden werden, zu denen es, wie in dieser Arbeit belegt werden konnte, im interkulturellen Paradigma so leicht kommt.

Der Fernsehauftritt der beiden Priester ist auch im Hinblick auf das Konzept des Widerstreits aufschlussreich. Damit komme ich auf einen Kerngedanken in den Arbeiten Lyotards zu sprechen, der im Hinblick auf Fremdsprachliche Diskursbewusstheit ebenfalls erörtert werden soll. Wie oben dargestellt hält Lyotard Leitdiskurse, sogenannte, große Erzählungen', in der Postmoderne für philosophisch und ethisch nicht mehr vertretbar. Er plädiert vielmehr dafür, inkommensurable Diskurse nicht um jeden Preis in der Diskursart des Rechts aufzulösen (litige/Rechtsstreit), sondern als Widerstreit (différend) zu erkennen

165 Im Wahlkampf, welcher der Wahl John F. Kennedys vorausging, spielten auch antikatholische Ängste eine Rolle. Kennedy bleibt bis heute der einzige römisch-katholische Präsident in der Geschichte der USA.

166 In der knapp achtminütigen Dokumentation über den Papstbesuch, welche unmittelbar vor dem Studiogespräch ausgestrahlt wurde, wurden zahlreiche Statements gläubiger Katholiken und eine Zusammenfassung der vom Papst gehaltenen Messe ausgestrahlt. Gegendemonstranten wurden zwar kurz erwähnt und eingeblendet (ca. 3 Sekunden lang), wurden jedoch nicht über die Gründe ihres Protestes befragt (vgl. Public Broadcasting Service 2008). 
und offenzuhalten. ${ }^{167}$ In Bezug auf Fremdsprachliche Diskursbewusstheit bedeutet dies, Äußerungen und Handlungen in bestehenden Diskursen, Diskurskategorien und Diskursordnungen bzw. in Praxen, Handlungskategorien und Sozialen Ordnungen zu verorten und auf das Phänomen des Widerstreits hin zu befragen. Ein solcher Widerstreit scheint im genannten Beispiel vorzuliegen: Der Diskurs des Säkularismus, der im ersten Verfassungszusatz der Verfassung der USA verankert ist, dürfte sich mit dem universellen Geltungsanspruch des Katholizismus nicht abschließend versöhnen lassen. Die Machtfragen, die in diesem Zusammenhang zu verhandeln sind, werden durch eine vordergründig für beide Seiten verständliche Übersetzung, wie sie Kramsch vorschlägt, nicht gelöst, sondern eher verschleiert. Fremdsprachliche Diskursbewusstheit bedeutet, Fragen wie die um den Einfluss religiöser Institutionen auf politische Entscheidungen sowohl in muttersprachlichen als auch in fremdsprachlichen Kontexten als Machtfragen zu erkennen. Da die Aushandlung solcher Machtfragen den Kern des Zusammenlebens in demokratischen Gesellschaften darstellt, müsste ein Ziel des Fremdsprachenunterrichts im Sinne Fremdsprachlicher Diskursbewusstheit darin bestehen, Lernende zur Teilhabe an eben solchen Aushandlungsprozessen zu befähigen.

Wenn sich dabei Konflikte als nicht lösbar herausstellen, dann liegt das möglicherweise nicht an der mangelnden Toleranz oder der geringen Empathie der Beteiligten, wie es die interkulturelle Pädagogik nahelegt. Im Licht von Lyotards Konzept des Widerstreits wird vielmehr erkennbar, dass Konflikte oft aus inkommensurablen Diskursen und Praxen entstehen. Dies bedeutet auch, dass bestimmte Konflikte von demokratischen Gesellschaften nicht abschließend beigelegt werden können. Auf einer allgemeineren Ebene legt das Fallbeispiel daher die Vermutung nahe, dass geradezu eine Grundbedingung für das Gelingen von Demokratie darin besteht, dass möglichst viele der an ihr Beteiligten dazu in der Lage sind, die postmoderne Unübersichtlichkeit der Pluralität von Diskursen auszuhalten. Fremdsprachenunterricht, der sich am Leitziel Fremdsprachliche Diskursbewusstheit orientiert, könnte hierzu einen Beitrag leisten.

Abschließend sollen nun einige Aspekte von Kollers Theorie transformatorischer Bildungsprozesse selbst auf ihre Bedeutung für das Konstrukt Fremdsprachliche Diskursbewusstheit hin befragt werden. Wie oben dargestellt wurde, spielt für Koller die Enstehung neuer Welt- und Selbstverhältnisse eine entscheidende Rolle, damit von Bildung im Sinne seiner Definition gesprochen werden kann.

167 Inwiefern Lyotards Prinzip des Widerstreits dabei selbst als, große Erzählung kritisiert werden könnte, wurde bereits in Kapitel 4.2.4. diskutiert. 
Koller (2012: 101) notiert hierzu, „[...] dass dieser Typ von Bildungsprozessen notwendigerweise mit der Entstehung neuer Figuren des Welt- und Selbstverhältnisses einher geht." Eine Frage, die sich in diesem Zusammenhang stellt, lautet jedoch, inwiefern dies möglicherweise einen so hohen Anspruch an Bildung darstellt, dass er im schulischen Kontext kaum eingelöst werden kann. Koller thematisiert diesen möglichen Einwand und relativiert seine Position im weiteren Verlauf seiner Überlegungen deutlich. Er spricht später nicht mehr von der Entstehung völlig neuer Figuren des Welt- und Selbstverhältnisses, sondern lediglich von einem „Anderswerden“ (ebd.: 169, Hervorhebung im Original).

Eine Frage, die sich in Bezug auf Koller Konzept in diesem Zusammenhang ebenfalls stellt, ist die nach der Beschaffenheit des „Neuen“, dessen Zustandekommen einen Bildungsprozess ausmacht, oder die nach der Richtung, in der ein „Anderswerden“ stattfindet. Nach Kollers vorläufiger Definition würde es sich auch dann um Bildungsprozesse handeln, wenn beispielsweise ein junger Mann aus einem liberalen Elternhaus sich einer neonazistischen Gruppierung anschließt, wenn eine junge türkischstämmige Frau aus einer gemäßigten muslimischen Familie zum Salafismus konvertiert, oder wenn ein vormals liberaler Politiker plötzlich den Standpunkt vertritt, dass Folter ein legitimes Mittel zur Wahrung der nationalen Sicherheit darstelle. In allen drei Fällen wäre davon auszugehen, dass Fremdheitserlebnisse zur Ersetzung bisheriger Formen der Weltund Selbstverhältnisse geführt haben und etwas Neues oder zumindest graduell Anderes entstanden ist. Die Beispiele machen deutlich, dass das für Koller zentrale Kriterium der Transformation für das Zustandekommen von Bildungsprozessen nicht hinreichend ist. Für sich allein genommen könnte es dazu führen, dass die Integration beliebiger Diskurse und Praxen als Bildung zu bezeichnen wäre. Man muss aber keine radikalen ethischen, politischen oder religiösen Positionen heranziehen, um zu zeigen, dass Koller selbst keineswegs einen solchen radikalen Relativismus favorisiert. So vertritt er in Bezug auf forschungsmethodologische Fragen klare Positionen und kritisiert, um ein Beispiel zu nennen, den Ansatz der Transkulturalität, der „eine kulturalisierende Reduktion der Interaktionspartner auf ihre jeweilige Herkunftskultur nahe[lege]“ (ebd.: 163). Stattdessen empfiehlt er einen diskurstheoretischen Zugriff. Insofern ist anzunehmen, dass Koller es durchaus als Bildungsprozess bezeichnen würde, wenn ein Erziehungswissenschaftler von einem transkulturellen zu einem diskurstheoretischen Ansatz übergehen würde - den umgekehrten Weg jedoch vermutlich nicht.

In Bezug auf den von Koller analysierten Roman, Eugenides' Selbstmordschwestern, lässt sich ähnlich argumentieren. Die Jugendlichen, welche die Selbstmorde miterleben und die durch sie ausgelösten radikalen Fremdheitserlebnisse 
in ihre eigenen Welt- und Selbstverhältnisse integrieren müssen, tun dies nicht, indem sie einen bestimmten Diskurs als Sinnangebot übernehmen. Sie halten vielmehr eben jene Diskurspluralität aus, die Koller im Anschluss an Lyotard in der Postmoderne sowohl philosophisch als auch ethisch für geboten hält. Für Koller handelt es sich bei den Selbstmordschwestern gerade deswegen um einen Bildungsroman: Eindeutige Sinnangebote werden abgelehnt, das damit verbundene Scheitern von Bildungsprozessen wird vorgeführt. Zumindest implizit ist also die Position zu erkennen, dass keine vollständige Beliebigkeit der Art oder Richtung der Transformation empfohlen wird. Koller (ebd.: 97) formuliert diese Einschränkung an einer Stelle auch explizit - allerdings lediglich in Form einer Fußnote:

Daran [an der Forderung, dass Transformationen dem Widerstreit der Diskursarten gerecht werden sollen] wird deutlich, dass mit Lyotard auch eine Antwort auf die Frage nach den normativen Implikationen des Konzepts transformatorischer Bidlungsprozesse möglich ist [...]. Nicht jede Transformation von Welt- und Selbstverhältnissen kann demzufolge als Bildungsprozess bezeichnet werden - wie einige Kritiker einwandten [...]. Der Begriff wäre im Anschluss an Lyotard auf solche Transformationen zu beschränken, die einem Widerstreit gerecht werden, für den es zuvor keine Artikulationsmöglichkeiten gab. Das schließt u.a. solche Transformationen aus, in denen die radikale Pluralität von Diskursarten und Orientierungsmustern verleugnet oder unterdrückt wird.

Diese Überlegungen sind auch für das Konstrukt Fremdsprachliche Diskursbewusstheit von Interesse. In Anlehnung an Lyotard und Koller ließe sich festhalten, dass zur Anbahnung Fremdsprachlicher Diskursbewusstheit im Fremdsprachenunterricht die Pluralität von Diskursen sichtbar zu machen und ihr Widerstreit als solcher zu thematisieren und offenzuhalten wäre. Das oben analysierte PBSStudiogespräch mit zwei katholischen Priestern wäre in dieser Perspektive neu zu bewerten. Es wäre nicht mehr als gelungene - und machttheoretisch gesprochen ausgewogene - Beilegung eines interkulturellen critical incident zu deuten. Vielmehr würde deutlich, dass die Studiogäste die „Chance, die von einem selbst als richtig oder wahr angenommenen Diskurse [...] durchzusetzen“ (vgl. Kap. 1.9.) ohne jeglichen Widerstand wahrnehmen konnten, mit anderen Worten: dass sie Macht ausübten.

Hier wird eine medienpädagogische Dimension der Bewusstmachung von Diskursen deutlich: Die Gesprächsführung des Moderators kann insofern als problematisch erkannt werden, als er es versäumt hat, den Widerstreit von Diskursen offenzulegen und auszuhalten. Dies kann verschiedene Gründe haben. Möglicherweise war ihm die große staatstheoretische Bedeutung des Begriffs secularism schlicht unbekannt. Wahrscheinlicher ist jedoch, dass er sein Verhältnis zu den eingeladenen Priestern als Gastverhältnis (miss-)verstand. Dies würde 
erklären, warum er keinen einzigen Einwand formulierte, sondern lediglich um Erklärungen bat. Sein Verhalten legt nahe, dass er sich im Rahmen der Gastgeberrolle angemessen verhalten wollte. Der Verlauf des Studiogesprächs ist somit für einen weiteren Aspekt interkultureller Fremdsprachendidaktik von Interesse, die Angemessenheit oder Adäquatheit (vgl. Fairclough 1992c). Solange der Widerstreit von Diskursen als interkulturell interpretiert wird, ist die Tendenz zu befürchten, dass Normvorstellungen über das jeweils angemessene Verhältnis von Gastgebern und Gästen eine Rolle spielen. Dabei ist es jedoch mehr als fraglich, ob dieses Verhältnis für das Erkennen, Austragen und gegebenenfalls Aushalten von Konflikten geeignet ist, mit denen in pluralen Gesellschaften gerechnet werden muss.

Kollers Theorie transformatorischer Bildungsprozesse hat sich somit für das Konstrukt Fremdsprachliche Diskursbewusstheit als äußerst anregend gezeigt. Ich möchte abschließend noch einmal an seine bereits zitierte abschließende Definition transformatorischer Bildungsprozesse erinnern:

Vielleicht wäre Bildung vor diesem Hintergrund nicht mehr zu begreifen als der Prozess einer produktiven Verarbeitung, die das Scheitern bzw. die Negativität überwinden oder ,aufheben' könnte, sondern als eine Art schwer zu beschreibender Doppelbewegung. Diese doppelte Bewegung bestünde darin, einerseits Fremdheitserfahrungen, Scheitern und Negativität als unhintergehbare conditio humana anzuerkennen, sie aber andererseits dennoch als Herausforderung ernst zu nehmen, die uns nötigt, nach einer Antwort zu suchen, die sich nicht auf deren resignierte Hinnahme beschränkt. (Koller 2012: 184)

Für die Anbahnung Fremdsprachlicher Diskursbewusstheit wäre es in diesem Sinne entscheidend, im Fremdsprachenunterricht die Auseinandersetzung mit Diskursen und Praxen zu ermöglichen. Lernende müssten hierfür im Laufe eines Bildungsgangs ausreichende Gelegenheiten haben, die notwendigen theoretischen Konzepte und (meta-)sprachlichen Mittel kennen zu lernen, und dieses Vorgehen wäre selbst transparent und somit reflexiv zugänglich zu machen. ${ }^{168}$

\subsection{Didaktische Prinzipien zur Anbahnung Fremdsprachlicher Diskursbewusstheit}

In den Überlegungen im theoriebildenden Teil dieser Arbeit wird der Frage nachgegangen, wie Fremdsprachliche Diskursbewusstheit als Zielkonstrukt für den Fremdsprachenunterricht beschaffen sein könnte. Dieses Konstrukt könnte

168 Eine ähnliche Position vertreten Bonnet und Breidbach (2007: 253), wenn sie schreiben, dass auch die ,bewusste Aufrechterhaltung" eines bestehenden Welt- und Selbstverhältnisses angesichts einer Infragestellung ein Bildungsprozess sein kann. 
dazu beitragen, so die hier vertretene Position, dass die in dieser Arbeit ausführlich erörterten Probleme interkultureller Fremdsprachendidaktik in neuem Licht reflektiert werden. Kulturelles Lernen könnte besser als bisher auf der Grundlage eines Kulturverständnisses erfolgen, das in der fremdsprachdidaktischen Theoriebildung seit langem favorisiert wird - und zwar, indem man auf den Begriff ,Kultur' weitgehend verzichtet.

Es bleiben jedoch an dieser Stelle der Überlegungen einige Fragen zunächst offen. Diese betreffen unter anderem die Empiriefähigkeit Fremdsprachlicher Diskursbewusstheit, ihr Verhältnis zu anderen wichtigen Konzepten des Fremdsprachenunterrichts wie z.B. Handlungsorientierung, ihre möglicherweise fächerübergreifende Relevanz, Methoden zu ihrer Anbahnung im Unterricht und ihre Evaluation.

Zur Beantwortung dieser Fragen ist weitere Forschung notwendig. Dennoch lassen sich schon jetzt einige Prinzipien ${ }^{169}$ formulieren, deren Beachtung unter günstigen Bedingungen zur Anbahnung Fremdsprachlicher Diskursbewusstheit beitragen kann. Diese Prinzipien stellen einen Versuch dar, ein unterrichtspraktisches Fazit dieser Arbeit zu formulieren. Sie zeigen somit Perspektiven für die Unterrichtsentwicklung, aber auch für weitere Forschung auf.

1. Topikalität. Diskurse sind sozial vermittelte Arten, wie, wann und von wem über bestimmte Themen gesprochen - und nicht gesprochen - werden kann. Analog hierzu sind Praxen sozial vermittelte Arten, wie sich wer in bestimmten Situationen verhalten - und nicht verhalten - kann. Diskurse und Praxen sind interdependent. Dies legt es nahe, Fremdsprachliche Diskursbewusstheit anhand bestimmter Kernthemen anzubahnen. Hierbei können und sollten jedoch auch neue diskursive Zusammenhänge sichtbar gemacht werden. So könnten etwa in einer fächerübergreifenden Unterrichtsreihe des Englisch-, Französisch- und Geschichtsunterrichts Hygiene-Diskurse des 19. Jahrhunderts in Verbindung mit Eugenik- und Rasse-Diskursen des 20. und 21. Jahrhunderts behandelt werden (vgl. zu diesem Beispiel Kap. 4.2.2.).

2. Vielstimmigkeit. Diskurse und Praxen bestehen aus einer Vielzahl von Äußerungen und Handlungen. Die Möglichkeiten, vielfältige Äußerungen zu rezipieren und Handlungen zu beobachten, haben sich im digitalen Zeitalter potenziert. Die Bedingungen sind somit ideal, um plurale Diskurse in

169 Wolfgang Hallet formuliert die Prinzipien 1-4 bereits 2008 (89f.) in einem Beitrag zur, Diskursfähigkeit.' Hier werden sie jedoch im Hinblick auf die Anbahnung Fremdsprachlicher Diskursbewusstheit beschrieben. Prinzip 4 heißt in Hallets Beitrag „Interaktionale Aushandlung" (ebd.: 90). 
mehrsprachigen Kontexten zu rekonstruieren und auf diese Weise Fremdsprachliche Diskursbewusstheit anzubahnen.

3. Multimodalität. Eine zentrale Eigenschaft digital vermittelter Inhalte ist die Vielfalt ihrer Codierungsformen. Lernende müssen in die Lage versetzt werden, nicht nur geschriebene Texte, sondern auch Bilder, Videos, Tabellen, Grafiken, Emoticons, Audio-Dateien usw. reflektiert verarbeiten zu können. Fremdsprachliche Diskursbewusstheit kann gefördert werden, wenn sie in diesem Rahmen versuchen, Diskurse und Praxen in mehrsprachigen Kontexten zu rekonstruieren.

4. Unabgeschlossenheit. Diskurse sind nicht ontologisch vorhanden, sondern können nur immer neu konstruiert, dekonstruiert und rekonstruiert werden. Hierfür sind interaktionale Aushandlungsprozesse unabdingbar. Das Zielkonstrukt Fremdsprachliche Diskursbewusstheit legt nahe, diese Aushandlungsprozesse zu ermöglichen und als solche reflexiv zugänglich zu machen. Dies betrifft insbesondere auch Bildungsdiskurse, da sie für die Lebenswelt von Lernenden hoch relevant sind.

5. Pluralität. Diskurse konkurrieren untereinander um Geltung. Für die Anbahnung Fremdsprachlicher Diskursbewusstheit ist zu reflektieren, welche Machtmechanismen dazu führen, dass Diskurse (sowie die ihnen übergeordneten Diskursordnungen und Diskurskategorien) in verschiedenen Diskursgemeinschaften ihren jeweiligen Geltungsanspruch durchsetzen können oder nicht. Hierfür bietet es sich an, lokale, regionale, nationale, internationale und globale Konflikte auf der Grundlage mehrsprachiger und multimodaler Texte zu bearbeiten.

6. Kontroversität. Fremdsprachliche Diskursbewusstheit kann gefördert werden, indem im Fremdsprachenunterricht um Geltung konkurrierende Diskurse und Praxen in mehrsprachigen Kontexten thematisiert werden. Hieraus können sich starke Kommunikationsanlässe ergeben.

7. Kontingenz. Diskurse und Praxen sind kontingent, tendieren aber dazu, die eigene Kontingenz zu invisibilisieren, z.B. indem sie sich als „alternativlos“ oder "natürlich“ zeigen. Fremdsprachliche Diskursbewusstheit kann angebahnt werden, indem in mehrsprachigen Kontexten sprachliche und außersprachliche Mechanismen zur Durchsetzung von Diskursen und Praxen reflektiert werden.

8. Ethisch-politische Dimension. Diskurse und Praxen müssen aus ethischer und politischer Sicht auf ihre Auswirkungen für das Zusammenleben in und die Partizipation an Diskursgemeinschaften befragt werden, die sich den Prinzipien Menschenrechte, Demokratie und Rechtsstaatlichkeit verschrieben 
haben. Die Anbahnung Fremdsprachlicher Diskursbewusstheit schließt mit ein, dass diese Prinzipien selbst als historisch gewachsene, legitimierungsund entwicklungsbedürftige Diskurse behandelt werden.

9. Bildungsdimension. Für die Anbahnung Fremdsprachlicher Diskursbewusstheit sollten Lernende dazu ermuntert werden, Diskurse und Praxen in mehrsprachigen Kontexten auf ihre Relevanz für die eigenen Welt- und Selbstverhältnisse zu befragen. Lehrkräften kommt hierbei nicht nur die pädagogische Aufgabe zu, diese Prozesse anzustoßen, sondern auch, die dabei entstehenden kognitiven, emotionalen und identitätsbezogenen Konflikte in ihrer Tragweite einzuschätzen und gegebenenfalls abzufedern.

10. Diskursivität des eigenen Standpunktes. Eine begründete Haltung zu Diskursen und Praxen kann nur durch den Rückgriff auf Diskurse erzielt werden. Bei der Anbahnung Fremdsprachlicher Diskursbewusstheit sollte auch dieser Umstand reflexiv erschlossen werden.

11. Terminologische Erschließung. Für die unterrichtliche Anbahnung Fremdsprachlicher Diskursbewusstheit ist eine Heranführung an die hierfür benötigten Konzepte und die entsprechende Terminologie notwendig. Lernende müssen hierfür nicht unerhebliche Abstraktionsleistungen erbringen. Diese Leistungen unterscheiden sich jedoch nicht prinzipiell von anderen, die in nicht-fremdsprachlichen Schulfächern erwartet werden.

12. Reflexivität. Fremdsprachliche Diskursbewusstheit als Zielsetzung pädagogischen Handelns sollte im Fremdsprachenunterricht immer wieder selbst zum Gegenstand von Reflexion werden.

Staatlich organisierte Bildung reproduziert gegebene gesellschaftliche Verhältnisse, indem sie jede Schülergeneration an bestehende diskursive Ordnungen heranführt. In der Schule wird eingeübt, was von wem in welchen Situationen gesagt oder getan werden kann - aber auch, was nicht gesagt und nicht getan werden darf. Diese Grenzziehungen gelten auch für einen Unterricht, der die genannten Prinzipien beachtet, um Fremdsprachliche Diskursbewusstheit anzubahnen. Sie zu verändern entzieht sich dem Einfluss der einzelnen Lehrkraft weitgehend - man denke etwa an zentrale Prüfungen, ministerielle Vorgaben oder die Lehr- und Lernbedingungen in jeder einzelnen Schule. Dennoch haben Lehrkräfte immer die Möglichkeit, Machtverhältnisse zu reflektieren, auch und gerade gemeinsam mit ihren Lernenden. Auf diese Weise lässt sich schon im kleinen Rahmen einer einzelnen Lerngruppe das transformatorische Potenzial von Bildungsprozessen stärken. Die genannten Prinzipien können bei diesem Anliegen hilfreich sein. Sie zu implementieren und zu überprüfen wäre ein vermutlich lohnendes Vorhaben für die Unterrichtsentwicklung und -forschung. 


\section{Fazit und Ausblick}

Auf den folgenden Seiten werden zunächst die Ergebnisse der Arbeit zusammengefasst. Anschließend erfolgt ein kurzer Ausblick auf weitere Forschung, die auf der Grundlage der hier entwickelten Überlegungen wünschenswert wäre.

Folgende Arbeitshypothese bildete den Ausgangspunkt der vorliegenden Arbeit:

Interkulturalität ist als Zielkonstrukt des Fremdsprachenunterrichts zu überdenken, weil der Kulturbegriff erstens einen Rückgriff auf überholte Kulturverständnisse, zweitens einen unreflektierten Umgang mit dem Dilemma von Universalismus und Kulturrelativismus begünstigt.

Diese Hypothese wurde mit folgenden Forschungsfragen überprüft:

Forschungsfrage 1: Wie sind ausgewählte Ansätze interkultureller Fremdsprachendidaktik hinsichtlich verschiedener Kulturverständnisse zu beurteilen?

Forschungsfrage 2: Wie sind ausgewählte Ansätze interkultureller Fremdsprachendidaktik hinsichtlich des Dilemmas von Universalismus und Kulturrelativismus zu beurteilen?

Die Bearbeitung dieser Forschungsfragen bestätigte die Arbeitshypothese in weiten Teilen (vgl. Kap. 3.6.). Die Auseinandersetzung mit Forschungsfrage 3 erschien in diesem Licht als potentiell nützlich für die fremdsprachendidaktische Theoriebildung. Sie lautete:

Wie könnte ein Zielkonstrukt für den Fremdsprachenunterricht beschaffen sein, das sowohl ein zeitgemäßes Kulturverständnis als auch einen reflektierten Umgang mit dem Dilemma von Universalismus und Kulturrelativismus anbahnt?

Für die Bearbeitung dieser Frage wurden drei Theoriekonstrukte herangezogen - ein soziologisch-sprachphilosophisches, ein sprachdidaktisches und ein bildungstheoretisches:

1. Das erste, soziologisch-sprachphilosophische Theoriekonstrukt ist die Diskurstheorie in der Tradition Michel Foucaults und in ihrer Weiterentwicklung durch Norman Fairclough (vgl. Kap. 4.2.). Es zeigt sich, dass das ihr zugrunde liegende sozialphilosophische Diskursverständnis ein mächtiges Werkzeug für die Reflexion der in den Forschungsfragen 1 und 2 bearbeiteten Problemlagen ist. Sprachliche und soziale Pluralität lässt sich mit dem Diskursbegriff wesentlich besser rekonstruieren, dekonstruieren und konstruieren als mit dem oft alltagssprachlich überlagerten Kulturbegriff. In Bezug auf die wichtige Frage nach dem Verhältnis des Individuums zu Diskursen und Praxen - das heißt zu sozial vorstrukturierten Arten des Sprechens und Handelns - hat sich dabei Faircloughs 
dialektische Sicht als gewinnbringend erwiesen. Dies ist für Bildungsprozesse entscheidend: Sie könnten kaum als Ausgangspunkt für sozialen Wandel verstanden werden, wenn individuelle Subjekte im streng Foucault'schen Sinne als Produkte von Diskursen verstanden würden, und nicht auch als die Urheber von deren Veränderung.

In Anlehnung an Fairclough wurden je vier Ebenen des Sprechens und Handelns unterschieden, zwischen denen wechselseitige Abhängigkeiten bestehen: Diskursordnungen (1), Diskurskategorien (2), Diskurse (3a) und Äußerungen (3b) bzw. Soziale Ordnungen (1), Handlungskategorien (2), Praxen (3a) und Handlungen (3b).

2. Das zweite, sprachdidaktische Theoriekonstrukt ist die sogenannte language awareness/Sprachbewusstheit, wie sie von Eric W. Hawkins, Carl James, Peter Garrett und anderen für den englischsprachigen Kontext sowie von Claus Gnutzmann, Dieter Wolff und anderen für den deutschsprachigen Kontext konzipiert bzw. weiterentwickelt wurde (vgl. Kap. 4.3.). Die Analyse verschiedener Modellierungen von language awareness hat gezeigt, dass für die hier bearbeitete Fragestellung vor allem drei Dimensionen von Sprache als Diskurs von Interesse sind: die affektive Domäne (affective domain), die machtbezogene Domäne (social domain, "power" domain) sowie die sprachstrukturelle Domäne (cognitive domain).

In Anlehnung an Sigmund Freuds Modell des psychischen Apparates wurde vorgeschlagen, im Hinblick auf bewusst machende Verfahren insgesamt vier Bewusstheitsebenen zu unterscheiden:

- Ebene (1): das Bewusste - vorhandenes, abgerufenes Wissen über Diskurse und Praxen: verbalisiertes Wissen, auf das die Aufmerksamkeit aktuell gerichtet ist.

- Ebene (2): das Vorbewusste - vorhandenes, abrufbares Wissen über Diskurse und Praxen: Wissen, das prinzipiell vorhanden und durch mehr oder weniger große willentliche Anstrengung abrufbar und verbalisierbar ist.

- Ebene (3): das Unbewusste - vorhandenes, nicht abrufbares Wissen über Diskurse und Praxen: Wissen, das prinzipiell vorhanden, jedoch auch durch große willentliche Anstrengung nicht ohne Unterstützung abrufbar oder verbalisierbar ist.

- Ebene (4): nicht vorhandenes, nicht abrufbares Wissen

Die hier vertretene Position lautet, dass Diskurse und Praxen im Fremdsprachenunterricht erschlossen und somit „bewusst gemacht“ werden können, indem Wissen der Ebenen 3 und 4 auf Ebene 1 (re-, de-)konstruiert wird - vorwiegend, aber nicht ausschließlich im Medium der Sprache. Das dabei verfolgte Ziel 
lautet, dieses Wissen langfristig auf Ebene 2 verfügbar zu halten. Als besonders förderlich für Fremdsprachliche Diskursbewusstheit wird angenommen, wenn dieses Vorgehen nicht nur ein Handlungsmodell für den Fremdsprachenunterricht darstellt, sondern wenn es auch selbst für Lernende zum Gegenstand von Reflexion wird. Neben dem auf diese Weise angebahnten Wissen über Diskurse und Praxen meint Fremdsprachliche Diskursbewusstheit auch eine Haltung, die quer zu den oben beschriebenen Ebenen von Bewusstheit liegt und sich dadurch auszeichnet, dass im Sinne einer "gleichschwebenden Aufmerksamkeit“ jederzeit mit Diskursen und Praxen - und mit zwischen ihnen auftretenden Differenzen gerechnet wird.

3. Das dritte, bildungstheoretische Theoriekonstrukt ist die Theorie transformatorischer Bildungsprozesse, die von Hans-Christoph Koller in Anlehnung an Wilhelm von Humboldt und an Jean-François Lyotard entwickelt wurde (vgl. Kap. 4.4.). Kollers Überlegungen zeigen, dass Differenzerfahrungen erforderlich sind, wenn Bildungsprozesse gefördert werden sollen, die über bloßes „Lernen“ in einem informationstheoretischen Sinn hinausgehen. Entscheidend ist in diesem Zusammenhang die Feststellung, dass Bildungprozesse weniger als abschließbare und abzuschließende Übergänge von jeweils einem Zustand in einen anderen zu sehen sind, sondern eher als dynamisch, offen und unabschließbar. In Abgrenzung zu Koller und Lyotard wurde jedoch unterstrichen, dass für Bildungskontexte weniger der auf der höchsten Abstraktionsebene angesiedelte Widerstreit von Diskursarten (in der hier vorgeschlagenen Terminologie: Diskursordnungen), sondern eher jener von Diskurskategorien und Diskursen relevant ist. Dabei wird angenommen, dass sich menschliches Sprechen und Handeln nicht vollständig in diskursiven Ordnungen erfassen und auflösen lässt, eine Feststellung Kollers, die hier als ,anthropologischer Rest“ bezeichnet wurde.

Es wird davon ausgegangen, dass Fremdsprachliche Diskursbewusstheit angebahnt wird, indem im Fremdsprachenunterricht die drei genannten Theoriekonstrukte berücksichtigt werden, indem also Diskurse und Praxen aus und in fremd- und muttersprachlichen Kontexten konstruiert, dekonstruiert und rekonstruiert werden, indem hierbei ihre affektiven, machtbezogenen und sprachstrukturellen Dimensionen reflektiert werden, und indem sie im Hinblick auf ihr bildendes, das heißt vor allem transformatorisches Potential befragt werden.

Ein Fremdsprachenunterricht, der sich an diesem Zielkonstrukt orientiert, führt die Lernenden bewusst an Differenzerfahrungen heran. Zum Leben in einer offenen Gesellschaft gehört die Einsicht, dass sich diese Differenzen nicht auflösen lassen, ja dass es im Sinne des Lyotard'schen Widerstreits (différend) wünschenswert ist, sie offenzuhalten. Ohne ein normatives Bezugssystem können Lernende 
dabei jedoch keine ethisch-politisch vertretbare kritische Urteilskompetenz aufbauen. Ebenso wenig können sie die für die persönliche Entwicklung entscheidende Frage beantworten, mit welchen der innerhalb und außerhalb der Schule zu findenden Sinnangebote sie möglicherweise ihre eigene Identität erweitern möchten, welche jedoch problematisch und daher abzulehnen sind. Ein solches normatives Bezugssystem ist die Allgemeine Erklärung der Menschenrechte (vgl. UN General Assembly 1948), die dem philosophischen und ethischen Prinzip universeller Menschenrechte Ausdruck verleiht. In engem Zusammenhang mit ihm stehen die Prinzipien Demokratie und Rechtsstaatlichkeit. Der Europarat empfiehlt diese drei Prinzipien als Grundlage aller Bildungseinrichtungen in Europa (vgl. Council of Europe 2010).

Die Menschenrechte sind komplexe, aber gleichzeitig offene diskursive Ordnungen. Sie stellen von allen UN-Mitgliedsstaaten zumindest grundsätzlich anerkannte Prinzipien dar. Zwar kommt es bekanntermaßen in vielen Teilen der Welt, auch in den westlichen Industrienationen, immer wieder zu mehr oder minder schweren Konflikten mit diesen Prinzipien. Diese Konflikte können jedoch nur dank der Tatsache beurteilt und im Hinblick auf Lösungsansätze bearbeitet werden, dass ein transnational als verbindlich angesehener Normenkatalog existiert. Es ist damit zu rechnen, dass in einer sich schnell verändernden Welt aus Modernisierungskrisen immer neue Konflikte entstehen werden. Dies zeigt z. B. die erst in jüngster Zeit technisch möglich gewordene flächendeckende staatliche Überwachung der Telekommunikation, die mit grundlegenden Prinzipien bürgerlicher Freiheit kollidiert. Auch die Menschenrechte stellen keine fertigen Lösungen für solche Konflikte bereit. Sie bieten jedoch eine Grundlage für die Suche nach Lösungen.

Bei der Bearbeitung von Konflikten auf Grundlage der Menschenrechte können durchaus auch in diesen selbst angelegte Widersprüche zutage treten. Das in der Arbeit diskutierte Beispiel der rituellen Beschneidung von Jungen veranschaulicht dies (vgl. Kap. 2.2.4.): Das Gericht, die Ethikkommission und der Deutsche Bundestag, die sich mit der Frage beschäftigten, hatten viele verschiedene Aspekte einer komplexen Thematik zu berücksichtigen. Dabei mussten sie auch zwischen zwei in der Allgemeinen Erklärung der Menschenrechte enthaltenen Ideen abwägen, dem Diskriminierungsverbot (UN General Assembly 1948, Art. 7) und der Religionsfreiheit (ebd., Art. 18).

Fremdsprachliche Diskursbewusstheit kann im Fremdsprachenunterricht angebahnt werden, so die hier vertretene Position, wenn die genannten Theoriekonstrukte berücksichtigt und immer neu aus der Perspektive der universellen 
Menschenrechtsidee reflektiert werden. Dieses Zusammenspiel ist in der folgenden Übersicht grafisch dargestellt.

Abb. 1: Fremdsprachliche Diskursbewusstheit

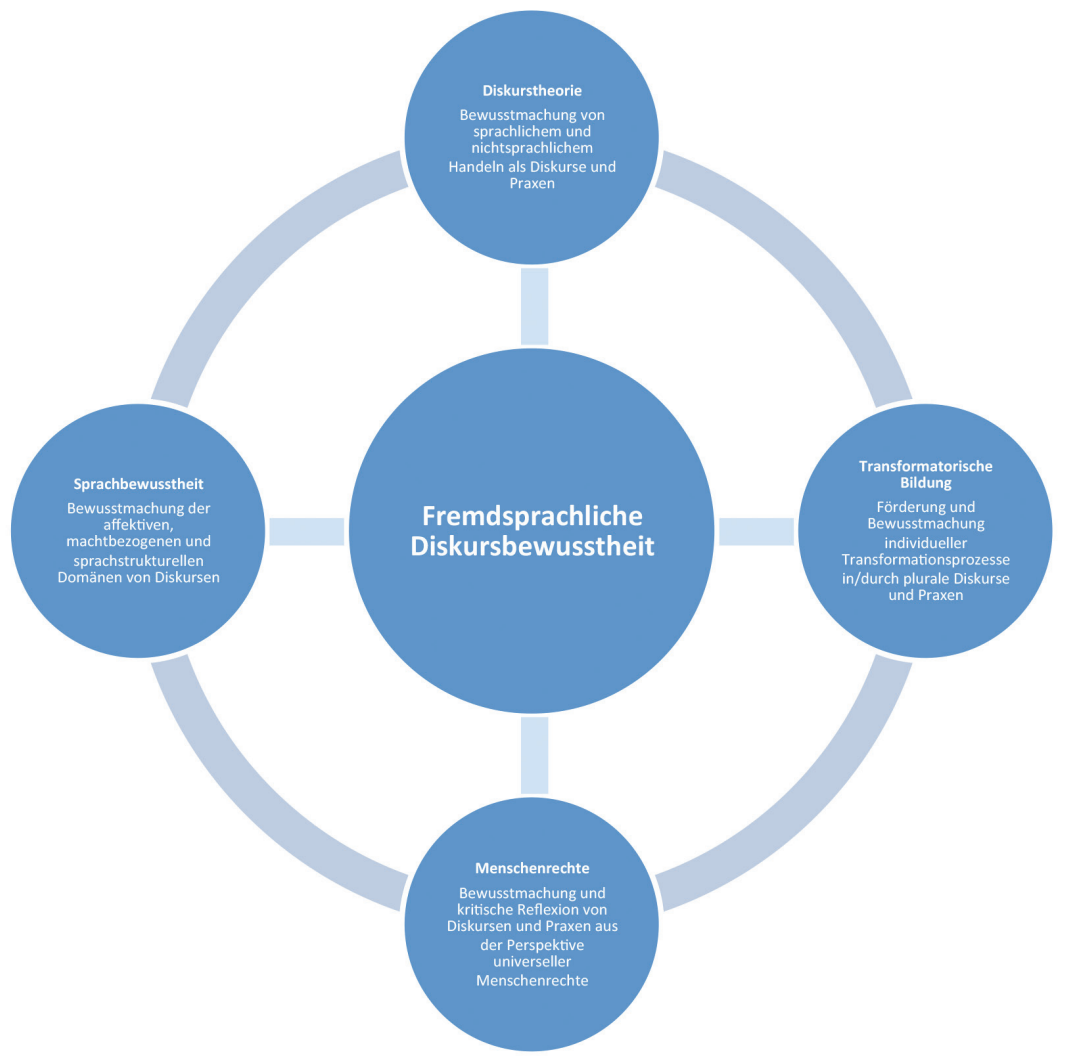

Abschließend sollen einige offene Fragen thematisiert werden, die sich in $\mathrm{Zu}$ sammenhang mit dem hier entwickelten Konstrukt stellen und die Ausgangspunkte für weitere Forschung sein können.

Da die Bildungswissenschaften in den vergangenen Jahren eine empirische Wende vollzogen haben, liegt bei einem theoretischen Konstrukt wie der hier entwickelten Fremdsprachlichen Diskursbewusstheit zunächst die Frage nach deren Empiriefähigkeit nahe. Im Verlauf der Arbeit wurden in diesem Zusammenhang vor allem zwei Aspekte diskutiert, die hier noch einmal aufgegriffen werden sollen. 
Wie Phänomene des menschlichen Bewusstseins empirisch erschlossen werden können, ist ein ungelöstes forschungsmethodologisches Problem. Dies liegt zum einen daran, dass das Bewusstsein selbst ein aktuelles Forschungsfeld im Grenzgebiet von Neurologie, Psychologie und zunehmend auch Computerwissenschaften darstellt, in dem mehr neue Fragen generiert als Antworten gefunden werden. Was genau Begriffe wie „Bewusstsein“,„Bewusstheit“ und „Bewusstmachung" bedeuten, wird daher mit großer Wahrscheinlichkeit auch für die fremdsprachendidaktische Forschung vage bleiben. Zum anderen ist damit zu rechnen, dass bei der empirischen Erforschung von Bewusstheit Phänomene möglicherweise erst durch die Datenerhebung selbst für Probanden bewusst werden. Das zu beobachtende Phänomen wird somit durch die Beobachtung stark beeinflusst oder möglicherweise erst durch sie erzeugt. Die empirische Erforschung von Bewusstsein bzw. Bewusstheit hat es demnach mit einer kaum zu umgehenden Form des Beobachterparadoxons zu tun.

Die Tatsache, dass ein Phänomen sich dem empirischen Zugriff weitgehend entzieht, sagt jedoch nichts über seine Bedeutung aus. In Bezug auf die Fremdsprachendidaktik ist festzuhalten, dass auch Interkulturelle Kompetenz sich als empirisch äußerst schwer zugänglich erwiesen hat. Dies hat jedoch ihren Aufstieg zum Leitkonzept fremdsprachlichen Lernens nicht verhindert. Zudem haben Versuche ihrer empirischen Erforschung auch die Reflexion auf der Theorieebene vorangebracht. Eine ähnliche Entwicklung wäre auch für das hier entworfene Konstrukt Fremdsprachliche Diskursbewusstheit wünschenswert.

$\mathrm{Zu}$ bedenken ist in diesem Zusammenhang ferner, dass die hier entwickelten Überlegungen ein passender Anlass sein könnten, um den Empirismus in Frage zu stellen, der die fremdsprachendidaktische Forschung aktuell zu dominieren scheint. Dabei lohnt sich einmal mehr der Blick in die Diskurstheorie: Wenn man davon ausgeht, dass manche Forschungsobjekte (wie Bildung, literacy, Bewusstheit, Interkulturelle Kompetenz, etc.) erst durch den jeweiligen Diskurs erzeugt werden, dann wäre auch der empirische Zugriff auf sie nicht als Abbild der Wirklichkeit, sondern als Teil eines Diskurses bzw. der ihm entsprechenden Praxis zu sehen (vgl. Fairclough 1992a: 41f).

Neben der Frage nach der Empiriefähigkeit des Konstruktes lautet eine weitere Frage, wie die hier entwickelten Überlegungen für die Unterrichtspraxis zugänglich gemacht werden können. Eine entscheidende Rolle werden dabei mit Sicherheit die Lehrkräfte spielen. Eine Aufgabe würde also darin bestehen, vielfältige und anschauliche Materialien für die Aus- und Weiterbildung im Hinblick auf Fremdsprachliche Diskursbewusstheit zu entwickeln. Diese wären keineswegs als Gegensatz zu bereits vorliegenden Materialien zum Interkulturellen Lernen zu 
konzipieren, sondern vielmehr als deren Weiterentwicklung unter einer neuen Perspektive. Mit dem Konstrukt Fremdsprachliche Diskursbewusstheit könnten auf diese Weise Problemfelder des (inter-)kulturell ausgerichteten Fremdsprachenunterrichts reflektiert und gleichzeitig eine Umsetzung seiner seit langer Zeit vorliegenden Zielsetzungen angestrebt werden. Deren Kern ist und bleibt die Vorbereitung junger Menschen auf die Teilhabe an einer vielsprachigen und komplexen Welt. 
Jochen Plikat - 978-3-631-70364-9

Downloaded from PubFactory at 01/11/2019 10:12:35AM

via free access 


\section{Abbildungsverzeichnis}

Abb. 1: Fremdsprachliche Diskursbewusstheit

299

\section{Tabellenverzeichnis}

Tab. 1: Norman Faircloughs Modell von Diskursen und Praxen

(Quelle: Fairclough 1989: 29).

218

Tab. 2: Erweitertes Modell von Diskursen und Praxen

219

Tab. 3: Ute Rampillons Modell von language awareness

(Quelle: Rampillon 1997: 176)

244 
Jochen Plikat - 978-3-631-70364-9

Downloaded from PubFactory at 01/11/2019 10:12:35AM

via free access 


\section{Literatur}

Abou, Sélim (1995): Menschenrechte und Kulturen. Bochum: Winkler.

Adelung, Johann Christoph (2001 [1793-1801]): Grammatisch-kritisches Wörterbuch der Hochdeutschen Mundart. Elektronische Volltext- und Faksimile-Edition nach der Ausgabe letzter Hand. Berlin: Directmedia (Digitale Bibliothek).

Adorno, Theodor W. (2006 [1959]): Theorie der Halbbildung. Frankfurt am Main: Suhrkamp.

Altmayer, Claus (2004): Kultur als Hypertext: $z u$ Theorie und Praxis der Kulturwissenschaft im Fach Deutsch als Fremdsprache. München: Iudicium.

Altmayer, Claus (2006): „,Kulturelle Deutungsmuster ${ }^{\circ}$ als Lerngegenstand. Zur kulturwissenschaftlichen Transformation der Landeskunde“. In: Fremdsprachen Lehren und Lernen. 35, S. 44-59.

Altmayer, Claus (2009): „Instrumente für die empirische Erforschung kultureller Lernprozesse im Kontext von Deutsch als Fremdsprache“. In: Hu, Adelheid; Byram, Michael (Hrsg.) Interkulturelle Kompetenz und fremdsprachliches Lernen. Tübingen: Narr, S. 123-138.

Altmayer, Claus (2010): „Konzepte von Kultur im Kontext von Deutsch als Fremd- und Zweitsprache“. In: Krumm, Hans-Jürgen; Fandrych, Christian; Hufeisen, Britta; u. a. (Hrsg.) Deutsch als Fremd- und Zweitsprache. Berlin: Walter de Gruyter, S. 1402-1413.

Altmayer, Claus (2012): „Rezension zu Caspari/Küster: Wege zu interkultureller Kompetenz". In: Fremdsprachen Lehren und Lernen. 41 (1), S. 131-133.

Amnesty International (2008): „Länderkurzbericht Malaysia“. Abgerufen am 02.06.2015 von https://www.amnesty.de/kurzinfo/2008/8/malaysia.

Antor, Heinz (2007): „Inter- multi- und transkulturelle Kompetenz: Bildungsfaktor im Zeitalter der Globalisierung". In: Antor, Heinz (Hrsg.) Fremde Kulturen verstehen - fremde Kulturen lehren: Theorie und Praxis der Vermittlung interkultureller Kompetenz. Heidelberg: Winter (Anglistische Forschungen), S. 111-126.

Ariely, Dan (2008): Predictably irrational: The hidden forces that shape our decisions. New York: Harper Collins.

Assmann, Jan (2003): Die mosaische Unterscheidung: oder der Preis des Monotheismus. München: Carl Hanser.

Association for Language Awareness (2012): „About“. Abgerufen am 07.06.2015 von http://www.languageawareness.org/web.ala/web/about/tout.php. 
$\mathrm{AU}=$ Americans United for Separation of Church and State (o. J.): „Homepage“. Abgerufen am 09.06.2015 von https://www.au.org.

Auernheimer, Georg (2002): „Kultur, Lebenswelt, Diskurs - drei konkurrierende Konzepte“. In: Tertium Comparationis. 8 (2), S. 93-103.

Baasner, Rainer; Zens, Maria (1996): Methoden und Modelle der Literaturwissenschaft: eine Einführung. Berlin: Erich Schmidt.

Baberowski, Jörg (2005): Der Sinn der Geschichte: Geschichtstheorien von Hegel bis Foucault. München: Beck.

Baberowski, Jörg (2006): „Diktaturen der Eindeutigkeit. Ambivalenz und Gewalt im Zarenreich und in der frühen Sowjetunion“. In: Baberowski, Jörg (Hrsg.) Moderne Zeiten? Krieg, Revolution und Gewalt im 20. Jahrhundert. Göttingen: Vandenhoeck \& Ruprecht, S. 37-59.

Bach, Gerhard (2010): „Mediating „Self“ and „Other" in Intercultural Learning“. In: Caspari, Daniela; Küster, Lutz (Hrsg.) Wege zu interkultureller Kompetenz. Frankfurt am Main: Lang (Kolloquium Fremdsprachenunterricht), S. 17-28.

Bach, Gerhard (2007): „Multiliteralität und der europäische Bildungsauftrag“. In: Elsner, Daniela; Küster, Lutz; Viebrock, Britta (Hrsg.) Fremdsprachenkompetenzen für ein wachsendes Europa. Frankfurt / M.: Lang (Kolloquium Fremdsprachenunterricht), S. 23-34.

Bachmann-Medick, Doris (2004): „Einleitung“. In: Bachmann-Medick, Doris; Clifford, James (Hrsg.) Kultur als Text. 2. Aufl. Tübingen: Francke (UTB Literaturwissenschaft, Kulturwisssenschaft), S. 7-64.

Bachmann-Medick, Doris (2006): Cultural Turns: Neuorientierungen in den Kulturwissenschaften. Reinbek: Rowohlt Taschenbuch Verlag (Rowohlts Enzyklopädie).

Baecker, Dirk (2001): Wozu Kultur? Berlin: Kadmos.

Baraldi, Claudio; Corsi, Giancarlo; Esposito, Elena (1997): GLU. Glossar zu Niklas Luhmanns Theorie sozialer Systeme. Frankfurt am Main: Suhrkamp.

Barthes, Roland (1966): „Introduction à l'analyse structurale des récits“. In: Communications. 8 (1), S. 1-27.

Barthes, Roland (1967): „Le discours de l'histoire“. In: Social Science Information. 6 (4), S. 63-75.

Baumgart, Franzjörg (2007): Erziehungs- und Bildungstheorien: Erläuterungen Texte - Arbeitsaufgaben. 3. Aufl. Bad Heilbrunn: Klinkhardt.

Bechtel, Mark (2003): Interkulturelles Lernen beim Sprachenlernen im Tandem. Eine diskursanalytische Untersuchung. Tübingen: Narr.

Bechtel, Mark (2009): „Empirische Untersuchung zu interkulturellem Lernen in deutsch-französischen Tandemkursen mit Hilfe der Diskursanalyse“. In: 
Hu, Adelheid; Byram, Michael (Hrsg.) Interkulturelle Kompetenz und fremdsprachliches Lernen. Tübingen: Narr, S. 139-158.

Bechtel, Mark (2013): „Förderung interkultureller Kompetenzen im Französischunterricht: Analyse einer Aufgabe aus Band 1 des Lehrwerks Découvertes - Série jaune“. In: Grünewald, Andreas; Plikat, Jochen; Wieland, Katharina (Hrsg.) Bildung - Kompetenz - Literalität: Fremdsprachenunterricht zwischen Standardisierung und Bildungsanspruch. Seelze: Friedrich-Verlag/Klett-Kallmeyer, S. 110-122.

Becht, Lukas; Geng, Johannes; Hirschfeld, Alexander (2010): „Zentrum und Peripherie im System der Massenmedien - Der partizipative Online-Journalismus und die Realität der Massenmedien 2.0“. In: Arbeitsgruppe „Zentrum und Peripherie in soziologischen Differenzierungstheorien“ (Hrsg.) Mythos Mitte. Wiesbaden: VS Verlag für Sozialwissenschaften / Springer Fachmedien Wiesbaden GmbH, Wiesbaden, S. 185-194.

Becker, Werner (1982): „Philosophischer Absolutismus und lebenspraktische Gewissheit“. In: Kuhlmann, Wolfgang; Böhler, Dietrich (Hrsg.) Kommunikation und Reflexion: zur Diskussion der Transzendentalpragmatik: Antworten auf Karl-Otto Apel. Frankfurt am Main: Suhrkamp, S. 288-303.

Beck, Ulrich (1986): Risikogesellschaft: auf dem Weg in eine andere Moderne. Frankfurt am Main: Suhrkamp (Edition Suhrkamp).

Beck, Ulrich (1993): Die Erfindung des Politischen: Zu einer Theorie reflexiver Modernisierung. Frankfurt am Main: Suhrkamp.

Beck, Ulrich (2002): Macht und Gegenmacht im globalen Zeitalter: neue weltpolitische Ökonomie. Frankfurt am Main: Suhrkamp.

Beck, Ulrich (2007): Was ist Globalisierung? Irrtümer des Globalismus - Antworten auf Globalisierung. Frankfurt am Main: Suhrkamp.

Benedict, Ruth (1989 [1934]): Patterns of culture. Boston [u.a.]: Houghton Mifflin.

Benkler, Yochai (2006): The wealth of networks: How social production transforms markets and freedom. New Haven Conn. u.a.: Yale Univ. Pr.

Bennett, Milton (1986): „A Developmental Approach To Training For Intercultural Sensitivity“. In: International Journal of Intercultural Relations. 10 (2), S. 179-196.

Berghaus, Margot (2011): Luhmann leicht gemacht: Eine Einführung in die Systemtheorie. 3. Aufl. Köln: Böhlau.

Bhabha, Homi K. (1994): The location of culture. London; New York: Routledge.

Bialystok, Ellen (1978): „A theoretical model of second language learning“. In: Language Learning. 28, S. 69-84. 
Bielefeldt, Heiner (1995): „Auf dem Weg zum interkulturellen Menschenrechtskonsens“. In: Piazolo, Michael (Hrsg.) Kulturelle Identität zwischen Tradition und Modernität: Zur Bedeutung sozio-kultureller Faktoren in der entwicklungspolitischen Zusammenarbeit. München: Akademischer Verlag, S. 97-112.

Bielefeldt, Heiner (1996): „Menschenrechte und Toleranz“. In: Wierlacher, Alois (Hrsg.) Kulturthema Toleranz: zur Grundlegung einer interdisziplinären und interkulturellen Toleranzforschung. München: Iudicium (Kulturthemen), S. 117-128.

Bielefeldt, Heiner (1997): „Menschenrechte - universaler Normkonsens oder eurozentrischer Kulturimperialismus?". In: Brocker, Manfred; Nau, Heino H. (Hrsg.) Ethnozentrismus: Möglichkeiten und Grenzen des interkulturellen Dialogs. Darmstadt: Wissenschaftliche Buchgesellschaft, S. 256-268.

Bieri, Peter (1994): „Was macht Bewusstsein zu einem Rätsel?“. In: Singer, Wolf (Hrsg.) Gehirn und Bewusstsein. Heidelberg; Berlin; Oxford: Spektrum Akad. Verl., S. 172-180.

Bischof, Monika; Kessling, Viola; Krechel, Rüdiger (1999): Landeskunde und Literaturdidaktik. Berlin: Langenscheidt.

Bleyhl, Werner (1994): „Das Lernen von Fremdsprachen ist interkulturelles Lernen“. In: Bausch, Karl-Richard; Christ, Herbert; Krumm, Hans-Jürgen (Hrsg.) Interkulturelles Lernen im Fremdsprachenunterricht. Tübingen: G. Narr, S. 9-20.

Bliesener, Ulrich (2002): „Vom interkulturellen Lernen“. In: Fehrmann, Georg; Klein, Erwin (Hrsg.) Interkulturelles Lernen im Fremdsprachenunterricht. Bonn: Romanistischer Verlag, S. 13-40.

Bluhm, Claudia; Deissler, Dirk; Scharloth, Joachim; u. a. (2000): „Linguistische Diskursanalyse: Überblick, Probleme, Perspektiven“. In: Sprache und Literatur in Wissenschaft und Unterricht. 88, S. 3-19.

Boas, Franz (1888): „The Indians of British Columbia“. In: Popular Science Monthly. 32 (37), S. 628-636.

Boas, Franz (1963 [1911]): The mind of primitive man. New York: Collier Books. Bohman, James (2004): „Expanding dialogue: The Internet, the public sphere and prospects for transnational democracy“. In: Crossley, Nick; Roberts, John Michael (Hrsg.) After Habermas: New perspectives on the public sphere. Oxford: Blackwell, S. 131-155.

Böhme, Hartmut (1996): „Vom Cultus zur Kultur(wissenschaft).Zur historischen Semantik des Kulturbegriffs". In: Glaser, Renate; Luserke, Matthias (Hrsg.) Literaturwissenschaft - Kulturwissenschaft: Positionen, Themen, Perspektiven. Opladen: Westdt. Verl., S. 48-68. 
Bonner, Raymond (2011): „The Media and 9/11: How We Did“. The Atlantic. Abgerufen am 11.07.2015 von http://www.theatlantic.com/national/archive/2011/09/ the-media-and-9-11-how-we-did/244818/.

Bonnet, Andreas; Breidbach, Stephan (2007): „Reflexion inszenierbar machen Die Bedeutung der Bildungsgangforschung für die Fremdsprachendidaktik“. In: Decke-Cornill, Helene; Hu, Adelheid; Meyer, Meinert A. (Hrsg.) Sprachen lernen und lehren. Die Perspektive der Bildungsgangsforschung. Opladen: Budrich, S. 251-270.

Bonnet, Andreas; Breidbach, Stephan (2013): „Blut ist im Schuh: Wie gut kleidet der Kompetenzbegriff die literarisch-ästhetische Bildung beim Tanz auf dem Hofball der Standardisierung?". In: Grünewald, Andreas; Plikat, Jochen; Wieland, Katharina (Hrsg.) Bildung - Kompetenz - Literalität: Fremdsprachenunterricht zwischen Standardisierung und Bildungsanspruch. Seelze: FriedrichVerlag/Klett-Kallmeyer, S. 20-35.

Bonnet, Andreas; Breidbach, Stephan; Hallet, Wolfgang (2009): „Fremdsprachlich handeln im Sachfach: Bilinguale Lernkontexte“. In: Bach, Gerhard; Timm, Johannes-Peter (Hrsg.) Englischunterricht. 4. Aufl. Tübingen, Basel: Francke, S. $172-198$.

Borges, Jorge Luis (1996): Otras inquisiciones. Buenos Aires: Emecé.

Bourdieu, Pierre (1980): Le sens pratique. Paris: Éditions de Minuit (Le Sens commun).

Brecht, Bertolt (1990): „Radiotheorie: 1927 bis 1932“. In: Hauptmann, Elisabeth (Hrsg.) Schriften zur Literatur und Kunst 1. Frankfurt am Main: Suhrkamp (Gesammelte Werke), S. 119-134.

Bredella, Lothar (1994): „Interkulturelles Verstehen zwischen Objektivismus und Relativismus". In: Bausch, Karl-Richard; Christ, Herbert; Krumm, Hans-Jürgen (Hrsg.) Interkulturelles Lernen im Fremdsprachenunterricht. Tübingen: G. Narr, S. 21-30.

Bredella, Lothar (1999): „Zielsetzungen interkulturellen Fremdsprachenunterrichts“. In: Bredella, Lothar; Delanoy, Werner (Hrsg.) Interkultureller Fremdsprachenunterricht. Tübingen: Narr, S. 85-120.

Bredella, Lothar (2000): „Fremdverstehen mit literarischen Texten“. In: Bredella, Lothar; Meißner, Franz-Joseph; Nünning, Ansgar; u. a. (Hrsg.) Wie ist Fremdverstehen lehr- und lernbar? Vorträge aus dem Graduiertenkolleg „Didaktik des Fremdverstehens". Tübingen: Narr, S. 133-163.

Bredella, Lothar (2001): ,Zur Dialektik von Eigenem und Fremdem beim interkulturellen Verstehen“. In: Der fremdsprachliche Unterricht Englisch. (5), S. 10-15.

Bredella, Lothar (2002): Literarisches und interkulturelles Verstehen. Tübingen: Narr (Giessener Beiträge zur Fremdsprachendidaktik). 
Bredella, Lothar (2007): „Fremde Welten entwerfen: Der Bildungssinn literarischer Texte“. In: Fäcke, Christiane; Wangerin, Wolfgang (Hrsg.) Neue Wege zu und mit literarischen Texten. Baltmannsweiler: Schneider Verlag Hohengehren, S. 30-50.

Bredella, Lothar (2010a): Das Verstehen des Anderen: Kulturwissenschaftliche und literaturdidaktische Studien. Tübingen: Narr.

Bredella, Lothar (2010b): „Trans- oder Interkulturalität als Bildungsziel des Fremdsprachenlehrens und -lernens?". In: ForumSprache. (4), S. 21-41.

Bredella, Lothar (2012): „Transkulturalität als Herausforderung für das interkulturelle Verstehen“. In: Fäcke, Christiane; Martinez, Hélène; Meißner, FranzJoseph (Hrsg.) Mehrsprachigkeit: Bildung - Kommunikation - Standards; [3. Bundeskongress des GMF]. Stuttgart [u.a.]: Klett, S. 39-56.

Bredella, Lothar; Christ, Herbert (1995): Didaktik des Fremdverstehens. Tübingen: Gunter Narr.

Bredella, Lothar; Delanoy, Werner (1999): Interkultureller Fremdsprachenunterricht. Tübingen: Narr.

Bredella, Lothar; Meißner, Franz-Joseph; Nünning, Ansgar; u. a. (2000): „Grundzüge einer Theorie und Didaktik des Fremdverstehens beim Lehren und Lernen fremder Sprachen “. In: Bredella, Lothar; Meißner, Franz-Joseph; Nünning, Ansgar; u. a. (Hrsg.) Wie ist Fremdverstehen lehr- und lernbar?. Tübingen: Narr, S. IX-LII.

Breidbach, Stephan (2003): „Transkulturalität: Paradigma für den bilingualen Sachfachunterricht“. In: Eckerth, Johannes; Wendt, Michael (Hrsg.) Interkulturelles und transkulturelles Lernen im Fremdsprachenunterricht. Frankfurt am Main: Lang, S. 219-234.

Breidbach, Stephan (2004): „Bildung, Kultur, Wissenschaft: Grundzüge einer reflexiven Wissenschaftsdidaktik für den bilingualen Sachfachunterricht". In: Bonnet, Andreas; Breidbach, Stephan (Hrsg.) Didaktiken im Dialog. Frankfurt am Main: Lang, S. 153-164.

Breidbach, Stephan (2007): Bildung, Kultur, Wissenschaft: Reflexive Didaktik für den bilingualen Sachfachunterricht. Münster: Waxmann.

Breugnot, Jacqueline (2000): „Fremdsprachen“. In: Reich, Hans H.; Holzbrecher, Alfred; Roth, Hans-Joachim (Hrsg.) Fachdidaktik interkulturell. Opladen: Leske + Budrich, S. 287-311.

Bundesverfassungsgericht (2003): „Beschluss vom 29. April 2003 - 1 BvR 436/03“. Abgerufen am 30.04.2015 von http://www.bundesverfassungsgericht.de/ent scheidungen/rk20030429_1bvr043603.html. 
Bundeszentrale für politische Bildung (2011): „Beutelsbacher Konsens“. Abgerufen am 14.04.2015 von http://www.bpb.de/die-bpb/51310/beutelsbacherkonsens.

Burwitz-Melzer, Eva (2005): „Kompetenzen für den Literaturunterricht heute: Ein Beitrag zur standardorientierten Didaktik des Fremdsprachenunterrichts". In: Fremdsprachen Lehren und Lernen. 34, S. 94-110.

Burwitz-Melzer, Eva (2006): „Interkulturelles und sprachliches Lernen mit fremdsprachlichen literarischen Texten: Zwei zentrale Elemente eines neuen Lesekompetenzmodells“. In: Fremdsprachen Lehren und Lernen. 35, S. 104120.

Burwitz-Melzer, Eva (2012): „Sprachenbewusstheit als Teilkompetenz des FSU“. In: Burwitz-Melzer, Eva; Königs, Frank G.; Krumm, Hans-Jürgen (Hrsg.) Sprachenbewusstheit im Fremdsprachenunterricht: Arbeitspapiere der 32. Frühjahrskonferenz zur Erforschung des Fremdsprachenunterrichts. Tübingen: Narr (Giessener Beiträge zur Fremdsprachendidaktik), S. 27-39.

Burwitz-Melzer, Eva; Königs, Frank G.; Krumm, Hans-Jürgen (Hrsg.) (2012): Sprachenbewusstheit im Fremdsprachenunterricht: Arbeitspapiere der 32. Frühjahrskonferenz zur Erforschung des Fremdsprachenunterrichts. Tübingen: Narr (Giessener Beiträge zur Fremdsprachendidaktik).

Byram, Michael (1997): Teaching and assessing intercultural communicative competence. Clevedon: Multilingual Matters.

Byram, Michael (Hrsg.) (2004): Routledge encyclopedia of language teaching and learning. London: Routledge.

Byram, Michael (2008): „Education for Intercultural Citizenship: Language teaching and Education for Citizenship - in Europe and beyond“. In: Doff, Sabine; Hüllen, Werner; Klippel, Friederike (Hrsg.) Visionen der Bildung durch Sprachen. Berlin; Zürich: Langenscheidt, S. 65-75.

Byram, Michael (2009): „Evaluation and/or Assessment of Intercultural Competence". In: Hu, Adelheid; Byram, Michael (Hrsg.) Interkulturelle Kompetenz und fremdsprachliches Lernen. Tübingen: Narr, S. 215-234.

Cambridge Dictionary Online (o. J.): „Eintrag ,secularism“. Abgerufen am 09.06.2015 von http://dictionary.cambridge.org/us/dictionary/british/secula rism? $\mathrm{q}=$ secularism.

Camerer, Rudolf (2007): „Sprache als Quelle aller Missverständnisse. Zum Verhältnis von Interkultureller Kompetenz und Sprachkompetenz". In: Zeitschrift für Interkulturellen Fremdsprachenunterricht. 12 (3), S. 11.

Caspari, Daniela (2008): „Zu den „Interkulturellen Kompetenzen“ in den Bildungsstandards“. In: Fäcke, Christiane; Hülk, Walburga; Klein, Franz-Josef 
(Hrsg.) Multiethnizität, Migration und Mehrsprachigkeit. Stuttgart: ibidemVerl., S. 19-35.

Caspari, Daniela; Küster, Lutz (2010): Wege zu interkultureller Kompetenz: Fremdsprachendidaktische Aspekte der Text- und Medienarbeit. Frankfurt am Main: Lang.

Cassany, Daniel (2007): „Aprender a escribir en español en la Europa plurilingüe“. In: Der fremdsprachliche Unterricht Spanisch. (17), S. 4-8.

Cassirer, Ernst (1994 [1942]): Zur Logik der Kulturwissenschaften: fünf Studien. 6. Aufl. Darmstadt: Wiss. Buchges.

Chua, Amy (2009): Day of empire: how hyperpowers rise to global dominance and why they fall. New York: Anchor Books.

Clarke, Austin (2003): Choosing his coffin: the best stories of Austin Clarke. Toronto: Thomas Allen Publishers.

Cope, Bill; Kalantzis, Mary (2010): „New Media, New Learning“. In: Cole, David R.; Pullen, Darren L. (Hrsg.) Multiliteracies in motion. New York: Routledge, S. 87-104.

Council of Europe (1982): Recommendation no. $R$ (98) 6 of the Committee of Ministers to Member States concerning modern languages. Strasbourg: Council of Europe.

Council of Europe (2010): Council of Europe Charter on Education for Democratic Citizenship and Human Rights Education: Recommendation CM/Rec (2010) 7 adopted by the Committee of Ministers of the Council of Europe on 11 May 2010 and explanatory memorandum. Strasbourg: Council Of Europe Publishing.

Cummins, James (1978): „Bilingualism and the development of metalinguistic awareness". In: Journal of Cross Cultural Psychology. (9), S. 131-149.

Dalton-Puffer, Christiane (2013): „Diskursfunktionen und generische Ansätze“. In: Hallet, Wolfgang; Königs, Frank G. (Hrsg.) Handbuch Bilingualer Unterricht. Seelze: Klett-Kallmeyer, S. 138-145.

Damasio, Antonio R. (2007): Der Spinoza-Effekt: Wie Gefühle unser Leben bestimmen. 4. Aufl. Berlin: List.

Decke-Cornill, Helene; Küster, Lutz (2015): Fremdsprachendidaktik: eine Einführung. 3. Aufl. Tübingen: narr/francke/attempto.

DeKeyser, Robert M. (2009): „Cognitive-Psychological Processes in Second Language Learning“. In: Long, Michael H.; Doughty, Catherine (Hrsg.) The handbook of language teaching. Chichester, U.K.; Malden, MA: Wiley-Blackwell (Blackwell handbooks in linguistics), S. 119-138. 
Dennett, Daniel C. (1991): Consciousness explained. Boston: Little, Brown and Co.

Dennett, Daniel C. (2002): „Where am I?“. In: Levitin, Daniel J. (Hrsg.) Foundations of cognitive psychology: core readings. Cambridge, Mass.: MIT Press, S. 23-34.

DES = Department of Education and Science (1975): „A Language for Life. Report of a Committee of Enquiry under the Chairmanship of Sir Alan Bullock“. Abgerufen am 14.04.2015 von http://www.educationengland.org.uk/ documents/bullock/.

Der Heilige Stuhl (1997): „Katechismus der katholischen Kirche“. Abgerufen am 13.06.2015 von http://www.vatican.va/archive/DEU0035/_P8B.HTM.

Desai, Neal; Pineda, Andre; Runquist, Majken; u. a. (2010): „Torture at Times: Waterboarding in the Media". Harvard Student Paper. Abgerufen am 11.07.2015 von http://nrs.harvard.edu/urn-3:HUL.InstRepos:4420886.

Dettmeyer, Reinhard (2006): Medizin \& Recht. Rechtliche Sicherheit für den Arzt. Heidelberg: Springer Medizin.

Deutscher Bundestag (2012): „Entwurf eines Gesetzes über den Umfang der Personensorge bei einer Beschneidung des männlichen Kindes. Drucksache 17/ 11295“. Abgerufen am 02.06.2015 von http://dip21.bundestag.de/dip21/ btd/17/112/1711295.pdf.

Deutscher Ethikrat (2012): „Pressemitteilung 9/2012: Ethikrat empfiehlt rechtliche und fachliche Standards für die Beschneidung". Abgerufen am 02.06.2015 von http://www.ethikrat.org/dateien/pdf/pressemitteilung-09-2012-empfeh lungen-fuer-die-beschneidung.pdf.

Diaz-Bone, Rainer; Krell, Gertraude (2009): „Einleitung: Diskursforschung und Ökonomie“. In: Diaz-Bone, Rainer; Krell, Gertraude (Hrsg.) Diskurs und Ökonomie Diskursanalytische Perspektiven auf Märkte und Organisationen. Wiesbaden: VS Verlag für Sozialwissenschaften / GWV Fachverlage GmbH, Wiesbaden, S. 9-34.

Donmall, B. Gillian (Hrsg.) (1985): Language awareness. London: Centre for Information on Language Teaching and Research.

Döring, Eberhard (1992): Karl R. Popper: Einführung in Leben und Werk. 2. Aufl. Bonn: Parerga.

Du Bois Reymond, Emil Heinrich (1872): Über die Grenzen des Naturerkennens. Leipzig: Veit.

Duerr, Hans Peter (1978): Traumzeit: über die Grenze zwischen Wildnis und Zivilisation. Frankfurt am Main: Suhrkamp.

Eckerth, Johannes; Wendt, Michael (2003): Interkulturelles und transkulturelles Lernen im Fremdsprachenunterricht. Frankfurt am Main: Lang. 
Edmondson, Willis (1997): „Sprachlernbewusstheit und Motivation beim Fremdsprachenlernen“. In: Fremdsprachen Lehren und Lernen. 26, S. 88-110.

EKD = Evangelische Kirche in Deutschland (Hrsg.) (1992): Stuttgarter Erklärungsbibel: die Heilige Schrift [Bibeltext in der revidierten Fassung von 1984]. Stuttgart: Deutsche Bibelgesellschaft.

Ellis, Rod (1997): SLA research and language teaching. Oxford; New York: Oxford University Press.

Elsner, Daniela; Küster, Lutz; Viebrock, Britta (2007): Fremdsprachenkompetenzen für ein wachsendes Europa: Das Leitziel „Multiliteralität“; [ausgewählte Beiträge der Internationalen Tagung „Multiliteralität und der Europäische Bildungsauftrag", die im Juni 2006 in Bremen stattfand]. Frankfurt / M.: Lang.

Engel, Gerhard (2007): „Die offene Gesellschaft und ihre neuen Feinde“. In: Aufklärung und Kritik. (13), S. 96-122.

Enzensberger, Hans Magnus (1970): „Baukasten zu einer Theorie der Medien“. In: Kursbuch. 20, S. 159-186.

Enzensberger, Hans Magnus (1982): „Eurozentrismus wider Willen. Ein politisches Vexierbild“. In: Politische Brosamen. Frankfurt am Main: Suhrkamp, S. 31-52.

Enzensberger, Hans Magnus (1988): Mittelmaß und Wahn. Frankfurt am Main: Suhrkamp.

Eriksen, Jens-Martin; Stjernfelt, Frederik (2012): The democratic contradictions of multiculturalism. New York, NY: Telos Press Pub.

Eugenides, Jeffrey (1993): The virgin suicides. New York: Warner Books.

Europarat (2001) (Hrsg.): GeR = Gemeinsamer europäischer Referenzrahmen für Sprachen: Lernen, lehren, beurteilen [Niveau A1, A2, B1, B2, C1, C2]. Berlin: Langenscheidt.

Fäcke, Christiane (2013): „Weiche Kompetenzen“ als Prüfstein zur Integration von Bildung und Standards". In: Grünewald, Andreas; Plikat, Jochen; Wieland, Katharina (Hrsg.) Bildung - Kompetenz - Literalität: Fremdsprachenunterricht zwischen Standardisierung und Bildungsanspruch. Seelze: Friedrich-Verlag/ Klett-Kallmeyer, S. 36-46.

Fairclough, Norman (1989): Language and power. London: Longman.

Fairclough, Norman (1992a): Discourse and social change. Cambridge: Polity.

Fairclough, Norman (1992b): „Introduction“. In: Fairclough, Norman (Hrsg.) Critical language awareness. London; New York: Longman, S. 1-29.

Fairclough, Norman (1992c): „The appropriacy of ,appropriateness“. In: Fairclough, Norman (Hrsg.) Critical language awareness. London; New York: Longman, S. 33-56. 
Fairclough, Norman (1995): Critical discourse analysis: The critical study of language. London; New York: Longman.

Fairclough, Norman (2003): Analysing discourse: Textual analysis for social research. London; New York: Routledge.

Fehling, Sylvia (2008): Language awareness und bilingualer Unterricht. Frankfurt am Main: Peter Lang.

Feyerabend, Paul (2004): Wider den Methodenzwang. Frankfurt am Main: Suhrkamp.

Flynn, James Robert (2012): Are we getting smarter? Rising IQ in the twenty-first century. Cambridge; New York: Cambridge University Press.

Forst, Rainer (2003): Toleranz im Konflikt: Geschichte, Gehalt und Gegenwart eines umstrittenen Begriffs. Frankfurt am Main: Suhrkamp.

Foucault, Michel (1969): Larchéologie du savoir. Paris: Gallimard.

Foucault, Michel (1971a): Lordre du discours: Leçon inaugurale au Collège de France prononcée le 2 dećembre 1970. Paris: Gallimard.

Foucault, Michel (1971b): „Nietzsche, la généalogie et l'histoire“. In: Bachelard, Suzanne (Hrsg.) Hommage à Jean Hyppolite. Paris: Presses Universitaires de France, S. 145-172.

Foucault, Michel (1972): Histoire de la folie à lâge classique. Paris: Gallimard.

Foucault, Michel (1976): Histoire de la sexualité. Paris: Gallimard.

Foucault, Michel (1997): Il faut défendre la société: cours au Collège de France, 1975-1976. Paris: Gallimard/Seuil (Hautes études).

Foucault, Michel (2006 [1975]): Surveiller et punir: Naissance de la prison. Paris: Gallimard.

Foucault, Michel (2007 [1966]): Les mots et les choses: Une archéologie des sciences humaines. Paris: Gallimard.

Frank, Manfred (1988): „Zum Diskursbegriff bei Foucault“. In: Fohrmann, Jürgen; Müller, Harro (Hrsg.) Diskurstheorien und Literaturwissenschaft. Frankfurt am Main: Suhrkamp (Suhrkamp Taschenbuch Materialien), S. 25-44.

Freire, Paulo (1993): Pädagogik der Unterdrückten: Bildung als Praxis der Freiheit. Reinbek bei Hamburg: Rowohlt.

Freire, Paulo (2009): „From Pedagogy of the Oppressed“. In: Darder, Antonia; Baltodano, Marta; Torres, Rodolfo D. (Hrsg.) The critical pedagogy reader. 2. Aufl. New York, NY: Routledge, S. 52-60.

Freud, Sigmund (2004 [1930]): Das Unbehagen in der Kultur und andere kulturtheoretische Schriften. Frankfurt am Main: Fischer-Taschenbuch-Verl. 
Freud, Sigmund (2012): Psychologie des Unbewußten (1912). 11. Aufl. Frankfurt am Main: S. Fischer (Freud-Studienausgabe in 10 Bänden. Hrsg. von Alexander Mitscherlich).

Freundlieb, Dieter (1975): „Zur Problematik einer Diskurstheorie der Wahrheit“. In: Zeitschrift für allgemeine Wissenschaftstheorie. VI (1), S. 82-107.

Fuller, Gary; Stecker, Robert; Wright, John P. (Hrsg.) (2000): John Locke. An essay concerning human understanding. London; New York: Routledge (Routledge philosophers in focus series).

Fundación Tomás de Aquino (2000): „Sancti Thomae de Aquino Quaestiones disputatae de veritate“. Corpus Thomisticum. Abgerufen am 09.06.2015 von http://www.corpusthomisticum.org/qdv15.html.

Gadamer, Hans-Georg (1975): Wahrheit und Methode: Grundzüge einer philosophischen Hermeneutik. 4. Aufl. Tübingen: Mohr.

Galeano, Eduardo (1993): El Libro de los abrazos: imágenes y palabras. Madrid: Siglo Veintiuno de España.

García Márquez, Gabriel (2003 [1981]): Crónica de una muerte anunciada. Barcelona: Debolsillo Random House Mondadori.

Garrett, Peter; James, Carl (1991): „Language Awareness: A way ahead“. In: James, Carl; Garrett, Peter (Hrsg.) Language awareness in the classroom. London; New York: Longman (Applied linguistics and language study), S. 306-318.

Garrett, Peter; James, Carl (2004): „Language awareness“. In: Byram, Michael (Hrsg.) Routledge encyclopedia of language teaching and learning. London: Routledge, S. 330-333.

Gazzaniga, Michael S. (2012): Die Ich-Illusion: wie Bewusstsein und freier Wille entstehen. München: Hanser.

Geertz, Clifford (1973): The interpretation of cultures: selected essays. New York: Basic Books.

Geertz, Clifford (1984): „Distinguished Lecture: Anti Anti-Relativism“. In: American Anthropologist. 86 (2), S. 263-278.

Glasenapp, Helmuth von (1996): Die fünf Weltreligionen: Hinduismus, Buddhismus, chinesischer Universismus, Christentum, Islam. München: Diederichs.

Glasersfeld, Ernst von; Köck, Wolfram Karl (2005): Radikaler Konstruktivismus: Ideen, Ergebnisse, Probleme. 1. Aufl., [Nachdr.]. Frankfurt am Main: Suhrkamp.

Gnutzmann, Claus (1997): „Language awareness. Geschichte, Grundlagen, Anwendungen“. In: Praxis des neusprachlichen Unterrichts. 3, S. 227-236.

Gnutzmann, Claus (2007): „Language Awareness, Sprachbewusstheit, Sprachbewusstsein". In: Bausch, Karl-Richard; Christ, Herbert; Krumm, Hans-Jürgen (Hrsg.) Handbuch Fremdsprachenunterricht. 5. Aufl. Tübingen: Francke. 
Gnutzmann, Claus (2010a): „Bewusstheit/Bewusstmachung“. In: Surkamp, Carola (Hrsg.) Metzler Lexikon Fremdsprachendidaktik: Ansätze, Methoden, Grundbegriffe. Stuttgart: Metzler, S. 16-17.

Gnutzmann, Claus (2010b): „Language Awareness“. In: Hallet, Wolfgang; Königs, Frank G. (Hrsg.) Handbuch Fremdsprachendidaktik. Seelze-Velber: Klett-Kallmeyer, S. 115-119.

Göller, Thomas (2003): „Menschenrechte und Interkulturalität“. In: Wierlacher, Alois; Bogner, Andrea (Hrsg.) Handbuch interkulturelle Germanistik. Stuttgart: J.B. Metzler, S. 126-132.

Government of Malaysia (2009): „Federal Constitution“. Abgerufen am 02.06.2015 von http://www.jac.gov.my/images/stories/akta/federalconstitution.pdf.

Granovetter, Mark (1973): „The Strength of Weak Ties“. In: American Journal of Sociology. 78 (6), S. 1360-1380.

Grotjahn, Rüdiger (2006): „Zur Methodologie der Fremdsprachenerwerbsforschung". In: Scherfer, Peter (Hrsg.) Vom Lehren und Lernen fremder Sprachen. Frankfurt am Main: Lang, S. 247-270.

Grünewald, Andreas; Küster, Lutz; Lüning, Marita (2011): „Kultur und Interkulturalität“. In: Meißner, Franz-Joseph; Krämer, Ulrich (Hrsg.) Spanischunterricht gestalten: Wege zu Mehrsprachigkeit und Mehrkulturalität. Seelze: KlettKallmeyer, S. 49-80.

Gudjons, Herbert (2006): Pädagogisches Grundwissen: Überblick, Kompendium, Studienbuch. 9. Aufl. Bad Heilbrunn: Klinkhardt.

Haberland, Hartmut (1999): „Text, discourse, discours: The latest report from the Terminology Vice Squad“. In: Journal of Pragmatics. 31, S. 911-918.

Habermas, Jürgen (1971): „Vorbereitende Bemerkungen zu einer Theorie der kommunikativen Kompetenz". In: Habermas, Jürgen; Luhmann, Niklas (Hrsg.) Theorie der Gesellschaft oder Sozialtechnologie. Frankfurt am Main: Suhrkamp, S. 101-141.

Habermas, Jürgen (1984): Vorstudien und Ergänzungen zur Theorie des kommunikativen Handelns. Frankfurt am Main: Suhrkamp.

Habermas, Jürgen (1988a): Der philosophische Diskurs der Moderne: Zwölf Vorlesungen. Frankfurt am Main: Suhrkamp.

Habermas, Jürgen (1988b [1981]): Theorie des kommunikativen Handelns Band 1. Frankfurt am Main: Suhrkamp.

Habermas, Jürgen (2006a): „Ein avantgardistischer Spürsinn für Relevanzen: Was den Intellektuellen auszeichnet“. In: Blätter für deutsche und internationale Politik. (5), S. 551-557. 
Habermas, Jürgen (2006b): „Political Communication in Media Society: Does Democracy Still Enjoy an Epistemic Dimension? The Impact of Normative Theory on Empirical Research". In: Communication Theory. 16, S. 411-426.

Habermas, Jürgen (2006c): Strukturwandel der Öffentlichkeit: Untersuchungen zu einer Kategorie der bürgerlichen Gesellschaft; mit einem Vorwort zur Neuauflage 1990. Frankfurt am Main: Suhrkamp.

Habermas, Jürgen (2008): „Medien, Märkte und Konsumenten - die seriöse Presse als Rückgrat der politischen Öffentlichkeit“. In: Habermas, Jürgen (Hrsg.) Ach, Europa. Frankfurt am Main: Suhrkamp, S. 131-137.

Habermas, Jürgen (2010): „Keine Demokratie kann sich das leisten“. Süddeutsche Zeitung online. Abgerufen am 14.04.2015 von http://www.sueddeutsche.de/ kultur/juergen-habermas-keine-demokratie-kann-sich-das-leisten-1.892340.

Hahn, Alois (1994): „Die soziale Konstruktion des Fremden“. In: Sprondel, Walter M. (Hrsg.) Die Objektivität der Ordnungen und ihre kommunikative Konstruktion. Frankfurt am Main: Suhrkamp, S. 140-163.

Haimerl, Kathrin (2010): „Dipl.-Deutsche“. Süddeutsche Zeitung online. Abgerufen am 14.04.2015 von http://www.sueddeutsche.de/politik/einbuergerungs test-dipl-deutsche-1.212662.

Hallet, Wolfgang (2002): Fremdsprachenunterricht als Spiel der Texte und Kulturen: Intertextualität als Paradigma einer kulturwissenschaftlichen Didaktik. Trier: WVT Wiss. Verl. Trier.

Hallet, Wolfgang (2007): „Close Reading and Wide Reading. Literature and Cultural History in a Unit on Philip K. Dick's ,Minority Report“'. In: American Studies / Amerikastudien. 52 (3), S. 381-397.

Hallet, Wolfgang (2008): „Diskursfähigkeit heute. Der Diskursbegriff in Piephos Theorie der kommunikativen Kompetenz und seine zeitgemäße Weiterentwicklung für die Fremdsprachendidaktik.". In: Legutke, Michael (Hrsg.) Kommunikative Kompetenz als fremdsprachendidaktische Vision. Tübingen: Narr, S. 76-96.

Hallet, Wolfgang (2011a): „Generisches Lernen. Muster und Strukturen der sprachlichen Interaktion erkennen und anwenden“. In: Der fremdsprachliche Unterricht Englisch. (114), S. 2-11.

Hallet, Wolfgang (2011b): Lernen fördern: Englisch: Unterricht in der Sekundarstufe. Seelze: Kallmeyer.

Hallet, Wolfgang (2012): „Die komplexe Kompetenzaufgabe. Fremdsprachige Diskursfähigkeit als kulturelle Teilhabe und Unterrichtspraxis.“. In: Hallet, Wolfgang; Krämer, Ulrich (Hrsg.) Kompetenzaufgaben im Englischunterricht. Seelze: Friedrich, S. 8-19. 
Hardy, Elaine (2013): „The Motorcycle Helmet Law“. Right to Ride. Abgerufen am 18.05.2015 von http://www.righttoride.co.uk/2013/02/07/motorcyclehelmet-law/.

Harris, Zellig S. (1952): „Discourse Analysis“. In: Language. 28, S. 1-30.

Häussler, Thomas (2006): „Die kritische Masse der Medien: Massenmedien und deliberative Demokratie. Skizze zu einer analytischen Umsetzung“. In: Imhof, Kurt; Blum, Roger; Bonfadelli, Heinz; u. a. (Hrsg.) Demokratie in der Mediengesellschaft. Wiesbaden: VS Verlag für Sozialwissenschaften (Mediensymposium Luzern), S. 304-318.

Hawkins, Eric W. (1984): Awareness of language: an introduction. Cambridge; New York: Cambridge University Press.

Hentig, Hartmut von (2004): Bildung: ein Essay. Weinheim; Basel: Beltz.

Herbst, Catharina (2004a): „Crónica de una muerte anunciada“. In: Der fremdsprachliche Unterricht Spanisch. 5, S. 40-51.

Herbst, Catharina (2004b): „Interkulturelles Lernen im Spanischunterricht am Beispiel von „Crónica de una muerte anunciada“ von Gabriel Garcia Márquez“. In: Hispanorama. 104, S. 95-100.

Herder, Johann Gottfried (1820 [1774]): Sämmtliche Werke zur Philosophie und Geschichte. Karlsruhe: Bureau der deutschen Klassiker.

Herder, Johann Gottfried (1841 [1784]): Ideen zur philosophie der geschichte der menschheit. Leipzig: J. F. Hartknoch.

Hoffman, Eva (1990): Lost in translation: a life in a new language. New York: Penguin Books.

Holquist, Michael (1990): Dialogism: Bakhtin and his world. London; New York: Routledge (New accents).

Holzbrecher, Alfred (2010): „Fachwissenschaftliche und fachdidaktische Überlegungen zum Interkulturellen Lernen - Kulturwissenschaftliche Grundlagen“. In: Krämer, Ulrich; Leupold, Eynar (Hrsg.) Französischunterricht als Ort interkulturellen Lernens. Seelze: Klett Kallmeyer, S. 22-29.

Honneth, Axel (2013): „Erziehung und demokratische Öffentlichkeit. Ein vernachlässigtes Kapitel der politischen Philosophie“. In: Müller, Hans-Rüdiger; Bohne, Sabine; Thole, Werner (Hrsg.) Erziehungswissenschaftliche Grenzgänge Markierungen und Vermessungen. Opladen; Berlin; Toronto: Budrich, S. 4157.

House of Lords (1976): „Motor-Cycle Crashhelmets (Religious Exemption) Bill (HLDeb 02 November 1976 vol 376 cc1163-75)“.Hansard Millbanksystems.Abgerufen am 18.05.2015 von http://hansard.millbanksystems.com/lords/1976/ nov/02/motor-cycle-crashhelmets-religious\#S5LV0376P0_19761102_ HOL_337. 
Hu, Adelheid (1995): „Spielen Vorurteile im Fremdsprachenunterricht eine positive Rolle?". In: Bredella, Lothar (Hrsg.) Verstehen und Verständigung durch Sprachenlernen?. Bochum: Brockmeyer, S. 405-412.

Hu, Adelheid (1996): „Interkultureller Fremdsprachenunterricht und die Heterogenität von „Kulturen“. Ergebnisse und Schlußfolgerungen einer qualitativ-empirischen Studie zu subjektiven Sprachlernkonzepten deutscher und taiwanesischer Jugendlicher". In: Zeitschrift für Interkulturellen Fremdsprachenunterricht. 1 (3), S. 16.

Hu, Adelheid (1999): „Interkulturelles Lernen. Eine Auseinandersetzung mit der Kritik an einem umstrittenen Konzept“. In: Zeitschrift für Fremdsprachenforschung. 10 (2), S. 277-303.

Hu, Adelheid (2008): „Interkulturelle Kompetenz. Ansätze zur Dimensionierung und Evaluation einer Schüsselkompetenz fremdsprachlichen Lernens“. In: Frederking, Volker (Hrsg.) Schwer messbare Kompetenzen. Baltmannsweiler: Schneider Hohengehren, S. 11-35.

Hu, Adelheid (2010): „Fremdverstehen und kulturelles Lernen“. In: Krumm, Hans-Jürgen; Fandrych, Christian; Hufeisen, Britta; u. a. (Hrsg.) Deutsch als Fremd- und Zweitsprache. Berlin: Walter de Gruyter, S. 1391-1402.

Hu, Adelheid; Byram, Michael (2009): „Introduction“. In: Hu, Adelheid; Byram, Michael (Hrsg.) Interkulturelle Kompetenz und fremdsprachliches Lernen. Tübingen: Gunter Narr Verlag, S. VII-XXV.

Hu, Adelheid; Leupold, Eynar (2008): „Kompetenzorientierung und Französischunterricht“. In: Tesch, Bernd; Leupold, Eynar; Köller, Olaf (Hrsg.) Bildungsstandards Französisch: konkret. Berlin: Cornelsen Scriptor, S. 51-87.

Hug, Michael (2007): „Sprachbewusstheit/Sprachbewusstsein - the state of the art“. In: Hug, Michael; Siebert-Ott, Gesa (Hrsg.) Sprachbewusstheit und Mehrsprachigkeit. Baltmannsweiler: Schneider Verlag Hohengehren, S. 10-31.

Humboldt, Wilhelm von (1960-1981): Werke in fünf Bänden. Darmstadt: Wissenschaftliche Buchgesellschaft.

Huntington, Samuel P. (1993): „The clash of civilizations?“. In: Foreign Affairs. 3 (72), S. 22-49.

Huntington, Samuel P. (1996): The clash of civilizations and the remaking of world order. New York: Simon \& Schuster.

Huster, Stefan; Brugger, Winfried (1997): „Die religiös-weltanschauliche Neutralität des Staates“. In: Zentrum für Interdisziplinäre Forschung: Mitteilungen. 3, S. 1-8.

Huxoll, Johannes (1999): „Zwischen KulturImperialismus und KulturRelativismus. Zur Begründung universeller Menschenrechte im Kontext der Interkulturalität“. In: polylog. (3), S. 65-76. 
Illich, Ivan (2003): Entschulung der Gesellschaft: Eine Streitschrift. 5. Aufl. München: Beck.

Innovative Media (2008): „Benedikt XVI.: Säkularisierung bedeutet geistliche Verkümmerung und ,Kult des Individuums"'. Zenit - Die Welt von Rom aus gesehen. Abgerufen am von http://www.zenit.org/de/articles/benedikt-xvisakularisierung-bedeutet-geistliche-verkummerung-und-kult-des-individu ums.

James, Carl; Garrett, Peter (1991): „The scope of Language Awareness“. In: James, Carl; Garrett, Peter (Hrsg.) Language awareness in the classroom. London; New York: Longman (Applied linguistics and language study), S. 3-20.

Jameson, Fredric (1992): Postmodernism, or, The Cultural Logic of Late Capitalism. London: Verso.

Johnson, Yvonne M.; Munch, Shari (2009): „Fundamental Contradictions in Cultural Competence“. In: Social Work. 3 (54), S. 220-231.

Kahl, Joachim (2007): „Grenzen der Toleranz: Laizistische Orientierung im Kampf der Ideen, Kulturen, Religionen“. In: Aufklärung und Kritik. (13), S. $123-135$.

Kahneman, Daniel (2012): Thinking, fast and slow. London: Penguin.

Kant, Immanuel (1781): Critik der reinen Vernunft. Riga: Hartknoch.

Kant, Immanuel (1982 [1803]): Ausgewählte Schriften zur Pädagogik und ihrer Begründung: ausgewählte pädagogische Schriften. 2. Aufl. Paderborn: F. Schöningh (Schöninghs Sammlung pädagogischer Schriften).

Kant, Immanuel (1991 [1784]): Schriften zur Anthropologie, Geschichtsphilosophie, Politik und Pädagogik 1. Werkausgabe Band XI. Herausgegeben von Wilhelm Weischedel. 9. Aufl. Frankfurt am Main: Suhrkamp.

Kauffmann, Sylvie (2007): „Devenue chrétienne, Lina Joy a tout perdu“. Le Monde. Abgerufen am 02.06.2015 von http://www.lemonde.fr/asie-pacifique/ article/2007/06/02/devenue-chretienne-lina-joy-a-tout-perdu_918070_3216. html.

Keller, Reiner (2010): „Wissenssoziologische Diskursanalyse und Systemtheorie“. In: John, René; Henkel, Anna; Rückert-John, Jana (Hrsg.) Die Methodologien des Systems. Wiesbaden: VS Verlag für Sozialwissenschaften, S. 241-272.

Kiefer, Markus (2008): „Bewusstsein“. In: Müsseler, Jochen (Hrsg.) Allgemeine Psychologie. 2. Aufl. Berlin [u.a.]: Spektrum, Akad. Verl., S. 154-188.

Kirchhoff, Sabine; Krämer, Walter (2010): Presse in der Krise. Wiesbaden: VS Verlag für Sozialwissenschaften.

Klieme, Eckhard; Eichler, Wolfgang; Helmke, Andreas; u. a. (2006): „Unterricht und Kompetenzerwerb in Deutsch und Englisch. Zentrale Befunde der Studie 
Deutsch-Englisch-Schülerleistungen-International (DESI)“. Deutsches Institut für Internationale Pädagogische Forschung. Abgerufen am 10.06.2015 von http://www.dipf.de/de/forschung/projekte/pdf/biqua/desi-zentrale-befunde.

Klöppner, Christin (in Vorbereitung): Interkulturelle Kompetenz im modernen Fremdsprachenunterricht und ihre Förderung in aktuellen Lehrwerken für den Spanischunterricht der Sekundarstufen I und II.

KMK = Ständige Konferenz der Kultusminister der Länder in der Bundesrepublik Deutschland (2003): „Bildungsstandards für die erste Fremdsprache (Englisch/Französisch) für den Mittleren Schulabschluss. (Beschluss der Kultusministerkonferenz vom 04. 12. 2003).“. Abgerufen am 14.04.2015 von http://www.kmk.org/fileadmin/veroeffentlichungen_beschluesse/2003/ 2003_12_04-BS-erste-Fremdsprache.pdf.

KMK = Ständige Konferenz der Kultusminister der Länder in der Bundesrepublik Deutschland (2009): „Stärkung der Demokratieerziehung (Beschluss der Kultusministerkonferenz vom 06.03.2009)“. Abgerufen am 14.04.2015 von http://www.kmk.org/fileadmin/veroeffentlichungen_beschluesse/2009/ 2009_03_06-Staerkung_Demokratieerziehung.pdf.

KMK = Ständige Konferenz der Kultusminister der Länder in der Bundesrepublik Deutschland (2012): „Bildungsstandards für die fortgeführte Fremdsprache (Englisch/Französisch) für die Allgemeine Hochschulreife (Beschluss der Kultusministerkonferenz vom 18.12.2012)“. Abgerufen am 14.04.2015 von http://www.kmk.org/fileadmin/veroeffentlichungen_beschluesse/2012/ 2012_10_18-Bildungsstandards-Fortgef-FS-Abi.pdf.

Knapp, Annelie (2013): „Still aware of language awareness?“. In: Fremdsprachen Lehren und Lernen. 42 (1), S. 65-79.

Knapp-Potthoff, Annelie (1997): „Sprach(lern)bewußtheit im Kontext“. In: Fremdsprachen Lehren und Lernen. 26, S. 9-23.

Knauf, Diethelm (1996): Cultural studies im Englischunterricht. Bremen: Ed. Temmen.

Koch, Iring (2008): „Konditionieren und implizites Lernen“. In: Müsseler, Jochen (Hrsg.) Allgemeine Psychologie. Berlin [u.a.]: Spektrum, Akad. Verl., S. 336374.

Köhnen, Ralph M. (2007): „Diskursanalyse“. In: Straub, Jürgen; Weidemann, Arne; Weidemann, Doris (Hrsg.) Handbuch interkulturelle Kommunikation und Kompetenz. Grundbegriffe, Theorien, Anwendungsfelder. Stuttgart; Weimar: Metzler, S. 415-427.

Koller, Hans-Christoph (1997): „Bildung in einer Vielfalt von Sprachen. Zur Aktualität Humboldts für die bildungstheoretische Diskussion unter den 
Bedingungen der (Post-)Moderne“. In: Koch, Lutz; Bauer, Walter (Hrsg.) Die Zukunft des Bildungsgedankens. Dt. Studien-Verl., S. 45-64.

Koller, Hans-Christoph (1999): Bildung und Widerstreit: Zur Struktur biographischer Bildungsprozesse in der (Post-)Moderne. München: W. Fink.

Koller, Hans-Christoph (2004): Grundbegriffe, Theorien und Methoden der Erziehungswissenschaft: Eine Einführung. Stuttgart: Kohlhammer.

Koller, Hans-Christoph (2007): „Probleme einer Theorie transformatorischer Bildungsprozesse“. In: Bildungsprozesse und Fremdheitserfahrung. Beiträge zu einer Theorie transformatorischer Bildungsprozesse. Bielefeld: transcript Verlag, S. 69-81.

Koller, Hans-Christoph (2012): Bildung anders denken: eine Einführung in die Theorie transformatorischer Bildungsprozesse. Stuttgart: Kohlhammer (Pädagogik).

Königs, Frank G. (2010): „Lernpsychologische und psycholinguistische Grundlagen des Fremdsprachenlernens“. In: Hallet, Wolfgang; Königs, Frank G. (Hrsg.) Handbuch Fremdsprachendidaktik. Seelze-Velber: Klett, Kallmeyer, S. 326-329.

Kramsch, Claire (1984): Interaction et discours dans la classe de langue. Paris: Hatier-Credif.

Kramsch, Claire (1995): „Andere Worte - andere Werte: Zum Verhältnis von Sprache und Kultur im Fremdsprachenunterricht". In: Bredella, Lothar (Hrsg.) Verstehen und Verständigung durch Sprachenlernen?. Bochum: Brockmeyer, S. 51-66.

Kramsch, Claire (1998): Language and culture. Oxford: Oxford University Press (Oxford introductions to language study).

Kramsch, Claire (1999): „Thirdness: The intercultural stance.“. In: Vestergaard, Torben (Hrsg.) Language, culture and identity. Aalborg: Centre for Languages and Intercultural Studies, Aalborg University Distribution, Aalborg University Press, S. 41-58.

Kramsch, Claire (2006): „From Communicative Competence to Symbolic Competence". In: The modern language journal. (90), S. 249-252.

Kramsch, Claire (2009): „Discourse, the symbolic dimension of Intercultural Competence“. In: Hu, Adelheid; Byram, Michael (Hrsg.) Interkulturelle Kompetenz und fremdsprachliches Lernen. Tübingen: Narr, S. 107-121.

Kramsch, Claire; Wellmon, Michael Chad (2008): „From Bildung durch Sprache to Language Ecology: The Uses of Symbolic Competence“. In: Doff, Sabine; Hüllen, Werner; Klippel, Friederike (Hrsg.) Visions of language in education = Visionen der Bildung durch Sprachen. Berlin; Zürich: Langenscheidt, S. 215-225. 
Kramsch, Claire; Whiteside, Anne (2008): „Language Ecology in Multilingual Settings. Towards a Theory of Symbolic Competence". In: Applied Linguistics. 29 (4), S. 645-671.

Krashen, Stephen D. (1981): Second language acquisition and second language learning. Oxford; New York: Pergamon Press.

Kristeva, Julia (1988): Étrangers à nous-mêmes. Paris: Fayard.

Kroeber, Alfred Louis; Kluckhohn, Clyde (1952): Culture. A critical review of concepts and definitions. Cambridge, Mass.: Harvard University Peabody Museum of American Archeology and Ethnology.

Krüper, Julian (2012): „LG Köln, Urt. v. 7.5.2012 - 151 Ns 169/11 (Religionstradition und Rechtskonvention: Die Unzulässigkeit religiöser Knabenbeschneidung)“. In: Zeitschrift für das Juristische Studium. 5 (4), S. 547-552.

Kucklick, Christoph (2014): Die granulare Gesellschaft. Wie das Digitale unsere Wirklichkeit auflöst. Berlin: Ullstein.

Kurtz, Jürgen (2012): „Sprachwissen und Sprachenbewusstheit: Theoretische Konstrukte und ihre Bedeutung für die Erforschung des schulischen Lehrens und Lernens fremder Sprachen“. In: Burwitz-Melzer, Eva; Königs, Frank G.; Krumm, Hans-Jürgen (Hrsg.) Sprachenbewusstheit im Fremdsprachenunterricht: Arbeitspapiere der 32. Frühjahrskonferenz zur Erforschung des Fremdsprachenunterrichts. Tübingen: Narr (Giessener Beiträge zur Fremdsprachendidaktik), S. 101-110.

Küster, Lutz (2003a): „Der Gegensatz „Transkulturalität“ und „Interkulturalität“ aus Sicht der deutschen Erziehungswissenschaft - Anschlussmöglichkeiten für die Fremdsprachendidaktik?". In: Eckerth, Johannes; Wendt, Michael (Hrsg.) Interkulturelles und transkulturelles Lernen im Fremdsprachenunterricht. Frankfurt am Main: Lang, S. 41-52.

Küster, Lutz (2003b): Plurale Bildung im Fremdsprachenunterricht: Interkulturelle und ästhetisch-literarische Aspekte von Bildung an Beispielen romanischer Fachdidaktik. Frankfurt am Main: Lang.

Küster, Lutz (2005): „Kulturverständnisse in Kulturwissenschaft und Fremdsprachendidaktik". In: Schumann, Adelheid (Hrsg.) Kulturwissenschaften und Fremdsprachendidaktik im Dialog. Frankfurt am Main: Lang (Kolloquium Fremdsprachenunterricht), S. 59-70.

Küster, Lutz (2010): „Die Arte-Sendereihe „Karambolage“ - ein Anlass interkulturellen Lernens im Französischunterricht?“. In: Caspari, Daniela; Küster, Lutz (Hrsg.) Wege zu interkultureller Kompetenz. Frankfurt am Main: Lang (Kolloquium Fremdsprachenunterricht), S. 39-49.

Küster, Lutz (2012): „Sprachliches Wissen, Sprachenbewusstheit und was noch? Anmerkungen zu einer „Rezeptur" fremdsprachlichen Lernens“. In: 
Burwitz-Melzer, Eva; Königs, Frank G.; Krumm, Hans-Jürgen (Hrsg.) Sprachenbewusstheit im Fremdsprachenunterricht: Arbeitspapiere der 32. Frühjahrskonferenz zur Erforschung des Fremdsprachenunterrichts. Tübingen: Narr (Giessener Beiträge zur Fremdsprachendidaktik), S. 91-100.

Küster, Lutz (2013): „Bildungsanspruch und Bildungsgehalt schulischen Fremdsprachenunterrichts. Ein kritischer (Rück)Blick auf Postulate und Praktiken“. In: Fremdsprachen Lehren und Lernen. 42 (1), S. 50-64.

Kymlicka, Will (1995): Multicultural citizenship: a liberal theory of minority rights. Oxford; New York: Clarendon Press; Oxford University Press.

Kymlicka, Will (2007): Multicultural odysseys: navigating the new international politics of diversity. Oxford; New York: Oxford University Press.

Langacker, Ronald W. (2008): „Cognitive grammar as a basis for language instruction“. In: Robinson, Peter; Ellis, Nick C. (Hrsg.) Handbook of cognitive linguistics and second language acquisition. New York: Routledge, S. 66-88.

Lavagno, Christian (2012): Jenseits der Ordnung: Versuch einer philosophischen Ataxiologie. Bielefeld: Transcript (Edition Moderne Postmoderne).

Lave, Jean; Wenger, Etienne (1991): Situated learning: Legitimate peripheral participation. Cambridge; New York: Cambridge University Press.

Leibniz, Gottfried Wilhelm (1998 [1714]): Monadologie: französisch/deutsch. Stuttgart: Philipp Reclam.

Lévi-Strauss, Claude (1985): The view from afar. Oxford: Blackwell.

Lévi-Strauss, Claude (1987 [1952]): Race et histoire. Paris: Denoël.

Lévi-Strauss, Claude (2001): Race et histoire [suivi de] Race et culture. Paris: Albin Michel; UNESCO.

Liessmann, Konrad Paul (2006): Theorie der Unbildung: Die Irrtümer der Wissensgesellschaft. 6. Aufl. Wien: Zsolnay.

Link-Heer, Ursula (2002): „Michel Foucault: Les mots et les choses (1966)“. In: Erhart, Walter; Jaumann, Herbert (Hrsg.) Jahrhundertbücher: Große Theorien von Freud bis Luhmann. 2. Aufl. München: Beck, S. 313-334.

Link, Jürgen (1988): „Literaturanalyse als Interdiskursanalyse. Am Beispiel des Ursprungs literarischer Symbolik in der Kollektivsymbolik“. In: Fohrmann, Jürgen; Müller, Harro (Hrsg.) Diskurstheorien und Literaturwissenschaft. Frankfurt am Main: Suhrkamp (Suhrkamp Taschenbuch Materialien), S. 284307.

Luhmann, Niklas (1995): Gesellschaftsstruktur und Semantik: Studien zur Wissenssoziologie der modernen Gesellschaft. Band 4. Frankfurt am Main: Suhrkamp. 
Luhmann, Niklas (1997): Die Kunst der Gesellschaft. Frankfurt am Main: Suhrkamp.

Lyotard, Jean-François (1979): La condition postmoderne: rapport sur le savoir. Paris: Éditions de Minuit (Collection Critique).

Lyotard, Jean-François (1983): Le différend. Paris: Editions de Minuit (Collection "Critique").

Lyotard, Jean-François (1987): Der Widerstreit. München: W. Fink.

Mall, Ram A. (1997): „Interkulturelle Philosophie und Historiographie“. In: Brocker, Manfred; Nau, Heino H. (Hrsg.) Ethnozentrismus: Möglichkeiten und Grenzen des interkulturellen Dialogs. Darmstadt: Wissenschaftliche Buchgesellschaft, S. 69-89.

Mall, Ram A. (1999): „Interkulturelle Philosophie und die Diskussion um die Menschenrechte“. In: Cesana, Andreas (Hrsg.) Interkulturalität - Grundprobleme der Kulturbegegnung. Mainz: Gutenberg Universität, S. 119-143.

Mayr, Stefan (2013): „Wer seine Rute schont, der hasst seinen Sohn“. Süddeutsche Zeitung online. Abgerufen am 14.04.2015 von http://www.sueddeutsche.de/ bayern/glaubensgemeinschaft-zwoelf-staemme-wer-seine-rute-schont-derhasst-seinen-sohn-1.1768495.

Meißner, Franz-Joseph (1999): „Menschenrechte und die Didaktik des Fremdverstehens“. In: Bredella, Lothar; Delanoy, Werner (Hrsg.) Interkultureller Fremdsprachenunterricht. Tübingen: Narr, S. 516-530.

Meißner, Franz-Joseph (2003): „Landeskunde versus interkulturelles Lernen und ihre zielsprachlichen Implikationen“. In: französisch heute. 34 (1), S. 58-86.

Mende, Janne (2011): Begründungsmuster weiblicher Genitalverstümmelung: zur Vermittlung von Kulturrelativismus und Universalismus. Bielefeld: Transcript Verlag (Kultur und soziale Praxis).

Meyer, Meinert A. (1992): „Negotiation of Meaning. Der Versuch einer handlungsorientierten Verknüpfung von Landeskunde und Politik im Englischunterricht (Sek II)“. In: Der fremdsprachliche Unterricht Englisch. (3), S. 16-21.

Meyer, Meinert A. (1993): „Fremdsprachenunterricht ohne Kultur? Zur Gewichtung sprachlich-kommunikativer und landeskundlicher Elemente aus pädagogischer Sicht“. In: Timm, Johannes-Peter; Vollmer, Helmut Johannes (Hrsg.) Kontroversen in der Fremdsprachenforschung. Bochum: Brockmeyer, S. 123-142.

Miller, Alice (2004): Am Anfang war Erziehung. Frankfurt am Main: Suhrkamp.

Mills, Sara (2007): Der Diskurs Begriff, Theorie, Praxis. Tübingen: Francke.

Mirbach, Thomas; Schaak, Torsten; Triebl, Katrin (2011): „Zwangsverheiratung in Deutschland - Anzahl und Analyse von Beratungsfällen. Wissenschaftliche 
Untersuchung im Auftrag des Bundesministeriums für Familie, Senioren, Frauen und Jugend.“. Abgerufen am 14.04.2015 von http://www.bmfsf.de/ RedaktionBMFSFJ/Broschuerenstelle/Pdf-Anlagen/Zwangsverheiratung-inDeutschland-Anzahl-und-Analyse-von-Beratungsf_C3_A4llen,property= pdf,bereich=bmfsf, sprache=de,rwb=true.pdf.

Mollenhauer, Klaus (2008): Vergessene Zusammenhänge: über Kultur und Erziehung. 7. Aufl. München: Juventa.

Möll, Marc-Pierre (2003): „Ist Aufklärung totalitär?: Zur „Dialektik der Aufklärung" von Horkheimer und Adorno". In: Aufklärung und Kritik. (2), S. 12-22.

Moore, Jerry D. (2009): Visions of culture: an annotated reader. Lanham, MD: AltaMira Press.

Morkötter, Steffi (2005): Language awareness und Mehrsprachigkeit: eine Studie zu Sprachbewusstheit und Mehrsprachigkeit aus der Sicht von Fremdsprachenlernern und Fremdsprachenlehrern. Frankfurt am Main; New York: Lang.

Müller-Funk, Wolfgang (2001): „Kultur, Kultur: Anmerkungen zu einem Zauberwort“. In: Merkur. 55 (7), S. 717-723.

Müller-Funk, Wolfgang (2010): Kulturtheorie Einführung in Schlüsseltexte der Kulturwissenschaften. Tübingen; Basel: Francke.

Münch, Richard (2009): Globale Eliten, lokale Autoritäten: Bildung und Wissenschaft unter dem Regime von Pisa, McKinsey \& Co. Frankfurt am Main: Suhrkamp.

Münker, Stefan (2009): Emergenz digitaler Öffentlichkeiten: Die Sozialen Medien im Web 2.0. Frankfurt am Main: Suhrkamp.

Münkler, Herfried (2006): „Angst essen Freiheit auf“. Süddeutsche Zeitung. München 30.9.2006, S. 2.

Nagel, Thomas (1974): „What is it like to be a bat?“. In: The Philosophical Review. 83 (4), S. 435-450.

Narcy-Combes, Jean-Paul (2010): „Illusion ontologique et pratique réflexive en didactique des langues". In: Le Français dans le monde. 48, S. 111-123.

Narcy-Combes, Jean-Paul (2013): „Responsabilité épistémologique, développement de la personnalité et didactique des langues: Un apport du concept de Bildung". In: Grünewald, Andreas; Plikat, Jochen; Wieland, Katharina (Hrsg.) Bildung - Kompetenz - Literalität: Fremdsprachenunterricht zwischen Standardisierung und Bildungsanspruch. Seelze: Friedrich-Verlag/Klett-Kallmeyer, S. 47-59.

Nick, Peter (2005): „Spiel mit der Differenz - Konstruktionen von Fremdheit, Kultur und Identität". In: Hamburger, Franz; Badawia, Tarek; Hummrich, Merle (Hrsg.) Migration und Bildung. Wiesbaden: VS Verlag für Sozialwissenschaften S. 245-256. 
Nieke, Wolfgang (2008): Interkulturelle Erziehung und Bildung: Wertorientierungen im Alltag. 3. Aufl. Opladen: Leske + Budrich.

Nünning, Ansgar (2001): „Fremdverstehen durch literarische Texte: von der Theorie zur Praxis“. In: Der fremdsprachliche Unterricht Englisch. 5 (53), S. 4-9.

Nünning, Ansgar (2009): „Vielfalt der Kulturbegriffe“. Bundeszentrale für politische Bildung. Abgerufen am 14.04.2015 von http://www.bpb.de/gesellschaft/ kultur/kulturelle-bildung/59917/kulturbegriffe? $\mathrm{p}=$ all.

Oettingen-Wallerstein, Maximilian (2008): Humes These: ein Klärungsversuch in der Sein-Sollens-Debatte. Würzburg: Königshausen \& Neumann (Epistemata. Reihe Philosophie).

Ort, Claus-Michael (2008): „Kulturbegriffe und Kulturtheorien“. In: Nünning, Ansgar; Nünning, Vera (Hrsg.) Einführung in die Kulturwissenschaften: theoretische Grundlagen, Ansätze, Perspektiven. Stuttgart; Weimar: Metzler, S. 1938.

Ott, Konrad (2000): „Jürgen Habermas: Theorie des kommunikativen Handelns (1981)“. In: Erhart, Walter; Jaumann, Herbert (Hrsg.) Jahrhundertbücher: Große Theorien von Freud bis Luhmann. München: C.H. Beck (Beck'sche Reihe), S. 383-406.

Parsons, Talcott; Platt, Gerald M. (1990): Die amerikanische Universität: ein Beitrag zur Soziologie der Erkenntnis. Frankfurt am Main: Suhrkamp.

Pelz, Heidrun (1996): Linguistik: Eine Einführung. 2. Aufl. Hamburg: Hoffmann und Campe.

Perlez, Jane (2006): „Once Muslim, Now Christian and Caught in the Courts“. The New York Times. Abgerufen am 02.06.2015 von http://www.nytimes. com/2006/08/24/world/asia/24malaysia.html?_r=0.

Perry, William G. (1970): Forms of intellectual and ethical development in the college years: a scheme. San Francisco: Jossey-Bass Publishers.

Pesce, Silvia G. (2010): Löse- und Lernprozesse bei der Bearbeitung grammatischkommunikativer Lernaufgaben: Eine Studie am Beispiel des Spanischen als Fremdsprache. Tübingen: Narr Francke Attempto.

Peukert, Helmut (1998): „Zur Neubestimmung des Bildungsbegriffs“. In: Meyer, Meinert A.; Reinartz, Andrea (Hrsg.) Bildungsgangdidaktik. Opladen: Leske + Budrich, S. 17-29.

Peukert, Helmut (1999): „Zur Logik transformatorischer Lernprozesse“. In: Pies, Ingo; Leschke, Martin (Hrsg.) Karl Poppers kritischer Rationalismus. Tübingen: Mohr Siebeck, S. 188-192.

Peukert, Helmut (2000): „Reflexionen über die Zukunft von Bildung“. In: Zeitschrift für Pädagogik. 46 (4), S. 507-524. 
Piepho, Hans-Eberhard (1974): Kommunikative Kompetenz als übergeordnetes Lernziel im Englischunterricht. Dornburg-Frickhofen: Frankonius-Verlag.

Piepho, Hans-Eberhard (1979): Kommunikative Didaktik des Englischunterrichts Sekundarstufe I: theoretische Begründung und Wege zur praktischen Einlösung eines fachdidaktischen Konzepts. Limburg: Frankonius.

Pies, Ingo; Leschke, Martin (1999): Karl Poppers kritischer Rationalismus. Tübingen: Mohr Siebeck.

Pinker, Steven (2003): The blank slate: the modern denial of human nature. London: Penguin.

Plikat, Jochen (2015): „Rezension zu Reimann, Daniel (2014): Transkulturelle kommunikative Kompetenz in den romanischen Sprachen: Theorie und Praxis des neokommunikativen und kulturell bildenden Französisch-, Spanisch-, Italienisch- und Portugiesischunterrichts. Stuttgart: Ibidem 2014“. In: Fremdsprachen Lehren und Lernen. 44 (2), S. 132-134.

Plikat, Jochen (2016): „Interkulturelle Kompetenz im Gemeinsamen europäischen Referenzrahmen - ein Modell für die heile Welt der Fremdsprachendidaktik?“. In: Bär, Marcus; Bernecker, Walther L.; Lüning, Marita (Hrsg.) Interkulturalität und Mehrsprachigkeit. Beiträge zu Sprache, Literatur und Kultur Spaniens und Lateinamerikas. Festschrift für Ursula Vences. Berlin: edition tranvía (Theorie und Praxis des modernen Spanischunterrichts), S. 272-285.

Popper, Karl R. (1992a): Die offene Gesellschaft und ihre Feinde: Band I: Der Zauber Platons. 7. Aufl. Tübingen: Francke.

Popper, Karl R. (1992b): Die offene Gesellschaft und ihre Feinde: Band II: Falsche Propheten: Hegel, Marx und die Folgen. 7. Aufl. Tübingen: Francke.

Pratt, Chris; Grieve, Robert (1984): „The development of metalinguistic awareness". In: Tunmer, William E.; Pratt, Chris; Herrmann, Michael L. (Hrsg.) Metalinguistic awareness in children. New York: Springer, S. 2-11.

Preuß, Ulrich K. (1998): „Die Belagerung des liberalen Verfassungsstaates durch die multikulturelle Gesellschaft“. In: Leviathan. (1), S. 60-76.

Public Broadcasting Service (2008): „Pope Benedict Says Church, American Society at a ,Crossroads“". Abgerufen am 09.06.2015 von http://www.pbs.org/ newshour/bb/religion/jan-june08/pope_04-17.html.

Rampillon, Ute (1997): „Be aware of awareness - oder: Beware of awareness? Gedanken zur Metakognition im Fremdsprachenunterricht der Sekundarstufe I“. In: Rampillon, Ute; Zimmermann, Günther (Hrsg.) Strategien und Techniken beim Erwerb fremder Sprachen. Ismaning: Hueber, S. 173-184.

Rathje, Stefanie (2006): „Interkulturelle Kompetenz - Zustand und Zukunft eines umstrittenen Konzepts“. In: Zeitschrift für Interkulturellen Fremdsprachenunterricht. 11 (3), S. 15. 
Rauhut, Franz (1953): „Die Herkunft der Worte und Begriffe ,Kultur, ,Civilisation' und ,Bildung “'. In: Germanisch-Romanische Monatsschrift. 34 (3), S. 81-91.

Rawls, John (1971): A theory of justice. Cambridge, MA: Belknap Press of Harvard University Press.

Rawls, John (1993): Political liberalism. New York: Columbia University Press (The John Dewey essays in philosophy).

Reckwitz, Andreas (2000): Die Transformation der Kulturtheorien: zur Entwicklung eines Theorieprogramms. Weilerswist: Velbrück Wissenschaft.

Reckwitz, Andreas (2001): „Multikulturalismustheorien und der Kulturbegriff: Vom Homogenitätsmodell zum Modell kultureller Interferenzen“. In: Berliner Journal für Soziologie. 2 (11), S. 179-200.

Reckwitz, Andreas (2004): „Die Kontingenzperspektive der „Kultur“. Kulturbegriffe, Kulturtheorien und das kulturwissenschaftliche Forschungsprogramm". In: Jaeger, Friedrich; Rüsen, Jörn (Hrsg.) Handbuch der Kulturwissenschaften, S. 1-20.

Reckwitz, Andreas (2007): „Kultursoziologie“. In: Straub, Jürgen (Hrsg.) Handbuch interkulturelle Kommunikation und Kompetenz: Grundbegriffe, Theorien, Anwendungsfelder. Stuttgart; Weimar: Metzler S. 201-211.

Reese-Schäfer, Walter (1995): Lyotard zur Einführung. 3. Aufl. Hamburg: Junius.

Reimann, Daniel (2014): Transkulturelle kommunikative Kompetenz in den romanischen Sprachen: Theorie und Praxis des neokommunikativen und kulturell bildenden Französisch-, Spanisch-, Italienisch- und Portugiesischunterrichts. Stuttgart: Ibidem.

Rippl, Susanne; Seipel, Christian (2008): Methoden kulturvergleichender Sozialforschung: eine Einführung. Wiesbaden: VS, Verl. für Sozialwiss.

Roche, Jörg (2013): Fremdsprachenerwerb, Fremdsprachendidaktik. 3. Aufl. Tübingen: Francke.

Rodi, Frithjof (1967): „Zur Metaphorik der Aneignung“. In: Bildung und Erziehung, S. 425-438.

Rösch, Heidi (2012): „Interkulturelle Kompetenz als Bildungsaufgabe“. In: Fäcke, Christiane; Martinez, Hélène; Meißner, Franz-Joseph (Hrsg.) Mehrsprachigkeit: Bildung - Kommunikation - Standards; [3. Bundeskongress des GMF]. Stuttgart: Klett, S. 26-38.

Rössler, Andrea (2010a): „Input-Standards und Opportunity-to-learn-Standards für die Schulung interkultureller Kompetenz im Fremdsprachenunterricht“. In: Caspari, Daniela; Küster, Lutz (Hrsg.) Wege zu interkultureller Kompetenz. Frankfurt am Main: Lang (Kolloquium Fremdsprachenunterricht), S. 115129. 
Rössler, Andrea (2010b): „Interkulturelle Kompetenz“. In: Meißner, Franz-Joseph; Tesch, Bernd (Hrsg.) Spanisch kompetenzorientiert unterrichten. Seelze: Kallmeyer, S. 137-149.

Rössler, Andrea (2012): „Wie gefährlich ist Taxifahren in Montevideo? Ein fiktionaler critical incident als Anlass zum interkulturellen und literarischen Lernen“. In: Altmann, Werner; Pardellas Velay, Rosamna; Vences, Ursula (Hrsg.) Historia hispánica. Su presencia y (re)presentación en Alemania. Festschrift für Walther L. Bernecker. Berlin: edition tranvía - Verlag Walter Frey, S. 219-228.

Röttger, Evelyn (1996): „Überlegungen zum Begriff des interkulturellen Lernens in der Fremdsprachendidaktik“. In: Zeitschrift für Fremdsprachenforschung. 2 (7), S. 155-170.

Rück, Nicola (2009): Auffassungen vom Fremdsprachenlernen monolingualer und plurilingualer Schülerinnen und Schüler. Kassel: Kassel Univ. Press.

Rushdie, Salman (1982a): „The Empire writes back with a vengeance“. The Times. London 7.3.1982.

Rushdie, Salman (1982b): „The New Empire within Britain“. In: New Society. (9), S. 417-420.

Said, Edward William (2003 [1978]): Orientalism. London: Penguin Books.

Sambanis, Michaela (2013): Fremdsprachenunterricht und Neurowissenschaften. Tübingen: Narr Francke Attempto.

Sandkühler, Hans Jörg (1996): „Das Recht und die pluralistische Demokratie. Naturrecht, Rechtspositivismus, Menschenrechte“. In: Dialektik. (1), S. 119-136.

Sarasin, Philipp (1996): „Subjekte, Diskurse, Körper“. In: Hardtwig, Wolfgang; Wehler, Hans Ulrich (Hrsg.) Kulturgeschichte heute. Göttingen: Vandenhoeck \& Ruprecht (Geschichte und Gesellschaft. Sonderheft), S. 131-164.

Sarasin, Philipp (2006): Michel Foucault zur Einführung. 2. Aufl. Hamburg: Junius.

Sarasin, Philipp (2009): „Das Reale der Diskursanalyse. Michel Foucaults Nähe zur Genetik und zur Evolutionstheorie“. Recherche. Zeitung für Wissenschaft. Abgerufen am 10.05.2015 von http://www.recherche-online.net/michel-fou caul.html.

Schaal, Gary S.; Heidenreich, Felix (2006): Einführung in die politischen Theorien der Moderne. Opladen, Farmington Hills: Budrich.

Schiffauer, Werner (1997): „Kulturalismus vs. Universalismus. Ethnologische Anmerkungen zu einer Debatte.“. In: Fremde in der Stadt: Zehn Essays über Kultur und Differenz. Frankfurt am Main: Suhrkamp, S. 144-156.

Schinschke, Andrea (1995): Literarische Texte im interkulturellen Lernprozess. Zur Verbindung von Literatur und Landeskunde im Fremdsprachenunterricht Französisch. Tübingen: Narr. 
Schlaich, Klaus (1972): Neutralität als Verfassungsrechtliches Prinzip. Tübingen: Mohr.

Schmenk, Barbara (2004): „Interkulturelles Lernen versus Autonomie?“. In: Börner, Wolfgang; Vogel, Klaus (Hrsg.) Emotion und Kognition im Fremdsprachenunterricht. Tübingen: Narr, S. 66-86.

Schmenk, Barbara (2005): „Mode, Mythos, Möglichkeiten oder Ein Versuch, die Patina des Lernziels „kommunikative Kompetenz“ abzukratzen“. In: Zeitschrift für Fremdsprachenforschung. 16 (1), S. 57-87.

Schmenk, Barbara (2008): Lernerautonomie: Karriere und Sloganisierung des Autonomiebegriffs. Tübingen: G. Narr (Giessener Beiträge zur Fremdsprachendidaktik).

Schmidt, Claudia (2010): „Sprachbewusstheit und Sprachlernbewusstheit“. In: Krumm, Hans-Jürgen; Fandrych, Christian; Hufeisen, Britta; u. a. (Hrsg.) Deutsch als Fremd- und Zweitsprache. Berlin: Walter de Gruyter, S. 1402-1413.

Schmidt, Paul F. (1955): „Some Criticisms of Cultural Relativism“. In: The Journal of Philosophy. 52 (25), S. 780-791, doi: 10.2307/2022285.

Schmidt, Richard (1990): „The role of consciousness in second language learning“. In: Applied Linguistics. 11, S. 129-158.

Schneider, Ulrich Johannes (1999): „Foucault und die Aufklärung“. In: Das Achtzehnte Jahrhundert. 23 (1), S. 13-25.

Schramm, Karen (2012): „Explizites Wissen über Sprachen und sprachliches Handeln - Lehrgrundlage, Lerngerüst und Zugangsschlüssel“. In: BurwitzMelzer, Eva; Königs, Frank G.; Krumm, Hans-Jürgen (Hrsg.) Sprachenbewusstheit im Fremdsprachenunterricht: Arbeitspapiere der 32. Frühjahrskonferenz zur Erforschung des Fremdsprachenunterrichts. Tübingen: Narr (Giessener Beiträge zur Fremdsprachendidaktik), S. 198-209.

Schröder, Konrad (2012): „Sprachbewusstheit und Sprachlernbewusstsein in den Bildungsstandards für die Allgemeine Hochschulreife der Kultusministerkonferenz: Modellierungen, Tragweite und Ansätze zur schulischen Realisierung“" In: Die Neueren Sprachen. 3, S. 27-48.

Schumann, Adelheid (2010): „Landeskunde“. In: Surkamp, Carola (Hrsg.) Metzler Lexikon Fremdsprachendidaktik: Ansätze, Methoden, Grundbegriffe. Stuttgart: Metzler, S. 158-160.

Seidl, Horst (1995): Über die Seele: griechisch-deutsch. Hamburg: Meiner.

Senatsverwaltung für Bildung, Jugend und Sport Berlin (2004): „Schulgesetz für das Land Berlin vom 26. Januar 2004“. Abgerufen am 13.06.2015 von http:// gesetze.berlin.de/jportal/portal/t/1ptj/page/bsbeprod.psml?pid=Dokument anzeige \&showdoccase $=1 \&$ ss_peid=Trefferliste\&documentnumber $=1 \&$ num 
berofresults $=1 \&$ fromdoctodoc $=$ yes $\&$ doc $. i d=j l r-S c h u l G B E r a h m e n \& d o c$. part $=X \&$ doc.price $=0.0 \# j$ lr-SchulGBErahmen.

Senatsverwaltung für Bildung, Jugend und Sport Berlin (2006): „Rahmenlehrplan für die Sekundarstufe I Spanisch“. Abgerufen am 14.04.2015 von http:// www.berlin.de/imperia/md/content/sen-bildung/schulorganisation/lehr plaene/sek1_spanisch.pdf?start\&ts=1150102062\&file=sek1_spanisch.pdf.

Sheriff, John K. (1994): Charles Peirce's Guess at the riddle. Grounds for human significance. Bloomington: Indiana University Press.

Simmel, Georg (1908): Soziologie. Untersuchungen über die Formen der Vergesellschaftung. Berlin: Duncker \& Humblot.

Spencer, Jonathan (1989): „Anthropology as a Kind of Writing“. In: Man (New Series). 24 (1), S. 145-164.

Spencer, Nathalie; Rowson, Jonathan; Bamfield, Louise (2014): Schüler richtig motivieren. London; Düsseldorf: The RSA/Vodafone-Stiftung.

Spiro, Melford E. (1986): „Cultural Relativism and the Future of Anthropology“. In: Cultural Anthropology. 1 (3), S. 259-286, doi: 10.2307/656192.

Stein, Edith (2008): Übersetzung: Des Hl. Thomas von Aquino Untersuchungen über die Wahrheit, Quaestiones disputatae de veritate. Freiburg im Breisgau: Herder (Edith Stein Gesamtausgabe, Bd. 23).

Steinbeis, Maximilian (2012): „Das Beschneidungs-Urteil aus Köln und die Frage Wozu?". Verfassungsblog. Abgerufen am 02.06.2015 von http://www.verfas sungsblog.de/das-beschneidungsurteil-aus-kln-und-die-frage-wozu/.

Stocking, George W. (Hrsg.) (1989): A Franz Boas reader: the shaping of American anthropology, 1883-1911. Chicago: Univ. of Chicago Press.

Straub, Jürgen (2007): „Kultur“. In: Straub, Jürgen; Weidemann, Arne; Weidemann, Doris (Hrsg.) Handbuch interkulturelle Kommunikation und Kompetenz. Grundbegriffe, Theorien, Anwendungsfelder. Stuttgart; Weimar: Metzler, S. 7-24.

Strenger, Carlo (2015): Zivilisierte Verachtung. Frankfurt am Main: Suhrkamp.

Sukopp, Thomas (2005): „Wider den radikalen Kulturrelativismus - Universalismus, Kontextualismus und Kompatibilismus“. In: Aufklärung und Kritik. 2, S. 136-154.

Surkamp, Carola (Hrsg.) (2010): Metzler Lexikon Fremdsprachendidaktik: Ansätze, Methoden, Grundbegriffe. Stuttgart: Metzler.

Surkamp, Carola (2012): „Literarische Texte im kompetenzorientierten Fremdsprachenunterricht“. In: Hallet, Wolfgang (Hrsg.) Kompetenzaufgaben im Englischunterricht. Seelze: Friedrich S. 77-90.

Taylor, Charles (2011): „,The politics of recognition“. In: Gutmann, Amy (Hrsg.) Multiculturalism. Princeton: Princeton University Press S. 25-73. 
Tenbruck, Friedrich Heinrich (1990): Die kulturellen Grundlagen der Gesellschaft: der Fall der Moderne. 2. Aufl. Opladen: Westdt. Verl.

The Executive Board, American Anthropological Association (1947): „Statement on Human Rights“. In: American Anthropologist. 49 (4), S. 539-543, doi: $10.2307 / 662893$.

The Holy See (2008): „Address of his Holiness Benedict XVI. National Shrine of the Immaculate Conception in Washington, D.C.“. Abgerufen am 09.06.2015 von http://w2.vatican.va/content/benedict-xvi/en/speeches/2008/april/docu ments/hf_ben-xvi_spe_20080416_bishops-usa.html.

The Library of Congress (1998): „Jefferson's Letter to the Danbury Baptists. The Final Letter, as Sent (Jan. 1. 1802)“. Information Bulletin. Abgerufen am 23.11.2015 von http://www.loc.gov/loc/lcib/9806/danpre.html.

The New London Group (1996): „A Pedagogy of Multiliteracies: Designing Social Futures". In: Harvard Educational Review. 66 (1), S. 60-93.

Thiele, Nina; Azadian, Ramin (2005): „Crónica de una muerte anunciada: Traditionelle Wertesysteme und machistischer Verhaltenskodex. Eine Unterrichtsreihe für die Jahrgangsstufen 12 und 13“. In: RAAbits Spanisch. (II/A1), S. 1-40.

Thiering, Christian (1998): „Medieneinsatz und Persönlichkeitsförderung im Fremdsprachenunterricht". In: Neusprachliche Mitteilungen aus Wissenschaft und Praxis. 51 (2), S. 66-73.

Thomas, Alexander (1996): Psychologie interkulturellen Handelns. Göttingen; Seattle: Hogrefe.

Tilg, Bernhard (2009): „Franz Boas' Stellungnahme zur Frage der Rasse und sein Engagement für die Rechte der Afroamerikaner“. In: Schmuhl, Hans-Walter (Hrsg.) Kulturrelativismus und Antirassismus: Der Anthropologe Franz Boas (1858-1942). Bielefeld: Transcript, S. 85-99.

Turki, Mohammed (1996): „Glauben und Wissen in der arabisch-islamischen Philosophie. Ibn Ruschd (Averroes) und der erste Versuch der Aufklärung im Islam“. In: Dialektik. (1), S. 29-42.

UN General Assembly (1948): „Universal Declaration of Human Rights“. Abgerufen am 20.04.2015 von http://www.un.org/en/documents/udhr/index.shtml.

Vatter, Christoph; Zapf, Elke Christine (2012): Interkulturelle Kompetenz. Erkennen - verstehen - handeln. Französisch. Stuttgart; Leipzig: Klett.

Vences, Ursula (2007): „Interkulturelles Lernen - weit mehr als Landeskunde“. In: Der fremdsprachliche Unterricht Spanisch. (16), S. 4-9.

Volkmann, Laurenz (2010): Fachdidaktik Englisch: Kultur und Sprache. Tübingen: Narr. 
Vollmer, Helmut Johannes (2001): „Zum Aufbau kritischer Diskurskompetenz bei zukünftigen Fremdsprachenlehrern“. In: Aguado, Karin; Riemer, Claudia; Henrici, Gert (Hrsg.) Wege und Ziele. Baltmannsweiler: Schneider-Verl. Hohengehren (Perspektiven Deutsch als Fremdsprache), S. 77-96.

Vollmer, Helmut Johannes (2010a): „Fachkompetenz als fachbasierte Diskursfähigkeit am Beispiel Geographie". In: Doff, Sabine (Hrsg.) Bilingualer Sachfachunterricht in der Sekundarstufe. Eine Einführung. Tübingen: Narr, S. 242-257.

Vollmer, Helmut Johannes (2010b): „Kompetenzforschung in den Fremdsprachendidaktiken. Ein Überblick.“. In: Aguado, Karin; Schramm, Karen; Vollmer, Helmut Johannes (Hrsg.) Fremdsprachliches Handeln beobachten, messen, evaluieren. Frankfurt am Main: Lang, S. 29-64.

Voltaire (1989): Traité sur la tolérance. Paris: Flammarion.

Voss, Ehler (2009): „Rezension zu: Lévi-Strauss, Claude: Traurige Tropen, Frankfurt am Main 2008.“. Kritikon. Abgerufen am 14.04.2015 von http://www. kritikon.de/issue/200907/63.

Warraq, Ibn (2007): Defending the West: A critique of Edward Said's „Orientalism“. Amherst, NY: Prometheus Books.

Watson, John B. (1925): Behaviorism. London: Kegan.

Watzlawick, Paul (2007): Wie wirklich ist die Wirklichkeit? Wahn, Täuschung, Verstehen. 6. Aufl. München: Piper.

Weber, Max (1980): Wirtschaft und Gesellschaft: Grundriss der verstehenden Soziologie. 5. Aufl. Tübingen: Mohr.

Weber, Peter; Becker-Mrotzek, Michael (2012): „Funktional-pragmatische Diskursanalyse als Forschungs- und Interpretationsmethode“. Fallarchiv Uni Kassel. Abgerufen am 14.04.2015 von http://www.fallarchiv.uni-kassel.de/ lernumgebung/diskursanalyse/.

Weber, Stefan (2010): „Systemtheorien der Medien“. In: Weber, Stefan (Hrsg.) Theorien der Medien. 2. Aufl. Konstanz: UVK Verl.-Ges. (UTB Medien- und Kommunikationswissenschaft, Literaturwissenschaft), S. 189-206.

Weinert, Franz E. (2001): Leistungsmessungen in Schulen. Weinheim: Beltz.

Welsch, Wolfgang (1994): „Transkulturalität. Lebensformen nach der Auflösung der Kulturen“.'In: Luger, Kurt; Renger, Rudi (Hrsg.) Dialog der Kulturen: die multikulturelle Gesellschaft und die Medien. Wien: Österreichischer Kunst- und Kulturverlag (Neue Aspekte in Kultur- und Kommunikationswissenschaft), S. 147-169.

Welsch, Wolfgang (1995): Vernunft: Die zeitgenössische Vernunftkritik und das Konzept der transversalen Vernunft. Frankfurt am Main: Suhrkamp.

Welsch, Wolfgang (1999): „Transkulturalität“. In: Cesana, Andreas (Hrsg.) Interkulturalität - Grundprobleme der Kulturbegegnung. Mainz: Gutenberg Universität, S. 45-72. 
Welsch, Wolfgang (2010): „Was ist eigentlich Transkulturalität?“. In: Darowska, Lucyna; Lüttenberg, Thomas; Machold, Claudia (Hrsg.) Hochschule als transkultureller Raum? Kultur, Bildung und Differenz in der Universität. Bielefeld: Transcript (Kultur und soziale Praxis), S. 39-66.

Wenzel, Horst (2007): Mediengeschichte vor und nach Gutenberg. Darmstadt: Wiss. Buchges.

White, Hayden (1973): Metahistory: the historical imagination in nineteenth-century Europe. Baltimore: Johns Hopkins University Press.

Wierlacher, Alois (Hrsg.) (1996): Kulturthema Toleranz. München: Iudicium (Kulturthemen).

Wierlacher, Alois (2003): ,,Toleranz“.In:Wierlacher, Alois; Bogner, Andrea (Hrsg.) Handbuch interkulturelle Germanistik. Stuttgart: J.B. Metzler, S. 316-326.

Wilson, Edward O. (2000): Sociobiology: the new synthesis. 25th anniversary ed. Cambridge, Mass: Belknap Press of Harvard University Press.

Wodak, Ruth (2009): ,,Von Wissensbilanzen und Benchmarking': Die fortschreitende Ökonomisierung der Universitäten. Eine Diskursanalyse.". In: Diaz-Bone, Rainer; Krell, Gertraude (Hrsg.) Diskurs und Ökonomie Diskursanalytische Perspektiven auf Märkte und Organisationen. Wiesbaden: VS Verlag für Sozialwissenschaften / GWV Fachverlage GmbH, S. 317-336.

Wolff, Dieter (1993): „Sprachbewußtheit und die Begegnung mit Sprachen“. In: Die Neueren Sprachen. 92 (6), S. 510-531.

Wulf, Christoph (2009): Anthropologie: Geschichte - Kultur - Philosophie. Aktualisierte Neuausgabe. Köln: Anaconda.

Zimmermann, Albert (1986): Thomas von Aquin: Von der Wahrheit. Hamburg: F. Meiner (Philosophische Bibliothek).

Žižek, Slavoj (1997): „Multiculturalism or the cultural logic of multinational capitalism?". In: New Left Review. 1 (225), S. 28-51.

Žižek, Slavoj (2009): Violence. Six sideways reflections. London: Profile Books (Big ideas).

Zydatiß, Wolfgang (2007): Deutsch-Englische Züge in Berlin (DEZIBEL): Eine Evaluation des bilingualen Sachfachunterrichts an Gymnasien; Kontext, Kompetenzen, Konsequenzen. Frankfurt am Main: Lang.

Zydatiß, Wolfgang (2010): „Die Überprüfung fächerübergreifender transferfähiger Diskurskompetenzen im bilingualen Sachfachunterricht“. In: Doff, Sabine (Hrsg.) Bilingualer Sachfachunterricht in der Sekundarstufe. Eine Einführung. Tübingen: Narr, S. 258-271. 